\title{
Waste Isolation Pilot Plant Annual Site Environmental Report for 2005
}

\author{
U.S. Department of Energy
}

September 2006

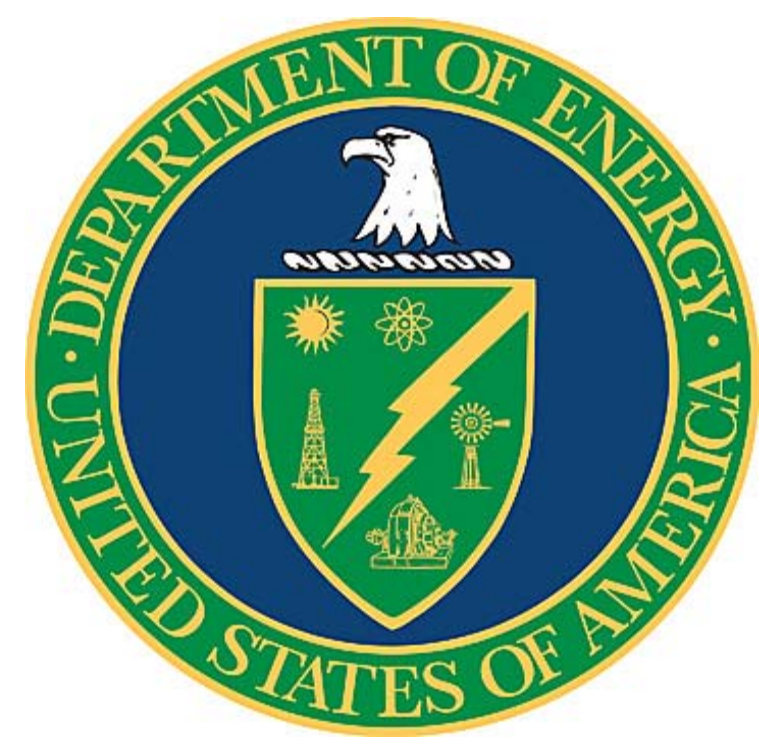



This document has been submitted as required to:

Office of Scientific and Technical Information

P.O. Box 62

Oak Ridge, TN 37831

Prices available from (865) 576-1188

Additional information about this document may be obtained by calling (800) 336-9477. Copies may be obtained by contacting the National Technical Information Service, U.S. Department of Commerce, 5285 Port Royal Road, Springfield, VA 22161

Processing and final preparation of this report was performed by the Waste Isolation Pilot Plant Management and Operating Contractor for the U.S. Department of Energy under Contract No. DE-AC29-01AL66444. 



\section{EXECUTIVE SUMMARY}

\section{Purpose}

The purpose of the Waste Isolation Pilot Plant Annual Site Environmental Report for 2005 (ASER) is to provide important information needed by the U.S. Department of Energy (DOE) to assess field environmental program performance and confirm compliance with environmental standards and requirements. This report provides information about the Waste Isolation Pilot Plant (WIPP) environmental performance to stakeholders and members of the public. The 2005 ASER also outlines significant environmental programs and efforts of environmental merit at WIPP for 2005. As stated in DOE Order 231.1A, Environment, Safety, and Health Reporting, the purpose of the ASER is to present summary environmental data that:

- $\quad$ Characterize site environmental management performance.

- $\quad$ Summarize environmental occurrences and responses reported during the calendar year.

- $\quad$ Confirm compliance with environmental standards and requirements.

- $\quad$ Highlight significant facility programs and efforts.

The DOE Carlsbad Field Office (CBFO) and Washington TRU Solutions LLC (WTS) are dedicated to maintaining high quality management of WIPP environmental resources. DOE Order 231.1A; DOE Order 450.1, Environmental Protection Program; and DOE Order 5400.5, Radiation Protection of the Public and Environment, require that the affected environment at and near DOE facilities be monitored to ensure the safety and health of the public and the environment.

This report was prepared in accordance with DOE Order 231.1A, and Guidance for the Preparation of Department of Energy (DOE) Annual Site Environmental Reports (ASERS) for Calendar Year 2005 (DOE, 2006). The order and the guidance require that DOE facilities submit an ASER to the DOE Headquarters Office of the Assistant Secretary for Environment, Safety, and Health. The WIPP Hazardous Waste Facility Permit (HWFP) further requires that the ASER be provided to the New Mexico Environment Department (NMED).

\section{Major Site Programs}

\section{$\underline{\text { Mission }}$}

The mission of WIPP is to safely and permanently dispose of transuranic (TRU) radioactive waste generated by the production of nuclear weapons and other activities related to the national defense of the United States. In $2005,8,480$ cubic meters $\left(\mathrm{m}^{3}\right)$ of TRU waste were emplaced at WIPP. From the first receipt of waste in March 1999 through the end of 2005, 34,289 $\mathrm{m}^{3}$ of TRU waste had been emplaced at WIPP. 
Monitoring and Surveillance

It is the DOE's policy to conduct its operations at WIPP in compliance with applicable environmental laws and regulations, and to protect human health and the environment. These are accomplished through a management system consisting of radiological and nonradiological environmental monitoring and surveillance and compliance with applicable environmental regulations. As part of this management system, the DOE collects data needed to detect and quantify potential impacts that WIPP may have on the surrounding environment. The Waste Isolation Pilot Plant Environmental Monitoring Plan (EMP) (DOE/WIPP 99-2194) outlines major environmental monitoring and surveillance activities at WIPP and WIPP's quality assurance/quality control (QA/QC) program as it relates to environmental monitoring.

As part of its monitoring programs, WIPP conducts both effluent (i.e., point source monitoring at release points such as the exhaust shaft, to detect and/or quantify potential dose rates) along with traditional pathway and receptor monitoring in the broader environment. These programs are also used to ensure that WIPP operations comply with DOE and other applicable federal and state standards and requirements. The WIPP Environmental Monitoring Program is designed to monitor potential pathways that radionuclides and other contaminants could take to reach the environment surrounding WIPP. Pathways monitored include air, groundwater, surface water, soils, sediments, vegetation, and game animals. The goal of the program is to determine if the local ecosystem has been, or is being, impacted by WIPP operations and, if so, to evaluate the geographic extent and the effects on the environment.

The Waste Isolation Pilot Plant Land Management Plan (LMP) (DOE/WIPP 93-004) was created in compliance with the WIPP Land Withdrawal Act of 1992 (LWA) (Public Law [Pub. L.] 102-579, as amended by Pub. L. 104-201, National Defense Authorization Act for Fiscal Year 1997). This plan identifies resource values, promotes multiple-use management, and identifies long-term goals for the management of WIPP lands. The LMP includes a land reclamation program that addresses both the short-term and longterm effects of WIPP operations. WIPP also conducts surveillance in the region surrounding the site to protect WIPP from potential trespass.

In this report, the WIPP environmental monitoring and surveillance programs are grouped as follows:

Environmental Radiological Programs

- $\quad$ Effluent

- $\quad$ Airborne particulates

- Groundwater

- $\quad$ Surface water

- Sediments

- Soil

- Biota 
Environmental Nonradiological Programs

- $\quad$ Land management

- Meteorology

- Volatile Organic Compounds

- $\quad$ Seismic Activity

- $\quad$ Liquid Effluent

Groundwater Protection Programs

- Groundwater quality

- Groundwater levels

- $\quad$ Pressure density surveys

- Shallow subsurface water quality

- Shallow subsurface water levels

In 2005, the results of each of these monitoring and surveillance programs, observations, and analytical data, demonstrated that (1) compliance with applicable environmental requirements was achieved and (2) the operations at the WIPP site have not had a negative impact on human health and the environment.

\section{Environmental Compliance}

WIPP is required to comply with applicable federal and state laws and DOE orders. In order to accomplish and document compliance with certain requirements, the following submittals, required on a routine basis, were prepared in 2005:

$\underline{\text { New Mexico Submittals }}$

A. Hazardous Waste Facility Permit (HWFP)

- 2004 Site Environmental Report

- Confirmatory VOCs [volatile organic compounds) and Mine Ventilation Rate Monitoring Report

- $\quad$ Quarterly Solid Waste Management Unit (SWMU) Activities

Progress Reports

- Waste Minimization Statement

- WIPP Groundwater Detection Monitoring Semiannual Groundwater Monitoring Reports

- $\quad$ Geotechnical Analysis Report

- $\quad$ Monthly Water Level Report 
B. Discharge Permit (DP-831)

- $\quad$ Semiannual Discharge Monitoring Reports

C. Superfund Amendments and Reauthorization Act of 1986

- $\quad$ Emergency and Hazardous Chemical Inventory Report

- Toxic Chemical Release Inventory Report

- 2005 Annual Polychlorinated Biphenyls Report

\section{Environmental Protection Agency Submittals}

- Delaware Basin Monitoring Annual Report

- WIPP Subsidence Monument Leveling Survey

- 2005 Annual Change Report

- Toxic Chemical Release Inventory Report

Other correspondence, regulatory submittals, monitoring reports, and the results of the EPA Annual Inspection as well as other inspections are described in Chapter 2 of this report.

\section{Key Initiatives}

\section{Pollution Prevention}

During 2005, three areas of pollution prevention (P2) were the focus, with strong positive results in each of these areas. The first was to improve employee awareness of P2. Employee awareness activities were conducted throughout the year to highlight DOE and WIPP commitment to pollution prevention. Although the project used many expected avenues such as articles in newsletters, an environmental booth in the Safety Fair, and improved General Employee Training (GET) on P2 and Environmental Management System (EMS), a major accomplishment was the formation of a "Green Team." Management support for this team demonstrates a commitment to heighten P2 and environmental awareness at WIPP. The team is able to develop and flesh out new ideas and assignments for distribution of materials is quicker and easier at the facility.

The second area was energy conservation and included energy usage improvement projects. One significant project was an air recirculation demonstration project for the waste handling and exhaust filter buildings. This energy improvement project is targeted to reduce approximately 40 percent of heating, ventilation, and air-conditioning (HVAC)-related lost energy in these buildings by going from a "once-through" to 
"recirculation" configuration. This project will be used for sharing information on how to modify HVAC systems at other DOE facilities.

The third area was the focus on recycling program improvements, with the WIPP site being the primary focus. During 2005, WIPP improved the visibility of and logistics of recycling with employees; making it easy for employees to recycle, to collect, store and routinely transport materials to the recycling vendor. For the town site (the SkeenWhitlock Building) the tracking system to quantify the amounts recycled was improved. The result of these efforts was demonstrated by an increase in the amount of paperbased materials recycled from 0.1 metric ton in 2004 to 15.5 metric tons in 2005.

\section{Environmental Management System}

Preparation for declaring compliance with DOE Order 450.1 was a key initiative for 2005 , as well as a continuation of 2004's focus. This order required the site Environmental Management Systems (EMSs) to be integrated with the Integrated Safety Management System (ISMS). For WIPP, these systems are described in the Waste Isolation Pilot Plant Environmental Management System Description (DOE/WIPP 05-3318) and the Integrated Safety Management System Description (DOE/CBFO 98-2276). The WIPP action plan for integration, an internal management assessment of the EMS, and an external assessment to verify compliance with the order were completed. As a result of this work, WIPP self-declared the project's conformance to requirements of the DOE order.

The WIPP EMS conforms to the guiding principles of the International Organization for Standardization (ISO) 14001, Environmental Management Systems - Specification with Guidance for Use (ISO, 1996), as shown in Figure 1. How the EMS is integrated into the site ISMS is described in both the EMS and ISMS documents. In addition, the commonality between the two systems is summarized in the WIPP ISMS/EMS Procedural Integration Table. 


\section{WIPP Environmental Management System (EMS)}

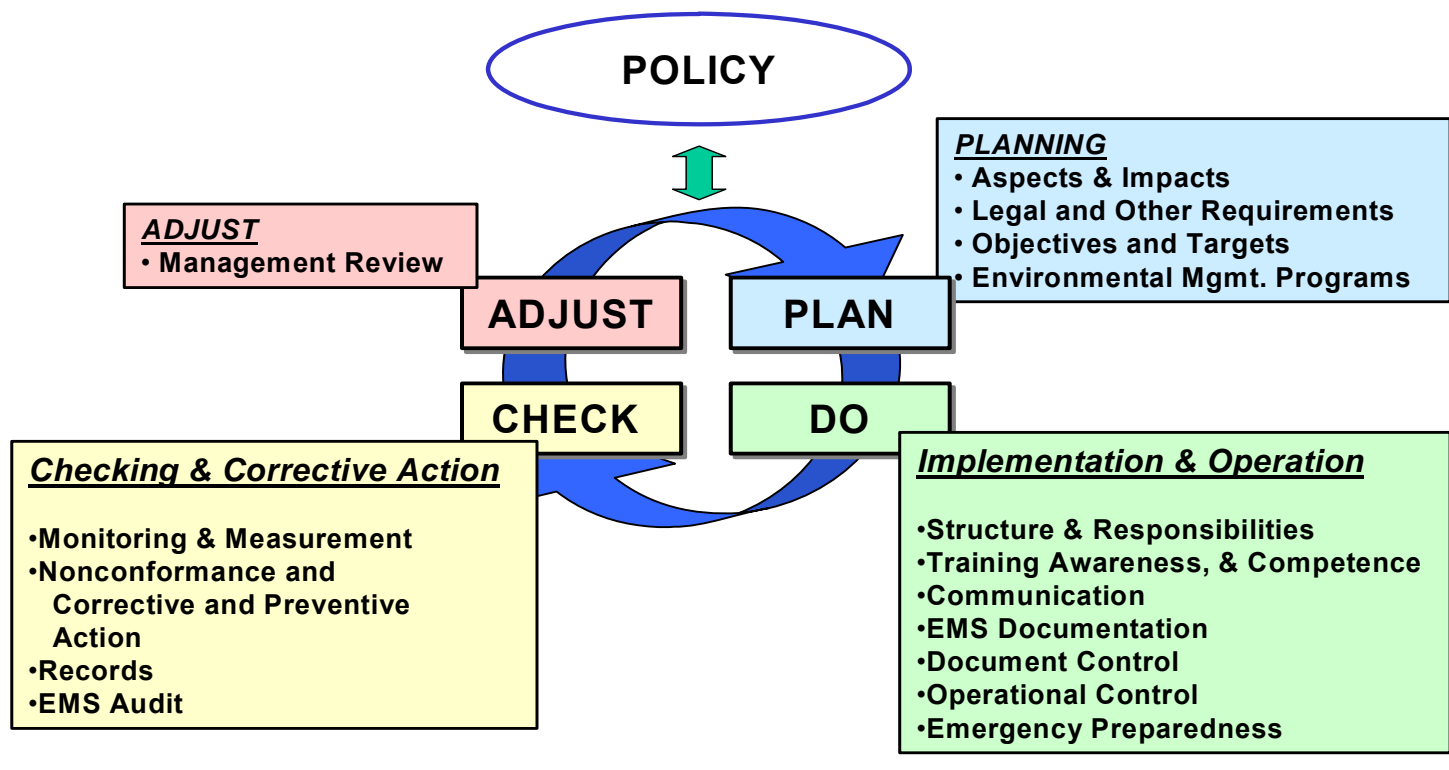

Figure 1 - WIPP Environmental Management System

The WIPP EMS is also integrated into overall site operations and management processes. Some examples of this integration with basic business processes are:

- $\quad$ EMS objective and target setting is integrated with the WIPP programmatic planning process.

- $\quad$ EMS awareness training is integrated with the project's overall training program.

- $\quad$ Environmental responsibilities are defined and operational control is maintained through integration with Conduct of Operations and Conduct of Maintenance programs and procedures.

- $\quad$ Emergency Preparedness and Response are fully integrated with the overall emergency planning process and managing of emergencies includes appropriate handling of safety, environmental, and operational considerations.

- $\quad$ Monitoring of environmental compliance and EMS is conducted through the project's assessment processes including internal Quality Assurance assessment program and management assessment program, the environmental group's Environmental Assessment Program and externally managed compliance and system assessments. 


\section{Performance Measures}

EMS effectiveness was measured using system indicators related to the three major environmental policy commitments (i.e., environmental stewardship, compliance with legal and internal requirements, and continual improvement in environmental performance.) These indicators were chosen by evaluation of underlying data, reviewed during the EMS annual review with management, and are the basis for the recommendation to management that the EMS continues to be suitable and effective for meeting WIPP's Environmental Policy. The indicators are summarized in the following table.

Table 1 - EMS Effectiveness Indicators

\begin{tabular}{|c|l|c|}
\hline $\begin{array}{c}|c| \\
\text { Policy Commitment } \\
\text { Stewardship }\end{array}$ & $\begin{array}{l}|c| \\
\text { Business milestones linked to significant aspects and } \\
\text { impacts }\end{array}$ & $\begin{array}{c}78 \% \\
(265 \text { of 338) }\end{array}$ \\
\hline & Significant aspects/impacts with business milestones & $\begin{array}{c}8 \% \\
(9 \text { of } 11)\end{array}$ \\
\hline & $\begin{array}{l}\text { Aspects and Impacts - Significant revisions to aspects and } \\
\text { impacts }\end{array}$ & 0 \\
\hline & P2 goals targeted to be accomplished in FY05 & $78 \%$ \\
& Reportable unauthorized contaminant releases & 0 \\
\hline & Notice of Violations & 0 \\
\hline & $\begin{array}{l}\text { Audits/Assessments/Agency Inspections performed related } \\
\text { to environmental compliance }\end{array}$ & $33^{1}$ \\
\hline & Total findings & 22 \\
\hline & Requirements assessed & 106 \\
\hline & Walk-arounds performed/repeat issues & $42 / 6$ \\
\hline & $\begin{array}{l}\text { Recommendations from FY 2004 Annual EMS Report } \\
\text { Implemented }\end{array}$ & 8 of 9 \\
\hline Continual Improvement & 8 \\
\hline & FY 2006 P2 goals set & 55 \\
\hline & Observations/recommendations identified in assessments \\
\hline
\end{tabular}

${ }^{1}$ Includes Internal - WTS/WRES and External - CBFO and Agencies

The data generated from implementation of the WIPP EMP are also indicators for environmental stewardship. This data, from radiological, nonradiological and land management monitoring, demonstrates there has been no adverse impact to human health or the environment from WIPP operations.

Measures for EMS integration with ISMS and system implementation were those established by the DOE to measure progress. The DOE measured progress toward system implementation according to ten indicators. With the EMS having been initially implemented in 1997 and maintained in compliance with the ISO 14001 standard, WIPP's mature EMS made a significant contribution to assuring the DOE indicators were met by the end of FY05 as reflected in Table 2. 
Waste Isolation Pilot Plant Annual Site Environmental Report for 2005 DOE/WIPP-06-2225

\begin{tabular}{|c|l|c|}
\hline \multicolumn{2}{|c|}{ Table 2 - DOE EMS Implementation Indicator Status } \\
\hline & \multicolumn{1}{|c|}{ Implementation Indicator } & Complete \\
\hline 1 & EMS Policy Statement issued & $\boldsymbol{V}$ \\
\hline 2 & EMS implementation training provided to personnel establishing system & $\boldsymbol{V}$ \\
\hline 3 & Significant environmental aspects/impacts identified & $\boldsymbol{V}$ \\
\hline 4 & Measurable environmental objectives and targets established & $\boldsymbol{V}$ \\
\hline 5 & Environmental Management Programs (EMPs) established to achieve objectives & $\boldsymbol{V}$ \\
\hline 6 & EMS awareness training developed & $\boldsymbol{V}$ \\
\hline 7 & Formal ongoing program for facility wide EMS awareness training in place & $\boldsymbol{V}$ \\
\hline 8 & EMS procedures established & $\boldsymbol{V}$ \\
\hline 9 & EMS in place, implemented and self-declaration protocol completed \\
\hline 10 & Site Manager's conformity declaration letter submitted to the DOE & \\
\hline
\end{tabular}

\section{Summary of Releases and Radiological Doses to the Public}

Doses to the Public and the Environment

The radiation dose to members of the public from WIPP operations has been calculated from WIPP effluent monitoring results and demonstrates compliance with federal regulations.

\section{Dose Limits}

The regulatory basis for WIPP is in Title 40 Code of Federal Regulations (CFR) Part 191, Subpart A, "Environmental Standards for Management and Storage." The referenced standard specifies that the combined annual dose equivalent to any member of the public in the general environment resulting from discharges of radioactive material and direct radiation from such management and storage shall not exceed 25 millirem (mrem) ("rem" is Roentgen Equivalent Man) to the whole body and 75 mrem to any critical organ. In addition, in a 1995 Memorandum of Understanding between the EPA and the DOE, the DOE agreed that WIPP would comply with 40 CFR Part 61, Subpart H, "National Emission Standards for Emissions of Radionuclides Other Than Radon from Department of Energy Facilities," hereafter referred to as the NESHAP (National Emissions Standards for Hazardous Air Pollutants), where it is appropriate. The NESHAP standard states that the emissions of radionuclides to the ambient air from Department of Energy facilities shall not exceed those amounts that would cause any member of the public to receive in any year an effective dose equivalent (EDE) of 10 mrem per year.

\section{Background Radiation}

Radiation is a natural part of the environment. There are several sources of naturally occurring radiation: cosmic and cosmogenic radiation (from outer space and the earth's atmosphere), terrestrial radiation (from the earth's crust), and internal radiation (naturally occurring radioactive material in our bodies). In addition to natural 
radioactivity, small amounts of radioactivity from aboveground nuclear weapons tests and from the 1986 Chernobyl nuclear accident are present in the environment. A potential source of radiation in the environment near and at the WIPP site is Project Gnome. Under Project Gnome, a nuclear device was detonated in bedded salt on December 10, 1961, approximately $9 \mathrm{~km}(5.4 \mathrm{mi})$ from the WIPP site. The Project Gnome shot vented into the atmosphere; therefore, environmental samples taken at WIPP may contain residual contamination from this occurrence. Together, natural radiation and residual fallout are called "background" radiation. All living organisms are constantly exposed to background radiation. Exposure to radioactivity from weapons testing fallout is quite small compared to natural radioactivity and continually gets smaller as radionuclides decay. The average annual dose received by a member of the public from naturally occurring radionuclides is approximately $3 \mathrm{mSv}$ (millisievert) (300 mrem) (NCRP [National Council on Radiation Protection and Measurements], 1987a). Site-specific background gamma measurements on the surface, conducted by Sandia National Laboratories at WIPP, showed average dose rate of $7.65 \mathrm{microR} / \mathrm{hour}$ (Minnema and Brewer, 1983) which would equate to the background gamma radiation dose of $0.67 \mathrm{mSv}$ (67.0 mrem) per year. A comprehensive radiological baseline study before WIPP operations was also documented in Statistical Summary of the Radiological Baseline Program for the Waste Isolation Pilot Plant (DOE/WIPP 92-037, 1992), which provides the basis for environmental background comparison after WIPP disposal operations commenced.

\section{Dose from Air Emissions}

WIPP has identified air emissions as the major pathway of concern for radionuclide transport during the receipt and emplacement of waste at WIPP. To determine the radiation dose received by members of the public from WIPP, WIPP used the emission monitoring and test procedure for DOE facilities (40 CFR §61.93, "Emission Monitoring and Test Procedure"), which requires the use of the EPA-approved CAP88-PC to calculate the effective dose equivalent to members of the public. CAP88-PC dose calculations are based on the assumption that exposed people remain at home during the entire year and all vegetables, milk, and meat consumed are home produced. Thus, this dose calculation is a maximum dose that encompasses dose from inhalation, plume submersion, deposition, and ingestion of air-emitted radionuclides.

\section{Total Dose from WIPP Operations}

The dose to an individual from the ingestion of WIPP-related radionuclides transported in water is nonexistent because drinking water for communities near WIPP comes from groundwater sources that are too far away to be affected by WIPP operations.

Game animals sampled during 2005 were deer, quail, fish, and rabbit. The only radionuclides detected were not different from baseline levels. By extrapolation, no dose from WIPP-related radionuclides has been received by any individual from this pathway (e.g., the ingestion of meat from game animals) during 2005. 
Based on the results of the WIPP Effluent Monitoring Program, concentrations of radionuclides in air emissions did not exceed regulatory dose limits set by 40 CFR Part 191, Subpart A, or by 40 CFR Part 61, Subpart H. The results indicate that the hypothetical maximally exposed individual (MEI) that resides year-round at the WIPP fence line receives a dose that is less than $8.86 \mathrm{E}-07 \mathrm{mSv}(8.86 \mathrm{E}-05 \mathrm{mrem})$ per year for the whole body, and is less than $1.41 \mathrm{E}-05 \mathrm{mSv}(1.41 \mathrm{E}-03 \mathrm{mrem})$ per year for the critical organ. These values are in compliance with the Subpart A requirements specified in 40 CFR §191.03(b). For NESHAP (40 CFR §61.92) standards, the EDE potentially received by the MEI residing $7.5 \mathrm{~km}$ (4.66 miles) west-northwest of WIPP was calculated to be $3.85 \mathrm{E}-08 \mathrm{mSv}(3.85 \mathrm{E}-06 \mathrm{mrem})$ per year whole body. This value is in compliance with the 40 CFR $\S 61.92$ requirements.

Chapter 4 of this report presents figures and tables that provide the EDE values from calendar years (CY) 1999 through 2005. Note that these EDE values are below the EPA limit specified in 40 CFR Part 191, Subpart A, and 40 CFR Part 61, Subpart H.

\section{Dose to Nonhuman Biota}

Dose limits that cause no deleterious effects on populations of aquatic and terrestrial organisms have been suggested by the NCRP and the International Atomic Energy Agency. These absorbed dose limits are:

- Aquatic Animals $10 \mathrm{mGy} / \mathrm{d}$ (milli Gray/day), (1 rad [Radiation Absorbed
Dose]/d)

- Terrestrial Plants $10 \mathrm{mGy} / \mathrm{d}(1 \mathrm{rad} / \mathrm{d})$

- Terrestrial Animals $1 \mathrm{mGy} / \mathrm{d}(0.1 \mathrm{rad} / \mathrm{d})$

The DOE requires discussion of radiation doses to nonhuman biota in the ASER using the DOE Technical Standard, DOE-STD-1153-2002, A Graded Approach for Evaluating Radiation Doses to Aquatic and Terrestrial Biota. This standard requires an initial screening phase using conservative assumptions.

This guidance was used to screen radionuclide concentrations observed around WIPP during 2005. The screening results indicate that radiation in the environment surrounding WIPP does not have a deleterious effect on populations of plants and animals.

\section{Release of Property Containing Residual Radioactive Material}

There was no release of radiologically contaminated materials or property in 2005. Preventing the release of contaminated materials or property at WIPP is accomplished through implementation of institutional controls. 


\section{TABLE OF CONTENTS}

EXECUTIVE SUMMARY

ACRONYMS, ABBREVIATIONS, AND UNITS OF MEASURE $\ldots \ldots \ldots \ldots \ldots$ xxii

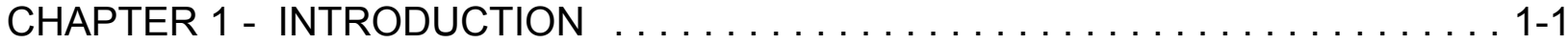

1.1 WIPP's Mission . . . . . . . . . . . . . . . . . . . . . . 1-2

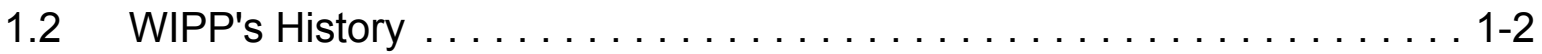

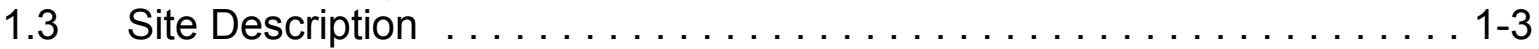

1.3.1 WIPP Property Areas $\ldots \ldots \ldots \ldots \ldots \ldots \ldots \ldots \ldots \ldots \ldots$

1.3.2 Population . . . . . . . . . . . . . . . . .

1.4 WIPP Environmental Program Information $\ldots \ldots \ldots \ldots \ldots \ldots \ldots .1-7$

1.4.1 Environmental Monitoring Plan . . . . . . . . . . . . 1-7

1.4.2 WIPP Environmental Monitoring Program and Surveillance

Activities ................................ 1-9

1.5 Environmental Performance . . . . . . . . . . . . . . . . . . . 1-9

1.6 Organization of This ASER $\ldots \ldots \ldots \ldots \ldots \ldots \ldots \ldots \ldots \ldots \ldots \ldots \ldots$

CHAPTER 2 - COMPLIANCE SUMMARY . . . . . . . . . . . .

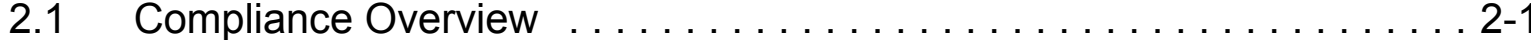

2.2 Compliance Status ........................... 2-1

2.2.1 Comprehensive Environmental Response, Compensation,

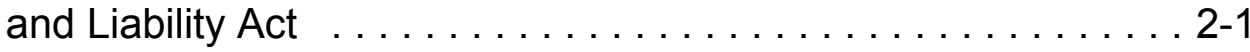

2.2.2 Resource Conservation and Recovery Act . . . . . . . . . . 2-2

2.2.3 National Environmental Policy Act . . . . . . . . . . . . . . . 2-5

2.2.4 Clean Air Act . . . . . . . . . . . . . . . . . . . . . . . . . . . . . 2-6

2.2 .5 Clean Water Act . . . . . . . . . . . . . . . . . . . . 2-7

2.2.6 New Mexico Water Quality Act . . . . . . . . . . . . . . . 2-7

2.2.7 Safe Drinking Water Act . . . . . . . . . . . . . . . . . 2-8

2.2.8 National Historic Preservation Act $\ldots \ldots \ldots \ldots \ldots \ldots \ldots . .2 .4$.

2.2.9 Toxic Substances Control Act . . . . . . . . . . . . . . . 2-9

2.2.10 Federal Insecticide, Fungicide, and Rodenticide Act . . . . . . 2-9

2.2.11 Endangered Species Act $\ldots \ldots \ldots \ldots \ldots \ldots \ldots \ldots \ldots .2-9$

2.2.12 Migratory Bird Treaty Act $\ldots \ldots \ldots \ldots \ldots \ldots \ldots \ldots \ldots .2-10$

2.2.13 Federal Land Policy and Management Act . . . . . . . . . . . 2 2-10

2.2.14 Federal Facilities Compliance Act $\ldots \ldots \ldots \ldots \ldots \ldots \ldots .2-11$

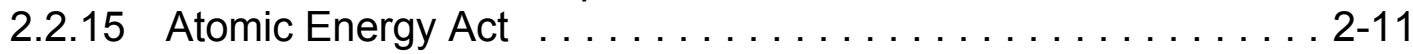

2.2.16 DOE Orders ......................... 2-14

2.2.17 Executive Orders ...................... 2-17

2.3 Other Significant Accomplishments and Ongoing Compliance

Activities . . . . . . . . . . . . . . . . . . . . . . . . . . . 2-20 
CHAPTER 3 - ENVIRONMENTAL MANAGEMENT SYSTEM $\ldots \ldots \ldots \ldots \ldots \ldots$ 3-1

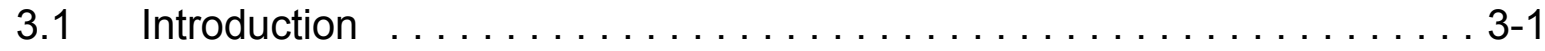

3.2 WIPP EMS Elements . . . . . . . . . . . . . . . . . . . . . 3-1

3.2.1 Policy .........................

3.2.2 Aspects and Impacts . . . . . . . . . . . . . . . . .

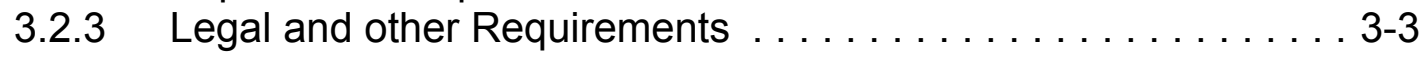

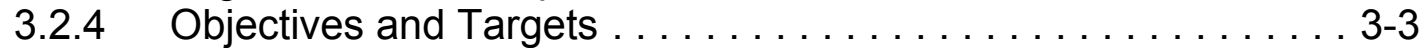

3.2.5 Environmental Management Program .............. 3-4

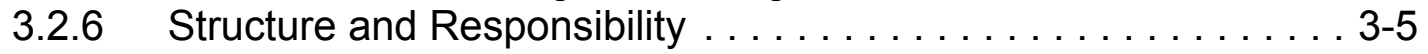

3.2.7 Training, Awareness and Competency $\ldots \ldots \ldots \ldots \ldots \ldots .3-5$

3.2 .8 Communication . . . . . . . . . . . . . . . . . . .

3.2 .9 EMS Documentation . . . . . . . . . . . . . . . . . . 3-6

3.2.10 Document Control and Records . . . . . . . . . . . . . 3-6

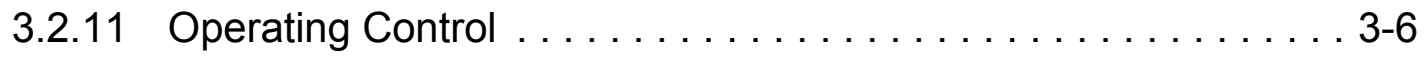

3.2.12 Emergency Preparedness and Response . . . . . . . . . 3-7

3.2.13 Measuring and Monitoring (Environmental Performance Measurement) . . . . . . . . . . . . . . . . . . . . 3-8

3.2.14 Corrective and Preventive Action . . . . . . . . . . . . 3-12

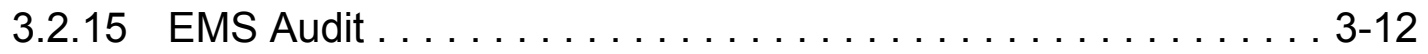

3.2.16 Management Review $\ldots \ldots \ldots \ldots \ldots \ldots \ldots \ldots \ldots \ldots . .12$

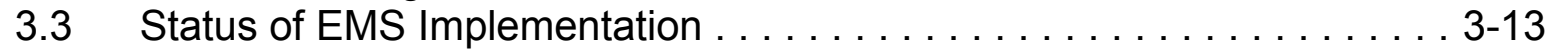

CHAPTER 4 - ENVIRONMENTAL RADIOLOGICAL PROGRAM INFORMATION . . 4-1

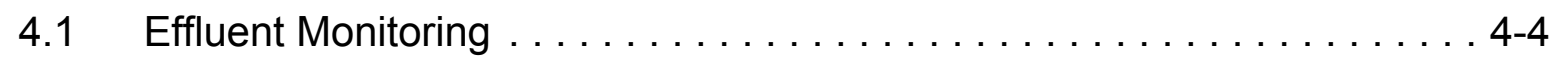

4.1.1 Sample Collection . . . . . . . . . . . . . . . . . 4-4

4.1.2 Sample Preparation . . . . . . . . . . . . . . . . 4 4

4.1.3 Determination of Individual Radionuclides . . . . . . . . . . 4-5

4.1.4 Results and Discussion ... . . . . . . . . . . . . . . 4-5

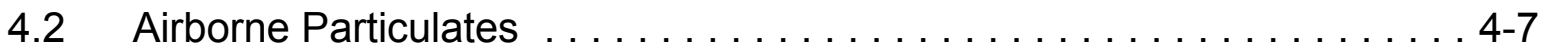

4.2.1 Sample Collection . . . . . . . . . . . . . . . .

4.2.2 Sample Preparation . . . . . . . . . . . . . . . . . . 4-8

4.2.3 Determination of Individual Radionuclides . . . . . . . . . 4-8

4.2.4 Results and Discussion ... . . . . . . . . . . . . 4-8

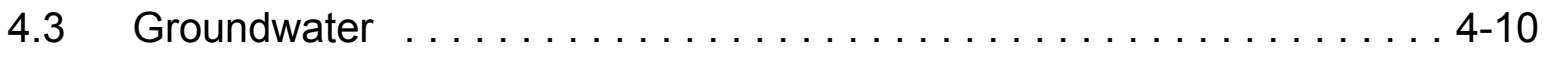

4.3.1 Sample Collection . . . . . . . . . . . . . . . . 4 .

4.3.2 Sample Preparation . . . . . . . . . . . . . . . 4-10

4.3.3 Determination of Individual Radionuclides . . . . . . . . . . 4-11

4.3.4 Results and Discussion . . . . . . . . . . . . . . 4-11

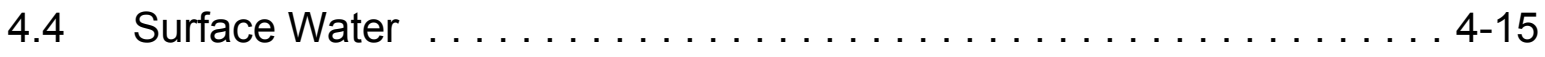

4.4.1 Sample Collection . . . . . . . . . . . . . . . . 4-15

4.4.2 Sample Preparation ................... 4-16

4.4.3 Determination of Individual Radionuclides . . . . . . . . . . 4-16

4.4.4 Results and Discussion . . . . . . . . . . . . . . 4-17

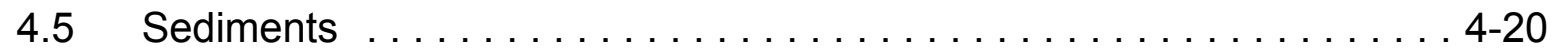

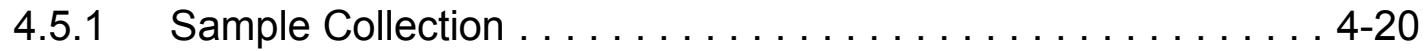

4.5.2 Sample Preparation $\ldots \ldots \ldots \ldots \ldots \ldots \ldots \ldots \ldots .4 .20$ 
4.5.3 Determination of Individual Radionuclides . . . . . . . . . 4-20

4.5.4 Results and Discussion . . . . . . . . . . . . . . 4-21

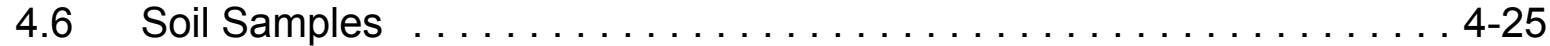

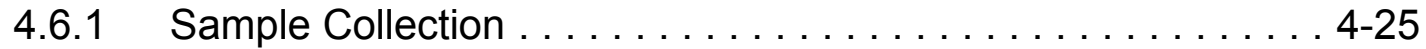

4.6.2 Sample Preparation . . . . . . . . . . . . . . . 4-26

4.6.3 Determination of Individual Radionuclides . . . . . . . . 4-26

4.6.4 Results and Discussion . . . . . . . . . . . . . . . . 4-26

$4.7 \quad$ Biota . . . . . . . . . . . . . . . . . . . . . . . . . . 4-30

4.7.1 Sample Collection .................... 4-30

4.7.2 Sample Preparation . . . . . . . . . . . . . . . . 4-30

4.7.3 Results and Discussion $\ldots \ldots \ldots \ldots \ldots \ldots \ldots \ldots \ldots .4 .31$

4.8 Potential Dose from WIPP Operations . . . . . . . . . . . . . . . 4 4-34

4.8.1 Dose Limits . . . . . . . . . . . . . . . . . . . . . . . 4-34

4.8.2 Background Radiation $\ldots \ldots \ldots \ldots \ldots \ldots \ldots \ldots \ldots \ldots 4.34$

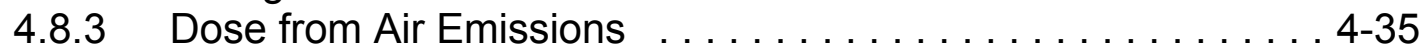

4.8.4 Total Potential Dose from WIPP Operations . . . . . . . 4-36

4.8.5 Dose to Nonhuman Biota . . . . . . . . . . . . . . . 4-38

4.8.6 Release of Property Containing Residual Radioactive

Material . . . . . . . . . . . . . . . . . . . . 4-40

4.9 Radiological Program Conclusions $\ldots \ldots \ldots \ldots \ldots \ldots \ldots \ldots$ 4-40

CHAPTER 5 - ENVIRONMENTAL NONRADIOLOGICAL PROGRAM

INFORMATION ........................ 5-1

5.1 Principal Functions of Nonradiological Sampling $\ldots \ldots \ldots \ldots \ldots \ldots$ 5-1

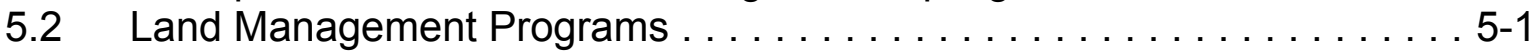

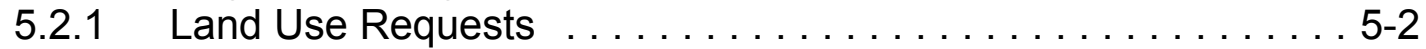

5.2 .2 Wildlife Population Monitoring ................. 5-2

5.2.3 Reclamation of Disturbed Lands . . . . . . . . . . . . . . . 5-2

5.2.4 Oil and Gas Surveillance $\ldots \ldots \ldots \ldots \ldots \ldots \ldots \ldots \ldots \ldots$

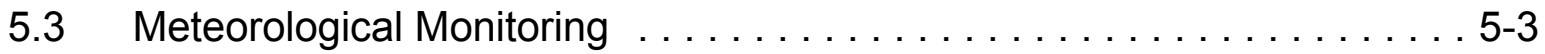

$5.3 .1 \quad$ Climatic Data . . . . . . . . . . . . . . . . . . . . . 5-4

5.3.2 Wind Direction and Wind Speed ................ 5-7

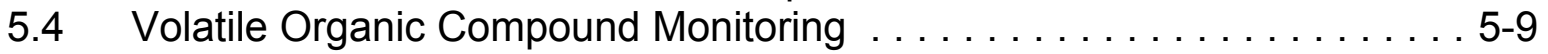

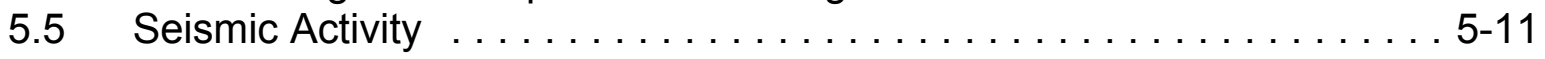

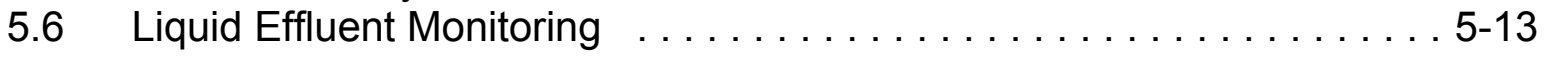

CHAPTER 6 - SITE HYDROLOGY, GROUNDWATER MONITORING, AND PUBLIC DRINKING WATER PROTECTION $\ldots \ldots \ldots \ldots \ldots \ldots 6-1$

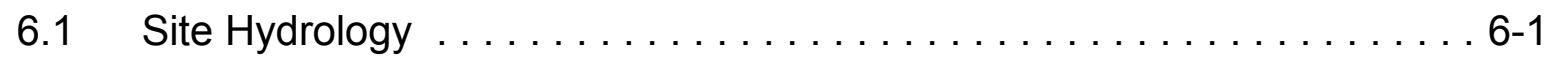

6.1 .1 Surface Hydrology $\ldots \ldots \ldots \ldots \ldots \ldots \ldots \ldots \ldots . \ldots \ldots 6.1$

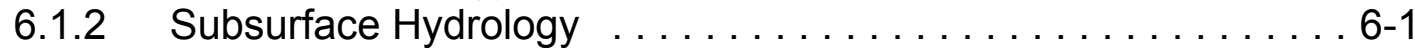

6.2 Groundwater Monitoring . . . . . . . . . . . . . . . . . . 6-4

6.2.1 Program Objectives . . . . . . . . . . . . . . . 6-4

6.2 .2 Summary of 2005 Activities . . . . . . . . . . . . . 6-4

6.2.3 Groundwater Quality Sampling . . . . . . . . . . . . 6-7

6.2.4 Evaluation of Groundwater Quality . . . . . . . . . . . 6-9 
6.2.5 Groundwater Level Surveillance . . . . . . . . . . . 6-10

6.2.6 Pressure Density Surveys $\ldots \ldots \ldots \ldots \ldots \ldots \ldots \ldots \ldots 6$ 6 $6 \ldots \ldots$

6.3 Drilling Activities . . . . . . . . . . . . . . . . . . . . . 6 $6-17$

6.4 Well Maintenance Activities . . . . . . . . . . . . . . . . . . . 6-18

6.5 Shallow Subsurface Water Monitoring Program . . . . . . . . . . 6-19

6.5.1 Shallow Subsurface Water Quality Sampling ... . . . . . . 6-22

6.5.2 Shallow Subsurface Water Level Surveillance . . . . . . . . . . 6-23

6.6 Public Drinking Water Protection . . . . . . . . . . . . . . . 6-25

CHAPTER 7 - QUALITY ASSURANCE $\ldots \ldots \ldots \ldots \ldots \ldots \ldots \ldots \ldots \ldots \ldots \ldots .1$

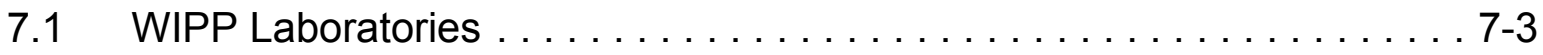

7.1.1 Completeness . . . . . . . . . . . . . . . . . . . . 7-3

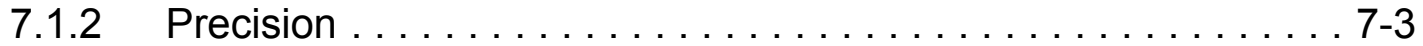

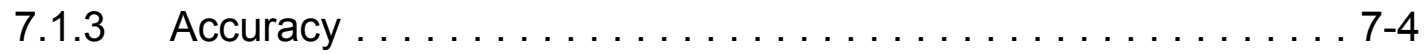

7.1.4 Comparability .....................

7.1.5 Representativeness . . . . . . . . . . . . . . . . .

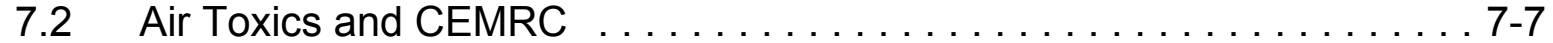

7.2.1 Completeness . . . . . . . . . . . . . . . . . . . . .7-7

7.2.2 Precision . . . . . . . . . . . .

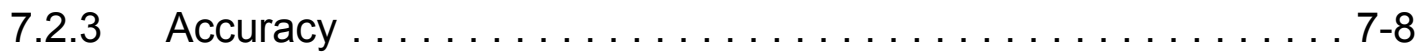

7.2 .4 Comparability ........................

7.2.5 Representativeness . . . . . . . . . . . . . . . . . 7-9

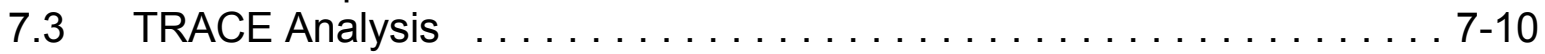

7.3.1 Completeness . . . . . . . . . . . . . . . . . . . .

7.3.2 Precision . . . . . . . . . . . . . . .

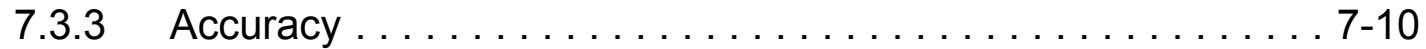

7.3.4 Comparability ......................... 7-11

7.3.5 Representativeness ................... 7-11

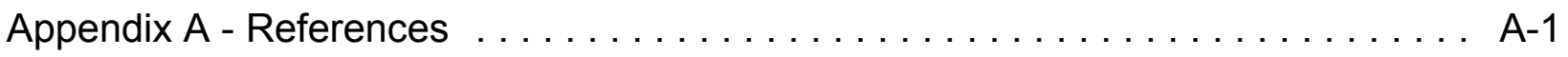

Appendix B - Active Environmental Permits $\ldots \ldots \ldots \ldots \ldots \ldots \ldots \ldots$ B-1

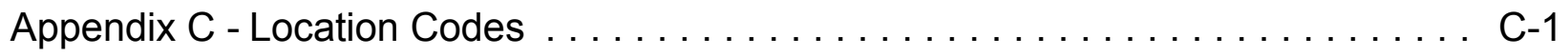

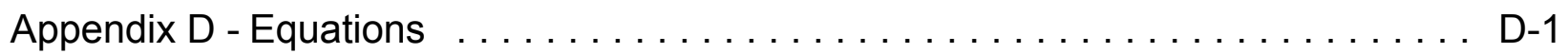

Appendix E - Time Trend Plots for Detectable Constituents in Groundwater ..... E-1

Appendix F - Groundwater Data Tables . . . . . . . . . . . . . . F F-1

Appendix G - Air Sampling Data: Concentrations of Radionuclides ........... G-1

Appendix $\mathrm{H}$ - Comparison of Detected Radionuclides to the Radiological Baseline 


\section{LIST OF TABLES}

Table $1 \quad$ EMS Effectiveness Indicators $\ldots \ldots \ldots \ldots \ldots \ldots \ldots$ vii

Table 2 DOE EMS Implementation Indicator Status $\ldots \ldots \ldots \ldots \ldots$ viii

Table $1.1 \quad 2005$ Environmental Sampling Schedule $\ldots \ldots \ldots \ldots \ldots \ldots \ldots$ 1-8

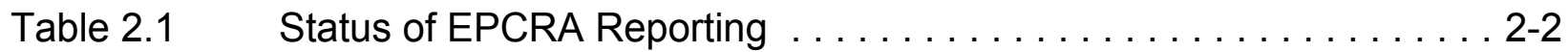

Table $2.2 \quad$ Permit Modification Requests and Notifications Submitted in 2005 . . 2-3

Table $2.3 \quad$ Materials Recycled at WIPP $\ldots \ldots \ldots \ldots \ldots \ldots \ldots \ldots \ldots .2-18$

Table 2.4 WIPP Waste Volumes Compared to Baseline, and Reduction Goals for FY 2005 . . . . . . . . . . . . . . . . . . . . . 2-21

Table 4.1 Activity $(\mathrm{Bq})$ of Quarterly Composite Air Samples from the WIPP Effluent Monitoring Stations A, B, and C for $2005 \ldots \ldots \ldots$. . . . 6

Table 4.2 Minimum, Maximum, and Average Radionuclide Concentrations $\left(\mathrm{Bq} / \mathrm{m}^{3}\right)$ in Air Filter Composites from Stations Surrounding the WIPP Site . . . . . . . . . . . . . . . . . . . . . . . . . 4-8

Table 4.3 Results of Duplicate Composite Air Filter Sampling . . . . . . . . 4 4-10

Table 4.4 Radionuclide Concentrations $(\mathrm{Bq} / \mathrm{L})$ in Groundwater from Wells at the WIPP Site . . . . . . . . . . . . . . . . . . . . 4-12

Table 4.5 Results of Duplicate Groundwater Sample Analysis for Sampling Round $20 \ldots \ldots \ldots \ldots \ldots \ldots \ldots \ldots \ldots \ldots \ldots \ldots$ 4 14

Table 4.6 Results of Duplicate Groundwater Sample Analysis for Sampling Round 21

Table 4.7 Uranium Concentrations $(\mathrm{Bq} / \mathrm{L})$ in Surface Water Near the WIPP Site

Table 4.8 Americium and Plutonium Concentrations $(\mathrm{Bq} / \mathrm{L})$ in Surface Water Near the WIPP Site

Table 4.9 Selected Radionuclide Concentrations $(\mathrm{Bq} / \mathrm{L})$ in Surface Water Near the WIPP Site

Table 4.10 Results of Duplicate Surface Water Sample Analysis

Table 4.11 Uranium Concentrations $(\mathrm{Bq} / \mathrm{g})$ in Sediment Near the WIPP Site . . 4-22 
Table 4.12 Americium and Plutonium Concentrations (Bq/g) in Sediment Near the WIPP Site

Table 4.13 Selected Radionuclide Concentrations $(\mathrm{Bq} / \mathrm{g})$ in Sediment Near the WIPP Site

Table 4.14 Results of Duplicate Sediment Sampling Analysis . . . . . . . . . 4-24

Table 4.15 Uranium Concentrations $(\mathrm{Bq} / \mathrm{g})$ in Soil Near the WIPP Site . . . . . 4-27

Table 4.16 Americium and Plutonium Concentrations (Bq/g) in Soil Near the WIPP Site . . . . . . . . . . . . . . . . . . . . . . . 4-27

Table 4.17 Selected Radionuclide Concentrations $(\mathrm{Bq} / \mathrm{g})$ in Soil Near the WIPP Site

Table 4.18 Results of Duplicate Soil Sampling Analysis in Soil Near the WIPP Site

Table 4.19 Radionuclide Concentrations (Bq/g Wet Mass) in Vegetation Near the WIPP Site

Table 4.20 Results of Duplicate Vegetation Sample Analysis $\ldots . \ldots \ldots \ldots$ 4-33

Table 4.21 Radionuclide Concentrations (Bq/g Wet Mass) in Deer, Quail, Rabbit, and Fish Near the WIPP Site

Table 4.22 Annual Estimated Average Radiation Dose Received by a Member of the Population of the United States from Naturally Occurring Radiation Sources

Table 4.23 WIPP Radiological Dose and Release Summary . . . . . . . . . 4-37

Table 4.24 General Screening Results for Potential Radiation Dose to Nonhuman Biota from Radionuclide Concentrations in Surface Water $(\mathrm{Bq} / \mathrm{L})$, Sediment $(\mathrm{Bq} / \mathrm{g})$, and Soil $(\mathrm{Bq} / \mathrm{g})$ Near the WIPP Site in 2005

Table 4.25 Dose to the Whole Body: 40 CFR $\S 191.03(b) \ldots \ldots \ldots \ldots \ldots .41$

Table 4.26 Dose to the Critical Organ: 40 CFR $\S 191.03(b) \ldots . \ldots \ldots \ldots .4 .42$

Table 4.27 Comparison of Effective Dose Equivalents to EPA Limit of $10 \mathrm{mrem} /$ year per $40 \mathrm{CFR} \S 61.92$

Table 5.1 Concentrations of Concern for Volatile Organic Compounds, from Attachment $\mathrm{N}$ of the HWFP (No. NM4890139088-TSDF) . . . 5-9 
Table 5.2 Volatile Organic Compound MRLs

Table 5.3 Sewage Lagoon and H-19 Semiannual Analytical Results for January 1 through June 30, 2005 . .

Table 5.4 Sewage Lagoon and H-19 Semiannual Analytical Results for July 1 through December 31, 2005

Table 5.5 Infiltration Control Evaporation Ponds Annual Analytical Results for January 1 through December 31, $2005 \ldots \ldots \ldots \ldots \ldots \ldots$. 5-15

Table 6.1 Summary of 2005 DOE Sitewide Groundwater Monitoring Program ..................... 6.5

Table 6.2 Analytical Parameters for Which Groundwater Was Analyzed . . . . . 6-8

Table 6.3 Pressure Density Survey for $2005 \ldots \ldots \ldots \ldots \ldots \ldots$ 6-16

Table 6.4 Elevation Survey Results $\left(\mathrm{NGVD}^{*}{ }^{*}\right) \ldots \ldots \ldots \ldots \ldots \ldots \ldots \ldots$ 6-19

Table 6.5 Survey Data of New Wells (NGVD29) $\ldots \ldots \ldots \ldots \ldots \ldots \ldots$ 6-19

Table 6.6 2005 Shallow Subsurface Water Quality Sampling Results . . . . . 6-22

Table $7.1 \quad$ NRIP for WIPP Laboratories, $2005 \ldots \ldots \ldots \ldots \ldots \ldots \ldots \ldots$. $\ldots \ldots$

Table 7.2 Mixed Analyte Performance Evaluation Review for WIPP Laboratories, $2005 \ldots \ldots \ldots \ldots \ldots \ldots \ldots \ldots \ldots \ldots$. $7-6$

Table $7.3 \quad 2004$ VOC Sample Comparison for CEMRC $\ldots \ldots \ldots \ldots \ldots .7$. . . . . . .

Table 7.4 Absolute Grade PT Program Assessment of Trace Analysis, Inc. October - November, $2005 \quad \ldots \ldots \ldots \ldots \ldots \ldots \ldots \ldots \ldots$. . . . . . . . . .

Table 7.5 Absolute Grade PT Program Assessment of Trace Analysis, Inc., Petroleum October - November, 2005 . . . . . . . . . . . . . . . 7-16

Table 7.6 Absolute Grade PT Program Assessment of Trace Analysis, Inc., Pesticides - October - November, 2005 . . . . . . . . . 7-17 
Waste Isolation Pilot Plant Annual Site Environmental Report for 2005

DOE/WIPP-06-2225

This page intentionally left blank 


\section{LIST OF FIGURES}

Figure $1 \quad$ WIPP Environmental Management System $\ldots \ldots \ldots \ldots \ldots \ldots$ vi

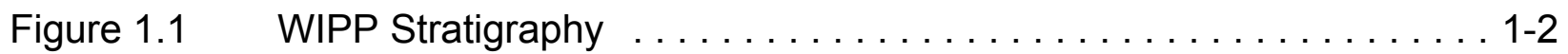

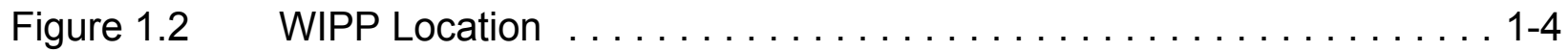

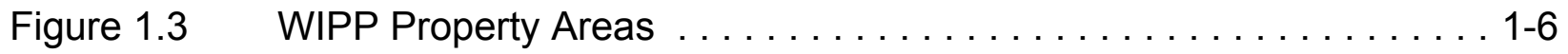

Figure 3.1 WIPP Waste Reduction Compared to Secretary of Energy's 2005 Goals . . . . . . . . . . . . . . . . . . . . . . . . . . . . . 3-4

Figure 3.2 Site Environmental (P2) Goals Scorecard . . . . . . . . . . . 3-9

Figure 3.3 WIPP Recycled vs Total Generated Wastes $\ldots \ldots \ldots \ldots \ldots \ldots$ 3-10

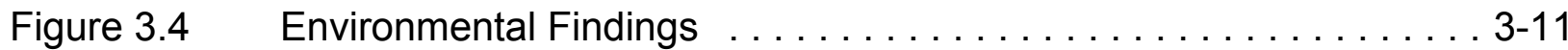

Figure 4.1 Air Sampling Locations on and Near the WIPP Facility $\ldots \ldots \ldots \ldots 4-7$

Figure 4.2 Routine Surface Water Sampling Locations . . . . . . . . . . . 4-16

Figure $4.3 \quad$ Sediment Sampling Sites $\ldots \ldots \ldots \ldots \ldots \ldots \ldots \ldots \ldots \ldots .4 .21$

Figure $4.4 \quad$ Routine Soil and Vegetation Sampling Areas . . . . . . . . . 4 4-25

Figure 4.5 Dose to Whole Body for Hypothetical Maximally Exposed Individual at the WIPP Fence Line . . . . . . . . . . . . . . 4-41

Figure 4.6 Dose to the Critical Organ for Hypothetical Maximally Exposed Individual at the WIPP Fence Line . . . . . . . . . . . . 4-42

Figure 4.7 WIPP Effective Dose Equivalent to the Off-Site Maximally Exposed Individual

Figure $5.1 \quad 2005$ Precipitation at WIPP . . . . . . . . . . . . . .

Figure $5.2 \quad 2005$ High Temperatures at WIPP $\ldots \ldots \ldots \ldots \ldots \ldots \ldots \ldots$

Figure $5.3 \quad 2005$ Average Temperatures at WIPP . . . . . . . . . . . . 5-6

Figure $5.4 \quad 2005$ Low Temperatures at WIPP . . . . . . . . . . . . 5-7

Figure $5.5 \quad 2004$ Wind Speed Direction at WIPP $\ldots \ldots \ldots \ldots \ldots \ldots \ldots \ldots .5-8$ 
Figure 5.6 Comparison of VOC MRLs and MCDs to Concentrations of Concern ......................... $5-11$

Figure $5.7 \quad$ WIPP Seismograph Station Locations $\ldots \ldots \ldots \ldots \ldots \ldots \ldots .4$. . . . . . .

Figure 6.1 Water Quality Sampling Program Wells $\ldots \ldots \ldots \ldots \ldots \ldots$ 6-6

Figure 6.2 Groundwater Level Surveillance Wells . . . . . . . . . . . . 6-7

Figure 6.3 Potentiometric Surface of the Culebra Dolomite, December $2005 \ldots$ 6-12

Figure $6.4 \quad$ Hydrograph of WQSP-1 $\ldots \ldots \ldots \ldots \ldots \ldots \ldots \ldots \ldots \ldots 6.13$

Figure $6.5 \quad$ Hydrograph of WQSP-2 $\ldots \ldots \ldots \ldots \ldots \ldots \ldots \ldots \ldots \ldots 6$ 6-13

Figure $6.6 \quad$ Hydrograph of WQSP-3 $\ldots \ldots \ldots \ldots \ldots \ldots \ldots \ldots \ldots \ldots .6 \ldots \ldots \ldots$

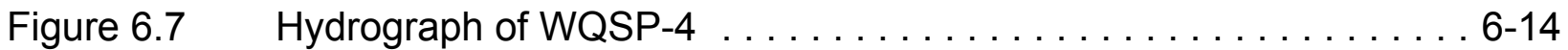

Figure $6.8 \quad$ Hydrograph of WQSP-5 $\ldots \ldots \ldots \ldots \ldots \ldots \ldots \ldots \ldots \ldots \ldots 6$ 6-15

Figure 6.9 Hydrograph of WQSP-6 $\ldots \ldots \ldots \ldots \ldots \ldots \ldots \ldots \ldots \ldots 6$ 6-15

Figure 6.10 Hydrograph of WQSP-6A $\ldots \ldots \ldots \ldots \ldots \ldots \ldots \ldots \ldots 6.16$

Figure 6.11 Locations of SSW Wells (Piezometers PZ-1 through 12; Wells C-2811, C-2505, C-2506, and C-2507 . . . . . . . . . . . . 6-21

Figure 6.12 Contour Plot of SSW Potentiometric Surface in the Santa Rosa Formation ........................... 6-24 


\section{ACRONYMS, ABBREVIATIONS, AND UNITS OF MEASURE}

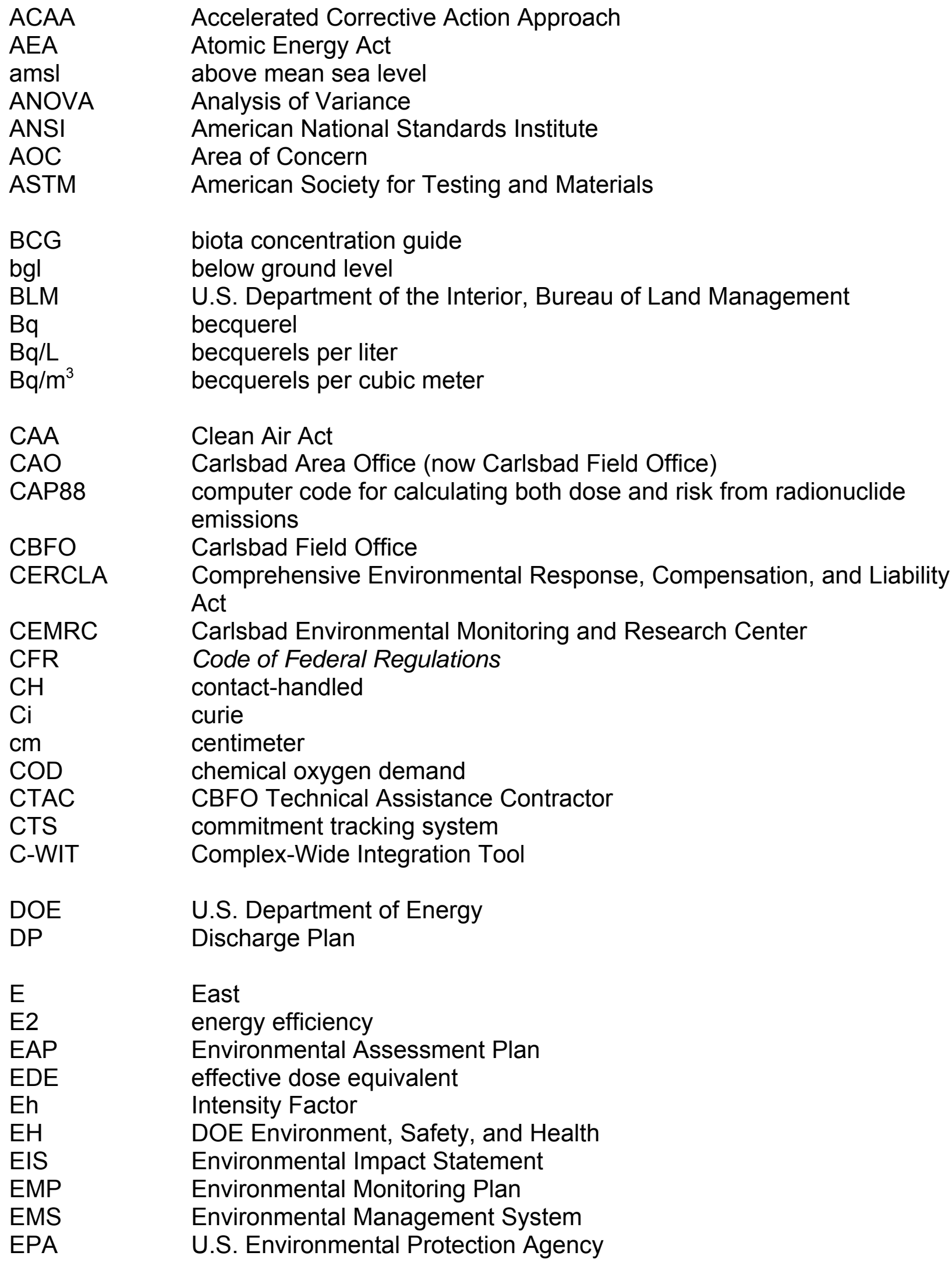




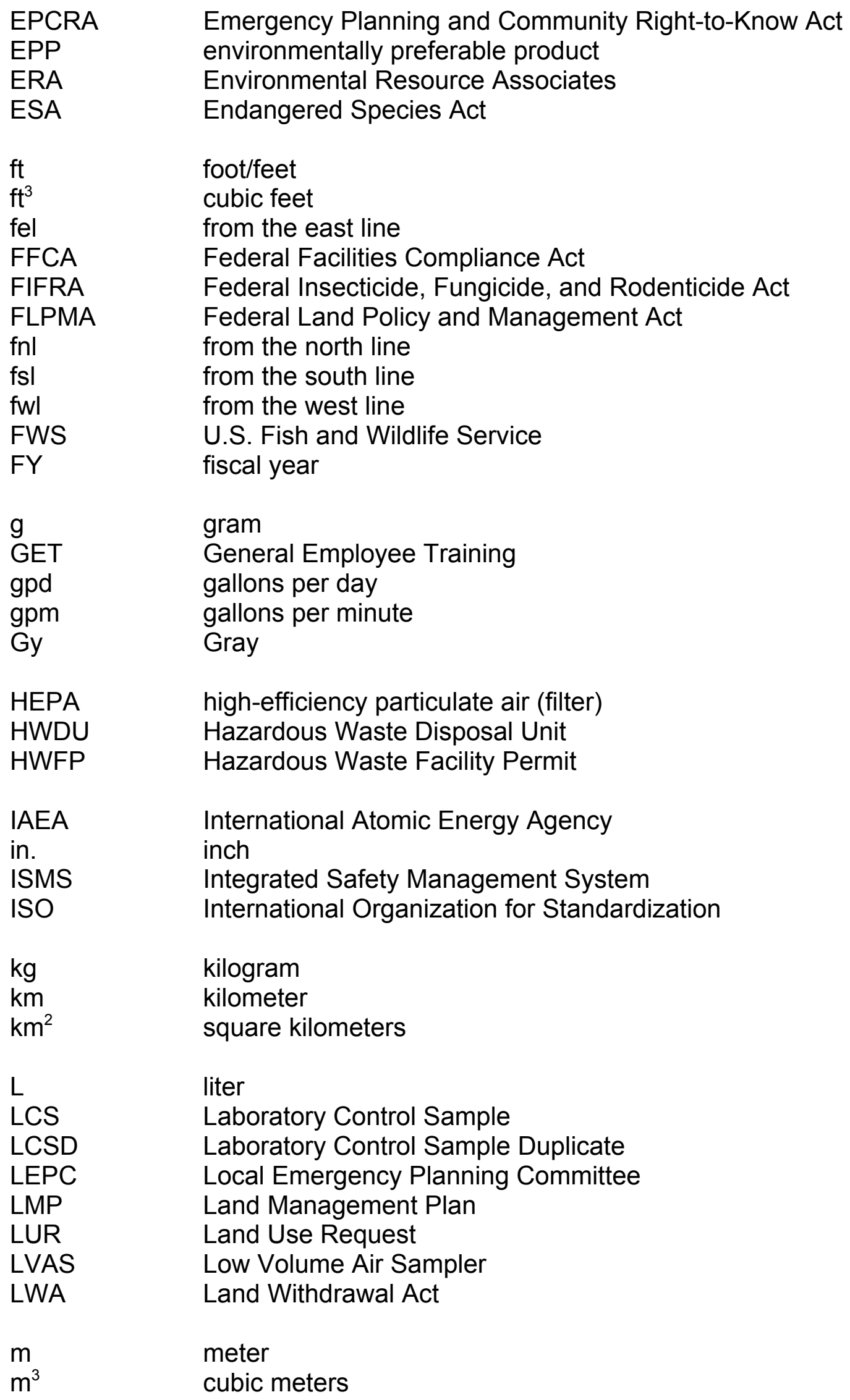




$\begin{array}{ll}\text { mBq } & \text { millibecquerel } \\ \text { MCD } & \text { Maximum Concentration Detected } \\ \text { MDC } & \text { Minimum Detectable Concentration } \\ \text { MDL } & \text { Method Detection Limit } \\ \text { MEI } & \text { maximally exposed individual } \\ \text { MeV } & \text { million electron volts } \\ \text { mg } & \text { milligram } \\ \text { mg/L } & \text { milligram per liter } \\ \text { MgO } & \text { magnesium oxide } \\ \text { mi } & \text { mile(s) } \\ \text { mi } & \text { square miles } \\ \text { ml } & \text { milliiter } \\ \text { M } & \text { molar } \\ \text { MOU } & \text { Memorandum of Understanding } \\ \text { MP } & \text { Management Policy } \\ \text { mrem } & \text { millirem } \\ \text { MRL } & \text { Method Reporting Limit } \\ \text { MSDS } & \text { material safety data sheet } \\ \text { mSv } & \text { millisievert } \\ \text { mSv/yr } & \text { millisievert per year } \\ \text { MT } & \text { metric ton } \\ \text { N } & \text { North } \\ \text { N/A } & \text { not applicable } \\ \text { N/C } & \text { not collected } \\ \text { NCRP } & \text { National Council for Radiation Protection and Measurements } \\ \text { NEPA } & \text { National Environmental Policy Act } \\ \text { NESHAP } & \text { National Emission Standards for Hazardous Air Pollutants } \\ \text { NFA } & \text { No Further Action } \\ \text { NHPA } & \text { National Historic Preservation Act } \\ \text { NIST } & \text { National Institute of Standards and Technology } \\ \text { NMAC } & \text { New Mexico Administrative Code } \\ \text { NMED } & \text { New Mexico Environment Department } \\ \text { NMIMT } & \text { New Mexico Institute of Mining and Technology } \\ \text { NMSA } & \text { New Mexico Statutes Annotated } \\ \text { NOI } & \text { Notice of Intent } \\ \text { NPDES } & \text { National Pollutant Discharge Elimination System } \\ \text { NQA } & \text { Nuclear Quality Assurance } \\ \text { NR } & \text { not reported } \\ \text { NRC } & \text { U.S. Nuclear Regulatory Commission } \\ \text { NRIP } & \text { National Institute of Standards and Technology Radiochemistry } \\ \text { NWPA } & \text { Intercomparison Program } \\ & \text { Nuclear Waste Policy Act } \\ \text { Oz } & \text { ounce } \\ \text { P\&A } & \\ & \text { plugged and abandoned } \\ & \end{array}$




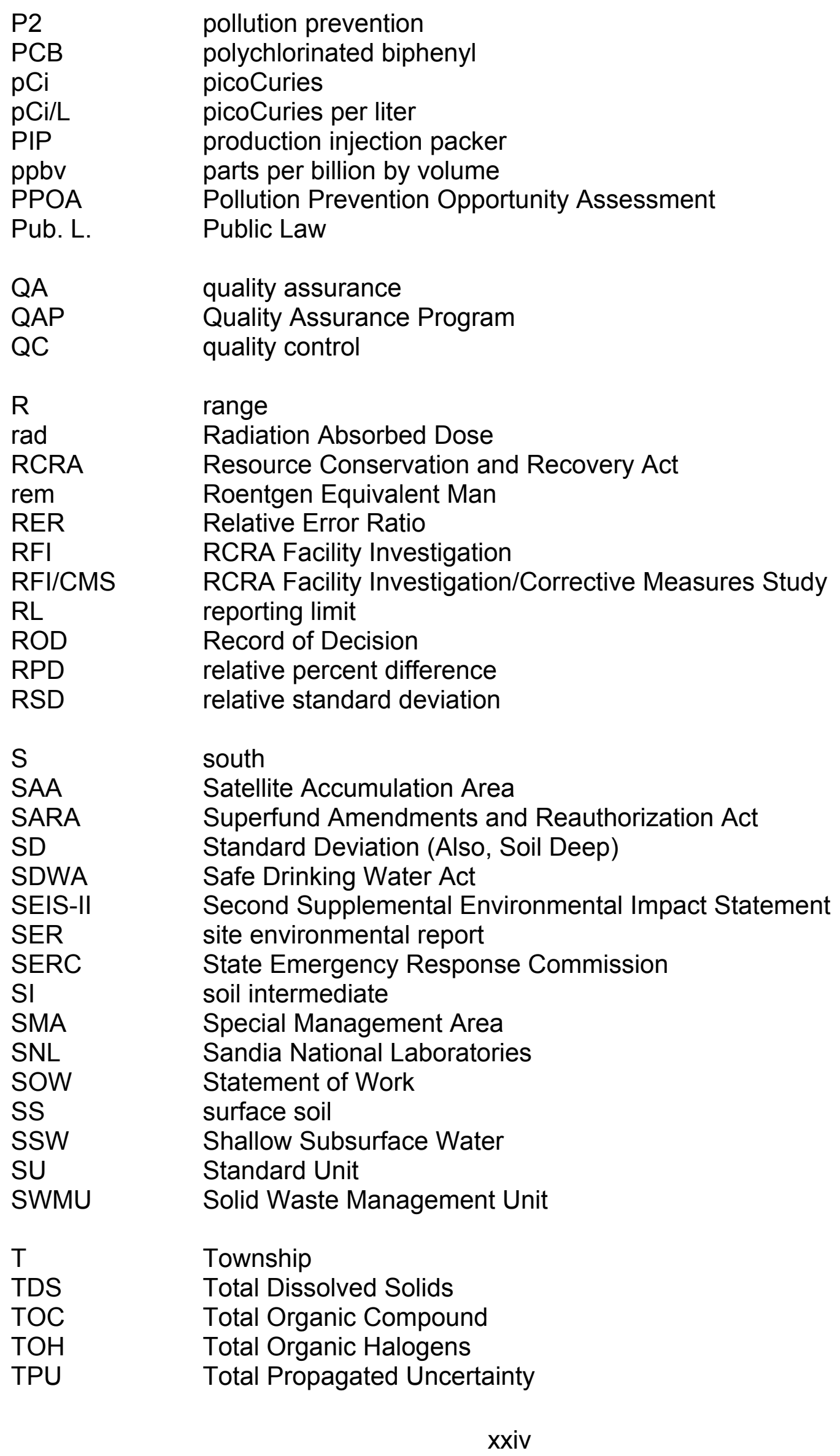




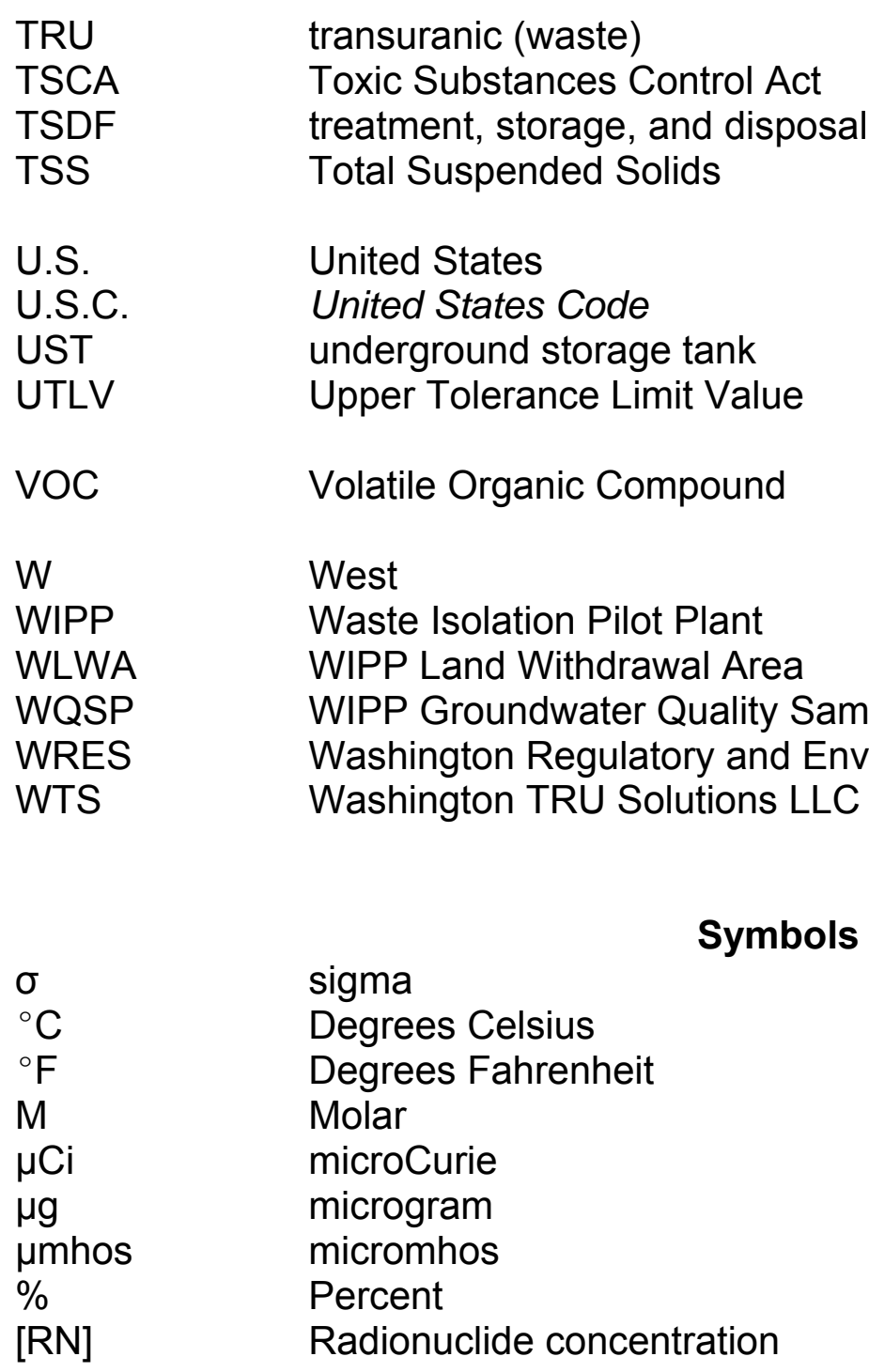


Waste Isolation Pilot Plant Annual Site Environmental Report for 2005

DOE/WIPP-06-2225

This page intentionally left blank 


\section{CHAPTER 1 - INTRODUCTION}

The purpose of this report is to provide information needed by the DOE to assess WIPP environmental performance and to make WIPP environmental information available to stakeholders and members of the public. This report has been prepared in accordance with DOE Order 231.1A and DOE guidance. This report documents the WIPP environmental monitoring and results for 2005.

The WIPP Project is authorized by the DOE National Security and Military Applications of Nuclear Energy Authorization Act of 1980 (Pub. L. 96-164). After more than 20 years of scientific study and public input, WIPP received its first shipment of waste on March 26, 1999.

Located in southeastern New Mexico, WIPP is the nation's first underground repository permitted to safely and permanently dispose of TRU radioactive and mixed waste generated through defense activities and programs. TRU waste is defined in the WIPP LWA as radioactive waste containing more than 100 nanocuries $(3,700$ becquerels [Bq]) of alpha-emitting TRU isotopes per gram of waste, with half-lives greater than 20 years except for high-level waste, waste that has been determined not to require the degree of isolation required by the disposal regulations, and waste the U.S. Nuclear Regulatory Commission (NRC) has approved for disposal. Most TRU waste is contaminated industrial trash, such as rags and old tools; sludges from solidified liquids; glass; metal; and other materials from dismantled buildings. The waste must also meet the WIPP Waste Acceptance Criteria.

When TRU waste arrives at WIPP, it is transported into the Waste Handling Building. The waste containers are removed from the shipping containers, placed on the waste hoist, and lowered to the repository level of 655 meters $(m)(2,150$ feet [ft]) below the surface. Next, the containers of waste are removed from the hoist and placed in excavated disposal rooms in the Salado Formation, a thick sequence of evaporite beds deposited approximately 250 million years ago (Figure 1.1). After each panel of seven rooms has been filled with waste, specially designed closures are constructed. When WIPP's panels have been filled, at the conclusion of WIPP operations, seals will be placed in the shafts. One of the main attributes of salt, as a rock formation in which to isolate radioactive waste, is the ability of the salt to creep, that is, to deform continuously over time. Excavations into which the waste-filled drums are placed will close eventually and the surrounding salt will flow around the drums and seal them within the formation. 


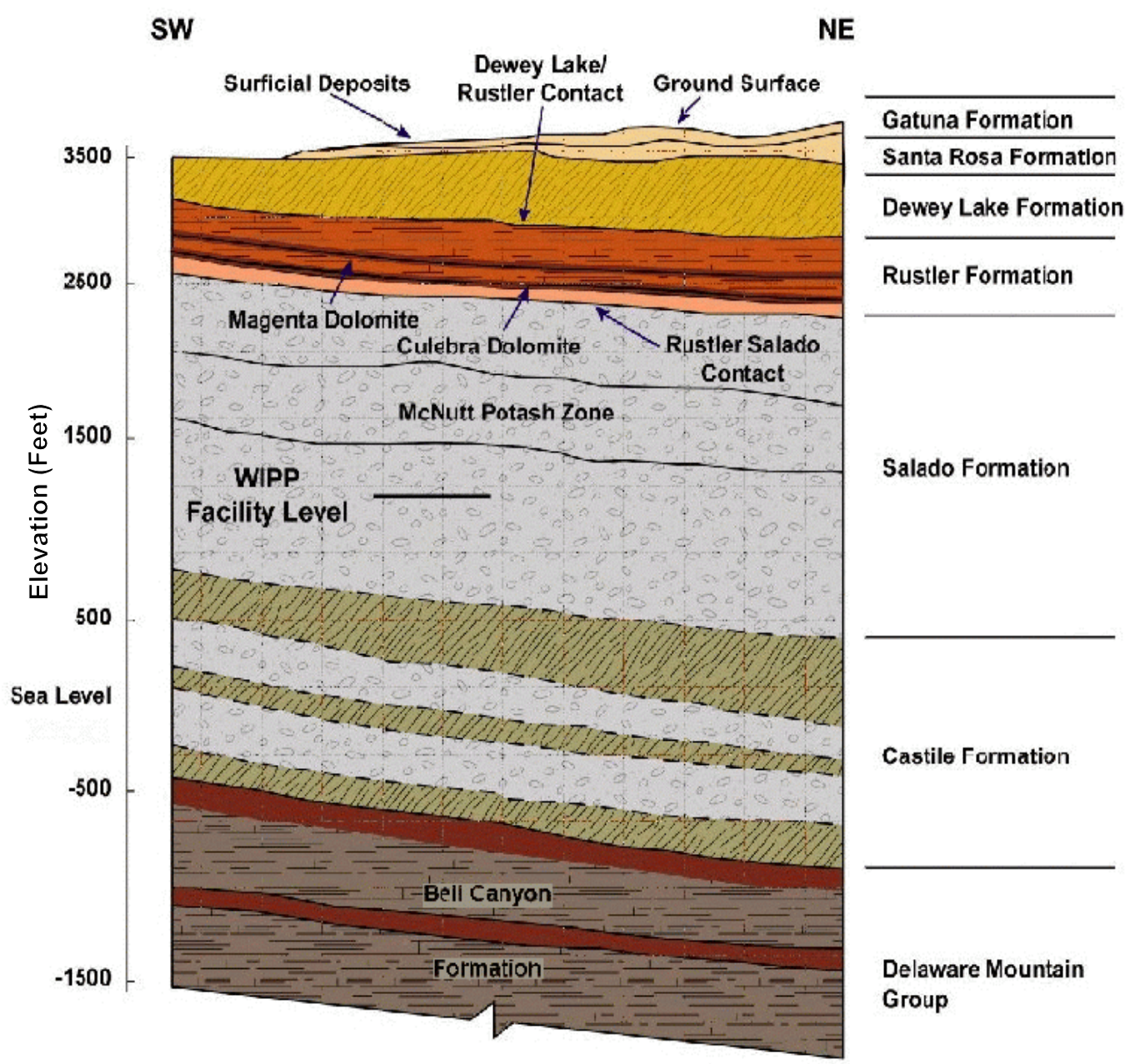

Figure 1.1 - WIPP Stratigraphy

Current TRU waste storage facilities at locations across the United States were never intended to provide permanent disposal. WIPP's mission is to provide for the safe, permanent, and environmentally sound disposal of TRU radioactive waste left from research, development, and production of nuclear weapons. Over the planned 35-year operational lifetime, WIPP is expected to receive approximately 37,000 shipments of waste from locations across the United States.

\section{$1.2 \quad$ WIPP's History}

Government officials and scientists initiated the WIPP site selection process in the 1950s. At that time, the National Academy of Sciences initiated an evaluation of stable geological formations to contain radioactive wastes for thousands of years. In 1955, 
after extensive study, salt deposits were recommended as a promising medium for the disposal of radioactive waste.

Salt deposits were selected as the host for the planned disposal of nuclear waste for several reasons. Most deposits of salt are found in stable geological areas with very little earthquake activity, assuring the stability of a waste repository. Salt deposits also demonstrate the absence of water that could move waste to the surface. Water, if it had been or were present, would have dissolved the salt beds. In addition, salt is relatively easy to mine. Finally, rock salt heals its own fractures because it is relatively plastic. This means salt formations will slowly and progressively move in to fill mined areas and will safely seal radioactive waste from the biosphere.

Government scientists searched for an appropriate site for the disposal of radioactive waste throughout the 1960s, and finally tested the area of southeastern New Mexico in the early 1970s. Salt formations at WIPP were deposited in thick beds during the evaporation of an ancient ocean, the Permian Sea. These geologic formations consist mainly of sodium chloride, the same substance as table salt. However, at WIPP, the salt is not granular, but in the form of solid rock. The main salt formation at WIPP is

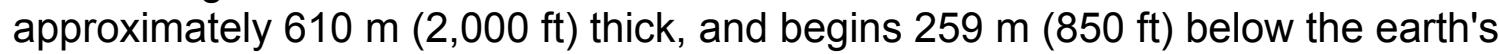
surface. Formed about 250 million years ago during the Permian Age, the large expanses of uninterrupted salt beds provide a geologic environment that is stable.

In 1979, Congress authorized the construction of WIPP, and the DOE constructed the facility during the 1980s. In late 1993, the DOE created the Carlsbad Area Office (CAO) (now CBFO) to lead the TRU waste disposal effort. The CBFO coordinates the TRU program at waste-generating sites and national laboratories.

In 1999, WIPP received its first waste shipment. On March 25, the first waste bound for WIPP departed Los Alamos National Laboratory in New Mexico; it arrived at WIPP the following morning, and the first wastes were placed underground later that day. On April 27, the first out-of-state shipment arrived at WIPP, from the Idaho National Engineering and Environmental Laboratory. Later in the year, on October 27, the Secretary of the NMED issued the WIPP HWFP, which allows WIPP to manage, store, and dispose of contact-handled $(\mathrm{CH})$ TRU mixed waste. Mixed waste is waste contaminated by both hazardous and radioactive substances. "Contact-handled mixed waste" is TRU mixed waste with a surface dose rate less than 200 mrem per hour. The surface dose rate is the measurable amount of radioactivity from neutrons and gamma rays at the external surface of the container.

\section{$1.3 \quad$ Site Description}

Located in Eddy County in the Chihuahuan Desert of southeastern New Mexico (Figure 1.2), the WIPP site encompasses approximately 41.1 square kilometers $\left(\mathrm{km}^{2}\right)$, or 16 square miles $\left(\mathrm{mi}^{2}\right)$. This part of New Mexico is relatively flat and is sparsely inhabited, with little surface water. The site is $42 \mathrm{~km}(26 \mathrm{mi})$ east of Carlsbad in a region known as Los Medaños (the Dunes). 


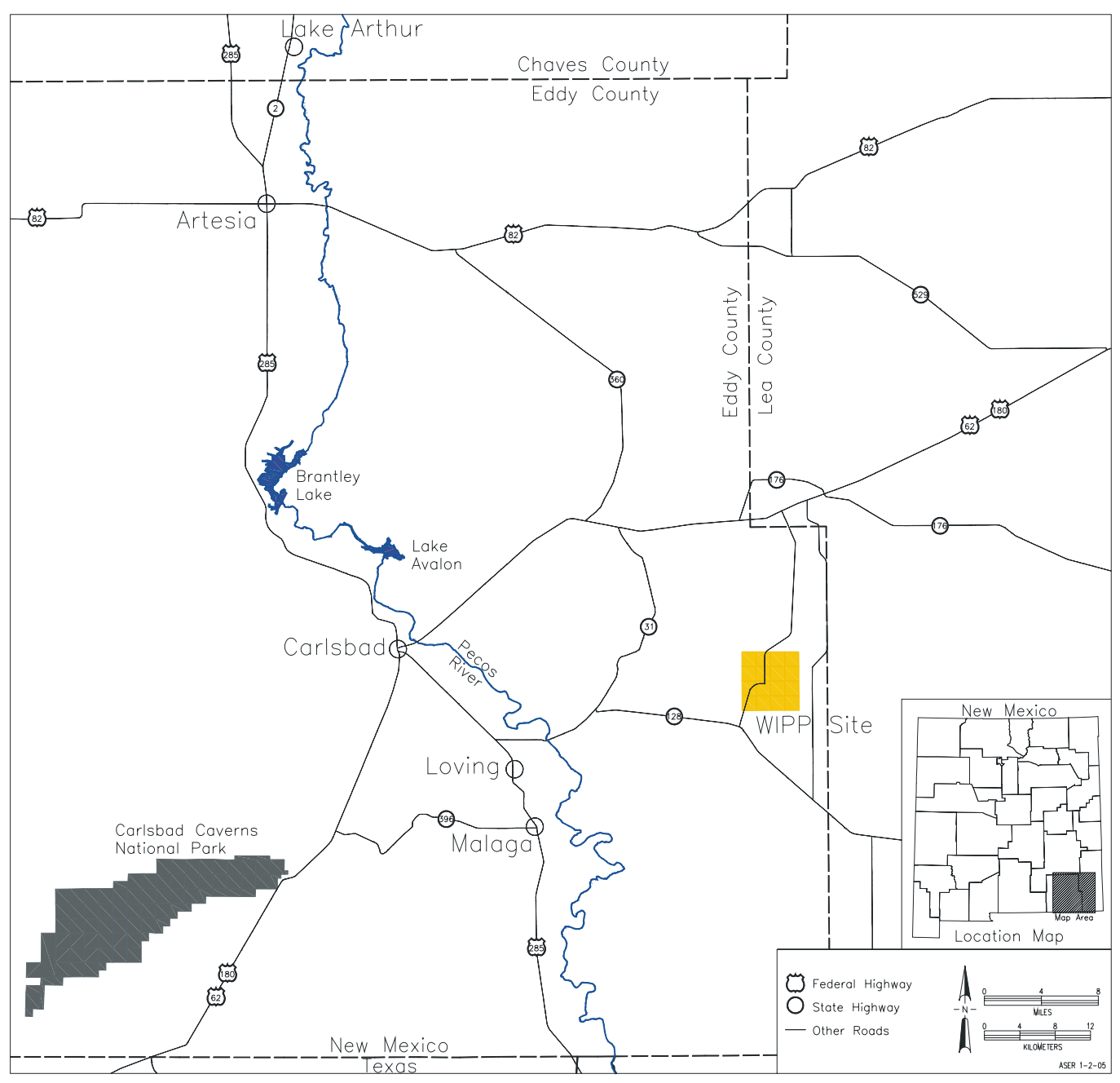

Figure 1.2 - WIPP Location

The WIPP LWA was signed into law on October 30, 1992, transferring the administration of federal land from the U.S. Department of the Interior to the DOE. With the exception of facilities within the boundaries of the posted $1.2 \mathrm{~km}^{2}\left(0.463 \mathrm{mi}^{2}\right)$ Exclusive Use Area, the surface land uses remain largely unchanged from pre-1992 uses, and are managed in accordance with accepted practices for multiple land use. However, mining and drilling for purposes other than those which support WIPP are prohibited within the WIPP site, with the exception of two mineral leases (see Section 5.2.4). The WIPP site boundary extends a minimum of $1.6 \mathrm{~km}(1 \mathrm{mi})$ beyond any of the WIPP underground developments.

The majority of the lands in the immediate vicinity of WIPP are managed by the U.S. Department of the Interior Bureau of Land Management (BLM). Land uses in the surrounding area include livestock grazing; potash mining; oil and gas exploration and production; and recreational activities such as hunting, camping, hiking, and bird watching. The region is home to diverse populations of animals and plants. 


\subsubsection{WIPP Property Areas}

Four property areas are defined within WIPP's boundary (Figure 1.3).

\section{Property Protection Area}

The interior core of the facility encompasses approximately $0.129 \mathrm{~km}^{2}\left(0.05 \mathrm{mi}^{2}\right)$ (approximately 35 acres) surrounded by a chain link fence. This area is under tight security and uniformed security personnel are on duty 24 hours a day.

\section{Exclusive Use Area}

The Exclusive Use Area is comprised of $1.2 \mathrm{~km}^{2}$ (297 acres). It is surrounded by a five-strand barbed wire fence and is restricted exclusively for the use of the DOE and its contractors and subcontractors in support of the project. This area is marked by the DOE warning (e.g., "no trespassing") signs and is patrolled by WIPP security personnel to prevent unauthorized activities or uses.

\section{Off-Limits Area}

The Off-Limits Area is an area where unauthorized entry and introduction of weapons and/or dangerous materials are prohibited. The Off-Limits Area includes $5.7 \mathrm{~km}^{2}$ $\left(2.2 \mathrm{mi}^{2}\right)$ (approximately1,421 acres). Pertinent prohibitions are posted at consistent intervals along the perimeter. Grazing and public thoroughfare will continue in this area unless these activities present a threat to the security, safety, or environmental quality of WIPP. This sector is patrolled by WIPP security personnel to prevent unauthorized activities or use.

\section{WIPP Land Withdrawal Area}

The WIPP site boundary delineates the perimeter of the $41.4 \mathrm{~km}^{2}\left(16 \mathrm{mi}^{2}\right)$ (approximately10,240 acres) WIPP Land Withdrawal Area (WLWA). This tract includes properties outlying the Property Protection Area, the Exclusive Use Area, and the Off-Limits Area. This sector is designated as a Multiple Land Use Area, and is managed accordingly. 
Waste Isolation Pilot Plant Annual Site Environmental Report for 2005 DOE/WIPP-06-2225

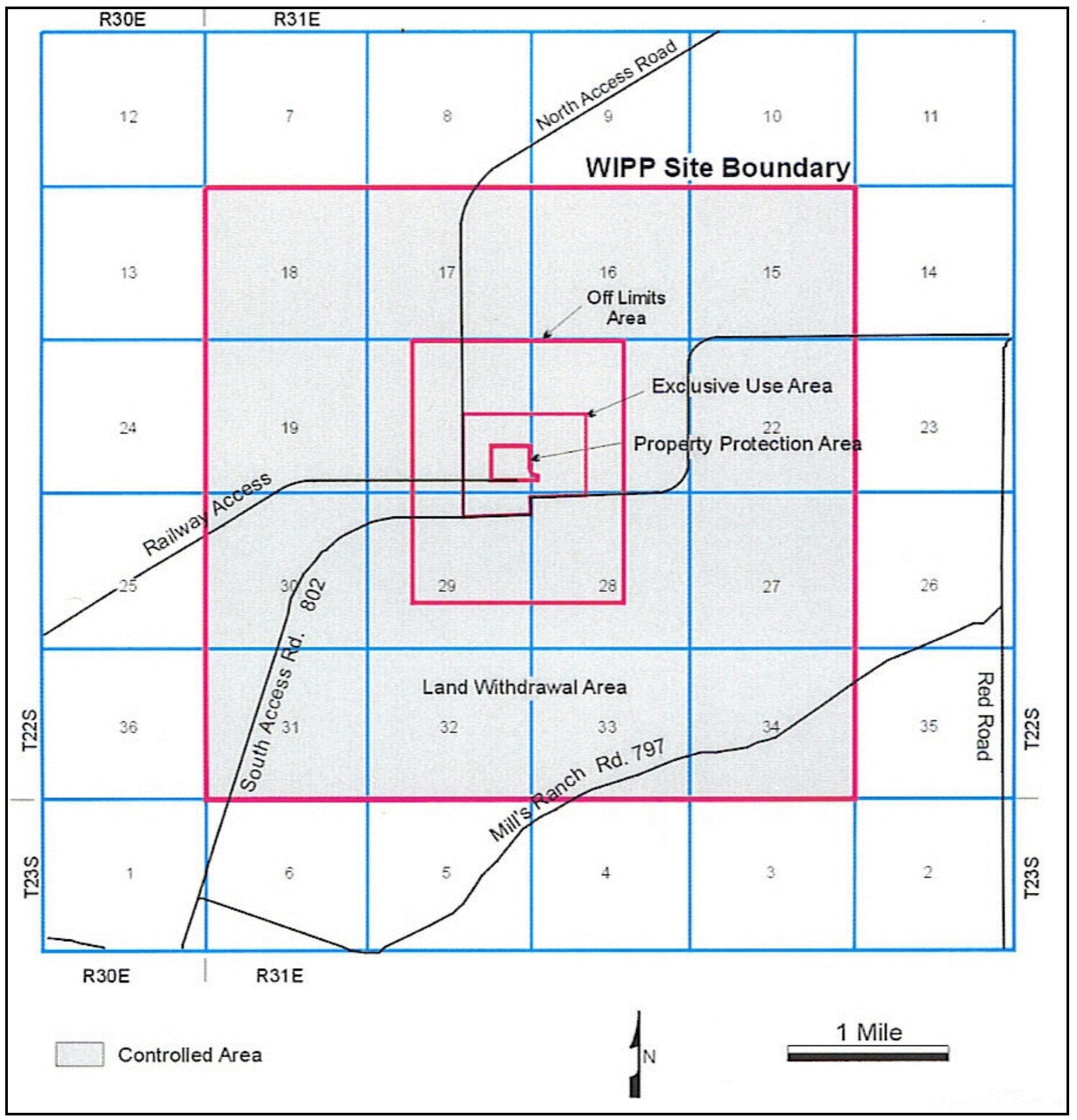

Figure 1.3 - WIPP Property Areas 
Special Management Areas

Certain properties used in the operation of WIPP (e.g., reclamation sites, well pads, roads) are, or may be, identified as Special Management Areas (SMA) in accordance with the LMP. An SMA designation is made due to values, resources, and/or circumstances that meet criteria for protection and management under special management designations. Unique resources of value that are in danger of being lost or damaged, areas where ongoing construction is occurring, fragile plant and/or animal communities, sites of archaeological significance, locations containing safety hazards, or sectors that may receive an unanticipated elevated security status would be suitable for designation as an SMA. Accordingly, the subject sector would receive special management emphasis under this stipulation. SMAs will be posted against trespass and will be safeguarded commensurate with applicable laws governing property protection. WIPP security personnel patrol these areas to prevent unauthorized access or use. In 2005, there were no areas designated as SMAs.

\subsubsection{Population}

Approximately 25 residents live within $16 \mathrm{~km}$ (10 mi) of the WIPP site (source: DOE/WIPP 93-004). The population within $16 \mathrm{~km}$ (10 mi) of WIPP is associated with ranching, oil and gas exploration/production, and potash mining. There are two nearby ranch residences, Smith Ranch and Mills Ranch. Air, soil, and vegetation are monitored there as part of the WIPP Environmental Monitoring Program.

The majority of the local population within $80.5 \mathrm{~km}$ (50 mi) of WIPP is concentrated in and around the communities of Carlsbad, Hobbs, Eunice, Loving, Jal, Lovington, and Artesia, New Mexico. The estimated population within this radius is 100,944 (source: 2000 census data). The nearest community is the village of Loving (estimated population 1,326), $29 \mathrm{~km}$ (18 mi) west-southwest of WIPP. The nearest major populated area is Carlsbad, $42 \mathrm{~km}$ (26 mi) west of WIPP. The estimated population of Carlsbad is 25,625 .

\subsection{WIPP Environmental Program Information}

The DOE's policy is to conduct its operations in compliance with applicable environmental laws and regulations, and to safeguard the integrity of the southeastern New Mexico environment. The DOE conducts effluent monitoring and environmental surveillance to verify that these objectives are met. WIPP employs various programs that implement environmental monitoring, environmental compliance, and land management activities. Environmental monitoring includes collecting and analyzing environmental samples from various media and evaluating whether WIPP activities have caused any adverse environmental impacts.

\subsubsection{Environmental Monitoring Plan}

The WIPP EMP outlines the program for monitoring the environment at the WIPP site, including the major environmental monitoring and surveillance activities at WIPP. The 
EMP also discusses the WIPP quality assurance/quality control (QA/QC) program as it relates to environmental monitoring. The purpose of the EMP is to outline how WIPP's effect on the local ecosystem is to be evaluated. Effluent and environmental monitoring provide data necessary to demonstrate compliance with applicable environmental protection regulations. The 2005 sampling schedule is provided in Table 1.1.

The number of samples taken can be driven by site conditions. For example, during dry periods there may be no surface water to sample at certain locations. Likewise, the number of samples for biota will also vary. For example, the number of rabbit available as samples of opportunity will vary as will fishing conditions that are affected by weather and algae levels in the water.

Table 1.1 - 2005 Environmental Sampling Schedule

\begin{tabular}{lcc}
\hline Type of Sample & $\begin{array}{c}\text { Number of Sampling } \\
\text { Locations }\end{array}$ & Sampling Frequency \\
\hline Waste water & 4 (minimum) & Semiannual $^{\mathrm{a}}$ \\
Stormwater & 5 & Annual $^{\mathrm{a}}$ \\
Airborne effluent & 3 & Periodic/Confirmatory $^{\text {Continuous }}$ \\
Meteorology & 2 & Weekly \\
Atmospheric particulate & 7 & Annual \\
Vegetation & 6 & Annual (samples of \\
Beef/Deer/Rabbits & Sitewide & opportunity) \\
& & Annual \\
Quail & Sitewide & Annual \\
Fish & 3 & Annual \\
Soil & 6 & Annual \\
Surface water & 13 & Semiannual \\
Groundwater & 7 & Annual \\
Sediment & 12 & As needed \\
Aerial photography & Sitewide & Semiweekly \\
Volatile organic compounds & 2 & \\
(VOCs) & &
\end{tabular}

The EMP describes the monitoring of naturally occurring and specific anthropogenic (human-made) radionuclides. The geographic scope of radiological sampling is based on projections of potential release pathways from the waste disposed of at WIPP. The EMP also describes monitoring of VOCs, groundwater chemistry, and other nonradiological environmental parameters, and collection of meteorological data. 


\subsubsection{WIPP Environmental Monitoring Program and Surveillance Activities}

WIPP's Environmental Monitoring Program includes monitoring of air, surface water, groundwater, sediments, soils, and biota (e.g., vegetation, select mammals, quail, and fish). Environmental monitoring activities are performed in accordance with procedures that govern how samples are to be taken, preserved, and transferred. Procedures also direct the verification and validation of environmental sampling data.

The atmospheric pathway, which can lead to the inhalation of radionuclides, has been determined to be the most likely exposure pathway to the public from WIPP. Therefore, airborne particulate sampling for alpha-emitting radionuclides is emphasized. Air sampling results are used to trend environmental radiological levels and determine if there has been a deviation from established baseline concentrations. The geographic scope of radiological sampling is based on projections of potential release pathways and nearby populations for the types of radionuclides in WIPP wastes, and includes Carlsbad, New Mexico, and nearby ranches.

Nonradiological environmental monitoring activities at WIPP consist of sampling and analyses designed to detect and quantify impacts of construction and operational activities, and verify compliance with applicable requirements. Ecological monitoring focuses on nonradiological effects of WIPP, such as impacts to wildlife habitat.

\subsection{Environmental Performance}

The DOE's environmental protection program (DOE Order 450.1) describes the DOE's commitment to environmental protection and pledges to implement sound stewardship practices that are protective of the air, water, land, and other natural and cultural resources. The provisions of DOE Order 450.1 are implemented by the WIPP environmental policy and the EMS. It also commits that the DOE will meet or exceed compliance with applicable environmental requirements.

In 2005, WIPP maintained compliance with applicable environmental laws, regulations, and permit conditions. Furthermore, analyses from the WIPP Environmental Monitoring Program have demonstrated that WIPP has not had an adverse impact on the environment. The WIPP Environmental Monitoring Program fulfills the environmental monitoring requirements of DOE Order 450.1. Detailed information on WIPP programs are contained in the remaining chapters.

\subsection{Organization of This ASER}

This report is organized as follows:

- $\quad$ Chapter 2 is the Compliance Summary.

- $\quad$ Chapter 3 presents the Environmental Management System. 
- $\quad$ Chapter 4 presents the WIPP's Environmental Radiological Protection Program and Dose Assessment.

- $\quad$ Chapter 5 presents WIPP's Environmental Non-Radiological Program information and results.

- $\quad$ Chapter 6 presents the WIPP's groundwater protection program and results.

- $\quad$ Chapter 7 contains information on Quality Assurance and results. 


\section{CHAPTER 2 - COMPLIANCE SUMMARY}

WIPP is required to comply with applicable federal and state statutes, the applicable regulations promulgated pursuant to these statutes, and DOE orders. Regulatory requirements are incorporated into facility plans and implementing procedures. The primary method for maintaining compliance with environmental requirements is through the use of engineered controls and written procedures, routine training of facility personnel, ongoing self-assessments, and personnel accountability.

\subsection{Compliance Overview}

In 2005, WIPP maintained compliance with applicable federal and state environmental statutes and regulations. The following sections list the environmental statutes/regulations applicable to WIPP, and describe significant accomplishments and ongoing compliance activities. A detailed breakdown of WIPP's compliance with environmental laws is available in the Waste Isolation Pilot Plant Biennial Environmental Compliance Report (DOE/WIPP 06-2171).

\subsection{Compliance Status}

A summary of WIPP compliance with major environmental regulations is presented below. A list of active WIPP environmental permits appears in Appendix B.

\subsubsection{Comprehensive Environmental Response, Compensation, and Liability Act}

The Comprehensive Environmental Response, Compensation, and Liability Act (CERCLA) (42 U.S.C. \$§9601, et seq.), or Superfund, establishes a comprehensive federal strategy for responding to, and establishing liability for, releases of hazardous substances from a facility to the environment. Any spills of hazardous substances that exceed a reportable quantity must be reported to the National Response Center under the provisions of CERCLA and 40 CFR Part 302, "Designation, Reportable Quantities, and Notification." Hazardous substance cleanup procedures are specified in 40 CFR Part 300, "National Oil and Hazardous Substances Pollution Contingency Plan." There were no reportable releases at WIPP in 2005, and no release sites have been identified at WIPP that would require cleanup under the provisions of CERCLA.

Superfund Amendments and Reauthorization Act of 1986

WIPP is required by the Superfund Amendments and Reauthorization Act of 1986 (SARA) Title III (42 U.S.C. §§11101) (also known as the Emergency Planning and Community Right-to-Know Act [EPCRA]) to submit (1) a list of hazardous chemicals present at the facility in excess of 10,000 pounds for which a Material Safety Data Sheet (MSDS) is required, (2) an Emergency and Hazardous Chemical Inventory Form (Tier II Form), which identifies the inventory of hazardous chemicals present during the preceding year, and (3) notification to the State Emergency Response Commission (SERC) and the Local Emergency Planning Committee (LEPC) of any accidental 
releases of hazardous chemicals in excess of reportable quantities. The list of hazardous chemicals and the Tier II Form are also submitted to the regional fire departments.

Section 313, Toxic Chemical Release Report, identifies requirements for facilities to submit a toxic chemical release report to the EPA and the resident state if toxic chemicals are used at the facility in excess of established threshold amounts.

The list of chemicals provides external emergency responders with information they may need when responding to a hazardous chemical emergency at WIPP. The Tier II Form, due on March 1 of each year, provides information to the public about hazardous chemicals above threshold planning quantities that a facility has on-site at any time during the year. WIPP submits the Tier II Form annually to each fire department with which the CBFO maintains a memorandum of understanding (MOU) and to the LEPC and SERC. The list of chemicals is a one-time notification unless new chemicals in excess of 10,000 pounds, or new information on existing chemicals, is received. WIPP made the last notification in 1999. The Toxic Chemical Release Report was submitted to the EPA and to the SERC prior to the July 1, 2005, reporting deadline. Table 2.1 presents the 2005 EPCRA reporting status. A response of "yes" indicates that the report was required and submitted.

Table 2.1 - Status of EPCRA Reporting

\begin{tabular}{|l|l|c|}
\hline \multicolumn{1}{|c|}{ EPCRA Section } & \multicolumn{1}{c|}{ Description of Reporting } & Status \\
\hline Sections 302-303 & Planning Notification & Further Notification Not Required \\
\hline Section 304 & EHS $^{\text {a }}$ Release Notification & Not Required \\
\hline Sections 311-312 & MSDS $^{\text {b }}$ Chemical Inventory & Yes \\
\hline Section 313 & TRI Reporting & Yes \\
\hline
\end{tabular}

${ }^{a}$ Extremely Hazardous Substance

${ }^{\mathrm{b}}$ Material Safety Data Sheet

Accidental Releases of Reportable Quantities of Hazardous Substances

During 2005, there were no releases of hazardous substances exceeding the reportable quantity limits.

\subsubsection{Resource Conservation and Recovery Act}

The Resource Conservation and Recovery Act (RCRA) (42 U.S.C. §6901, et seq.) was enacted in 1976. Implementing regulations were promulgated in May 1980. This body of regulations ensures that hazardous waste is managed and disposed of in a way that protects human health and the environment. The Hazardous and Solid Waste Amendments of 1984 prohibit land disposal of hazardous waste unless treatment standards are met or specific exemptions apply. The amendments also emphasize waste minimization. 
The NMED is authorized by the EPA to implement the hazardous waste program in New Mexico pursuant to the New Mexico Hazardous Waste Act (New Mexico Statutes Annotated [NMSA] $§ \$ 74-4-1$, et seq., 1978). The technical standards for hazardous waste treatment, storage, and disposal facilities in New Mexico are outlined in 20.4.1.500 New Mexico Administrative Code (NMAC) (incorporating 40 CFR Part 264). The hazardous waste management permitting program is administered through 20.4.1.900 NMAC (incorporating 40 CFR Part 270).

\section{Hazardous Waste Facility Permit}

The WIPP HWFP was issued on October 27, 1999, and became effective November 26, 1999. The HWFP authorized WIPP to receive, store, and dispose of $\mathrm{CH}$ TRU mixed waste. Two storage units (the Parking Area Container Storage Unit and the Waste Handling Building Container Storage Unit) and seven Underground Hazardous Waste Disposal Units (HWDUs 1 through 7) are currently permitted for the disposal of $\mathrm{CH}$ TRU waste.

In 2005, ten HWFP modifications were submitted to the NMED in accordance with 20.4.1.900 NMAC (incorporating 40 CFR Part 270). These modifications included nine Class 1 notifications and one Class $1^{*}$ request (Table 2.2). The Class 1 changes were generally corrections/updates to information in the HWFP, such as changes in the name of the general manager and other administrative changes. The Class $1^{*}$ was required to revise the closure schedule. No Class 2 or Class 3 changes were submitted in 2005. Table 2.2 provides details on the modification requests and notices.

\section{Table 2.2 - Permit Modification Requests and Notifications Submitted in 2005}

\begin{tabular}{|c|c|c|}
\hline Class & Description & Date Submitted \\
\hline Class 1 & $\begin{array}{l}\text { Permit Modification Notice to Update Surface and Repository Figures } \\
\text { and Flowsheets }\end{array}$ & February 4, 2005 \\
\hline Class 1 & $\begin{array}{l}\text { Permit Modification Notice to Revise: WTS General Manager, } \\
\text { Emergency Coordinator List, Refresher Training to an Annual } \\
\text { Requirement and Correct: Typographical Error in Training Plan and } \\
\text { Permit Inconsistencies }\end{array}$ & February 4, 2005 \\
\hline Class 1 & Permit Modification Notification Update Repository Figures & February 11, 2005 \\
\hline Class $1^{*}$ & Permit Modification Request to Change to Closure Schedule for Panel 2 & February 24,2005 \\
\hline Class 1 & $\begin{array}{l}\text { Permit Modification Notification for Additional Waste Handling Equipment } \\
\text { to Support Magnesium Oxide Emplacement }\end{array}$ & March 24, 2005 \\
\hline Class 1 & $\begin{array}{l}\text { Permit Modification Notification Administrative \& Informational Changes } \\
\text { to Attachments B and B6 }\end{array}$ & April 27, 2005 \\
\hline Class 1 & $\begin{array}{l}\text { Permit Modification Notification to Revise Language for Compacted } \\
\text { 55-Gallon Drums With Rigid Liners }\end{array}$ & April 27, 2005 \\
\hline Class 1 & $\begin{array}{l}\text { Permit Modification Notification Change in Department of Energy, } \\
\text { Carlsbad Field Office Manager }\end{array}$ & July 19,2005 \\
\hline
\end{tabular}


Waste Isolation Pilot Plant Annual Site Environmental Report for 2005 DOE/WIPP-06-2225

Table 2.2 - Permit Modification Requests and Notifications Submitted in 2005

\begin{tabular}{|c|l|l|}
\hline Class & \multicolumn{1}{|c|}{ Description } & \multicolumn{1}{|c|}{ Date Submitted } \\
\hline Class 1 & $\begin{array}{l}\text { Class 1 RCRA Permit Modification Correcting Typographical Error in } \\
\text { Table B-10 }\end{array}$ & October 24, 2005 \\
\hline Class 1 & $\begin{array}{l}\text { Class 1 Permit Modification to Update Webpage Name and Change } \\
\text { CBFO Manager }\end{array}$ & $\begin{array}{l}\text { December 16, } \\
2005\end{array}$ \\
\hline
\end{tabular}

WIPP continued to work with the NMED in 2005 by responding to two Notices of Deficiency on Class 3 modification requests that had been submitted previously. These responses included combining two modification requests regarding receipt of $\mathrm{RH}$ waste and waste analysis plan changes, and updating information on container management provisions.

\section{Underground Storage Tanks}

Title 40 CFR Part 280 addresses underground storage tanks (USTs) containing petroleum products or hazardous chemicals. Requirements for UST management pertain to the design, construction, installation, and operation of USTs, as well as notification and corrective action requirements in the event of a release and actions required for out-of-service USTs. The NMED has been authorized by the EPA to regulate USTs, and implements the EPA program through 20.5 NMAC. WIPP maintains two USTs registered with the NMED.

\section{Hazardous Waste Generator Compliance}

Nonradioactive hazardous waste is currently generated through routine facility operations, and is managed in satellite accumulation areas (SAAs) and a "less-than-90-day" storage area. Hazardous waste generated at WIPP is characterized, packaged, labeled, and manifested to off-site treatment, storage, and disposal facilities in accordance with the requirements codified in 20.4.1.300 NMAC, incorporating 40 CFR Part 262, "Standards Applicable to Generators of Hazardous Waste."

\section{WIPP Solid Waste Management Units and Areas of Concern}

Module VII of the HWFP contains corrective action requirements for the WIPP Solid Waste Management Units (SWMUs) and Areas of Concern (AOCs). The HWFP identified fifteen SWMUs requiring a RCRA Facility Investigation (RFI), three SWMUs not requiring an RFI (the Hazardous Waste Management Units), and eight AOCs in the WLWA. The SWMUs and eight AOCs identified in the HWFP are associated with natural resource exploration activities prior to the development of WIPP, or early WIPP mineral assessment and geologic studies to support facility construction. There was no SWMU classification change during 2005. 


\section{Program Deliverables and Schedule}

WIPP is in compliance with the HWFP reporting requirements contained in Module VII, Table 1 RFI/CMS (Corrective Measures Study) Schedule of Compliance. In 2005, WIPP continued to submit quarterly progress reports.

The WIPP Sampling and Analysis Plan for Solid Waste Management Units and Areas of Concern (DOE/WIPP 00-2014) addresses the current permit requirements for an RFI of SWMUs and AOCs. It uses the results of previous investigations performed at WIPP and expands the investigations as required by the HWFP. As an alternative to the RFI specified in Module VII of the HWFP, current NMED guidance identifies an Accelerated Corrective Action Approach (ACAA) that may be used for all SWMUs and AOCs. This ACAA is used to replace the standard RFI Work Plan and Report sequence for all current SWMUs and AOCs with a more flexible decision-making approach. The ACAA process allows a facility to proceed on an accelerated time line.

The ACAA process was used to produce a No Further Action (NFA) report and petition, which were submitted to the NMED in October 2002. If an NFA determination is granted, WIPP will prepare an HWFP modification request to remove the 15 SWMUs and 8 AOCs from the HWFP.

WIPP is also in compliance with the HWFP conditions related to reporting as noted below:

- The annual Waste Minimization Certification Statement was completed and placed in the operating record as of November 2005 and was transmitted by the CBFO to the NMED.

$\bullet$

HWFP Module IV, Section F, Maintenance and Monitoring, requires annual reports evaluating the geomechanical monitoring program and describing the implementation and results (data and analysis) of the Confirmatory VOC Monitoring Program and the Mine Ventilation Rate Monitoring Plan. WIPP continued to comply with these requirements by preparation and submission of these annual reports in October of 2005, representing July 1, 2004 through June 30, 2005 results.

HWFP Module V, Section V.J.2.a, requires reports of the analytical results for semiannual detection monitoring program (DMP) well samples and duplicates as well as results of the statistical analysis of the samples from which the determination was made that there is or is no statistically significant evidence of contamination. WIPP submitted these reports to the NMED for Sampling Rounds 19 and 20 in 2005.

\subsubsection{National Environmental Policy Act}

The National Environmental Policy Act (NEPA) (42 U.S.C. $\S \S 4321$, et seq.) requires the federal government to use all practicable means to consider potential environmental 
impacts of proposed projects as part of the decision-making process. The NEPA also dictates that the public shall be allowed to review and comment on proposed projects that have the potential to significantly affect the environment.

NEPA requirements are detailed in the Council on Environmental Quality regulations in 40 CFR Parts 1500 through 1508. The DOE codified its requirements for implementing the council's regulations in 10 CFR Part 1021. Title 10 CFR $\$ 1021.331$ requires that, following completion of each environmental impact statement (EIS) and its associated Record of Decision (ROD), the DOE prepare a mitigation action plan that addresses mitigation commitments expressed in the ROD. The first WIPP Mitigation Action Plan was prepared in 1991. Additionally, the CBFO tracks the performance of mitigation commitments in WIPP's annual mitigation report. This report is issued in July of each year.

Day-to-day operational compliance with the NEPA at WIPP is achieved through implementation of a NEPA compliance plan and procedure. Forty projects were reviewed and approved by the CBFO NEPA Compliance Officer through the NEPA screening and approval process in 2005 . These projects were primarily equipment upgrades at the WIPP site. These approvals were in addition to routine activities which have been predetermined to be bounded by existing NEPA documentation and which do not require additional evaluation by the CBFO NEPA Compliance Officer.

The DOE issued a supplemental analysis (SA) (DOE/EIS-0026-SA05, Supplement Analysis for the Waste Isolation Pilot Plant Site Wide Operations) in April 2005, which examined the impacts of ongoing WIPP, sitewide operations. In particular, this SA examined changes to WIPP sitewide and transportation operations and new information gathered since the preparation of the 1997 Waste Isolation Pilot Plant Disposal Phase Final Supplemental Environmental Impact Statement (SEIS-II, DOE/EIS-0026-S-2) to determine if these changes and new information were such that a new EIS would be required. The SA concluded that a supplement to the WIPP SEIS-II is not required.

\subsubsection{Clean Air Act}

The Clean Air Act (CAA) (42 U.S.C. §7401, et seq.) provides for the preservation, protection, and enhancement of air quality. Both the state of New Mexico and the EPA have authority for regulating compliance with portions of the CAA. Radiological effluent monitoring in compliance with EPA requirements is discussed in Section 2.2.15.

The CAA established National Ambient Air Quality Standards for six "criteria" pollutants: sulfur oxides, particulate matter, carbon monoxide, ozone, nitrogen dioxide, and lead. The initial 1993 WIPP air emissions inventory was developed as a baseline document to calculate maximum potential hourly and annual emissions of both hazardous and criteria pollutants. Based on the current air emissions inventory, WIPP operations do not exceed the 10-ton-per-year emission limit for any individual hazardous air pollutant or the 25-ton-per-year limit for any combination of hazardous air pollutant emissions, or the 10-ton-per-year emission limit for criteria pollutants except for total suspended particulate matter and particulate matter less than 10 microns in diameter. Particulate 
matter is produced from fugitive sources related to the management of salt tailings. Consultation with NMED Air Quality Bureau resulted in the determination that a permit is not required for fugitive emissions of particulate matter that result from WIPP operations. Proposed facility modifications are reviewed to determine if they will create new air emission sources and require permit applications.

Based on the initial 1993 air emissions inventory, the WIPP site is not required to obtain CAA permits. WIPP was required to obtain a New Mexico Air Quality Control Regulation 702, Operating Permit (recodified in 2001 as 20.2.72 NMAC, "Construction Permits") for two backup diesel generators at the site in 1993. There have been no activities or modifications to the operating conditions of the diesel generators that would require reporting under the conditions of the permit.

\subsubsection{Clean Water Act}

The Clean Water Act (33 U.S.C. $§ \S 1251$, et seq.) establishes provisions for the issuance of permits for discharges into waters of the United States. The regulation defining the scope of the permitting process is contained in 40 CFR $\$ 122.1(\mathrm{~b})(1)$, which states that "The NPDES [National Pollutant Discharge Elimination System] program requires permits for the discharge of 'pollutants' from any 'point source' into 'waters of the United States."'

WIPP does not have any discharges into waters of the United States and is not subject to regulation under the NPDES program. All waste waters generated at WIPP are either disposed of off-site or managed in on-site, lined evaporation ponds.

\subsubsection{New Mexico Water Quality Act}

The New Mexico Water Quality Act (\$§74-6-1, et seq., NMSA 1978) created the New Mexico Water Quality Control Commission and tasked the commission with the development of regulations to protect New Mexico ground and surface water. New Mexico water quality regulations for ground and surface water protection are contained in 20.6.2 NMAC. WIPP does not have any discharges to surface water but does have a discharge permit for discharges that could impact groundwater.

WIPP initially was issued a permit from the NMED Ground Water Quality Bureau for the operation of the WIPP sewage treatment facility in January 1992. The discharge permit was renewed and modified to include the $\mathrm{H}-19$ Evaporation Pond in July 1997. The $\mathrm{H}-19$ Evaporation Pond is used for the treatment of wastewater generated during groundwater monitoring activities, water removed from sumps in the underground, and condensation from the mine ventilation system's duct work. This permit was renewed in April of 2003.

Two semiannual discharge monitoring reports were submitted to the NMED for the 2005 reporting period to demonstrate compliance with the inspection, monitoring, and reporting requirements identified in the discharge plan. The monitoring results are presented in Section 5.6. 
At the request of the Ground Water Quality Bureau in September 2004, a permit modification application was submitted by WIPP to the Ground Water Quality Bureau on March 4, 2005 that included:

- $\quad$ An evaluation of all options for the ultimate disposition of salt piles.

- $\quad$ A more comprehensive closure plan addressing the final disposition of all active and inactive salt piles.

- $\quad$ A description of the solid waste management units outlined in the RCRA Facility Assessment and Hazardous Waste Facility Permit.

On August 5, 2005, the Ground Water Quality Bureau requested additional information regarding the permit application which was provided on September 12, 2005.

During this reporting period, WIPP contracted a specialist in synthetic liner leak detection and location to assess the condition of the sewage lagoons using an electronic method that meets the requirements of ASTM Standard D-6747-04, "Standard Guide for Selection of Techniques for Electrical Detection of Potential Leak Paths in Geomembrane." The leak detection results indicated that sewage lagoons contained no more leaks than occur in newly installed single lined ponds using conventional installation methods and following rigorous construction quality assurance/quality control techniques. The results of a leak test and a proposal to replace and/or repair the liners in the sewage lagoons were submitted to the NMED on November 3, 2005. The NMED approved the proposal to replace and/or repair the liners over a five-year period.

\subsubsection{Safe Drinking Water Act}

The Safe Drinking Water Act (SDWA) (42 U.S.C. §300f, et seq.) provides the regulatory strategy for protecting public water supply systems and underground sources of drinking water. New Mexico's drinking water regulations are contained in 20.7.10 NMAC, which adopts, by reference, 40 CFR Part 141, "National Primary Drinking Water Regulations," and 40 CFR Part 143, "National Secondary Drinking Water Regulations." Water is supplied to WIPP by the city of Carlsbad.

WIPP qualifies for a reduced monitoring schedule under 40 CFR $\S 141.86(d)(4)$, and is required to sample for lead and copper every three years. WIPP last sampled drinking water in August 2005. All samples were below action levels as specified by New Mexico monitoring requirements for lead and copper in tap water. The next lead and copper samples will be collected between June and September 2008.

Bacterial samples were collected and residual chlorine levels were tested monthly throughout 2005. Chlorine levels were reported to the NMED monthly. All bacteriological analytical results were below the SDWA regulatory limits. 


\subsubsection{National Historic Preservation Act}

The National Historic Preservation Act (NHPA) (16 U.S.C. $§ 470$, et seq.) was enacted to protect the nation's cultural resources and establish the National Register of Historic Places. Three archaeological investigations were conducted for WIPP during 2005, prior to initiating drilling for five exploratory monitoring wells. None of the investigations revealed the presence of archaeological artifacts.

\subsubsection{Toxic Substances Control Act}

The Toxic Substances Control Act (TSCA) (15 U.S.C. §2601, et seq.) was enacted to provide information about all chemicals and to control the production of new chemicals that might present an unreasonable risk of injury to health or the environment. The TSCA authorizes the EPA to require testing of old and new chemical substances. The TSCA also provides the EPA authority to regulate the manufacturing, processing, import, use, and disposal of chemicals.

PCBs are one of the compounds regulated by the TSCA. The PCB storage and disposal regulations are listed in the applicable subparts of 40 CFR Part 761 . On May 15, 2003, EPA Region VI approved the disposal of waste containing PCBs per the Initial Report. The WIPP site began receiving PCB contaminated waste February 5, 2005. The required PCB annual report was submitted to EPA Region VI on July 6 , 2005.

\subsubsection{Federal Insecticide, Fungicide, and Rodenticide Act}

The Federal Insecticide, Fungicide, and Rodenticide Act (FIFRA) (7 U.S.C. $\S \S 136$, et seq.) authorizes the EPA to regulate the registration, certification, use, storage, disposal, transportation, and recall of pesticides. FIFRA authorizes the EPA to establish regulations and procedures regarding the disposal or storage of packages and containers of pesticides and the disposal or storage of excess amounts of such pesticides. The FIFRA regulations are found in 40 CFR Parts 150-189.

All applications of restricted-use pesticides at WIPP are conducted by commercial pesticide contractors who are required to meet federal and state standards. These contractors store and dispose of pesticides off-site. General-use pesticides are stored according to label instructions. Used, empty cans are discarded by WIPP personnel into SAA containers and managed as hazardous waste.

\subsubsection{Endangered Species Act}

The Endangered Species Act (ESA) (16 U.S.C. §§1531, et seq.) was enacted in 1973 to prevent the extinction of certain species of animals and plants. This act provides strong measures to help alleviate the loss of species and their habitats, and places restrictions on activities that may affect endangered and threatened animals and plants to help ensure their continued survival. With limited exceptions, this act prohibits activities that could impact protected species, unless a permit is granted from the USFWS. A 
biological assessment and "formal consultation," followed by the issuance of a "biological opinion" by the USFWS, may be required for any species that is determined to be in potential jeopardy.

To ensure that WIPP environmental protection programs are current in their consideration of sensitive and protected species, a threatened and endangered species survey was conducted from August to November 1996. No threatened or endangered species were found within the WIPP LWA boundaries during the 1996 survey. The DOE has determined that activities associated with the operation of WIPP will have no impact on any threatened or endangered species. Considerations pertaining to protected species are implemented in accordance with the LMP during the deliberation and administration of projects conducted on WIPP lands.

Although there are no known species of plants or animals at the WIPP site which are protected by the ESA, the Lesser Prairie Chicken, which is a candidate for listing under the ESA, has been known to reside within the WIPP LWA and other areas impacted by WIPP activities (e.g., drilling boreholes). Therefore, WIPP has instituted measures to protect the Lesser Prairie Chicken and its habitat in consultation with the BLM. These protective measures include limiting time periods during which work activities may be performed during the Lesser Prairie Chicken's breeding season, and reclaiming impacted areas by mounding the land and planting the soil with prescribed seed mixes.

\subsubsection{Migratory Bird Treaty Act}

The Migratory Bird Treaty Act (16 U.S.C. $\$ \S 703$, et seq.) is intended to protect birds that have common migratory flyways between the United States and Canada, Mexico, Japan, and Russia. The act makes it unlawful "at any time, by any means or in any manner, to pursue, hunt, take, capture, kill, or attempt to take, capture, or kill . . . any migratory bird, any part, nest, or eggs of any such bird" unless specifically authorized by the Secretary of the Interior by direction or through regulations permitting and governing these actions.

Under the Migratory Bird Treaty Act, the CBFO is required to consult annually with the FWS with respect to impacts on migratory game birds and crows resulting from the hunting activities permitted on WIPP lands. Hunting privileges for the public within the WIPP withdrawal area are subject to regulations implementing the Migratory Bird Treaty Act (50 CFR Part 20, "Migratory Bird Hunting"), which regulate the harvest of migratory birds by specifying the mode of harvest, hunting seasons, and possession limits. There were no migratory birds taken by WIPP activities during 2005.

\subsubsection{Federal Land Policy and Management Act}

The objective of the Federal Land Policy and Management Act (FLPMA; 43 U.S.C. $\S \S 1701$, et seq.) is to ensure that:

... public lands be managed in a manner that will protect the quality of scientific, scenic, historical, ecological, environmental, air 
and atmospheric, water resource, and archeological values; that, where appropriate, will preserve and protect certain public lands in their natural condition; that will provide food and habitat for fish and wildlife and domestic animals; and that will provide for outdoor recreation and human occupancy and use.

Title II under FLPMA, Land Use Planning; Land Acquisition and Disposition, directs the Secretary of the Interior to prepare and maintain an inventory of all public lands and to develop and maintain, with public involvement, land-use plans regardless of whether subject public lands have been classified as withdrawn, set aside, or otherwise designated. The DOE developed, and operates in accordance with, the WIPP LMP, which is described in further detail in Section 5.2.

Under Title V, Rights-of-Way, the Secretary of the Interior is authorized to grant, issue, or renew rights-of-way over, upon, under, or through public lands. To date, several right-of-way reservations and land-use permits have been granted to the DOE.

Examples of right-of-way permits include those obtained for a water pipeline, an access road, a caliche borrow pit, and a sampling station. Each "facility" (road, pipeline, railroad, etc.) is maintained and operated in accordance with the stipulations provided in the respective right-of-way reservation. Areas that are the subject of a right-of-way reservation are reclaimed and revegetated consistently with the terms of the right-ofway. A list of WIPP active environmental permits, including rights-of-way, is in Appendix $B$ of this report.

\subsubsection{Federal Facilities Compliance Act}

The Federal Facilities Compliance Act (FFCA) of 1992 (42 U.S.C. §§6912, 6939c, and 6961) amended Section 6001 of the Solid Waste Disposal Act and was designed to bring federal facilities (including those under the DOE) into full compliance with RCRA. The FFCA waives the government's sovereign immunity, allowing fines and penalties to be imposed for RCRA violations at DOE facilities. In addition, the FFCA requires that the DOE facilities provide comprehensive data to the EPA and state regulatory agencies on mixed waste inventories, treatment capacities, and treatment plans for each site. The FFCA ensures that the public will be informed of waste treatment options and encourages active public participation in the decisions affecting federal facilities. The FFCA does not require disposal plans. Furthermore, the waste that is designated by the Secretary of Energy for disposal at WIPP is exempted from the land disposal restriction treatment requirements found in 42 U.S.C. $\$ 6924(\mathrm{~m})$, pursuant to Section 9 of the WIPP LWA.

\subsubsection{Atomic Energy Act}

The Atomic Energy Act (AEA) of 1954, as amended (42 U.S.C. §§2011, et seq.), initiated a national program for research, development, and use of atomic energy for both national defense and domestic civilian purposes. The authority of the EPA to establish generally applicable standards for the protection of the public and the environment from radiation is derived from the AEA, as amended; the Nuclear Waste 
Policy Act of 1982 (NWPA) (42 U.S.C. \$10101, et seq.); the Reorganization Plan of 1970, and the WIPP LWA. Under the WIPP LWA, Congress required the DOE to submit a Compliance Certification Application (CCA) to demonstrate WIPP compliance with the EPA radioactive waste disposal standards. Congress also required that the EPA certify the DOE's compliance before the disposal of TRU was could commence. The DOE demonstrated compliance with the EPA's final disposal regulations in accordance with the criteria of 40 CFR Part 194, "Criteria for the Certification and Recertification of the WIPP's Compliance with the 40 CFR part 191 Disposal Regulations," with the submittal of a Compliance Certification Application (CCA) to the EPA in October 1996. The EPA certified WIPP as a TRU waste disposal facility on May 18, 1998. Section 8 of the LWA requires the EPA, subsequent to the initial certification, to conduct periodic recertifications of compliance beginning five years after the initial receipt of TRU waste for disposal (March 26, 1999) and at five-year intervals thereafter until the end of the decommissioning phase. The DOE submitted a Compliance Recertification Application (CRA) to the EPA on March 26, 2004. The EPA informed the DOE that its CRA was complete on September 29, 2005. This Notification of Completeness of the Department of Energy's Compliance Recertification Application for the Waste Isolation Pilot Plant was reported in the Federal Register (FR) on October 20, 2005 (70 FR 61107-61111, 2005).

The requirements of 40 CFR Part 191 also allow the EPA to oversee WIPP's protection of human health and the environment from radiation in accordance with 40 CFR 191 Subpart A, "Environmental Standards for Management and Storage." These standards set the operational term requirements limiting annual radiation doses to members of the public from the management and storage operations at disposal facilities operated by the DOE and not regulated by either the NRC or agreement states. The annual dose equivalent, to any member of the public in the general environment resulting from discharges of radioactive material and direct radiation from management and storage may not exceed 25 mrem to the whole body and 75 mrem to any other critical organ. Compliance with 40 CFR 191, Subpart A, is established by radiological monitoring and sampling of the air pathway. In order to confirm that the air pathway is the only credible pathway for radiological releases, WIPP implements a radiological ground water surveillance program, biota sampling program and off-site radiological air monitoring program. The results of monitoring and dose calculations have confirmed that there have been no releases of radionuclides that may adversely impact the public. WIPP has conducted periodic confirmatory monitoring since receipt of waste began in March 1999. Results of the monitoring program demonstrate compliance with the dose limits discussed above and are addressed in further detail in Chapter 4.

WIPP is subject to EPA inspections in accordance with 40 CFR $\$ 194.21$. The EPA conducted the following audits and inspections at the WIPP site in 2005.

On February 8 and 9, 2005, the EPA conducted limited audits of three WIPP QA organizations, including the CBFO, Sandia National Laboratories (SNL), and WTS. The purpose of these audits was to confirm compliance with the Organization element of the Nuclear Quality Assurance (NQA) standards. Three QA programs were demonstrated to be properly executed. The EPA identified one finding of nonconformance during the 
CBFO audit. The DOE had not completed corrective actions for a previous finding of nonconformance identified in November 2004. This previous finding against the CBFO was for not providing sufficient authority and independence to its QA organization. The DOE promptly issued a directive that effectively provided the CBFO QA Manager with sufficient authority and independence, and updated one of three administrative documents to resolve this finding. However, two documents still required updates and, therefore, the EPA issued a new finding of nonconformance. Audits at SNL and WTS found no organizational nonconformances. (EPA, 2005a)

From May 17 to May 19, 2005, the EPA inspected the waste emplacement process and procedures at WIPP. The EPA identified one concern related to maintaining information on the magnesium oxide (MgO) emplacement in the WIPP underground. As a result of the concern, the EPA requested the CBFO to "back-populate" the WIPP Waste Information System with the amount of $\mathrm{MgO}$ in the repository, by room, to facilitate future estimates of the total $\mathrm{MgO}$ emplaced. (EPA, 2005b)

During the week of July 11, 2005, the EPA performed inspections of the WIPP waste management and storage operations and the monitoring program. As a result of the inspection, the EPA determined that the activities related to emissions monitoring during waste management and storage continue to comply with the requirements of $40 \mathrm{CFR}$ Part 191, Subpart A. The EPA also determined that the DOE continues to adequately monitor the parameters that are important to the long-term containment of waste, as identified in the EPA's 1998 Certification Decision. (EPA, 2005c)

From July 19 to July 21,2005 , the EPA conducted limited audits of five QA organizations for WIPP: the CBFO, SNL, Los Alamos National Laboratory-Carlsbad Operations (LANL-CO), Carlsbad Environmental Monitoring and Research Center (CEMRC), and WTS. The purpose of the audits was to confirm continued compliance with the Organization element of the NQA standards. The investigation of activities selected for the audit samples showed that the five QA programs continue to be properly executed. The EPA identified one finding of nonconformance during the July 2005 CBFO audit. The CBFO had yet to complete the realignment of the QA function to report directly to the Office of the Manager. Two documents still required approval to complete the realignment. On August 30, 2005, and September 21, 2005, the EPA conducted follow-up audits to confirm approval of the two DOE documents. (EPA, 2005d)

The audits at SNL, WTS, LANL-CO, and CEMRC found that organizational nonconformances did not exist at these organizations. (EPA, 2005d)

The WIPP-specific criteria also established reporting requirements for the DOE. The criterion of 40 CFR $\$ 194.4$ provides requirements and schedules for reporting planned and unplanned changes that are significant or nonsignificant to the certification/ recertification. This section also addresses reporting requirements for a release or expected release and the required reporting schedules. In 2005, the DOE did not submit any reports on significant planned or unplanned changes to the EPA nor did they report any releases or expected releases. On November 17, 2005, the DOE submitted 
The Annual Change Report - 2004-2005, DOE/WIPP 05-3317, documenting nonsignificant changes to the certification that occurred between July 1, 2004, and June 30, 2005.

Notifications, nonsignificant changes, and relevant reports issued in 2005 included:

- Notification of the schedule for waste emplacement in Panel 3 and the beginning of closure for Panel 2.

- $\quad$ Notification that the Multiple Element Germanium Array Project would include conducting a Copper Electroforming Project as part of the ongoing physics research in the WIPP underground Q-room.

- $\quad$ EPA approval of the DOE's December 14, 2004, request to dispose of 21 compressed debris waste drums from the Rocky Flats Environmental Technology Site on March 9, 2005.

- $\quad$ EPA determination that the DOE had fulfilled the EPA's conditions related to $\mathrm{MgO}$ and the emplacement of supercompacted and approval for disposal of supercompacted waste in the WIPP repository.

- $\quad$ EPA Notification of Completeness of the Department of Energy's Compliance Recertification Application for the Waste Isolation Pilot Plant, on September 29, 2005.

- $\quad$ Issuance of the Geotechnical Analysis Report for July 2003 - June 2004, DOE/WIPP 05-3177, in March 2005.

- Issuance of the Delaware Basin Monitoring Annual Report, DOE/WIPP 99-2308, Revision 6, in September 2005.

- Issuance of the Waste Isolation Pilot Plant 2004 Site Environmental Report, DOE/WIPP 05-2225, in September 2005.

- $\quad$ Issuance of the WIPP Subsidence Monument Leveling Survey 2005, DOE/WIPP 06-2293, on December 8, 2005.

\subsubsection{DOE Orders}

The DOE uses a system of orders, notices, directives, and policies to implement its programs under the AEA and to ensure compliance with the requirements of the AEA. An assessment process is in place to assure compliance with environmental, safety, and health-related orders. 


\subsubsection{DOE Order 151.1C, Comprehensive Emergency Management System}

This order establishes requirements for emergency planning, categorization, preparedness, response, notification, public protection, and readiness assurance activities. The applicable requirements of this order are implemented through the WIPP emergency management program, the emergency response program, the training program, the emergency readiness program, the records management program, and the RCRA Contingency Plan.

\subsubsection{DOE Order 225.1A, Accident Investigation}

The objective of this order is to prescribe requirements for conducting investigations of certain accidents occurring at DOE operations and sites; prevent the recurrence of such accidents; and contribute to improved environmental protection and safety and health of DOE employees, contractors, and the public. This order is implemented through the WIPP Root Cause Analysis procedure.

\subsubsection{DOE Order 231.1A, Environment, Safety and Health Reporting}

This order specifies collection and reporting of information on environment, safety, and health that are required by law or regulation, or that are essential for evaluating DOE operations and identifying opportunities for improvement needed for planning purposes within the DOE. The order specifies the reports that must be filed, the persons or organizations responsible for filing the reports, the recipients of the reports, the format in which the reports must be prepared, and the schedule for filing the reports. This order is implemented at WIPP through the Annual NEPA Planning Summary, Environmental Monitoring Plan, the ASER, the Hazardous and Universal Waste Management Plan, the HWFP Reporting and Notifications Compliance Plan, the Radiation Safety Manual, the dosimetry program, the fire protection program, and WIPP procedures.

\subsubsection{DOE Order 414.1C, Quality Assurance}

This order provides DOE policy, sets forth principles, and assigns responsibilities for establishing, implementing, and maintaining programs, plans, and actions to ensure quality achievement in DOE programs. This order is implemented through the WIPP QA program documents.

\subsubsection{DOE Order 435.1, Radioactive Waste Management}

The objective of this order is to ensure that all DOE radioactive waste, including TRU waste that is disposed at the WIPP site, is managed in a manner that is protective of workers and the public. In the event that a conflict exists between any requirements of this order and the WIPP LWA regarding their application to WIPP, the requirements of the LWA prevail. WIPP implements the requirements of this order through the Waste Acceptance Criteria, and procedures governing the management and disposal of site-generated radioactive waste. 


\subsubsection{DOE Order 450.1, Environmental Protection Program}

This order requires that DOE sites implement sound stewardship practices that are protective of the air, water, land, natural and cultural resources, and cost effectively meet or exceed compliance requirements. It requires that this be accomplished by implementing an EMS that is part of the site ISMS. The site EMSs were to be implemented by December 31, 2005. WIPP has operated using an EMS that is in alignment with the ISO 14001 EMS Standard since 1997 and was certified to that Standard in 1998. After this order was issued, the existing EMS was evaluated and actions were taken to assure integration into the site ISMS and to verify implementation. In October 2005, WIPP self-declared compliance with the order's requirements as a result of this work. Chapter 3 provides the detailed discussion of the WIPP EMS and its implementation status.

\subsubsection{DOE Order 451.1B, National Environmental Policy Act Compliance Program}

This order establishes DOE requirements and responsibilities for implementing the NEPA, the Council on Environmental Quality Regulations Implementing the Procedural Provisions of NEPA (40 CFR Parts 1500-1508), and the DOE NEPA Implementing Procedures (10 CFR Part 1021). This order is implemented at WIPP through compliance plans and a screening procedure. These tools are used to evaluate environmental impacts associated with proposed activities and to determine if additional analyses are required.

\subsubsection{DOE Order 5400.5, Radiation Protection of the Public and the Environment}

This order, along with portions of DOE Order 231.1A, establishes standards and requirements for operations of the DOE and its contractors with respect to protecting members of the public and the environment against undue risk from radiation. Activities and analyses describing compliance with the applicable requirements of the order are contained in DOE/WIPP 95-2065. Monitoring activities to document compliance with the order are described in the WIPP ALARA (as low as reasonably achievable) program manual, the EMP, the records management program, and the radiation safety manual.

\subsubsection{DOE Order 5480.4, Environmental Protection, Safety and Health Protection Standards (Portions)}

This order specifies and provides requirements for the application of the mandatory environmental protection, safety, and health standards applicable to all DOE and contractor operations, contains a listing of those standards, and identifies the sources of the mandatory and reference standards. The standards are implemented through the RCRA Contingency Plan; the MOC transportation program, and the hazardous waste management plan. Portions of this order have been replaced by DOE Order 440.1A, Worker Protection Management for DOE Federal and Contractor Employees. 


\subsubsection{Executive Orders}

Executive Orders (EOs) are legally binding orders given by the President, acting as the head of the Executive Branch, to Federal Administrative Agencies. EOs are generally used to direct federal agencies and officials in their execution of congressionally established laws or policies. Compliance with the EOs in this section is accomplished through the WIPP programs, plans, and procedures that comply with the EO's implementing DOE Order. Compliance is confirmed through the WIPP assessment process.

\subsubsection{Executive Order 13101, Greening the Government Through Waste Prevention, Recycling, and Federal Acquisition}

This executive order requires that federal agencies incorporate waste prevention and recycling into operations, establish goals for solid waste prevention and recycling, develop and implement affirmative procurement programs, purchase environmentally preferable products/materials, and track purchases of EPA-designated guideline items. Programs for $\mathrm{P} 2$ and affirmative procurement (purchase of environmentally preferable products) is also mandated by the RCRA. The DOE adopted and implemented the Environmentally Preferable Products (EPP) Program in response to these requirements. This program requires all DOE sites to develop and institute P2 and affirmative procurement plans.

WIPP has integrated these requirements into its operation through implementation of the WIPP Pollution Prevention Program Plan (WP 02-EC.11) and WIPP Affirmative Procurement Plan (WP 02-EC.07). Both programs underwent a thorough review and update during 2005 to assure that they accurately define and communicate site methods for meeting requirements.

The WIPP P2 program facilitates integration of P2 into operations through five mechanisms. These mechanisms and WIPP progress in these areas are summarized in the following paragraphs.

First, WIPP uses annual goals to maintain organizational focus and direct P2 action. Prior to 2005, the project goals focused on meeting the Secretary's P2 goals. Following the accomplishment of the Secretary's goals in 2004, WIPP established new P2 goals for 2005. The 2005 goals are discussed in Section 3.2.4. A detailed description of progress toward meeting these goals is included in Figure 3.2 and Section 3.2.13.

The second mechanism is to continue actions to maintain employee awareness of Pollution Prevention. In 2005, actions to increase employee awareness included:

- Publication of articles on various P2 topics in WIPP's two primary employee newsletters.

- $\quad$ Focusing on P2 through the Earth Day promotion. 
- $\quad$ Upgrading the GET courses.

Additionally, the $\mathrm{P} 2$ website was redesigned and made visible and accessible to all employees through the WIPP intranet's homepage. A P2 Committee or "Green Team" was established in $\mathbf{2 0 0 5}$ and will play a key role in maintaining employee awareness.

Pollution Prevention Opportunity Assessments (PPOAs) are the third mechanism used to integrate P2 into WIPP operations. These assessments are used to evaluate potential opportunities for improving various facets of P2 performance (recycling, affirmative procurement, waste minimization, waste prevention). Three PPOAs were undertaken and/or implemented in 2005 as summarized below:

PPOA 05-001: Recycling Plastic Drinking Water Bottles in the Underground Recycling of plastic water bottles in underground was evaluated and initiated in May 2005.

PPOA 05-002: Wash Bay Water - Eliminating or Reducing RCRA Waste (Assessment) -

This assessment focused on eliminating or reducing the quantity of hazardous wastewater generated as a result of routine, but infrequent, washing of mining equipment. Further research will be required to implement this P2 activity.

PPOA 05-003: Recycle/Reuse of Miscellaneous Scrap Lumber (Assessment) This assessment focused on identifying and implementing a viable recycling/reuse method for scrap lumber generated at WIPP. The assessment concluded that an employee recycling program was the only potentially viable option to date.

The fourth mechanism used to integrate $\mathrm{P} 2$ is maintaining a healthy recycling program. WIPP's recycling program was improved in 2005. Improvements to logistics for recycling of paper, cardboard, and plastics at WIPP were instituted. Improvements included making it easy for employees to recycle by providing conveniently accessible recycling bins, streamlining on-site collection and storage methods, and establishing a reliable means for transporting these items to the local recycling vendor. The improvements resulted in an increase in the amount of these materials recycled as well as supplementing the strong recycling program for other items. Toner cartridge recycling was arranged contractually with a vendor.

Table 2.3 identifies the volumes recycled at WIPP for FY 2004 and FY 2005. 
Waste Isolation Pilot Plant Annual Site Environmental Report for 2005 DOE/WIPP-06-2225

\begin{tabular}{|l|c|c|}
\hline \multicolumn{1}{c}{ Table 2.3 - Materials Recycled at WIPP } \\
\hline $\begin{array}{l}\text { Recycled Material } \\
\text { (metric tons) }\end{array}$ & FY 2004 & FY 2005 \\
\hline Paper & 0.1 & 15.5 \\
\hline Aluminum cans & 0.3 & 0.3 \\
\hline Cardboard & 4.7 & 5.5 \\
\hline Toner cartridges & 0 & 0.5 \\
\hline Wooden Pallets & 0 & 3.2 \\
\hline Oil & 5.8 & 3.9 \\
\hline $\begin{array}{l}\text { Fluorescent bulbs/high-pressure sodium } \\
\text { bulbs }\end{array}$ & 0.3 & 0.2 \\
\hline Wet batteries & 12.1 & 13.4 \\
\hline Silver & 0 & 0 \\
\hline Ethylene glycol & 4.5 & 4.9 \\
\hline Scrap metal & 100.4 & 81.3 \\
\hline Plastic & 0 & 0.4 \\
\hline Computer equipment & 3.9 & 4.3 \\
\hline Other Recycled Items & 0 & 12.8 \\
\hline Total Recycled - Sanitary \& RCRA & 132.1 & 146.1 \\
\hline
\end{tabular}

RCRA waste does not include oil and ethylene glycol totals.

The fifth mechanism for integrating P2 is to continually improve the site's program for acquiring environmentally preferred products (EPPs). EPPs include recycled content, bio-based and energy efficient products. While the program structure is provided in the WIPP Affirmative Procurement Plan (WP 02-EC.07), the consideration and purchase of cost-effective EPPs are achieved through imbedding the program requirements into acquisition procedures and training for both requisitioners and credit card purchasers, and integrating requirements into contracts.

For 2005, 100 percent of WIPP purchases of standard copy paper, toner cartridges and commercial sanitary tissue products met the EPA's recycled content requirements as a result of including the requirements in the contract terms. In addition, WIPP's hardware standards specify equipment that is energy star compliant. Purchasers must request approval when purchasing computers that are not specified in the standard.

Site environmental compliance and procurement personnel are in the process of improving WIPP's ability to quantify purchases of other EPPs including office supplies or equipment or other materials. This improvement will result in vendors and/or contractors providing routine reports of EPPs purchased and used for the project. Full implementation of this process improvement is slated for FY 2007. 


\subsubsection{Executive Order 13123, Greening the Government Through Efficient Energy Management}

This executive order recognizes that the federal government is the nation's largest energy consumer. Consequently, federal government agencies are required to significantly improve energy management at federal facilities in order to save taxpayer dollars and reduce emissions that contribute to air pollution and global climate change. Federal government agencies are expected to adopt energy efficiency (E2) in building design, construction, and operation. Federal government agencies are expected to promote E2, water conservation, and the use of renewable energy products, and help foster markets for emerging technologies. DOE Order 430.2A established requirements for each DOE site that directs agencies operations to meet or exceed the expectations in the Executive Order.

WIPP implements the requirements of this order through the submittal of biannual energy management plans that address actions and progress in the seventeen energy efficiency leadership goals established in the DOE order. These plans summarize the significant progress the WIPP site has made in this arena and demonstrate compliance with this order.

\subsubsection{Executive Order 13148, Greening the Government Through Leadership in Environmental Management}

This executive order requires development of environmental management systems, environmental compliance audit programs, reporting under EPCRA, reduction of toxic releases and off-site transfers of toxic chemicals, reduction of the use of toxic chemicals, hazardous substances, and pollutants, and generation of hazardous and radioactive waste, reductions in ozone-depleting substances, and environmentally and economically beneficial landscaping. Compliance is maintained with this order and is more fully described in within this chapter and Chapter 3.

\subsection{Other Significant Accomplishments and Ongoing Compliance Activities}

\section{Pollution Prevention and Energy Efficiency}

$\mathrm{P} 2$ is integrated into the EMS starting with management's commitment to P2 through the WIPP Environmental Policy. It is further implemented in WIPP operations through multiple plans, programs, and procedures that assure that waste minimization, recycling, and affirmative procurement is integrated with routine business practices and operations. The detailed discussion of the WIPP Pollution Prevention Program is included in Section 2.2.17.1, which addresses Executive Order 13101.

DOE Secretarial Pollution Prevention and Energy Efficiency Goals were established in 1999. These goals focused on reducing the generation of hazardous, low-level radioactive, low-level mixed radioactive, TRU, and sanitary wastes. The goals were to be achieved by the end of 2005 , with the exception of the sanitary waste goal, which was to be achieved by the end of 2010. WIPP achieved all of the goals applicable to its 
scope of operations by the end of FY 2004. Although WIPP did not generate any leaded brine water in 2004, it did in 2005, and this contributed towards WIPP not meeting the DOE reduction goal for RCRA hazardous waste this reporting year. The percentage reduction in RCRA hazardous waste was 86 percent compared to the goal of 90 percent. The summary of WIPP's performance related to the pollution prevention goals is included in Table 2.4 .

Table 2.4 - WIPP Waste Volumes Compared to Baseline, and Reduction Goals for FY 2005

\begin{tabular}{|c|c|c|c|c|c|c|}
\hline \multirow[b]{2}{*}{ Waste Type } & \multirow[b]{2}{*}{ Baseline* $^{*}$} & \multicolumn{2}{|c|}{2004} & \multicolumn{2}{|c|}{2005} & \multirow{2}{*}{$\begin{array}{c}\text { DOE } \\
\text { Reduction } \\
\text { Goal }\end{array}$} \\
\hline & & Generated $^{*}$ & $\begin{array}{c}\% \\
\text { Reduced }\end{array}$ & Generated $^{*}$ & $\begin{array}{c}\% \\
\text { Reduced }\end{array}$ & \\
\hline $\begin{array}{l}\text { RCRA Hazardous (1993 and } \\
1995 \text { baseline) }\end{array}$ & 63.8 & 1.1 & 98 & 9 & 86 & 90 \\
\hline $\begin{array}{l}\text { Low-Level Radioactive (2000 } \\
\text { baseline) }\end{array}$ & 0.8 & 0 & 100 & 0 & 100 & 80 \\
\hline $\begin{array}{l}\text { Low-Level Mixed Radioactive } \\
\text { ( } 2000 \text { baseline) }\end{array}$ & 0.02 & 0 & 100 & 0 & 100 & 80 \\
\hline Transuranic Wastes & 0 & 0 & N/A & 0 & $\mathrm{~N} / \mathrm{A}$ & 80 \\
\hline Sanitary (1993 baseline) & 1224 & 91.2 & 92 & 92.9 & 92 & 75 \\
\hline
\end{tabular}

* Volumes stated in metric tons

$\mathrm{N} / \mathrm{A}=$ Not applicable

The baseline years used for determining progress toward the goals are as noted in the table. The RCRA hazardous baseline quantity includes the hazardous waste generated in 1993 plus the leaded brine generated in 1995 (the year these brines first tested as hazardous for lead). There is no baseline amount for TRU waste because WIPP does not generate TRU waste. Also, the generation of low-level and low-level mixed radioactive waste at the WIPP facility has been insignificant since 2003 when the WIPP Laboratory began to operate under an interface agreement with the New Mexico State University at its facility.

\section{Environmental Compliance Assessments}

Assessments, also referred to as audits, of activities at the WIPP facility are routinely performed to evaluate that processes are in place to comply with applicable environmental regulatory requirements. Internal assessments include those performed by the WTS Quality Assurance Department where the assessment scope includes environmental regulatory compliance and those conducted through the WIPP environmental organization's Environmental Assessment Plan (EAP) (WP 02-EC.13). There are external assessments performed by the CBFO and its technical contractor as well as audits performed by state and federal agencies. The results of the both internal and external assessments/audits were analyzed as part of the Measuring and Monitoring element of the EMS. The results of the analysis provide an overview of the WIPP compliance status and EMS effectiveness. The results of the analysis are more fully discussed in Chapter 3. 
Of the internal assessments performed, those conducted through the EAP were focused on environmental compliance. For 2005, there were three assessments performed under the EAP. These assessments are summarized in the following paragraphs.

On January 19 and 20, 2005, an assessment focusing on compliance with the requirements for managing site-generated hazardous waste was conducted. This assessment resulted in corrective actions being completed in the areas of maintenance of appropriate aisle space distance in waste storage areas and assuring that managers responsible for employees who manage hazardous waste take required training.

On June 29 and 30, 2005, an assessment of compliance with requirements of the HWFP Contingency Plan and HWFP waste handling requirements was performed. Three corrective actions were taken as a result of this assessment. These were focused on updating the emergency coordinators contact information list, updating training modules to be more consistent with the HWFP training outline, and assuring the annual review of the contingency plan is completed and documented through the WIPP Commitment Tracking System (CTS).

On September 27, 2005, WIPP's authorized site for external disposal of nonhazardous water was assessed for compliance with regulatory requirements. There were no corrective actions necessary as a result of this assessment and it was confirmed that the site is appropriate for disposal of nonhazardous water from WIPP well work.

In addition to the compliance assessments, an internal management assessment was performed from April 27 through May 31, 2005, to verify the status of implementation of DOE Order 450.1. The assessment concluded that the EMS was adequately established, documented and implemented. There was one corrective action required to incorporate significant environmental aspects/impacts more clearly into the GET modules. This was completed prior to the end of 2005.

\section{$\underline{\text { DOE Audits/Assessments }}$}

There were seven audits, assessments, or surveillance audits conducted by the Carlsbad Field Office during FY 2005. The scope of each included some facet of compliance with environmental requirements. There were four corrective actions completed, which focused on improvements to the Meteorological Data Program and its execution. None of the corrective actions were deemed significant conditions adverse to quality.

\section{Environmentally Beneficial Landscaping Practices}

Of the WIPP activities, reclamation of areas such as the well pads for groundwater monitoring wells that are plugged and abandoned and site roads that are closed, are those that provide the most routine opportunity for applying sound reclamation practices. WIPP had no activities in 2005 in this area. In addition, WIPP did not construct or modify new areas that required landscaping. 


\section{Ozone Depleting Substances}

WIPP internal procedures control the acquisition of chemicals and hazardous materials including ozone depleting substances (ODS). In addition, procedures include periodic checks for the presence of ODS. WIPP did not have ODS on-site during 2005. 
Waste Isolation Pilot Plant Annual Site Environmental Report for 2005

DOE/WIPP-06-2225

This page intentionally left blank 


\section{CHAPTER 3 - ENVIRONMENTAL MANAGEMENT SYSTEM}

\subsection{Introduction}

EMSs are widely recognized by both government and industry as effective mechanisms for achieving an organization's policy commitments for environmental performance. An EMS is based on using the continuous improvement cycle to improve its environmental performance. This cycle begins with planning, the foundation that establishes the organizational commitments to environmental performance via policy. This is followed by implementing the plan and monitoring the organization's environmental performance as it executes the plan. Finally, management reviews environmental performance and the effectiveness of the system, identifying desired improvements. These improvements then initiate the next continuous improvement cycle.

Executive Order 13148, Greening the Government through Leadership in Environmental Management, requires that federal agencies implement an EMS. Further, the DOE issued DOE Order 450.1 requiring that DOE sites implement an EMS that is integrated with their ISMS by December 31, 2005. This order established the DOE's intent that these EMSs enable sound environmental stewardship practices that are protective of air, water, land, and other natural and cultural resources affected by DOE operations. The order also set the expectation that these systems would enable meeting compliance requirements in a cost-effective manner.

Subsequent to the executive and DOE orders being issued, WIPP analyzed the status of its system and identified the necessary action plan for closing any gaps compared to the requirements. WIPP completed the integration action plan, had the system assessed, and self-declared compliance with the order's requirements in October 2005.

WIPP recognized the value of managing its potential environmental impacts and compliance responsibilities prior to issuance of the executive and DOE orders listed above. It developed and implemented its EMS in 1997, and was certified as having met the International Organization for Standards (ISO) 14001 EMS standard in July of 1998. WIPP continued to be ISO-certified until 2003 when the decision was made to maintain the EMS in alignment with the ISO standard without continuing the formal certification process.

The WIPP policy establishes protection of workers, the public, and the environment as the highest priority in carrying out its mission. The WIPP EMS strengthens compliance with legal requirements, $\mathrm{P} 2$, and continual improvement, as well as assuring that environmental accountability is integrated in the decision-making process.

\subsection{WIPP EMS Elements}

\subsubsection{Policy}

Washington TRU Solutions LLC (WTS), as management and operating contractor for this project, had a strong environmental policy in place prior to the time the EMS was 
first implemented. As a result of integration of the EMS into the ISMS, the Environmental Policy was reviewed and updated to be a policy jointly issued by the CBFO and WTS in FY 2005 (CBFO/WTS Environmental Policy Statement, DOE/WIPP-04-3310). It has since been reaffirmed through reissuance of the policy by the WTS General Manager and CBFO Manager.

Senior management has committed WIPP to achieve and maintain high standards of environmental quality and to provide a safe and healthful workplace for employees while achieving its mission. The environmental policy provides the foundation for the EMS, and identifies the EMS as the mechanism to meet WIPP commitments to:

- $\quad$ Comply with requirements applicable to WIPP

- $\quad$ Be good environmental stewards (working with stakeholders, correcting incidents, minimizing harm to environmental resources and using safe, responsible and cost-effective $\mathrm{P} 2$ measures)

- $\quad$ Seek continual improvement in environmental performance.

\subsubsection{Aspects and Impacts}

Activities, aspects, and impacts for WIPP have remained relatively constant since the EMS was first implemented as a result of the stability of the WIPP mission. However, small changes, or upgrades, have been made over time for clarification purposes. The following aspects have been identified as having potentially significant impacts.

- $\quad$ Safe management of TRU wastes

- $\quad$ Potential impact: decreased exposure of people and environment both at WIPP and generator sites

- $\quad$ Potential release of pollutants from managing TRU and TRU mixed wastes, hazardous materials, site-generated hazardous and nonhazardous wastes, solid waste management units, and the wastewater treatment system

- $\quad$ Potential impact: Contamination of soil, water, air, or biota

- Use of electricity

- $\quad$ Potential impact: Loss of use of natural resources

- $\quad$ Stormwater runoff

- $\quad$ Potential impact: Contamination of soil, water, or biota 
- $\quad$ Potential impact: Compromised stewardship of wildlife, fauna, habitat, and/or historically or culturally significant sites

Aspects and impacts are reviewed several times during the course of the year. These include environmental reviews of proposed projects, and a more formal, holistic review performed in preparation for the annual EMS review by senior managers. Significance is determined by considering both environmental and business factors such as the probability of occurrence, the scale and severity of the potential impact, associated regulatory and legal issues, as well as new DOE orders or concerns of interested parties and affects to the public and stakeholder opinions of the project.

\subsubsection{Legal and other Requirements}

Environmental requirements are identified as they are issued as draft or proposed and in final rules and orders. Identification is accomplished through monthly review of environmentally related Federal Register and New Mexico Administrative Code publications as well as new DOE orders or proposed changes to existing DOE orders. Subject matter experts are consulted to confirm applicability. Then the change is assessed for potential impacts and needed changes are initiated to plans, procedures, and training to institutionalize compliance with the new or revised requirements. Environmental requirements and compliance status are summarized for WIPP and are available to the public in the Waste Isolation Pilot Plant Biennial Environmental Compliance Report (DOE/WIPP 06-2171) and Chapter 2 of this report.

\subsubsection{Objectives and Targets}

Setting objectives and targets for addressing the impacts associated with significant aspects is a cornerstone in the planning process of an EMS. At WIPP, this is carried out by managers' review of the significant aspects and impacts during the annual fiscal year programmatic planning process. New or revised business objectives and targets are developed with milestones in the context of the aspects and impacts. Approved objectives and targets are then incorporated into the Complex-Wide Integration Tool (C-WIT) where progress is tracked throughout the year. For FY 2005, 78 percent of business milestones were linked to managing potentially significant environmental aspects.

Sitewide environmental objectives related to P2 are also set each fiscal year. Until FY 2005, WIPP focused on achieving the goals that the Secretary of Energy set for the DOE to achieve by the end of FY 2005. WIPP's performance exceeded two of the three goals applicable to WIPP as shown in Figure 3.1. 


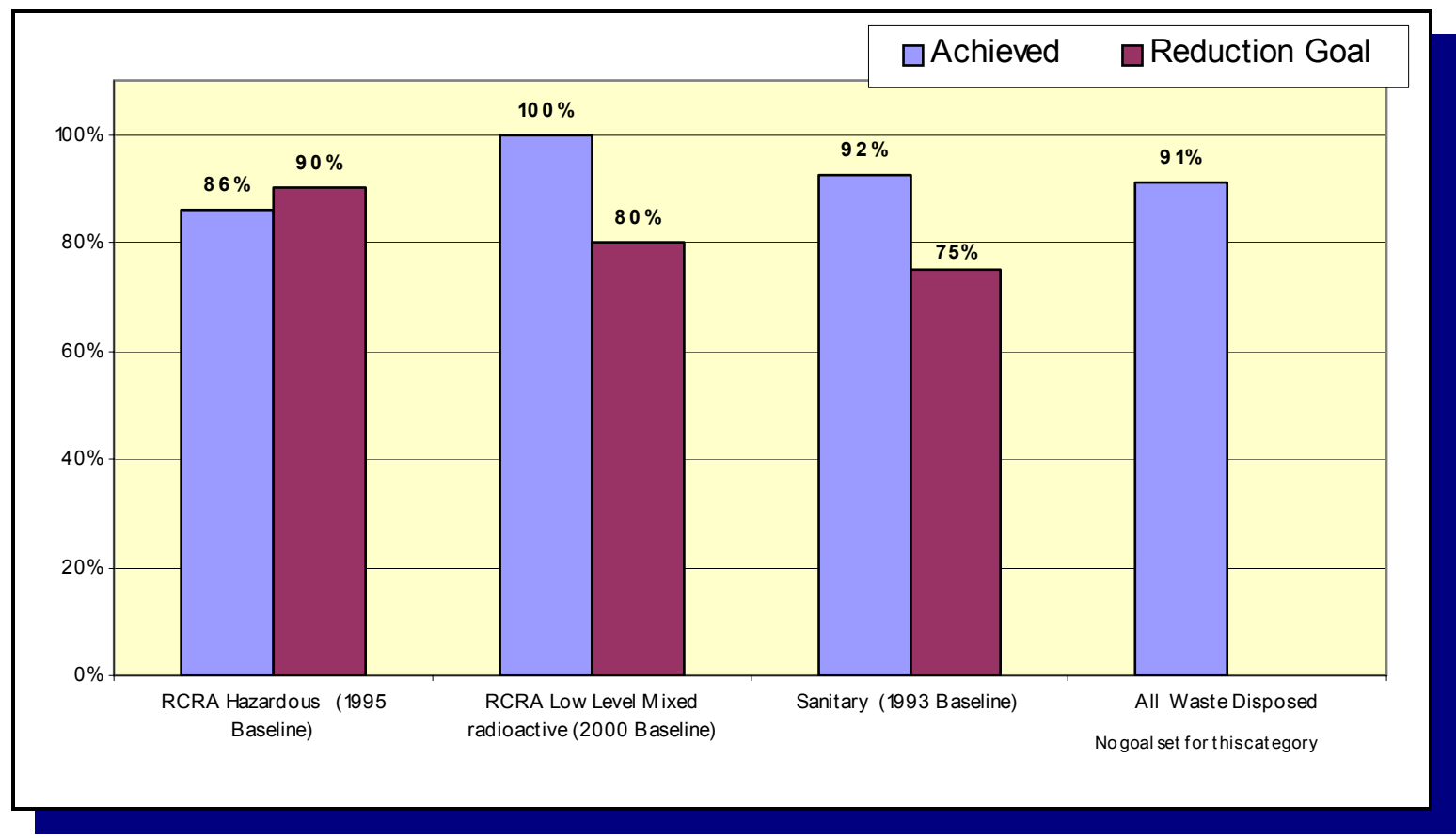

Figure 3.1 - WIPP Waste Reduction Compared to Secretary of Energy's 2005 Goals

The CBFO and WTS jointly established nine goals targeted for completion in FY 2005. The goals focused on reducing use of resources in the areas of water, paper, and electricity consumption; improving recycling and employee awareness; and increasing the number of PPOAs performed. Of the nine goals targeted for completion in FY 2005, WIPP achieved seven as discussed in Section 3.2.13 and demonstrated in Figure 3.2.

\subsubsection{Environmental Management Program}

The next planning step is to identify resource needs and assure that they are obtained. At WIPP, this has been integrated into the business process for developing current and out-year programs along with their associated project milestones. A key tool for monitoring progress toward meeting milestones is a project management tracking system called the C-WIT. In addition, the WIPP P2 Committee (the Green Team) assists organizations in planning for and achieving P2 goals. These steps are repeated annually.

Programs, procedures, and training modules have been developed and are implemented as necessary to meet compliance requirements. Employees are trained for conformance with the programs and procedures as applicable to their job scope. Programs, procedures and training include those for natural resources protection, P2, affirmative procurement, waste management, management of mined materials (i.e., salt), and environmental monitoring. Provision of resources for implementation of these plans is then accomplished through the normal business budget setting process. 


\subsubsection{Structure and Responsibility}

Management's role is to provide the resources essential to implement and control the EMS. These resources include training, funding, human resources, specialized skills and technology. To help facilitate this at WIPP, management has designated EMS Coordinators in both the CBFO and WTS organizations. The coordinators are responsible for maintaining the EMS in accordance with the principles of ISO 14001 and for monitoring and reporting on the effectiveness of the system to management.

EMS responsibilities shared by all employees are included in the GET module. This training module is reviewed and updated each year. Updates assure that responsibilities for protection of the environment and minimizing any potentially significant impacts are current and meet changing environmental stewardship, compliance, and continual improvement needs.

Specific roles and responsibilities related to compliance issues are integrated into the work procedures necessary to carry out the project. For example, a training module provides the knowledge necessary for employees to be qualified as hazardous waste workers. This, in turn, enables personnel to understand their responsibilities and how to manage this significant aspect so that any negative impacts from hazardous waste management tasks are prevented or mitigated.

\subsubsection{Training, Awareness and Competency}

Awareness and initial training on the EMS is included in the GET training as discussed in Section 3.2.6.

The WIPP training program is comprehensive, mature, and based on the DOE's methodology for job scope and needs analysis and program design. Specific training and qualification standards have been set for personnel whose work has the potential to result in significant environmental impact. The standards include those for waste handling, waste management (including TRU mixed, TRU, hazardous and other wastes), mining, and maintenance. The frequency of training required for qualification for specific jobs is established and WTS Technical Training initiates and carries out training based on the defined frequency.

\subsubsection{Communication}

Internal communication related to the EMS, including compliance and P2, is accomplished via multiple mechanisms. The primary way WIPP communicates requirements and expectations is through the programs, plans, and procedures that integrate environmental requirements into daily work processes. Other methods include meetings (e.g., budget meetings, staff meetings, all hands meetings), employee performance reviews, and internal newsletters. The WIPP Plan of the Day meeting is a key communication tool that allows operating and support staff to understand each day's work plan and the interactions necessary to execute the plan in a safe, environmentally sound manner. 
Communication with the public occurs as WIPP invites review and input on draft NEPA documents. The process for implementing the NEPA also assures that information is provided to the public related to significant environmental activities. A toll-free information line is maintained and made available to the public for inquiries regarding any topic or issue. Additionally, documents such as this report and the Biennial Environmental Compliance Report, reports submitted to regulatory agencies, and some information contained in the WIPP Waste Information System are available to the public.

\subsubsection{EMS Documentation}

The WIPP EMS is documented through the Waste Isolation Pilot Plant Environmental Management System Description (DOE/WIPP 05-3318). The programs, procedures, and reports that implement each EMS element are documented in the WIPP EMS Map organized in the context of the ISO 14001 standard. This document is reviewed annually during the preparation of the EMS Annual Report to Management for needed improvements. The EMS document is updated, as needed, after the management's annual review of the system.

\subsubsection{Document Control and Records}

WIPP has a mature, comprehensive, and documented system for document management as established through a writer's guide and records management program. WIPP maintains an electronic document control system to manage development, review, approval and revision of documents. This enables systematic review and input by affected organizations with documentation for each step of the review and approval process.

\subsubsection{Operating Control}

The EMS Aspects and Impacts Table identifies the organizations that are associated with managing WIPP activities so that potential impacts are mitigated. WIPP has three core programs that implement actions to minimize risk by assuring that the integrity (design, operation and maintenance) of facilities and assets is maintained. The documents implementing these programs are Engineering Conduct of Operations (WP 09), Conduct of Operations (WP 10-2), and Maintenance Operations Instruction Manual (WP 04-CO), with their supporting procedures and work instructions.

Implementation of the Engineering Conduct of Operations assures that requirements for design, physical configuration, and documentation of structures, systems, and components are met and that personnel are properly trained and qualified and understand their related responsibilities.

Conduct of Operations establishes expectations for operating practices, control activities, communications, control of equipment, operations turnover and operations procedures. Operating procedures are fundamental to this program and are developed, 
reviewed, approved and required to be followed to ensure the facility is operated within its design basis.

The WIPP Maintenance Operations Instruction Manual provides the program structure for conducting maintenance at the WIPP site so that equipment integrity is maintained. It assures that position responsibilities and requirements for the Preventive Maintenance Program are defined. Implementation assures personnel are trained appropriately, responsibilities are understood and the Preventive Maintenance Program is effective.

\subsubsection{Emergency Preparedness and Response}

WIPP emergency preparedness and response capabilities are maintained through extensive planning, training, drills, drill analysis and implementing improvement actions. Extensive planning is evidenced by the overarching Emergency Management Program and sub-tier plans for managing the transfer of information during and after an event (e.g., mine rescue, fires and responding to incidents/accidents associated with transportation of TRU waste from the generator sites to WIPP). Planning and implementation involves the many organizations and individuals that would play a part in responding to an incident including the communications, operations, environmental compliance and safety departments. Supporting these plans are over twenty procedures for handling specific types of emergencies identified through the Waste Isolation Pilot Plant Contact-Handled Waste Handling Emergency Planning Hazards Assessment (DOE/WIPP-02-3286). These encompass mine rescue, surface and underground fires, hazardous material spill response, and severe weather, as well as security and medical emergencies. Ancillary procedures related to event recovery, categorization of operational incidents and reporting occurrences are also in place.

Training and practicing response skills are a high priority at WIPP. The WIPP training program for the various facets of emergency management is extensive with nearly twenty self-study or classroom training courses provided to employees based on their emergency preparedness and response roles. Over the course of FY 2005, there were over 500 participants in emergency preparedness and response training courses.

Emergency Management conducts drills and exercises according to an annual drill and exercise plan. Members of the emergency response organization are required to participate in a minimum of one drill each year to demonstrate proficiency in their assigned role. A full-participation exercise is conducted each year to test integrated capabilities. Performance during the exercises is critiqued by an independent group and any findings are addressed and managed through the CTS. 


\subsubsection{Measuring and Monitoring (Environmental Performance Measurement)}

There are three arenas in which environmental performance is monitored. Analysis of data in these arenas becomes the basis for determining the effectiveness of the EMS in achieving policy commitments. These arenas are monitoring for:

- $\quad$ Environmental stewardship

- $\quad$ Compliance with legal requirements

- Continual improvement in environmental performance

\section{Monitoring for Environmental Stewardship}

Initial implementation of the Waste Isolation Pilot Plant Environmental Monitoring Plan (DOE/WIPP 99-2194), during the planning and preoperational phases of the project established the WIPP baseline environmental conditions. Continuing implementation monitors for environmental effects during the site operations phase. The plan directs the programs for monitoring of radiological and nonradiological effects and land management, as well as providing the criteria and methods for data analysis and quality assurance. Data from the radiological, nonradiological and land management monitoring programs for FY 2005 indicate that there has been no impact to human health or the environment from WIPP operations. Detailed analysis and summaries of the monitoring results are included in Chapters 4 through 6.

The degree to which management of significant aspects and impacts is integrated into the business programmatic planning process is an indicator of environmental stewardship. As noted in the Executive Summary, the business planning process set over three hundred milestones for FY 2005, with 78 percent being related to the management of a significant environmental aspect and impact. This demonstrates the management of significant aspects and impacts is highly integrated in the business planning (budgeting) processes.

In FY 2005, WIPP had zero reportable, unauthorized contaminant releases, which is another indicator for the policy commitment to environmental stewardship.

Progress toward accomplishing P2 goals is WIPP's final indicator for environmental stewardship. WIPP achieved seven of the nine P2 goals set for FY 2005. This indicates WIPP has integrated P2 into the EMS and is actively working to minimize its environmental footprint through resource conservation and waste minimization. Goals and progress began to be reported quarterly during FY 2005 using a scorecard, which is provided on the P2 website for easy organizational access and is included as Figure 3.2.

Notable achievements were decreasing domestic water consumption by 41 percent compared to the WIPP FY 2003 baseline, completing three PPOAs and increasing the metric tons of office paper and cardboard recycled by over four times the FY 2004 baseline. This represents a recycle to generation rate of 59 percent (Figure 3.3). 


\section{Waste Isolation Pilot Plant Annual Site Environmental Report for 2005 DOE/WIPP-06-2225}

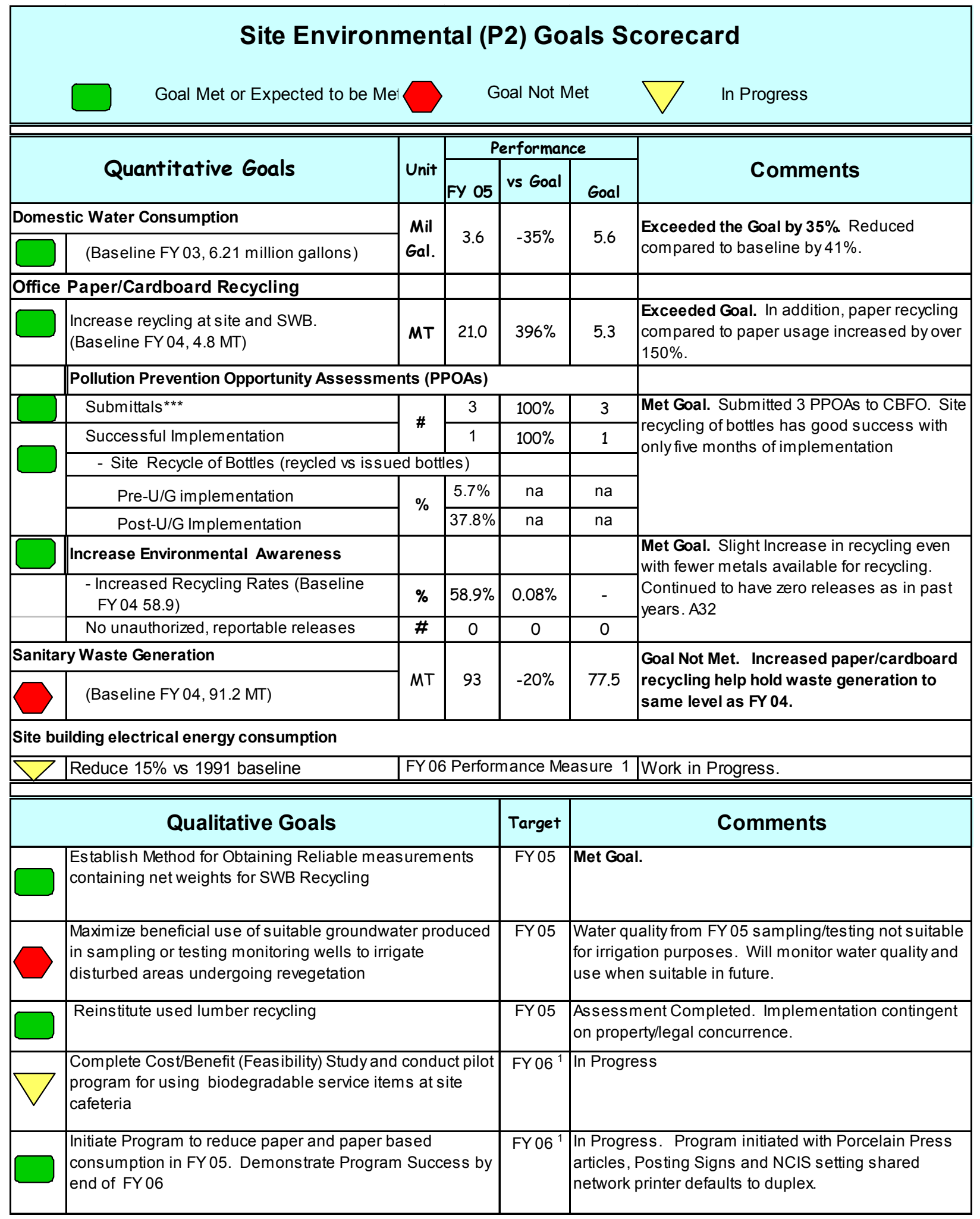

Figure 3.2 - Site Environmental (P2) Goals Scorecard 


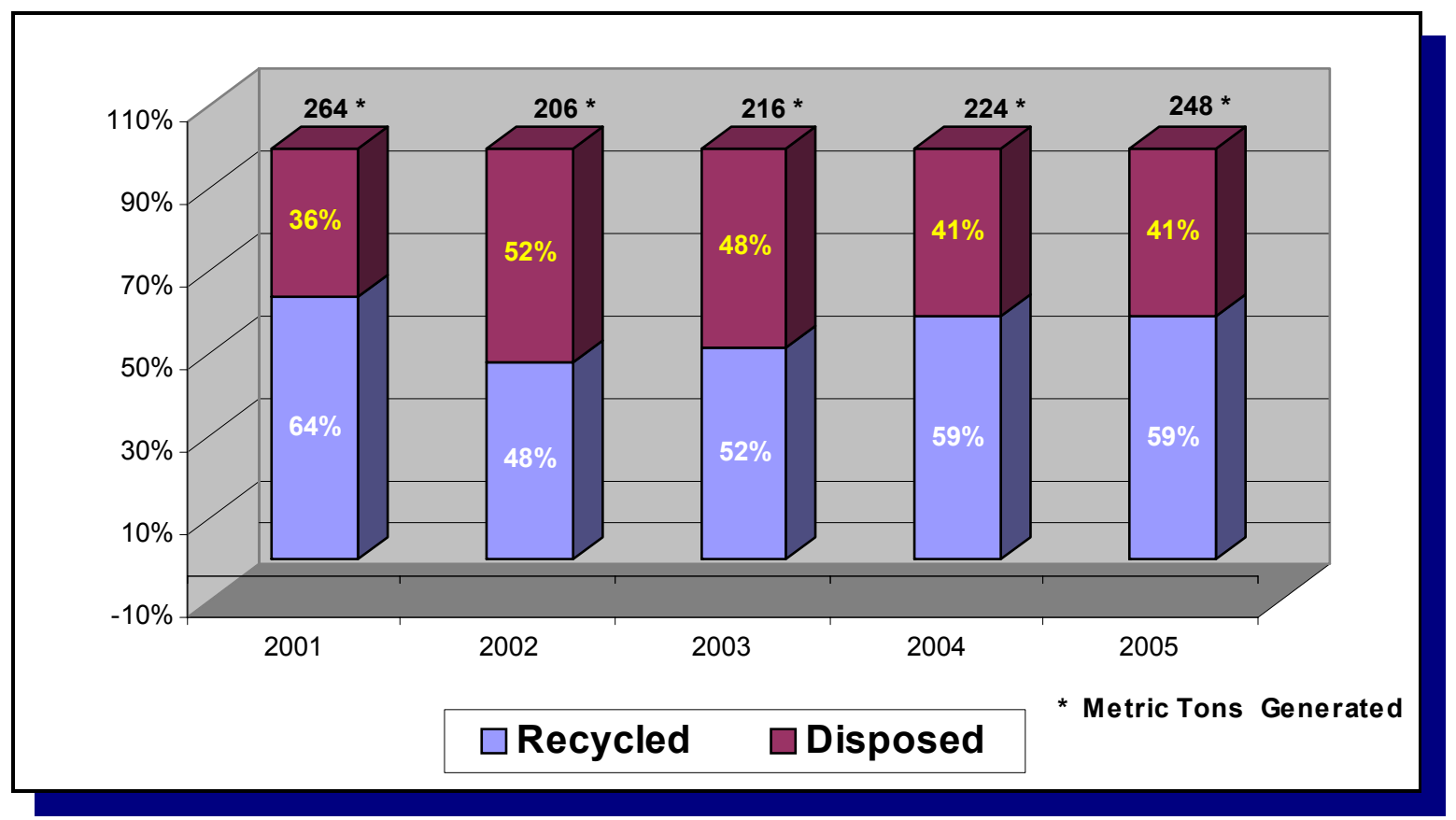

Figure 3.3 - WIPP Recycled vs Total Generated Wastes

The two goals not met were a reduction in the site sanitary (household) waste and using groundwater from monitoring activities for reclamation of areas within the WIPP property boundary. Although the site sanitary waste reduction goal was not met (see Figure 3.2), generation was held to approximately the same level as FY 2004. This was accomplished by the increase in paper/cardboard recycling volumes offsetting increased waste generated as a result of a heightened focus on site cleanliness. Water produced from groundwater monitoring activities was tested in accordance with the P2 goal of beneficial reuse; however, the water was determined to be unsuitable for use. Thus, there was not an opportunity to meet this goal.

\section{Monitoring for Compliance}

Compliance with requirements is monitored through a multi-tiered assessment system. The system includes both internally and externally (independently) led assessments. Monitoring is done by examining the number of findings, their significance, progress made toward correction, and which EMS elements the findings indicate have opportunities for improvement. Results for FY 2005 demonstrate that WIPP has a robust system to check for compliance. Audit/assessment conclusions indicated that WIPP programs, procedures, activities, controls, and requirements were adequate, implemented, and effective.

Thirty-three audits/assessments related to over one hundred broad subject matter compliance requirements (e.g., DOE Order 450.1, hazardous waste regulations, Hazardous Waste Facility Permit conditions) and hundreds of detailed supporting 
requirements such as those found in procedures and plans, were performed in FY 2005. Audits and assessments were performed by WTS, Washington Regulatory and Environmental Services (WRES), the CBFO Technical Assistance Contractor (CTAC), and the EPA. Twenty-two findings were identified, which represented no more than 2 percent of the issues related to the assessed requirements.

Another valuable approach for looking at assessment results as indicators for compliance is to determine the significance of the issues identified. In FY 2005 there were no issues identified that resulted in a notice of violation, and only six findings were directly related to a regulatory or permit requirement. Three of the six pertained to actions required for training, aisle space maintenance, and sampling requirements. The other three were related to documentation.

Findings are also analyzed to determine which of the EMS elements and ISMS core functions are associated with them. The results of this analysis are summarized in Figure 3.4.

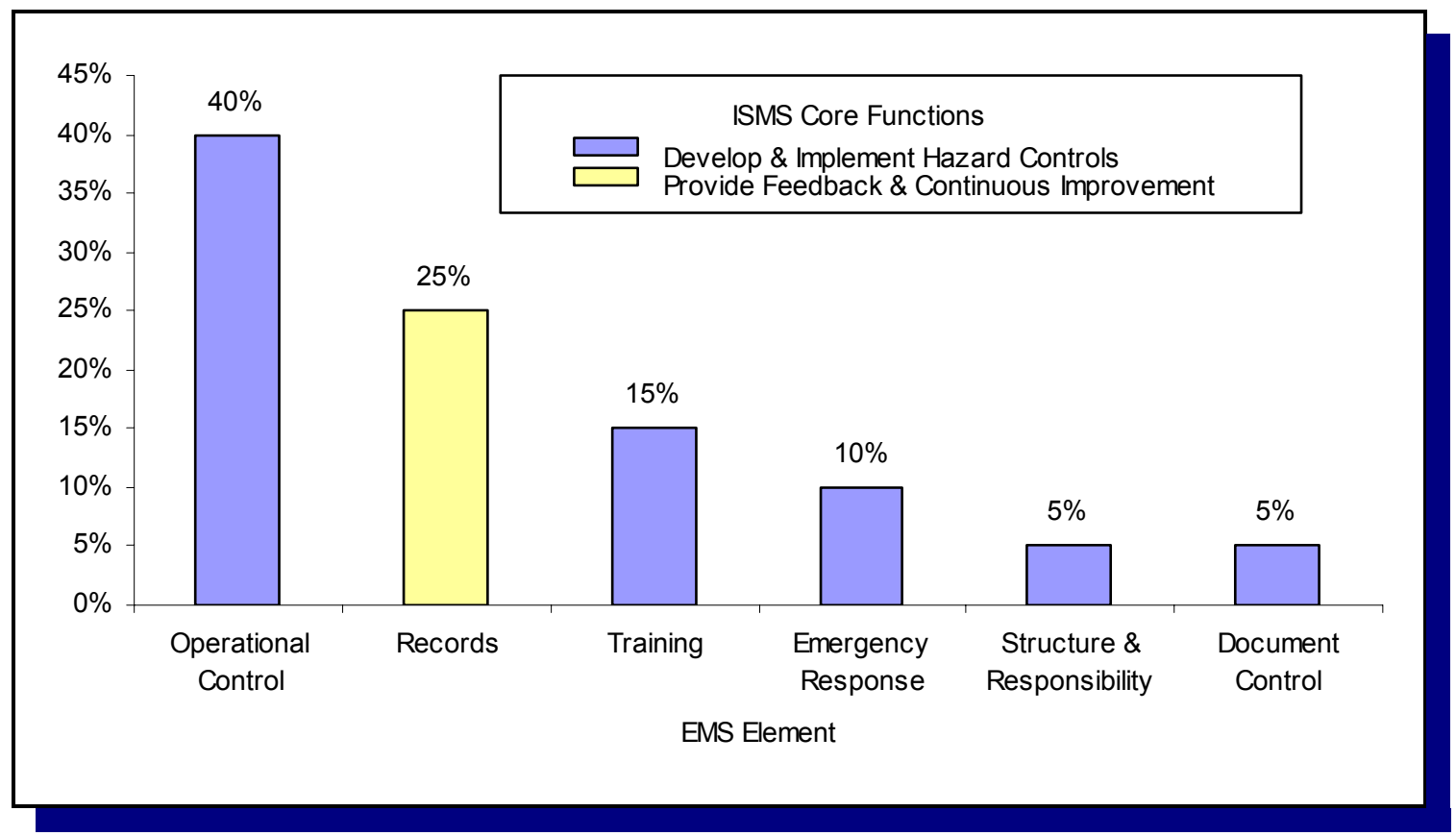

Figure 3.4 - Environmental Findings

Sixty-five percent (or thirteen) of the findings were associated with the EMS elements of Operational Control and Records. The Operational Control element, which correlates to the ISMS function Develop and Implement Hazard Controls, encompasses accomplishing work through development and implementation of thorough and clear procedures. The records element of the EMS includes assuring environmental records are identified and managed according to established procedures. Of the 65 percent, approximately half were related to administrative issues (e.g., using approved forms, completely filling out forms, or providing necessary certification statements). The 
remaining issues ranged from assuring an appropriate procedure was in place, to complete execution of the procedure.

Monitoring for Continual Improvement

WIPP measures the effectiveness of its continual improvement of environmental performance by evaluating whether recommendations from the prior year's EMS annual report have been implemented, whether P2 goals are continually reviewed and revised, and the identification of improvement opportunities via the various assessment programs functioning for the project. In these areas, eight of nine system improvement recommendations from the 2004 EMS Annual Management Review were implemented; eight new P2 goals were set for FY 2006; and 55 observations/recommendations were identified from consideration in the various assessments that were performed related to environmental management.

\subsubsection{Corrective and Preventive Action}

WIPP has institutionalized a robust process for managing corrective and preventive action through its Issues Management Program. The Issues Management Committee reviews and verifies concerns, and requires appropriate corrective/preventive action plans be developed and implemented. Monitoring the completion of action plans is accomplished through the CTS. Issues that are managed through this process include environmental issues, issues raised by employees, assessment findings, and actions identified through WIPP's incident investigation process.

\subsubsection{EMS Audit}

An ISMS review/assessment is performed annually and includes integration of EMS into the ISMS and implementation of the EMS. The FY 2005 review confirmed that the EMS is effectively integrated into the WIPP ISMS and implemented. Recommendations for improvement from the prior year's review have been addressed and incorporated into the EMS. The review also identified three areas for improvement, two of which have been completed and one that will be completed by the end of FY 2006.

In addition to the ISMS review, WTS performed an internal management assessment and a third party contractor performed a surveillance audit of the implementation of the WIPP EMS. Both the management assessment and surveillance audit confirmed that the EMS meets the requirements of DOE Order 450.1 and is effectively implemented.

\subsubsection{Management Review}

CBFO and WTS EMS Coordinators prepare an EMS Annual Report to Management, which is the basis for senior management's review of the effectiveness of the system and their directing system improvements for the upcoming fiscal year. The annual report is based on analyzing the performance indicator data described in the Measuring and Monitoring element. The conclusion reached in the FY 2005 annual report is that 
the EMS remains suitable and effective for achieving policy, and the policy continues to reflect the organization's commitment to environmental performance.

The FY 2005 review also recommended enhancements in the following six areas:

1. Reinforce or emphasize responsibility to follow programs and procedures and to assure they accurately communicate work processes and do not conflict with one another.

2. Communicate $\mathrm{P} 2$ goals to the organization, with each department setting supporting goal(s) and routinely (quarterly) reporting progress toward the goals.

3. Strengthen the process for establishing and managing EMS objectives/targets.

4. Establish EMS system indicators that will be meaningful over time based on evaluating the indicators in this annual report or other potential indicators.

5. Continue efforts to maintain P2 awareness.

6. Retire the WTS environmental and P2 policy statements, which are redundant to the CBFO/WTS Environmental Policy Statement to provide clarity of focus for the organization.

Actions to address these areas will be completed in FY 2006.

\subsection{Status of EMS Implementation}

Federal agencies are required to provide data in the form of a scorecard communicating progress in implementing its EMS. WIPP has completed each of the ten scorecard measures, indicating the EMS is in place and meets requirements. The scorecard measures whether a site has:

1. Issued an EMS Policy Statement.

2. Provided EMS implementation training to personnel establishing the system.

3. Identified its significant environmental aspects.

4. Established and documented measurable environmental objectives and targets.

5. Established environmental management programs specifically to achieve each of its environmental objectives and targets.

6. Developed a program for EMS awareness training. 
7. Implemented a formal, ongoing program to conduct facility-wide EMS awareness training.

8. Established all EMS procedures (e.g., objectives and targets, environmental aspects and impacts, corrective action, self-assessment, management review)

9. Implemented an EMS and completed the Self-Declaration Protocol in accordance with agency policy or have obtained third-party certification (i.e., ISO 14001 or National Environmental Performance Track).

10. Submitted the Site Manager's conformity declaration letter.

During FY 2005, WIPP completed the actions required to integrate the EMS into the ISMS. Since the WIPP EMS was developed and has remained in alignment with the ISO 14001 standard, actions to implement an EMS conforming to DOE Order 450.1 and to integrate the EMS with the ISMS were limited. One of the most significant actions completed was by the CBFO and WTS jointly reviewing, revising where appropriate, and reissuing the Environmental Policy and EMS Description. In addition, both the EMS and ISMS description documents describe integration of the two systems and an EMS/ISMS procedural crosswalk has been made available to employees through the internal environmental website.

Challenges and lessons learned arise from the growing maturity of an EMS. At WIPP, one lesson learned has been that adequate planning must take place for the transfer of knowledge regarding the site EMS as personnel turnover occurs. This transfer is vital for the system to retain its usefulness. Another lesson learned is that EMS awareness must be routinely reinforced, particularly when many of its core processes are being integrated into other business processes.

As confirmed through the analysis of environmental data in these three arenas, discussed in Section 3.2.13, and used in preparation for the EMS Annual Report to Management, the WIPP EMS continues to be suitable and effective for achieving the projects environmental policy. 


\section{CHAPTER 4 - ENVIRONMENTAL RADIOLOGICAL PROGRAM INFORMATION}

DOE Order 450.1 states that the DOE must "conduct environmental monitoring, as appropriate, to support the site's ISMS, to detect, characterize, and respond to releases from DOE activities; assess impacts; estimate dispersal patterns in the environment; characterize the pathways of exposures and doses to members of the public; characterize the exposures and doses to individuals, to the population; and to evaluate the potential impacts to the biota in the vicinity of the DOE activity."

Radionuclides present in the environment, whether naturally occurring or human-made, contribute to radiation doses to humans. Therefore, environmental monitoring around nuclear facilities is imperative to characterize radiological baseline conditions, identify any releases, and determine their effects, should they occur.

The WIPP Environmental Monitoring Program describes the monitoring of air, groundwater, surface water, soils, sediments and biota to characterize the radiological environment around the WIPP facility. This program is carried out in accordance with the DOE/WIPP 99-2194. The radiological monitoring portion of this plan meets the requirements contained in DOE/EH-00173T, Environmental Regulatory Guide for Radiological Effluent Monitoring.

The purpose of WIPP Effluent Monitoring Program is to determine whether radionuclides are being released from WIPP operations, including the underground storage areas and the Waste Handling Building. The WIPP Effluent Monitoring Program requires monitoring to quantify releases of radioactivity from WIPP activities into the environment, and to assure that releases do not cause exposures in excess of regulatory limits. The regulatory limits for the WIPP Effluent Monitoring Program can be found in 40 CFR Part 191, Subpart A. The referenced standard specifies that the combined annual dose equivalent to any member of the public in the general environment resulting from discharges of radioactive material and direct radiation from such management and storage shall not exceed $25 \mathrm{mrem}$ to the whole body and 75 mrem to any critical organ. In addition, in a 1995 Memorandum of Understanding between the EPA and the DOE, the DOE agreed that WIPP would comply with 40 CFR Part 61, Subpart H (NESHAP). The NESHAP standard states that the emissions of radionuclides to the ambient air from DOE facilities shall not exceed those amounts which would cause any member of the public to receive in any year an EDE of 10 mrem per year.

The radiological environment near WIPP includes natural radioactivity, global fallout and, potentially, radioactive contamination remaining from Project Gnome. Under Project Gnome, a nuclear device was detonated underground in bedded salt on December 10, 1961. The test site for Project Gnome was located approximately $9 \mathrm{~km}$ $(5.4 \mathrm{mi})$ southwest of the WIPP site. The Project Gnome shot vented into the atmosphere. Therefore, environmental samples in the vicinity of the WIPP site may contain small amounts of fission products from fallout and residual contamination from Project Gnome in addition to natural radioactivity. 
Natural background radiation, global fallout, and remaining radioactive contamination from Project Gnome together comprise the radiological baseline for WIPP. A report entitled Statistical Summary of the Radiological Baseline Program for the Waste Isolation Pilot Plant (DOE/WIPP 92-037) summarizes the radiological baseline data obtained at and near the WIPP site during the period from 1985 through 1989, prior to the time that WIPP became operational. Radioisotope concentrations in environmental media sampled under the current ongoing monitoring are compared with this baseline to gain information regarding annual fluctuations. Appendix $\mathrm{H}$ presents figures which compare the highest concentrations of radionuclides detected from the WIPP Environmental Monitoring Program to the baseline data.

Environmental media sampled include airborne particulates, soil, surface water, groundwater, sediments and animal and vegetable biota. These samples are analyzed for ten radionuclides, including natural uranium $\left({ }^{234} \mathrm{U},{ }^{235} \mathrm{U}\right.$, and $\left.{ }^{238} \mathrm{U}\right) ;{ }^{40} \mathrm{~K}$; actinides expected to be present in the waste $\left({ }^{238} \mathrm{Pu},{ }^{239+240} \mathrm{Pu}\right.$, and $\left.{ }^{241} \mathrm{Am}\right)$, and major fission products $\left({ }^{137} \mathrm{Cs},{ }^{60} \mathrm{Co}\right.$, and $\left.{ }^{90} \mathrm{Sr}\right)$. Environmental levels of these radionuclides can provide corroborating information on which to base conclusions regarding releases from WIPP operations, in the event of potential radionuclide releases detected by the WIPP effluent monitoring system.

Radionuclides were considered "detected" in a sample if the measured concentration or activity was greater than the total propagated uncertainty (TPU) at the 2 sigma level, and greater than the minimum detectable concentration (MDC). This methodology was patterned after that described in Hanford Decision Level for Alpha Spectrometry Bioassay Analyses Based on the Sample-Specific Total Propagated Uncertainty (MacLellan, 1999). The MDC was determined by the analytical laboratories based on the natural background radiation, the analytical technique, and inherent characteristics of the analytical equipment. The MDC represents the minimum concentration of a radionuclide detectable in a given sample using the given equipment and techniques with a specific statistical confidence (usually 95 percent). TPU is an estimate of the uncertainty in the measurement due to all sources, including counting error, measurement error, chemical recovery error, detector efficiency, randomness of radioactive decay and any other sources of uncertainty.

Measurements of radioactivity are actually probabilities due to the random nature of the disintegration process. A sample is decaying as it is being measured, so no finite value can be assigned. Instead, the ranges of possible activities are reported by incorporating the total propagated uncertainties of the method. For radionuclides determined by gamma spectrometry $\left({ }^{137} \mathrm{Cs},{ }^{60} \mathrm{Co}\right.$, and $\left.{ }^{40} \mathrm{~K}\right)$, an additional factor considered in the determination of detectability is the confidence level with which the peak or peaks associated with the particular radionuclide can be identified by the gamma spectrometry software. In accordance with the Statement of Work for the laboratory analyses, gamma spectroscopy samples with confidence levels less than 90 percent are not considered "detects," regardless of their magnitudes compared to the MDC and TPU. Sample results are also normalized with the instrument background and/or the method blank. If either of those measurements have greater activity ranges than the actual 
sample, it is possible to get negative values on one end of the reported range of activities. Additional information on the equations used is contained in Appendix D.

The WIPP Laboratories perform these analyses for all radiological samples. The WIPP Laboratories use highly sensitive radiochemical analysis and detection techniques that result in very low detection limits. This allows detection of radionuclides at levels far below those of environmental and human health concern. The MDCs attained by the WIPP Laboratories are below the recommended MDCs specified in ANSI N13.30, which provides performance criteria for radiobioassay.

Comparisons of radionuclide concentrations were made between years and locations using the statistical procedure, ANOVA (Analysis of Variance) for those data sets containing sufficient "detects" to make such comparisons statistically meaningful. When this or other statistical tests were used, the $p$-value was reported. The $p$-value is the probability under the null hypothesis of observing a value as unlikely or more unlikely than the value of the test statistic. In many cases, scientists have accepted a value of $p<0.05$ as indicative of a difference between samples. However, interpretation of $p$ requires some judgment on the part of the reader and individual readers may choose to defend higher or lower values of $p$ as their cutoff value. For this report, $p<0.05$ was used.

\section{Effluent Monitoring}

The WIPP Effluent Monitoring Program has three effluent air monitoring stations. These monitoring stations are known as Effluent Monitoring Stations A, B, and C. Each station employs one or more fixed air samplers, collecting particulate from the effluent air stream using a Versapor ${ }^{\circledR}$ filter. Instruments at Station A sample the unfiltered underground exhaust air. Samples collected at Station B represent the underground exhaust air after HEPA (high-efficiency particulate air) filtration and, sometimes, nonfiltered air during maintenance. Samples collected at Station $C$ represent the air from the Waste Handling Building after HEPA filtration. For each sampling event, chainof-custody forms are initiated to track and maintain an accurate written record of filter sample handling and treatment from the time of sample collection through laboratory procedures to disposal.

In the Effluent Monitoring Program, filter samples from all three effluent air monitoring stations are typically analyzed for ${ }^{238} \mathrm{Pu},{ }^{239+240} \mathrm{Pu},{ }^{241} \mathrm{Am}$, and ${ }^{90} \mathrm{Sr}$. The five radionuclides, which make up 98 percent of the total repository radioactivity, are based upon the TRU inventory expected to be in place at the WIPP. Plutonium-239 and ${ }^{240} \mathrm{Pu}$ are difficult to distinguish by alpha spectrometry because their peak energies are separated by less than $0.02 \mathrm{MeV}$. As a result, these two peaks appear to overlap on the spectrum and are reported as ${ }^{239+240} \mathrm{Pu}$.

\section{Environmental Monitoring}

The purpose of radiological environmental monitoring is to measure radionuclides in the ambient environmental media. This allows for a comparison of sample data to results 
from previous years and to baseline data, to determine what, if any, impact WIPP is having on the surrounding environment (see Appendix $\mathrm{H}$ for comparison graphs). WIPP's radiological monitoring includes sampling and analysis of air, groundwater, surface water, sediment, soil and biota for ten radionuclides. For each sampling event, chain-of-custody forms are initiated to track and maintain an accurate written record of sample handling and treatment from the time of sample collection through delivery to the laboratory. Internal chain of custody forms are used by the laboratory to track and maintain custody while samples are being analyzed.

The radionuclides analyzed are ${ }^{238} \mathrm{Pu},{ }^{239+240} \mathrm{Pu},{ }^{241} \mathrm{Am},{ }^{234} \mathrm{U},{ }^{235} \mathrm{U},{ }^{238} \mathrm{U},{ }^{137} \mathrm{Cs},{ }^{60} \mathrm{Co},{ }^{40} \mathrm{~K}$, and ${ }^{90} \mathrm{Sr}$. Isotopes of plutonium and americium were analyzed because they are the most significant alpha-emitting radionuclides among the constituents of TRU wastes received at the WIPP site. Uranium isotopes were analyzed because they are prominent alpha-emitting radionuclides in the natural environment.

Strontium-90, ${ }^{60} \mathrm{Co}$, and ${ }^{137} \mathrm{Cs}$ are analyzed to demonstrate the ability to quantify these beta and gamma-emitting contaminants should they appear in the TRU waste stream. Potassium-40, a natural gamma-emitting radionuclide which is ubiquitous in the earth's crust, was also monitored.

\subsection{Effluent Monitoring}

\subsubsection{Sample Collection}

Stations $\mathrm{A}, \mathrm{B}$, and $\mathrm{C}$ are monitored with one or more fixed air samplers. The volume of air sampled at each station varies depending on the sampling location and configuration. Each system is designed to provide a representative sample using a $3.0 \mu \mathrm{m}, 47-\mathrm{mm}$ diameter Versapor ${ }^{\circledR}$ membrane filter.

Daily (24-hours) filter samples are collected from Station $A$ from the unfiltered underground exhaust stream. Each day at Station A, approximately $80 \mathrm{~m}^{3}\left(2,818 \mathrm{ft}^{3}\right)$ of air is filtered through the Versapor ${ }^{\circledR}$ filter.

Weekly (24 hours/seven days per week) filter samples are collected at Stations B and $C$. Station $B$ represents the underground exhaust air after HEPA filtration and, sometimes, nonfiltered air during maintenance. Each week at Station B, approximately $575 \mathrm{~m}^{3}\left(20,304 \mathrm{ft}^{3}\right)$ of air is filtered through the Versapor ${ }^{\circledR}$ filter. Weekly filter samples are also collected at Station C, which represents the air from the Waste Handling Building after HEPA filtration. Each week at Station C, approximately $232 \mathrm{~m}^{3}\left(8,191 \mathrm{ft}^{3}\right)$ of air is filtered through the Versapor ${ }^{\circledR}$ filter. Based on the indicated sampling periods, these air volumes are within \pm 10 percent of the volume derived using the flow rate set point of $0.057 \mathrm{~m}^{3} / \mathrm{min}\left(2 \mathrm{ft}^{3} / \mathrm{min}\right)$ for Stations $A$ and B. The air volume for Station $C$ is within \pm 10 percent of the volume derived using the flow rate required for isokinetic sampling conditions and the indicated sampling period. The sample flow rate for Station $\mathrm{C}$ varies according to the exhaust air flow in the Waste Handling Building in order to maintain isokinetic sampling conditions. 
The filter samples are composited each quarter for Stations B and C. Because of the large number of samples from Station A, these samples were composited monthly. Samples were analyzed radiochemically for ${ }^{241} \mathrm{Am},{ }^{238} \mathrm{Pu},{ }^{239+240} \mathrm{Pu}$, and ${ }^{90} \mathrm{Sr}$, the components of the $\mathrm{CH}$ waste at WIPP expected to produce 98 percent of the potential radiation dose to humans.

\subsubsection{Sample Preparation}

Monthly and quarterly filter samples are composited. The composites are transferred into a Pyrex beaker, spiked with appropriate tracers $\left({ }^{243} \mathrm{Am}\right.$, and $\left.{ }^{242} \mathrm{Pu}\right)$, and heated in a Muffle furnace at $250^{\circ} \mathrm{C}\left(482^{\circ} \mathrm{F}\right)$ for two hours, followed by two hours at $375^{\circ} \mathrm{C}\left(707^{\circ} \mathrm{F}\right)$ and six hours at $525^{\circ} \mathrm{C}\left(977^{\circ} \mathrm{F}\right)$.

The ash is cooled, transferred quantitatively into a Teflon beaker by rinsing with concentrated nitric acid, and heated with concentrated hydrofluoric acid until completely dissolved. Hydrofluoric acid is removed by evaporating to dryness.

Approximately 25 milliliters $(\mathrm{mL})(0.845$ fluid ounce [oz]) of concentrated nitric acid and one gram $(0.0353 \mathrm{oz})$ of boric acid are added, heated, and finally evaporated to dryness. The residue was dissolved in $8 \mathrm{M}$ (molar) nitric acid for gamma spectrometry and determinations of ${ }^{90} \mathrm{Sr}$ and alpha-emitting radionuclides.

\subsubsection{Determination of Individual Radionuclides}

Gamma-emitting radionuclides are measured in the air filters by gamma spectrometry. Strontium-90 and alpha-emitting radionuclides are determined by sequential separation and counting. Strontium-90 is counted with a gas proportional counter. Determination of actinides involves co-precipitation, ion exchange separation, and alpha spectrometry.

\subsubsection{Results and Discussion}

Out of 20 total composite samples, none had detectable radioactivity (Table 4.1). In all cases, either the 2 sigma TPU or the MDC was found to be greater than the estimated values. In cases when the 2 sigma TPU values were greater than the MDC, the 2 sigma TPU values were used as input nuclide data in the CAP88-PC computer model to calculate the EDEs to members of the public (see Section 4.8). These include the 2 sigma TPU values from the following composite air samples: Station $A,{ }^{241} \mathrm{Am}$, during the months of August, October, and November 2005; Station A, ${ }^{238} \mathrm{Pu}$, during the months of October and November 2005; Station A, ${ }^{239+240} \mathrm{Pu}$, during the month of April 2005; Stations B and C, ${ }^{241} \mathrm{Am}$, third and fourth quarters of 2005; Stations B and C, ${ }^{239+240} \mathrm{Pu}$, fourth quarter of 2005 ; and all results of ${ }^{90} \mathrm{Sr}$ from Stations $\mathrm{A}, \mathrm{B}$, and $\mathrm{C}$. In all other cases, the MDC values were used as nuclide data in the CAP88-PC computer model (see Section 4.8).

Sampling was routinely performed in the underground using fixed air samplers and continuous air monitors. Evaluation of the filter sample results indicate that there were no detectable releases that exceeded $25 \mathrm{mrem}$ to the whole body and $75 \mathrm{mrem}$ to any 


\section{Waste Isolation Pilot Plant Annual Site Environmental Report for 2005 DOE/WIPP-06-2225}

critical organ in accordance with the provisions of 40 CFR §191.03(b), from the WIPP facility. In addition, there were no detectable releases that exceeded the $10 \mathrm{mrem}$ per year limit and the 0.1 mrem per year limit for periodic confirmatory sampling in accordance with the provisions of 40 CFR $\S 61.94$, from the WIPP facility.

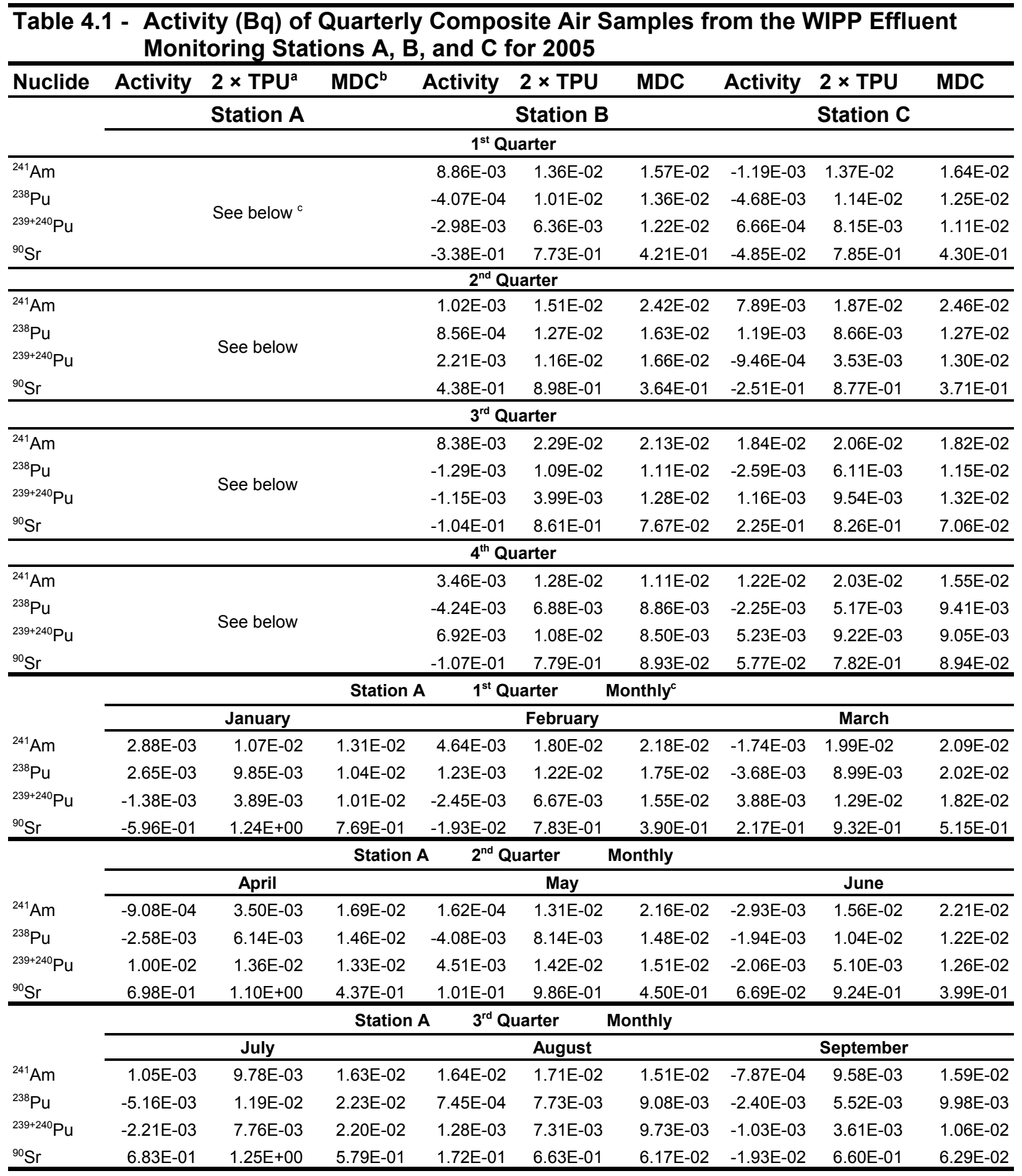




\section{Table 4.1 - Activity (Bq) of Quarterly Composite Air Samples from the WIPP Effluent} Monitoring Stations A, B, and C for 2005

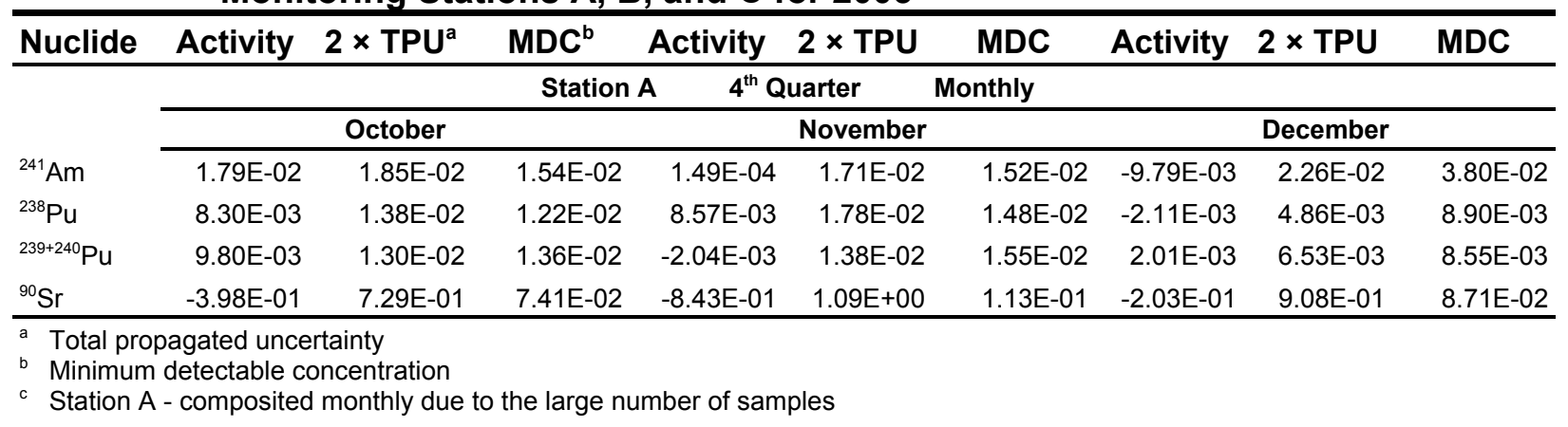

\subsection{Airborne Particulates}

\subsubsection{Sample Collection}

Weekly airborne particulate samples are collected from seven locations around WIPP (Figure 4.1) using low volume air samplers (LVASs). Locations were selected based on the prevailing wind direction. Location codes are shown in Appendix C. Each week at each sampling location, approximately $600 \mathrm{~m}^{3}\left(21,187 \mathrm{ft}^{3}\right)$ of air is filtered through a 4.7-cm (1.85-in.) diameter glass microfiber filter using a low-volume continuous air sampler.

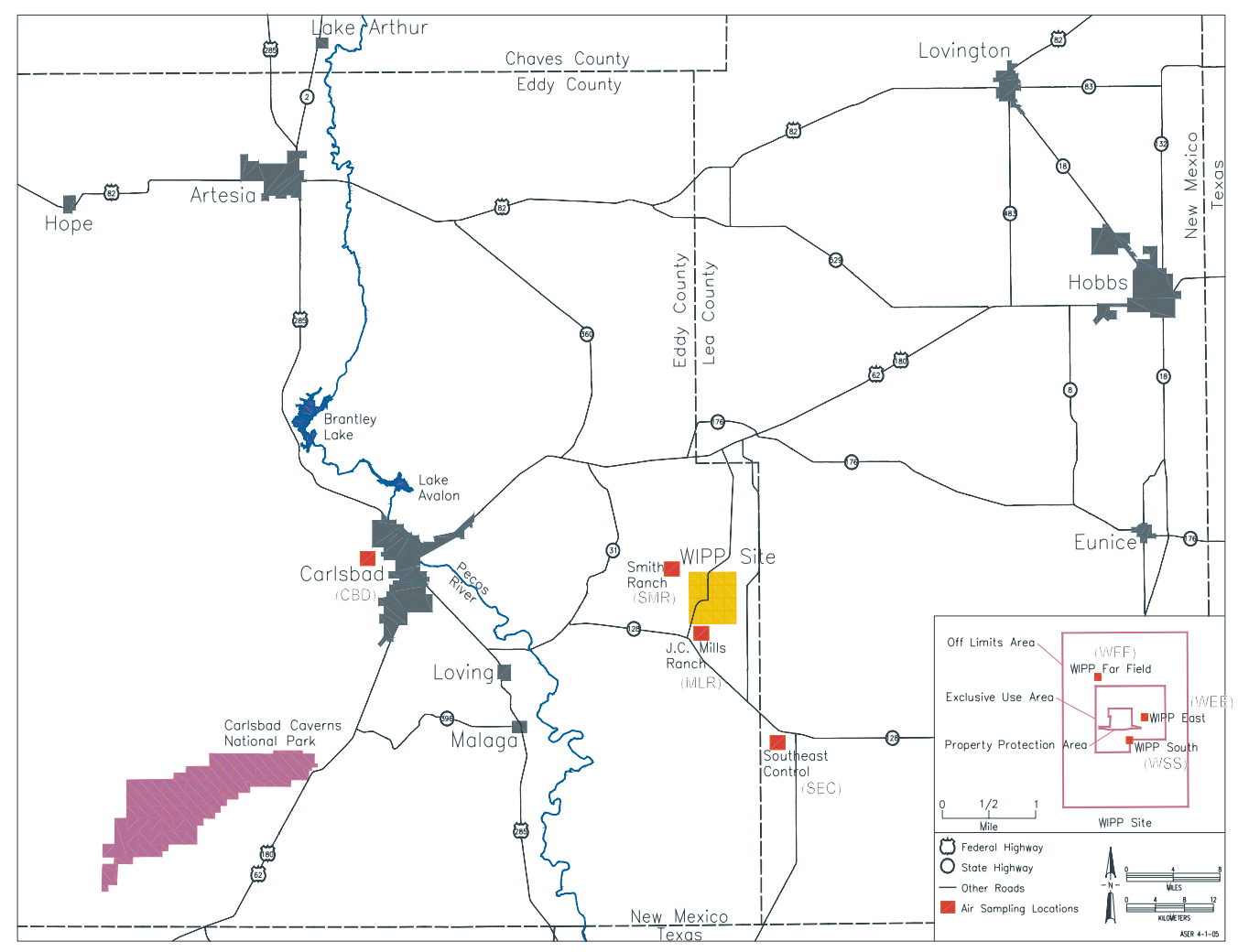

Figure 4.1 - Air Sampling Locations on and Near the WIPP Facility 


\subsubsection{Sample Preparation}

Weekly air particulate samples are composited for each quarter. The composites are transferred into a Pyrex beaker, spiked with appropriate tracers $\left({ }^{243} \mathrm{Am}\right.$ and $\left.{ }^{242} \mathrm{Pu}\right)$, and heated in a Muffle furnace at $250^{\circ} \mathrm{C}\left(482^{\circ} \mathrm{F}\right)$ for two hours, followed by two hours at $375^{\circ} \mathrm{C}\left(707^{\circ} \mathrm{F}\right)$ and six hours at $525^{\circ} \mathrm{C}\left(977^{\circ} \mathrm{F}\right)$.

The ash is cooled, transferred quantitatively into a Teflon beaker by rinsing with concentrated nitric acid, and heated with concentrated hydrofluoric acid until completely dissolved. Hydrofluoric acid is removed by evaporating to dryness.

Approximately $25 \mathrm{~mL}(0.845 \mathrm{oz})$ of concentrated nitric acid and one gram $(0.0353 \mathrm{oz})$ of boric acid are added, heated, and finally evaporated to dryness. The residue is dissolved in $8 \mathrm{M}$ nitric acid for gamma spectrometry and determinations of ${ }^{90} \mathrm{Sr}$ and alpha-emitting radionuclides.

\subsubsection{Determination of Individual Radionuclides}

Gamma-emitting radionuclides are measured in the air filters by gamma spectrometry. Strontium-90 and alpha-emitting radionuclides are determined by sequential separation and counting. Strontium-90 is counted with a gas proportional counter. Determination of actinides involved co-precipitation, ion exchange separation, and alpha spectrometry.

\subsubsection{Results and Discussion}

The minimum, maximum, and average concentrations for all sampling locations combined are reported in Table 4.2. Detailed data for each station are reported in Appendix G (Table G.1).

Natural uranium isotopes were not detected in the composite samples (Table G.1). Whenever the word "sample" is used in this section, it should be taken to mean "composite sample" and does not include blanks. Uranium-235, ${ }^{234} \mathrm{U}$ and ${ }^{238} \mathrm{U}$ were not detected at any of the sampling locations. None of these isotopes were detected so ANOVA comparisons between years and among locations were not performed.

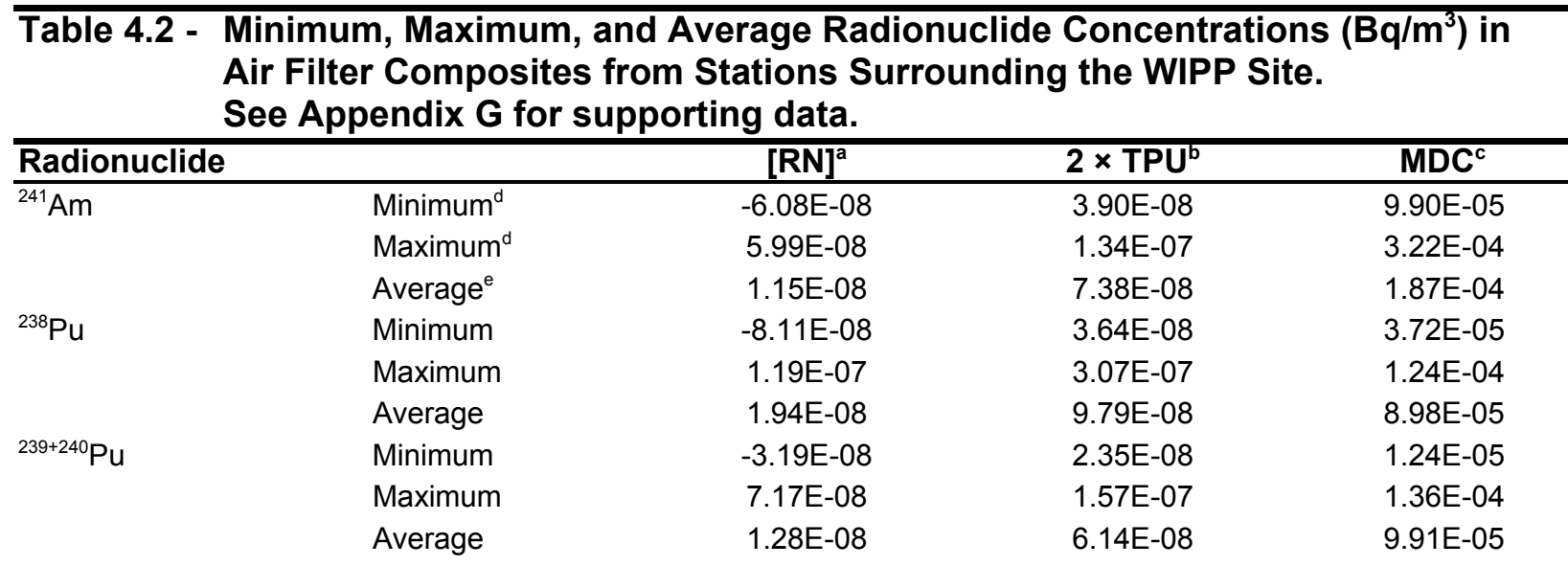




\begin{tabular}{|c|c|c|c|c|}
\hline Radionuclide & & {$[R]^{a}{ }^{a}$} & $2 \times T_{P U^{b}}$ & $\mathrm{MDC}^{\mathrm{C}}$ \\
\hline \multirow[t]{3}{*}{${ }^{234} \mathrm{U}$} & Minimum & $1.70 \mathrm{E}-06$ & $3.09 \mathrm{E}-07$ & $8.54 \mathrm{E}-04$ \\
\hline & Maximum & 3.66E-06 & 5.57E-07 & 1.40E-03 \\
\hline & Average & 2.36E-06 & 4.11E-07 & 1.21E-03 \\
\hline \multirow[t]{3}{*}{${ }^{235} \mathrm{U}$} & Minimum & $6.27 \mathrm{E}-08$ & 8.47E-08 & 1.61E-04 \\
\hline & Maximum & 2.44E-07 & $1.56 \mathrm{E}-07$ & $2.23 E-04$ \\
\hline & Average & $1.48 \mathrm{E}-07$ & 1.15E-07 & 1.89E-04 \\
\hline \multirow[t]{3}{*}{${ }^{238} \mathrm{U}$} & Minimum & 1.73E-06 & 3.10E-07 & $5.32 \mathrm{E}-04$ \\
\hline & Maximum & $3.42 \mathrm{E}-06$ & 5.36E-07 & 8.54E-04 \\
\hline & Average & 2.26E-06 & 4.01E-07 & 7.09E-04 \\
\hline \multirow[t]{3}{*}{${ }^{40} \mathrm{~K}$} & Minimum & 1.32E-04 & $1.24 \mathrm{E}-04$ & 1.67E-04 \\
\hline & Maximum & $9.72 \mathrm{E}-04$ & 4.19E-04 & $6.58 \mathrm{E}-04$ \\
\hline & Average & 3.84E-04 & $2.20 \mathrm{E}-04$ & 2.96E-04 \\
\hline \multirow[t]{3}{*}{${ }^{60} \mathrm{Co}$} & Minimum & $-2.17 \mathrm{E}-05$ & 1.93E-05 & 2.39E-05 \\
\hline & Maximum & $6.22 \mathrm{E}-05$ & 3.96E-05 & $6.15 \mathrm{E}-05$ \\
\hline & Average & 8.63E-06 & $2.88 \mathrm{E}-05$ & 3.34E-05 \\
\hline \multirow[t]{3}{*}{${ }^{90} \mathrm{Sr}$} & Minimum & $-3.91 \mathrm{E}-06$ & $2.59 \mathrm{E}-06$ & 1.09E-06 \\
\hline & Maximum & $2.80 \mathrm{E}-06$ & 7.36E-06 & 1.91E-03 \\
\hline & Average & $-8.89 \mathrm{E}-07$ & 4.26E-06 & $1.24 \mathrm{E}-03$ \\
\hline \multirow[t]{3}{*}{${ }^{137} \mathrm{Cs}$} & Minimum & $-6.97 \mathrm{E}-05$ & 1.55E-06 & 1.80E-05 \\
\hline & Maximum & 1.13E-05 & 5.32E-05 & 5.98E-05 \\
\hline & Average & $-5.97 \mathrm{E}-06$ & $2.38 \mathrm{E}-05$ & 2.85E-05 \\
\hline \multicolumn{5}{|c|}{$\begin{array}{l}\text { Radionuclide concentration, values are for eight locations, four quarterly composites (Appendix G). } \\
\text { Total propagated uncertainty } \\
\text { Minimum detectable concentration } \\
\text { Minimum and maximum reported for each radionuclide are based on [RN] while the associated } 2 \times \text { TPU and MDC values are } \\
\text { inherited with the specific [RN]. }\end{array}$} \\
\hline
\end{tabular}

Plutonium-238, ${ }^{239+240} \mathrm{Pu}$, and ${ }^{241} \mathrm{Am}$ were not detected in any LVAS samples in 2005. Concentrations of ${ }^{40} \mathrm{~K}$ (Table G.1) were detected in approximately two thirds of the samples. Potassium- 40 is ubiquitous in the earth's crust and thus would be expected to show up in environmental air samples. There was no significant difference in the concentrations of ${ }^{40} \mathrm{~K}$ detected among locations (ANOVA, $p=0.502$ ) or between 2004 and 2005 (ANOVA, $p=0.864$ ). The highest concentration of ${ }^{40} \mathrm{~K}$ observed $\left(9.72 \mathrm{E}-04 \mathrm{~Bq} / \mathrm{m}^{3}\right)$ was somewhat higher than the baseline values (upper 99th percentile: $3.2 \mathrm{E}-04 \mathrm{~Bq} / \mathrm{m}^{3}$ ). These are both extremely small concentrations. Since airborne ${ }^{40} \mathrm{~K}$ is mostly due to resuspension from soils, concentrations are highly variable, and it is not surprising that some sample results are outside the range of baseline values. This, coupled with the fact that there is no ${ }^{40} \mathrm{~K}$ in WIPP waste streams, suggests that the measured concentrations were not due to WIPP operations.

Cesium-137 and ${ }^{90} \mathrm{Sr}$ were not detected in any samples in 2005. Cobalt-60 was detected in one sample at $6.22 \mathrm{E}-05 \mathrm{~Bq} / \mathrm{m}^{3}$, which was slightly greater than the baseline value (upper $99^{\text {th }}$ percentile $<2.7 \mathrm{E}-05 \mathrm{~Bq} / \mathrm{m}^{3}$ ). Since ${ }^{60} \mathrm{Co}$ was only detected in one sample, there was insufficient data for ANOVA comparisons between years or among locations. 
Duplicate air particulate samples were collected by moving a portable sampler from one location to another every quarter: MLR in the first quarter, SMR in the second quarter, CBD in the third quarter, and SEC in the fourth quarter. The samples were collected by both samplers under identical conditions at all four locations. The duplicate samples were analyzed to check the reproducibility of the data. Relative error ratios (RERs) for all duplicate pairs for which both the sample and the duplicate contained a detectable concentration of a radionuclide were calculated. The RER is shown in Table 4.3. A RER value greater than one at CBD location indicates poor reproducibility. This is most likely due to variations in the particle concentrations seen by the two samplers.

Table 4.3 - Results of Duplicate Composite Air Filter Sampling. Units are Bq/m³. See Appendix $\mathrm{C}$ for sampling location codes.

\begin{tabular}{|c|c|c|c|c|c|c|c|c|c|}
\hline Loc: & Quarter & & & Sample & & & Duplicate & & \\
\hline & & & [RN] $^{a}$ & $2 \times$ TPU $^{b}$ & MDC $^{c}$ & RN & $2 \times \mathrm{TPU}$ & MDC & RER $^{\mathrm{d}}$ \\
\hline CBD & 3 & ${ }^{40} \mathrm{~K}$ & $2.38 \mathrm{E}-04$ & $1.58 \mathrm{E}-04$ & $2.36 \mathrm{E}-04$ & $5.93 \mathrm{E}-04$ & $2.36 \mathrm{E}-04$ & $3.19 \mathrm{E}-04$ & 1.51 \\
\hline
\end{tabular}

${ }^{a}$ Radionuclide concentration

b Total propagated uncertainty

${ }^{\mathrm{c}}$ Minimum detectable concentration

${ }^{d}$ Relative error ratio

\subsection{Groundwater}

\subsubsection{Sample Collection}

Groundwater samples were collected twice in 2005 from seven different wells around the WIPP site as shown in Figure 6.1. Six of these wells are completed in the Culebra Member of the Rustler Formation (wells WQSP-1 through WQSP-6) and the seventh (well WQSP-6A) is completed in the Dewey Lake Redbeds Formation. Approximately three bore volumes (approximately 3,800 liters [L] [1,004 gallons]) of water are pumped out of each well before collecting approximately $38 \mathrm{~L}$ (10 gallons) of water samples. The water samples are collected from depths ranging from 180-270 $\mathrm{m}$ (591-886 ft) from six wells (WQSP-1 to WQSP-6), and from a depth of $69 \mathrm{~m}$ (226 ft) from WQSP-6A. Approximately $8 \mathrm{~L}$ ( 2 gallons) of water are sent to the laboratory for the determination of radionuclides of interest. The rest of the samples are used to analyze for nonradiological parameters or are put into storage. The radiological samples are acidified to $\mathrm{pH} \leq 2$ by titrating with concentrated nitric acid.

\subsubsection{Sample Preparation}

Groundwater sample containers are shaken to distribute suspended material evenly, and an aliquot is measured into a glass beaker. Tracers $\left({ }^{232} \mathrm{U},{ }^{243} \mathrm{Am}\right.$, and $\left.{ }^{242} \mathrm{Pu}\right)$ and carriers (strontium nitrate and barium nitrate) are added and the sample is then digested using concentrated nitric acid and hydrofluoric acid. The sample is then heated to dryness and wet ashed using concentrated nitric acid and hydrogen peroxide. Finally, the sample is heated to dryness again and the isotopic separation process is initiated. 


\subsubsection{Determination of Individual Radionuclides}

The acidified water samples are used for the determination of the gamma-emitting radionuclides ${ }^{40} \mathrm{~K},{ }^{60} \mathrm{Co}$, and ${ }^{137} \mathrm{Cs}$, by gamma spectrometry. An aliquot of approximately $0.5 \mathrm{~L}(16.9 \mathrm{oz})$ is used for the determination of ${ }^{90} \mathrm{Sr}$ by gas proportional counter. Another aliquot is used for the sequential determinations of the uranium isotopes, the plutonium isotopes, and ${ }^{241} \mathrm{Am}$ by alpha spectrometry. Preparation of these samples for counting involves the co-precipitation of the actinides with an iron carrier, ion exchange chromatographic separation of individual radionuclides, and source preparation by micro-precipitation.

\subsubsection{Results and Discussion}

Isotopes of naturally occurring uranium were detected in every well in 2005 (Table 4.4). The concentrations of uranium isotopes were compared between 2004 and 2005 and also among sampling locations using ANOVA. Although significant variability was observed among sampling locations for uranium isotopes (ANOVA, ${ }^{234} \mathrm{U} p=4.7 \mathrm{E}-05$, ${ }^{235} \mathrm{U} p=0.129,{ }^{238} \mathrm{U} p=3.4 \mathrm{E}-05$ ), there was no significant difference in the concentrations of uranium isotopes between 2004 and 2005 (ANOVA, ${ }^{234} \mathrm{U} p=0.590$, ${ }^{235} \mathrm{U} p=0.626,{ }^{238} \mathrm{U} p=0.637$ ). Variability among sampling locations is expected since natural uranium in the earth's crust is distributed in a nonhomogenous fashion, and this variation is reflected in the amounts of uranium dissolved into groundwater.

Concentrations of uranium isotopes were also compared with baseline levels observed between 1985 and 1989. Concentrations of ${ }^{238} \mathrm{U}$ were within the 99 percent confidence interval ranges of baseline levels (DOE/WIPP 92-037). Both ${ }^{234} \mathrm{U}$ and ${ }^{235} \mathrm{U}$ were somewhat higher than the 99 percent confidence interval ranges of baseline levels. The highest concentration of ${ }^{234} \mathrm{U}$ observed $(1.34 \mathrm{~Bq} / \mathrm{L})$ and the highest concentration of ${ }^{235} \mathrm{U}$ observed $(5.04 \mathrm{E}-02 \mathrm{~Bq} / \mathrm{L}$ ) were barely higher than baseline values (upper $99^{\text {th }}$ percentiles $=1.30 \mathrm{~Bq} / \mathrm{L}$ and $3.10 \mathrm{E}-02 \mathrm{~Bq} / \mathrm{L}$, respectively). However, these are both extremely small concentrations and no statistically significant increase was observed between the years 2004 and 2005. Therefore, it is concluded that WIPP operation has not resulted in changes in the radiological background in the vicinity of the WIPP site.

Plutonium-238, ${ }^{239+240} \mathrm{Pu}$, and ${ }^{241} \mathrm{Am}$ were also analyzed in these groundwater samples (Table 4.4). Plutonium-238, ${ }^{239+240} \mathrm{Pu}$, and ${ }^{241} \mathrm{Am}$ were not detected in any of the wells. None of these isotopes were detected, so ANOVA comparisons between years and among locations were not performed.

Cesium-137 and ${ }^{90} \mathrm{Sr}$ were not detected in any of the samples. Cobalt-60 was not detected in any of the samples except for one sample taken from well WQSP-5. Even so, the concentrations of ${ }^{60} \mathrm{Co}$ observed during this reporting year fall within the 99 percent confidence interval range of the baseline concentrations. Since ${ }^{60} \mathrm{Co}$ was only detected in one sample, there was insufficient data for ANOVA comparisons between years or among locations. 


\section{Waste Isolation Pilot Plant Annual Site Environmental Report for 2005 DOE/WIPP-06-2225}

Potassium-40 was detected in all samples except for one sample taken from well WQSP-6 and both samples from WQSP-6A (Table 4.4). Potassium is ubiquitous throughout the earth's crust. The levels are higher than average in these sampling wells due to the extremely briny nature of the Culebra water and its proximity to the Salado formation, resulting in a high level of dissolved potassium salts. Even so, the concentrations of ${ }^{40} \mathrm{~K}$ observed during this reporting year fall within the 99 percent confidence interval range of the baseline concentrations. There was a significant difference in ${ }^{40} \mathrm{~K}$ concentrations among sampling locations (ANOVA $p=2.93 \mathrm{E}-07$ ), but not between 2004 and 2005 (ANOVA $p=0.982$ ). The difference in ${ }^{40} \mathrm{~K}$ concentrations is because this isotope is naturally occurring in the earth's crust and the concentration varies in different locations.

Table 4.4 - Radionuclide Concentrations (Bq/L) in Groundwater from Wells at the WIPP Site. See Chapter 6 for the sampling locations.

\begin{tabular}{|c|c|c|c|c|c|c|c|c|c|c|}
\hline Location & $\begin{array}{l}\text { Sampling } \\
\text { Round }\end{array}$ & {$[R N]^{a}$} & $2 \times T_{P U}^{b}$ & MDC $^{c}$ & [RN] & $2 \times$ TPU & MDC & [RN] & $2 \times$ TPU & MDC \\
\hline & & & ${ }^{241} \mathrm{Am}$ & & & ${ }^{238} \mathrm{Pu}$ & & & ${ }^{239+240} \mathrm{Pu}$ & \\
\hline \multirow[t]{2}{*}{ WQSP-1 } & 20 & 2.39E-04 & 5.69E-04 & $8.04 \mathrm{E}-04$ & $3.28 \mathrm{E}-05$ & 4.69E-04 & $6.79 \mathrm{E}-04$ & 2.63E-04 & $5.52 \mathrm{E}-04$ & $6.29 \mathrm{E}-04$ \\
\hline & 21 & $-6.31 \mathrm{E}-04$ & 8.75E-04 & 7.88E-04 & $9.42 \mathrm{E}-04$ & 1.26E-03 & 8.68E-04 & 1.46E-04 & 7.02E-04 & $9.29 \mathrm{E}-04$ \\
\hline \multirow[t]{2}{*}{ WQSP-2 } & 20 & $-1.42 \mathrm{E}-04$ & 3.15E-04 & 8.28E-04 & $-6.13 \mathrm{E}-04$ & 5.35E-04 & 1.39E-03 & $0.00 \mathrm{E}+00$ & $0.00 E+00$ & $6.80 \mathrm{E}-04$ \\
\hline & 21 & $-1.36 \mathrm{E}-04$ & 3.13E-04 & 7.93E-04 & $-1.18 \mathrm{E}-05$ & $9.71 \mathrm{E}-04$ & $1.03 \mathrm{E}-03$ & $0.00 \mathrm{E}+00$ & $9.62 \mathrm{E}-04$ & $1.08 \mathrm{E}-03$ \\
\hline \multirow[t]{2}{*}{ WQSP-3 } & 20 & 1.82E-04 & 1.89E-03 & $2.23 \mathrm{E}-03$ & $-7.78 \mathrm{E}-04$ & 1.41E-03 & 5.19E-03 & 4.23E-04 & $9.10 \mathrm{E}-04$ & $2.57 \mathrm{E}-03$ \\
\hline & 21 & 1.98E-04 & 5.34E-04 & 7.14E-04 & 1.01E-03 & $1.05 E-03$ & $5.45 \mathrm{E}-04$ & 9.89E-05 & 3.93E-04 & $5.81 \mathrm{E}-04$ \\
\hline \multirow[t]{2}{*}{ WQSP-4 } & 20 & 2.60E-04 & 7.23E-04 & 8.80E-04 & -1.06E-04 & $2.42 \mathrm{E}-04$ & $5.50 \mathrm{E}-04$ & $6.90 \mathrm{E}-05$ & 3.46E-04 & $5.00 \mathrm{E}-04$ \\
\hline & 21 & 1.89E-04 & 8.35E-04 & 8.05E-04 & $-2.83 E-04$ & 4.03E-04 & 4.91E-04 & 3.62E-05 & $3.90 \mathrm{E}-04$ & 4.93E-04 \\
\hline \multirow[t]{2}{*}{ WQSP-5 } & 20 & $-6.99 \mathrm{E}-05$ & 8.01E-04 & 8.28E-04 & -1.91E-04 & $1.27 \mathrm{E}-03$ & $1.28 \mathrm{E}-03$ & $1.59 \mathrm{E}-04$ & 1.03E-03 & $1.23 \mathrm{E}-03$ \\
\hline & 21 & $-1.99 \mathrm{E}-04$ & 4.6 & 9.1 & $-2.28 \mathrm{E}-04$ & & 4.13E-04 & -4.80 & 1.46E-04 & $25 \mathrm{E}-04$ \\
\hline \multirow[t]{2}{*}{ WQSP-6 } & 20 & $1.59 \mathrm{E}-04$ & 7.54E-04 & 7.60E-04 & 3.03E-05 & $3.02 \mathrm{E}-04$ & $4.78 \mathrm{E}-04$ & $-6.06 \mathrm{E}-05$ & 1.65E-04 & $4.28 \mathrm{E}-04$ \\
\hline & 21 & 4.96E-04 & 9.3 & & 1.5 & & 4.72E-04 & & & $9 \mathrm{E}-04$ \\
\hline \multirow[t]{3}{*}{ WQSP-6A } & 20 & 2.16E-04 & $6.84 \mathrm{E}-04$ & 1.14E-03 & $1.02 \mathrm{E}-04$ & 3.22E-04 & 5.89E-04 & 1.71E-04 & 4.74E-04 & 5.39E-04 \\
\hline & 21 & 2.11E-04 & $5.70 \mathrm{E}-04$ & 7.32E-04 & $-3.58 \mathrm{E}-04$ & 9.17E-04 & 7.85E-04 & $-1.40 \mathrm{E}-04$ & 3.69E-04 & $3.10 \mathrm{E}-04$ \\
\hline & & & ${ }^{234} \mathrm{U}$ & & & ${ }^{235} \mathrm{U}$ & & & ${ }^{238} \mathrm{U}$ & \\
\hline \multirow[t]{2}{*}{ WQSP-1 } & 20 & $1.29 E+00$ & $6.05 E-02$ & $=-03$ & $1.31 \mathrm{E}-02$ & $3.50 \mathrm{E}-03$ & $8.35 \mathrm{E}-04$ & $2.18 \mathrm{E}-01$ & $1.54 \mathrm{E}-02$ & $1.13 \mathrm{E}-03$ \\
\hline & 21 & $1.31 \mathrm{E}+00$ & 7.56E-02 & 2.1 & 2.32E-02 & 5.7 & 1.17E-03 & 2.05E-01 & E-02 & 1E-03 \\
\hline \multirow[t]{2}{*}{ WQSP-2 } & 20 & 5.95E-01 & 3.53E-02 & 1.85E-03 & 1.04E-02 & 3.48E-03 & 9.90E-04 & $9.50 \mathrm{E}-02$ & 1.02E-02 & 1.32E-03 \\
\hline & 21 & $1.34 E+00$ & 5.38E-02 & 1.68E-03 & $1.60 \mathrm{E}-02$ & $3.20 \mathrm{E}-03$ & $6.20 \mathrm{E}-04$ & $2.10 \mathrm{E}-01$ & 1.26E-02 & $.12 \mathrm{E}-03$ \\
\hline \multirow[t]{2}{*}{ WQSP-3 } & 20 & 2.06E-01 & 1.69E-02 & $1.98 \mathrm{E}-03$ & $5.12 \mathrm{E}-03$ & 2.47E-03 & $1.04 \mathrm{E}-03$ & 3.05E-02 & 5.56E-03 & $1.43 \mathrm{E}-03$ \\
\hline & 21 & $2.62 \mathrm{E}-01$ & 1.62E-02 & 1.77E-03 & 4.84E-03 & 1.94E-03 & $7.28 \mathrm{E}-04$ & 3.51E-02 & 4.83E-03 & $1.21 \mathrm{E}-03$ \\
\hline \multirow[t]{2}{*}{ WQSP-4 } & 20 & 5.83E-01 & 2.90E-02 & $1.28 \mathrm{E}-03$ & 1.44E-02 & 3.38E-03 & 7.16E-04 & 9.87E-02 & 8.66E-03 & $9.20 \mathrm{E}-04$ \\
\hline & 21 & 6.13E-01 & 3.19E-02 & $1.62 \mathrm{E}-03$ & 2.62E-02 & 4.56E-03 & 8.18E-04 & 1.18E-01 & 1.03E-02 & 1.13E-03 \\
\hline \multirow[t]{2}{*}{ WQSP-5 } & 20 & $6.38 \mathrm{E}-01$ & 3.36E-02 & 1.48E-03 & 7.89E-03 & $2.73 \mathrm{E}-03$ & 8.49E-04 & 8.43E-02 & 8.62E-03 & $1.02 \mathrm{E}-03$ \\
\hline & 21 & 4.98E-01 & 3.67E-02 & 1.95E-03 & 5.04E-02 & 9.34E-03 & 1.31E-03 & 9.34E-02 & 1.20E-02 & $1.48 \mathrm{E}-03$ \\
\hline \multirow[t]{2}{*}{ WQSP-6 } & 20 & $6.05 \mathrm{E}-01$ & 3.19E-02 & $1.74 \mathrm{E}-03$ & 3.77E-03 & $1.81 \mathrm{E}-03$ & $2.04 \mathrm{E}-03$ & 8.17E-02 & 8.21E-03 & 1.18E-03 \\
\hline & 21 & 4.84E-01 & 2.34E-02 & 1.67E-03 & 1.10E-02 & $2.60 \mathrm{E}-03$ & 6.07E-04 & 7.10E-02 & $6.41 \mathrm{E}-03$ & 1.13E-03 \\
\hline \multirow[t]{3}{*}{ WQSP-6A } & 20 & 2.23E-01 & 1.39E-02 & 1.44E-03 & 4.60E-03 & $1.84 \mathrm{E}-03$ & $6.95 \mathrm{E}-04$ & 1.21E-01 & 9.36E-03 & $9.58 \mathrm{E}-04$ \\
\hline & 21 & 2.15E-01 & 1.30E-02 & 1.72E-03 & 7.06E-03 & 2.10E-03 & $6.26 \mathrm{E}-04$ & 1.19E-01 & 8.80E-03 & 1.17E-03 \\
\hline & & & ${ }^{40} \mathrm{~K}$ & & & ${ }^{60} \mathrm{Co}$ & & & ${ }^{137} \mathrm{Cs}$ & \\
\hline \multirow[t]{2}{*}{ WQSP-1 } & 20 & $1.62 \mathrm{E}+01$ & $4.03 E+00$ & $3.91 \mathrm{E}+00$ & $1.40 \mathrm{E}-01$ & $3.19 \mathrm{E}-01$ & $3.77 \mathrm{E}-01$ & $-3.76 \mathrm{E}-02$ & $1.56 \mathrm{E}-01$ & $2.92 \mathrm{E}-01$ \\
\hline & 21 & $1.28 \mathrm{E}+01$ & $4.80 \mathrm{E}+00$ & $6.52 \mathrm{E}+00$ & $-3.48 \mathrm{E}-01$ & 5.39E-01 & 5.70E-01 & -1.93E-01 & 3.23E-01 & 5.83E-01 \\
\hline \multirow[t]{2}{*}{ WQSP-2 } & 20 & $1.81 \mathrm{E}+01$ & $4.02 \mathrm{E}+00$ & $3.10 \mathrm{E}+00$ & 2.29E-02 & 3.22E-01 & 3.70E-01 & 7.74E-02 & $2.41 \mathrm{E}-01$ & $2.88 \mathrm{E}-01$ \\
\hline & 21 & $1.68 \mathrm{E}+01$ & $4.12 \mathrm{E}+00$ & $3.94 \mathrm{E}+00$ & $0.00 \mathrm{E}+00$ & $0.00 \mathrm{E}+00$ & 3.65E-01 & $2.54 \mathrm{E}-02$ & 2.31E-01 & $2.75 \mathrm{E}-01$ \\
\hline WQSP-3 & 20 & $5.34 \mathrm{E}+01$ & $9.46 \mathrm{E}+00$ & $3.41 \mathrm{E}+00$ & 3.28E-01 & 3.30E-01 & 4.03E-01 & 1.03E-01 & $2.50 \mathrm{E}-01$ & $3.00 \mathrm{E}-01$ \\
\hline
\end{tabular}


Table 4.4 - Radionuclide Concentrations (Bq/L) in Groundwater from Wells at the WIPP Site. See Chapter 6 for the sampling locations.

\begin{tabular}{|c|c|c|c|c|c|c|c|c|c|c|}
\hline Location & $\begin{array}{c}\text { Sampling } \\
\text { Round }\end{array}$ & {$[\mathrm{RN}]^{\mathrm{a}}$} & $2 \times$ TPU $^{\mathrm{b}}$ & MDC $^{c}$ & [RN] & $2 \times$ TPU & MDC & [RN] & $2 \times$ TPU & MDC \\
\hline & 21 & $5.06 \mathrm{E}+01$ & $9.17 \mathrm{E}+00$ & $4.48 E+00$ & $-1.97 \mathrm{E}-01$ & $3.51 \mathrm{E}-01$ & 3.70E-01 & $7.26 \mathrm{E}-03$ & $2.54 \mathrm{E}-01$ & $2.99 \mathrm{E}-01$ \\
\hline \multirow[t]{2}{*}{ WQSP-4 } & 20 & $2.28 \mathrm{E}+01$ & $5.14 \mathrm{E}+00$ & $4.53 E+00$ & $-3.53 \mathrm{E}-01$ & $3.76 \mathrm{E}-01$ & 3.76E-01 & $-3.58 \mathrm{E}-02$ & 2.52E-01 & $2.92 \mathrm{E}-01$ \\
\hline & 21 & $2.54 \mathrm{E}+01$ & $5.30 \mathrm{E}+00$ & $4.27 E+00$ & 3.83E-01 & 3.77E-01 & 4.57E-01 & $-3.01 \mathrm{E}-01$ & $3.44 \mathrm{E}-01$ & $3.49 \mathrm{E}-01$ \\
\hline \multirow[t]{2}{*}{ WQSP-5 } & 20 & $1.22 \mathrm{E}+01$ & $3.25 \mathrm{E}+00$ & $3.28 \mathrm{E}+00$ & 1.19E-01 & 2.89E-01 & 3.44E-01 & 1.70E-01 & 2.38E-01 & $2.90 \mathrm{E}-01$ \\
\hline & 21 & $1.21 \mathrm{E}+01$ & $4.13 E+00$ & $5.23 E+00$ & 6.94E-01 & 3.39E-01 & 4.58E-01 & 7.99E-02 & 2.93E-01 & 3.51E-01 \\
\hline \multirow[t]{2}{*}{ WQSP-6 } & 20 & $5.88 \mathrm{E}+00$ & $4.39 \mathrm{E}+00$ & $6.81 E+00$ & $-2.90 \mathrm{E}-01$ & $5.29 \mathrm{E}-01$ & 5.49E-01 & $-2.69 \mathrm{E}-01$ & 4.85E-01 & 5.32E-01 \\
\hline & 21 & $6.86 \mathrm{E}+00$ & $2.18 \mathrm{E}+00$ & $2.34 \mathrm{E}+00$ & $-4.19 \mathrm{E}-02$ & $3.21 \mathrm{E}-01$ & $3.60 \mathrm{E}-01$ & -1.07E-01 & 2.34E-01 & 2.63E-01 \\
\hline \multirow[t]{3}{*}{ WQSP-6A } & 20 & $2.94 \mathrm{E}+00$ & $3.59 \mathrm{E}+00$ & $5.76 \mathrm{E}+00$ & 5.23E-01 & 4.77E-01 & 5.47E-01 & $-3.19 \mathrm{E}-01$ & 4.74E-01 & $5.14 \mathrm{E}-01$ \\
\hline & 21 & $4.35 E+00$ & $3.71 \mathrm{E}+00$ & $5.81 E+00$ & $-2.00 \mathrm{E}-01$ & $5.28 \mathrm{E}-01$ & 5.73E-01 & $-5.16 \mathrm{E}-01$ & 5.61E-01 & 5.90E-01 \\
\hline & & & ${ }^{90} \mathrm{Sr}$ & & & & & & & \\
\hline \multirow[t]{2}{*}{ WQSP-1 } & 20 & $1.30 \mathrm{E}-02$ & $2.64 \mathrm{E}-02$ & $1.34 \mathrm{E}-02$ & & & & & & \\
\hline & 21 & $-3.83 E-03$ & 3.26E-02 & 2.86E-03 & & & & & & \\
\hline \multirow[t]{2}{*}{ WQSP-2 } & 20 & 4.07E-03 & $2.60 \mathrm{E}-02$ & 1.18E-02 & & & & & & \\
\hline & 21 & $-8.80 \mathrm{E}-04$ & 2.02E-02 & $1.98 \mathrm{E}-03$ & & & & & & \\
\hline \multirow[t]{2}{*}{ WQSP-3 } & 20 & 3.77E-03 & $2.43 \mathrm{E}-02$ & 1.13E-02 & & & & & & \\
\hline & 21 & 1.10E-02 & 2.26E-02 & $2.25 \mathrm{E}-03$ & & & & & & \\
\hline \multirow[t]{2}{*}{ WQSP-4 } & 20 & 1.83E-02 & 2.12E-02 & $6.50 \mathrm{E}-03$ & & & & & & \\
\hline & 21 & $2.38 \mathrm{E}-02$ & 3.67E-02 & $3.94 \mathrm{E}-03$ & & & & & & \\
\hline \multirow[t]{2}{*}{ WQSP-5 } & 20 & $-7.04 \mathrm{E}-03$ & 4.03E-02 & 1.67E-02 & & & & & & \\
\hline & 21 & $-6.31 \mathrm{E}-03$ & 3.86E-02 & $3.92 \mathrm{E}-03$ & & & & & & \\
\hline \multirow[t]{2}{*}{ WQSP-6 } & 20 & -8.06E-04 & 2.29E-02 & 1.11E-02 & & & & & & \\
\hline & 21 & $-1.46 \mathrm{E}-02$ & 2.53E-02 & $2.61 \mathrm{E}-03$ & & & & & & \\
\hline \multirow[t]{2}{*}{ WQSP-6A } & 20 & $-1.31 \mathrm{E}-02$ & 3.77E-02 & $2.21 \mathrm{E}-02$ & & & & & & \\
\hline & 21 & 1.63E-02 & $2.27 \mathrm{E}-02$ & $2.29 \mathrm{E}-03$ & & & & & & \\
\hline
\end{tabular}

a Radionuclide concentration

b Total propagated uncertainty

${ }^{c}$ Minimum detectable concentration

Duplicate samples for all radionuclides analyzed were collected from each of the wells as a check on the reproducibility of the sampling and measurement techniques employed. RERs for all duplicate pairs for which both the sample and the duplicate contained a detectable concentration of a radionuclide were calculated. These RERs are shown in Table 4.5 for Sampling Round 20 and in Table 4.6 for Sampling Round 21. Thirty-one of the RER values were less than one, indicating no difference between duplicate samples and good reproducibility. However, 21 of the duplicates from Round 20 and 21 had an RER greater than 1, indicating poor reproducibility. This is most likely due to inhomogeneities in the distributions of the radioisotope within the wells. 
Table 4.5 - Results of Duplicate Groundwater Sample Analysis for Sampling Round 20. Units are Bq/L. See Chapter 6 for sampling locations.

\begin{tabular}{|c|c|c|c|c|c|c|c|c|}
\hline \multirow[t]{2}{*}{ Location } & & \multicolumn{3}{|c|}{ Sample } & \multicolumn{3}{|c|}{ Duplicate } & \multirow[b]{2}{*}{ RER $^{\mathrm{d}}$} \\
\hline & & [RN] $^{\mathrm{a}}$ & $2 \times$ TPU $^{b}$ & $\mathrm{MDC}^{\mathrm{c}}$ & [RN] & $2 \times \mathrm{TPU}$ & MDC & \\
\hline \multirow[t]{3}{*}{ WQSP-1 } & ${ }^{234} U$ & $1.29 \mathrm{E}+00$ & 6.05E-02 & 1.64E-03 & $1.19 E+00$ & 5.30E-02 & 1.54E-03 & 1.24 \\
\hline & ${ }^{235} \mathrm{U}$ & 1.31E-02 & 3.50E-03 & 8.35E-04 & 1.77E-02 & 3.67E-03 & 7.14E-04 & 0.91 \\
\hline & ${ }^{238} \mathrm{U}$ & 2.18E-01 & 1.54E-02 & 1.13E-03 & $2.12 \mathrm{E}-01$ & 1.39E-02 & 1.04E-03 & 0.29 \\
\hline \multirow[t]{4}{*}{ WQSP-2 } & ${ }^{234} U$ & 5.95E-01 & 3.53E-02 & $1.85 \mathrm{E}-03$ & $1.32 E+00$ & 9.17E-02 & 2.24E-03 & 7.38 \\
\hline & ${ }^{235} \mathrm{U}$ & 1.04E-02 & $3.48 \mathrm{E}-03$ & 9.90E-04 & $2.40 \mathrm{E}-02$ & 6.84E-03 & $1.49 \mathrm{E}-03$ & 1.77 \\
\hline & ${ }^{238} \mathrm{U}$ & 9.50E-02 & 1.02E-02 & 1.32E-03 & $1.94 \mathrm{E}-01$ & 2.06E-02 & 1.71E-03 & 4.31 \\
\hline & ${ }^{40} \mathrm{~K}$ & $1.81 \mathrm{E}+01$ & $4.02 \mathrm{E}+00$ & $3.10 \mathrm{E}+00$ & $2.21 \mathrm{E}+01$ & $4.57 \mathrm{E}+00$ & $2.96 \mathrm{E}+00$ & 0.66 \\
\hline \multirow[t]{4}{*}{ WQSP-3 } & ${ }^{234} U$ & 2.06E-01 & 1.69E-02 & 1.98E-03 & 2.57E-01 & 2.26E-02 & 2.22E-03 & 1.81 \\
\hline & ${ }^{235} \mathrm{U}$ & $5.12 \mathrm{E}-03$ & 2.47E-03 & 1.04E-03 & $6.20 \mathrm{E}-03$ & 3.17E-03 & 1.35E-03 & 0.27 \\
\hline & ${ }^{238} \mathrm{U}$ & 3.05E-02 & 5.56E-03 & 1.43E-03 & 4.44E-02 & 7.92E-03 & 1.67E-03 & 1.44 \\
\hline & ${ }^{40} \mathrm{~K}$ & $5.34 \mathrm{E}+01$ & $9.46 \mathrm{E}+00$ & $3.41 \mathrm{E}+00$ & $5.14 \mathrm{E}+01$ & $9.18 \mathrm{E}+00$ & $3.69 \mathrm{E}+00$ & 0.15 \\
\hline \multirow[t]{4}{*}{ WQSP-4 } & ${ }^{234} U$ & 5.83E-01 & $2.90 \mathrm{E}-02$ & 1.28E-03 & 5.27E-01 & 2.68E-02 & 1.26E-03 & 1.41 \\
\hline & ${ }^{235} \mathrm{U}$ & 1.44E-02 & 3.38E-03 & 7.16E-04 & 5.97E-03 & 2.13E-03 & 6.86E-04 & 2.11 \\
\hline & ${ }^{238} \mathrm{U}$ & 9.87E-02 & 8.66E-03 & $9.20 \mathrm{E}-04$ & 8.62E-02 & $7.85 \mathrm{E}-03$ & 8.97E-04 & 1.07 \\
\hline & ${ }^{40} \mathrm{~K}$ & $2.28 \mathrm{E}+01$ & $5.14 \mathrm{E}+00$ & $4.53 \mathrm{E}+00$ & $2.47 E+01$ & $5.41 \mathrm{E}+00$ & $4.56 \mathrm{E}+00$ & 0.25 \\
\hline \multirow[t]{4}{*}{ WQSP-5 } & ${ }^{234} U$ & 6.38E-01 & 3.36E-02 & 1.48E-03 & 5.35E-01 & 3.07E-02 & 1.51E-03 & 2.26 \\
\hline & ${ }^{235} \mathrm{U}$ & 7.89E-03 & 2.73E-03 & 8.49E-04 & 5.80E-03 & $2.41 \mathrm{E}-03$ & 8.87E-04 & 0.57 \\
\hline & ${ }^{238} \mathrm{U}$ & 8.43E-02 & $8.62 \mathrm{E}-03$ & $1.02 \mathrm{E}-03$ & 7.44E-02 & 8.30E-03 & 1.05E-03 & 0.83 \\
\hline & ${ }^{40} \mathrm{~K}$ & $1.22 \mathrm{E}+01$ & $3.25 \mathrm{E}+00$ & $3.28 \mathrm{E}+00$ & $9.22 \mathrm{E}+00$ & $5.28 \mathrm{E}+00$ & $7.94 \mathrm{E}+00$ & 0.48 \\
\hline \multirow[t]{3}{*}{ WQSP-6 } & ${ }^{234} U$ & $6.05 \mathrm{E}-01$ & 3.19E-02 & 1.74E-03 & 5.93E-01 & 3.03E-02 & 1.72E-03 & 0.27 \\
\hline & ${ }^{235} \mathrm{U}$ & 3.77E-03 & 1.81E-03 & 2.04E-03 & 7.71E-03 & $2.56 \mathrm{E}-03$ & 2.02E-03 & 1.26 \\
\hline & ${ }^{238} \mathrm{U}$ & 8.17E-02 & 8.21E-03 & 1.18E-03 & 7.96E-02 & 7.91E-03 & 1.16E-03 & 0.18 \\
\hline \multirow[t]{3}{*}{ WQSP-6A } & ${ }^{234} U$ & 2.23E-01 & 1.39E-02 & 1.44E-03 & 2.37E-01 & 1.81E-02 & 1.68E-03 & 0.61 \\
\hline & ${ }^{235} \mathrm{U}$ & 4.60E-03 & 1.84E-03 & 6.95E-04 & $1.08 \mathrm{E}-02$ & 3.49E-03 & $9.71 \mathrm{E}-04$ & 1.57 \\
\hline & ${ }^{238} \mathrm{U}$ & $1.21 \mathrm{E}-01$ & 9.36E-03 & 9.58E-04 & $1.26 \mathrm{E}-01$ & $1.20 \mathrm{E}-02$ & 1.19E-03 & 0.33 \\
\hline
\end{tabular}

${ }^{a}$ Radionuclide concentration

${ }^{\mathrm{b}}$ Total propagated uncertainty

${ }^{c}$ Minimum detectable concentration

${ }^{\mathrm{d}}$ Relative error ratio

Table 4.6 - Results of Duplicate Groundwater Sample Analysis for Sampling Round 21. Units are $\mathrm{Bq} / \mathrm{L}$. See Chapter 6 for sampling locations.

\begin{tabular}{|c|c|c|c|c|c|c|c|c|}
\hline \multicolumn{2}{|l|}{ Location } & \multicolumn{3}{|c|}{ Sample } & \multicolumn{3}{|c|}{ Duplicate } & \multirow[b]{2}{*}{ RER $^{d}$} \\
\hline \multirow{3}{*}{ WQSP-1 } & & {$[R N]^{a}$} & $2 \times$ TPU $^{b}$ & MDC $^{c}$ & [RN] & $2 \times$ TPU & MDC & \\
\hline & ${ }^{234} U$ & $1.31 \mathrm{E}+00$ & 7.56E-02 & $2.19 \mathrm{E}-03$ & $1.33 E+00$ & $5.72 \mathrm{E}-02$ & $1.78 \mathrm{E}-03$ & 0.21 \\
\hline & ${ }^{235} \mathrm{U}$ & 2.32E-02 & $5.79 \mathrm{E}-03$ & 1.17E-03 & $2.21 \mathrm{E}-02$ & $3.95 \mathrm{E}-03$ & 6.71E-04 & 0.16 \\
\hline \multirow{6}{*}{ WQSP-2 } & ${ }^{238} \mathrm{U}$ & 2.05E-01 & 1.82E-02 & 1.61E-03 & 2.20E-01 & 1.37E-02 & $1.21 \mathrm{E}-03$ & 0.66 \\
\hline & ${ }^{40} \mathrm{~K}$ & $1.28 \mathrm{E}+01$ & $4.80 \mathrm{E}+00$ & $6.52 \mathrm{E}+00$ & $1.76 \mathrm{E}+01$ & $4.25 \mathrm{E}+00$ & $4.00 \mathrm{E}+00$ & 0.75 \\
\hline & ${ }^{234} U$ & $1.34 E+00$ & 5.38E-02 & 1.68E-03 & $1.31 E+00$ & 5.63E-02 & 1.71E-03 & 0.39 \\
\hline & ${ }^{235} \mathrm{U}$ & 1.60E-02 & $3.20 \mathrm{E}-03$ & $6.20 \mathrm{E}-04$ & $2.45 \mathrm{E}-02$ & 4.18E-03 & 6.61E-04 & 1.61 \\
\hline & ${ }^{238} \mathrm{U}$ & 2.10E-01 & 1.26E-02 & 1.12E-03 & $1.95 \mathrm{E}-01$ & $1.26 \mathrm{E}-02$ & $1.15 \mathrm{E}-03$ & 0.84 \\
\hline & ${ }^{40} \mathrm{~K}$ & $1.68 \mathrm{E}+01$ & $4.12 E+00$ & $3.94 \mathrm{E}+00$ & $2.04 \mathrm{E}+01$ & $5.52 E+00$ & $6.37 E+00$ & 0.52 \\
\hline
\end{tabular}




\begin{tabular}{|c|c|c|c|c|c|c|c|c|}
\hline \multirow[t]{2}{*}{ Location } & & \multicolumn{3}{|c|}{ Sample } & \multicolumn{3}{|c|}{ Duplicate } & \multirow[b]{2}{*}{ RER $^{d}$} \\
\hline & & {$[\mathrm{RN}]^{\mathrm{a}}$} & $2 \times T_{P U}^{b}$ & $\mathrm{MDC}^{\mathrm{c}}$ & [RN] & $2 \times \mathrm{TPU}$ & MDC & \\
\hline \multirow[t]{4}{*}{ WQSP-3 } & ${ }^{234} \mathrm{U}$ & $2.62 \mathrm{E}-01$ & $1.62 \mathrm{E}-02$ & $1.77 \mathrm{E}-03$ & $2.30 \mathrm{E}-01$ & $1.47 \mathrm{E}-02$ & $1.77 \mathrm{E}-03$ & 1.46 \\
\hline & ${ }^{235} \mathrm{U}$ & $4.84 \mathrm{E}-03$ & 1.94E-03 & $7.28 \mathrm{E}-04$ & $2.51 \mathrm{E}-03$ & $1.41 \mathrm{E}-03$ & 7.31E-04 & 0.97 \\
\hline & ${ }^{238} \mathrm{U}$ & $3.51 \mathrm{E}-02$ & $4.83 \mathrm{E}-03$ & $1.21 \mathrm{E}-03$ & $3.38 \mathrm{E}-02$ & $4.72 \mathrm{E}-03$ & $1.21 \mathrm{E}-03$ & 0.19 \\
\hline & ${ }^{40} \mathrm{~K}$ & $5.06 \mathrm{E}+01$ & $9.17 \mathrm{E}+00$ & $4.48 \mathrm{E}+00$ & $5.74 \mathrm{E}+01$ & $1.05 E+01$ & $6.31 \mathrm{E}+00$ & 0.49 \\
\hline \multirow[t]{4}{*}{ WQSP-4 } & ${ }^{234} \mathrm{U}$ & 6.13E-01 & 3.19E-02 & 1.62E-03 & $6.23 \mathrm{E}-01$ & $3.15 \mathrm{E}-02$ & $1.56 \mathrm{E}-03$ & 0.22 \\
\hline & ${ }^{235} \mathrm{U}$ & $2.62 \mathrm{E}-02$ & 4.56E-03 & $8.18 \mathrm{E}-04$ & $1.58 \mathrm{E}-02$ & 3.57E-03 & 7.48E-04 & 1.80 \\
\hline & ${ }^{238} \mathrm{U}$ & $1.18 \mathrm{E}-01$ & 1.03E-02 & $1.13 \mathrm{E}-03$ & 1.13E-01 & $9.56 \mathrm{E}-03$ & $1.08 \mathrm{E}-03$ & 0.36 \\
\hline & ${ }^{40} \mathrm{~K}$ & $2.54 \mathrm{E}+01$ & $5.30 \mathrm{E}+00$ & $4.27 \mathrm{E}+00$ & $2.37 \mathrm{E}+01$ & $6.56 \mathrm{E}+00$ & $8.21 \mathrm{E}+00$ & 0.20 \\
\hline \multirow[t]{4}{*}{ WQSP-5 } & ${ }^{234} \mathrm{U}$ & 4.98E-01 & 3.67E-02 & 1.95E-03 & $5.55 \mathrm{E}-01$ & $2.61 \mathrm{E}-02$ & $1.40 \mathrm{E}-03$ & 1.27 \\
\hline & ${ }^{235} \mathrm{U}$ & $5.04 \mathrm{E}-02$ & $9.34 \mathrm{E}-03$ & 1.31E-03 & 1.10E-02 & $2.63 \mathrm{E}-03$ & $6.26 \mathrm{E}-04$ & 4.06 \\
\hline & ${ }^{238} \mathrm{U}$ & 9.34E-02 & $1.20 \mathrm{E}-02$ & 1.48E-03 & 8.32E-02 & 7.07E-03 & $9.27 \mathrm{E}-04$ & 0.73 \\
\hline & ${ }^{40} \mathrm{~K}$ & $1.21 \mathrm{E}+01$ & $4.13 E+00$ & $5.23 E+00$ & $9.87 E+00$ & $3.42 E+00$ & $4.32 E+00$ & 0.42 \\
\hline \multirow[t]{4}{*}{ WQSP-6 } & ${ }^{234} U$ & $4.84 \mathrm{E}-01$ & 2.34E-02 & 1.67E-03 & 4.92E-01 & $2.38 \mathrm{E}-02$ & $1.70 \mathrm{E}-03$ & 0.24 \\
\hline & ${ }^{235} \mathrm{U}$ & 1.10E-02 & $2.60 \mathrm{E}-03$ & $6.07 \mathrm{E}-04$ & 1.19E-02 & $2.83 \mathrm{E}-03$ & $6.43 \mathrm{E}-04$ & 0.23 \\
\hline & ${ }^{238} \mathrm{U}$ & 7.10E-02 & $6.41 \mathrm{E}-03$ & 1.13E-03 & 7.31E-02 & $6.73 \mathrm{E}-03$ & 1.16E-03 & 0.23 \\
\hline & ${ }^{40} \mathrm{~K}$ & $6.86 \mathrm{E}+00$ & $2.18 \mathrm{E}+00$ & $2.34 \mathrm{E}+00$ & $1.30 \mathrm{E}+01$ & $3.18 \mathrm{E}+00$ & $3.77 \mathrm{E}+00$ & 1.59 \\
\hline \multirow[t]{3}{*}{ WQSP-6A } & ${ }^{234} U$ & 2.15E-01 & 1.30E-02 & $1.72 \mathrm{E}-03$ & $3.40 \mathrm{E}-01$ & 1.87E-02 & $1.78 \mathrm{E}-03$ & 5.49 \\
\hline & ${ }^{235} \mathrm{U}$ & 7.06E-03 & 2.10E-03 & $6.26 \mathrm{E}-04$ & $1.68 \mathrm{E}-02$ & 3.51E-03 & $6.94 \mathrm{E}-04$ & 2.38 \\
\hline & ${ }^{238} \mathrm{U}$ & 1.19E-01 & 8.80E-03 & 1.17E-03 & $1.05 \mathrm{E}-01$ & 8.65E-03 & $1.23 \mathrm{E}-03$ & 1.13 \\
\hline
\end{tabular}

\subsection{Surface Water}

\subsubsection{Sample Collection}

Surface water samples are collected from various locations around the WIPP site, as shown in Figure 4.2 (see Appendix $C$ for location codes). If a particular surface water collection location is dry, only the sediment is collected. Sediment results are described in Section 4.5.

Water from the sampling location is used to rinse 3.78-L (1-gallon) polyethylene containers at least three times. Approximately $3.78 \mathrm{~L}$ (1 gallon) of water is collected from each location. The samples are acidified immediately after collection with concentrated nitric acid to $\mathrm{pH} \leq 2$. Later, the samples are transferred to the WIPP Laboratories for analysis. Chain of custody is maintained throughout the process. 


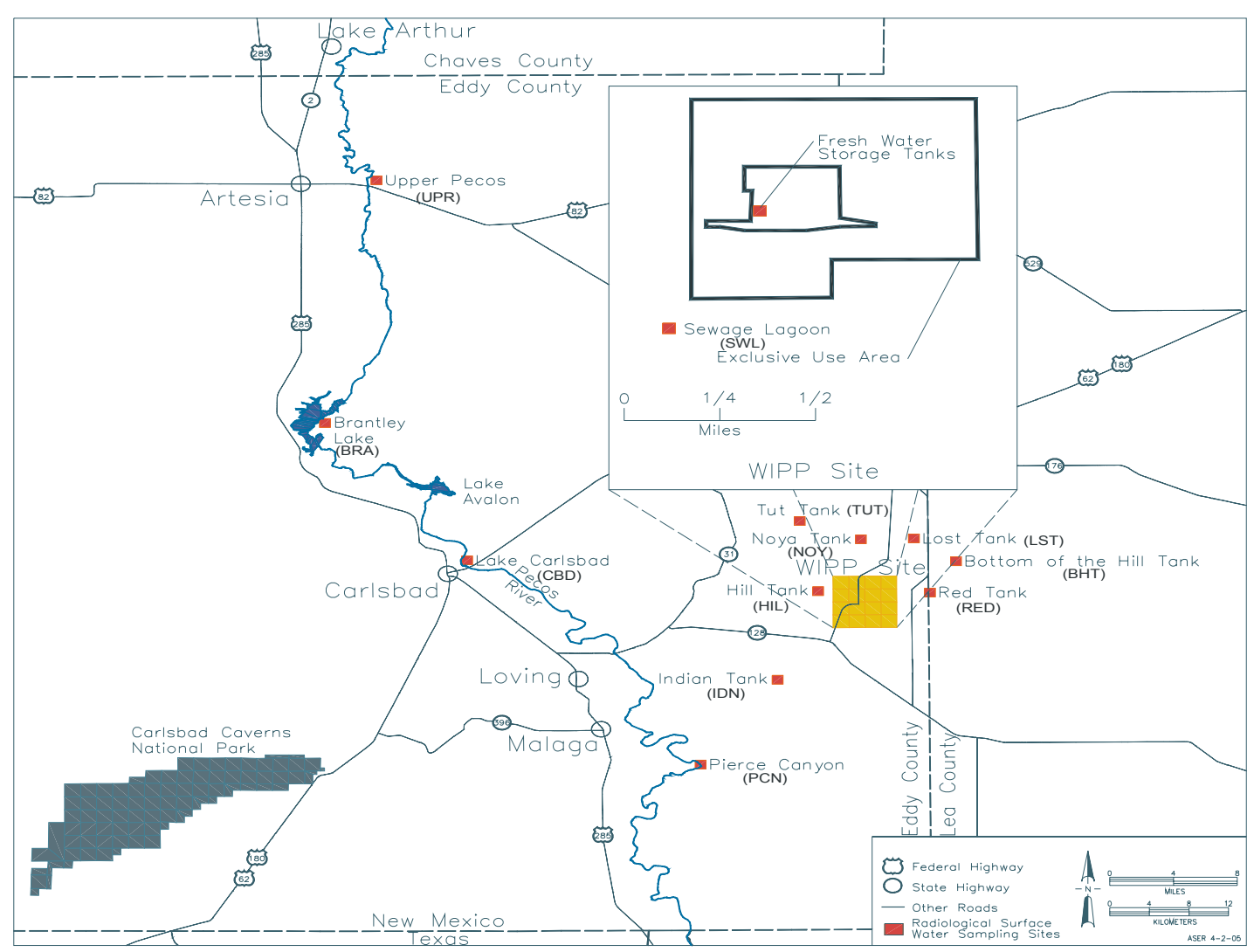

Figure 4.2 - Routine Surface Water Sampling Locations

\subsubsection{Sample Preparation}

Surface water sample containers are shaken to distribute suspended material evenly, and an aliquot is measured into a glass beaker. Tracers $\left({ }^{232} \mathrm{U},{ }^{243} \mathrm{Am}\right.$, and ${ }^{242} \mathrm{Pu}$ ) and carriers (strontium nitrate and barium nitrate) are added and the sample is then digested using concentrated nitric acid and hydrofluoric acid. The sample is then heated to dryness and wet ashed using concentrated nitric acid and hydrogen peroxide. Finally, the sample is heated to dryness again and the isotopic separation process is initiated.

\subsubsection{Determination of Individual Radionuclides}

Gamma-spectrometry is used for the determination of ${ }^{40} \mathrm{~K},{ }^{60} \mathrm{Co}$, and ${ }^{137} \mathrm{Cs}$.

Strontium-90, a beta-emitting radionuclide, is determined by chemical separation and counting using a gas proportional counter. Uranium, plutonium, and americium are determined by alpha spectrometry. These alpha-emitting radionuclides are separated from the bulk of water samples by co-precipitation with an iron carrier. Ion-exchange chromatography is used for the separation of individual radionuclides. 


\subsubsection{Results and Discussion}

Uranium-234 was detected in all samples of surface water (Table 4.7). Uranium-235 was detected in seven of fifteen samples (including duplicates). Eight samples had ${ }^{235} \mathrm{U}$ as a nondetect. Uranium-238 was detected in all samples except COW. The concentrations of uranium isotopes were compared between 2004 and 2005 and also among sampling locations using ANOVA for those sites sampled and detected in both years. Although significant variability was observed among sampling locations for two uranium isotopes (ANOVA, ${ }^{234} \mathrm{U} p=3.12 \mathrm{E}-05,{ }^{235} \mathrm{U} p=0.151$, and ${ }^{238} \mathrm{U} p=0.0110$ ), there was no significant difference in the concentrations of uranium isotopes between 2004 and 2005 (ANOVA, ${ }^{234} \cup p=0.757,{ }^{235} \mathrm{U} p=0.987$, and ${ }^{238} \mathrm{U} p=0.333$ ). Variability among sampling locations is expected since natural uranium in the earth's crust varies widely and this variation is reflected in the amounts of uranium dissolved into surface water.

Table 4.7 - Uranium Concentrations (Bq/L) in Surface Water Near the WIPP Site. See Appendix $\mathrm{C}$ for the sampling location codes.

\begin{tabular}{|c|c|c|c|c|c|c|c|c|c|}
\hline Location & [RN] $^{\mathrm{a}}$ & $2 \times \operatorname{TPU}^{\mathrm{b}}$ & $M C^{c}$ & [RN] & $2 \times$ TPU & MDC & [RN] & $2 \times$ TPU & MDC \\
\hline & & ${ }^{234} U$ & & & ${ }^{235} \mathrm{U}$ & & & ${ }^{238} \mathrm{U}$ & \\
\hline BRA & $9.78 \mathrm{E}-02$ & 8.48E-03 & 1.74E-03 & $4.24 \mathrm{E}-03$ & $1.81 \mathrm{E}-03$ & $6.98 \mathrm{E}-04$ & 4.54E-02 & $5.46 \mathrm{E}-03$ & 1.19E-03 \\
\hline CBD & 1.13E-01 & 1.32E-02 & 2.19E-03 & 1.47E-03 & 1.61E-03 & 1.26E-03 & 5.23E-02 & 8.48E-03 & 1.65E-03 \\
\hline cow & 2.30E-03 & $1.12 \mathrm{E}-03$ & 1.68E-03 & 4.41E-04 & $6.13 \mathrm{E}-04$ & $6.45 \mathrm{E}-04$ & 7.39E-04 & $6.90 \mathrm{E}-04$ & 1.15E-03 \\
\hline FWT & 5.65E-02 & $6.40 \mathrm{E}-03$ & 1.76E-03 & 1.79E-03 & 1.22E-03 & 7.39E-04 & 2.29E-02 & 3.92E-03 & 1.23E-03 \\
\hline HIL & 8.96E-03 & 2.55E-03 & 1.81E-03 & 1.07E-03 & 1.00E-03 & 7.91E-04 & $6.80 \mathrm{E}-03$ & $2.20 \mathrm{E}-03$ & 1.27E-03 \\
\hline IDN & 1.13E-02 & $2.74 \mathrm{E}-03$ & 1.76E-03 & 1.02E-03 & 9.09E-04 & 7.43E-04 & 1.01E-02 & 2.58E-03 & 1.23E-03 \\
\hline IDN DUP & 1.32E-02 & 2.47E-03 & 1.62E-03 & 8.27E-04 & 6.92E-04 & 5.70E-04 & 1.29E-02 & 2.44E-03 & 1.09E-03 \\
\hline LST & 8.78E-03 & 2.72E-03 & 1.90E-03 & 3.95E-04 & 8.05E-04 & 8.91E-04 & 4.97E-03 & 2.04E-03 & 1.35E-03 \\
\hline NOY & $3.42 \mathrm{E}-03$ & $1.45 \mathrm{E}-03$ & 1.74E-03 & 5.23E-04 & 6.60E-04 & 6.95E-04 & 2.08E-03 & 1.13E-03 & 1.19E-03 \\
\hline $\mathrm{PCN}$ & 1.66E-01 & $1.58 \mathrm{E}-02$ & 2.10E-03 & $4.54 \mathrm{E}-03$ & $2.52 \mathrm{E}-03$ & 1.14E-03 & $8.48 \mathrm{E}-02$ & $1.05 \mathrm{E}-02$ & $1.55 \mathrm{E}-03$ \\
\hline PKT & 4.24E-03 & 1.76E-03 & 1.82E-03 & $-3.16 \mathrm{E}-05$ & 1.67E-04 & 8.07E-04 & 2.16E-03 & 1.28E-03 & $1.28 \mathrm{E}-03$ \\
\hline RED & 8.49E-03 & 2.15E-03 & 1.70E-03 & 4.86E-04 & 5.90E-04 & 6.46E-04 & 4.61E-03 & $1.58 \mathrm{E}-03$ & 1.15E-03 \\
\hline TUT & 1.02E-02 & 2.61E-03 & 1.75E-03 & 7.20E-04 & 8.16E-04 & 7.25E-04 & 8.37E-03 & 2.33E-03 & 1.21E-03 \\
\hline TUT DUP & 7.58E-03 & 2.11E-03 & 1.71E-03 & $6.82 \mathrm{E}-04$ & 7.33E-04 & 6.77E-04 & 8.43E-03 & 2.22E-03 & 1.18E-03 \\
\hline UPR & 1.36E-01 & $1.65 \mathrm{E}-02$ & 2.40E-03 & $9.15 \mathrm{E}-03$ & $4.25 \mathrm{E}-03$ & $1.51 \mathrm{E}-03$ & 6.83E-02 & 1.10E-02 & $1.85 \mathrm{E}-03$ \\
\hline
\end{tabular}

Concentrations of uranium isotopes were also compared with baseline levels observed between 1985 and 1989 (DOE/WIPP 92-037). The highest concentrations for tanks and tank-like structures for all three uranium isotopes were within the 99 percent confidence interval ranges of baseline levels. Likewise, the highest concentrations of all three uranium isotopes for samples taken from the Pecos River and associated bodies of water were within the baseline.

These water samples were also analyzed for ${ }^{238} \mathrm{Pu},{ }^{239+240} \mathrm{Pu}$, and ${ }^{241} \mathrm{Am}$ (Table 4.8). None of these isotopes were detected so ANOVA comparisons between years and among locations were not performed. 
Table 4.8 - Americium and Plutonium Concentrations (Bq/L) in Surface Water Near the WIPP Site. See Appendix $C$ for the sampling location codes.

\begin{tabular}{|c|c|c|c|c|c|c|c|c|c|}
\hline Lo & L & $2 \times T$ & - & N] & $2 \times$ TPU & IDC & ?N] & $2 \times$ TPU & IDC \\
\hline & & ${ }^{241} \mathrm{Am}$ & & & ${ }^{238} \mathrm{Pu}$ & & & ${ }^{239+240} \mathrm{Pu}$ & \\
\hline RA & $2.30 \mathrm{E}-05$ & $3.55 \mathrm{E}-04$ & $\overline{1 \mathrm{E}-04}$ & -04 & $5.58 \mathrm{E}-04$ & ZE-U4 & $\overline{04}$ & $5.49 \mathrm{E}-04$ & $30 \mathrm{E}$ \\
\hline$B D$ & $6 E-05$ & & 7E-04 & E-04 & & 1E-04 & 38E-05 & & $60 \mathrm{E}-04$ \\
\hline ow & 5.17E-05 & $4.26 \mathrm{E}$ & 60E-04 & 94E-04 & & $1 \mathrm{E}-04$ & 46E-05 & $E-04$ & 47E-04 \\
\hline NT & $.30 \mathrm{E}-05$ & 3.58E-04 & 5.89E-04 & $-1.46 \mathrm{E}-04$ & 2.7 & E-04 & 3.87E-04 & 5. & 82E-04 \\
\hline $\mathrm{L}$ & $1.52 \mathrm{E}-04$ & 5.86E-04 & .08E-04 & $-4.66 \mathrm{E}-05$ & 1.34 & $1 \mathrm{E}-04$ & $-2.15 E-05$ & -05 & 20E-04 \\
\hline DN & 2.55E-04 & 4.78 & $5.81 \mathrm{E}-04$ & $-1.46 \mathrm{E}-04$ & 2.97 & 5.13E-04 & 2.41E-04 & 4. & $49 \mathrm{E}-04$ \\
\hline $\mathrm{ND}$ & $1.71 \mathrm{E}-04$ & 3.33E-04 & 5.43E-04 & $-9.10 \mathrm{E}-05$ & 2.62E-04 & $6.18 \mathrm{E}-04$ & $-4.19 \mathrm{E}-05$ & 1. & $54 \mathrm{E}-04$ \\
\hline ST & 4.02E-04 & 04 & $.15 E-04$ & $-5.45 E-05$ & 4.20 & $5 \mathrm{E}-04$ & $.09 E-04$ & $E-04$ & 23E-04 \\
\hline OY & 1.66E-04 & 4.81 & $5.59 \mathrm{E}-04$ & -7.71E-05 & 1.7 & 3.87E-04 & 1.80E-04 & 3. & $.36 \mathrm{E}-04$ \\
\hline $\mathrm{CN}$ & 4.34E-04 & $5.71 \mathrm{E}-04$ & $6.10 \mathrm{E}-04$ & $-1.50 \mathrm{E}-04$ & 3.04 & 5.35E-04 & $-5.54 \mathrm{E}-05$ & 1. & $.83 E-04$ \\
\hline KT & 23E-04 & $2.84 \mathrm{E}$ & $7.0 s$ & $56 \mathrm{E}-05$ & 4.2 & $\mathrm{E}-04$ & $-5.11 \mathrm{E}-05$ & -04 & $.70 \mathrm{E}-04$ \\
\hline ED & 6.91E-05 & 3.86E-04 & 5.39E-04 & $-2.89 \mathrm{E}-04$ & $6.4 C$ & 1.10E-03 & $5.25 E-04$ & $E-03$ & $.14 \mathrm{E}-03$ \\
\hline UT & $-6.62 E-05$ & 4.25E-04 & $6.20 \mathrm{E}-04$ & -8.02E-05 & 5.1 & 5.38E-04 & 7.38E-05 & 4. & $5.74 \mathrm{E}-04$ \\
\hline UT D & 4.06E-04 & $6.61 \mathrm{E}-04$ & $6.46 \mathrm{E}-04$ & $-1.62 \mathrm{E}-04$ & 2.82E-04 & 4.31E-04 & $-3.06 \mathrm{E}-05$ & 1.2 & 4.68E-04 \\
\hline JPR & 1.41E-04 & 4.61E-04 & $6.17 \mathrm{E}-04$ & 7.51E-06 & 2.88E-04 & 3.86E-04 & $1.62 \mathrm{E}-04$ & 3.25E-04 & 4.34E-04 \\
\hline
\end{tabular}

a Radionuclide concentration

b Total propagated uncertainty

c Minimum detectable concentration

Neither ${ }^{137} \mathrm{Cs}$ nor ${ }^{90} \mathrm{Sr}$ were detected in any of the samples (Table 4.9). Cobalt-60 was detected in 40 percent of the samples with the highest detected concentration at location BRA; concentration of $1.17 \mathrm{E}+00 \mathrm{~Bq} / \mathrm{L}$. Detected concentrations were very close to the MDCs and the MDCs fall within the total error associated with the results (Table 4.9). Comparison of these values with baseline data shows that they fell within the 99 percent confidence interval ranges of the baseline concentrations (DOE/WIPP 92-037). Since ${ }^{60} \mathrm{Co}$ was detected in six samples in 2005 but only in two samples in 2004, there were insufficient data for ANOVA comparisons between years or among locations.

Potassium-40 was detected in 20 percent of the surface water samples (Table 4.9). Potassium is ubiquitous throughout the earth's crust, so it is expected to be found in some surface water samples due to leaching from sediments. Comparison of detected ${ }^{40} \mathrm{~K}$ with baseline data shows that they fell within the 99 percent confidence interval ranges of the baseline concentrations (DOE/WIPP 92-037). Since there were less detected concentrations in 2005 than in 2004, there were insufficient data for ANOVA comparisons between years or among locations. 
Waste Isolation Pilot Plant Annual Site Environmental Report for 2005 DOE/WIPP-06-2225

Table 4.9 - Selected Radionuclide Concentrations (Bq/L) in Surface Water Near the WIPP Site. See Appendix $\mathrm{C}$ for the sampling location codes.

\begin{tabular}{|c|c|c|c|c|c|c|}
\hline Location & {$[\mathbf{R N}]^{\mathrm{a}}$} & $2 \times$ TPU $^{\mathrm{b}}$ & MDC $^{c}$ & [RN] & $2 \times$ TPU & MDC \\
\hline & \multicolumn{3}{|c|}{${ }^{137} \mathrm{Cs}$} & \multicolumn{3}{|c|}{${ }^{60} \mathrm{Co}$} \\
\hline BRA & $-1.27 \mathrm{E}-01$ & $4.75 \mathrm{E}-01$ & $\overline{5.31 \mathrm{E}-01}$ & $1.17 \mathrm{E}+00$ & $5.75 \mathrm{E}-01$ & $6.62 \mathrm{E}-01$ \\
\hline CBD & 7.58E-02 & $2.72 \mathrm{E}-01$ & $3.09 \mathrm{E}-01$ & 2.35E-01 & $3.53 \mathrm{E}-01$ & $4.21 \mathrm{E}-01$ \\
\hline cow & 7.70E-02 & 2.84E-01 & 3.21E-01 & 1.18E-01 & 3.46E-01 & 4.02E-01 \\
\hline FWT & $-1.19 \mathrm{E}-01$ & $2.84 \mathrm{E}-01$ & 3.22E-01 & 1.01E-01 & $3.90 \mathrm{E}-01$ & $4.48 \mathrm{E}-01$ \\
\hline HIL & $2.54 \mathrm{E}-01$ & 2.84E-01 & 3.31E-01 & 1.69E-01 & 3.72E-01 & 4.32E-01 \\
\hline IDN & 2.32E-01 & $2.74 \mathrm{E}-01$ & 3.22E-01 & $3.70 \mathrm{E}-01$ & $3.48 \mathrm{E}-01$ & $4.28 \mathrm{E}-01$ \\
\hline IDN DUP & 2.12E-01 & 4.76E-01 & 5.32E-01 & $1.10 \mathrm{E}+00$ & 5.95E-01 & $6.83 \mathrm{E}-01$ \\
\hline LST & $1.89 \mathrm{E}-01$ & 2.81E-01 & 3.42E-01 & 5.27E-01 & $3.68 \mathrm{E}-01$ & 4.70E-01 \\
\hline NOY & $-3.88 \mathrm{E}-01$ & 4.97E-01 & $5.21 \mathrm{E}-01$ & $6.73 \mathrm{E}-01$ & $5.73 \mathrm{E}-01$ & $6.52 \mathrm{E}-01$ \\
\hline $\mathrm{PCN}$ & $-1.85 \mathrm{E}-01$ & 2.89E-01 & $2.99 \mathrm{E}-01$ & 2.51E-01 & 3.71E-01 & 4.40E-01 \\
\hline PKT & $-3.80 \mathrm{E}-03$ & 2.66E-01 & 3.15E-01 & 1.41E-01 & $3.80 \mathrm{E}-01$ & 4.39E-01 \\
\hline RED & 1.43E-02 & $2.62 \mathrm{E}-01$ & 3.11E-01 & $5.94 \mathrm{E}-01$ & 3.35E-01 & 4.47E-01 \\
\hline TUT & $-6.33 \mathrm{E}-02$ & $4.77 \mathrm{E}-01$ & $5.26 \mathrm{E}-01$ & 7.67E-01 & $5.98 \mathrm{E}-01$ & $6.78 \mathrm{E}-01$ \\
\hline TUT DUP & 1.98E-02 & 2.62E-01 & 3.12E-01 & $3.37 \mathrm{E}-01$ & 3.40E-01 & 4.25E-01 \\
\hline \multirow[t]{2}{*}{ UPR } & $-1.92 \mathrm{E}-01$ & 2.39E-01 & 3.31E-01 & 7.03E-02 & $3.58 \mathrm{E}-01$ & $4.12 \mathrm{E}-01$ \\
\hline & \multicolumn{3}{|c|}{${ }^{90} \mathrm{Sr}$} & \multicolumn{3}{|c|}{${ }^{40} \mathrm{~K}$} \\
\hline BRA & $8.52 \mathrm{E}-03$ & $2.04 \mathrm{E}-02$ & $2.08 \mathrm{E}-03$ & $6.08 \mathrm{E}+00$ & $4.74 \mathrm{E}+00$ & $7.42 \mathrm{E}+00$ \\
\hline CBD & $6.51 \mathrm{E}-03$ & $2.08 \mathrm{E}-02$ & $2.14 \mathrm{E}-03$ & $-8.47 \mathrm{E}-01$ & $3.93 E+00$ & $4.17 \mathrm{E}+00$ \\
\hline cow & $-8.02 E-04$ & $2.22 \mathrm{E}-02$ & $2.56 \mathrm{E}-03$ & $1.46 \mathrm{E}+00$ & $1.46 \mathrm{E}+00$ & $2.28 \mathrm{E}+00$ \\
\hline FWT & $-1.35 \mathrm{E}-02$ & $2.18 \mathrm{E}-02$ & $2.58 \mathrm{E}-03$ & $3.08 E+00$ & $4.16 \mathrm{E}+00$ & $4.87 \mathrm{E}+00$ \\
\hline HIL & 7.79E-03 & $2.20 \mathrm{E}-02$ & $2.28 \mathrm{E}-03$ & $2.54 \mathrm{E}+00$ & 3.57E+00 & $4.20 \mathrm{E}+00$ \\
\hline IDN & $-7.59 \mathrm{E}-03$ & 2.19E-02 & 2.57E-03 & $3.81 \mathrm{E}+00$ & $3.82 \mathrm{E}+00$ & $4.57 \mathrm{E}+00$ \\
\hline IDN DUP & $-4.80 \mathrm{E}-03$ & $2.22 \mathrm{E}-02$ & 2.62E-03 & $4.62 \mathrm{E}+00$ & $4.70 \mathrm{E}+00$ & $7.49 \mathrm{E}+00$ \\
\hline LST & $1.81 \mathrm{E}-03$ & $2.27 \mathrm{E}-02$ & $2.41 \mathrm{E}-03$ & $2.76 \mathrm{E}+00$ & $3.90 \mathrm{E}+00$ & $4.58 \mathrm{E}+00$ \\
\hline NOY & 4.61E-03 & $2.21 \mathrm{E}-02$ & 2.33E-03 & $5.26 \mathrm{E}+00$ & $4.58 \mathrm{E}+00$ & $7.23 E+00$ \\
\hline $\mathrm{PCN}$ & $-1.50 \mathrm{E}-03$ & $2.02 \mathrm{E}-02$ & $2.10 \mathrm{E}-03$ & $3.16 \mathrm{E}+00$ & $3.44 \mathrm{E}+00$ & $4.15 E+00$ \\
\hline PKT & $-7.94 \mathrm{E}-03$ & $2.72 \mathrm{E}-02$ & 3.20E-03 & $5.28 \mathrm{E}+00$ & $3.56 \mathrm{E}+00$ & $4.57 \mathrm{E}+00$ \\
\hline RED & $-7.86 \mathrm{E}-03$ & $2.18 \mathrm{E}-02$ & $2.37 \mathrm{E}-03$ & $6.57 \mathrm{E}+00$ & $3.15 E+00$ & $4.35 \mathrm{E}+00$ \\
\hline TUT & $-6.60 \mathrm{E}-03$ & $2.35 \mathrm{E}-02$ & $2.76 \mathrm{E}-03$ & $1.34 \mathrm{E}+01$ & $5.83 \mathrm{E}+00$ & $6.70 E+00$ \\
\hline TUT DUP & $-8.17 \mathrm{E}-03$ & $2.26 \mathrm{E}-02$ & $2.66 \mathrm{E}-03$ & $3.00 \mathrm{E}+00$ & $3.75 \mathrm{E}+00$ & $4.50 \mathrm{E}+00$ \\
\hline UPR & 7.00E-03 & $2.04 \mathrm{E}-02$ & $2.09 \mathrm{E}-03$ & $1.73 \mathrm{E}+00$ & $3.72 \mathrm{E}+00$ & $4.32 \mathrm{E}+00$ \\
\hline
\end{tabular}

Duplicate samples were collected from two locations (IDN and TUT) to check the reproducibility of the sampling and measurement techniques. Radioisotope concentrations for samples and their duplicates passing the criteria for detection were compared by calculation of the associated RER values (Table 4.10). All RER values IDN and TUT were less than 1.0, indicating no difference between duplicate samples and confirming good reproducibility. 
Table 4.10 - Results of Duplicate Surface Water Sample Analysis. Results are Bq/L. See Appendix $C$ for sampling location codes.

\begin{tabular}{|c|c|c|c|c|c|c|c|c|}
\hline \multicolumn{2}{|c|}{ Location } & \multicolumn{3}{|c|}{ Sample } & \multicolumn{3}{|c|}{ Duplicate } & \multirow[b]{2}{*}{ RER $^{\mathrm{d}}$} \\
\hline \multirow{4}{*}{ IDN } & & [RN] $^{\mathrm{a}}$ & $2 \times$ TPU $^{b}$ & MDC $^{c}$ & [RN] & $2 \times$ TPU & MDC & \\
\hline & ${ }^{234} \mathrm{U}$ & 1.13E-02 & $2.74 \mathrm{E}-03$ & $1.76 \mathrm{E}-03$ & $1.32 \mathrm{E}-02$ & $2.47 \mathrm{E}-03$ & $1.62 \mathrm{E}-03$ & 0.52 \\
\hline & ${ }^{235} \mathrm{U}$ & $1.02 \mathrm{E}-03$ & $9.09 \mathrm{E}-04$ & 7.43E-04 & 8.27E-04 & $6.92 \mathrm{E}-04$ & $5.70 \mathrm{E}-04$ & 0.17 \\
\hline & ${ }^{238} \mathrm{U}$ & $1.01 \mathrm{E}-02$ & 2.58E-03 & 1.23E-03 & 1.29E-02 & 2.44E-03 & 1.09E-03 & 0.79 \\
\hline TUT & ${ }^{234} U$ & $1.02 \mathrm{E}-02$ & $2.61 \mathrm{E}-03$ & $1.75 \mathrm{E}-03$ & $7.58 \mathrm{E}-03$ & $2.11 \mathrm{E}-03$ & $1.71 \mathrm{E}-03$ & 0.78 \\
\hline TUT & ${ }^{238} \mathrm{U}$ & 8.37E-03 & 2.33E-03 & 1.21E-03 & $8.43 \mathrm{E}-03$ & $2.22 \mathrm{E}-03$ & $1.18 \mathrm{E}-03$ & 0.02 \\
\hline
\end{tabular}

${ }^{a}$ Radionuclide concentration

${ }^{\mathrm{b}}$ Total propagated uncertainty

${ }^{c}$ Minimum detectable concentration

${ }^{\mathrm{d}}$ Relative error ratio

\subsection{Sediments}

\subsubsection{Sample Collection}

Sediment samples are collected from 12 locations around the WIPP site, mostly from the same water bodies from which the surface water samples are collected (Figure 4.3, see Appendix $C$ for location codes). The samples are collected in 1-I plastic containers from the top $15 \mathrm{~cm}$ (6 in.) of the sediments of the water bodies and transferred to the WIPP Laboratories for the determination of individual radionuclides.

\subsubsection{Sample Preparation}

Sediment samples are dried at $110^{\circ} \mathrm{C}\left(230^{\circ} \mathrm{F}\right)$ for several hours and homogenized by grinding to smaller particle sizes. A $2 \mathrm{~g}(0.08 \mathrm{oz})$ aliquot is dissolved by heating it with a mixture of nitric, hydrochloric, and hydrofluoric acids. The residue is heated with nitric and boric acids to remove hydrofluoric acid. Finally, the residue is dissolved in hydrochloric acid for the determination of individual radionuclides.

\subsubsection{Determination of Individual Radionuclides}

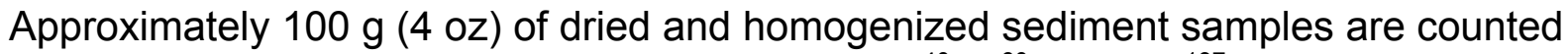
by gamma-spectrometry for the determinations of ${ }^{40} \mathrm{~K}$, ${ }^{60} \mathrm{Co}$, and ${ }^{137} \mathrm{Cs}$. Strontium-90 is determined from an aliquot of dissolved sediment samples by chemical separation and beta proportional counting. Uranium, plutonium, and americium are determined by alpha spectrometry after chemical separations, micro-precipitating, and filtering onto micro-filter papers. 


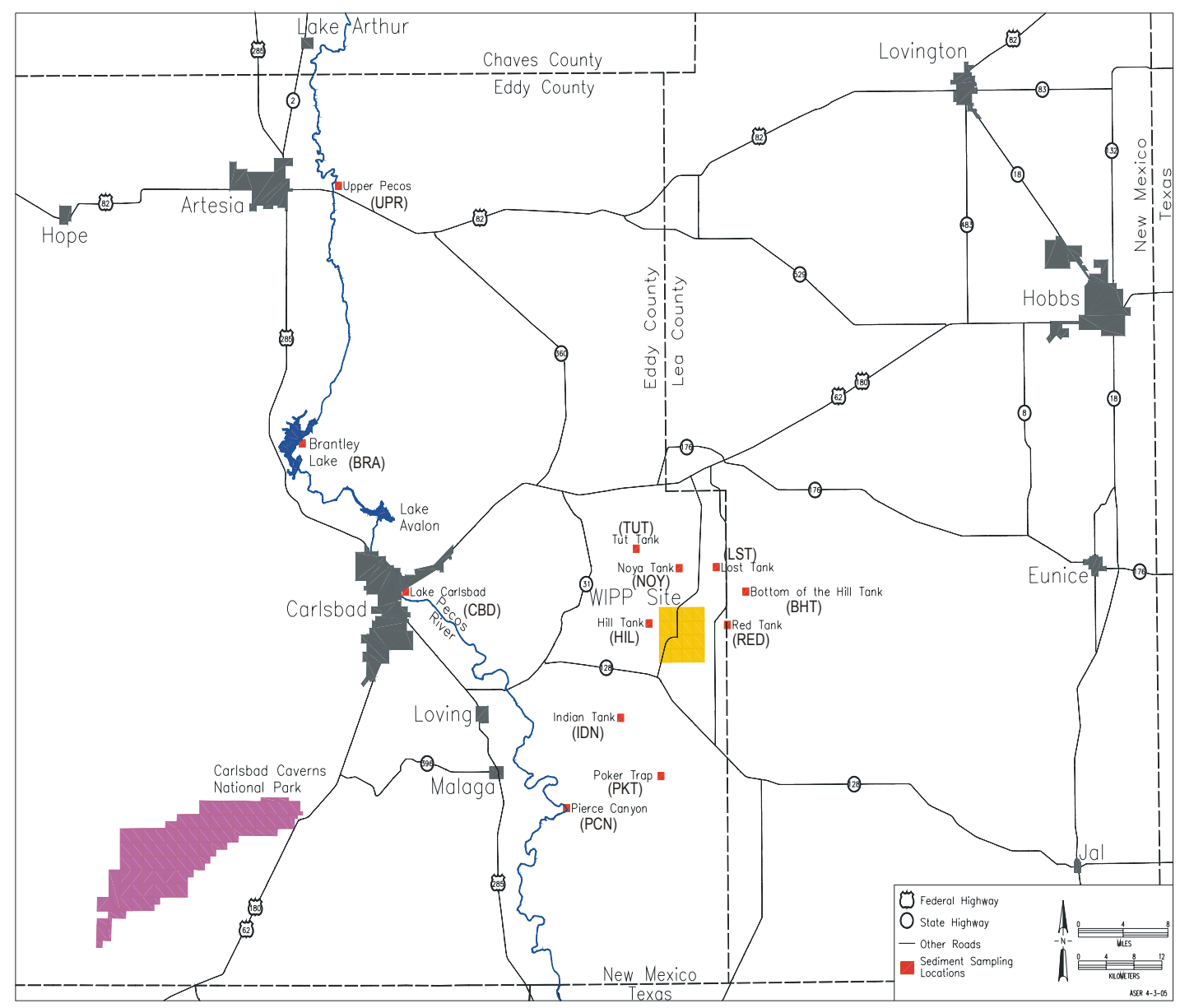

Figure 4.3 - Sediment Sampling Sites

\subsubsection{Results and Discussion}

Uranium-234, ${ }^{235} \mathrm{U}$, and ${ }^{238} \mathrm{U}$ were detected in every sediment sample (Table 4.11). There was not a significant variation in uranium isotope concentration among sampling locations (ANOVA ${ }^{234} \cup p=0.186,{ }^{235} \cup p=0.0551,{ }^{238} \cup p=0.432$ ). There was a significant difference between detected uranium isotope concentrations between 2004 and 2005 (ANOVA ${ }^{234} U p=0.0202,{ }^{235} U p=0.0523,{ }^{238} U p=0.00586$ ) with higher concentrations in 2004. Concentrations of detected uranium isotopes with the exception of ${ }^{234} \mathrm{U}$ (highest detected concentration: $2.69 \mathrm{E}-02 \mathrm{~Bq} / \mathrm{g}$ ) fell within the 99 percent confidence interval ranges of the baseline data $\left({ }^{234} \mathrm{U}: 2.60 \mathrm{E}-02 \mathrm{~Bq} / \mathrm{g}\right.$; ${ }^{235} \mathrm{U}: 3.20 \mathrm{E}-03 \mathrm{~Bq} / \mathrm{g} ;{ }^{238} \mathrm{U}: 5.00 \mathrm{E}-02 \mathrm{~Bq} / \mathrm{g}$ ). 
Table 4.11 - Uranium Concentrations (Bq/g) in Sediment Near the WIPP Site. See Appendix $\mathrm{C}$ for the sampling location codes.

\begin{tabular}{|c|c|c|c|c|c|c|c|c|c|}
\hline Loc & $2 \mathrm{~N}]^{\mathrm{a}}$ & $2 \times$ TPU $^{b}$ & MDC $^{c}$ & $\mathrm{RN]}$ & $2 \times$ TPU & MDC & RN] & $2 \times$ TPU & MDC \\
\hline & \multicolumn{3}{|c|}{${ }^{234} U$} & \multicolumn{3}{|c|}{${ }^{235} \mathrm{U}$} & \multicolumn{3}{|c|}{${ }^{238} \mathrm{U}$} \\
\hline RA & 2 & 1.76E-03 & 3 & 3 & $4.18 E-04$ & . & 02 & 1.60E-03 & 14E-04 \\
\hline HT & 2.08E-02 & $2.70 \mathrm{E}-03$ & -03 & 69E-03 & 04 & -04 & 42E-02 & 2.95 & $E-04$ \\
\hline BD & & & & & & & & 3 & -04 \\
\hline IL & E-02 & 1.47 & & 1.2 & 04 & & 1.84E-02 & $1.56 \mathrm{~b}$ & 07E-04 \\
\hline $\mathrm{DN}$ & 2.02E-02 & 1.65E-03 & 1.17 & $1.30 \mathrm{E}-03$ & 4.29 & -04 & 2.24E-02 & 1.76 & E-04 \\
\hline $\mathrm{NL}$ & $\mathrm{E}-02$ & & & 2.1 & & & $2.20 \mathrm{E}-02$ & 1.7 & $E-04$ \\
\hline ST & -03 & 9.6 & 1.2 & 6.9 & 04 & -04 & E-03 & 1.0 & E-04 \\
\hline OY & -02 & & & 6.7 & 3.00 & & $1.22 \mathrm{E}-02$ & 1.22 & $.05 \mathrm{E}-04$ \\
\hline$C N$ & -02 & 1.9 & & 1.3 & 4.50 & -04 & $=-02$ & 1.6 & 3E-04 \\
\hline KT & E-02 & 1.6 & 1. & $1 . \mathrm{C}$ & 04 & 04 & -02 & 1.59 & $19 E-04$ \\
\hline ED & & & & $8.30 \mathrm{E}$ & 4.13 & $E-04$ & 1.12E-02 & $1.42 \mathrm{E}$ & 46E-04 \\
\hline UT & & & & & 04 & & -02 & 1.61 & $.08 \mathrm{E}-04$ \\
\hline FUT & & $1.39 \mathrm{E}$ & & & & & $1.78 \mathrm{E}-02$ & $1.54 \mathrm{E}$ & $.09 \mathrm{E}-04$ \\
\hline JPR & 1.75E-02 & 1.50E-03 & 1.20E-03 & $8.42 \mathrm{E}-04$ & 3.36E-04 & $2.78 \mathrm{E}-04$ & 1.77E-02 & 1.51E-03 & 7.06E-04 \\
\hline
\end{tabular}

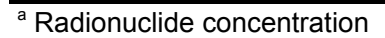

${ }^{\mathrm{b}}$ Total propagated uncertainty

${ }^{\mathrm{c}}$ Minimum detectable concentration

Sediment samples were analyzed for ${ }^{241} \mathrm{Am},{ }^{238} \mathrm{Pu}$, and ${ }^{239+240} \mathrm{Pu}$ (Table 4.12). Neither ${ }^{238} \mathrm{Pu}$ and ${ }^{241} \mathrm{Am}$ were detected. Plutonium-239+240 was detected in approximately 29 percent of the samples with the highest detected concentration at location PKT; 4.72E$04 \mathrm{~Bq} / \mathrm{g}$. Since there were no detected concentrations of ${ }^{239+240} \mathrm{Pu}$ in 2004 , a statistical comparison between years and sampling locations was not prepared. Comparison of detected values with baseline data shows that they fell within the 99 percent confidence interval ranges of the baseline concentrations (DOE/WIPP 92-037).

Table 4.12 - Americium and Plutonium Concentrations (Bq/g) in Sediment Near the WIPP Site. See Appendix $C$ for sampling location codes.

\begin{tabular}{|c|c|c|c|c|c|c|c|c|c|}
\hline Location & {$[R N]^{a}$} & $2 \times$ TPU $^{b}$ & MDC $^{c}$ & {$[R N]$} & $2 \times \mathrm{TPU}$ & MDC & {$[\mathrm{RN}]$} & $2 \times \mathrm{TPU}$ & MDC \\
\hline & & ${ }^{241} \mathrm{Am}$ & & & ${ }^{238} \mathrm{Pu}$ & & & ${ }^{239+240} \mathrm{Pu}$ & \\
\hline BRA & 2.09E-05 & $1.29 \mathrm{E}-04$ & 2.33E-04 & $-1.11 \mathrm{E}-04$ & 1.80E-04 & 3.03E-04 & 3.33E-05 & $1.84 \mathrm{E}-04$ & $3.40 \mathrm{E}-04$ \\
\hline BHT & 6.15E-05 & $1.45 \mathrm{E}-04$ & 2.18E-04 & $6.11 \mathrm{E}-05$ & $1.55 \mathrm{E}-04$ & $2.29 \mathrm{E}-04$ & 3.68E-04 & 2.71E-04 & $2.66 \mathrm{E}-04$ \\
\hline CBD & 8.14E-05 & 1.68E-04 & 2.33E-04 & $6.43 E-05$ & 1.96E-04 & 2.25E-04 & 2.69E-04 & 2.27E-04 & 2.62E-04 \\
\hline HIL & 1.76E-05 & 1.16E-04 & 2.05E-04 & 2.62E-06 & 1.00E-04 & 1.99E-04 & -1.71E-05 & 4.91E-05 & 2.36E-04 \\
\hline IDN & $-2.69 \mathrm{E}-06$ & 1.10E-04 & 2.05E-04 & $-5.00 \mathrm{E}-05$ & 9.48E-05 & 2.13E-04 & $1.85 E-04$ & 2.25E-04 & 2.38E-04 \\
\hline IDN DUP & 5.23E-05 & 1.47E-04 & $1.94 \mathrm{E}-04$ & $3.54 \mathrm{E}-04$ & $5.22 \mathrm{E}-04$ & $3.68 \mathrm{E}-04$ & 2.92E-04 & 3.62E-04 & $3.91 \mathrm{E}-04$ \\
\hline LST & 8.50E-05 & 2.14E-04 & 2.24E-04 & $2.70 \mathrm{E}-05$ & $1.04 \mathrm{E}-04$ & 1.81E-04 & 1.18E-04 & $1.45 \mathrm{E}-04$ & 2.17E-04 \\
\hline NOY & 8.68E-05 & 1.64E-04 & $2.20 \mathrm{E}-04$ & 9.93E-05 & 1.99E-04 & 2.74E-04 & 5.07E-05 & $1.39 \mathrm{E}-04$ & $3.11 \mathrm{E}-04$ \\
\hline PCN & $-8.13 E-06$ & 1.14E-04 & 2.05E-04 & $3.44 \mathrm{E}-05$ & $1.60 \mathrm{E}-04$ & 2.10E-04 & $-1.25 \mathrm{E}-05$ & 4.66E-05 & $2.34 \mathrm{E}-04$ \\
\hline PKT & $1.68 \mathrm{E}-05$ & $1.29 \mathrm{E}-04$ & $1.94 \mathrm{E}-04$ & $-2.91 \mathrm{E}-05$ & $1.75 \mathrm{E}-04$ & $2.39 \mathrm{E}-04$ & $4.72 \mathrm{E}-04$ & $3.40 \mathrm{E}-04$ & $2.63 \mathrm{E}-04$ \\
\hline RED & 1.57E-04 & 1.66E-04 & 1.85E-04 & -3.07E-05 & 5.82E-05 & 1.64E-04 & 1.63E-05 & $6.70 \mathrm{E}-05$ & $1.89 \mathrm{E}-04$ \\
\hline TUT & 3.86E-05 & 1.17E-04 & 1.94E-04 & -2.96E-05 & $6.04 \mathrm{E}-05$ & 1.77E-04 & 4.22E-04 & $1.07 \mathrm{E}-04$ & $2.01 \mathrm{E}-04$ \\
\hline TUT DUP & 6.56E-05 & $1.29 \mathrm{E}-04$ & 1.88E-04 & 2.18E-05 & 1.07E-04 & 1.81E-04 & $6.15 E-05$ & $8.03 E+00$ & $1.73 \mathrm{E}-04$ \\
\hline UPR & 5.88E-05 & 1.36E-04 & 2.13E-04 & 7.71E-07 & $6.23 E-05$ & $1.48 \mathrm{E}-04$ & 2.28E-05 & 6.56E-05 & 2.18E-04 \\
\hline
\end{tabular}

a Radionuclide concentration

b Total propagated uncertainty

c Minimum detectable concentration 
Cesium-137 was detected in all the sediment samples (Table 4.13) except BRA and RED. Although concentrations varied among sampling locations (ANOVA, $p=0.0109$ ), there was no statistically significant difference in concentrations between 2004 and 2005 (ANOVA, $p=0.678$ ). In addition, all detected ${ }^{137} \mathrm{Cs}$ concentrations except one (IDN 3.59E-02 Bq/g) fell within the 99 percent confidence interval range of baseline concentrations $(3.50 \mathrm{E}-02 \mathrm{~Bq} / \mathrm{g})$. Although ${ }^{137} \mathrm{Cs}$ is a fission product, it is ubiquitous in soils because of global fallout from atmospheric nuclear weapons testing (Beck and Bennett, 2002; and UNSCEAR, 2000).

Strontium-90 was not detected in any sediment samples. Cobalt-60 was not detected in any sediment samples except CBD. There were insufficient detections to permit analysis of variance among sampling locations or between years. The detected concentration is very close to the MDC, and the MDC falls within the total error associated with the results (Table 4.13). Comparison of these values with baseline data shows that they fell within the 99 percent confidence interval ranges of the baseline concentrations (DOE/WIPP 92-037).

Potassium-40 was detected in all sediment samples (Table 4.13). Although concentrations varied among sampling locations (ANOVA, $p=0.0354$ ), there was no statistically significant difference in concentrations between 2004 and 2005 (ANOVA, $p=0.709$ ). All detected concentrations of ${ }^{40} \mathrm{~K}$ observed in these samples were within the 99 percent confidence interval range of baseline concentrations.

Table 4.13 - Selected Radionuclide Concentrations (Bq/g) in Sediment Near the WIPP Site. See Appendix $C$ for the sampling location codes.

\begin{tabular}{|c|c|c|c|c|c|c|}
\hline Location & {$[R N]^{a}$} & $2 \times$ TPU $^{b}$ & $\mathrm{MDC}^{\mathrm{C}}$ & [RN] & $2 \times$ TPU & MDC \\
\hline & \multicolumn{3}{|c|}{${ }^{137} \mathrm{Cs}$} & \multicolumn{3}{|c|}{${ }^{60} \mathrm{Co}$} \\
\hline BRA & $-3.32 \mathrm{E}-04$ & 4.89E-04 & $7.08 \mathrm{E}-04$ & $2.36 \mathrm{E}-04$ & 7.60E-04 & $8.48 \mathrm{E}-04$ \\
\hline $\mathrm{BHT}$ & 1.26E-02 & 1.67E-03 & 5.51E-04 & $-6.20 \mathrm{E}-05$ & 9.65E-04 & $1.05 \mathrm{E}-03$ \\
\hline CBD & 6.79E-03 & 9.32E-04 & 4.96E-04 & 8.76E-04 & 7.69E-04 & 8.60E-04 \\
\hline HIL & 8.21E-04 & 2.57E-04 & 5.49E-04 & $-5.22 E-04$ & 9.64E-04 & $1.01 \mathrm{E}-03$ \\
\hline IDN & 3.59E-03 & 5.53E-04 & 4.86E-04 & $-4.37 E-04$ & 8.96E-04 & 9.41E-04 \\
\hline IDN DUP & $2.95 \mathrm{E}-03$ & 4.73E-04 & 5.09E-04 & 8.95E-04 & 8.07E-04 & $9.00 \mathrm{E}-04$ \\
\hline LST & 6.83E-04 & 3.12E-04 & 4.56E-04 & 2.96E-04 & 5.95E-04 & $6.80 \mathrm{E}-04$ \\
\hline NOY & 1.77E-03 & 3.35E-04 & 4.64E-04 & 5.56E-04 & $8.12 \mathrm{E}-04$ & $9.00 \mathrm{E}-04$ \\
\hline PCN & 5.65E-04 & $1.86 \mathrm{E}-04$ & 3.63E-04 & 1.47E-04 & $6.58 \mathrm{E}-04$ & 7.35E-04 \\
\hline PKT & 3.48E-03 & 5.51E-04 & 4.99E-04 & 2.88E-04 & 8.63E-04 & 9.62E-04 \\
\hline RED & 4.90E-04 & 5.30E-04 & 6.33E-04 & 2.04E-04 & 7.20E-04 & 8.03E-04 \\
\hline TUT & 8.79E-04 & 3.32E-04 & 4.71E-04 & 7.42E-04 & 8.03E-04 & 8.94E-04 \\
\hline TUT DUP & 1.43E-03 & 4.26E-03 & 5.60E-04 & 6.97E-05 & $1.01 \mathrm{E}-03$ & $1.11 \mathrm{E}-03$ \\
\hline \multirow[t]{2}{*}{ UPR } & $5.64 \mathrm{E}-04$ & 3.30E-04 & 5.01E-04 & 1.63E-04 & 8.18E-04 & $9.08 \mathrm{E}-04$ \\
\hline & \multicolumn{3}{|c|}{${ }^{90} \mathrm{Sr}$} & \multicolumn{3}{|c|}{${ }^{40} \mathrm{~K}$} \\
\hline BRA & $7.95 \mathrm{E}-05$ & $6.77 \mathrm{E}-03$ & $2.07 \mathrm{E}-03$ & 4.52E-01 & 5.92E-02 & $7.43 E-03$ \\
\hline BHT & 4.41E-04 & 6.01E-03 & $2.00 \mathrm{E}-03$ & 7.80E-01 & $1.05 E-01$ & 8.35E-03 \\
\hline CBD & 2.03E-03 & 7.63E-03 & 2.16E-03 & 5.28E-01 & 6.91E-02 & $9.11 \mathrm{E}-03$ \\
\hline
\end{tabular}


Table 4.13 - Selected Radionuclide Concentrations (Bq/g) in Sediment Near the WIPP Site. See Appendix $C$ for the sampling location codes.

\begin{tabular}{lcccccc}
\hline Location & [RN] $^{\mathbf{a}}$ & $\mathbf{2} \times$ TPU $^{\mathbf{b}}$ & \multicolumn{1}{l}{ MDC $^{\mathbf{c}}$} & \multicolumn{1}{c}{$[\mathbf{R N}]$} & $\mathbf{2} \times \mathbf{T P U}$ & \multicolumn{1}{l}{ MDC } \\
\hline HIL & $4.89 \mathrm{E}-03$ & $8.38 \mathrm{E}-03$ & $2.23 \mathrm{E}-03$ & $1.03 \mathrm{E}+00$ & $1.34 \mathrm{E}-01$ & $8.00 \mathrm{E}-03$ \\
IDN & $4.98 \mathrm{E}-04$ & $6.32 \mathrm{E}-03$ & $2.11 \mathrm{E}-03$ & $7.69 \mathrm{E}-01$ & $9.98 \mathrm{E}-02$ & $8.38 \mathrm{E}-03$ \\
IDN DUP & $1.96 \mathrm{E}-03$ & $6.03 \mathrm{E}-03$ & $2.08 \mathrm{E}-03$ & $7.11 \mathrm{E}-01$ & $9.26 \mathrm{E}-02$ & $9.50 \mathrm{E}-03$ \\
LST & $4.73 \mathrm{E}-03$ & $8.03 \mathrm{E}-03$ & $2.19 \mathrm{E}-03$ & $3.27 \mathrm{E}-01$ & $4.33 \mathrm{E}-02$ & $6.07 \mathrm{E}-03$ \\
NOY & $7.44 \mathrm{E}-04$ & $6.73 \mathrm{E}-03$ & $2.06 \mathrm{E}-03$ & $7.32 \mathrm{E}-01$ & $9.53 \mathrm{E}-02$ & $9.54 \mathrm{E}-03$ \\
PCN & $-1.82 \mathrm{E}-03$ & $5.62 \mathrm{E}-03$ & $2.05 \mathrm{E}-03$ & $3.05 \mathrm{E}-01$ & $4.05 \mathrm{E}-02$ & $6.72 \mathrm{E}-03$ \\
PKT & $5.05 \mathrm{E}-03$ & $6.30 \mathrm{E}-03$ & $2.09 \mathrm{E}-03$ & $5.53 \mathrm{E}-01$ & $7.47 \mathrm{E}-02$ & $8.18 \mathrm{E}-03$ \\
RED & $-4.79 \mathrm{E}-04$ & $6.11 \mathrm{E}-03$ & $2.09 \mathrm{E}-03$ & $3.57 \mathrm{E}-01$ & $4.87 \mathrm{E}-02$ & $6.96 \mathrm{E}-03$ \\
TUT & $-1.61 \mathrm{E}-03$ & $7.10 \mathrm{E}-03$ & $2.21 \mathrm{E}-03$ & $7.77 \mathrm{E}-01$ & $1.01 \mathrm{E}-01$ & $9.88 \mathrm{E}-03$ \\
TUT DUP & $5.02 \mathrm{E}-03$ & $7.44 \mathrm{E}-03$ & $2.21 \mathrm{E}-03$ & $9.43 \mathrm{E}-01$ & $1.25 \mathrm{E}-01$ & $8.21 \mathrm{E}-03$ \\
UPR & $3.45 \mathrm{E}-03$ & $7.84 \mathrm{E}-03$ & $2.19 \mathrm{E}-03$ & $5.19 \mathrm{E}-01$ & $7.02 \mathrm{E}-02$ & $7.70 \mathrm{E}-03$ \\
\hline
\end{tabular}

${ }^{a}$ Radionuclide concentration

${ }^{\mathrm{b}}$ Total propagated uncertainty

${ }^{\mathrm{c}}$ Minimum detectable concentration

Duplicate analyses were performed for all the radionuclides in sediment samples from sampling locations IDN and TUT (Table 4.14). RERs were calculated for all isotopes for which the concentrations in both original and duplicate samples were detected. The RERs were less than 1.0 for all isotopes and locations, indicating acceptable reproducibility, with the exception of ${ }^{235} \mathrm{U}$ and ${ }^{137} \mathrm{Cs}$ at IDN and ${ }^{234} \mathrm{U},{ }^{40} \mathrm{~K}$, and ${ }^{137} \mathrm{Cs}$ at TUT. Six of the RER values were less than one, indicating good reproducibility, and four duplicates had an RER greater than one, indicating poor reproducibility. RERs greater than one were most likely due to inhomogeneities in the distributions of the radioisotope within the sampling locations.

Table 4.14 - Results of Duplicate Sediment Sampling Analysis. Units are Bq/g. See Appendix $\mathrm{C}$ for sampling location codes.

\begin{tabular}{|c|c|c|c|c|c|c|c|c|}
\hline \multicolumn{2}{|c|}{ Location } & \multicolumn{3}{|c|}{ Sample } & \multicolumn{3}{|c|}{ Duplicate } & \multirow[b]{2}{*}{$R R^{d}$} \\
\hline & & [RN] $^{\mathrm{a}}$ & $2 \times$ TPU $^{b}$ & MDC $^{c}$ & [RN] & $2 \times$ TPU & MDC & \\
\hline \multirow[t]{5}{*}{ IDN } & ${ }^{234} \mathrm{U}$ & $2.02 \mathrm{E}-02$ & 1.65E-03 & $1.17 \mathrm{E}-03$ & $2.10 \mathrm{E}-02$ & 1.73E-03 & $1.17 \mathrm{E}-03$ & 0.33 \\
\hline & ${ }^{235} \mathrm{U}$ & 1.30E-03 & 4.29E-04 & 2.82E-04 & $2.10 \mathrm{E}-03$ & 5.49E-04 & 2.84E-04 & 1.15 \\
\hline & ${ }^{238} \mathrm{U}$ & $2.24 \mathrm{E}-02$ & 1.76E-03 & 7.09E-04 & $2.20 \mathrm{E}-02$ & 1.77E-03 & 7.11E-04 & 0.16 \\
\hline & ${ }^{40} \mathrm{~K}$ & 7.69E-01 & 9.98E-02 & 8.38E-03 & 7.11E-01 & $9.26 \mathrm{E}-02$ & 9.50E-03 & 0.43 \\
\hline & ${ }^{137} \mathrm{Cs}$ & 3.59E-03 & 5.53E-04 & 4.86E-04 & 2.95E-03 & 4.73E-04 & 5.09E-04 & 0.88 \\
\hline \multirow[t]{5}{*}{ TUT } & ${ }^{234} \mathrm{U}$ & 1.83E-02 & 1.57E-03 & 1.17E-03 & $1.49 \mathrm{E}-02$ & $1.39 \mathrm{E}-03$ & 1.17E-03 & 1.62 \\
\hline & ${ }^{235} \mathrm{U}$ & 1.30E-03 & 4.24E-04 & 2.81E-04 & $9.78 \mathrm{E}-04$ & $3.72 \mathrm{E}-04$ & 2.82E-04 & 0.57 \\
\hline & ${ }^{238} \mathrm{U}$ & 1.92E-02 & 1.61E-03 & 7.08E-04 & $1.78 \mathrm{E}-02$ & $1.54 \mathrm{E}-03$ & $7.09 \mathrm{E}-04$ & 0.63 \\
\hline & ${ }^{40} \mathrm{~K}$ & 7.77E-01 & 1.01E-01 & $9.88 \mathrm{E}-03$ & $9.43 \mathrm{E}-01$ & $1.25 \mathrm{E}-01$ & $8.21 \mathrm{E}-03$ & 1.03 \\
\hline & ${ }^{137} \mathrm{Cs}$ & 8.79E-04 & 3.32E-04 & 4.71E-04 & 1.43E-03 & 4.26E-04 & $5.60 \mathrm{E}-04$ & 1.02 \\
\hline
\end{tabular}

\footnotetext{
Radionuclide concentration

b Total propagated uncertainty

c Minimum detectable concentration

${ }^{\mathrm{d}}$ Relative error ratio
} 


\subsection{Soil Samples}

\subsubsection{Sample Collection}

Soil samples are collected from near the low-volume air samplers at six different locations around the WIPP site: MLR, SEC, SMR, WEE, WFF, and WSS (Figure 4.4). Samples are collected from each location in three incremental profiles: surface soil (SS, 0-2 cm [0-0.8 in.]), intermediate soil (SI, 2-5 cm [0.8-2 in.]), and deep soil (SD, 5-10 cm [2-4 in.]). Measurements of radionuclides in depth profiles provide information about their vertical movements in the soil systems.

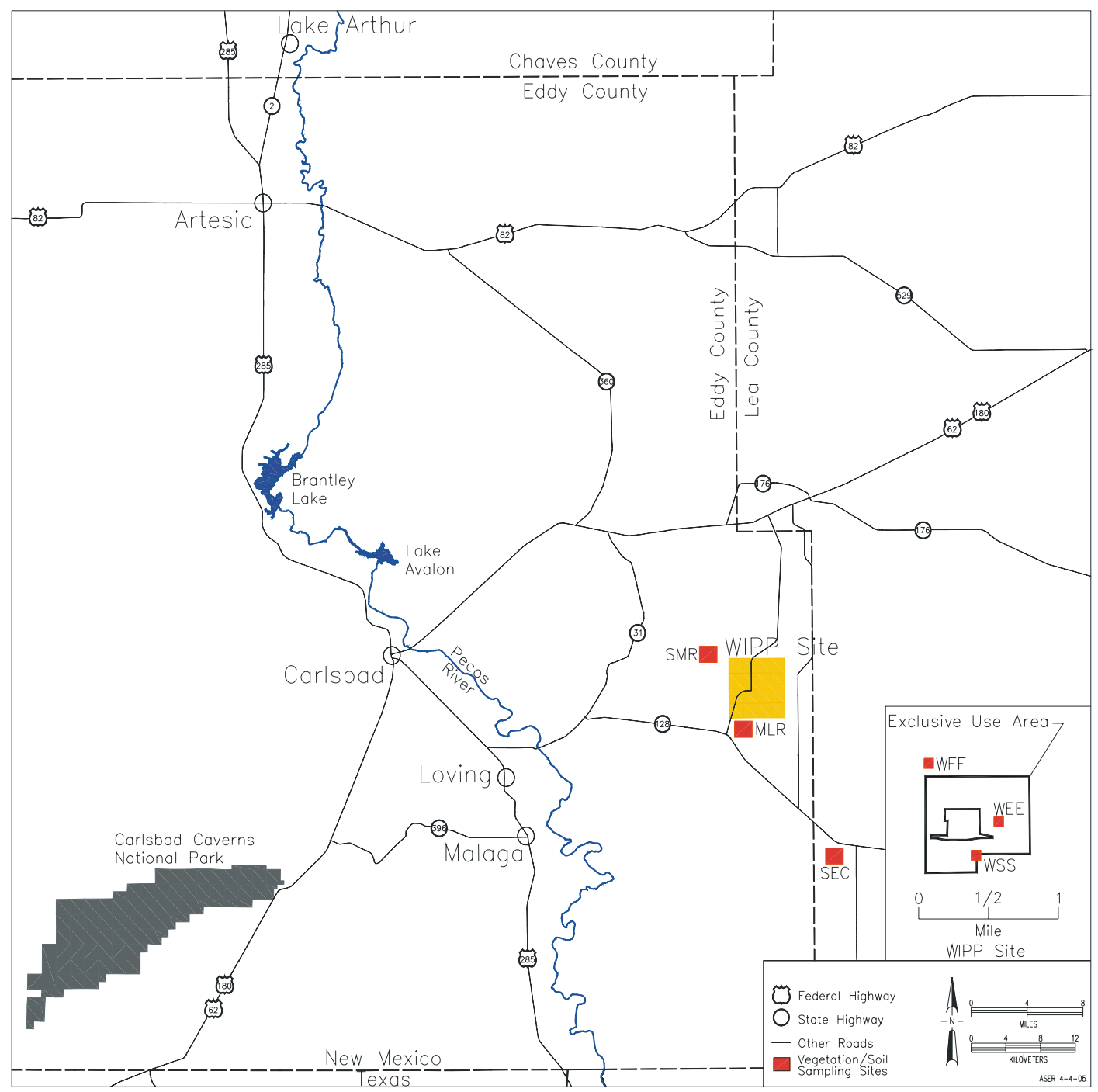

Figure 4.4 - Routine Soil and Vegetation Sampling Areas 


\subsubsection{Sample Preparation}

Soil samples are dried at $110^{\circ} \mathrm{C}\left(230^{\circ} \mathrm{F}\right)$ for several hours and homogenized by grinding to small particle sizes. Two grams $(0.08 \mathrm{oz})$ of soil is dissolved by heating it with a mixture of nitric, hydrochloric, and hydrofluoric acids. Finally, the sample is heated with nitric and boric acids, and the residue is dissolved in hydrochloric acid for the determination of individual radionuclides.

\subsubsection{Determination of Individual Radionuclides}

Gamma-emitting radionuclides $\left({ }^{40} \mathrm{~K},{ }^{60} \mathrm{Co}\right.$, and $\left.{ }^{137} \mathrm{Cs}\right)$ are determined by counting an aliquot of well-homogenized ground soil samples by gamma spectrometry.

Strontium- 90 is analyzed from an aliquot of the sample solution by separating it from other stable and radioactive elements using radiochemical techniques and beta counting using a proportional counter. Another aliquot of the sample solution is used for the sequential determinations of the alpha-emitting radionuclides ${ }^{234} \mathrm{U},{ }^{235} \mathrm{U}$, and ${ }^{238} \mathrm{U}$; ${ }^{238} \mathrm{Pu}$ and ${ }^{239+240} \mathrm{Pu}$; and ${ }^{241} \mathrm{Am}$. These radionuclides are separated from the bulk of the inorganic materials present in the soil samples and from one another by radiochemical separations including co-precipitation and ion-exchange chromatography. Finally, the samples are micro-precipitated, filtered onto micro-filters, and counted on the alpha spectrometer.

\subsubsection{Results and Discussion}

Uranium-234, ${ }^{235} \mathrm{U}$, and ${ }^{238} \mathrm{U}$ were detected in every soil sample in 2005 (Table 4.15). There was significant variation in uranium isotope concentration for ${ }^{234} \mathrm{U}$ among sampling locations (ANOVA, ${ }^{234} \mathrm{U} p=0.0325 ;{ }^{235} \mathrm{U} p=0.902 ;{ }^{238} \mathrm{Up}=0.0627$ ). There was a significant difference between detected uranium isotope concentrations for ${ }^{235} \mathrm{U}$ between 2004 and 2005 (ANOVA, ${ }^{234} \mathrm{U} p=0.940 ;{ }^{235} \mathrm{U} p=0.00437 ;{ }^{238} \mathrm{U} p=0.972$ ), with 2004 being higher for ${ }^{235} \mathrm{U}$.

In 2005 , of the detected uranium isotopes $\left({ }^{234} \mathrm{U}\right.$, highest concentration: $4.05 \mathrm{E}-02 \mathrm{~Bq} / \mathrm{g}$; ${ }^{235} \mathrm{U}$, highest concentration: $2.54 \mathrm{E}-03 \mathrm{~Bq} / \mathrm{g}$; and ${ }^{238} \mathrm{U}$, highest concentration: $4.25 \mathrm{E}-02 \mathrm{~Bq} / \mathrm{g}$ ), ${ }^{234} \mathrm{U}$ and ${ }^{238} \mathrm{U}$ were somewhat higher than the 99 percent confidence interval range of baseline concentrations $(3.70 \mathrm{E}-02 \mathrm{~Bq} / \mathrm{g}$ and $3.20 \mathrm{E}-02 \mathrm{~Bq} / \mathrm{g}$, respectively) (DOE/WIPP 92-037). The highest concentrations were noted at the SEC site. However, these detected concentrations were similar to the range of natural concentrations of uranium found in soils throughout the world. The average concentration of ${ }^{238} \mathrm{U}$ in soil (upper crust) is $3.6 \mathrm{E}-02 \mathrm{~Bq} / \mathrm{g}$ (NCRP Report No. 94, 1977). The consistency of the measured uranium concentrations with natural uranium in soils throughout the world, the natural variability of uranium in soils, and the fact that none of the actinides, which would be expected to be released along with uranium, were detected in concentrations in excess of baseline quantities, suggests that these soil concentrations follow a pattern of natural variability consistent with the existence of natural uranium, without enhancement from the WIPP facility. 
Table 4.15 - Uranium Concentrations (Bq/g) in Soil Near the WIPP Site. See Appendix C for the sampling location codes.

\begin{tabular}{|c|c|c|c|c|c|c|c|c|c|c|}
\hline Location & $\begin{array}{c}\text { Depth } \\
\text { (cm) }\end{array}$ & {$[R N]^{a}$} & $2 \times T_{P} U^{b}$ & $M^{\prime} C^{c}$ & [RN] & $2 \times \mathrm{TPU}$ & MDC & [RN] & $2 \times \mathrm{TPU}$ & MDC \\
\hline & & & ${ }^{234} \mathrm{U}$ & & & ${ }^{235} \mathrm{U}$ & & & ${ }^{238} \mathrm{U}$ & \\
\hline MLR & $0-2$ & 2.33E-02 & $1.89 \mathrm{E}-03$ & 03 & .04 ᄃ -03 & $4.62 \mathrm{E}-04$ & 2.5 & $2.43 E-02$ & $1.94 \mathrm{E}-03$ & E-04 \\
\hline MLR & $2-5$ & 2.45E-02 & $1.82 \mathrm{E}-03$ & -03 & 1.18E-03 & $4.02 \mathrm{E}-04$ & 2.43E-04 & 2.47E-02 & 1.83E-03 & $5.34 \mathrm{E}-04$ \\
\hline MLR & $5-10$ & 2.29E-02 & $1.72 \mathrm{E}-03$ & $1.01 \mathrm{E}-03$ & 9.71E-04 & $3.61 \mathrm{E}-04$ & $2.40 \mathrm{E}-04$ & $2.33 E-02$ & 1.73E-03 & 5.32E-04 \\
\hline SEC & $0-2$ & 4.05E-02 & $3.22 \mathrm{E}-03$ & 1.03E-03 & $2.54 \mathrm{E}-03$ & 8.02E-04 & 2.97E-04 & 4.25E-02 & 3.31E-03 & $5.85 \mathrm{E}-04$ \\
\hline SEC & $2-5$ & 3.34 & $2.86 \mathrm{E}-03$ & & & & & & & \\
\hline SEC & $5-10$ & 1.77E-02 & $1.62 \mathrm{E}-03$ & $9.80 \mathrm{E}-04$ & $6.40 \mathrm{E}-04$ & $3.22 \mathrm{E}-04$ & 2.34E-04 & $1.80 \mathrm{E}-02$ & 1.63E-03 & 5.34E-04 \\
\hline SMR & $0-2$ & 3.37E-02 & $2.41 \mathrm{E}-03$ & $9.85 \mathrm{E}-04$ & 1.92E-03 & 5.67E-04 & $2.40 \mathrm{E}-04$ & 3.64E-02 & 2.53E-03 & 5.39E-04 \\
\hline SMR & $2-5$ & 3.09E-02 & $2.20 \mathrm{E}-03$ & 9.77E-04 & 1.71E-03 & $5.11 \mathrm{E}-04$ & 2.29E-04 & 3.10E-02 & $2.20 \mathrm{E}-03$ & 5.31E-04 \\
\hline SMR & $5-10$ & 3.14E-02 & $2.40 \mathrm{E}-03$ & $9.94 \mathrm{E}-04$ & 1.64E-03 & $5.50 \mathrm{E}-04$ & 2.51E-04 & $3.20 \mathrm{E}-02$ & 2.42E-03 & $5.48 \mathrm{E}-04$ \\
\hline WEE & $0-2$ & 2.02 & & & 6.85 & & & & & $=-04$ \\
\hline WEE & $2-5$ & 1.93E-02 & $1.66 \mathrm{E}-03$ & 1.03E-03 & 5.81E-04 & $2.98 \mathrm{E}-04$ & $2.54 \mathrm{E}-04$ & 1.82E-02 & $E-03$ & 5.43E-04 \\
\hline WEE & $5-10$ & 2.65 & $2.02 \mathrm{E}-03$ & & 1.49 & $5 E-04$ & 2.5 & 2.4 & & $5.46 \mathrm{E}-04$ \\
\hline WFF & $0-2$ & 1.41E-02 & $1.68 \mathrm{E}-03$ & $9.44 \mathrm{E}-04$ & 5.16E-04 & $3.42 \mathrm{E}-04$ & 2.68E-04 & 1.33E-02 & 1.63E-03 & $4.98 \mathrm{E}-04$ \\
\hline WFF & $2-5$ & 1.17E-02 & 1.30E-03 & $9.09 \mathrm{E}-04$ & 7.61E-04 & 4.04E-04 & 2.60E-04 & 1.13E-02 & 1.27E-03 & 4.63E-04 \\
\hline WFF & $5-10$ & 1.42E-02 & $1.64 \mathrm{E}-03$ & $9.37 \mathrm{E}-04$ & 7.03E-04 & $4.78 \mathrm{E}-04$ & $3.29 \mathrm{E}-04$ & 1.40E-02 & 1.62E-03 & $4.91 \mathrm{E}-04$ \\
\hline WSS & $0-2$ & 2.08E-02 & 1.87E-03 & $1.04 \mathrm{E}-03$ & 9.56E-04 & 4.19E-04 & $2.74 \mathrm{E}-04$ & 1.91E-02 & $1.78 \mathrm{E}-03$ & 5.59E-04 \\
\hline WSS & $2-5$ & 1.94E-02 & $1.74 \mathrm{E}-03$ & 1.03E-03 & 5.88E-04 & 3.16E-04 & 2.64E-04 & $1.74 \mathrm{E}-02$ & 1.63E-03 & 5.51E-04 \\
\hline WSS & $5-10$ & 2.68E-02 & 1.88E-03 & 1.01E-03 & $1.26 \mathrm{E}-03$ & 4.06E-04 & 2.39E-04 & 2.66E-02 & 1.87E-03 & 5.31E-04 \\
\hline
\end{tabular}

${ }^{a}$ Radionuclide concentration

${ }^{\mathrm{b}}$ Total propagated uncertainty

${ }^{\mathrm{c}}$ Minimum detectable concentration

Plutonium-238, ${ }^{239+240} \mathrm{Pu}$, and ${ }^{241} \mathrm{Am}$ were also analyzed in these soil samples (Table 4.16). Plutonium-238 was not detected in any of the samples.

Plutonium-239+240 was detected in nine samples and ${ }^{241} \mathrm{Am}$ was detected in one sample. There were insufficient detections of ${ }^{241} \mathrm{Am}$ to permit analysis of variance among sampling locations or between years. In comparison with the results for 2004, there was an increase in the number of detected concentrations for ${ }^{239+240} \mathrm{Pu}$ and a decrease in the number of detected concentrations for ${ }^{238} \mathrm{Pu}$. There were insufficient detections of ${ }^{239+240} \mathrm{Pu}$ in 2004 for ANOVA comparisons between years and among locations. However, the detected concentrations of all three actinides fell within the 99 percent confidence interval ranges of their respective baseline values (DOE/WIPP 92-037). Historically, soil samples collected in the same locations have shown positive results on numerous occasions (DOE/WIPP 03-2225). The Gnome Site lies approximately $9 \mathrm{~km}$ southwest of the WIPP boundary and was contaminated with actinides and fission products in 1961 when an underground detonation of a 3-kiloton ${ }^{239} \mathrm{Pu}$ device vented to the surface. 
Table 4.16 - Americium and Plutonium Concentrations (Bq/g) in Soil Near the WIPP Site. See Appendix $\mathrm{C}$ for the sampling location codes.

\begin{tabular}{|c|c|c|c|c|c|c|c|c|c|c|}
\hline Location & $\begin{array}{c}\text { Depth } \\
\text { (cm) }\end{array}$ & {$[R N]^{a}$} & $2 \times T^{\prime b} U^{b}$ & $M^{\prime} C^{c}$ & [RN] & $2 \times \mathrm{TPU}$ & MDC & [RN] & $2 \times \mathrm{TPU}$ & MDC \\
\hline & & \multicolumn{3}{|c|}{${ }^{241} \mathrm{Am}$} & \multicolumn{3}{|c|}{${ }^{238} \mathrm{Pu}$} & \multicolumn{3}{|c|}{${ }^{239+240} \mathrm{Pu}$} \\
\hline MLR & $0-2$ & 2.02E-04 & 1.81E-04 & 2.87E-04 & 2.84E-04 & 4.35E-04 & 3.89E-04 & 1.68E-04 & $2.90 \mathrm{E}-04$ & $3.64 \mathrm{E}-04$ \\
\hline MLR & $2-5$ & 1.17E-04 & $1.29 \mathrm{E}-04$ & 2.84E-04 & $6.70 \mathrm{E}-05$ & 1.86E-04 & 2.77E-04 & 4.14E-04 & 3.26E-04 & $2.52 \mathrm{E}-04$ \\
\hline MLR & $5-10$ & 1.60E-04 & 1.54E-04 & $2.80 \mathrm{E}-04$ & 2.45E-05 & 8.91E-05 & $2.29 \mathrm{E}-04$ & 4.18E-04 & $2.55 \mathrm{E}-04$ & $2.04 \mathrm{E}-04$ \\
\hline SEC & $0-2$ & $3.09 \mathrm{E}-04$ & 2.57E-04 & 2.96E-04 & 8.57E-05 & 4.65E-04 & 3.82E-04 & 1.27E-04 & $3.41 \mathrm{E}-04$ & $3.94 \mathrm{E}-04$ \\
\hline SEC & $2-5$ & 2.03E-04 & 2.19E-04 & 2.99E-04 & $1.28 \mathrm{E}-04$ & 2.62E-04 & 3.03E-04 & $8.29 \mathrm{E}-04$ & 4.79E-04 & $2.78 \mathrm{E}-04$ \\
\hline SEC & $5-10$ & 5.09E-05 & 1.46E-04 & 3.05E-04 & $1.08 \mathrm{E}-04$ & $1.94 \mathrm{E}-04$ & $2.00 \mathrm{E}-04$ & $1.30 \mathrm{E}-04$ & $1.54 \mathrm{E}-04$ & $2.12 \mathrm{E}-04$ \\
\hline SMR & $0-2$ & $2.04 \mathrm{E}-04$ & $2.08 \mathrm{E}-04$ & 3.08E-04 & 9.51E-05 & 3.05E-04 & $2.90 \mathrm{E}-04$ & 1.06E-03 & $5.22 \mathrm{E}-04$ & $2.65 \mathrm{E}-04$ \\
\hline SMR & $2-5$ & $9.08 \mathrm{E}-05$ & $1.59 \mathrm{E}-04$ & 2.89E-04 & 4.54E-05 & $1.48 \mathrm{E}-04$ & 2.42E-04 & 5.54E-04 & $3.14 \mathrm{E}-04$ & 2.17E-04 \\
\hline SMR & $5-10$ & 1.65E-04 & $2.22 \mathrm{E}-04$ & 3.08E-04 & $-4.24 \mathrm{E}-05$ & 8.64E-05 & $2.48 \mathrm{E}-04$ & 1.93E-04 & 2.16E-04 & $2.23 \mathrm{E}-04$ \\
\hline WEE & $0-2$ & 1.97E-04 & 2.04E-04 & 3.18E-04 & 2.79E-05 & 8.85E-05 & 2.31E-04 & 7.19E-04 & 3.47E-04 & 2.06E-04 \\
\hline WEE & $2-5$ & 8.41E-05 & 1.14E-04 & $2.70 \mathrm{E}-04$ & $9.11 \mathrm{E}-05$ & $1.38 \mathrm{E}-04$ & $2.08 \mathrm{E}-04$ & 3.58E-04 & 2.16E-04 & $1.83 \mathrm{E}-04$ \\
\hline WEE & $5-10$ & -1.36E-06 & 1.06E-04 & 3.01E-04 & 4.45E-05 & 1.16E-04 & $2.20 \mathrm{E}-04$ & 4.85E-04 & 2.65E-04 & $1.95 \mathrm{E}-04$ \\
\hline WFF & $0-2$ & $3.20 \mathrm{E}-05$ & 8.93E-05 & 2.84E-04 & -1.61E-05 & $1.84 \mathrm{E}-04$ & 2.09E-04 & $6.11 \mathrm{E}-05$ & $1.44 \mathrm{E}-04$ & 2.33E-04 \\
\hline WFF & $2-5$ & 7.32E-05 & $1.47 \mathrm{E}-04$ & 3.11E-04 & $0.00 \mathrm{E}+00$ & $1.04 \mathrm{E}-04$ & $1.88 \mathrm{E}-04$ & 6.19E-05 & 1.12E-04 & 2.13E-04 \\
\hline WFF & $5-10$ & 2.47E-05 & 1.23E-04 & 3.04E-04 & $5.04 \mathrm{E}-05$ & $1.44 \mathrm{E}-04$ & 2.05E-04 & 5.54E-05 & $1.41 \mathrm{E}-04$ & $2.30 \mathrm{E}-04$ \\
\hline WSS & $0-2$ & 1.33E-04 & $1.50 \mathrm{E}-04$ & 2.75E-04 & $-1.09 \mathrm{E}-04$ & $2.10 \mathrm{E}-04$ & 4.09E-04 & 4.47E-04 & 4.96E-04 & $3.84 \mathrm{E}-04$ \\
\hline WSS & $2-5$ & 8.23E-05 & 1.46E-04 & 2.84E-04 & $-1.04 \mathrm{E}-04$ & $1.75 \mathrm{E}-04$ & 3.31E-04 & 3.65E-04 & 3.43E-04 & 3.06E-04 \\
\hline WSS & $5-10$ & 1.15E-04 & 1.45E-04 & 2.79E-04 & -1.46E-05 & 1.05E-04 & 2.17E-04 & 4.91E-05 & 1.08E-04 & 1.92E-04 \\
\hline
\end{tabular}

${ }^{\text {a }}$ Radionuclide concentration

${ }^{\mathrm{b}}$ Total propagated uncertainty

${ }^{\mathrm{c}}$ Minimum detectable concentration

Potassium-40 was detected in every sample (Table 4.17). This naturally occurring gamma-emitting radionuclide is ubiquitous in soils. The concentration of ${ }^{40} \mathrm{~K}$ was significantly different among sampling locations (ANOVA, $p=1.46 \mathrm{E}-04$ ), but not different between 2004 and 2005 (ANOVA, $p=0.836$ ). Potassium-40 concentrations at some locations (highest concentration: 4.28E-01 Bq/g) were higher than the 99 percent confidence interval range of baseline levels (3.40E-01 Bq/g) (DOE/WIPP 92-037). However, the range of concentrations observed is consistent with the average natural ${ }^{40} \mathrm{~K}$ concentration in soils around the world $(4.00 \mathrm{E}-01 \mathrm{~Bq} / \mathrm{g}[1.08 \mathrm{E}+1 \mathrm{pCi} / \mathrm{g}]$; NCRP, 1987a).

Cesium-137 was detected in all soil samples (Table 4.17). There was no significant difference in the concentrations of ${ }^{137} \mathrm{Cs}$ detected among locations (ANOVA, $p=0.0841$ ) or between 2004 and 2005 (ANOVA, $p=0.423$ ). In addition, all ${ }^{137} \mathrm{Cs}$ concentrations fell within the 99 percent confidence interval range of baseline values. Although ${ }^{137} \mathrm{Cs}$ is a fission product, it is ubiquitous in soils because of global fallout from atmospheric nuclear weapons testing (Beck and Bennett, 2002; and UNSCEAR, 2000).

Strontium-90 was not detected at any sampling locations (Table 4.17). Cobalt-60 was detected in seven of the soil samples. Since there were no detected samples in 2004, there was insufficient data to permit analysis of variance among sampling locations or between years. However, comparison of detected values with baseline data shows that they fell within the 99 percent confidence interval ranges of the baseline concentrations (DOE/WIPP 92-037). 
Table 4.17 - Selected Radionuclide Concentrations (Bq/g) in Soil Near the WIPP Site. See Appendix C for sampling location codes.

\begin{tabular}{|c|c|c|c|c|c|c|c|}
\hline Location & $\begin{array}{c}\text { Depth } \\
\text { (cm) }\end{array}$ & {$[\mathbf{R N}]^{a}$} & $2 \times$ TPU $^{b}$ & $M^{\prime} C^{c}$ & [RN] & $2 \times$ TPU & MDC \\
\hline & & & ${ }^{137} \mathrm{Cs}$ & & & ${ }^{60} \mathrm{Co}$ & \\
\hline MLR & $0-2$ & $3.21 \mathrm{E}-03$ & $6.27 \mathrm{E}-04$ & 5.62E-04 & 3.65E-05 & 7.13E-04 & 7.86E-04 \\
\hline MLR & $2-5$ & 3.18E-03 & $6.10 \mathrm{E}-04$ & 5.27E-04 & 4.54E-04 & 6.51E-04 & 7.46E-04 \\
\hline MLR & $5-10$ & 2.95E-03 & $4.68 \mathrm{E}-04$ & 4.60E-04 & $1.94 \mathrm{E}-03$ & 7.11E-04 & 8.06E-04 \\
\hline SEC & $0-2$ & 4.63E-03 & 9.19E-04 & 1.03E-03 & $9.28 \mathrm{E}-04$ & 6.65E-04 & 7.52E-04 \\
\hline SEC & $2-5$ & 4.13E-03 & 7.41E-04 & 5.71E-04 & 2.73E-04 & $6.14 \mathrm{E}-04$ & 6.97E-04 \\
\hline SEC & $5-10$ & $1.86 \mathrm{E}-03$ & 7.52E-04 & 1.11E-03 & 8.50E-04 & 6.69E-04 & 7.56E-04 \\
\hline SMR & $0-2$ & 4.56E-03 & 8.65E-04 & 7.80E-04 & 8.33E-05 & 6.61E-04 & 7.33E-04 \\
\hline SMR & $2-5$ & 3.04E-03 & 7.58E-04 & 9.73E-04 & 8.56E-04 & 6.86E-04 & 7.74E-04 \\
\hline SMR & $5-10$ & $2.80 \mathrm{E}-03$ & 5.75E-04 & 5.51E-04 & 1.04E-04 & 6.30E-04 & 6.99E-04 \\
\hline WEE & $0-2$ & $2.46 \mathrm{E}-03$ & 4.93E-04 & 4.39E-04 & 2.25E-04 & 5.97E-04 & 6.77E-04 \\
\hline WEE & $2-5$ & $2.49 \mathrm{E}-03$ & $5.18 \mathrm{E}-04$ & 5.75E-04 & 1.19E-03 & 6.73E-04 & 7.63E-04 \\
\hline WEE & $5-10$ & 9.32E-04 & $3.25 \mathrm{E}-04$ & 4.33E-04 & 4.54E-04 & $6.13 E-04$ & 7.08E-04 \\
\hline WFF & $0-2$ & 7.54E-04 & 2.88E-04 & 3.92E-04 & 1.90E-04 & $5.49 \mathrm{E}-04$ & $6.21 \mathrm{E}-04$ \\
\hline WFF & $2-5$ & 1.23E-03 & 3.59E-04 & 4.72E-04 & 5.12E-04 & $6.50 \mathrm{E}-04$ & 7.30E-04 \\
\hline WFF & $5-10$ & $1.62 \mathrm{E}-03$ & 3.71E-04 & 3.77E-04 & 1.80E-04 & 5.67E-04 & 6.37E-04 \\
\hline WSS & $0-2$ & $4.08 \mathrm{E}-03$ & $6.90 \mathrm{E}-04$ & $6.10 \mathrm{E}-04$ & $1.03 \mathrm{E}-03$ & $6.67 \mathrm{E}-04$ & 7.57E-04 \\
\hline WSS & $2-5$ & 2.85E-03 & 5.72E-04 & 5.29E-04 & $-1.99 \mathrm{E}-04$ & $6.58 \mathrm{E}-04$ & 7.03E-04 \\
\hline \multirow[t]{2}{*}{ WSS } & $5-10$ & 1.37E-03 & 2.82E-04 & 4.14E-04 & $9.38 \mathrm{E}-04$ & $6.80 \mathrm{E}-04$ & 7.69E-04 \\
\hline & & & ${ }^{90} \mathrm{Sr}$ & & & ${ }^{40} \mathrm{~K}$ & \\
\hline MLR & $0-2$ & $-2.42 \mathrm{E}-03$ & $6.78 \mathrm{E}-03$ & 4.77E-03 & $4.28 \mathrm{E}-01$ & 7.01E-02 & $5.71 \mathrm{E}-03$ \\
\hline MLR & $2-5$ & $3.47 \mathrm{E}-03$ & 7.16E-03 & 4.97E-03 & 3.99E-01 & $6.54 \mathrm{E}-02$ & 6.63E-03 \\
\hline MLR & $5-10$ & $-6.95 \mathrm{E}-04$ & 6.96E-03 & $4.95 \mathrm{E}-03$ & 4.02E-01 & $5.29 \mathrm{E}-02$ & $8.28 \mathrm{E}-03$ \\
\hline SEC & $0-2$ & $2.62 \mathrm{E}-03$ & 5.34E-03 & $1.52 \mathrm{E}-03$ & $2.44 \mathrm{E}-01$ & $3.27 \mathrm{E}-02$ & 8.04E-03 \\
\hline SEC & $2-5$ & 4.48E-03 & 5.49E-03 & 1.57E-03 & $2.52 \mathrm{E}-01$ & 4.18E-02 & 5.98E-03 \\
\hline SEC & $5-10$ & $2.96 \mathrm{E}-03$ & 5.69E-03 & $1.69 \mathrm{E}-03$ & 3.04E-01 & 4.04E-02 & 8.06E-03 \\
\hline SMR & $0-2$ & $2.75 \mathrm{E}-03$ & 5.94E-03 & 1.92E-03 & 3.46E-01 & 5.69E-02 & $6.20 \mathrm{E}-03$ \\
\hline SMR & $2-5$ & $3.56 \mathrm{E}-03$ & 5.78E-03 & 1.73E-03 & 3.87E-01 & $5.12 \mathrm{E}-02$ & 8.38E-03 \\
\hline SMR & $5-10$ & $2.57 \mathrm{E}-03$ & $5.75 \mathrm{E}-03$ & $1.75 \mathrm{E}-03$ & 3.59E-01 & 5.91E-02 & $5.77 \mathrm{E}-03$ \\
\hline WEE & $0-2$ & -1.81E-03 & $6.95 \mathrm{E}-03$ & 4.91E-03 & $2.69 \mathrm{E}-01$ & 4.45E-02 & 5.75E-03 \\
\hline WEE & $2-5$ & 1.13E-03 & 7.63E-03 & 5.76E-03 & 3.00E-01 & 3.99E-02 & 8.38E-03 \\
\hline WEE & $5-10$ & 3.32E-03 & 7.56E-03 & $5.57 \mathrm{E}-03$ & 2.77E-01 & 4.59E-02 & 5.59E-03 \\
\hline WFF & $0-2$ & $-1.22 \mathrm{E}-03$ & 6.52E-03 & 4.39E-03 & 2.04E-01 & 3.41E-02 & 4.97E-03 \\
\hline WFF & $2-5$ & $-2.43 E-04$ & $6.48 \mathrm{E}-03$ & $4.30 \mathrm{E}-03$ & $2.19 \mathrm{E}-01$ & 2.96E-02 & 8.06E-03 \\
\hline WFF & $5-10$ & $-2.32 \mathrm{E}-03$ & 6.34E-03 & $4.12 \mathrm{E}-03$ & 2.32E-01 & 3.85E-02 & 5.21E-03 \\
\hline WSS & $0-2$ & $-2.86 \mathrm{E}-03$ & 7.88E-03 & 6.41E-03 & 3.12E-01 & 4.12E-02 & 8.20E-03 \\
\hline WSS & $2-5$ & $-3.02 \mathrm{E}-03$ & 7.41E-03 & 5.83E-03 & $3.01 \mathrm{E}-01$ & 4.97E-02 & 6.16E-03 \\
\hline WSS & $5-10$ & 1.27E-04 & $6.86 \mathrm{E}-03$ & 4.83E-03 & 3.05E-01 & 4.05E-02 & $8.24 \mathrm{E}-03$ \\
\hline
\end{tabular}

${ }^{a}$ Radionuclide concentration

${ }^{\mathrm{b}}$ Total propagated uncertainty

${ }^{\mathrm{C}}$ Minimum detectable concentration

Soil samples collected from one location (WFF) were divided into two parts and analyzed separately (Table 4.18). RERs were calculated for those duplicate pairs for which each sample and duplicate were detected. Approximately 73 percent of the RER 
values were less than one, indicating no difference between duplicate samples and good reproducibility. However, four duplicates had an RER greater than 1, indicating poor reproducibility. This is most likely due to inhomogeneities in the distributions of the radioisotope in the location.

Table 4.18 - Results of Duplicate Soil Sampling Analysis in Soil Near the WIPP Site. Units are Bq/g. See Appendix C for sampling location codes.

\begin{tabular}{|c|c|c|c|c|c|c|c|c|c|}
\hline \multirow[t]{2}{*}{ Location } & \multicolumn{2}{|c|}{$\begin{array}{c}\text { Depth } \\
\text { (cm) }\end{array}$} & \multicolumn{3}{|c|}{ Sample } & \multicolumn{3}{|c|}{ Duplicate } & \multirow[b]{2}{*}{ RER $^{d}$} \\
\hline & & & {$[R N]^{a}$} & $2 \times \operatorname{TPU}^{b}$ & MDC $^{c}$ & [RN] & $2 \times$ TPU & MDC & \\
\hline WFF & $0-2$ & ${ }^{234} U$ & $1.41 \mathrm{E}-02$ & $1.68 \mathrm{E}-03$ & 9.44E-04 & 1.65E-02 & 1.92E-03 & 9.57E-04 & 0.94 \\
\hline WFF & $2-5$ & & 1.17E-02 & 1.30E-03 & 9.09E-04 & $1.45 \mathrm{E}-02$ & 2.00E-03 & 9.93E-04 & 1.17 \\
\hline WFF & $5-10$ & & 1.42E-02 & 1.64E-03 & 9.37E-04 & 1.31E-02 & 1.57E-03 & 9.36E-04 & 0.48 \\
\hline WFF & $0-2$ & ${ }^{235} U$ & 5.16E-04 & $3.42 \mathrm{E}-04$ & 2.68E-04 & 8.74E-04 & 4.73E-04 & 2.84E-04 & 0.61 \\
\hline WFF & $2-5$ & & 7.61E-04 & 4.04E-04 & 2.60E-04 & 7.61E-04 & 4.04E-04 & $2.60 \mathrm{E}-04$ & 0.00 \\
\hline WFF & $5-10$ & & 7.03E-04 & 4.78E-04 & 3.29E-04 & 4.19E-04 & 3.07E-04 & 2.59E-04 & 0.50 \\
\hline WFF & $0-2$ & ${ }^{238} \mathrm{U}$ & 1.33E-02 & 1.63E-03 & 4.98E-04 & 1.69E-02 & $1.94 \mathrm{E}-03$ & $5.11 \mathrm{E}-04$ & 1.42 \\
\hline WFF & $2-5$ & & 1.13E-02 & 1.27E-03 & 4.63E-04 & $1.54 \mathrm{E}-02$ & 2.06E-03 & 5.47E-04 & 1.69 \\
\hline WFF & $5-10$ & & 1.40E-02 & 1.62E-03 & 4.91E-04 & 1.13E-02 & $1.45 \mathrm{E}-03$ & 4.90E-04 & 1.24 \\
\hline WFF & $0-2$ & ${ }^{40} \mathrm{~K}$ & 2.04E-01 & $3.41 \mathrm{E}-02$ & 4.97E-03 & 2.02E-01 & $2.74 \mathrm{E}-02$ & 7.96E-03 & 0.05 \\
\hline WFF & $2-5$ & & 2.19E-01 & 2.96E-02 & 8.06E-03 & $2.20 \mathrm{E}-01$ & 2.96E-02 & 7.88E-03 & 0.02 \\
\hline WFF & $5-10$ & & 2.32E-01 & 3.85E-02 & 5.21E-03 & 2.06E-01 & 2.72E-02 & 6.05E-03 & 0.55 \\
\hline WFF & $0-2$ & ${ }^{137} \mathrm{Cs}$ & 7.54E-04 & 2.88E-04 & 3.92E-04 & $9.65 E-04$ & $2.45 \mathrm{E}-04$ & 4.22E-04 & 0.56 \\
\hline WFF & $2-5$ & & 1.23E-03 & 3.59E-04 & 4.72E-04 & 1.34E-03 & 3.72E-04 & 4.79E-04 & 0.21 \\
\hline WFF & $5-10$ & & 1.62E-03 & $3.71 \mathrm{E}-04$ & $3.77 \mathrm{E}-04$ & 1.81E-03 & $3.02 \mathrm{E}-04$ & $3.13 E-04$ & 0.40 \\
\hline
\end{tabular}

${ }^{a}$ Radionuclide concentration

${ }^{\mathrm{b}}$ Total propagated uncertainty

${ }^{c}$ Minimum detectable concentration

${ }^{\mathrm{d}}$ Relative error ratio

\subsection{Biota}

\subsubsection{Sample Collection}

Rangeland vegetation samples are collected from the same six locations from which the soil samples are collected (Figure 4.4). Also collected are fauna samples when available. All biota samples are analyzed for concentrations of the radionuclides of interest.

\subsubsection{Sample Preparation}

\section{$\underline{\text { Vegetation }}$}

The vegetation samples are chopped into 2.5-5-cm (1-2-in.) pieces, mixed together well, and air dried at room temperature. Weighed aliquots are taken from the bulk of the chopped vegetation samples from each location. The aliquots are transferred into separate containers and dried at $100^{\circ} \mathrm{C}\left(212^{\circ} \mathrm{F}\right)$. Gamma spectrometric determinations of ${ }^{40} \mathrm{~K},{ }^{60} \mathrm{Co}$, and ${ }^{137} \mathrm{Cs}$ are performed directly from these aliquots. The samples are then dry-ashed, followed by wet-ashing and dissolution in $8 \mathrm{M}$ nitric acid. Aliquots from the dissolved samples are taken for the determinations of ${ }^{90} \mathrm{Sr},{ }^{234} \mathrm{U},{ }^{235} \mathrm{U},{ }^{238} \mathrm{U},{ }^{238} \mathrm{Pu}$, ${ }^{239+240} \mathrm{Pu}$, and ${ }^{241} \mathrm{Am}$. 


\section{Animals}

The samples of tissue are placed in a digestion beaker, concentrated nitric acid is added to cover the sample and the sample is heated until nearly dry. The sample is then wet ashed using nitric acid and hydrogen peroxide until the residue is light colored. The residue is dissolved in nitric acid and transferred to a Teflon beaker. Concentrated hydrofluoric acid is added and the sample is heated to dryness. Concentrated nitric acid and boric acid are added and the sample is heated again to dryness. The sample is then dissolved in nitric acid and transferred back into its original glass beaker. It is then heated in a Muffle furnace at $350-375^{\circ} \mathrm{C}\left(652-707^{\circ} \mathrm{F}\right)$ for $8-12$ hours. If gamma analysis is required, $0.5 \mathrm{M}$ nitric acid is added to the sample to $500 \mathrm{~mL}(16.9 \mathrm{oz})$, and it is heated to dryness after counting is completed. The sample then undergoes another wet ashing and made ready for the isotopic separation process.

\subsubsection{Results and Discussion}

\section{$\underline{\text { Vegetation }}$}

Uranium-238 was detected in one of six vegetation samples. Neither ${ }^{234} U$ nor ${ }^{235} U$ were detected in any of the samples (Table 4.19). Since ${ }^{234} \mathrm{U}$ or ${ }^{235} \mathrm{U}$ were not detected and ${ }^{238} \mathrm{U}$ was only detected in one sample, there were insufficient data for ANOVA comparisons. In addition, comparison of the detected uranium concentration with the baseline value suggests higher concentrations of ${ }^{238} \mathrm{U}$ in 2005 than during the years in which the baseline data were collected (1985-1989, DOE/WIPP 92-037). The word "suggest" must be used, as the small sample sizes analyzed in the baseline study did not permit the fitting of probability distributions to the baseline results. This resulted in comparisons of 2005 data having to be made to the mean of a few baseline samples as opposed to the upper $99^{\text {th }}$ percentile as was done for other environmental media. This was true for all radioisotopes in vegetation samples.

Americium-241, ${ }^{238} \mathrm{Pu}$, and ${ }^{239+240} \mathrm{Pu}$ were not detected in any of the vegetation samples (Table 4.19); therefore a statistical comparison between years was not prepared.

Potassium-40 was detected in every vegetation sample (Table 4.19). The detected concentrations of ${ }^{40} \mathrm{~K}$ in vegetation was not significantly different among locations (ANOVA, $p=0.0820$ ) or between 2004 and 2005 (ANOVA, $p=0.164$ ). In addition, ${ }^{40} \mathrm{~K}$ concentrations fell within the range of baseline levels.

Cesium-137 was not detected in vegetation samples. ${ }^{60} \mathrm{Co}$ was detected in one of the six vegetation samples. Strontium-90 was not detected at any of the sampling locations (Table 4.19). Since ${ }^{90} \mathrm{Sr}$ or ${ }^{137} \mathrm{Cs}$ were not detected and ${ }^{60} \mathrm{Co}$ was only detected in one sample, there was insufficient data for ANOVA comparisons. No comparison with baseline data was available for the ${ }^{60} \mathrm{Co}$ concentrations, as it was not reported for vegetation samples analyzed for the baseline report (DOE/WIPP 92-037). 
Waste Isolation Pilot Plant Annual Site Environmental Report for 2005 DOE/WIPP-06-2225

Table 4.19 - Radionuclide Concentrations (Bq/g Wet Mass) in Vegetation Near the WIPP Site. See Appendix $\mathrm{C}$ for sampling location codes.

\begin{tabular}{|c|c|c|c|c|c|c|c|c|c|}
\hline Location & {$[\mathrm{RN}]^{\mathrm{a}}$} & $2 \times \mathrm{TPU}^{\mathrm{b}}$ & MDC $^{c}$ & [RN] & $2 \times$ TPU & MDC & [RN] & $2 \times$ TPU & MDC \\
\hline & \multicolumn{3}{|c|}{${ }^{241} \mathrm{Am}$} & \multicolumn{3}{|c|}{${ }^{238} \mathrm{Pu}$} & \multicolumn{3}{|c|}{${ }^{239+240} \mathrm{Pu}$} \\
\hline MLR & 3.26E-05 & 5.51E-05 & 1.63E-04 & $-5.30 \mathrm{E}-06$ & 1.83E-05 & $1.31 \mathrm{E}-04$ & 3.54E-05 & 6.35E-05 & 1.68E-04 \\
\hline SEC & 3.31E-05 & 5.58E-05 & 2.75E-04 & $-1.98 \mathrm{E}-05$ & 3.28E-05 & 1.25E-04 & 2.38E-05 & 4.23E-05 & 1.62E-04 \\
\hline SMR & 6.01E-05 & 6.42E-05 & 2.68E-04 & $-9.32 E-06$ & 4.76E-05 & 1.27E-04 & $-3.10 \mathrm{E}-06$ & $1.34 \mathrm{E}-05$ & 1.64E-04 \\
\hline WEE & $-2.00 \mathrm{E}-05$ & 3.36E-05 & 1.64E-04 & 3.55E-06 & 4.50E-05 & 1.33E-04 & 4.72E-06 & 4.41E-05 & 1.70E-04 \\
\hline WFF & 2.53E-05 & 4.85E-05 & 2.69E-04 & $-2.12 \mathrm{E}-05$ & 3.96E-05 & 1.39E-04 & $-2.05 E-05$ & $3.90 \mathrm{E}-05$ & 1.76E-04 \\
\hline \multirow[t]{2}{*}{ WSS } & $2.14 \mathrm{E}-06$ & 3.29E-05 & 2.69E-04 & -1.47E-05 & 2.99E-05 & $1.29 \mathrm{E}-04$ & 2.61E-05 & 4.74E-05 & 1.67E-04 \\
\hline & \multicolumn{3}{|c|}{${ }^{234} U$} & \multicolumn{3}{|c|}{${ }^{235} \mathrm{U}$} & \multicolumn{3}{|c|}{${ }^{238} \mathrm{U}$} \\
\hline MLR & $1.01 \mathrm{E}-03$ & $2.45 \mathrm{E}-04$ & $1.40 \mathrm{E}-03$ & 6.51E-05 & 7.38E-05 & $2.34 \mathrm{E}-04$ & 1.10E-03 & $2.54 \mathrm{E}-04$ & $9.06 \mathrm{E}-04$ \\
\hline SEC & 7.81E-04 & 2.43E-04 & 1.41E-03 & 4.09E-05 & 6.83E-05 & 2.49E-04 & 6.86E-04 & 2.27E-04 & 9.17E-04 \\
\hline SMR & 5.91E-04 & 1.90E-04 & 1.40E-03 & 9.37E-05 & 8.57E-05 & 2.38E-04 & $5.40 \mathrm{E}-04$ & $1.82 \mathrm{E}-04$ & 9.08E-04 \\
\hline WEE & 8.90E-04 & 2.18E-04 & 1.40E-03 & 4.55E-05 & 5.82E-05 & 2.30E-04 & 6.33E-04 & 1.83E-04 & 9.02E-04 \\
\hline WFF & 7.52E-04 & 2.06E-04 & 1.40E-03 & 8.49E-05 & 7.85E-05 & 2.33E-04 & 7.74E-04 & 2.09E-04 & 9.05E-04 \\
\hline \multirow[t]{2}{*}{ WSS } & $1.22 \mathrm{E}-03$ & 2.84E-04 & $1.41 \mathrm{E}-03$ & 9.99E-05 & 8.94E-05 & $2.40 \mathrm{E}-04$ & 6.96E-04 & $2.13 \mathrm{E}-04$ & $9.11 \mathrm{E}-04$ \\
\hline & \multicolumn{3}{|c|}{${ }^{137} \mathrm{Cs}$} & \multicolumn{3}{|c|}{${ }^{60} \mathrm{Co}$} & \multicolumn{3}{|c|}{${ }^{90} \mathrm{Sr}$} \\
\hline MLR & $-6.02 E-04$ & 2.05E-03 & 2.95E-03 & 1.76E-04 & 2.68E-03 & $3.01 \mathrm{E}-03$ & 1.78E-03 & $2.21 \mathrm{E}-03$ & 1.75E-03 \\
\hline SEC & $-5.02 E-04$ & 1.31E-03 & 1.48E-03 & $-5.06 E-04$ & 1.73E-03 & 1.90E-03 & 1.51E-03 & $2.29 \mathrm{E}-03$ & 1.76E-03 \\
\hline SMR & $-9.85 E-04$ & 2.42E-03 & 3.07E-03 & 1.03E-03 & 2.79E-03 & $3.16 \mathrm{E}-03$ & $-7.18 \mathrm{E}-04$ & $2.16 \mathrm{E}-03$ & 1.76E-03 \\
\hline WEE & $-3.66 \mathrm{E}-04$ & $1.26 \mathrm{E}-03$ & 1.44E-03 & $-6.88 \mathrm{E}-04$ & 1.85E-03 & 2.01E-03 & $5.40 \mathrm{E}-04$ & $2.22 \mathrm{E}-03$ & 1.76E-03 \\
\hline WFF & 4.78E-04 & $1.25 \mathrm{E}-03$ & 1.49E-03 & $-1.21 \mathrm{E}-03$ & 1.87E-03 & 1.96E-03 & 1.56E-03 & $2.28 \mathrm{E}-03$ & 1.76E-03 \\
\hline \multirow[t]{2}{*}{ WSS } & $-1.24 \mathrm{E}-03$ & $2.40 \mathrm{E}-03$ & $3.04 \mathrm{E}-03$ & 3.37E-03 & $2.62 \mathrm{E}-03$ & 3.06E-03 & 1.77E-03 & $2.33 \mathrm{E}-03$ & 1.77E-03 \\
\hline & \multicolumn{3}{|c|}{${ }^{40} \mathrm{~K}$} & & & & & & \\
\hline MLR & 5.42E-01 & 9.16E-02 & 3.43E-02 & & & & & & \\
\hline SEC & $5.18 \mathrm{E}-01$ & 8.68E-02 & 2.17E-02 & & & & & & \\
\hline SMR & 8.87E-01 & $1.45 \mathrm{E}-01$ & $3.52 \mathrm{E}-02$ & & & & & & \\
\hline WEE & 4.69E-01 & 7.91E-02 & 2.23E-02 & & & & & & \\
\hline WFF & 5.35E-01 & 8.93E-02 & 2.10E-02 & & & & & & \\
\hline WSS & 3.39E-01 & $6.11 \mathrm{E}-02$ & 3.54E-02 & & & & & & \\
\hline
\end{tabular}

${ }^{a}$ Radionuclide concentration

b Total propagated uncertainty

${ }^{\mathrm{C}}$ Minimum detectable concentration

A duplicate analysis of the vegetation sample from sampling location SEC was performed for all the radionuclides of interest. RERs were calculated for those duplicate pairs for which each sample and duplicate were detected (Table 4.20). The duplicates had an RER greater than 1, indicating poor reproducibility. This is most likely due to inhomogeneities in the distributions of the radioisotope in the location. 
Table 4.20 -Results of Duplicate Vegetation Sample Analysis. Units are Bq/g. See Appendix C for sampling location codes.

\begin{tabular}{|c|c|c|c|c|c|c|c|c|}
\hline \multirow{2}{*}{\multicolumn{2}{|c|}{ Location }} & \multicolumn{3}{|c|}{ Sample } & \multicolumn{3}{|c|}{ Duplicate } & \multirow[b]{2}{*}{ RER $^{\mathrm{d}}$} \\
\hline & & {$[\mathrm{RN}]^{\mathrm{a}}$} & $2 \times$ TPU $^{b}$ & MDC $^{c}$ & [RN] & $2 \times$ TPU & MDC & \\
\hline SEC & ${ }^{40} \mathrm{~K}$ & 5.18E-01 & 8.68E-02 & $2.17 \mathrm{E}-02$ & $3.11 \mathrm{E}-01$ & $5.45 \mathrm{E}-02$ & $2.16 \mathrm{E}-02$ & 2.02 \\
\hline
\end{tabular}

${ }^{a}$ Radionuclide concentration

b Total propagated uncertainty

${ }^{c}$ Minimum detectable concentration

${ }^{d}$ Relative error ratio

\section{$\underline{\text { Animals }}$}

$\mathrm{K}-40$ was detected in the deer, quail, rabbit and fish samples (Table 4.21). Strontium-90 was detected in the quail and rabbit samples. The remaining isotopes of interest were not detected in the animal samples. Although there were too few samples to allow statistical comparison between years, detected radionuclide concentrations in all samples fell within the range of concentrations for the same animals determined during baseline data analyses (DOE/WIPP 92-037). These results can be used only as a gross indication of uptakes, as the sample sizes are too small to provide a robust analysis; however, the data do not suggest any contribution to animal uptake of the radionuclides of interest due to WIPP operations. Due to the limited sample sizes of only one sample per animal type, duplicate analyses were not performed.

Table 4.21 - Radionuclide Concentrations (Bq/g Wet Mass) in Deer, Quail, Rabbit, and Fish Near the WIPP Site. See Appendix C for sampling location codes.

\begin{tabular}{|c|c|c|c|c|c|c|c|c|c|}
\hline & {$[\mathrm{RN}]^{\mathrm{a}}$} & $2 \times \mathrm{TPU}^{\mathrm{b}}$ & $M^{\prime} C^{c}$ & [RN] & $2 \times \mathrm{TPU}$ & MDC & [RN] & $2 \times$ TPU & MDC \\
\hline & \multicolumn{3}{|c|}{${ }^{241} \mathrm{Am}$} & \multicolumn{3}{|c|}{${ }^{238} \mathrm{Pu}$} & \multicolumn{3}{|c|}{${ }^{239+240} \mathrm{Pu}$} \\
\hline Deer (SOO) & $1.30 \mathrm{E}-06$ & $1.71 \mathrm{E}-06$ & $1.87 \mathrm{E}-04$ & 3.77E-07 & $8.76 \mathrm{E}-07$ & $8.74 \mathrm{E}-05$ & $-1.22 \mathrm{E}-07$ & 3.59E-07 & $9.97 \mathrm{E}-05$ \\
\hline Quail (WFF) & 5.53E-07 & 4.96E-06 & $3.15 E-04$ & 1.78E-06 & 5.34E-06 & 1.65E-04 & 8.23E-06 & 8.25E-06 & $1.28 \mathrm{E}-04$ \\
\hline Rabbit (SOO) & 4.41E-07 & $1.39 \mathrm{E}-06$ & $3.10 \mathrm{E}-04$ & $-1.16 \mathrm{E}-06$ & $2.15 \mathrm{E}-06$ & 1.87E-04 & 2.41E-07 & $9.89 \mathrm{E}-07$ & $1.50 \mathrm{E}-04$ \\
\hline \multirow[t]{2}{*}{ Fish (PCN) } & 1.10E-06 & 2.05E-06 & 3.83E-05 & 9.07E-09 & 7.33E-07 & 7.50E-05 & 1.93E-07 & 5.89E-07 & $6.26 \mathrm{E}-05$ \\
\hline & \multicolumn{3}{|c|}{${ }^{234} U$} & \multicolumn{3}{|c|}{${ }^{235} \mathrm{U}$} & \multicolumn{3}{|c|}{${ }^{238} \mathrm{U}$} \\
\hline Deer (SOO) & $2.39 \mathrm{E}-06$ & $2.01 \mathrm{E}-06$ & $7.81 \mathrm{E}-04$ & $2.61 \mathrm{E}-07$ & $9.68 \mathrm{E}-07$ & $1.00 \mathrm{E}-04$ & $1.51 \mathrm{E}-06$ & $1.57 \mathrm{E}-06$ & $3.60 \mathrm{E}-04$ \\
\hline Quail (WFF) & $1.71 \mathrm{E}-04$ & 2.31E-05 & $1.29 \mathrm{E}-03$ & 1.32E-05 & $6.82 \mathrm{E}-06$ & 2.00E-04 & 1.83E-04 & 2.39E-05 & 7.07E-04 \\
\hline Rabbit (SOO) & 4.55E-05 & 8.34E-06 & $1.28 \mathrm{E}-03$ & 6.91E-06 & 3.60E-06 & 2.12E-04 & 3.73E-05 & 7.53E-06 & 7.43E-04 \\
\hline \multirow[t]{2}{*}{ Fish (PCN) } & 2.07E-04 & 1.59E-05 & $1.04 \mathrm{E}-03$ & $1.04 \mathrm{E}-05$ & 3.55E-06 & $1.86 \mathrm{E}-04$ & 1.08E-04 & 1.09E-05 & $5.58 \mathrm{E}-04$ \\
\hline & \multicolumn{3}{|c|}{${ }^{137} \mathrm{Cs}$} & \multicolumn{3}{|c|}{${ }^{60} \mathrm{Co}$} & \multicolumn{3}{|c|}{${ }^{90} \mathrm{Sr}$} \\
\hline Deer (SOO) & $-2.42 E-05$ & $2.31 \mathrm{E}-04$ & $2.61 \mathrm{E}-04$ & 5.06E-05 & $2.57 \mathrm{E}-04$ & $2.83 E-04$ & $-2.97 \mathrm{E}-05$ & 5.91E-05 & $5.41 \mathrm{E}-05$ \\
\hline Quail (WFF) & 8.68E-05 & 3.83E-04 & 4.56E-04 & $6.03 E-05$ & 5.26E-04 & $6.04 \mathrm{E}-04$ & $3.51 \mathrm{E}-04$ & 1.30E-04 & 4.38E-05 \\
\hline Rabbit (SOO) & $2.50 \mathrm{E}-05$ & $1.71 \mathrm{E}-04$ & 2.03E-04 & $-5.33 E-05$ & $2.54 \mathrm{E}-04$ & 2.81E-04 & 8.24E-04 & $1.25 \mathrm{E}-04$ & $3.18 \mathrm{E}-05$ \\
\hline \multirow[t]{2}{*}{ Fish (PCN) } & 1.10E-04 & 1.98E-04 & 2.40E-04 & $-5.49 \mathrm{E}-05$ & 3.03E-04 & 3.37E-04 & $-7.44 \mathrm{E}-06$ & 1.05E-04 & $1.81 \mathrm{E}-03$ \\
\hline & & ${ }^{40} \mathrm{~K}$ & & & & & & & \\
\hline Deer (SOO) & $1.00 \mathrm{E}-01$ & 1.64E-02 & $3.24 \mathrm{E}-03$ & & & & & & \\
\hline Quail (WFF) & 1.10E-01 & $1.89 \mathrm{E}-02$ & 4.64E-03 & & & & & & \\
\hline Rabbit (SOO) & $1.08 \mathrm{E}-01$ & 1.77E-02 & $2.46 \mathrm{E}-03$ & & & & & & \\
\hline Fish (PCN) & $1.01 \mathrm{E}-01$ & $1.66 \mathrm{E}-02$ & 2.37E-03 & & & & & & \\
\hline
\end{tabular}

\footnotetext{
${ }^{a}$ Radionuclide concentration

${ }^{\mathrm{b}}$ Total propagated uncertainty

${ }^{\mathrm{c}}$ Minimum detectable concentration
} 


\subsection{Potential Dose from WIPP Operations}

\subsubsection{Dose Limits}

Compliance with the regulatory standards is determined by comparing annual radiation doses to the regulatory limits. The regulatory limits can be found in 40 CFR Part 191, Subpart A. The referenced standard specifies that the combined annual dose equivalent to any member of the public in the general environment resulting from discharges of radioactive material and direct radiation from such management and storage shall not exceed $25 \mathrm{mrem}$ to the whole body and $75 \mathrm{mrem}$ to any critical organ. In addition, in a 1995 MOU between the EPA and the DOE, the DOE agreed that WIPP would comply with NESHAP. The NESHAP standard states that the emissions of radionuclides to the ambient air from DOE facilities shall not exceed those amounts that would cause any member of the public to receive in any year an EDE of 10 mrem per year. The EDE is the weighted sum of the doses to the individual organs of the body. The dose to each organ is weighted according to the risk that dose represents. These organ doses are then added together, and that total is the EDE. In this manner, the risk from different sources of radiation can be controlled by a single standard.

Compliance with the above regulatory requirements is determined by monitoring, extracting and calculating the EDE. Calculating the EDE to members of the public requires the use of CAP88-PC or other EPA approved computer models and procedures. The WIPP Effluent Monitoring Program generally uses CAP88-PC. CAP88-PC is a set of computer programs, datasets and associated utility programs for estimating dose and risk from radionuclide air emissions. CAP88-PC uses a Gaussian Plume dispersion model, which predicts air concentrations, deposition rates, concentrations in food, and intake rates for people. CAP88-PC estimates dose and risk to individuals and populations from multiple pathways. Dose and risk is calculated for ingestion, inhalation, ground level air immersion, and ground surface irradiation exposure pathways.

The SDWA (40 CFR §141.66) states that average annual concentrations for beta- and gamma-emitting human-made radionuclides in drinking water shall not result in an annual dose equivalent greater than $0.04 \mathrm{mSv}(4 \mathrm{mrem})$. It is important to note that all of these dose equivalent limits are set for radionuclides released to the environment from DOE operations. They do not include, but are limits in addition to, doses from natural background radiation or from medicinal procedures.

\subsubsection{Background Radiation}

There are several sources of natural radiation: cosmic and cosmogenic radiation (from outer space and the earth's atmosphere), terrestrial radiation (from the earth's crust), and internal radiation (naturally occurring radiation in our bodies, such as ${ }^{40} \mathrm{~K}$ ). The most common sources of terrestrial radiation are uranium, thorium, and their decay products. Potassium-40 is another source of terrestrial radiation. While not a major radiation source, ${ }^{40} \mathrm{~K}$ in the southeastern New Mexico environment may be due to the deposition of tailings from local potash mining. Radon gas, a decay product of uranium, 
is a widely known naturally occurring terrestrial radionuclide. In addition to natural radioactivity, small amounts of radioactivity from aboveground nuclear weapons tests that occurred from 1945 through 1980 and the 1986 Chernobyl nuclear accident are also present in the environment. Together, these sources of radiation are called "background" radiation. Every human is constantly exposed to background radiation. Exposure to radioactivity from weapons testing fallout is quite small compared to natural radioactivity and continually gets smaller as radionuclides decay.

Naturally occurring radiation in our environment can deliver both internal and external doses. Internal dose is received as a result of the intake of radionuclides. The major routes of intake of radionuclides for members of the public are ingestion and inhalation. Ingestion includes the intake of the radionuclides from eating and drinking contaminated food or drink. Inhalation includes the intake of radionuclides through breathing radioactive particulates such as the decay products of radon. External dose can occur from submersion in contaminated air or deposition of contaminants on surfaces. The average annual dose received by a member of the public from naturally occurring radionuclides is approximately $3 \mathrm{mSv}$ (300 mrem) (Table 4.22).

\section{Table 4.22 - Annual Estimated Average Radiation Dose Received by a Member of the Population of the United States from Naturally Occurring Radiation Sources (adapted from NCRP, 1987)}

\begin{tabular}{lcc}
\hline \multicolumn{1}{c}{ Source } & \multicolumn{2}{c}{ Average Annual EDE } \\
& $(\mathrm{mSv})$ & (mrem) \\
\hline Inhaled (Radon and Decay Products) & 2 & 200 \\
Internal Radionuclides & 0.39 & 39 \\
Terrestrial Radiation & 0.28 & 28 \\
Cosmic Radiation & 0.27 & 27 \\
Cosmogenic Radioactivity & 0.01 & 1 \\
Rounded Total from Natural Sources & 3 & 300 \\
\hline
\end{tabular}

\subsubsection{Dose from Air Emissions}

The 40 CFR 191, Subpart A, standard limits radiation doses to members of the public in the general environment. WIPP has identified air emissions as the major pathway of concern.

Compliance with Subpart A (40 CFR §191.03[b]) and the NESHAP (40 CFR §61.92) standards is determined by comparing annual radiation doses to the MEl. As recommended by the EPA, the DOE utilizes computer modeling to calculate radiation doses for compliance with the Subpart A and NESHAP standards. Compliance procedures for DOE facilities (40 CFR §61.93[a]) require the use of CAP88-PC or AIRDOS-PC computer models, or an equivalent, to calculate dose to members of the public. Source term input for CAP88-PC was determined by radiochemical analyses of filter air samples taken from Stations A, B, and C. Air filter samples were analyzed for ${ }^{241} \mathrm{Am},{ }^{239+240} \mathrm{Pu},{ }^{238} \mathrm{Pu}$, and ${ }^{90} \mathrm{Sr}$ because these radionuclides constitute over 98 percent 
of the dose potential from $\mathrm{CH}$ waste. Measured activity values greater than the 2 sigma TPU and MDC values were used as a part of the source terms for the air emission pathway. For measured results less than the 2 sigma TPU and MDC values, either the 2 sigma TPU or MDC values, whichever were greater, were used as part of the source term (see Table 4.1). CAP88-PC dose calculations are based on the assumption that exposed persons remain at home during the entire year and all vegetables, milk, and meat consumed are home produced. Thus, this dose calculation is a maximum potential dose which encompasses dose from inhalation, submersion, deposition, and ingestion of air emitted radionuclides.

\subsubsection{Total Potential Dose from WIPP Operations}

The radiation dose equivalent received by members of the public as a result of the management and storage of TRU radioactive wastes at any disposal facility operated by the DOE is regulated under 40 CFR Part 191, Subpart A. Specific standards state that the combined annual dose equivalent to any member of the public in the general environment resulting from the discharges of radioactive material and direct radiation from management and storage shall not exceed $0.25 \mathrm{mSv}(25 \mathrm{mrem})$ to the whole body and $0.75 \mathrm{mSv}$ (75 mrem) to any other critical organ. Section 4.8.4.3 discusses the potential dose equivalent received from radionuclides released to the air from WIPP. The following sections discuss the potential dose equivalent through other pathways and the total potential dose equivalent a member of the public may have received from WIPP operations during 2005.

\subsubsection{Potential Dose from Water Ingestion Pathway}

The potential dose to individuals from the ingestion of WIPP-related radionuclides transported in water is determined to be near zero for several reasons. Drinking water for communities near WIPP comes from groundwater sources which are not expected to be affected by potential WIPP contaminants based on current radionuclide transport scenarios summarized in DOE/WIPP 95-2065. The only credible pathway for contaminants from WIPP to accessible groundwater is through the Culebra Member of the Rustler Formation as stated in DOE/CAO 96-2184, Title 40 CFR Part 191 Compliance Certification Application for the Waste Isolation Pilot Plant. Water from the Culebra is naturally not potable due to high levels of total dissolved solids (TDS). Water from the Dewey Lake Redbeds Formation is suitable for livestock consumption having TDS values below $10,000 \mathrm{mg} / \mathrm{L}$. Groundwater and surface water samples collected around WIPP during 2005 did not contain radionuclide concentrations discernable from those in samples collected prior to WIPP receiving waste.

\subsubsection{Potential Dose from Wild Game Ingestion}

Game animals sampled during 2005 were mule deer, rabbit, fish, and quail. The only radionuclides detected were not different from baseline levels measured prior to commencement of waste shipments to WIPP. Therefore, no dose from WIPP-related radionuclides could have been received by any individual from this pathway during 2005. 


\subsubsection{Total Potential Dose from All Pathways}

At WIPP, the only credible pathway to humans was through air emissions and, therefore, this was the only pathway for which a dose was calculated. The total radiological dose and atmospheric release at WIPP in 2005 is summarized in Table 4.23 for the regulations in both 40 CFR §61.92 and 40 CFR §191.03(b).

In compliance with 40 CFR Part 191, Subpart A, the receptor selected is assumed to reside year-round at the WIPP fence line, located $350 \mathrm{~m}$ in the northwest sector. For 2005 , the dose to this receptor was estimated to be less than $8.86 \mathrm{E}-07 \mathrm{mSv}(8.86 \mathrm{E}-05$ mrem) per year for the whole body and less than 1.41E-05 mSv (1.41E-03 mrem) per year to the critical organ. These values are in compliance with the requirements specified in 40 CFR §191.03(b).

For NESHAP (40 CFR §61.92) standards, the EDE potentially received by the MEI in 2005 assumed to be residing $7.5 \mathrm{~km}$ (4.66 miles) west-northwest of WIPP was calculated to be less than $3.85 \mathrm{E}-08 \mathrm{mSv}$ (3.85E-06 mrem) per year for the whole body. These values are in compliance with 40 CFR $\S 61.92$ requirements.

As required by DOE Order 5400.5, Chapter II, Section 6.b., the collective dose to the public within $80 \mathrm{~km}$ (50 miles) of the site has been evaluated. The collective dose to the public is a factor considered in developing the field program for the ALARA process as required by DOE Order 5400.5, Chapter II, Section 2.a.(2).

Table 4.23 - WIPP Radiological Dose and Release Summary

\begin{tabular}{|c|c|c|c|c|c|c|c|}
\hline \multicolumn{8}{|c|}{ WIPP Radiological Atmospheric Releases ${ }^{a}$ During 2005} \\
\hline \multicolumn{2}{|r|}{${ }^{238} \mathrm{Pu}$} & \multicolumn{2}{|r|}{${ }^{239+240} \mathrm{Pu}$} & \multicolumn{2}{|c|}{${ }^{241} \mathrm{Am}$} & \multicolumn{2}{|r|}{${ }^{90} \mathrm{Sr}$} \\
\hline \multirow{2}{*}{\multicolumn{2}{|c|}{$\begin{array}{l}4.15 \mathrm{E}-08 \mathrm{Ci}^{\mathrm{b}} \\
1.54 \mathrm{E} 03 \mathrm{~Bq}^{\mathrm{c}}\end{array}$}} & \multirow{2}{*}{\multicolumn{2}{|c|}{$\begin{array}{l}4.01 \mathrm{E}-08 \mathrm{Ci} \\
1.48 \mathrm{E} 03 \mathrm{~Bq}\end{array}$}} & \multirow{2}{*}{\multicolumn{2}{|c|}{$\begin{array}{l}5.89 \mathrm{E}-08 \mathrm{Ci} \\
2.18 \mathrm{E} 03 \mathrm{~Bq}\end{array}$}} & \multirow{2}{*}{\multicolumn{2}{|c|}{$\begin{array}{l}2.74 \mathrm{E}-06 \mathrm{Ci} \\
1.01 \mathrm{E} 05 \mathrm{~Bq}\end{array}$}} \\
\hline & & & & & & & \\
\hline \multicolumn{8}{|c|}{ WIPP Radiological Dose Reporting Table in 2005} \\
\hline \multirow{2}{*}{ Pathway } & \multicolumn{2}{|c|}{$\begin{array}{l}\text { EDE to the Maximally } \\
\text { Exposed Individual } \\
\text { at } 7,500 \text { Meters WNW }\end{array}$} & \multirow{2}{*}{$\begin{array}{l}\% \text { of EPA } \\
10 \text {-mrem/ } \\
\text { Year Limit to } \\
\text { Member of } \\
\text { the Public }\end{array}$} & \multicolumn{2}{|c|}{$\begin{array}{l}\text { Estimated Population Dose } \\
\text { Within } 50 \text { miles }\end{array}$} & \multirow{2}{*}{$\begin{array}{c}\text { Estimated } \\
\text { Population } \\
\text { Within } \\
50 \text { Miles }^{d}\end{array}$} & \multirow{2}{*}{$\begin{array}{c}\begin{array}{c}\text { Estimated } \\
\text { Natural } \\
\text { Radiation } \\
\text { Population } \\
\text { Dose }^{\mathrm{e}}\end{array} \\
\text { (person-rem) }\end{array}$} \\
\hline & (mrem/year) & (mSv/year) & & $\begin{array}{c}\text { (person- } \\
\text { rem/year) }\end{array}$ & $\begin{array}{c}\text { (person-Sv/ } \\
\text { year) }\end{array}$ & & \\
\hline Air & 3.85E-06 & $3.85 \mathrm{E}-08$ & 3.85E-05 & 1.07E-05 & 1.07E-07 & 100,944 & 30,288 \\
\hline Water & $N / A^{e}$ & N/A & N/A & N/A & N/A & N/A & $\mathrm{N} / \mathrm{A}$ \\
\hline $\begin{array}{c}\text { Other } \\
\text { Pathways }\end{array}$ & N/A & N/A & N/A & N/A & N/A & $\mathrm{N} / \mathrm{A}$ & N/A \\
\hline
\end{tabular}


Waste Isolation Pilot Plant Annual Site Environmental Report for 2005 DOE/WIPP-06-2225

\begin{tabular}{|c|c|c|c|c|c|c|}
\hline \multicolumn{7}{|c|}{ WIPP Radiological Dose Reporting Table in 2005} \\
\hline \multirow[t]{2}{*}{ Pathway } & \multicolumn{2}{|c|}{$\begin{array}{l}\text { Dose equivalent to the whole } \\
\text { body of the receptor who } \\
\text { resides year-round at WIPP } \\
\text { fence line } 350 \text { meters NW }\end{array}$} & \multirow[t]{2}{*}{$\begin{array}{c}\% \text { of EPA } \\
\text { 25-mrem/year } \\
\text { whole body } \\
\text { limit }\end{array}$} & \multicolumn{2}{|c|}{$\begin{array}{l}\text { Dose equivalent to the critical } \\
\text { organ of the receptor who } \\
\text { resides year-round at WIPP } \\
\text { fence line } 350 \text { meters NW }\end{array}$} & \multirow[t]{2}{*}{$\begin{array}{c}\% \text { of EPA } \\
75 \text {-mrem/year } \\
\text { critical organ } \\
\text { limit }\end{array}$} \\
\hline & (mrem/year) & (mSv/year) & & (mrem/year) & (mSv/year) & \\
\hline Air & 8.86E-05 & 8.86E-07 & 3.54E-04 & $1.41 \mathrm{E}-03$ & $1.41 \mathrm{E}-05$ & $1.88 \mathrm{E}-03$ \\
\hline Water & $N / A^{f}$ & N/A & N/A & N/A & $\mathrm{N} / \mathrm{A}$ & N/A \\
\hline $\begin{array}{c}\text { Other } \\
\text { Pathways }\end{array}$ & N/A & $\mathrm{N} / \mathrm{A}$ & $\mathrm{N} / \mathrm{A}$ & N/A & $\mathrm{N} / \mathrm{A}$ & $\mathrm{N} / \mathrm{A}$ \\
\hline \multicolumn{7}{|c|}{$\begin{array}{l}\text { Total releases from the combination of Stations A, B, and C. Values are calculated from detected activities } \\
\text { (where activities were less than MDA) and multiplied by the ratio of flow to stack flow volumes. } \\
\text { Curies } \\
\text { Becquerels } \\
\text { Source: } 2000 \text { Census Data } \\
\text { Estimated natural radiation populations dose }=\text { (Estimated population within } 50 \text { miles }) \times(300 \mathrm{mrem} / \text { year }) \\
\text { Not applicable at WIPP }\end{array}$} \\
\hline
\end{tabular}

\subsubsection{Dose to Nonhuman Biota}

Dose limits for populations of aquatic and terrestrial organisms are discussed in NCRP Report No. 109, Effects of lonizing Radiation on Aquatic Organisms (NCRP, 1991), and the International Atomic Energy Agency (IAEA Technical Report Series No. 332). Those dose limits are:

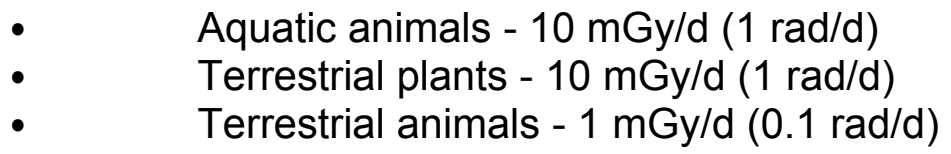

The DOE has considered establishing these dose standards for aquatic and terrestrial biota in proposed rule 10 CFR Part 834, "Radiation Protection of the Public and the Environment," but has delayed finalizing this rule until guidance for demonstrating compliance was developed. A Graded Approach for Evaluating Radiation Doses to Aquatic and Terrestrial Biota (DOE-STD-1153-2002) was developed to meet this need. The DOE requires reporting of radiation doses to nonhuman biota in the ASER using DOE-STD-1153-2002.

DOE-STD-1153-2002 requires an initial general screening using conservative assumptions. In the initial screen, biota concentration guides (BCGs) are derived using conservative assumptions for a variety of generic organisms. Maximum concentrations of radionuclides detected in soil, sediment, and water during environmental monitoring are divided by the BCGs and the results are summed for each organism. If the sum of these fractions is less than 1, the site is deemed to have passed the screen and no further action is required. This screening evaluation is intended to provide a very conservative evaluation of whether the site is in compliance with the recommended limits. 
This guidance was used to screen radionuclide concentrations observed around WIPP during 2005 using the maximum radionuclide concentrations listed in Table 4.24, and the sum of fractions was less than one for all media.

Table 4.24 -General Screening Results for Potential Radiation Dose to Nonhuman Biota from Radionuclide Concentrations in Surface Water (Bq/L), Sediment (Bq/g), and Soil (Bq/g) Near the WIPP Site in 2005

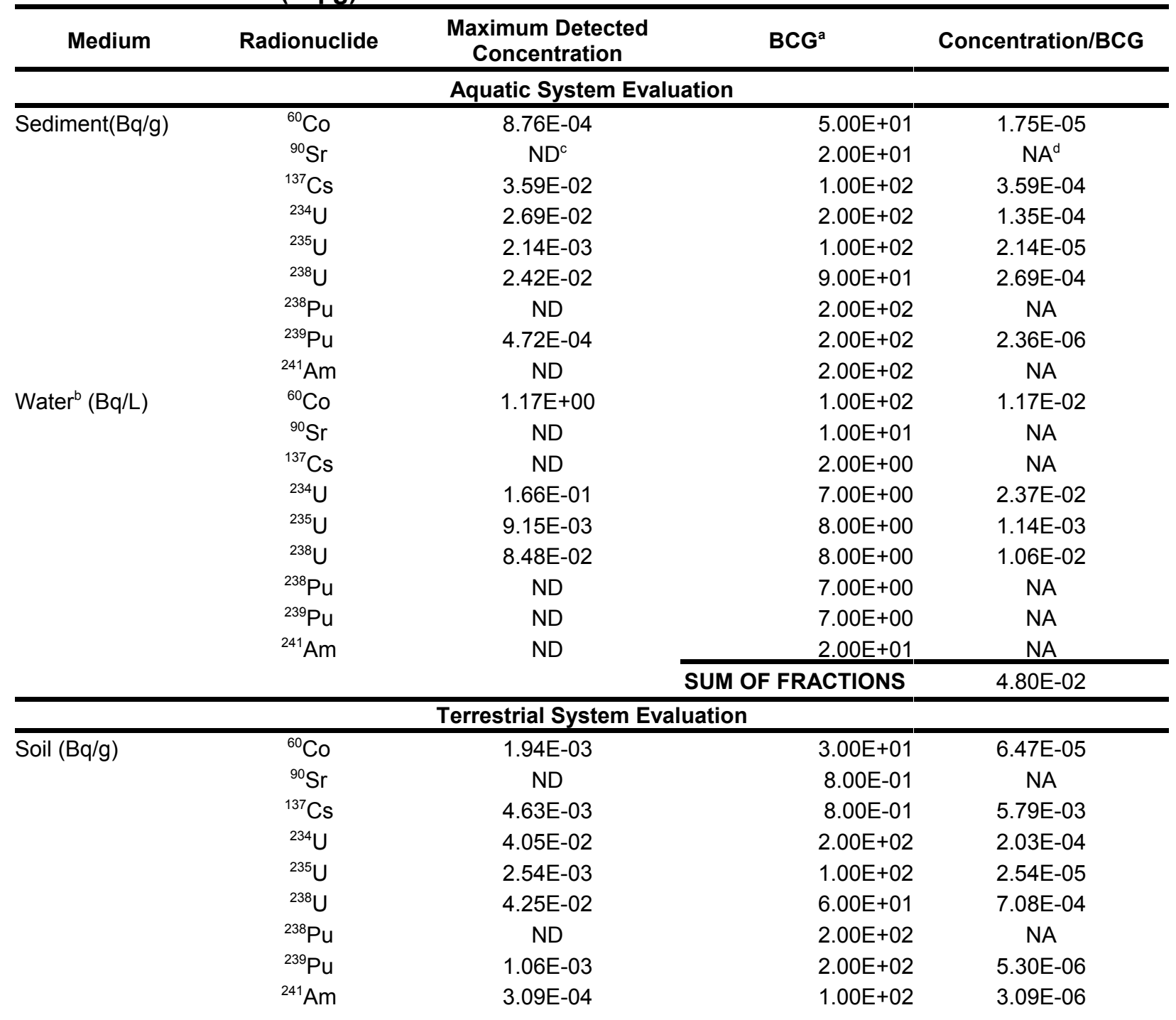




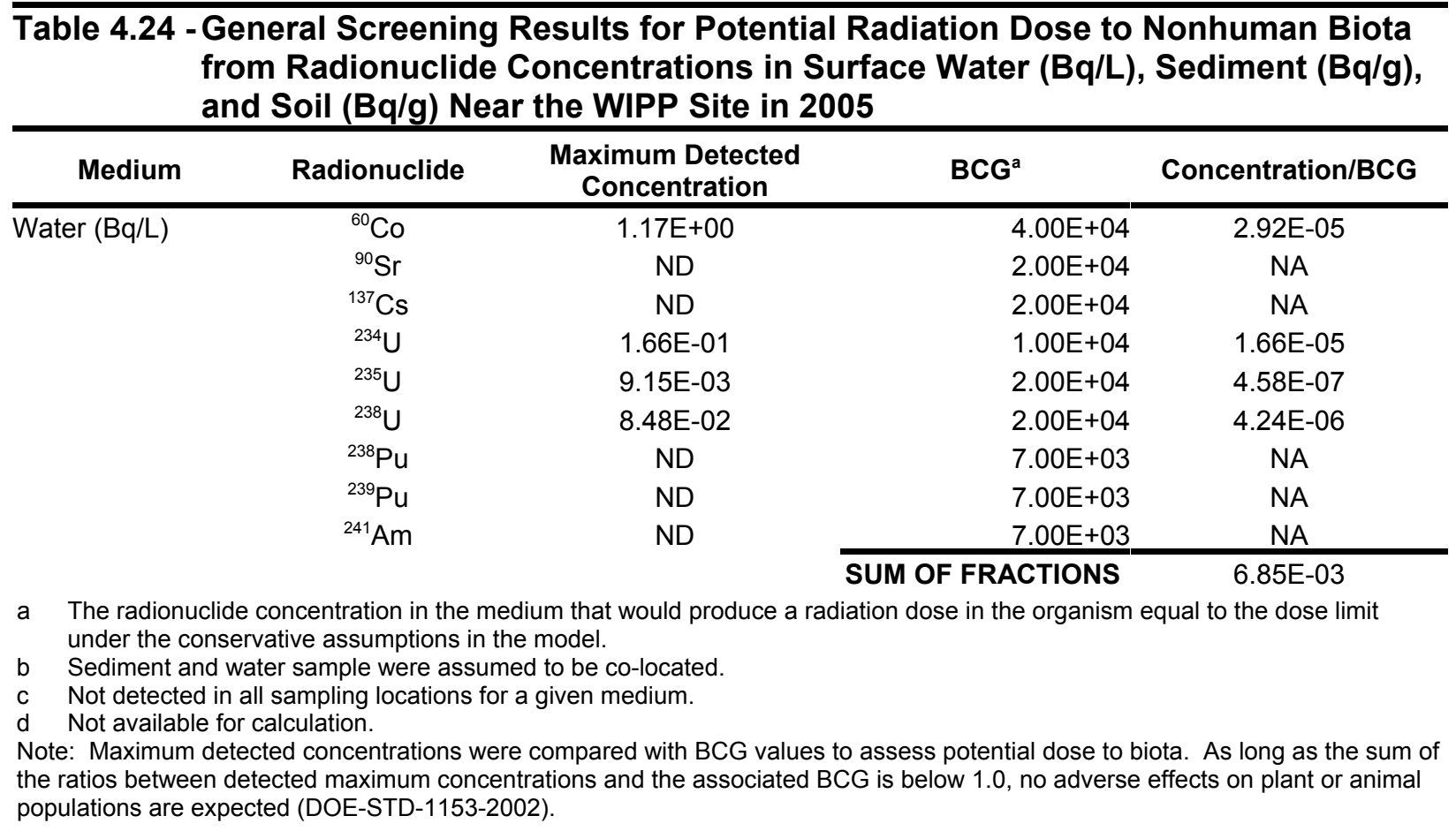

\subsubsection{Release of Property Containing Residual Radioactive Material}

There was no release of radiologically contaminated materials or property in 2005. The release of contaminated materials or property at WIPP is prevented based on institutional controls.

\subsection{Radiological Program Conclusions}

\section{Effluent Monitoring}

For 2005, the EDE to the receptor (hypothetical MEI) who resides year-round at the WIPP fence line is less than $8.86 \mathrm{E}-07 \mathrm{mSv}(8.86 \mathrm{E}-05 \mathrm{mrem})$ per year for the whole body, and is less than $1.41 \mathrm{E}-05 \mathrm{mSv}(1.41 \mathrm{E}-03 \mathrm{mrem})$ per year for the critical organ. For the WIPP Effluent Monitoring Program, Figure 4.5 and Table 4.25 show the dose to the whole body for the hypothetical MEI for CY 1999 to CY 2005. In addition, Figure 4.6 and Table 4.26 show the dose to the critical organ for the hypothetical MEI for CY 1999 to CY 2005. These dose equivalent values are below the $25 \mathrm{mrem}$ to the whole body and 75 mrem to any critical organ in accordance with the provisions of 40 CFR §191.03(b). 


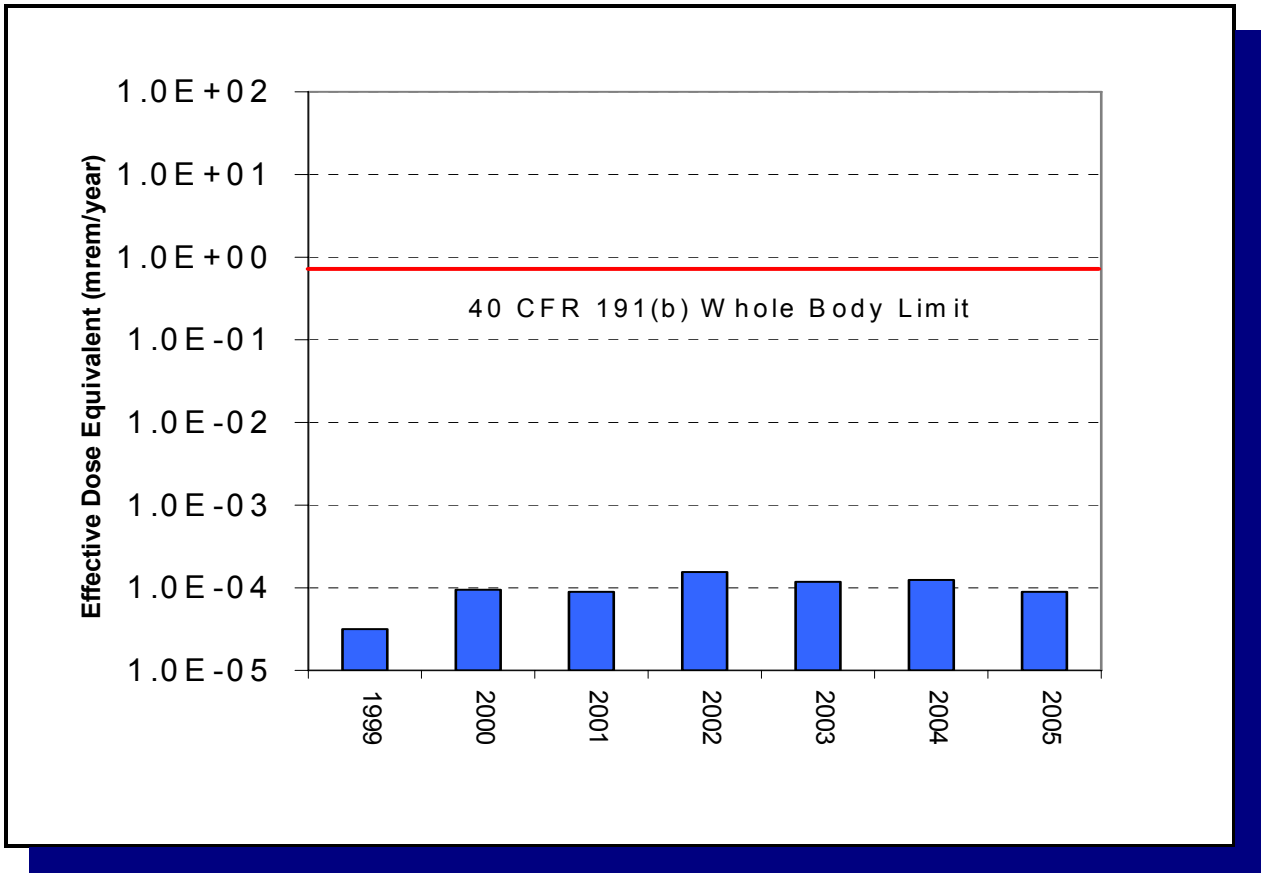

Figure 4.5 - Dose to Whole Body for Hypothetical Maximally Exposed Individual at the WIPP Fence Line

Table 4.25 - Dose to the Whole Body: 40 CFR \$191.03(b)

\begin{tabular}{|c|c|c|}
\hline Year & Annual Dose (mrem/yr) & Percent of EPA Limit \\
\hline 1999 & $3.10 \mathrm{E}-05$ & 124 millionth \\
\hline 2000 & $9.35 \mathrm{E}-05$ & 374 millionth \\
\hline 2001 & $8.99 \mathrm{E}-05$ & 360 millionth \\
\hline 2002 & $1.51 \mathrm{E}-04$ & 604 millionth \\
\hline 2003 & $1.15 \mathrm{E}-04$ & 460 millionth \\
\hline 2004 & $1.27 \mathrm{E}-04$ & 508 millionth \\
\hline 2005 & $8.86 \mathrm{E}-03$ & 354 millionth \\
\hline $\begin{array}{c}\text { 40 CFR §191.03(b) } \\
\text { Whole Body Limit }\end{array}$ & 25 & \\
\hline
\end{tabular}




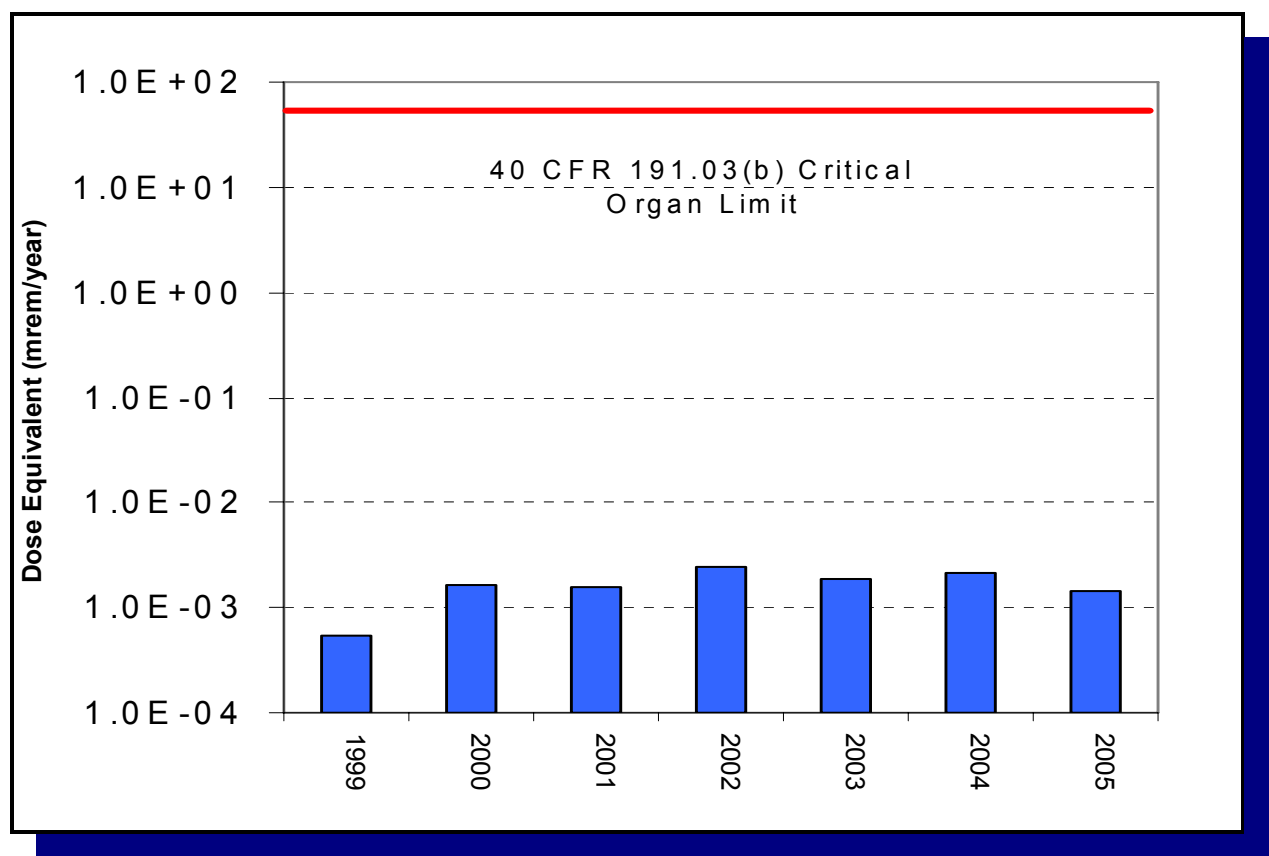

Figure 4.6 - Dose to the Critical Organ for Hypothetical Maximally Exposed Individual at the WIPP Fence Line

Table 4.26 - Dose to the Critical Organ: 40 CFR §191.03(b)

\begin{tabular}{|c|c|c|}
\hline Year & Annual Dose (mrem/yr) & Percent of EPA Limit \\
\hline 1999 & $5.30 \mathrm{E}-04$ & 707 millionth \\
\hline 2000 & $1.63 \mathrm{E}-03$ & 2170 millionth \\
\hline 2001 & $1.56 \mathrm{E}-03$ & 2080 millionth \\
\hline 2002 & $2.46 \mathrm{E}-03$ & 3280 millionth \\
\hline 2003 & $1.85 \mathrm{E}-03$ & 2470 millionth \\
\hline 2004 & $2.11 \mathrm{E}-03$ & 2810 millionth \\
\hline 2005 & $1.41 \mathrm{E}-03$ & 1880 millionth \\
\hline $\begin{array}{l}\text { 40 CFR §191.03(b) } \\
\text { Critical Organ Limit }\end{array}$ & 75 & \\
\hline
\end{tabular}

In addition, for 2005, the EDE to the MEI individual from normal operations conducted at the WIPP is less than 3.85E-08 mSv (3.85E-06 mrem) per year. For the WIPP Effluent Monitoring Program, Figure 4.7 and Table 4.27 show the EDE to the MEI for CY 1999 to CY 2005. Note that these EDE values are more than six orders of magnitude below the EPA NESHAP standard of 10 mrem per year as specified in 40 CFR $§ 61.92$. 


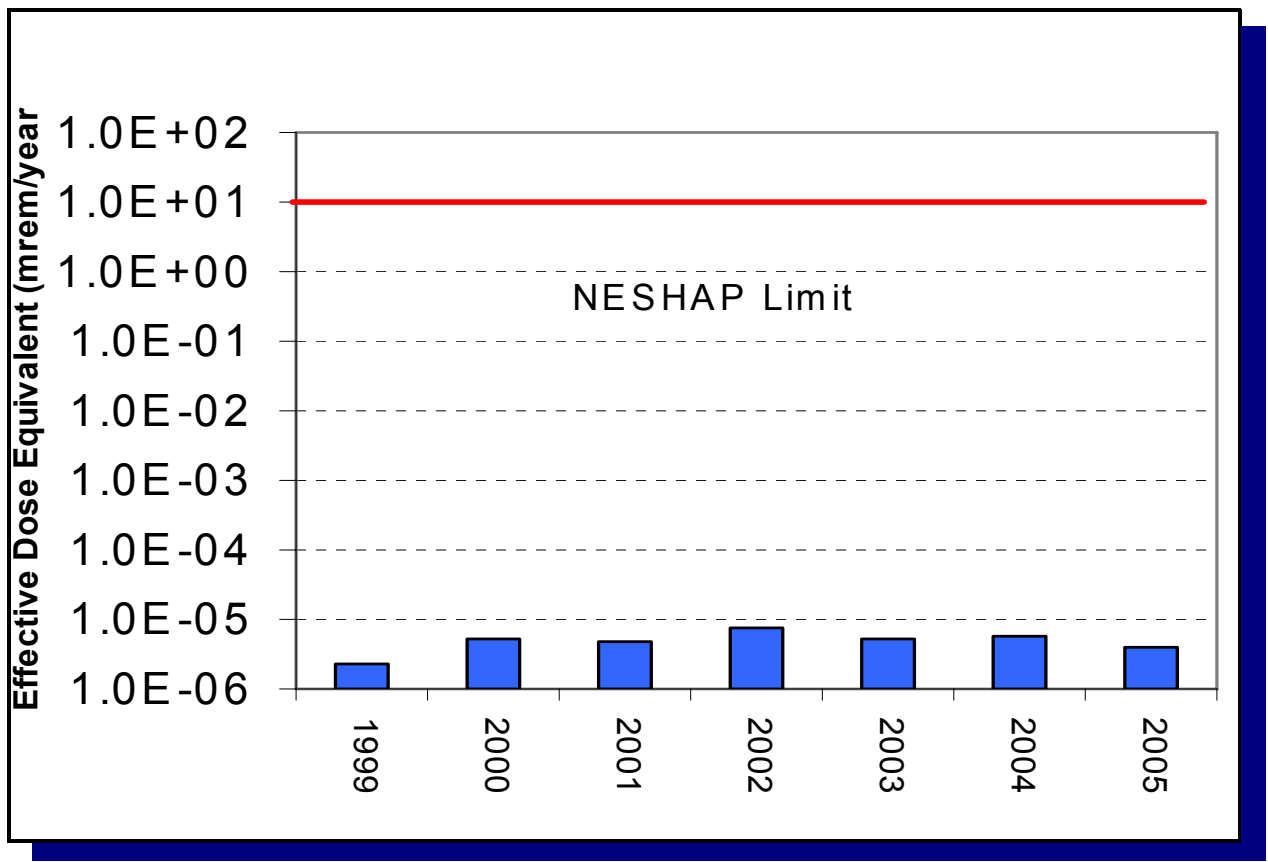

Figure 4.7 - WIPP Effective Dose Equivalent to the Off-Site Maximally Exposed Individual

Table 4.27 - Comparison of Effective Dose Equivalents to EPA
\begin{tabular}{|c|c|c|}
\hline Limit of $\mathbf{1 0}$ mrem/year per $\mathbf{4 0}$ CFR $\mathbf{6 1 . 9 2}$ \\
\hline Year & Annual Dose (mrem/yr) & Percent of EPA Limit \\
\hline 1999 & $2.23 \mathrm{E}-06$ & 22.3 millionth \\
\hline 2000 & $5.18 \mathrm{E}-06$ & 51.8 millionth \\
\hline 2001 & $4.96 \mathrm{E}-06$ & 49.6 millionth \\
\hline 2002 & $7.61 \mathrm{E}-06$ & 76.1 millionth \\
\hline 2003 & $5.43 \mathrm{E}-06$ & 54.3 millionth \\
\hline 2004 & $5.69 \mathrm{E}-06$ & 56.9 millionth \\
\hline 2005 & $3.85 \mathrm{E}-06$ & 38.5 millionth \\
\hline
\end{tabular}

\section{Environmental Monitoring}

Radionuclide concentrations observed in environmental monitoring were extremely small and comparable to radiological baseline levels. Appendix $\mathrm{H}$ contains graphs comparing detected concentrations of radionuclides to their respective baseline values. In cases where the radionuclide concentrations slightly exceeded baseline levels (uranium isotopes and ${ }^{40} \mathrm{~K}$ in some samples), these differences are most likely due to natural spatial variability and they are so far below the regulatory limit that they are nonimpactive. 
Waste Isolation Pilot Plant Annual Site Environmental Report for 2005

DOE/WIPP-06-2225

This page intentionally left blank 


\section{CHAPTER 5 - ENVIRONMENTAL NONRADIOLOGICAL PROGRAM INFORMATION}

Nonradiological programs at WIPP include land management, meteorological monitoring, volatile organic compound (VOC) monitoring, seismic monitoring, certain aspects of liquid effluent, and groundwater monitoring. VOC monitoring is performed to comply with the provisions of the WIPP Hazardous Waste Facility Permit. Surface water monitoring is performed in accordance with the WIPP Discharge Permit (DP-831). Radiological groundwater monitoring is discussed in Chapter 4.

\subsection{Principal Functions of Nonradiological Sampling}

The principal functions of the nonradiological environmental surveillance program are to:

- $\quad$ Assess the impacts of WIPP operations on the surrounding ecosystem;

- Monitor ecological conditions in the Los Medaños region;

- $\quad$ Provide environmental data which are important to the mission of the WIPP project, but which have not or will not be acquired by other programs; and

- $\quad$ Comply with applicable commitments identified with existing agreements (e.g., BLM/DOE MOU and Interagency Agreements).

\subsection{Land Management Programs}

On October 30, 1992, the WIPP LWA was approved by Congress. This act transferred the responsibility for the management of the WLWA from the Secretary of the Interior to the Secretary of Energy. In accordance with Sections 3(a)(1) and (3) of the act, these lands:

... are withdrawn from all forms of entry, appropriation, and disposal under the public land laws ... are reserved for the use of the Secretary ... for the construction, experimentation, operation, repair and maintenance, disposal, shutdown, monitoring, decommissioning, and other authorized activities associated with the purposes of WIPP as set forth in Section 213 of the Department of Energy National Security and Military Application of the Nuclear Energy Authorization Act of 1980 (Pub. L. 96-164; 93 Stat. 1259, 1265), and this Act.

The DOE developed the LMP as required by Section 4 of the WIPP LWA. The LMP identifies resource values, promotes multiple-use management, and identifies long-term goals for the management of WIPP lands until the culmination of the decommissioning phase. The LMP was developed in consultation and cooperation with the BLM and the state of New Mexico. Changes or amendments to the plan require the involvement of the BLM, the state of New Mexico, and affected stakeholders. 
The LMP encourages direct communication among stakeholders, including federal and state agencies, involved in managing the resources within, or activities impacting the areas adjacent to, the WLWA. It sets forth cooperative arrangements and protocols for addressing WIPP-related land management actions. Commitments contained in current permits, agreements, or concurrent Memoranda of Understanding (MOUs) with other agencies will be respected when addressing and evaluating land use management activities and future amendments that affect the management of WIPP lands.

\subsubsection{Land Use Requests}

Parties who wish to conduct activities that may impact lands under the jurisdiction of WIPP, but outside the Property Protection Area, are required by the LMP to prepare a Land Use Request (LUR). A LUR consists of a narrative description of the project, a completed environmental review, and a map depicting the location of the proposed activity. The LUR, and associated NEPA documents, are used to determine if applicable regulatory requirements have been met prior to the approval of a proposed project. A LUR may be submitted to the Land Use Coordinator by any WIPP organization or outside entity wishing to complete any construction, right-of-way, pipeline easement, or similar action within the WLWA or on lands used in the operation of WIPP, under the jurisdiction of the DOE. During 2005, 14 LURs were submitted for review and approval; all met applicable criteria and were approved.

\subsubsection{Wildlife Population Monitoring}

In 1995, the U.S. Department of the Interior Fish and Wildlife Service (USFWS), provided an updated list of threatened and endangered species for Eddy and Lea Counties, New Mexico. Included were 18 species that may be present on WIPP lands. A comprehensive evaluation in support of the SEIS-II (DOE/EIS-0026-S-2) was conducted in 1996 to determine the presence or absence of threatened or endangered species in the vicinity of WIPP and WIPP's effect on these species. Results indicated that activities associated with the operation of WIPP had no impact on any threatened or endangered species.

WIPP continues to consider resident species when planning activities that may impact their habitat in accordance with the DOE/BLM MOU, the Joint Powers Agreement with the state of New Mexico, and 50 CFR Part 17, "Endangered and Threatened Plants and Wildlife." One example of considering resident species has included protecting the Lesser Prairie Chicken (a candidate for listing under the ESA) and its habitat in accordance with BLM guidance. The Lesser Prairie Chicken has been known to inhabit the WIPP Land Withdrawal Area and areas impacted by WIPP activities.

\subsubsection{Reclamation of Disturbed Lands}

Reclamation serves to mitigate the effects of WIPP-related activities on affected plant and animal communities. The objective of the reclamation program is to reclaim lands used in the operation of WIPP that are no longer commissioned for WIPP operations. 
Reclamation activities are intended to reduce soil erosion, increase the rate of plant colonization and succession, and provide habitat for wildlife in disturbed areas.

WIPP follows a reclamation program and a long-range reclamation plan in accordance with the LMP and specified permit conditions. As locations are identified for reclamation, WIPP personnel reclaim these areas by using the best acceptable reclamation practices. Seed mixes used reflect those species indigenous to the area with priority given to those plant species which are conducive to soil stabilization, wildlife, and livestock needs. Additionally, special seed mixes identified by the BLM are used where necessary to preserve the habitat of the Lesser Prairie Chicken.

\subsubsection{Oil and Gas Surveillance}

Oil and gas activities within $1.6 \mathrm{~km}(1 \mathrm{mi})$ of the WIPP boundary are routinely monitored in accordance with the LMP to identify new activities associated with oil and gas exploration and production, including:

$\begin{array}{ll}- & \text { Drilling } \\ \text { - } & \text { Survey staking } \\ \text { - } & \text { Geophysical exploration } \\ \text { - } & \text { Pipeline construction } \\ \text { - } & \text { Changes in well status } \\ \text { Anomalous occurrences (e.g., leaks, spills, accidents, etc.) }\end{array}$

During 2005, WIPP surveillance teams conducted 24 scheduled surveillances and more than 100 field inspections.

Field personnel drove onto approximately 104 well locations to inspect for conditions that may compromise WIPP properties. Surveillances were conducted as needed, usually in response to reports of flow line leaks. During 2005, no major leaks or occurrences were observed. Minor incidents, such as small leaks, were encountered and courtesy notifications were provided to the well operators.

Proposed new well locations, staked within one mile of the WIPP site, are field verified. This ensures that the proposed location is of sufficient distance from the WIPP boundary to protect the WIPP site from potential trespass. If a well is within $330 \mathrm{ft}$ of the WLWA, the driller is required to submit daily deviation surveys to the WIPP Land Use Coordinator to assess the horizontal drift of the well bore during drilling. During 2005, daily logs were transmitted to WIPP for six new wells. Deviation calculations showed that there were no trespass conditions.

\subsection{Meteorological Monitoring}

The WIPP meteorological station is located $600 \mathrm{~m}(1,970 \mathrm{ft})$ northeast of the Waste Handling Building. The main function of the station is to provide data for atmospheric dispersion modeling. The station measures and records wind speed, wind direction, 


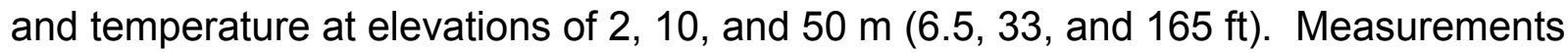
taken at $10 \mathrm{~m}$ (33 ft) are provided in this report. The station also records ground-level measurements of barometric pressure, relative humidity, precipitation, and solar radiation.

\subsubsection{Climatic Data}

The precipitation at the WIPP site for 2005 was $417.4 \mathrm{~mm}$ (16.4 in.). Figure 5.1 displays the monthly precipitation at WIPP.

January 1, 2005 to December 31, 2005

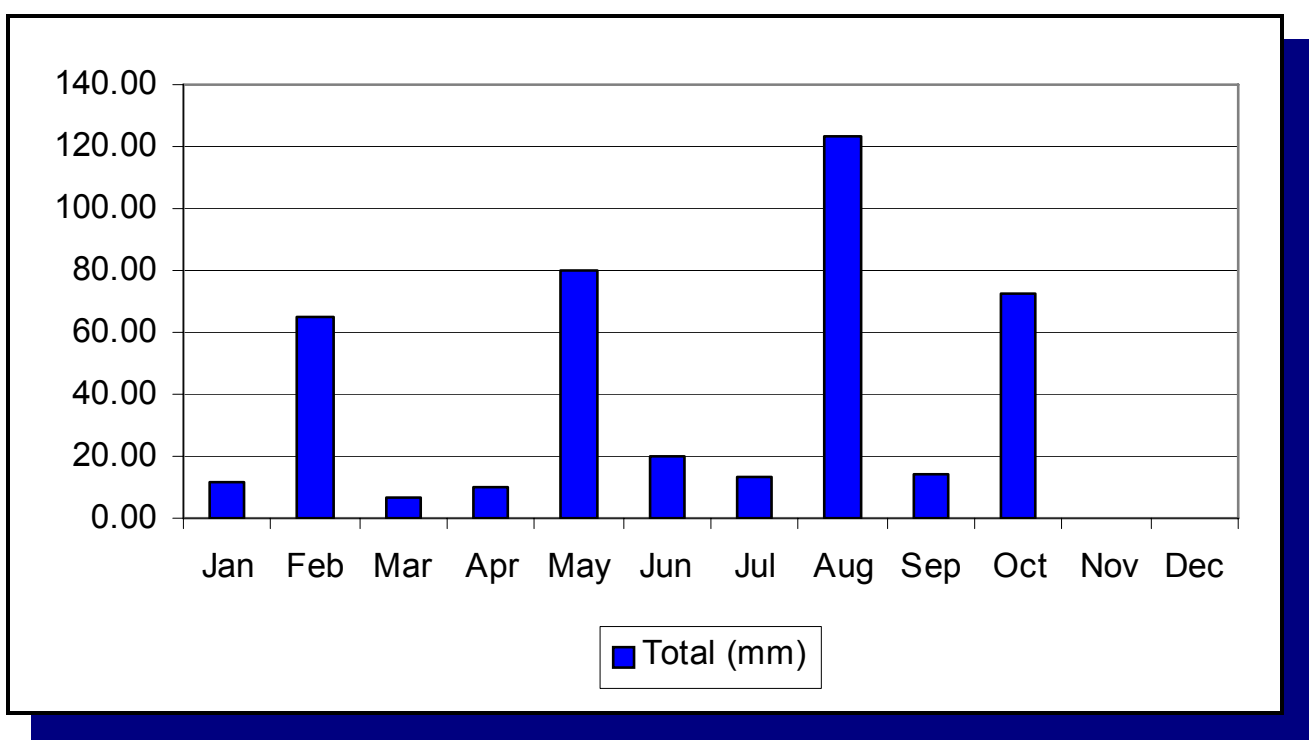

Figure 5.1 - 2005 Precipitation at WIPP

\begin{tabular}{cr} 
Month & \multicolumn{1}{r}{$\begin{array}{r}\text { Total } \\
(\mathbf{m m})\end{array}$} \\
Jan & 11.94 \\
Feb & 65.02 \\
Mar & 6.60 \\
Apr & 9.65 \\
May & 80.33 \\
Jun & 20.06 \\
Jul & 13.21 \\
Aug & 123.45 \\
Sep & 14.22 \\
Oct & 72.89 \\
Nov & 0.00 \\
Dec & 0.00
\end{tabular}


The mean temperature at the WIPP site in 2005 was $16.8^{\circ} \mathrm{C}\left(62.2^{\circ} \mathrm{F}\right)$. The mean monthly temperatures for the WIPP area ranged from $27.0^{\circ} \mathrm{C}\left(80.6^{\circ} \mathrm{F}\right)$ during July to $8.2^{\circ} \mathrm{C}\left(46.8^{\circ} \mathrm{F}\right)$ in December. The lowest recorded temperature was $-13.0^{\circ} \mathrm{C}\left(8.6^{\circ} \mathrm{F}\right)$ in December. The maximum recorded temperature was $39.8^{\circ} \mathrm{C}\left(103.6^{\circ} \mathrm{F}\right)$ in July. Monthly temperatures are illustrated in Figures 5.2, 5.3, and 5.4.

Temperature Report - Highs

January 1, 2005, to December 31, 2005, Elevation 10.0 Meters

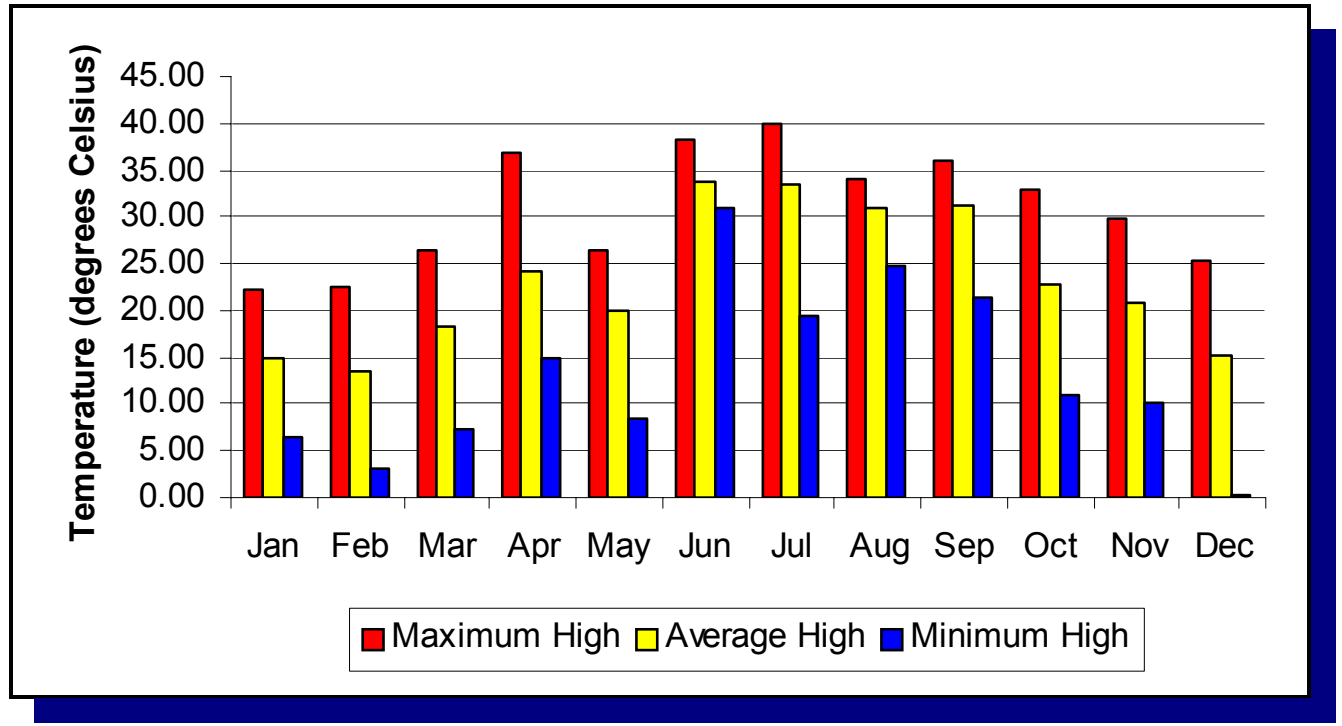

Figure 5.2 - 2005 High Temperatures at WIPP

$\begin{array}{lccc}\text { Month } & \begin{array}{c}\text { Maximum } \\ \text { High } \\ 22.23^{\circ} \mathrm{C}\end{array} & \begin{array}{c}\text { Average } \\ \text { High } \\ 14.83^{\circ} \mathrm{C}\end{array} & \begin{array}{c}\text { Minimum } \\ \text { High }\end{array} \\ \text { Jan } & 22.51^{\circ} \mathrm{C} \\ \text { Feb } & 22.39^{\circ} \mathrm{C} & 13.62^{\circ} \mathrm{C} & 3.11^{\circ} \mathrm{C} \\ \text { Mar } & 26.46^{\circ} \mathrm{C} & 18.21^{\circ} \mathrm{C} & 7.18^{\circ} \mathrm{C} \\ \text { Apr } & 36.71^{\circ} \mathrm{C} & 24.30^{\circ} \mathrm{C} & 14.81^{\circ} \mathrm{C} \\ \text { May } & 26.51^{\circ} \mathrm{C} & 19.92^{\circ} \mathrm{C} & 8.32^{\circ} \mathrm{C} \\ \text { Jun } & 38.15^{\circ} \mathrm{C} & 33.78^{\circ} \mathrm{C} & 30.93^{\circ} \mathrm{C} \\ \text { Jul } & 39.83^{\circ} \mathrm{C} & 33.43^{\circ} \mathrm{C} & 19.48^{\circ} \mathrm{C} \\ \text { Aug } & 33.96^{\circ} \mathrm{C} & 31.00^{\circ} \mathrm{C} & 24.86^{\circ} \mathrm{C} \\ \text { Sep } & 35.94^{\circ} \mathrm{C} & 31.23^{\circ} \mathrm{C} & 21.34^{\circ} \mathrm{C} \\ \text { Oct } & 32.99^{\circ} \mathrm{C} & 22.77^{\circ} \mathrm{C} & 10.87^{\circ} \mathrm{C} \\ \text { Nov } & 29.69^{\circ} \mathrm{C} & 20.84^{\circ} \mathrm{C} & 10.20^{\circ} \mathrm{C} \\ \text { Dec } & 25.37^{\circ} \mathrm{C} & 15.05^{\circ} \mathrm{C} & 0.29^{\circ} \mathrm{C}\end{array}$


Temperature Report - Averages

January 1, 2005, to December 31, 2005, Elevation 10.0 Meters

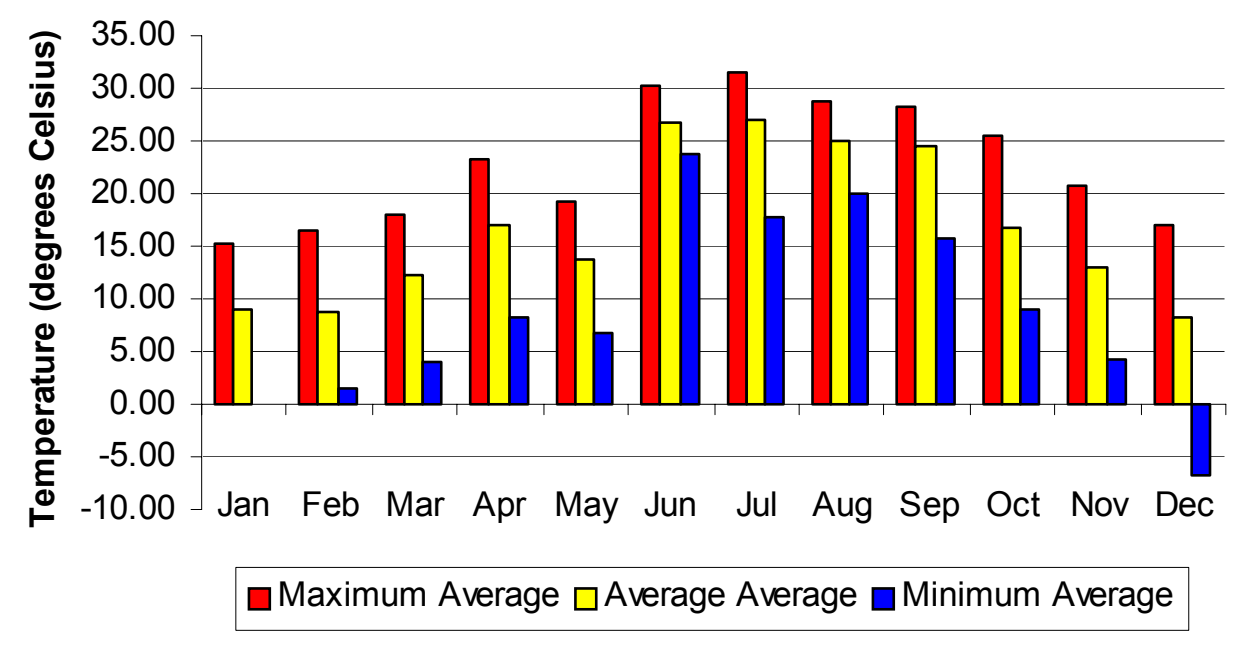

Figure 5.3 - 2005 Average Temperatures at WIPP

$\begin{array}{lccc}\text { Month } & \begin{array}{c}\text { Maximum } \\ \text { Average }\end{array} & \begin{array}{c}\text { Average } \\ \text { Average }\end{array} & \begin{array}{c}\text { Minimum } \\ \text { Average }\end{array} \\ \text { Jan } & 15.18^{\circ} \mathrm{C} & 9.02^{\circ} \mathrm{C} & 0.10^{\circ} \mathrm{C} \\ \text { Feb } & 16.55^{\circ} \mathrm{C} & 8.66^{\circ} \mathrm{C} & 1.40^{\circ} \mathrm{C} \\ \text { Mar } & 17.88^{\circ} \mathrm{C} & 12.25^{\circ} \mathrm{C} & 4.03^{\circ} \mathrm{C} \\ \text { Apr } & 23.30^{\circ} \mathrm{C} & 17.03^{\circ} \mathrm{C} & 8.19^{\circ} \mathrm{C} \\ \text { May } & 19.13^{\circ} \mathrm{C} & 13.63^{\circ} \mathrm{C} & 6.82^{\circ} \mathrm{C} \\ \text { Jun } & 30.15^{\circ} \mathrm{C} & 26.71{ }^{\circ} \mathrm{C} & 23.75^{\circ} \mathrm{C} \\ \text { Jul } & 31.44^{\circ} \mathrm{C} & 27.02^{\circ} \mathrm{C} & 17.81^{\circ} \mathrm{C} \\ \text { Aug } & 28.67^{\circ} \mathrm{C} & 24.93^{\circ} \mathrm{C} & 19.94^{\circ} \mathrm{C} \\ \text { Sep } & 28.23^{\circ} \mathrm{C} & 24.49^{\circ} \mathrm{C} & 15.77^{\circ} \mathrm{C} \\ \text { Oct } & 25.61^{\circ} \mathrm{C} & 16.85^{\circ} \mathrm{C} & 8.92^{\circ} \mathrm{C} \\ \text { Nov } & 20.64^{\circ} \mathrm{C} & 13.11^{\circ} \mathrm{C} & 4.36^{\circ} \mathrm{C} \\ \text { Dec } & 17.09^{\circ} \mathrm{C} & 8.16^{\circ} \mathrm{C} & -6.84^{\circ} \mathrm{C}\end{array}$


Temperature Report - Lows

January 1, 2005, to December 31, 2005, Elevation 10.0 meters

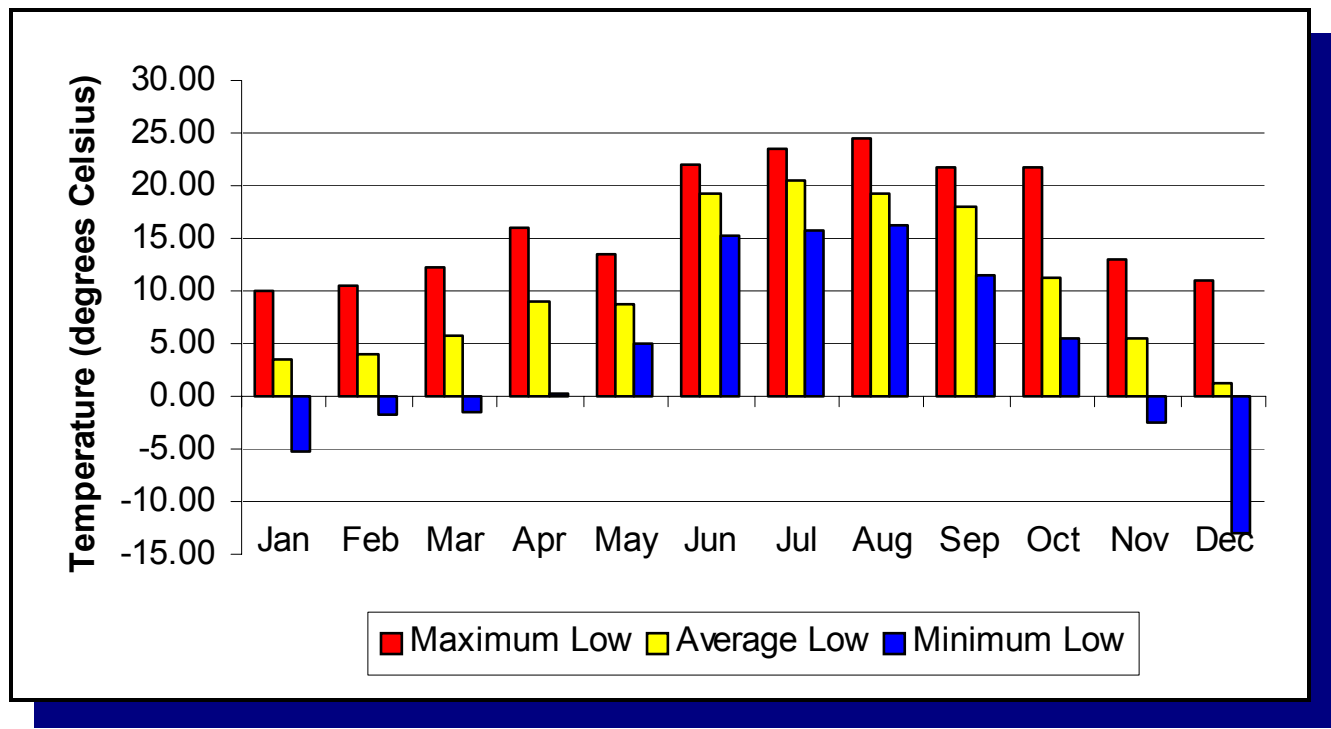

Figure 5.4 - 2005 Low Temperatures at WIPP

\begin{tabular}{lccc} 
Month & $\begin{array}{c}\text { Maximum } \\
\text { Low } \\
\text { Jan }\end{array}$ & $\begin{array}{c}\text { Average } \\
\text { Low }\end{array}$ & $\begin{array}{c}\text { Minimum } \\
\text { Low }\end{array}$ \\
Feb & $10.51^{\circ} \mathrm{C}$ & $3.39^{\circ} \mathrm{C}$ & $-5.25^{\circ} \mathrm{C}$ \\
Mar & $3.95^{\circ} \mathrm{C}$ & $-1.67^{\circ} \mathrm{C}$ \\
Apr & $12.31^{\circ} \mathrm{C}$ & $5.70^{\circ} \mathrm{C}$ & $-1.44^{\circ} \mathrm{C}$ \\
May & $16.07^{\circ} \mathrm{C}$ & $8.95^{\circ} \mathrm{C}$ & $0.35^{\circ} \mathrm{C}$ \\
Jun & $13.39^{\circ} \mathrm{C}$ & $8.72^{\circ} \mathrm{C}$ & $5.05^{\circ} \mathrm{C}$ \\
Jul & $21.91^{\circ} \mathrm{C}$ & $19.29^{\circ} \mathrm{C}$ & $15.15^{\circ} \mathrm{C}$ \\
Aug & $23.44^{\circ} \mathrm{C}$ & $20.45^{\circ} \mathrm{C}$ & $15.86^{\circ} \mathrm{C}$ \\
Sep & $24.43^{\circ} \mathrm{C}$ & $19.31^{\circ} \mathrm{C}$ & $16.31^{\circ} \mathrm{C}$ \\
Oct & $21.81^{\circ} \mathrm{C}$ & $18.01^{\circ} \mathrm{C}$ & $11.44^{\circ} \mathrm{C}$ \\
Nov & $21.64^{\circ} \mathrm{C}$ & $11.37^{\circ} \mathrm{C}$ & $5.53^{\circ} \mathrm{C}$ \\
Dec & $13.05^{\circ} \mathrm{C}$ & $5.57^{\circ} \mathrm{C}$ & $-2.54^{\circ} \mathrm{C}$ \\
\hline & $11.04^{\circ} \mathrm{C}$ & $1.32^{\circ} \mathrm{C}$ & $-13.03^{\circ} \mathrm{C}$
\end{tabular}

\subsubsection{Wind Direction and Wind Speed}

Winds in the WIPP area are predominantly from the southeast. In 2005, wind speed measured at the $10-\mathrm{m}$ (33-ft) level was calm (less than 0.5 meters per second $[\mathrm{m} / \mathrm{s}]$ ) (1.1 miles per hour [mph]) approximately one percent of the time. Winds of 3.71 to $6.30 \mathrm{~m} / \mathrm{s}$ (8.30 to $14.09 \mathrm{mph}$ ) were the most prevalent over 2005 , occurring 35.8 percent of the time. Figure 5.5 displays the annual wind data at WIPP for 2005. 


\section{Wind Speed Report (Meters/Second)}

January 1, 2005, to December 31, 2005, Elevation 10.0 Meters

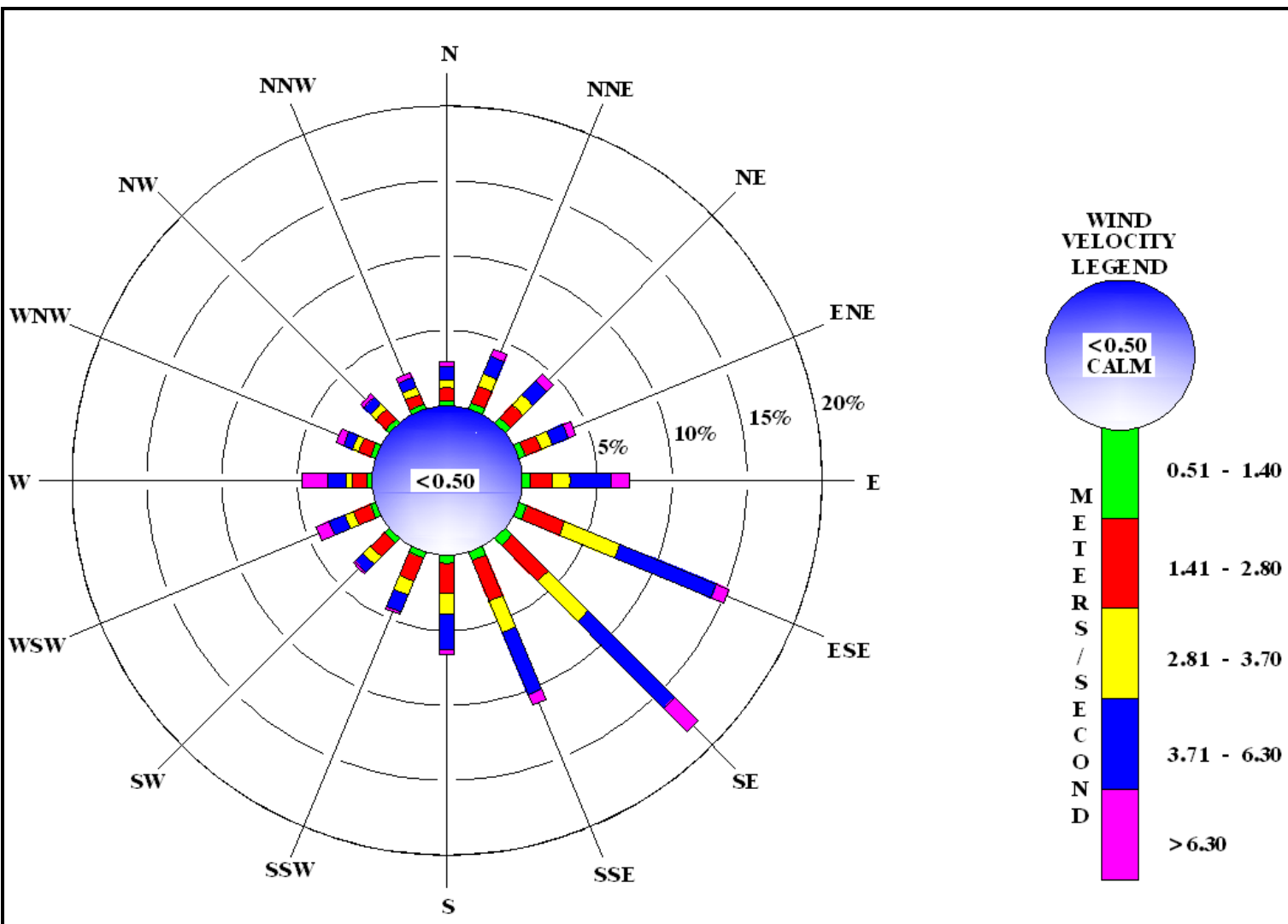

Figure 5.5 - 2004 Wind Speed Direction at WIPP

\begin{tabular}{|c|c|c|c|c|c|c|c|}
\hline Wind Direction & $0.0-.50$ & $0.51-1.40$ & $1.41-2.8$ & 2.81-3.70 & $3.71-6.30$ & $>6.30$ & $\begin{array}{c}\text { Total Percent } \\
\text { Occurrence by } \\
\text { Direction }\end{array}$ \\
\hline $\bar{E}$ & 0.13 & 0.55 & 1.45 & 1.20 & 2.73 & 1.13 & 7.18 \\
\hline ENE & 0.07 & 0.47 & 1.13 & 0.79 & 1.16 & 0.56 & 4.17 \\
\hline NE & 0.08 & 0.47 & 1.20 & 0.93 & 1.31 & 0.63 & 4.62 \\
\hline NNE & 0.05 & 0.41 & 1.21 & 0.91 & 1.28 & 0.51 & 4.36 \\
\hline$N$ & 0.03 & 0.31 & 0.87 & 0.55 & 0.87 & 0.36 & 2.99 \\
\hline NNW & 0.1 & 0.30 & 0.74 & 0.49 & 0.69 & 0.36 & 2.68 \\
\hline NW & 0.07 & 0.31 & 0.93 & 0.53 & 0.62 & 0.30 & 2.76 \\
\hline WNW & 0.07 & 0.35 & 0.83 & 0.47 & 0.64 & 0.52 & 2.88 \\
\hline W & 0.02 & 0.37 & 0.93 & 0.46 & 1.22 & 1.73 & 4.73 \\
\hline WSW & 0.04 & 0.37 & 1.18 & 0.63 & 1.33 & 0.96 & 4.52 \\
\hline SW & 0.04 & 0.40 & 1.33 & 0.69 & 0.74 & 0.16 & 3.37 \\
\hline SSW & 0.06 & 0.38 & 1.70 & 1.00 & 1.24 & 0.16 & 4.53 \\
\hline S & 0.05 & 0.54 & 2.02 & 1.37 & 2.38 & 0.29 & 6.64 \\
\hline SSE & 0.05 & 0.61 & 2.92 & 2.26 & 4.50 & 0.73 & 11.06 \\
\hline SE & 0.1 & 0.65 & 3.39 & 3.76 & 8.16 & 2.22 & 18.28 \\
\hline ESE & 0.08 & 0.59 & 2.73 & 3.98 & 6.94 & 0.92 & 15.23 \\
\hline & $1.02 \%$ & $7.07 \%$ & $24.55 \%$ & $20.01 \%$ & $35.81 \%$ & $11.55 \%$ & \\
\hline
\end{tabular}




\subsection{Volatile Organic Compound Monitoring}

VOC monitoring was implemented on April 21, 1997, in accordance with WP12-VC.01, Confirmatory Volatile Organic Compound Monitoring Program. This program is a requirement of the HWFP Condition IV.D and Attachment N. VOC monitoring is performed to verify that VOCs emitted by the waste are within the concentration limits specified by the HWFP.

Nine target compounds, which contribute approximately 99 percent of the calculated human health risks from RCRA constituents, were chosen for monitoring. These target compounds are shown in Table 5.1.

Sampling for target compounds is performed at two air monitoring stations. The stations are identified as VOC-A, located downstream from hazardous waste disposal unit Panel 1 in Drift E300, and VOC-B, located upstream from the active panel. In January of 2005, VOC-B was located in Drift S2520 as Panel 2 was the active panel. In April of 2005, Panel 3 became the active panel. VOC-B was moved to Drift S3080, upstream from Panel 3. As waste is placed in new panels, VOC-B will be relocated to ensure that it samples underground air before it passes the waste panels. The location of VOC-A is not anticipated to change.

Target compounds found in VOC-B represent background concentrations found in the underground. The VOC concentrations measured at this location are the sum of background concentrations entering the mine through the air intake shaft plus additional concentrations contributed by facility operations upstream of the waste panels. Differences measured between the two stations represent any VOC contributions from the waste panels. Any positive concentration differences in the annual averages between the two stations must be less than the concentrations of concern listed in Attachment $\mathrm{N}$ of the HWFP (Table 5.1).

\begin{tabular}{lc}
\hline $\begin{array}{c}\text { Table 5.1 - Concentrations of Concern for Volatile Organic Compounds, } \\
\text { from Attachment N of the HWFP (No. NM4890139088-TSDF) }\end{array}$ \\
\hline \multicolumn{1}{c}{ Compound } & Concentration of Concern ppbv $\mathbf{~}^{\mathbf{a}}$ \\
\hline 1,1,1-Trichloroethane & 590 \\
1,1,2,2-Tetrachloroethane & 50 \\
1,1-Dichloroethylene & 100 \\
1,2-Dichloroethane & 45 \\
Carbon tetrachloride & 165 \\
Chlorobenzene & 220 \\
Chloroform & 180 \\
Methylene chloride & 1930 \\
Toluene & 190 \\
\hline
\end{tabular}

${ }^{a}$ Parts per billion by volume

VOC sampling reported in this section was performed using guidance included in Compendium Method TO-14A, Compendium Methods for the Determination of Toxic 
Organic Compounds in Ambient Air (EPA, 1999). The samples were analyzed using gas chromatography/mass spectrometry under an established QA/QC program. Laboratory analytical procedures were developed based on the concepts contained in both TO-14A and the draft EPA Contract Laboratory Program Volatile Organics Analysis of Ambient Air in Canisters (EPA, 1994).

The routine method reporting limits (MRLs) or maximum concentrations detected (MCDs) are shown in Table 5.2. For dilution factors greater than one, the $5.0 \mathrm{ppbv}$ and $2.0 \mathrm{ppbv}$ values are multiplied by the dilution factor to calculate the MRLs for the diluted sample. It should be noted that the MRLs are between 22 times and 386 times lower than the respective concentrations of concern for the nine target compounds.

The results of $2005 \mathrm{VOC}$ monitoring indicated an increase in the frequency and concentration of carbon tetrachloride, toluene, and 1,1,1-trichloroethane in air downstream of Panel 1. Although the sample results for 2005 showed an increase in VOC detections, all VOC sample results were well below the concentrations of concern listed in Table 5.1.

\begin{tabular}{lcc}
\hline \multicolumn{1}{c}{ Table 5.2 - Volatile Organic Compound MRLs and MCD } \\
\hline \multicolumn{1}{c}{ Compound } & $\begin{array}{c}\text { MRL } \\
\text { (ppbv) }\end{array}$ & $\begin{array}{c}\text { MCD } \\
\text { (ppbv) }\end{array}$ \\
\hline 1,1,1-Trichloroethane & 5 & 28.99 \\
1,1,2,2-Tetrachloroethane & 2 & $<$ MRL \\
1,1-Dichloroethylene & 5 & $<$ MRL \\
1,2-Dichloroethane & 2 & $<$ MRL \\
Carbon Tetrachloride & 2 & 51.3 \\
Chlorobenzene & 2 & $<$ MRL \\
Chloroform & 2 & $<$ MRL \\
Methylene chloride & 5 & $<$ MRL \\
Toluene & 5 & 13.52 \\
\hline
\end{tabular}

${ }^{\mathrm{a}}$ Parts per billion by volume 
Figure 5.6 contains a comparison of the values shown in Tables 5.1 and 5.2; COCs, MRLs, and MCDs.

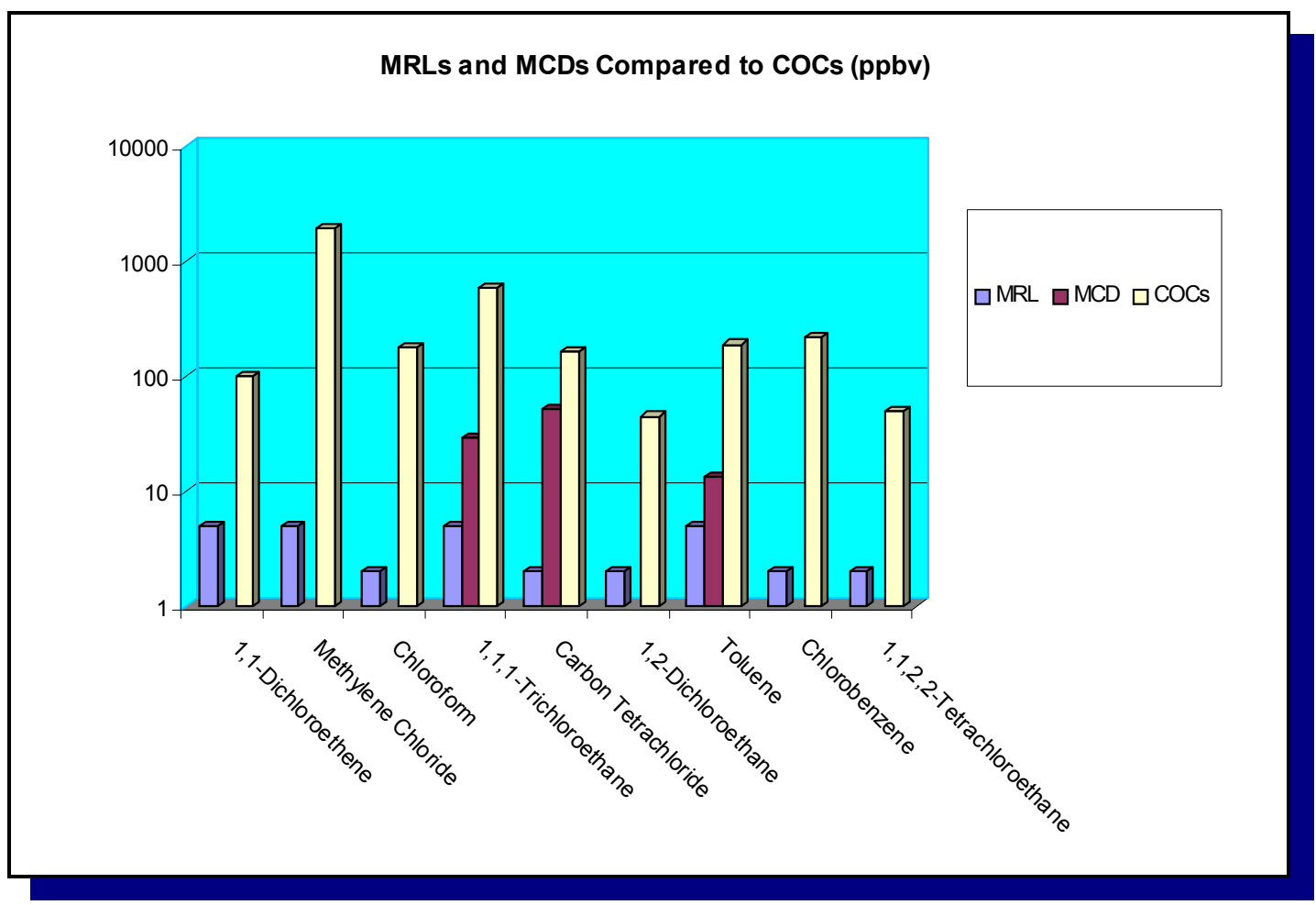

Figure 5.6 - Comparison of VOC MRLs and MCDs to Concentrations of Concern

\subsection{Seismic Activity}

WIPP is located about $100 \mathrm{~km}$ (62 mi) east of the western margin of the Permian Basin. The geologic structure and tectonic pattern of the Permian Basin are chiefly the result of large-scale subsidence and uplift during the Paleozoic era. The broad basin is divided into a series of subbasins which passed through their last stage of significant subsidence during the Late Permian Age. The Delaware subbasin occupies the southwestern portion of the Permian Basin and hosts the WIPP site. It is bordered by the Roosevelt Uplift to the north, the Marathon Thrust Belt to the south, the Central (Permian) Basin Platform to the east, and the Sierra Diablo Platform and Guadalupe and Sacramento Mountains to the west. The Delaware Basin contains a thick sequence of evaporite layers.

All major tectonic elements of the Delaware Basin were essentially formed before deposition of the Permian evaporites, and the region has been relatively stable since then. Deep-seated faults are rare, except along the western and eastern basin margins, and there is no evidence of young, deep-seated faults inside the basin. Researchers suspect that some low-magnitude earthquakes may result from secondary oil recovery (water flooding) because of their shallow depths. 
Currently, seismicity within $300 \mathrm{~km}$ (186 mi) of the WIPP site is being monitored by the New Mexico Institute of Mining and Technology (NMIMT) using data from a nine-station network approximately centered on the site (Figure 5.7). Station signals are transmitted to the NMIMT Seismological Observatory in Socorro. When appropriate, readings from the WIPP network stations are combined with readings from an additional NMIMT network in the central Rio Grande Rift. Occasionally, data are also exchanged with the University of Texas at El Paso and Texas Tech University in Lubbock, both of which operate stations in West Texas.

The mean operational efficiency of the WIPP seismic monitoring stations during 2005 was approximately 89.8 percent. From January 1 through December 31, 2005, locations for 203 seismic events were recorded within $300 \mathrm{~km}$ (186 mi) of WIPP. These data included origin times, epicenter coordinates, and magnitudes. The strongest recorded event (magnitude 3.8) occurred on December 19, 2005, and was located approximately $85 \mathrm{~km}(53 \mathrm{mi})$ northwest of the site. The closest event to the site was located approximately $46 \mathrm{~km}(29 \mathrm{mi})$ northwest and had a magnitude of 0.9 . These events had no effect on WIPP structures.

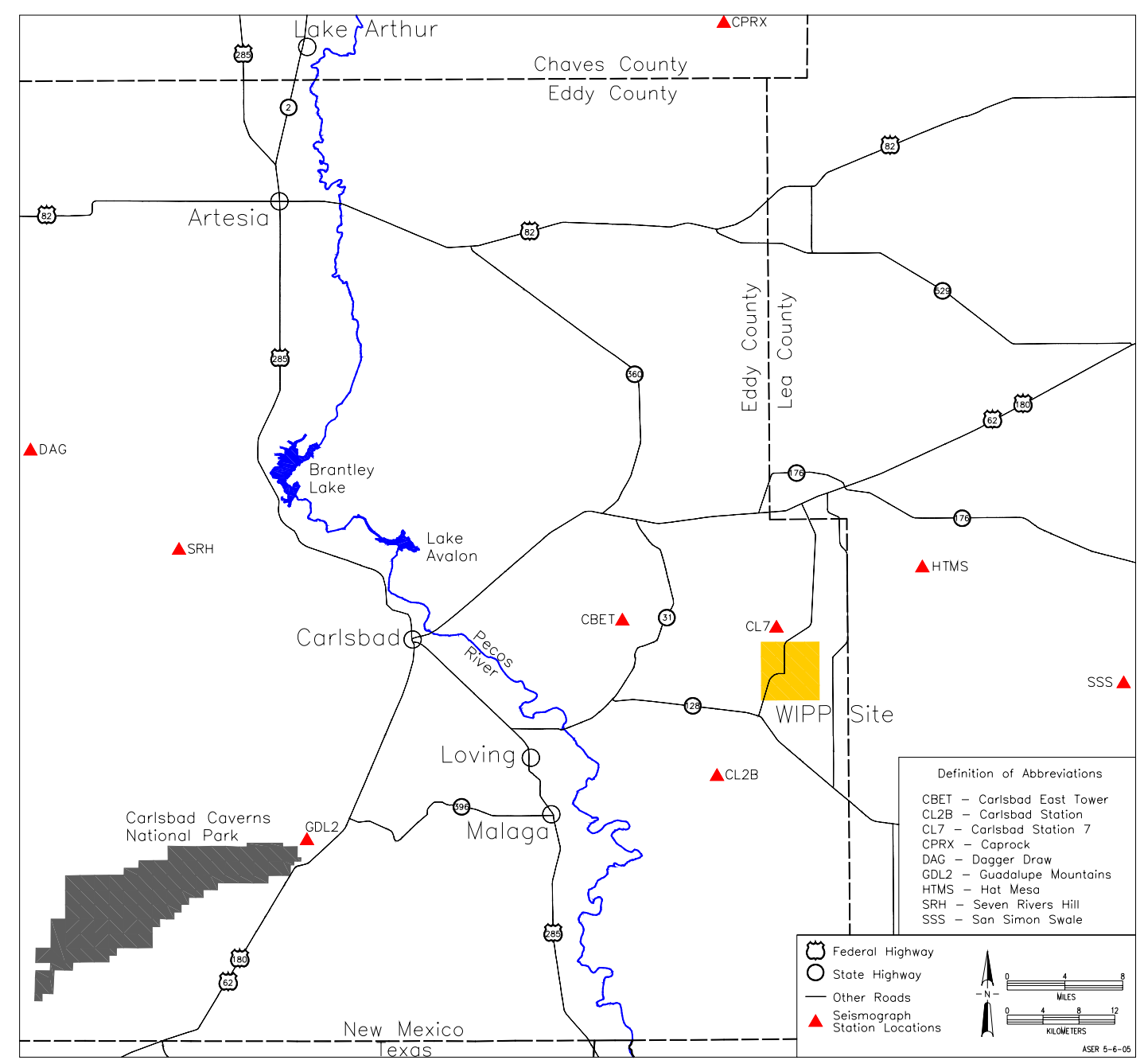

Figure 5.7 - WIPP Seismograph Station Locations 


\subsection{Liquid Effluent Monitoring}

The NMED Ground and Surface Water Protection regulations set forth in 20.6.2 NMAC regulate discharges that could impact surface water or groundwater. WIPP compliance with the Ground and Surface Water Protection Regulations is discussed in Chapter 2, Section 2.2.6. The WIPP site has no discharges that could impact surface water. WIPP does have a discharge permit, DP-831, for discharges to the sewage lagoons and the $\mathrm{H}-19$ Evaporation Pond, and for the control of subsurface infiltration from active and inactive salt piles.

The WIPP sewage system consists of lined ponds that allow for the evaporation of liquids. The sewage treatment facility is permitted for the disposal of up to $87,064 \mathrm{~L}$ (23,000 gallons) per day of sewage effluent and up to 7,570 liters (2,000 gallons) of nonhazardous brine water to the north evaporation pond.

The H-19 Evaporation Pond is permitted for the treatment of up to $30,283 \mathrm{~L}$ $(8,000$ gallons) per day of nonhazardous brine waters from groundwater monitoring and observation wells, mine dewatering and condensate collected from the mine ventilation system. The permit also authorizes the discharge of up to $378 \mathrm{~L}$ (100 gallons) of neutralized acid waste; however, neutralized acid waste is no longer generated at WIPP.

A discharge permit modification approved on December 22, 2003, addressed infiltration of storm water containing high TDS to the subsurface from a 16-acre salt pile accumulated from mining. In accordance with the discharge permit modification, a new salt storage area with a 60-mil synthetic liner and an associated double-lined evaporation pond with leak detection was constructed to contain and evaporate salt contact storm water runoff. Additionally, the salt pile evaporation pond and three storm water evaporation ponds were lined with 60-mil high-density polyethylene liners to collect storm water runoff for evaporation and minimize the infiltration of storm water.

Discharge monitoring reports are submitted semiannually to the NMED to demonstrate compliance with the inspection, monitoring, and reporting requirements identified in the discharge permit. The discharge permit requires semiannual sampling of the sewage lagoons and the $\mathrm{H}-19$ Evaporation Pond and annual sampling of the storm water infiltration control ponds. There are no regulatory limits associated with the analytes. Detection limits vary with each analytical event based on the required sample dilutions. Analytical data from the discharge monitoring reports are summarized in Tables 5.3 through 5.5. Subsurface shallow water monitoring results are outlined in Chapter 6, Section 6.5. 


\section{Waste Isolation Pilot Plant Annual Site Environmental Report for 2005 DOE/WIPP-06-2225}

Table 5.3 - Sewage Lagoon and H-19 Semiannual Analytical Results for January 1 through June 30, 2005

\begin{tabular}{|c|c|c|c|c|c|c|c|c|}
\hline \multirow{2}{*}{\begin{tabular}{|c|} 
Analyte \\
Nitrate $(\mathrm{mg} / \mathrm{L})$
\end{tabular}} & \multicolumn{2}{|c|}{$\begin{array}{c}\text { Influent to Facultative } \\
\text { Lagoon System }\end{array}$} & \multicolumn{2}{|c|}{ Evaporation Pond B } & \multicolumn{2}{|c|}{ Evaporation Pond C } & \multicolumn{2}{|c|}{$\begin{array}{l}\text { H-19 Evaporation } \\
\text { Pond }\end{array}$} \\
\hline & $<0.435$ & & $<0.10$ & & $N / A^{a}$ & & $\mathrm{~N} / \mathrm{A}$ & \\
\hline $\mathrm{TKN}^{\mathrm{b}}(\mathrm{mg} / \mathrm{L})$ & 59.1 & & 19 & & $\mathrm{~N} / \mathrm{A}$ & & $\mathrm{N} / \mathrm{A}$ & \\
\hline $\operatorname{TDS}^{\mathrm{c}}(\mathrm{mg} / \mathrm{L})$ & 522 & & 6,840 & & 8,970 & & 285,000 & \\
\hline & Activity & TPU $2 \sigma^{d}$ & Activity & TPU $2 \sigma$ & Activity & TPU $2 \sigma$ & Activity & TPU $2 \sigma$ \\
\hline $\left.\mathrm{U}^{233 / 234} \mathrm{~Bq} / \mathrm{L}\right)^{\mathrm{e}}$ & $5.32 \mathrm{E}-02$ & $6.72 \mathrm{E}-03$ & 1.16E-02 & 3.45E-03 & $1.81 \mathrm{E}-02$ & $3.86 \mathrm{E}-03$ & $7.37 \mathrm{E}-01$ & $3.85 \mathrm{E}-02$ \\
\hline $\mathrm{U}^{235}(\mathrm{~Bq} / \mathrm{L})$ & $6.61 \mathrm{E}-04$ & $8.61 \mathrm{E}-04$ & $5.18 \mathrm{E}-04$ & $9.13 \mathrm{E}-04$ & $2.25 \mathrm{E}-04$ & 5.19E-04 & 9.95E-03 & $3.05 E-03$ \\
\hline $\mathrm{U}^{238}(\mathrm{~Bq} / \mathrm{L})$ & $2.26 \mathrm{E}-02$ & $4.25 \mathrm{E}-03$ & 5.03E-03 & 2.27E-03 & $6.43 \mathrm{E}-03$ & $2.28 \mathrm{E}-03$ & $1.75 \mathrm{E}-01$ & $1.35 \mathrm{E}-02$ \\
\hline $\mathrm{Pu}^{238}(\mathrm{~Bq} / \mathrm{L})$ & $-1.28 \mathrm{E}-04$ & $2.55 \mathrm{E}-04$ & $0.00 \mathrm{E}+00$ & 3.93E-04 & $-4.50 \mathrm{E}-05$ & 3.53E-04 & 7.35E-04 & $1.60 \mathrm{E}-03$ \\
\hline $\mathrm{Pu}^{239+240}(\mathrm{~Bq} / \mathrm{L})$ & $-4.90 \mathrm{E}-05$ & $1.58 \mathrm{E}-04$ & $6.54 \mathrm{E}-05$ & $3.44 \mathrm{E}-04$ & $3.14 \mathrm{E}-04$ & $4.16 \mathrm{E}-04$ & $-3.21 \mathrm{E}-04$ & $7.92 \mathrm{E}-04$ \\
\hline $\mathrm{Am}^{241}(\mathrm{~Bq} / \mathrm{L})$ & $5.95 \mathrm{E}-04$ & $7.82 \mathrm{E}-04$ & $2.30 \mathrm{E}-04$ & 5.05E-04 & $1.28 \mathrm{E}-04$ & $4.53 \mathrm{E}-04$ & $1.85 \mathrm{E}-04$ & $5.48 \mathrm{E}-04$ \\
\hline $\mathrm{Sr}^{90}(\mathrm{~Bq} / \mathrm{L})$ & $3.32 \mathrm{E}-04$ & $4.02 \mathrm{E}-02$ & 1.01E-03 & 2.97E-02 & $-4.08 \mathrm{E}-03$ & $2.85 E-02$ & $6.14 \mathrm{E}-03$ & $4.32 \mathrm{E}-02$ \\
\hline
\end{tabular}

Table 5.4 - Sewage Lagoon and H-19 Semiannual Analytical Results for July 1 through December 31, 2005

\begin{tabular}{|c|c|c|c|c|c|c|c|c|}
\hline \multirow{2}{*}{$\frac{\text { Analyte }}{\text { Nitrate }(\mathrm{mg} / \mathrm{L})}$} & \multicolumn{2}{|c|}{\begin{tabular}{|c|} 
Influent to Facultative \\
Lagoon System
\end{tabular}} & \multicolumn{2}{|c|}{ Evaporation Pond B } & \multicolumn{2}{|c|}{ Evaporation Pond C } & \multicolumn{2}{|c|}{$\begin{array}{l}\text { H-19 Evaporation } \\
\text { Pond }\end{array}$} \\
\hline & $<1.00$ & & $N / A^{a}$ & & $\mathrm{~N} / \mathrm{A}$ & & $\mathrm{N} / \mathrm{A}$ & \\
\hline $\mathrm{TKN}^{\mathrm{b}}(\mathrm{mg} / \mathrm{L})$ & 46.2 & & $\mathrm{~N} / \mathrm{A}$ & & $\mathrm{N} / \mathrm{A}$ & & $\mathrm{N} / \mathrm{A}$ & \\
\hline $\operatorname{TDS}^{\mathrm{c}}(\mathrm{n}$ & 472 & & 0,700 & & 18,500 & & 322,000 & \\
\hline & Activity & TPU $2 \sigma^{d}$ & Activity & TPU $2 \sigma$ & Activity & TPU $2 \sigma$ & Activity & TPU $2 \sigma$ \\
\hline $\mathrm{U}^{233 / 234}(\mathrm{~Bq} / \mathrm{L})^{\mathrm{e}}$ & $6.05 \mathrm{E}-02$ & 7.95E-03 & 9.50E-03 & $2.21 \mathrm{E}-03$ & 9.32E-03 & $2.10 \mathrm{E}-03$ & 9.61E-01 & 4.70E-02 \\
\hline $\mathrm{U}^{235}(\mathrm{~Bq} / \mathrm{L})$ & $3.45 \mathrm{E}-03$ & $2.03 E-03$ & 2.57E-04 & 4.66E-04 & $-3.52 \mathrm{E}-05$ & $1.41 \mathrm{E}-04$ & $2.37 \mathrm{E}-02$ & 4.64E-03 \\
\hline $\mathrm{U}^{238}(\mathrm{~Bq} / \mathrm{L})$ & 1.92E-02 & 4.30E-03 & $4.02 E-03$ & 1.44E-03 & 3.84E-03 & $1.35 \mathrm{E}-03$ & $2.36 \mathrm{E}-01$ & $1.61 \mathrm{E}-02$ \\
\hline $\mathrm{Pu}^{238}(\mathrm{~Bq} / \mathrm{L})$ & $3.35 \mathrm{E}-04$ & $1.23 \mathrm{E}-03$ & $-2.68 \mathrm{E}-04$ & $4.26 \mathrm{E}-04$ & $-3.98 \mathrm{E}-05$ & $4.84 \mathrm{E}-04$ & $-7.18 \mathrm{E}-05$ & 1.99E-04 \\
\hline $\mathrm{Pu}^{239+240}(\mathrm{~Bq} / \mathrm{L})$ & $-3.71 \mathrm{E}-04$ & $7.16 \mathrm{E}-04$ & $-9.80 \mathrm{E}-05$ & $2.58 \mathrm{E}-04$ & $-4.55 \mathrm{E}-05$ & 1.70E-04 & $-3.07 E-05$ & 1.30E-04 \\
\hline $\mathrm{Am}^{241}(\mathrm{~Bq} / \mathrm{L})$ & $-5.90 \mathrm{E}-05$ & 7.75E-04 & 4.73E-06 & 5.43E-04 & $-3.19 \mathrm{E}-05$ & 5.33E-04 & $-2.74 \mathrm{E}-04$ & $5.28 \mathrm{E}-04$ \\
\hline $\mathrm{Sr}^{90}(\mathrm{~Bq} / \mathrm{L})$ & $5.83 \mathrm{E}-03$ & $7.41 \mathrm{E}-02$ & $4.85 \mathrm{E}-02$ & $4.85 \mathrm{E}-02$ & $4.39 \mathrm{E}-03$ & $4.22 \mathrm{E}-02$ & $2.94 \mathrm{E}-02$ & $6.87 \mathrm{E}-02$ \\
\hline
\end{tabular}

a N/A: The analytical parameter is not required.

b Total Kjeldahl Nitrogen (as N).

c Total Dissolved Solids.

d TPU $2 \sigma=$ total propagated uncertainty at 2-sigma (95\% confidence interval).

e Becquerel per liter. 
Waste Isolation Pilot Plant Annual Site Environmental Report for 2005 DOE/WIPP-06-2225

Table 5.5 - Infiltration Control Evaporation Ponds Annual Analytical Results for January 1 through December 31, 2005

\begin{tabular}{|l|c|c|c|c|c|c|}
\hline \multicolumn{1}{|c|}{ Evaporation Pond } & $\begin{array}{c}\text { Chloride } \\
\mathbf{m g} / \mathbf{L}\end{array}$ & $\begin{array}{c}\text { Nitrate-N } \\
\mathbf{m g} / \mathbf{L}\end{array}$ & $\begin{array}{c}\text { Sulfate } \\
\mathbf{m g} / \mathbf{L}\end{array}$ & $\begin{array}{c}\text { TDS } \\
\mathbf{m g} / \mathbf{L}\end{array}$ & $\begin{array}{c}\text { Selenium } \\
\mathbf{m g} / \mathbf{L}\end{array}$ & $\begin{array}{c}\text { Chromium } \\
\mathbf{m g} / \mathbf{L}\end{array}$ \\
\hline Salt Pile Evaporation Pond & 50,500 & 0.226 & 478 & 67,000 & $<0.0100$ & $<0.0100$ \\
\hline $\begin{array}{l}\text { Salt Storage Extension } \\
\text { Evaporation Basin }\end{array}$ & 223,000 & 2.83 & 8,330 & 339,000 & $<0.0100$ & $<0.0100$ \\
\hline Pond 1 & 22.4 & 1.58 & 9.57 & 107 & $<0.0100$ & $<0.0100$ \\
\hline Pond 2 & 38.2 & 1.00 & 2.50 & 378 & $<0.0100$ & $<0.0100$ \\
\hline Pond A & 150 & 1.00 & 0.500 & 115 & $<0.0100$ & $<0.0100$ \\
\hline
\end{tabular}


Waste Isolation Pilot Plant Annual Site Environmental Report for 2005

DOE/WIPP-06-2225

This page intentionally left blank 


\section{CHAPTER 6 - SITE HYDROLOGY, GROUNDWATER MONITORING, AND PUBLIC DRINKING WATER PROTECTION}

Current groundwater monitoring activities at WIPP are outlined in the WIPP Groundwater Monitoring Program Plan (WP 02-1). In addition, WIPP has detailed procedures for performing specific activities, such as pumping system installations, field parameter analyses and documentation, and QA records management. Groundwater monitoring activities are also defined in the EMP.

\subsection{Site Hydrology}

The hydrology at and surrounding the WIPP site has been studied extensively over the last 29 years. A summary of the hydrology in this area is contained in the following sections. Figure 1.1 presents the WIPP stratigraphy.

\subsubsection{Surface Hydrology}

Surface water is absent at the WIPP site. The nearest significant surface water body, Laguna Grande de la Sal, is about 13 kilometers (8 miles) west-southwest of the center of the WIPP site in Nash Draw where shallow brine ponds occur. Small, manmade livestock watering holes ("tanks") occur several kilometers from the WIPP site, but are not hydrologically connected to the formations overlying the WIPP repository.

\subsubsection{Subsurface Hydrology}

Several water-bearing zones have been identified and extensively studied at and near the WIPP site. Limited amounts of potable water are found in the middle Dewey Lake Redbeds and the overlying Triassic Dockum group in the vicinity of WIPP. Two waterbearing units, the Culebra and Magenta Dolomites, occur in the Rustler Formation and produce brackish to saline water at and in the vicinity of the site. Another very low transmissivity, saline water-bearing zone is the Rustler-Salado contact.

\subsubsection{Hydrology of the Castile Formation}

The Castile Formation is composed of a sequence of three thick anhydrite beds separated by two thick halite beds. This formation acts as an aquitard, separating the Salado Formation from the underlying water-bearing sandstones of the Bell Canyon Formation. In the halite zones, the occurrence of circulating groundwater is restricted because halite at these depths does not readily maintain secondary porosity, open fractures, or solution channels.

No regional groundwater flow system is present in the Castile Formation in the vicinity of WIPP. The only significant water present in the formation occurs in isolated brine reservoirs in fractured anhydrite. These brine reservoirs are unconnected with surrounding aquifers or the surface, and have little potential to dissolve the host rocks or move through them. 


\subsubsection{Hydrology of the Salado Formation}

The massive halite beds within the Salado Formation host the WIPP facility horizon. The Salado Formation represents a regional aquiclude due to the hydraulic properties of the bedded halite that forms most of the formation. In the halites, the presence of circulating groundwater is restricted because halites do not readily maintain primary porosity, solution channels, or open fractures.

The results of permeability testing, both within the facility and from the surface, are generally consistent with a hydraulic conductivity of the undisturbed salt mass of less than $6.5 \mathrm{E}-09 \mathrm{~m}$ per day $(\mathrm{m} / \mathrm{d})(2.1 \mathrm{E}-08 \mathrm{ft} / \mathrm{d})$, with the more pure (less argillaceous) halites having even lower permeability. Anhydrite interbeds typically have hydraulic conductivities ranging from $6.5 \mathrm{E}-09 \mathrm{~m} / \mathrm{d}$ to $6.5 \mathrm{E}-07 \mathrm{~m} / \mathrm{d}(2.1 \mathrm{E}-08$ to $2.1 \mathrm{E}-06 \mathrm{ft} / \mathrm{d})$ (Beauheim and Roberts, 2002). The only significant variation to these extremely low permeabilities occurs in the immediate vicinity of the underground workings (Stormont et al., 1991). This increase is believed to be a result of near-field fracturing due to the excavation.

\subsubsection{Hydrology of the Rustler-Salado Contact}

In Nash Draw and areas immediately west of the site, the contact exists as a dissolution residue capable of transmitting water. Eastward from Nash Draw toward the WIPP site, the amount of dissolution decreases and the transmissivity of this interval decreases. (Mercer, 1983).

\subsubsection{Hydrology of the Culebra Member}

The Culebra Member of the Rustler Formation is the most transmissive hydrologic unit in the WIPP site area and is considered the most significant potential hydrologic pathway for a radiologic release to the accessible environment.

Tests show that the Culebra is a fractured, heterogeneous system with varying local anisotropic characteristics (Mercer and Orr, 1977; Mercer, 1983; Beauheim, 1986, 1987; Beauheim and Ruskauff, 1998). Calculated transmissivities for the Culebra within the WIPP site boundary have a wide range with values between $8.4 \mathrm{E}-03$ to approximately $6.4 \mathrm{~m}^{2} / \mathrm{d}\left(9.0 \mathrm{E}-02\right.$ to approximately $\left.69 \mathrm{ft}^{2} / \mathrm{d}\right)$; the majority of the values are less than $9.3 \mathrm{E}-02 \mathrm{~m}^{2} / \mathrm{d}\left(1 \mathrm{ft}^{2} / \mathrm{d}\right)$ (Beauheim, 1987). Transmissivities generally decrease from west to east across the site area. The regional flow direction of groundwater in the Culebra is generally to the south.

\subsubsection{Hydrology of the Magenta Member}

The Magenta Dolomite is situated above the Culebra and, though not the water-bearing zone of interest for monitoring of a facility release, is of interest in understanding waterlevel changes that occur in the Culebra. The Magenta has been tested in 18 cased and open holes at and around the WIPP site. Transmissivities within the WIPP site range 
from 2.0E-04 to $3.5 \mathrm{E}-02 \mathrm{~m}^{2} / \mathrm{d}\left(2.1 \mathrm{E}-03\right.$ to $3.8 \mathrm{E}-01 \mathrm{ft}^{2} / \mathrm{d}$ ) (Beauheim et al., 1991; Beauheim and Ruskauff, 1998).

\subsubsection{Hydrology of the Dewey Lake Redbeds}

The Dewey Lake Redbeds Formation at the WIPP site is approximately $152 \mathrm{~m}$ (500 ft) thick and consists of alternating thin beds of siltstone and fine-grained sandstone. The upper Dewey Lake consists of a thick, generally unsaturated section. The middle Dewey Lake is the interval immediately above a cementation change, from carbonate (above) to sulfate (below), where saturated conditions and a natural water table have been identified in limited areas. The average saturated thickness is $5.1 \mathrm{~m}(16.6 \mathrm{ft})$. An anthropogenic saturated zone has been observed in the overlying Santa Rosa Formation and in the upper part of the Dewey Lake Redbeds since 1995. This is described in Sections 6.5 and 6.6. The lower Dewey Lake is below the sulfate cementation change, with much lower permeabilities.

WIPP monitoring well WQSP-6A intersects natural water in the Dewey Lake. At this location, the saturated horizon is within the middle portion of the formation. The saturated zone at well WQSP-6A is both vertically and laterally distinct from the water at $\mathrm{C}-2811$, which is located about one mile to the northeast. The Dewey Lake generally does not yield a water supply to wells; however, about one mile south of the WIPP site, domestic and stock supply wells produce water from the middle Dewey Lake (Cooper and Glanzman, 1971).

\subsubsection{Hydrology of the Gatuña and Santa Rosa Formations}

The Gatuña Formation unconformably overlies the Santa Rosa Formation at the WIPP site. This formation ranges in thickness from approximately 6 to $9 \mathrm{~m} \mathrm{(19}$ to $31 \mathrm{ft}$ ) at the WIPP site and consists of silt, sand, and clay, with deposits formed in localized depressions.

The Gatuña is water-bearing in some areas, with saturation occurring in discontinuous perched zones. However, because of its erratic distribution, the Gatuña has no known continuous saturation zone. Drilling at the WIPP site, including 30 exploration borings drilled between 1978 and 1979, did not identify any saturated zones in the Gatuña (Daniel B. Stephens \& Associates, Inc., 2003).

Water in the Santa Rosa has been found in the center part of the WIPP site and since no water was found in this zone during the mapping of the shafts in 1980s, this water is deemed to be anthropogenic (Daniel B. Stephens \& Associates, Inc., 2003). To assess the quantity and quality of this water, piezometers PZ-1 to PZ-12 were installed in the area between the WIPP shafts. Also, three wells, C-2505, C-2506 and C-2507 were drilled and tested in 1996 and 1997 (Exhaust Shaft Hydraulic Assessment Data Report, DOE/WIPP 97-2219). 


\subsection{Groundwater Monitoring}

\subsubsection{Program Objectives}

The objectives of the Groundwater Monitoring Program are to:

- $\quad$ Determine the physical and chemical characteristics of groundwater;

- Maintain surveillance of groundwater levels and water chemistry surrounding the WIPP facility throughout the operational lifetime of the facility; and

- Document and identify effects, if any, of WIPP operations on groundwater parameters.

Data obtained by the WIPP Groundwater Monitoring Program support two major programs at WIPP: (1) the RCRA Detection Monitoring Program supporting the HWFP in compliance with 20.4.1.500 NMAC, and (2) performance assessment supporting the Compliance Certification Application (DOE/CAO 96-2184) and five-year recertification applications.

Baseline water chemistry data were collected from 1995 through 1997 and reported in the Waste Isolation Pilot Plant RCRA Background Groundwater Quality Baseline Report (DOE/WIPP 98-2285). The baseline data were expanded in 2000 to include ten rounds of sampling instead of five. The data were published in Addendum 1, Waste Isolation Pilot Plant RCRA Background Groundwater Quality Baseline Update Report (IT Corporation, 2000). These baseline data are compared to water quality data collected semiannually at DMP wells.

\subsubsection{Summary of 2005 Activities}

Groundwater monitoring support activities during 2005 included drilling of five new wells, well development, testing, groundwater quality sampling and groundwater level surveillance. Table 6.1 categorizes WIPP groundwater monitoring activities according to DOE SER guidance. The guidance calls for the wells to be classified by purpose (i.e., remediation, waste management, and environmental surveillance). All of the WIPP groundwater monitoring wells are used for environmental surveillance. Radiological data from 2005 from the groundwater monitoring program are summarized in Chapter 4. The remainder of the results from the groundwater monitoring program are contained in this chapter. 
Waste Isolation Pilot Plant Annual Site Environmental Report for 2005 DOE/WIPP-06-2225

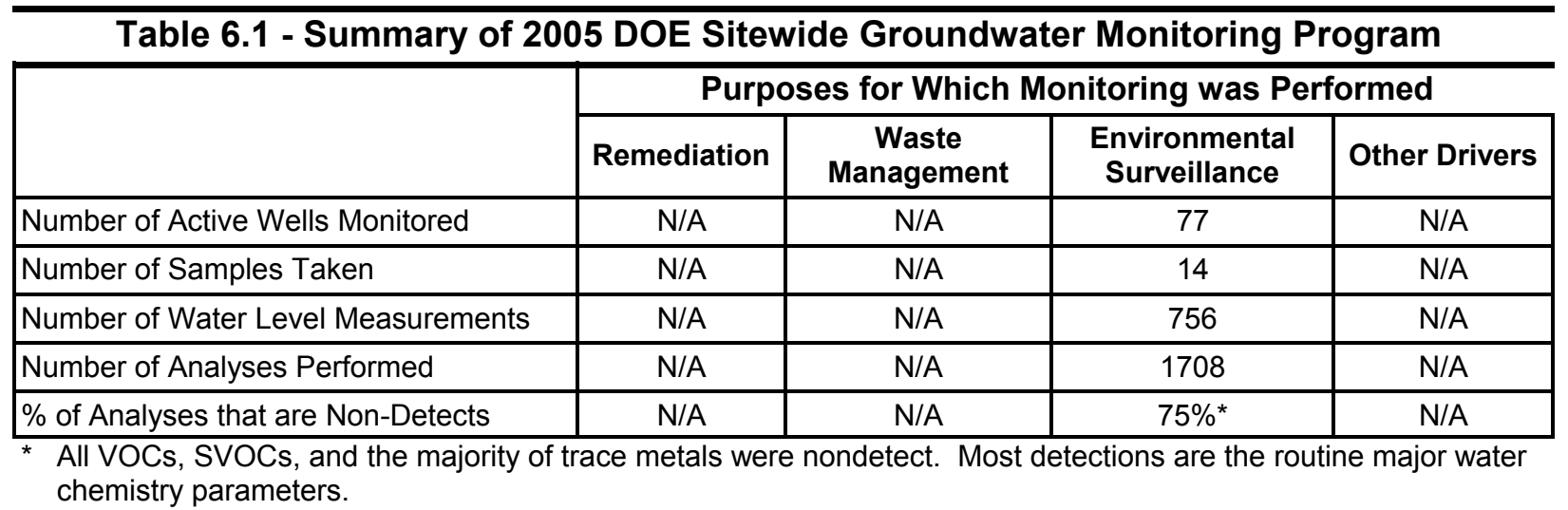

Groundwater quality samples were gathered twice from seven DMP wells: six wells completed in the Culebra (WQSP-1 through WQSP-6) and one well completed in the Dewey Lake (WQSP-6A; Figure 6.1).

The total amount of water removed from the Culebra as a result of Water Quality Sampling was 13,287 gallons. A total of 2,208 gallons were removed from the Dewey Lake for the same purpose.

Five new wells completed in the Culebra were constructed in 2005: SNL-6, SNL-8, SNL-13, SNL-14, and SNL-15. These wells were drilled to provide new hydraulic testing locations to help determine the cause of rising water levels in the Culebra.

Well development took place at six wells in 2005; SNL-6, SNL-8, SNL-13, SNL-14, SNL-15 and WIPP-11. The total number of gallons removed from the Culebra as a result of well development was 54,385. Total gallons removed for each of these activities were estimated based on flow rates, well bore volumes and flow meter readings.

Six wells were pumped or bailed for hydrologic testing or maintenance activities in 2005 in the Culebra. These wells were SNL-2, SNL-1, SNL-14, WIPP-30, H-12 and WIPP-11. A total of 2,078,769 gallons of water were removed from the Culebra during these activities.

Groundwater surface elevation data were gathered from 77 well bores located across the WIPP region (Figure 6.2), six of which were equipped with production-injectionpackers (PIPs) to allow groundwater level surveillance of more than one producing zone through the same well. 
Waste Isolation Pilot Plant Annual Site Environmental Report for 2005 DOE/WIPP-06-2225

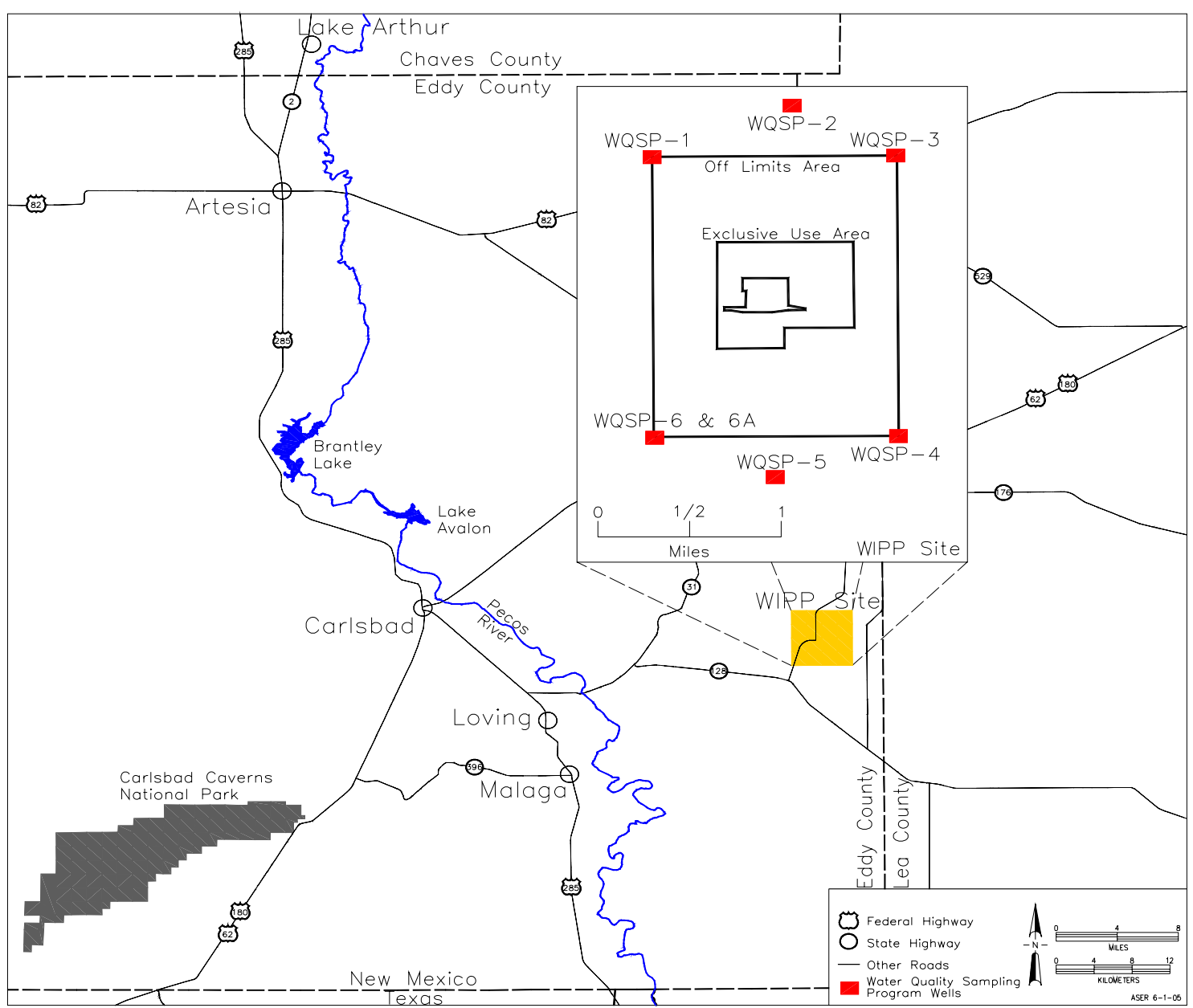

Figure 6.1 - Water Quality Sampling Program Wells (inset shows location of the DMP wells) 


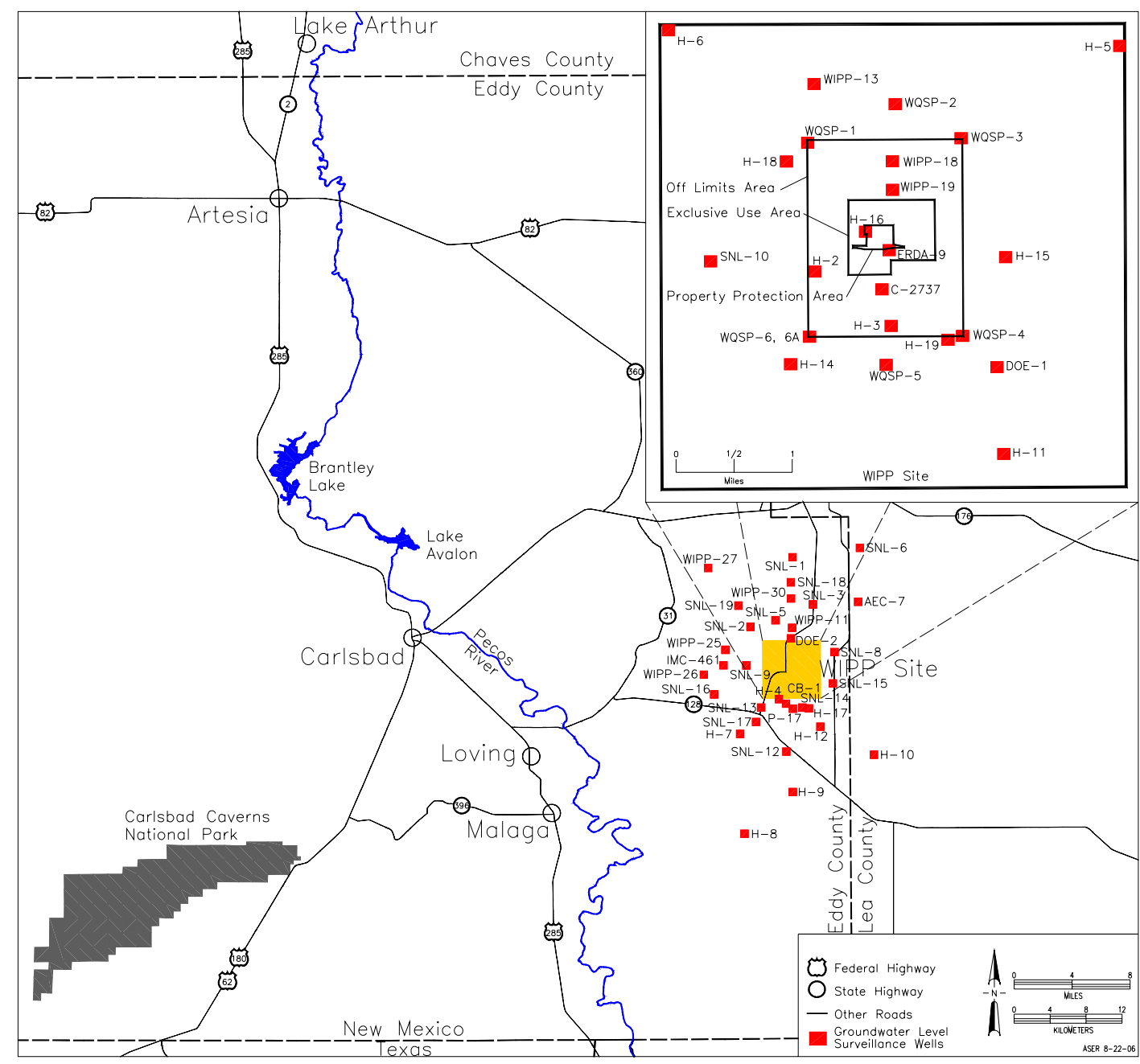

Figure 6.2 - Groundwater Level Surveillance Wells (insert represents the groundwater surveillance wells in WIPP site Land Withdrawal Area)

\subsubsection{Groundwater Quality Sampling}

The HWFP Module $V$ requires groundwater quality sampling twice a year, from March through May (Round 20 for 2005) and, again, from September through November (Round 21 for 2005). Sampling for groundwater quality was performed at seven DMP well sites during 2005 (Figure 6.1). Field analyses for Eh (redox potential, an indicator of oxidation or reduction of chemical species), specific gravity, specific conductance, acidity or alkalinity, chloride, divalent cations, and total iron were performed periodically during the sampling.

The HWFP specifies the point of compliance as "the vertical surface located at the hydraulically downgradient limit of the underground HWDUs that extends to the Culebra Member of the Rustler Formation." The HWFP groundwater monitoring network was not installed immediately downgradient of this plane. However, due to the relatively 
unique containment and transport aspects of the site, monitoring at the sited locations would allow for detection of releases before contaminants could be released beyond the WLWA boundary.

Wells WQSP-1, WQSP-2, and WQSP-3 were located hydrologically upgradient of the WIPP shaft area. The locations of the three upgradient wells were selected to be representative of the flow vectors of groundwater moving downgradient onto the WIPP site. WQSP-4, WQSP-5, and WQSP-6 were located hydrologically downgradient of the WIPP shaft area based on the greatest velocity magnitude of groundwater flow leaving the area. WQSP-4 was also specifically located to monitor the zone of higher transmissivity around wells DOE-1 and $\mathrm{H}-11$. WQSP-6a was installed in the Dewey Lake at the WQSP-6 well pad to assess shallower groundwater conditions at this location.

The difference between the depth of the WIPP repository and the depth of the DMP wells varies from $387 \mathrm{~m}$ to $587 \mathrm{~m}(1,271 \mathrm{ft}$ to 1,925 ft). The DOE does not anticipate finding WIPP-related contamination in groundwater because no pathways for migration of hazardous constituents exists via groundwater to the accessible environment. For migration to occur there must be a driving force or hydraulic gradient. During the disposal phase, the underground disposal areas are at or near atmospheric pressure, while the hydrostatic fluid pressures in the Salado, Castile, Culebra, and Magenta are well above atmospheric pressure inducing flow towards the repository openings.

Table 6.2 lists the analytical parameters included in the 2005 groundwater-sampling program.

\begin{tabular}{|c|c|c|c|c|c|}
\hline CAS No. ${ }^{a}$ & Parameter & $\begin{array}{c}\text { EPA } \\
\text { Method } \\
\text { Number }\end{array}$ & CAS No. & Parameter & $\begin{array}{c}\text { EPA } \\
\text { Method } \\
\text { Number }\end{array}$ \\
\hline $71-55-6$ & 1,1,1-Trichloroethane & $8260 B$ & $7782-50-5$ & Chloride & 300 \\
\hline $79-34-5$ & 1,1,2,2-Tetrachloroethane & $8260 \mathrm{~B}$ & & Densityb & \\
\hline $79-00-5$ & 1,1,2-Trichloroethane & $8260 \mathrm{~B}$ & $7727-37-9$ & Nitrate (as N) & 300 \\
\hline $75-34-3$ & 1,1-Dichloroethane & $8260 B$ & & $\mathrm{pH}$ & 150.1 \\
\hline $75-35-4$ & 1,1-Dichloroethylene & $8260 \mathrm{~B}$ & & Specific conductance & 120.1 \\
\hline $107-06-2$ & 1,2-Dichloroethane & $8260 \mathrm{~B}$ & & Sulfate & 300 \\
\hline $56-23-5$ & Carbon tetrachloride & $8260 B$ & & Total dissolved solids (TDS) & 160.1 \\
\hline $108-90-7$ & Chlorobenzene & $8260 B$ & & Total organic carbon (TOC) & 415.1 \\
\hline $67-66-3$ & Chloroform & $8260 \mathrm{~B}$ & & Total organic halogen $(\mathrm{TOH})$ & 9020B \\
\hline $540-59-0$ & cis-1,2-Dichloroethylene & $8260 \mathrm{~B}$ & & Total suspended solids (TSS) & 160.2 \\
\hline $540-59-0$ & trans-1, 2-Dichloroethylene & $8260 B$ & & & \\
\hline $78-93-3$ & Methyl ethyl ketone & $8260 \mathrm{~B}$ & & & \\
\hline $75-09-2$ & Methylene chloride & $8260 \mathrm{~B}$ & & & \\
\hline $127-18-4$ & Tetrachloroethylene & $8260 B$ & $7440-36-0$ & Alkalinity & 310.1 \\
\hline $108-88-3$ & Toluene & $8260 B$ & $7440-38-2$ & Antimony & $6010 \mathrm{~B}$ \\
\hline $79-01-6$ & Trichloroethylene & $8260 B$ & $7440-39-3$ & Arsenic & 6010B \\
\hline
\end{tabular}


Waste Isolation Pilot Plant Annual Site Environmental Report for 2005 DOE/WIPP-06-2225

\begin{tabular}{|c|c|c|c|c|c|}
\hline CAS No. ${ }^{a}$ & Parameter & $\begin{array}{c}\text { EPA } \\
\text { Method } \\
\text { Number }\end{array}$ & CAS No. & Parameter & $\begin{array}{c}\text { EPA } \\
\text { Method } \\
\text { Number }\end{array}$ \\
\hline $75-69-4$ & Trichlorofluoromethane & $8260 B$ & $7440-41-7$ & Barium & $6010 \mathrm{~B}$ \\
\hline $75-01-4$ & Vinyl chloride & $8260 B$ & $7440-43-9$ & Beryllium & 6010B \\
\hline $1330-20-7$ & Xylene & $8260 B$ & $7440-70-2$ & Cadmium & $6010 \mathrm{~B}$ \\
\hline $95-50-1$ & 1,2-Dichlorobenzene & $8270 \mathrm{C}$ & $7440-47-3$ & Calcium & $6010 \mathrm{~B}$ \\
\hline $106-46-7$ & 1,4-Dichlorobenzene & $8270 \mathrm{C}$ & $7439-89-6$ & Chromium & $6010 B$ \\
\hline $51-28-5$ & 2,4-Dinitrophenol & $8270 \mathrm{C}$ & $7439-92-1$ & Iron & $6010 \mathrm{~B}$ \\
\hline $121-14-2$ & 2,4-Dinitrotoluene & $8270 \mathrm{C}$ & $7439-95-4$ & Lead & 6010B \\
\hline $95-48-7$ & 2-Methylphenol & $8270 \mathrm{C}$ & $7439-97-6$ & Magnesium & 6010B \\
\hline \multirow{2}{*}{$\begin{array}{l}108-39-4 / \\
106-44-5\end{array}$} & \multirow{2}{*}{$\begin{array}{l}\text { 3-Methylphenol/ } \\
\text { 4-Methylphenol }\end{array}$} & \multirow[t]{2}{*}{$8270 \mathrm{C}$} & 2023473 & Mercury & $7470 A$ \\
\hline & & & 2023692 & Nickel & $6010 \mathrm{~B}$ \\
\hline $118-74-1$ & Hexachlorobenzene & $8270 \mathrm{C}$ & $7782-49-2$ & Potassium & $6010 \mathrm{~B}$ \\
\hline $67-72-1$ & Hexachloroethane & $8270 \mathrm{C}$ & $7440-22-4$ & Selenium & $6010 \mathrm{~B}$ \\
\hline $98-95-3$ & Nitrobenzene & $8270 \mathrm{C}$ & $7440-23-5$ & Silver & $6010 \mathrm{~B}$ \\
\hline $87-86-5$ & Pentachlorophenol & $8270 \mathrm{C}$ & $7440-28-0$ & Sodium & $6010 \mathrm{~B}$ \\
\hline $110-86-1$ & Pyridine & $8270 \mathrm{C}$ & $7440-62-2$ & Thallium & $6010 B$ \\
\hline $78-83-1$ & Isobutanol & 8015B & $7440-66-6$ & Vanadium & $6010 B$ \\
\hline
\end{tabular}

\subsubsection{Evaluation of Groundwater Quality}

The quality of the Culebra water sampled near WIPP is naturally poor and not suitable for human consumption or for agricultural purposes, because the TDS concentrations are generally above 10,000 milligrams per liter (mg/L). In 2005, TDS concentrations in the Culebra varied from a low of $13,900 \mathrm{mg} / \mathrm{L}$ to a high of $250,500 \mathrm{mg} / \mathrm{L}$. The groundwater of the Culebra is considered to be Class III water by EPA guidelines.

Water quality measurements performed in the Dewey Lake indicate that the water is considerably better quality than that from the Culebra. In 2005, the TDS values in water from the well WQSP-6A, obtained from the Dewey Lake Formation, were less than $4,000 \mathrm{mg} / \mathrm{L}$. This water is suitable for livestock consumption, and is classified as Class II water by EPA guidelines. Saturation of the Dewey Lake in the area of WIPP is discontinuous. In addition to this naturally occurring groundwater, anthropogenic shallow subsurface water has been encountered in the upper Dewey Lake at the Santa Rosa contact (see Section 6.5).

Because of the highly variable transmissivity and TDS values within the Culebra, baseline groundwater quality was defined for each individual well. The analytical results for detectable constituents are plotted as Time Trend Plots compared to the baseline established prior to 2000 (Appendix E, Figures E.1 through E.98). The results of 
analyses for each parameter or constituent for the two sampling sessions in 2005 (Rounds 20 and 21) are summarized in Appendix F, Tables F.1 through F.7.

In these tables, either the $95^{\text {th }}$ upper tolerance limit value (UTLV) or the $95^{\text {th }}$ percentile value (as calculated for the background sampling rounds) is presented for each parameter depending on the type of distribution exhibited by the parameter or constituent. Both values represent the value beneath which 95 percent of the values in a population are expected to occur. The UTLVs were calculated for data that exhibited a normal or a lognormal distribution. The $95^{\text {th }}$ percentile was determined for data that were considered nonparametric; having neither a normal nor a lognormal distribution. Due to the large number of nondetectable concentrations of organic compounds, the limits for organic compounds were considered nonparametric and based on the contract required reporting limit for the contract laboratory. These values have been recomputed after baseline sampling was completed in 2000, and were used for sampling Rounds 20 and 21 to evaluate potential contamination of the local groundwater.

In a few isolated cases during 2005, reported concentrations of some parameters, such as sulfate and some major cations slightly exceeded the calculated $95^{\text {th }}$ percentile or the $95^{\text {th }}$ UTLV. Such exceedences do not indicate the presence of contamination. The $95^{\text {th }}$ UTLV or percentile is a value representing where 5 percent of the concentration in the population will be greater than the UTLV or percentile. WIPP groundwater in the Culebra has very high concentrations of dissolved solids and major cations and anions. The laboratory reported concentrations for parameters such as sulfate and chloride are variable from sampling round to round. A previous contract analytical laboratory exhibited some difficulty performing the analyses for $\mathrm{TOH}$, due to very high chloride concentrations, and some of the cations found in the highly concentrated brines. For Rounds 20 and 21 in 2005, a new contract laboratory performed the TOH analysis. This new laboratory reported much more consistent results for TOH during Rounds 20 and 21.

\subsubsection{Groundwater Level Surveillance}

Groundwater surface elevations in the vicinity of WIPP have been and may still be affected by localized disturbances, such as pumping tests for site characterization, water quality sampling, or well development. Other causes of groundwater surface elevation changes may be natural groundwater level fluctuations and industrial water use for agriculture, mining, and resource exploration.

Well bores were used to perform surveillance of six water-bearing zones in the WIPP area:

- Shallow Subsurface water (Santa Rosa/Dewey Lake Interface)

- $\quad$ Dewey Lake Redbeds

- Magenta

- Culebra

- Rustler/Salado Contact

- Bell Canyon 
The two zones of interest are the Culebra and Magenta (see Figure 1.1). Throughout 2005, water levels in 47 Culebra wells were measured each month and 14 wells in the Magenta. One well measurement was taken in the Dewey Lake Redbeds Formation monthly and two measurements were taken in the Bell Canyon. One measurement was taken each month in the Rustler/Salado contact. Fifteen measurements were taken in the shallow zone of the Santa Rosa/Dewey Lake interface. In 2005, groundwater level measurements were taken monthly in at least one accessible well bore at each well site for each available formation (Figure 6.2). Redundant well bores (well bores located on well pads with multiple wells completed in the same formation) at each well site were measured on a quarterly basis (Appendix F, Table F.8).

Six existing well bores (WIPP-30-Culebra/Magenta, C-2737-Culebra/Magenta, WIPP-25-Culebra/Magenta, WIPP-27-Culebra/Magenta, H-9c-Culebra/Magenta, and $\mathrm{H}-15-C u l e b r a / M a g e n t a)$ were completed at multiple depths. By using packers, these well bores can monitor more than one formation.

Groundwater elevation measurements in the Culebra indicate that the flow of groundwater is north to south at the center of the WIPP site (Figure 6.3). Regionally, the flow is from the north to the southwest. Water elevation trend analysis was performed in 37 of 47 wells completed in the Culebra. Rising water level trends were noted in 22 wells while 15 of the wells had falling trends; however, 13 of the 15 wells with falling trends were influenced by a twenty-two-day pumping test on well SNL-14. The two wells with falling trends that were not affected by the SNL-14 pump test were $\mathrm{H}-7 \mathrm{~b} 1$ and WIPP-26. Both wells are far field and both had downward trends of less than $0.5 \mathrm{ft}$.

The HWFP requires that the NMED be notified if a cumulative groundwater surface elevation change of more than $2 \mathrm{ft}$ is observed in any DMP well which is not attributable to site tests or natural stabilization of the site hydrologic system. None of the DMP wells had such a change in 2005.

Groundwater level data were transmitted on a monthly basis to the NMED, SNL, and the CBFO Technical Assistance Contractor. A copy of the data was placed in the operating record for inspection by authorized agencies.

Culebra flow rates across the WLWA were determined by developing a potentiometric surface map of freshwater heads in the Culebra (Figure 6.3), identifying three flow paths across the site, and calculating the linear velocity for these flow paths using the following equation.

$\mathrm{V}=\mathrm{Ki} / \mathrm{n}_{\mathrm{e}}$

Where:

$\mathrm{K}=$ geometric mean of hydraulic conductivity values for the flow segment

$\mathrm{i}=$ hydraulic gradient across the flow segment $(\mathrm{dh} / \mathrm{dl})$

$\mathrm{n}_{\mathrm{e}}=$ the effective porosity $(16 \%)$ 
The linear velocity across the WLWA ranged from a high of $1.28 \mathrm{E}-03 \mathrm{~m} / \mathrm{d}(4.22 \mathrm{E}-03$ $\mathrm{ft} / \mathrm{d})$ to a low of $7.30 \mathrm{E}-04 \mathrm{~m} / \mathrm{d}(2.39 \mathrm{E}-03 \mathrm{ft} / \mathrm{d})$. The average linear velocity across the WLWA was calculated to be $1.03 \mathrm{E}-03 \mathrm{~m} / \mathrm{d}(3.38 \mathrm{E}-03 \mathrm{ft} / \mathrm{d})$.

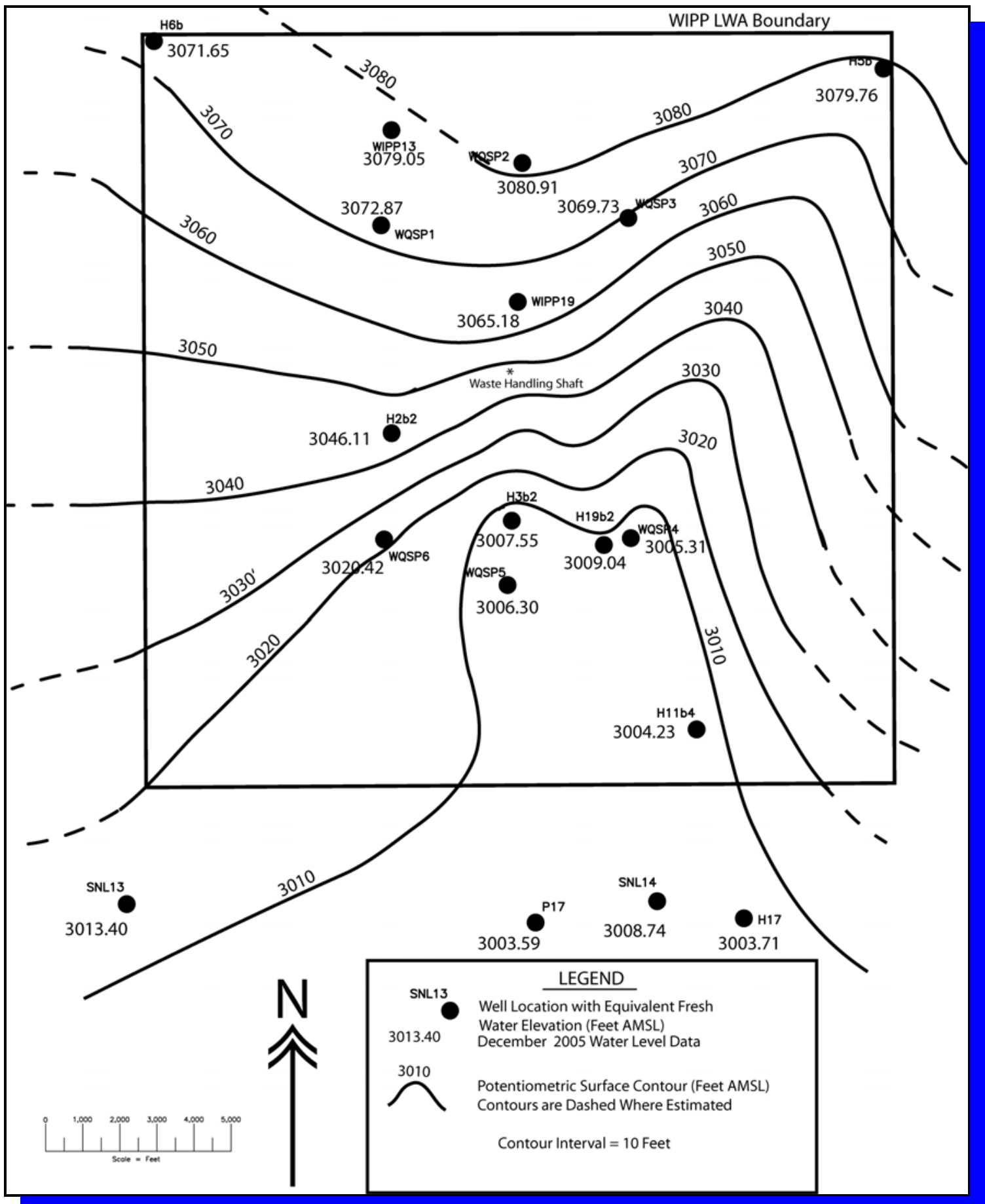

Figure 6.3 - Potentiometric Surface of the Culebra Dolomite, December 2005 
Figures 6.4 through 6.10 provide hydrographs of the DMP wells for 2005 .

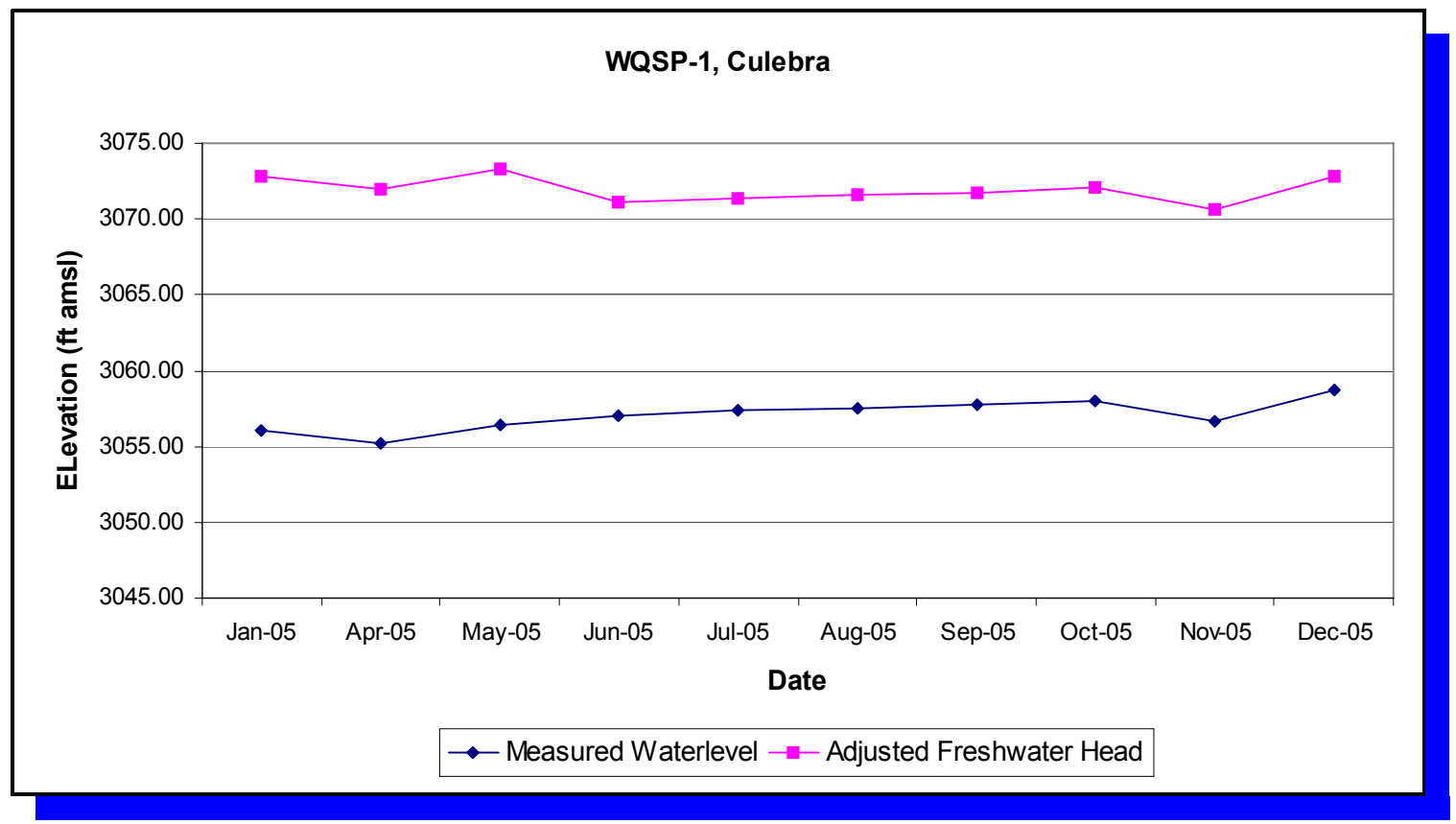

Figure 6.4 - Hydrograph of WQSP-1

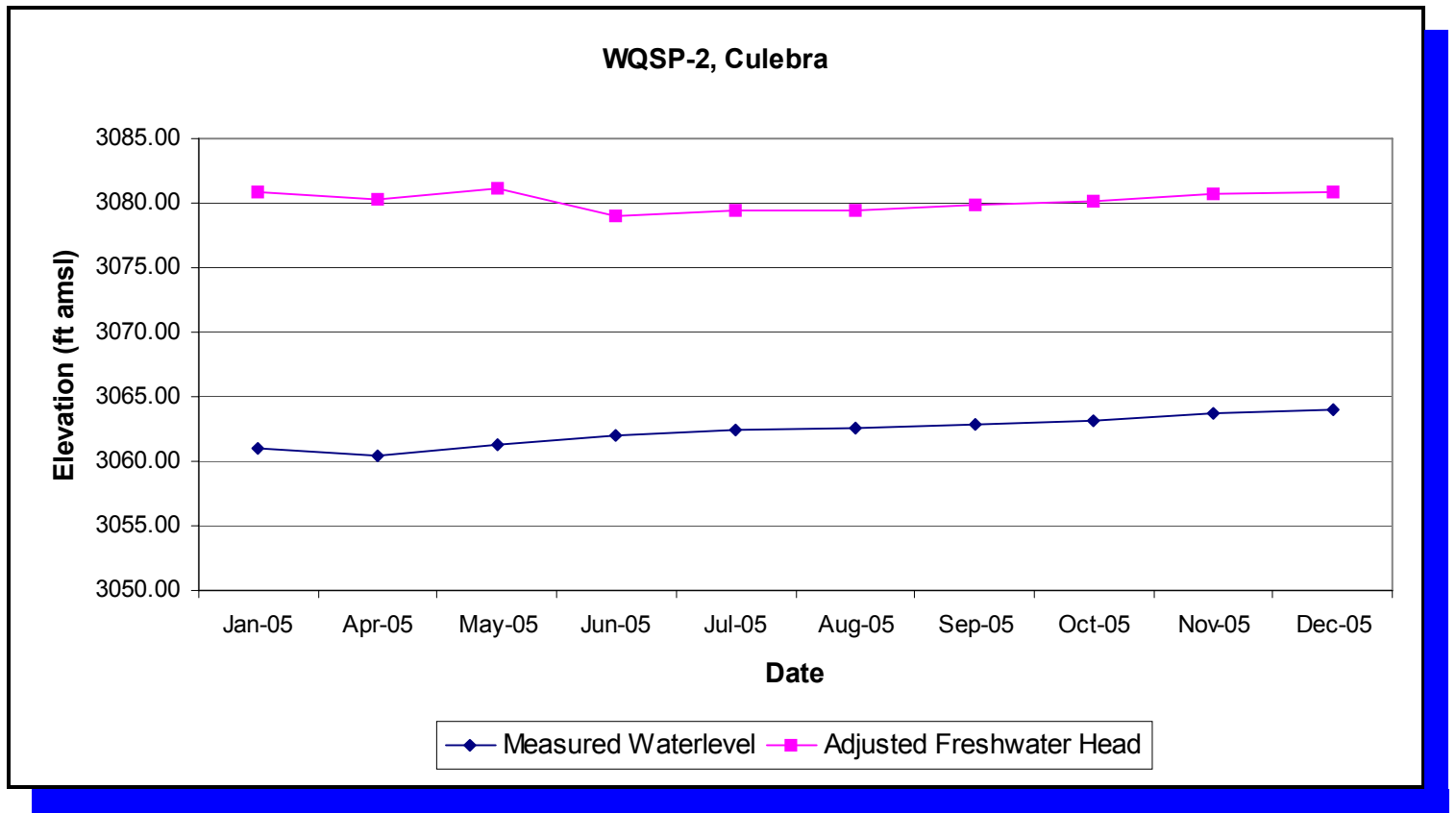

Figure 6.5 - Hydrograph of WQSP-2 


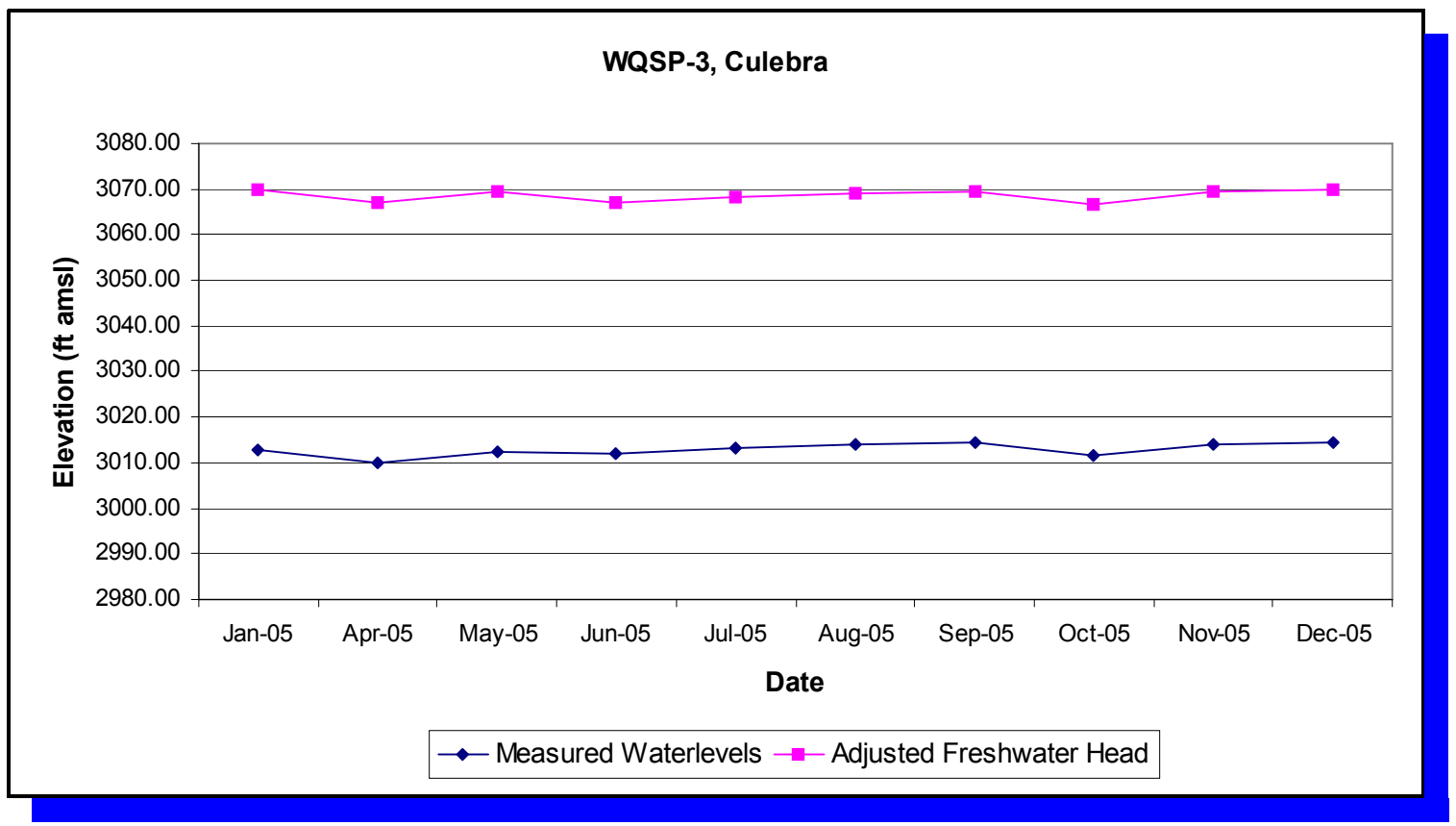

Figure 6.6 - Hydrograph of WQSP-3

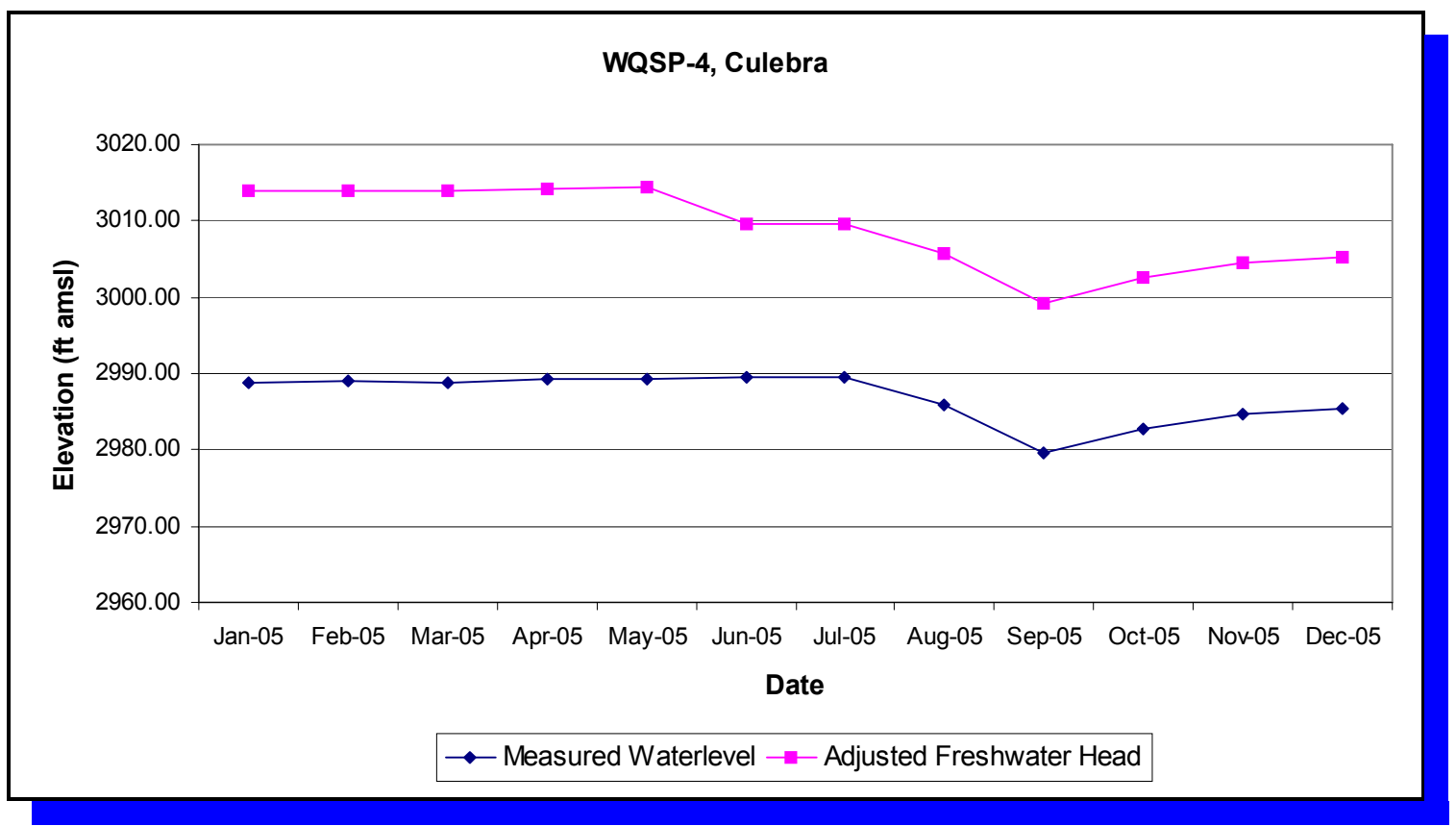

Figure 6.7 - Hydrograph of WQSP-4 


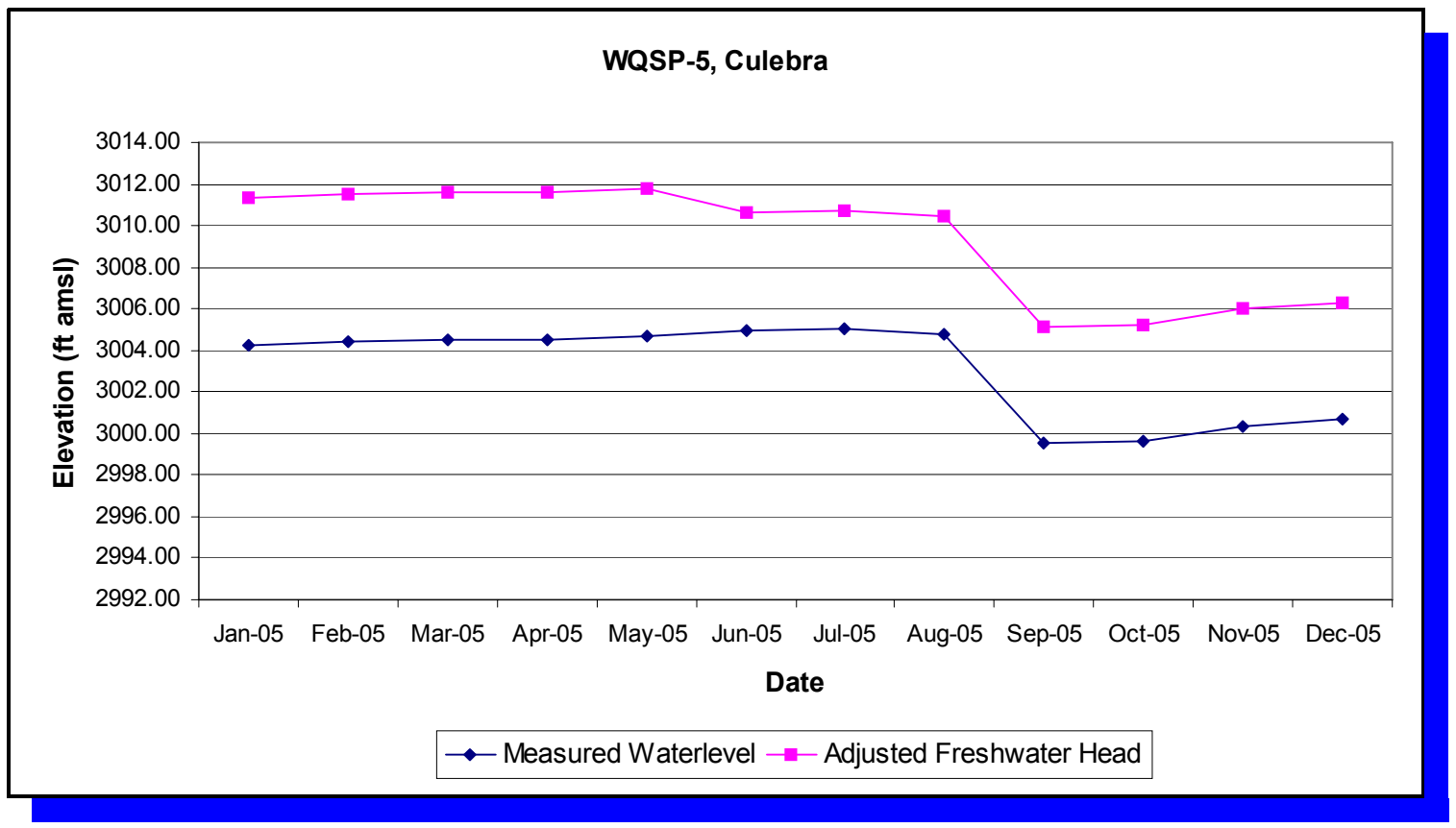

Figure 6.8 - Hydrograph of WQSP-5

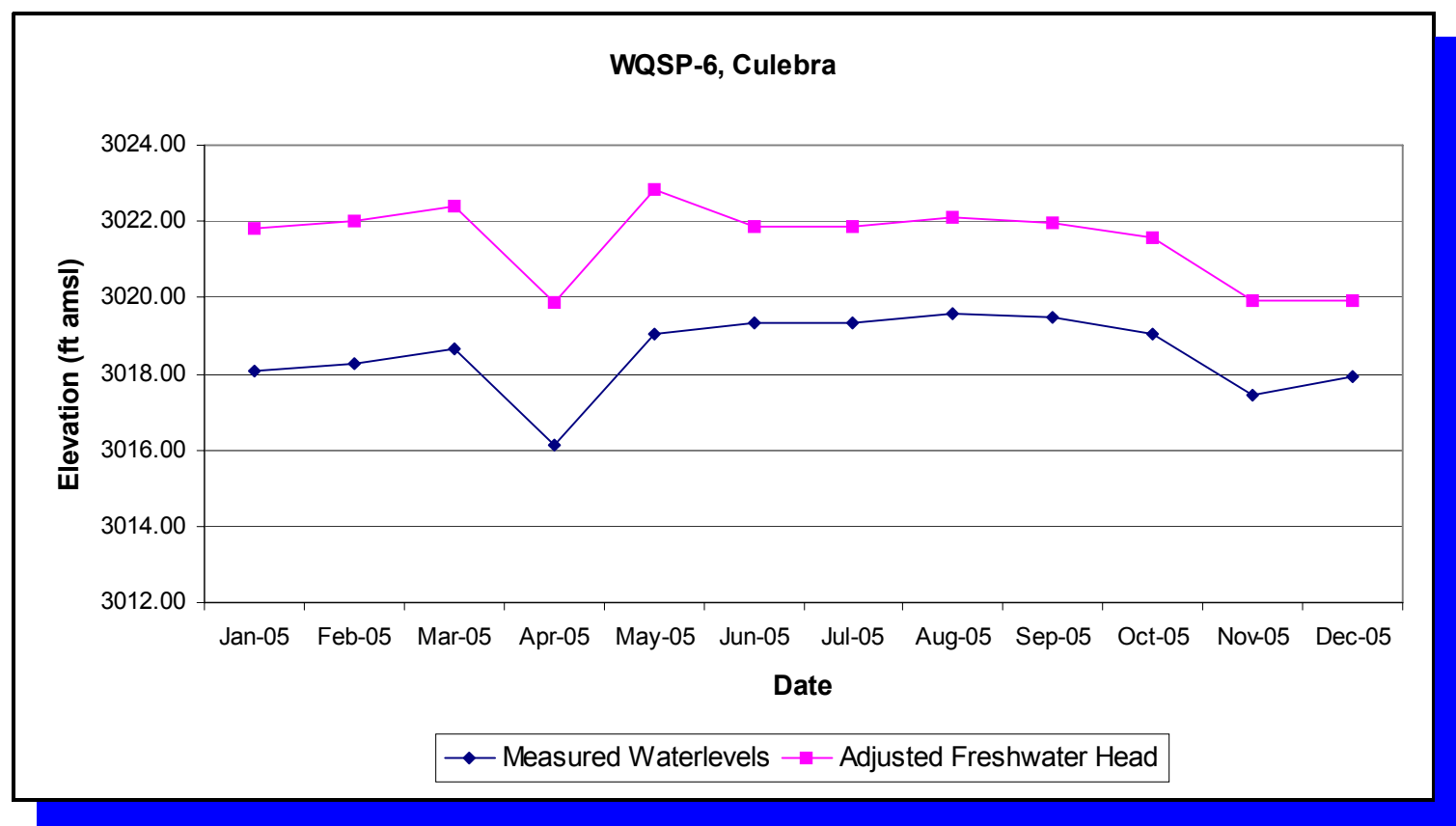

Figure 6.9 - Hydrograph of WQSP-6 


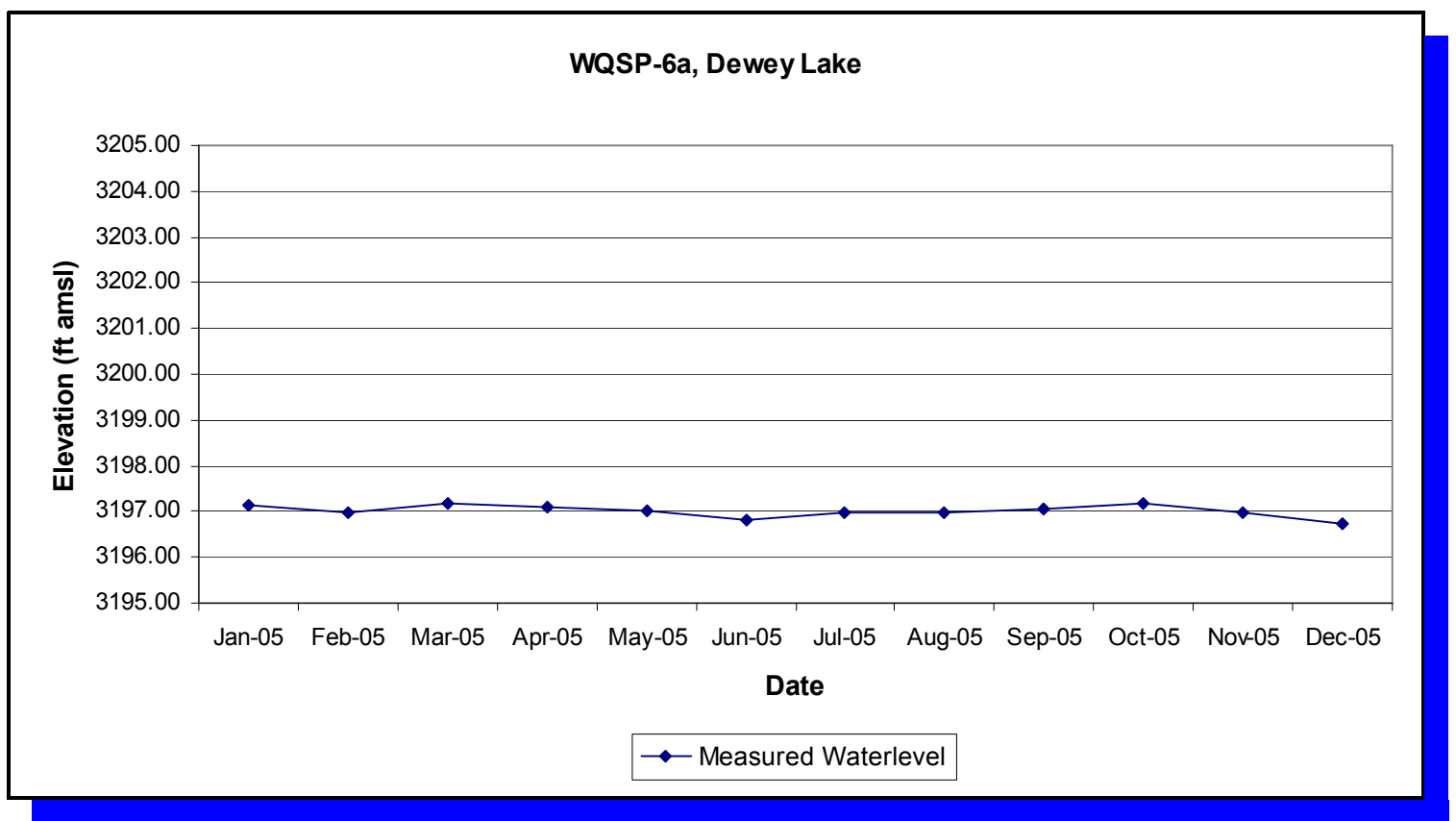

Figure 6.10 - Hydrograph of WQSP-6A

\subsubsection{Pressure Density Surveys}

At WIPP, variable TDS concentrations result in variability in groundwater density. WIPP measures the density of well-bore fluids in water level monitoring wells to adjust water levels to their equivalent fresh-water head values. This allows more accurate determination of relative water levels between wells.

In 2005, pressure-density measurements were taken in 43 wells, as shown in Table 6.3.

Table 6.3 - Pressure Density Survey for 2005

\begin{tabular}{|c|c|c|c|}
\hline Well Name & Date & Hydraulic Unit & Density \\
\hline $\mathrm{DOE}-1$ & $11 / 01 / 05$ & Culebra & $1.113 \mathrm{~g} / \mathrm{cc}$ \\
\hline $\mathrm{H}-02 \mathrm{~b} 1$ & $10 / 27 / 05$ & Magenta & $1.021 \mathrm{~g} / \mathrm{cc}$ \\
\hline $\mathrm{H}-02 \mathrm{~b} 2$ & $10 / 27 / 05$ & Culebra & $1.010 \mathrm{~g} / \mathrm{cc}$ \\
\hline $\mathrm{H}-03 \mathrm{~b} 2$ & $11 / 15 / 05$ & Culebra & $1.056 \mathrm{~g} / \mathrm{cc}$ \\
\hline $\mathrm{H}-03 \mathrm{~b} 1$ & $10 / 28 / 05$ & Magenta & $1.016 \mathrm{~g} / \mathrm{cc}$ \\
\hline $\mathrm{H}-04 \mathrm{~b}$ & $11 / 15 / 05$ & Culebra & $1.037 \mathrm{~g} / \mathrm{cc}$ \\
\hline $\mathrm{H}-04 \mathrm{c}$ & $10 / 28 / 05$ & Magenta & $1.018 \mathrm{~g} / \mathrm{cc}$ \\
\hline $\mathrm{H}-05 \mathrm{~b}$ & $10 / 24 / 05$ & Culebra & $1.106 \mathrm{~g} / \mathrm{cc}$ \\
\hline $\mathrm{C}-2737$ & $11 / 11 / 05$ & Culebra & $1.037 \mathrm{~g} / \mathrm{cc}$ \\
\hline $\mathrm{H}-06 \mathrm{~b}$ & $10 / 04 / 05$ & Culebra & $1.054 \mathrm{~g} / \mathrm{cc}$ \\
\hline $\mathrm{H}-06 \mathrm{c}$ & $10 / 04 / 05$ & Magenta & $1.021 \mathrm{~g} / \mathrm{cc}$ \\
\hline $\mathrm{H}-07 \mathrm{~b} 1$ & $11 / 01 / 05$ & Culebra & $1.009 \mathrm{~g} / \mathrm{cc}$ \\
\hline $\mathrm{H}-08 \mathrm{a}$ & $12 / 01 / 05$ & Magenta & $1.045 \mathrm{~g} / \mathrm{cc}$ \\
\hline $\mathrm{H}-9 \mathrm{c}$ & $12 / 01 / 05$ & Culebra & $1.016 \mathrm{~g} / \mathrm{cc}$ \\
\hline $\mathrm{H}-10 \mathrm{a}$ & $11 / 29 / 05$ & Magenta & $1.009 \mathrm{~g} / \mathrm{cc}$ \\
\hline
\end{tabular}


Waste Isolation Pilot Plant Annual Site Environmental Report for 2005 DOE/WIPP-06-2225

\begin{tabular}{|c|c|c|c|}
\hline \multicolumn{5}{|c|}{ Table 6.3 - Pressure Density Survey for 2005 } \\
\hline Well Name & Date & Hydraulic Unit & Density \\
\hline H-10c & $11 / 29 / 05$ & Culebra & $1.016 \mathrm{~g} / \mathrm{cc}$ \\
\hline H-11b2 & $11 / 01 / 05$ & Magenta & $1.044 \mathrm{~g} / \mathrm{cc}$ \\
\hline H-11b4 & $11 / 15 / 05$ & Culebra & $1.075 \mathrm{~g} / \mathrm{cc}$ \\
\hline $\mathrm{H}-12$ & $11 / 28 / 05$ & Culebra & $1.076 \mathrm{~g} / \mathrm{cc}$ \\
\hline $\mathrm{H}-14$ & $10 / 27 / 05$ & Magenta & $1.023 \mathrm{~g} / \mathrm{cc}$ \\
\hline $\mathrm{H}-17$ & $11 / 28 / 05$ & Culebra & $1.149 \mathrm{~g} / \mathrm{cc}$ \\
\hline $\mathrm{H}-18$ & $11 / 02 / 05$ & Magenta & $1.016 \mathrm{~g} / \mathrm{cc}$ \\
\hline $\mathrm{H}-19 \mathrm{~b} 0$ & $11 / 15 / 05$ & Culebra & $1.079 \mathrm{~g} / \mathrm{cc}$ \\
\hline IMC-461 & $10 / 04 / 05$ & Culebra & $1.036 \mathrm{~g} / \mathrm{cc}$ \\
\hline SNL-1 & $09 / 29 / 05$ & Culebra & $1.051 \mathrm{~g} / \mathrm{cc}$ \\
\hline SNL-2 & $10 / 24 / 05$ & Culebra & $1.019 \mathrm{~g} / \mathrm{cc}$ \\
\hline SNL-3 & $10 / 24 / 05$ & Culebra & $1.034 \mathrm{~g} / \mathrm{cc}$ \\
\hline SNL-5 & $09 / 28 / 05$ & Culebra & $1.019 \mathrm{~g} / \mathrm{cc}$ \\
\hline SNL-8 & $11 / 29 / 05$ & Culebra & $1.056 \mathrm{~g} / \mathrm{cc}$ \\
\hline SNL-9 & $09 / 29 / 05$ & Culebra & $1.038 \mathrm{~g} / \mathrm{cc}$ \\
\hline SNL-12 & $12 / 01 / 05$ & Culebra & $1.015 \mathrm{~g} / \mathrm{cc}$ \\
\hline SNL-13 & $11 / 17 / 05$ & Culebra & $1.062 \mathrm{~g} / \mathrm{cc}$ \\
\hline SNL-14 & $11 / 17 / 05$ & Culebra & $1.057 \mathrm{~g} / \mathrm{cc}$ \\
\hline SNL-15 & $12 / 14 / 05$ & Culebra & $1.230 \mathrm{~g} / \mathrm{cc}$ \\
\hline P-17 & $11 / 30 / 05$ & Culebra & $1.070 \mathrm{~g} / \mathrm{cc}$ \\
\hline AEC-7 & $12 / 14 / 05$ & Culebra & $1.209 \mathrm{~g} / \mathrm{cc}$ \\
\hline WIPP-11 & $11 / 02 / 05$ & Culebra & $1.043 \mathrm{~g} / \mathrm{cc}$ \\
\hline WIPP-13 & $10 / 25 / 05$ & Culebra & $1.048 \mathrm{~g} / \mathrm{cc}$ \\
\hline WIPP-18 & $10 / 25 / 05$ & Magenta & $1.013 \mathrm{~g} / \mathrm{cc}$ \\
\hline WIPP-19 & $10 / 25 / 05$ & Culebra & $1.060 \mathrm{~g} / \mathrm{cc}$ \\
\hline WIPP-25 & $11 / 30 / 05$ & Culebra & $1.013 \mathrm{~g} / \mathrm{cc}$ \\
\hline WIPP-26 & $11 / 30 / 05$ & Culebra & $1.011 \mathrm{~g} / \mathrm{cc}$ \\
\hline WIPP-30 & $11 / 14 / 05$ & Culebra & $1.019 \mathrm{~g} / \mathrm{cc}$ \\
\hline
\end{tabular}

\subsection{Drilling Activities}

Five new wells were drilled and completed in the Culebra during 2005: SNL-13, SNL-14, SNL-15, SNL-8, and SNL-6, in that order. These wells were drilled to provide new monitoring and testing locations to support continued area-wide modeling of groundwater flow in the Culebra. The new hydrologic testing and modeling is intended to address the issue of region-wide rises in Culebra water levels observed over the past several years. The wells were drilled to the south, east, and northeast of the WIPP to provide additional geologic and hydrologic information such as degree of dissolution in the upper Salado, fracturing and transmissivity of the Culebra along a suspected zone of higher transmissivity south of WIPP, and hydrologic information from lower transmissivity areas east and northeast of WIPP.

SNL-13 (permitted by the New Mexico State Engineer as C-3139) was drilled during April 2005 to provide geological data and hydrological testing of the Culebra southwest of WIPP along the interpreted margin of upper Salado dissolution along the southeast arm of Nash Draw. Specific details of drilling, geophysical description, and well 
completion will be presented in the Basic Data Report for Drillhole SNL-13 (C-3139), DOE/WIPP 05-3319.

SNL-14 (permitted by the New Mexico State Engineer as C-3140) was drilled and completed in May 2005 to provide geological data and hydrological testing of the Culebra in an area south of the WIPP site. Specific details of drilling, geophysical descriptions, and well completion can be found in the Basic Data Report for Drillhole SNL-14 (C-3140), DOE/WIPP 05-3320.

SNL-15 (permitted by the New Mexico State Engineer as C-3152) was drilled and completed in June 2005 to provide geological data and hydrological testing of the Culebra in an area east of the WIPP site. Specific details of drilling, geophysical descriptions, and well completion can be found in the Basic Data Report for Drillhole SNL-15 (C-3152), DOE/WIPP 05-3325.

SNL-8 (permitted by the New Mexico State Engineer as C-3150) was drilled and completed in June 2005 to provide geological data and hydrological testing of the Culebra in an area east of the WIPP site. Specific details of drilling, geophysical descriptions, and well completion can be found in the Basic Data Report for Drillhole SNL-8 (C-3150), DOE/WIPP 05-3324.

SNL-6 (permitted by the New Mexico State Engineer as C-3151) was drilled and completed over the period from July through September 2005 to provide geological data and hydrological testing of the Culebra in an area northeast of the WIPP site. Specific details of drilling, geophysical descriptions, and well completion can be found in the Basic Data Report for Drillhole SNL-6 (C-3151), DOE/WIPP 05-3323.

\subsection{Well Maintenance Activities}

Well maintenance activities for 2005 consisted of reconfiguration of ten monitoring network wells to single completion intervals and plugging and abandonment of fourteen monitoring wells.

Sixteen wells were surveyed for elevation reference in 2005 because they were new completions or the well was reconfigured to optimize data collection. These wells were SNL-6, SNL-8, SNL-13, SNL-14, SNL-15 (new completions), H-3d, WIPP-18, H-3b1, $\mathrm{H}-2 \mathrm{~b} 1, \mathrm{H}-2 \mathrm{~b} 2, \mathrm{H}-14, \mathrm{H}-4 \mathrm{c}, \mathrm{H}-11 \mathrm{~b} 2, \mathrm{H}-5 \mathrm{c}, \mathrm{H}-18$, and $\mathrm{H}-6 \mathrm{c}$ (resurveyed existing wells). Elevation survey results are shown in Table 6.4; new well survey data are shown in Table 6.5. 
Waste Isolation Pilot Plant Annual Site Environmental Report for 2005 DOE/WIPP-06-2225

\begin{tabular}{|c|c|c|c|}
\hline \multicolumn{4}{|c|}{ Table 6.4 - Elevation Survey Results (NGVD29*) } \\
\hline Well \# & Date Surveyed & $\begin{array}{c}\text { Casing Elevation } \\
\text { (ft amsl) }\end{array}$ & $\begin{array}{c}\text { Ground Level } \\
\text { Elevation } \\
\text { (ft amsl) }\end{array}$ \\
\hline H-3d & $10 / 25 / 05$ & $3,390.71$ & 3,387 \\
\hline WIPP-18 & $10 / 25 / 05$ & $3,457.74$ & 3,456 \\
\hline H-3b1 & $10 / 25 / 05$ & $3,390.68$ & 3,389 \\
\hline H-2b1 & $10 / 25 / 05$ & $3,378.47$ & 3,378 \\
\hline H-2b2 & $10 / 25 / 05$ & $3,378.31$ & 3,377 \\
\hline$H-14$ & $10 / 25 / 05$ & $3,347.13$ & 3,346 \\
\hline$H-4 c$ & $10 / 25 / 05$ & $3,334.09$ & 3,334 \\
\hline$H-11 b 2$ & $10 / 25 / 05$ & $3,411.91$ & 3,411 \\
\hline$H-5 c$ & $10 / 25 / 05$ & $3,506.06$ & 3,506 \\
\hline$H-18$ & $10 / 25 / 05$ & $3,414.27$ & 3,413 \\
\hline$H-6 c$ & $10 / 25 / 05$ & $3,348.52$ & 3,348 \\
\hline
\end{tabular}

${ }^{*}$ National Geodetic Vertical Datum of 1929

Table 6.5 - Survey Data of New Wells (NGVD29)

\begin{tabular}{|c|c|l|l|l|c|}
\hline Well No. & $\begin{array}{c}\text { Date } \\
\text { Surveyed }\end{array}$ & $\begin{array}{c}\text { Coordinate } \\
\mathbf{X}\end{array}$ & $\begin{array}{c}\text { Coordinate } \\
\mathbf{Y}\end{array}$ & $\begin{array}{c}\text { Casing } \\
\text { Elevation } \\
\text { (ft amsI) }\end{array}$ & $\begin{array}{c}\text { Benchmark } \\
\text { Elevation } \\
\text { (ft amsI) }\end{array}$ \\
\hline SNL-6 & $10 / 07 / 05$ & 692337.51 & 542849.55 & $3,646.11$ & $3,643.42$ \\
\hline SNL-8 & $06 / 15 / 05$ & 683169.23 & 504820.01 & $3,555.79$ & $3,553.18$ \\
\hline SNL-13 & $06 / 15 / 05$ & 656370.31 & 484695.33 & $3,294.23$ & $3,291.61$ \\
\hline SNL-14 & $06 / 15 / 05$ & 671395.94 & 484745.66 & $3,368.38$ & $3,365.71$ \\
\hline SNL-15 & $06 / 05 / 05$ & 682542.25 & 493512.95 & $3,481.23$ & $3,479.22$ \\
\hline
\end{tabular}

\subsection{Shallow Subsurface Water Monitoring Program}

Shallow subsurface water occurs beneath the WIPP site at a depth of less than $100 \mathrm{ft} \mathrm{bgl}$ at the contact between the Santa Rosa Formation and the upper Dewey Lake Redbeds Formation (Figure 6.11). The formations containing shallow water yield generally less than one gallon per minute in monitoring wells and piezometers and contain high concentrations of TDS and chloride. The origin of this water is believed to be primarily from anthropogenic causes, with some contribution from natural sources. The shallow subsurface water occurs not only under the WIPP site surface facilities but also to the south as indicated by shallow water in drill hole C-2811, about one half mile south of the Waste Handling Shaft (Figure 6.11). Natural shallow groundwater occurs in the middle part of the Dewey Lake Redbeds Formation at the southern portion of the WIPP site and to the south of the WIPP site. To date, there is no indication that the shallow subsurface water has affected the naturally occurring groundwater in the Dewey Lake Redbeds Formation. 
Since discovery of the shallow subsurface water in the exhaust shaft in 1995, 12 piezometers and four wells (C-2505, C-2506, C-2507, and C-2811) have been part of a monitoring program to measure spatial and temporal changes in shallow subsurface water levels and water quality. Shallow subsurface water monitoring activities during 2005 included shallow subsurface water level surveillance at these 16 locations (Figure 6.11).

An application was submitted to the NMED Ground Water Quality Bureau to modify the existing Discharge Permit, DP-831, to address discharges associated with salt storage operations. In this application it was proposed to build a new salt storage area and a new salt storage evaporation basin, and to reshape the existing salt pile and close it by installing a geotextile/synthetic liner cover. Additionally, the application proposed installing synthetic liners in all existing evaporation ponds at the facility. The liners are designed to limit infiltration of surface water to the shallow subsurface. The DP-831 permit modification application also proposed a monitoring and sampling plan for the shallow subsurface water well/piezometer network.

The application was approved by the NMED Ground Water Quality Bureau and a Discharge Permit Modification for DP-831 was issued on December 22, 2003. The permit included all modifications to the salt storage and evaporation pond operations described above. Additionally, the permit contained specific language that addressed the monitoring program for the shallow subsurface water monitoring network. The permit requires quarterly monitoring of water levels and semiannual sampling from 12 wells/piezometers. Required parameters for laboratory analysis are nitrate, sulfate, chloride, TDS, selenium, and chromium. Field parameters $(\mathrm{pH}$, conductivity, and temperature) are also to be measured during serial sampling. Additional information regarding the status of this permit is found in Section 2.2.6. 
Waste Isolation Pilot Plant Annual Site Environmental Report for 2005 DOE/WIPP-06-2225

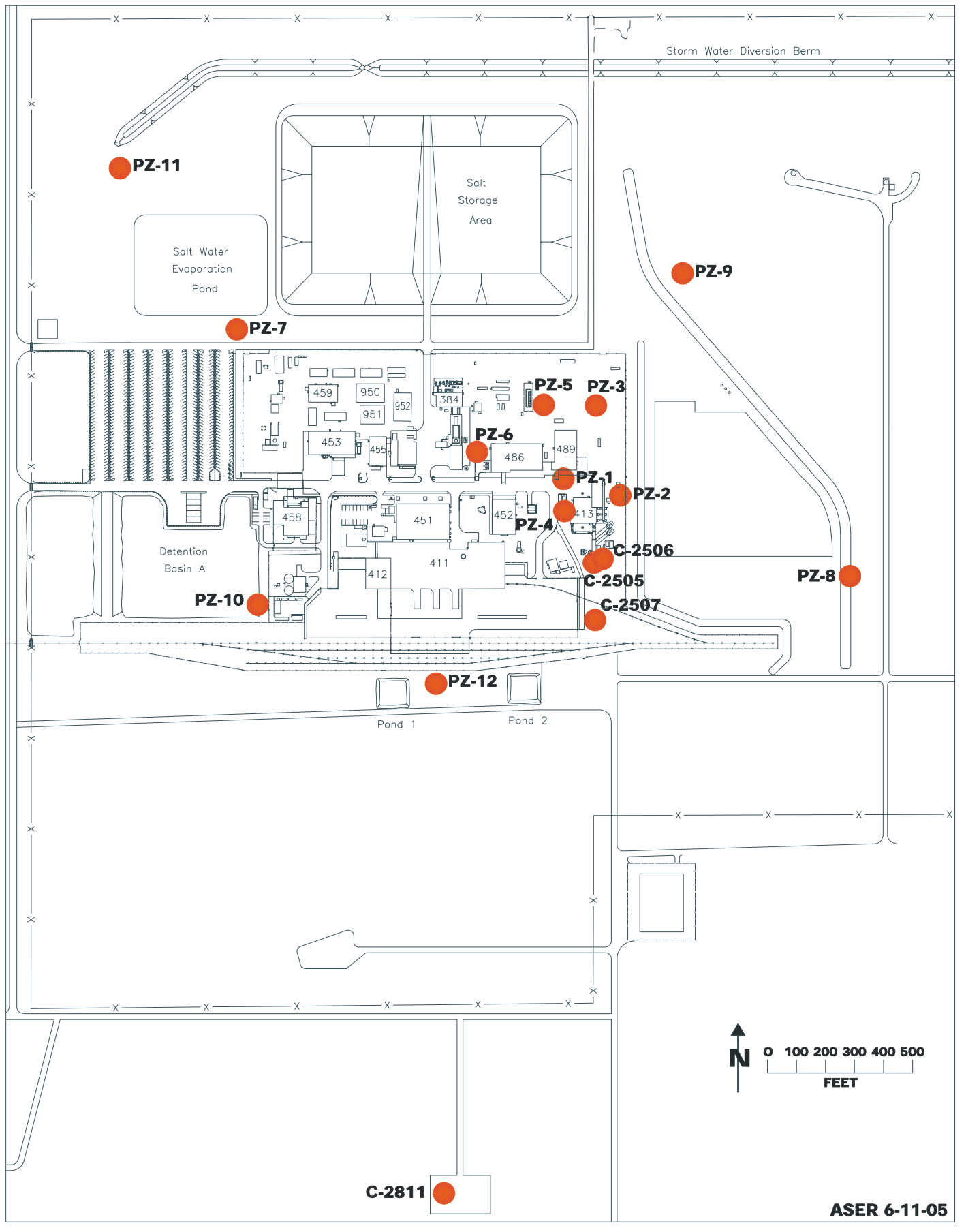

Figure 6.11 - Locations of SSW Wells (Piezometers PZ-1 through 12; Wells C-2811, C-2505, C-2506, and C-2507 


\section{Waste Isolation Pilot Plant Annual Site Environmental Report for 2005 DOE/WIPP-06-2225}

\subsubsection{Shallow Subsurface Water Quality Sampling}

DP-831, as modified, requires ten SSW wells to be sampled on a semiannual basis. Wells PZ-1, PZ-5, PZ-6, PZ-7, PZ-9, PZ-10, PZ-11, PZ-12, C-2811, and C-2507 are sampled for this program. All wells were sampled in May and October 2005 and laboratory analyzed for the parameters presented in the previous section. Results are indicated in Table 6.6.

\begin{tabular}{|c|c|c|c|c|c|c|c|}
\hline \multirow[b]{2}{*}{$\begin{array}{l}\text { Monitoring } \\
\text { Site }\end{array}$} & \multicolumn{5}{|c|}{ General Chemistry Parameters } & \multicolumn{2}{|c|}{ Trace Metals } \\
\hline & $\begin{array}{c}\text { Sample } \\
\text { Date }\end{array}$ & $\begin{array}{l}\text { Nitrate } \\
\text { (mg/L) }\end{array}$ & $\begin{array}{l}\text { Sulfate } \\
\text { (mg/L) }\end{array}$ & $\begin{array}{l}\text { Chloride } \\
\text { (mg/L) }\end{array}$ & $\begin{array}{c}\text { TDS } \\
\text { (mg/L) }\end{array}$ & $\begin{array}{l}\text { Selenium } \\
\text { (mg/L) }\end{array}$ & $\begin{array}{c}\text { Chromium } \\
\text { (mg/L) }\end{array}$ \\
\hline PZ-1 & $5 / 17 / 05$ & 1.47 & 2,640 & 62,300 & 100,500 & 0.0600 & 0.0770 \\
\hline PZ-1 & $10 / 11 / 05$ & 2.59 & 1,950 & 54,900 & 74,800 & 0.0430 & $<0.0100$ \\
\hline PZ-5 & $5 / 17 / 05$ & 2.96 & 3,260 & 46,000 & 65,400 & 0.0930 & 0.0670 \\
\hline PZ-5 & $10 / 11 / 05$ & 5.14 & 769 & 14,000 & 32,800 & 0.0620 & $<0.0100$ \\
\hline PZ-6 & $5 / 17 / 05$ & 4.25 & 3,610 & 109,000 & 160,500 & 0.0500 & 0.0540 \\
\hline PZ-6 & $10 / 11 / 05$ & $<20.0$ & 2,850 & 83,800 & 106000 & 0.0210 & $<0.0100$ \\
\hline PZ-7 & $5 / 16 / 05$ & 4.02 & 2,530 & 42,100 & 65,900 & 0.0820 & 0.0940 \\
\hline PZ-7 & $10 / 10 / 05$ & 6.37 & 2,770 & 61,000 & 88,000 & 0.0470 & $<0.0100$ \\
\hline PZ-9 & $5 / 17 / 05$ & 2.82 & 5,090 & 182,000 & 164,000 & 0.0500 & 0.0710 \\
\hline PZ-9 & $10 / 11 / 05$ & $<20.0$ & 3,930 & 85,500 & 107,000 & 0.0220 & $<0.0100$ \\
\hline PZ-10 & $5 / 16 / 05$ & 3.63 & 572 & 416 & 1,756 & 0.0440 & 0.0370 \\
\hline PZ-10 & $10 / 10 / 05$ & 3.34 & 515 & 318 & 1,720 & 0.0150 & $<0.0100$ \\
\hline PZ-11 & $5 / 16 / 05$ & 4.63 & 2,890 & 66,000 & 100,000 & $<0.0100$ & $<0.0100$ \\
\hline PZ-11 & $10 / 10 / 05$ & $<20.0$ & 2,950 & 84,300 & 129,000 & 0.0130 & $<0.0100$ \\
\hline PZ-12 & $5 / 16 / 05$ & 8.85 & ,679 & 3,730 & 5,890 & 0.0510 & 0.0540 \\
\hline PZ-12 & $10 / 10 / 05$ & 426 & 805 & 3,790 & 7,740 & 0.0200 & $<0.0100$ \\
\hline C-2811 & $5 / 16 / 05$ & 6.02 & 524 & 1,930 & 3,740 & 0.0580 & 0.0530 \\
\hline C-2811 & $10 / 10 / 05$ & 7.48 & 584 & 2,250 & 4,410 & 0.0340 & $<0.0100$ \\
\hline C-2507 & $5 / 17 / 05$ & 7.94 & 860 & 1,370 & 3,340 & 0.0780 & 0.0630 \\
\hline C-2507 & $10 / 11 / 05$ & 6.13 & 920 & 1,630 & 3,240 & 0.0470 & $<0.0100$ \\
\hline
\end{tabular}

When the SSW wells and piezometers were sampled in October 2005, all SSW infiltration areas had been lined for two months. When the May 2005 sampling event occurred, the SSW infiltration area still not lined was Pond A. Below is a summary discussion of Total Dissolved Solids (TDS) and Chloride (Cl); both trend indicators.

Piezometers PZ-7 and PZ-11 are located near the old Salt Storage Area (SSA) and the Salt Pile Evaporation Pond (SPEP), respectively. These wells have been influenced by the solute disposition in the SPEP and through infiltration of rainfall through the SSA prior to the lining of these source areas. TDS and $\mathrm{Cl}$ concentrations fluctuated in 2005. Concentrations appear to be influenced by rainfall with a one to two-month lag period. 
There appears to be an increase in TDS and $\mathrm{Cl}$ concentrations one to two months after a significant rain event.

TDS and $\mathrm{Cl}$ are the lowest in PZ-10. Pond A had only been lined for two months prior to the October 2005 sampling and was not lined prior to the May 2005 sampling event. Pond A captures most of the run-off water from the WIPP site and is relatively fresh rainwater.

PZ-12 is located south of the WIPP site between Pond 1 and Pond 2. Before these two ponds were lined the SSW was influenced by more freshwater infiltration from these ponds than after; however the TDS and $\mathrm{Cl}$ concentrations are still on a decreasing trend, more so after the liner installation. This might be due to a lesser water contribution overall from the lined, higher-concentration recharge sources.

C-2811 is located further south of the WIPP facility, down-gradient from PZ-12. This well has lower TDS and Cl than PZ-12. Owing to the newness of the lined sources, temporal trends are not fully defined. This pertains both to water levels and SSW piezometer concentrations.

\subsubsection{Shallow Subsurface Water Level Surveillance}

Sixteen wells were used to perform surveillance of the shallow subsurface waterbearing horizon in the Santa Rosa Formation and the upper portion of the Dewey Lake Redbeds Formation. Water levels were collected quarterly for all locations presented in Figure 6.11 (Appendix F, Table F.8). Well PZ-8 is dry.

Groundwater elevation measurements in the shallow subsurface water indicate that flow moves east and south away from a potentiometric high located near PZ-7 adjacent to the Salt Pile Evaporation Pond (Figure 6.12). A potentiometric low is located near both PZ-12 and PZ-8. 


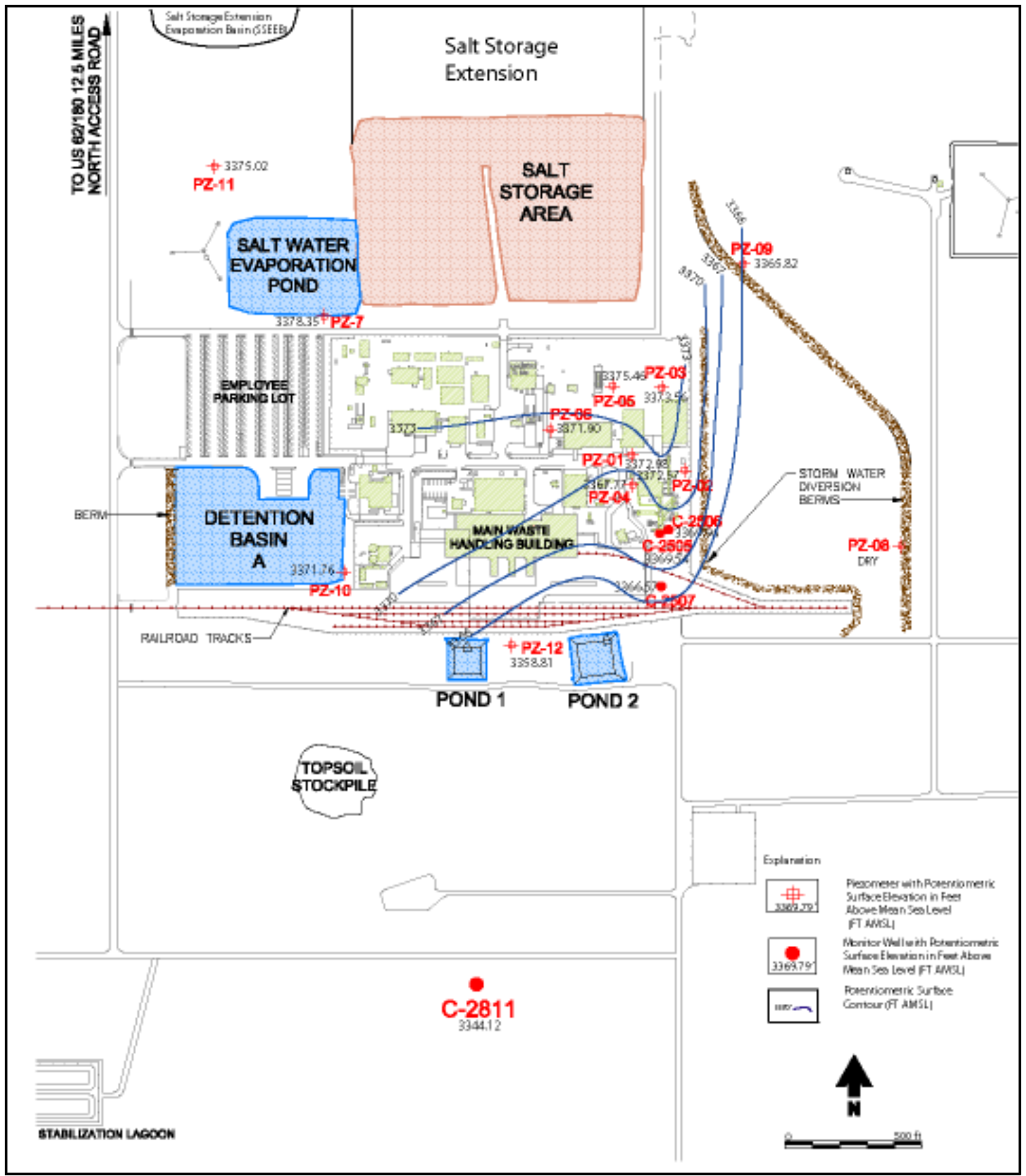

Figure 6.12 - Contour Plot of SSW Potentiometric Surface in the Santa Rosa Formation 


\subsection{Public Drinking Water Protection}

The water wells nearest the WIPP site that are using the natural shallow groundwater for domestic use are the Barn Well and Ranch Well located on the J. C. Mills Ranch. These wells are located approximately three miles south-southwest of the WIPP surface facilities, and about 1.75 miles south of WQSP-6A (see Figure 6.1 for location of WQSP-6A). TDS concentrations in the Barn Well have ranged from 630 to $720 \mathrm{mg} / \mathrm{L}$, and TDS concentrations in the Ranch Well have ranged from 2,800 to 3,300 mg/L (DOE, 1996).

Because of the nearest potable water supply at the Mills Ranch and the discovery of shallow subsurface water at the site, a water budget analysis of the shallow subsurface water was performed by Daniel B. Stephens \& Associates. The analysis was performed to evaluate important hydrologic processes controlling the shallow subsurface water and provide:

- An estimate of the volume of water contained within the perched zone

- Quantification of seepage inputs to the SSW from past and current practices

- A model of SSW accumulation, flow conditions, and potential long-term migration

- Determination of the effects of engineered seepage reduction measures that could be implemented at existing seepage sources

The water budget analysis included compilation of recorded discharges, site drainage summary, surface infiltration modeling, saturated flow modeling, and long-term migration modeling. Water budget results indicated that seepage from five primary sources (salt pile and four surface water detention basins) provided sufficient recharge to account for the observed shallow subsurface water saturated lens and that the lens is expected to spread.

The potential extent for long-term shallow subsurface water migration was examined by expanding the saturated flow model domain to include the 16-square-mile WIPP land withdrawal area. The long-term migration model simulations indicated that the engineered seepage controls would substantially reduce the extent of migration (Daniel B. Stephens \& Associates, Inc., 2003).

When the SSW wells and piezometers were sampled in October, all SSW infiltration areas had been lined for two months. When the May 2005 sampling event occurred, the SSW infiltration area still not lined was Pond A. Below is a summary discussion of Total Dissolved Solids (TDS) and Chloride (Cl); both trend indicators.

Piezometers PZ-7 and PZ-11 are located near the old Salt Storage Area (SSA) and the Salt Pile Evaporation Pond (SPEP), respectively. These wells have been influenced by the solute disposition in the SPEP and through infiltration of rainfall through the SSA prior to the lining of these source areas. TDS and Cl concentrations fluctuated in 2005. 
Concentrations appear to be influenced by rainfall with a one to two-month lag period. One to two months after a significant rain event there appears to be an increase in TDS and $\mathrm{Cl}$ concentrations.

TDS and $\mathrm{Cl}$ are the lowest in PZ-10. Pond A had only been lined for two months prior to the October 2005 sampling and was not lined prior to the May 2005 sampling event. Pond A captures most of the run-off water from the WIPP site and is relatively fresh rainwater.

PZ-12 is located south of the WIPP site between Pond 1 and Pond 2. Before these two ponds were lined the SSW was influenced by more freshwater infiltration from these ponds than after; however the TDS and $\mathrm{Cl}$ concentrations are still on a decreasing trend, more so after the liner installation. This might be due to a lesser water contribution overall from the lined, higher-concentration recharge sources.

C-2811 is located further south of the WIPP facility, down-gradient from PZ-12. This well has lower TDS and Cl than PZ-12. Owing to the newness of the lined sources, temporal trends are not fully defined. This pertains both to water levels and SSW piezometer concentrations. 


\section{CHAPTER 7 - QUALITY ASSURANCE}

The fundamental objective of a QA program, as applied to environmental work, is to ensure that high-quality measurements are produced and reported from the analyses of samples collected using proven methods and practices. The defensibility of data generated by laboratories must be based on sound scientific principles, method evaluations, and data verification and validation.

In 2005, WIPP Laboratories performed the radiological analyses of WIPP environmental samples, while contract laboratories, CEMRC, in Carlsbad, New Mexico and Trace Analysis, in Lubbock, Texas, performed the nonradiological analyses. All laboratories were required contractually to have documented QA programs, including standard procedures to perform the work. All laboratories, with the exception of CEMRC, were required to participate in intercomparison programs with such entities as the National Institute of Standards and Technology Radiochemistry Intercomparison Program (NRIP), the Mixed Analyte Performance Evaluation Program (MAPEP), the Environmental Resource Associates ${ }^{\circledR}$ (ERA) interlaboratory assessment, and/or any other reputable intercomparison program. Internal evaluation of comparison samples was performed as part of the initial laboratory qualification. CEMRC was subjected to comparison samples that were also analyzed by Air Toxics. Results of this comparison are discussed in Section 7.2.4. Laboratories used by the WIPP program are required to meet the applicable requirements of the CBFO Quality Assurance Program Document (QAPD) (DOE/CBFO-94-1012).

The laboratories also used one or more of these accepted protocols in their QA program:

- $\quad$ American Society of Mechanical Engineers NQA [Nuclear Quality Assurance] -1-1989; ASME NQA-2a-1990 addenda, part 2.7, to ASME NQA-2-1989 edition, and ASME NQA-3-1989 edition (excluding Section 2.1(b) and (c), and Section 17.1)

- $\quad$ Title 10 CFR Part 50, Appendix B, "Quality Assurance Criteria for Nuclear Power Plants and Fuel Reprocessing Plants"

- $\quad$ EPA/600 14-83-004, QAMS-005/80, Interim Guidelines and Specification for Preparing Quality Assurance Project Plans

- $\quad$ NRC Regulatory Guide 4.15, Rev. 1, Quality Assurance for Radiological Monitoring Program-Effluent Streams and the Environment

- $\quad$ HPS N13.30 ANSI [American National Standards Institute], Performance Criteria for Radiobioassay 
- $\quad$ ISO/IEC DIS 17025, General Requirements for the Competence of Testing and Calibration Laboratories, International Organization for Standardization.

- $\quad$ National Environmental Laboratory Accreditation Program (NELAP)

The WIPP sampling program and its analytical laboratories operate in accordance with Quality Assurance Plans and Quality Assurance Project Plans that include elements described in the Uniform Federal Policy (UFP) for Implementing Environmental Quality Systems, issued in January 2003; and the associated Draft Uniform Federal Policy for Quality Assurance Project Plans, issued in August 2003 (an implementation tool for meeting certain requirements within DOE Order 450.1 concerning environmental data quality). These plans contain such elements as:

- Management and Organization

- Quality System and Description

- $\quad$ Personnel Qualification and Training

- $\quad$ Procurement of Products and Services

- Documents and Records

- $\quad$ Computer hardware and Software

- Planning

- Management of Work Process (Standard Operating Procedures)

- $\quad$ Assessment and Response

- $\quad$ Quality Improvement

Assessments and audits were performed to ensure that the quality of the systems, processes, and deliverables were maintained or improved. Along with protocols listed above, WIPP must also implement DOE Order 414.1C, Quality Assurance. The parameters for performance evaluations are completeness, precision, accuracy, comparability, and representativeness.

Representativeness is the extent to which measurements actually represent the true environmental condition or population at the time a sample was collected. The primary objective of environmental monitoring is to protect the health and safety of the population surrounding the WIPP facility. Samples of ambient air, surface water, sediment, soil, groundwater, and biota were collected from areas representative of potential pathways for intake. 
The samples were collected using generally accepted methodologies for environmental sampling and approved procedures, ensuring they were representative of the media sampled. These samples were analyzed for natural radioactivity, fallout radioactivity from nuclear weapons tests, and other anthropogenic radionuclides. The reported concentrations at various locations were representative of the baseline information for radionuclides of interest at the WIPP facility.

In 2005, three laboratories provided services to WIPP. Sections 7.1, 7.2, and 7.3 discuss the quality control results for the WIPP Laboratories, CEMRC, and Trace Analysis respectively, in terms of how they met the performance evaluation parameters.

\subsection{WIPP Laboratories}

\subsubsection{Completeness}

The Statement of Work (SOW) for analyses performed by WIPP Laboratories states that "analytical completeness, as measured by the amount of valid data collected versus the amount of data expected or needed, shall be greater than 90 percent for WTS sampling programs." For radiological sampling and analysis programs, this contract requirement translates into the following quantitative definition.

Completeness is expressed as the number of samples analyzed with valid results as a percent of the total number of samples submitted for analysis, or

$$
\% C=\frac{V}{n} \times 100
$$

Where:

$\% \mathrm{C}=$ Percent Completeness

$V=$ Number of Samples with Valid Results

$\mathrm{n}=$ Number of Samples Submitted for Analysis

Samples and measurements for all environmental media (air particulate composites, groundwater, surface water, soil, sediment, and animal and plant tissues) were 100 percent complete for 2005 .

\subsubsection{Precision}

The SOW states that analytical precision (as evaluated through replicate measurements) will meet or surpass control criteria or guidelines established in the industry-standard methods used for sample analysis. To ensure overall quality of analysis of environmental samples, precision was evaluated for both sample collection 
and sample analysis. Precision or reproducibility in sample collection was evaluated through comparison of analytical results for duplicate collected samples. A portable low-volume air sampler was rotated in each quarter from location to location, and was operated along with routine stationary air particulate samplers. The results of these duplicate comparisons are shown in Table 4.3 for the four quarters of 2005 . The duplicate samples for other environmental media were collected at the same time, same place, and under similar conditions as routine samples. Tables 4.3, 4.6, 4.10, 4.14, 4.18, and 4.20 show duplicate results for air filter composites, groundwater, surface water, sediment, soil, and vegetation samples, respectively.

The measure of precision used is the Relative Error Ratio (RER). The RER is expressed as follows:

$$
R E R=\frac{\mid(\text { MeanActivity })_{\text {ori }}-(\text { MeanActivity })_{\text {dup }} \mid}{\sqrt{(2 \times S D)^{2}{ }_{\text {ori }}+(2 \times S D)^{2} \text { dup }}}
$$

Where:

$\begin{array}{lll}(\text { Mean Activity })_{\text {ori }} & = & \text { Mean Activity of Original Sample } \\ (\text { Mean Activity })_{\text {dup }} & = & \text { Mean Activity of Duplicate Sample } \\ \text { SD } & = & \text { Standard Deviation of Original and Duplicate Samples }\end{array}$

RER results equal to or less than one are acceptable and considered to demonstrate reproducibility. RERs for some collection duplicates were less than one for multiple constituents, indicating good reproducibility of sampling techniques and methods. One or more duplicate pairs for air particulates, groundwater, sediments, soil, and vegetation showed RERs greater than one, indicating poor reproducibility (Tables 4.3, 4.5, 4.6, $4.14,4.18$, and 4.20$)$. The cause is unclear but may be due to inhomogeneities in the sampled media.

Laboratory precision was verified through analysis by the laboratory of replicate samples. Replicate analyses are performed on 10 percent of samples when sample volume allows. A second aliquot is taken of the chosen sample and prepared and analyzed with the associated batch. If the sample replicates do not meet the RER acceptance criterion, the entire batch is re-aliquoted and analyzed again. If the RER acceptance criterion is not met the second time, it indicates that the original sample is inhomogeneous. All laboratory replicates passed the RER acceptance criterion, indicating acceptable laboratory precision.

\subsubsection{Accuracy}

The SOW requires accuracy (as evaluated through analytical spikes) to meet or surpass control criteria or guidelines established in the industry-standard methods used for sample analysis. Instrument accuracy was assured/controlled by using National 
Institute of Standards and Technology (NIST) traceability for instrument calibration. Overall analytical accuracy is maintained through the use of NIST-traceable, spiked, laboratory control samples (LCSs). Analysis of LCSs containing the isotopes of interest is performed on a 10 percent basis (one per every ten samples or part thereof). Results must be within plus or minus 20 percent of the known values. If this criterion is not met, the entire batch of samples is reanalyzed. LCS results for each isotope are tracked on a running basis on control charts. All LCS results fell within the acceptable ranges, indicating good accuracy.

Accuracy is also ensured through participation by the laboratory in the DOE MAPEP and NRIP interlaboratory comparison programs, as discussed in more detail in Section 7.1.4 below. Under these programs, the WIPP Laboratories sample analysis results of furnished samples are compared with the results obtained by the MAPEP and NRIP. Performance is established by percent bias, calculated as shown below.

$$
\% \text { Bias }=\frac{\left(A_{m}-A_{k}\right)}{A_{k}} \times 100
$$

Where:

$\begin{array}{lll}\% \text { Bias } & = & \text { Percent Bias } \\ A_{m} & = & \text { Measured Sample Activity } \\ A_{k} & = & \text { Known Sample Activity }\end{array}$

\subsubsection{Comparability}

The SOW requires analytical comparability to be assured through the consistent use of standard sampling and analytical methods, and analytical methods that are equivalent in method performance criteria and reporting units for specific lists of target parameters. Sampling comparability is maintained through the use of standardized sample collection methods and procedures that govern the disposition of the samples and their transfer to the laboratory. The WIPP Laboratories ensure consistency through the use of standard analytical methods coupled with specific procedures that govern the handling of samples and the reporting of analysis results.

Comparability is reinforced through participation by the WIPP Laboratories in interlaboratory comparison programs. In 2005, the WIPP Laboratories participated in the DOE MAPEP and the NRIP programs. The MAPEP and NRIP prepared QC samples containing various alpha-, beta-, and gamma-emitting nuclides in synthetic urine, synthetic feces, air filter, water, soil, and vegetation media and distribute them to participating laboratories. The programs are interlaboratory comparisons in that results from the participants are compared with the experimentally determined results of MAPEP and NRIP. Also, the administering programs assess the results as acceptable or not, based on the accuracy of the analyses.

Tables 7.1 and 7.2 contain the NRIP comparisons for synthetic urine and synthetic feces, and MAPEP results for air filter, water, soil, and vegetation, respectively for 2005. 
Results of the NRIP comparisons for 2005 are presented in Table 7.1. NRIP results were rated as "P" (for pass) for all applicable radionuclides in synthetic urine and synthetic feces. All MAPEP bias results were acceptable (-25 percent/+50 percent) for all radionuclides and media of interest at the WIPP site.

\subsubsection{Representativeness}

According to the SOW, analytical representativeness is assured through the application of technically sound and accepted approaches for environmental investigations, industry-standard procedures for sample collection, and monitoring for potential sample cross-contamination through the analysis of field-generated and laboratory blank samples. These conditions were satisfied through the sample collection and analysis practices of the WIPP Environmental Monitoring Program. The environmental media samples (air, groundwater, surface water, soil, sediment, and biota) were collected from areas representative of potential pathways for intake. The samples were collected using generally accepted methodologies for environmental sampling and approved procedures, ensuring that they would be representative of the media sampled. Both sample collection blanks and analytical method blanks were used to check for cross-contamination and ensure sample purity.

Table 7.1 - NRIP for WIPP Laboratories, 2005

\begin{tabular}{|c|c|c|c|c|c|c|c|c|c|c|c|c|}
\hline \multirow[b]{3}{*}[RN]{$^{b}$} & \multicolumn{6}{|c|}{ Synthetic Urine (Bq/sample) } & \multicolumn{4}{|c|}{ Synthetic Feces (Bq/g) } & \multirow[b]{3}{*}{$\mathbf{E}$} & \multirow[b]{3}{*}{$\begin{array}{c}\% \\
\text { Bias }\end{array}$} \\
\hline & \multicolumn{2}{|c|}{ Reported } & \multicolumn{2}{|c|}{ NIST $^{a}$} & \multirow[b]{2}{*}{ E. ${ }^{c}$} & \multirow[b]{2}{*}{$\begin{array}{c}\% \\
\text { Bias }\end{array}$} & \multicolumn{2}{|c|}{ Reported } & \multicolumn{2}{|c|}{ NIST } & & \\
\hline & Value & $\begin{array}{l}\% 2 \sigma \\
\text { Error }\end{array}$ & Value & $\begin{array}{l}\% 2 \sigma \\
\text { Error }\end{array}$ & & & Value & $\begin{array}{l}\% 2 \sigma \\
\text { Error }\end{array}$ & Value & $\begin{array}{l}\% 2 \sigma \\
\text { Error }\end{array}$ & & \\
\hline${ }^{241} \mathrm{Am}$ & 0.8431 & 9.541 & 0.897 & 0.64 & $P$ & -6.01 & 1.45 & 13.15 & 1.4 & 0.64 & $\mathrm{P}$ & 3.57 \\
\hline${ }^{238} \mathrm{Pu}$ & 1.101 & 7.622 & 0.997 & 0.68 & $P$ & 10.4 & 1.35 & 18.6 & 1.546 & 0.68 & $\mathrm{P}$ & -12.7 \\
\hline${ }^{239+240} \mathrm{Pu}$ & 1.02 & 7.805 & 0.936 & 0.68 & $\mathrm{P}$ & 8.97 & 1.23 & 19.3 & 1.463 & 0.68 & $\mathrm{P}$ & -15.9 \\
\hline${ }^{90} \mathrm{Sr}$ & 2.803 & 13.84 & 2.256 & 0.74 & $\mathrm{P}$ & 24.2 & 3.1 & 20 & 3.442 & 0.74 & $\mathrm{P}$ & -9.94 \\
\hline${ }^{234} U$ & 2.197 & 5.43 & 2.224 & 0.98 & $P$ & -1.21 & 3.04 & 7.42 & 3.476 & 0.98 & $P$ & -12.5 \\
\hline${ }^{235} \mathrm{U}$ & 0.1078 & 21.4 & 0.106 & 0.62 & $P$ & 1.7 & 0.171 & 27.9 & 0.166 & 0.62 & $\mathrm{P}$ & 3.01 \\
\hline${ }^{238} \mathrm{U}$ & 2.272 & 5.37 & 2.309 & 0.6 & $\mathrm{P}$ & -1.6 & 3.29 & 7.13 & 3.608 & 0.6 & $\mathrm{P}$ & -8.81 \\
\hline
\end{tabular}

${ }^{a}$ National Institute of Standards and Technology

${ }^{\text {b }}$ Radionuclide

${ }^{c}$ Evaluation Rating $(P=$ pass, $F=$ fail)

\begin{tabular}{|c|c|c|c|c|c|c|c|c|}
\hline \multirow[b]{2}{*}[\mathbf{RN}]{$^{\mathrm{a}}$} & \multicolumn{4}{|c|}{$\begin{array}{c}\text { MATRIX: Air Filter (Bq/Sample) } \\
\text { MAPEP-05RdF13 }\end{array}$} & \multicolumn{4}{|c|}{$\begin{array}{l}\text { MATRIX: Water Standard (Bq/L) } \\
\text { MAPEP-05 MaW13 }\end{array}$} \\
\hline & $\begin{array}{l}\text { Reported } \\
\text { Value }\end{array}$ & $\begin{array}{l}\text { MAPEP }^{b} \\
\text { Value }\end{array}$ & $\mathrm{E}^{\mathrm{c}}$ & $\%$ Bias & $\begin{array}{l}\text { Reported } \\
\text { Value }\end{array}$ & $\begin{array}{l}\text { MAPEP } \\
\text { Value }\end{array}$ & E & $\%$ Bias \\
\hline${ }^{241} \mathrm{Am}$ & 0.1005 & 0.102 & $A$ & -1.5 & 1.621 & 1.72 & A & -5.8 \\
\hline${ }^{60} \mathrm{Co}$ & 3.08 & 3.03 & A & 1.7 & 266.4 & 251 & A & 6.1 \\
\hline${ }^{134} \mathrm{Cs}$ & 3.182 & 3.51 & $A$ & -9.3 & 119.8 & 127 & A & -5.7 \\
\hline${ }^{137} \mathrm{Cs}$ & 2.173 & 2.26 & A & -3.9 & 318 & 332 & A & -4.2 \\
\hline${ }^{238} \mathrm{Pu}$ & 0.192 & 0.195 & A & -1.5 & 0.0162 & 0.018 & A & 10 \\
\hline${ }^{239+240} \mathrm{Pu}$ & 0.157 & 0.165 & A & -4.8 & 2.489 & 2.4 & A & 3.7 \\
\hline
\end{tabular}


Waste Isolation Pilot Plant Annual Site Environmental Report for 2005 DOE/WIPP-06-2225

\begin{tabular}{|c|c|c|c|c|c|c|c|c|}
\hline${ }^{90} \mathrm{Sr}$ & 1.249 & 1.35 & $A$ & -7.5 & 0.0128 & $\mathrm{NR}$ & $\bar{A}$ & $N R^{d}$ \\
\hline${ }^{234 / 233} \mathrm{U}$ & 0.358 & 0.34 & A & 5.3 & 3.409 & 3.24 & A & 5.2 \\
\hline${ }^{238} \mathrm{U}$ & 0.358 & 0.352 & A & 1.7 & 3.567 & 3.33 & A & 7.1 \\
\hline \multicolumn{5}{|c|}{$\begin{array}{c}\text { MATRIX: Soil Standard (Bq/kg) } \\
\text { MAPEP-05-MaS13 }\end{array}$} & \multicolumn{4}{|c|}{$\begin{array}{c}\text { MATRIX: Vegetation (Bq/sample) } \\
\text { MAPEP-05-RdV13 }\end{array}$} \\
\hline [RN] & $\begin{array}{l}\text { Reported } \\
\text { Value }\end{array}$ & $\begin{array}{l}\text { MAPEP } \\
\text { Value }\end{array}$ & $\mathrm{E}$ & $\%$ Bias & $\begin{array}{l}\text { Reported } \\
\text { Value }\end{array}$ & $\begin{array}{l}\text { MAPEP } \\
\text { Value }\end{array}$ & E & $\%$ Bias \\
\hline${ }^{241} \mathrm{Am}$ & 101.5 & 109 & A & -6.9 & 0.132 & 0.145 & A & -9 \\
\hline${ }^{60} \mathrm{Co}$ & 215 & 212 & A & 1.4 & 2.593 & 3.15 & A & -17.7 \\
\hline${ }^{134} \mathrm{Cs}$ & 592 & 759 & W & -22 & 3.73 & 5 & A & -25.4 \\
\hline${ }^{137} \mathrm{Cs}$ & 276 & 315 & A & -12.4 & 3.09 & 4.11 & A & -24.8 \\
\hline${ }^{238} \mathrm{Pu}$ & 0.638 & 0.48 & A & NR & 0.2262 & 0.224 & A & 1 \\
\hline${ }^{239+240} \mathrm{Pu}$ & 90.61 & 89.5 & A & 1.2 & 0.001 & 0.001 & A & 0 \\
\hline${ }^{90} \mathrm{Sr}$ & 597 & 640 & A & -6.7 & NR & 1.65 & NR & NR \\
\hline${ }^{234 / 233} \mathrm{U}$ & 62.2 & 62.5 & A & -0.5 & 0.0928 & 0.0844 & A & 10 \\
\hline${ }^{238} \mathrm{U}$ & 246.1 & 249 & A & -1.2 & 0.4344 & 0.407 & A & 6.7 \\
\hline
\end{tabular}

${ }^{a}$ Mixed Analyte Performance Evaluation Program

${ }^{\mathrm{b}}$ Radionuclide

${ }^{\mathrm{C}}$ Evaluation Rating $(\mathrm{A}=$ acceptable, $\mathrm{W}=$ Acceptable with warning, $\mathrm{N}=$ Not acceptable)

${ }^{\mathrm{d}}$ Not Reported

\subsection{Air Toxics and CEMRC}

The Carlsbad Environmental Monitoring and Research Center (CEMRC) performed the analyses of VOC samples collected in the WIPP underground during 2005.

\subsubsection{Completeness}

Completeness is defined in WP 12-VC.01, Confirmatory Volatile Organic Compound Monitoring Plan, as being "the percentage of the ratio of the number of valid sample results received versus the total number of samples collected." The VOC monitoring program must maintain a completeness of 90 percent. For 2005, 220 samples were collected, of which 220 produced valid data. This results in a program completion percentage of 100 percent.

\subsubsection{Precision}

Precision is evaluated by two means in the VOC monitoring program. These are by comparing laboratory duplicate samples and also field duplicate samples. The laboratory duplicate samples consist of an LCS and Laboratory Control Sample Duplicate (LCSD). The field duplicate is a duplicate sample that is collected parallel 
with the original sample. Both of these duplicate samples are evaluated using the "Relative Percent Difference (RPD)" as defined in WP 12-VC.01. The RPD is calculated using the following equation.

$$
R P D=\frac{(A-B)}{(|A+B|) / 2} \times 100
$$

Where: $A=$ Original Sample Result

B = Duplicate Sample Result

During 2005, a LCS and LCSD were generated and evaluated for every sample batch that was analyzed. The result from the evaluation of the comparison resulted in 100 percent of the data within the acceptable range.

Field duplicate samples did not yield high enough concentrations to make a precision determination. All but five of the detections that were reported were estimated concentrations that were very minute. Any detection that is determined below the reporting limit is qualified as estimated. Each of the five that were detected met the precision criteria.

\subsubsection{Accuracy}

The VOC monitoring program evaluates both quantitative and qualitative accuracy. The quantitative evaluation includes performance verification for instrument calibrations, LCS recoveries, and sample internal standard areas. Qualitative evaluation consists of the evaluation of standard ion abundance for the instrument tune; that is, a mass calibration check performed prior to analyses of calibration curves and samples.

\subsubsection{Quantitative Accuracy}

\section{$\underline{\text { Instrument Calibrations }}$}

Instrument calibrations are required to have a Relative Standard Deviation (RSD) percentage of less than 30 percent for each analyte of the calibration. This is calculated by first calculating the Relative Response Factor (RRF) as indicated below:

$$
\begin{aligned}
& \text { RRF }=\frac{(\text { Analyte Response })(\text { Internal Standard Concentration })}{(\text { Internal Standard Response)(Analyte Concentration) }} \\
& \text { RSD }=\frac{\text { Standard Deviation of RRF }}{\text { Average RRF of Analyte } \times 100}
\end{aligned}
$$

During 2005, 100 percent of instrument calibrations met the $\pm<30$ percent criteria. 


\section{$\underline{\text { LCS recoveries }}$}

LCS recoveries are required to have a percent recovery of $\pm<25$ percent. LCS recoveries are calculated as follows:

Percent Recovery $=$ Concentration Result Introduced Concentration $\times 100$

During 2005, 100 percent of the LCS recoveries met the $\pm<25$ percent criterion.

\section{Internal Standard Area}

Internal standard areas are compared to a calibrated standard to evaluate accuracy. The acceptance criteria is \pm 40 percent.

During 2005, 100 percent of all standards met this criterion.

\subsubsection{Qualitative Accuracy}

The standard ion abundance criteria for bromofluorobenzene is used to evaluate the accuracy of the analytical system in the identification of target analytes as well as unknown contaminants (qualitative accuracy). This ensures that the instrumentation is correctly identifying individual compounds during the analysis of air samples.

During 2005, all ion abundance criteria were within tolerance.

\subsubsection{Comparability}

For initial qualification in 2004, the CEMRC analyzed audit canisters prepared by Shaw Environmental in 2004. These canisters contained a mixture of the nine target compounds. Duplicate samples were submitted to Air Toxics LTD for analytical comparison, and the CEMRC results were tested against results submitted by Air Toxics. CEMRC successfully identified all of the compounds within the 25 percent acceptance criteria for each compound.

\subsubsection{Representativeness}

The VOC monitoring program is designed to provide the best representation of the underground air in the disposal circuit. Sampling locations are designated based on where the air enters and exits the disposal units. Sample representativeness is achieved by collecting VOC samples continuously over a six-hour period. By collecting samples in this manner, rather than an instantaneous sample, fluctuations in VOC concentration during the six-hour period are captured. 
Waste Isolation Pilot Plant Annual Site Environmental Report for 2005 DOE/WIPP-06-2225

\begin{tabular}{lccccc}
\hline \multicolumn{5}{c}{ Table 7.3 - 2004 VOC Sample Comparison for CEMRC } \\
\hline Compound & $\begin{array}{c}\text { Air Toxics } \\
\text { (ppbv) }\end{array}$ & $\begin{array}{c}\text { CEMRC } \\
\text { (ppbv) }\end{array}$ & RPD \% & Passing Criteria & Results \\
\hline 1,1,1-Trichloroethane & 18.3 & 17.09 & 6.8 & $\pm 25 \%$ & Pass \\
1,1,2,2-Tetrachloroethane & 14.6 & 12.74 & 13.6 & $\pm 25 \%$ & Pass \\
1,1-Dichloroethene & 16.6 & 17.92 & 7.6 & $\pm 25 \%$ & Pass \\
1,2-Dichloroethane & 19 & 16.66 & 13.1 & $\pm 25 \%$ & Pass \\
Carbon Tetrachloride & 17.3 & 17.59 & 1.7 & $\pm 25 \%$ & Pass \\
Chlorobenzene & 14.6 & 14.49 & 0.8 & $\pm 25 \%$ & Pass \\
Chloroform & 17.6 & 16.84 & 4.4 & $\pm 25 \%$ & Pass \\
Methylene Chloride & 15.3 & 17.02 & 10.6 & $\pm 25 \%$ & Pass \\
Toluene & 15.3 & 15.4 & 0.7 & $\pm 25 \%$ & Pass \\
\hline Reported concentrations are three sample averages & & & &
\end{tabular}

Reported concentrations are three sample averages

ppbv $=$ parts per billion by volume

\subsection{TRACE Analysis}

TRACE Analysis of Lubbock, Texas, was subcontracted for 2005 to perform the analyses of groundwater samples collected at the WIPP site.

\subsubsection{Completeness}

The WIPP Detection Monitoring Program samples seven monitoring wells twice each year. For 2005, all seven wells were sampled for all required parameters on schedule. TRACE Analysis completed all required analyses without losing sample or data integrity and provided all analytical results as prescribed by the HWFP. For 2005, 14 sets of water samples were collected of which the vast majority produced complete and valid data. In a few isolated cases, some reported values were classified as unusable due to recoveries in matrix spike/spike duplicate samples or recoveries in other quality control samples. For 2005, the completeness percentage was 99 percent.

\subsubsection{Precision}

Precision for water quality analyses was based on the RPD between reported concentrations for the original sample analyses and the duplicate analyses as well as the results for LCSs and LCSDs. For 2005, precision was very good for both sampling Rounds 20 and 21 . The precision for the general chemistry analyses averaged 2.63 percent RPD. Precision for metals averaged 2.43 percent RPD. Precision for VOCs and SVOCs were both less than one percent RPD.

\subsubsection{Accuracy}

Accuracy of the groundwater-sample analyses is based on the percentage of recovery of individual chemical parameters from the LCSs and LCSDs. The recoveries from the LCSs and LCSDs are evaluated to determine if they exceeded the \pm 25 percent criterion for the general chemistry parameters, metals, and VOCs. SVOC recoveries are evaluated based on the individual prescribed recovery ranges specific to each chemical 
compound. For 2005, all recoveries from LCSs and LCSDs were within the acceptable range for general chemistry, metals and VOCs. The majority of SVOC recovery results were also within the acceptable range except for a few isolated instances. Three SVOC LCS and LCSD results were recovered above the prescribed recovery percentage range (Round 20) and ten SVOC results were recovered above the percentage range (Round 21).

\subsubsection{Comparability}

TRACE Analysis, Inc., participated in an Absolute Grade PT Program interlaboratory assessment. For the assessment program, running from October to November 2005, analysis of blind performance standards (Tables 7.4, 7.5, and 7.6), 183 of 189 (97 percent) parameters were acceptable.

\subsubsection{Representativeness}

The Groundwater Detection Monitoring Program is designed to collect representative groundwater samples from specific monitoring well locations. During the sampling process, serial samples are collected to help determine when final samples should be collected. Field water quality analyses are conducted to determine that the water being pumped from the monitoring wells is stable and representative of the natural groundwater at each well. A final sample is collected only when it is determined from serial sampling that the produced water is representative of natural groundwater at each location.

\begin{tabular}{|c|c|c|c|c|c|}
\hline Parameter & Units & $\begin{array}{l}\text { Reported } \\
\text { Value }\end{array}$ & $\begin{array}{l}\text { Assigned } \\
\text { Value }\end{array}$ & $\begin{array}{c}\text { Acceptance } \\
\text { Limits }\end{array}$ & $\begin{array}{c}\text { Performance } \\
\text { Evaluation }^{\mathrm{b}}\end{array}$ \\
\hline $\mathrm{pH}$ & $\mathrm{SU}^{\mathrm{a}}$ & 6.52 & 6.6 & $6.40-6.80$ & ACCEPT \\
\hline Cyanide & $\mathrm{mg} / \mathrm{L}$ & 0.311 & 0.395 & $0.218-0.577$ & ACCEPT \\
\hline Phenolics, total & $\mathrm{mg} / \mathrm{L}$ & 1.5 & 1.37 & $0.758-1.99$ & ACCEPT \\
\hline Grease \& Oil (Gravimeteric) & $\mathrm{mg} / \mathrm{L}$ & 61.2 & 64.7 & $43.6-77.2$ & ACCEPT \\
\hline Total Residual Chlorine & $\mathrm{mg} / \mathrm{L}$ & 0.46 & 0.6 & $0.436-0.758$ & CK FOR ERROR \\
\hline Mercury & $\mu \mathrm{g} / \mathrm{L}$ & 9.09 & 8.8 & $5.42-12.0$ & ACCEPT \\
\hline Hexavalent Chromium & $\mu \mathrm{g} / \mathrm{L}$ & 412 & 315 & $254-372$ & NOT ACCEPT \\
\hline \multicolumn{6}{|l|}{ Minerals } \\
\hline Total solids at $105^{\circ} \mathrm{C}$ & $\mathrm{mg} / \mathrm{L}$ & 521 & 563 & $507-619$ & CK FOR ERROR \\
\hline Total Dissolved Solids & $\mathrm{mg} / \mathrm{L}$ & 443 & 460 & $352-568$ & ACCEPT \\
\hline Conductivity at $25^{\circ} \mathrm{C}$ & $\mu$ mhos & 346 & 342 & $304-380$ & ACCEPT \\
\hline Alkalinity as $\mathrm{CaCO} 3$ & $\mathrm{mg} / \mathrm{L}$ & 24 & 29.1 & $24.2-35.3$ & NOT ACCEPT \\
\hline Chloride & $\mathrm{mg} / \mathrm{L}$ & 130 & 158 & $136-179$ & NOT ACCEPT \\
\hline Fluoride & $\mathrm{mg} / \mathrm{L}$ & 2.48 & 2.65 & $2.20-3.11$ & ACCEPT \\
\hline Potassium & $\mathrm{mg} / \mathrm{L}$ & 17.4 & 19.6 & $16.1-23.4$ & ACCEPT \\
\hline Sodium & $\mathrm{mg} / \mathrm{L}$ & 14.8 & 16.6 & $14.1-19.4$ & CK FOR ERROR \\
\hline Sulfate & $\mathrm{mg} / \mathrm{L}$ & 22.1 & 24 & $19.0-28.5$ & ACCEPT \\
\hline
\end{tabular}


Table 7.4 - Absolute Grade PT Program Assessment of Trace Analysis, Inc. October - November, 2005

\begin{tabular}{|c|c|c|c|c|c|}
\hline Parameter & Units & $\begin{array}{c}\text { Reported } \\
\text { Value }\end{array}$ & $\begin{array}{c}\text { Assigned } \\
\text { Value }\end{array}$ & $\begin{array}{c}\text { Acceptance } \\
\text { Limits }\end{array}$ & $\begin{array}{l}\text { Performance } \\
\text { Evaluation }^{\mathrm{b}}\end{array}$ \\
\hline \multicolumn{6}{|l|}{ Hardness } \\
\hline Total suspended solids & $\mathrm{mg} / \mathrm{L}$ & 85.2 & 88.4 & $72.7-98.1$ & ACCEPT \\
\hline Calcium & $\mathrm{mg} / \mathrm{L}$ & 49.2 & 48.8 & $43.6-55.4$ & ACCEPT \\
\hline Magnesium & $\mathrm{mg} / \mathrm{L}$ & 24.5 & 24.96 & 21.3-28.6 & ACCEPT \\
\hline Calcium hardness as $\mathrm{CaCO}_{3}$ & $\mathrm{mg} / \mathrm{L}$ & 123 & 122 & $109-138$ & ACCEPT \\
\hline Total hardness as $\mathrm{CaCO}_{3}$ & $\mathrm{mg} / \mathrm{L}$ & 224 & 224 & $197-256$ & ACCEPT \\
\hline \multicolumn{6}{|l|}{ Demand } \\
\hline BOD & $\mathrm{mg} / \mathrm{L}$ & 166 & 146 & $74.2-219$ & ACCEPT \\
\hline CBOD & $\mathrm{mg} / \mathrm{L}$ & 147 & 126 & 56.5-195 & ACCEPT \\
\hline COD & $\mathrm{mg} / \mathrm{L}$ & 219 & 243 & $190-274$ & ACCEPT \\
\hline TOC & $\mathrm{mg} / \mathrm{L}$ & 99.6 & 96 & $80.3-110$ & ACCEPT \\
\hline \multicolumn{6}{|l|}{ Nutrients } \\
\hline Ammonia as $\mathrm{N}$ & $\mathrm{mg} / \mathrm{L}$ & 3.92 & 4.05 & $2.91-5.23$ & ACCEPT \\
\hline Nitrate as $\mathrm{N}$ & $\mathrm{mg} / \mathrm{L}$ & 7.32 & 7.67 & $5.98-9.27$ & ACCEPT \\
\hline Ortho-phosphate as $\mathrm{P}$ & $\mathrm{mg} / \mathrm{L}$ & 4 & 3.41 & $2.80-4.06$ & CK FOR ERROR \\
\hline Total phosphorus as $\mathrm{P}$ & $\mathrm{mg} / \mathrm{L}$ & 1.69 & 1.76 & $1.39-2.17$ & ACCEPT \\
\hline Total kjeldahl nitrogen as $\mathrm{N}$ & $\mathrm{mg} / \mathrm{L}$ & 5.88 & 13.6 & $9.03-17.6$ & NOT ACCEPT \\
\hline \multicolumn{6}{|l|}{ Trace Metals } \\
\hline Aluminum & $\mu \mathrm{g} / \mathrm{L}$ & 1010 & 1000 & $806-1187$ & ACCEPT \\
\hline Antimony & $\mu \mathrm{g} / \mathrm{L}$ & 723 & 791 & $560-950$ & ACCEPT \\
\hline Arsenic & $\mu \mathrm{g} / \mathrm{L}$ & 181 & 189 & $155-223$ & ACCEPT \\
\hline Barium & $\mu \mathrm{g} / \mathrm{L}$ & 888 & 900 & $781-1015$ & ACCEPT \\
\hline Beryllium & $\mu \mathrm{g} / \mathrm{L}$ & 124 & 130 & $109-147$ & ACCEPT \\
\hline Boron & $\mu \mathrm{g} / \mathrm{L}$ & 1270 & 1250 & $1025-1457$ & ACCEPT \\
\hline Cadmium & $\mu \mathrm{g} / \mathrm{L}$ & 630 & 610 & $521-693$ & ACCEPT \\
\hline Chromium & $\mu \mathrm{g} / \mathrm{L}$ & 821 & 850 & $742-961$ & ACCEPT \\
\hline Cobalt & $\mu \mathrm{g} / \mathrm{L}$ & 923 & 920 & $810-1031$ & ACCEPT \\
\hline Copper & $\mu \mathrm{g} / \mathrm{L}$ & 336 & 340 & $306-375$ & ACCEPT \\
\hline Iron & $\mu \mathrm{g} / \mathrm{L}$ & 714 & 720 & $635-816$ & ACCEPT \\
\hline Lead & $\mu \mathrm{g} / \mathrm{L}$ & 1490 & 1440 & $1226-1607$ & ACCEPT \\
\hline Manganese & $\mu \mathrm{g} / \mathrm{L}$ & 752 & 750 & $673-833$ & ACCEPT \\
\hline Molybdenum & $\mu \mathrm{g} / \mathrm{L}$ & 365 & 380 & $321-435$ & ACCEPT \\
\hline Nickel & $\mu g / L$ & 671 & 660 & $594-739$ & ACCEPT \\
\hline Selenium & $\mu \mathrm{g} / \mathrm{L}$ & 1190 & 1200 & $955-1389$ & ACCEPT \\
\hline Silver & $\mu \mathrm{g} / \mathrm{L}$ & 590 & 530 & $45-607$ & CK FOR ERROR \\
\hline Strontium & $\mu \mathrm{g} / \mathrm{L}$ & 109 & 110 & $93.7-126$ & ACCEPT \\
\hline Thallium & $\mu \mathrm{g} / \mathrm{L}$ & 646 & 610 & $496-729$ & ACCEPT \\
\hline Vanadium & $\mu g / L$ & 232 & 230 & $201-258$ & ACCEPT \\
\hline Zinc & $\mu g / L$ & 585 & 580 & $498-669$ & ACCEPT \\
\hline
\end{tabular}


Table 7.4 - Absolute Grade PT Program Assessment of Trace Analysis, Inc. October - November, 2005

\begin{tabular}{|c|c|c|c|c|c|}
\hline Parameter & Units & $\begin{array}{c}\text { Reported } \\
\text { Value }\end{array}$ & $\begin{array}{c}\text { Assigned } \\
\text { Value }\end{array}$ & $\begin{array}{c}\text { Acceptance } \\
\text { Limits }\end{array}$ & $\begin{array}{l}\text { Performance } \\
\text { Evaluation }^{\mathrm{b}}\end{array}$ \\
\hline \multicolumn{6}{|l|}{ PCBs in $\mathrm{H}_{2} \mathrm{O}$ (Standard \#2) } \\
\hline Aroclor 1242 & $\mu \mathrm{g} / \mathrm{L}$ & $<0.5$ & 0 & 0 & ACCEPT \\
\hline Aroclor 1221 & $\mu g / L$ & $<0.5$ & 0 & 0 & ACCEPT \\
\hline Aroclor 1232 & $\mu \mathrm{g} / \mathrm{L}$ & $<0.50$ & 0 & 0 & ACCEPT \\
\hline Aroclor 1248 & $\mu g / L$ & $<0.50$ & 0 & 0 & ACCEPT \\
\hline Aroclor 1254 & $\mu g / L$ & 1.79 & 3.41 & $1.53-4.57$ & CK FOR ERROR \\
\hline Aroclor 1260 & $\mu g / L$ & $<0.50$ & 0 & 0 & ACCEPT \\
\hline \multicolumn{6}{|l|}{ PCBs in $\mathrm{H}_{2} \mathrm{O}$ (Standard \#1) } \\
\hline Aroclor 1242 & $\mu g / L$ & $<0.5$ & 9.11 & $2.52-12.8$ & NOT ACCEPT \\
\hline Aroclor 1221 & $\mu g / L$ & $<0.5$ & 0 & 0 & ACCEPT \\
\hline Aroclor 1232 & $\mu g / L$ & 1.87 & 0 & 0 & NOT ACCEPT \\
\hline Aroclor 1248 & $\mu \mathrm{g} / \mathrm{L}$ & $<0.50$ & 0 & 0 & ACCEPT \\
\hline Aroclor 1254 & $\mu g / L$ & $<0.50$ & 0 & 0 & ACCEPT \\
\hline Aroclor 1260 & $\mu g / L$ & $<0.50$ & 0 & 0 & ACCEPT \\
\hline \multicolumn{6}{|l|}{ PCBs in Oil (Standard \#1) } \\
\hline Aroclor $1016 / 1242$ & $\mathrm{mg} / \mathrm{kg}$ & 0 & 0 & 0 & ACCEPT \\
\hline Aroclor 1254 & $\mathrm{mg} / \mathrm{kg}$ & 12.4 & 23 & $1.83-35.8$ & ACCEPT \\
\hline Aroclor 1260 & $\mathrm{mg} / \mathrm{kg}$ & 0 & 0 & 0 & ACCEPT \\
\hline \multicolumn{6}{|l|}{ PCBs in Oil (Standard \#2) } \\
\hline Aroclor $1016 / 1242$ & $\mathrm{mg} / \mathrm{kg}$ & 0 & 0 & 0 & ACCEPT \\
\hline Aroclor 1254 & $\mathrm{mg} / \mathrm{kg}$ & 0 & 0 & 0 & ACCEPT \\
\hline Aroclor 1260 & $\mathrm{mg} / \mathrm{kg}$ & 21.4 & 33.1 & $6.06-46.7$ & ACCEPT \\
\hline \multicolumn{6}{|l|}{ Volatiles } \\
\hline Acetone & $\mu g / L$ & $\mathrm{~N} / \mathrm{A}$ & $\mathrm{N} / \mathrm{A}$ & $\mathrm{N} / \mathrm{A}$ & NOT REPORTED \\
\hline Acetonitrile & $\mu g / L$ & $\mathrm{~N} / \mathrm{A}$ & $\mathrm{N} / \mathrm{A}$ & $\mathrm{N} / \mathrm{A}$ & NOT REPORTED \\
\hline Acrylonitrile & $\mu g / L$ & $N / A$ & $\mathrm{~N} / \mathrm{A}$ & $\mathrm{N} / \mathrm{A}$ & NOT REPORTED \\
\hline Acrolein & $\mu g / L$ & N/A & $\mathrm{N} / \mathrm{A}$ & $\mathrm{N} / \mathrm{A}$ & NOT REPORTED \\
\hline Benzene & $\mu g / L$ & 41.8 & 38 & $27.0-48.8$ & ACCEPT \\
\hline Bromodichloromethane & $\mu g / L$ & 37.9 & 33.6 & $23.5-45.3$ & ACCEPT \\
\hline Bromoform & $\mu g / L$ & 54.7 & 48 & $30.5-66.0$ & ACCEPT \\
\hline Bromomethane & $\mu g / L$ & 54.2 & 48 & $19.2-76.8$ & ACCEPT \\
\hline 2-Butanone (MEK) & $\mu g / L$ & $\mathrm{~N} / \mathrm{A}$ & $\mathrm{N} / \mathrm{A}$ & $\mathrm{N} / \mathrm{A}$ & NOT REPORTED \\
\hline Carbon disulfide & $\mu \mathrm{g} / \mathrm{L}$ & 19.6 & 17.2 & $6.88-27.5$ & ACCEPT \\
\hline Carbon tetrachloride & $\mu g / L$ & 51.8 & 48 & $26.4-65.6$ & ACCEPT \\
\hline Chlorobenzene & $\mu g / L$ & 47.4 & 44 & $31.7-55.3$ & ACCEPT \\
\hline Chlorodibromomethane & $\mu g / L$ & N/A & $\mathrm{N} / \mathrm{A}$ & $\mathrm{N} / \mathrm{A}$ & NOT REPORTED \\
\hline Chloroethane & $\mu g / L$ & $<1.0$ & 0 & 0 & ACCEPT \\
\hline 2-Chloroethylvinylether & $\mu g / L$ & N/A & $\mathrm{N} / \mathrm{A}$ & N/A & NOT REPORTED \\
\hline Chloroform & $\mu g / L$ & 57.2 & 48 & $33.2-62.1$ & ACCEPT \\
\hline Chloromethane & $\mu g / L$ & 83.9 & 72 & $28.8-115.0$ & ACCEPT \\
\hline $\mathrm{DBCP}$ & $\mu g / L$ & N/A & $\mathrm{N} / \mathrm{A}$ & $\mathrm{N} / \mathrm{A}$ & NOT REPORTED \\
\hline 1,2-Dibromoethane (EDB) & $\mu g / L$ & 24.1 & 22.4 & $12.8-51.2$ & ACCEPT \\
\hline Dibromomethane & $\mu g / L$ & 54.5 & 48 & $19.2-76.8$ & ACCEPT \\
\hline 1,2-Dichlorobenzene & $\mu g / L$ & 45.9 & 44 & $30.3-57.3$ & ACCEPT \\
\hline 1,3-Dichlorobenzene & $\mu g / L$ & 45.5 & 44 & $29.5-56.3$ & ACCEPT \\
\hline
\end{tabular}


Table 7.4 - Absolute Grade PT Program Assessment of Trace Analysis, Inc. October - November, 2005

\begin{tabular}{|c|c|c|c|c|c|}
\hline Parameter & Units & $\begin{array}{c}\text { Reported } \\
\text { Value }\end{array}$ & $\begin{array}{l}\text { Assigned } \\
\text { Value }\end{array}$ & $\begin{array}{c}\text { Acceptance } \\
\text { Limits }\end{array}$ & $\begin{array}{l}\text { Performance } \\
\text { Evaluation }^{\mathrm{b}}\end{array}$ \\
\hline 1,4-Dichlorobenzene & $\mu \mathrm{g} / \mathrm{L}$ & 42.6 & 44 & $29.6-55.8$ & ACCEPT \\
\hline Dichlorodifluoromethane & $\mu \mathrm{g} / \mathrm{L}$ & $<1.0$ & 0 & 0 & ACCEPT \\
\hline 1,1-Dichloroethane & $\mu g / L$ & 57.4 & 48 & $32.8-65.7$ & ACCEPT \\
\hline 1,2-Dichloroethane & $\mu \mathrm{g} / \mathrm{L}$ & 185 & 144 & $100.0-188.0$ & CK FOR ERROR \\
\hline 1,1-Dichloroethylene & $\mu \mathrm{g} / \mathrm{L}$ & 35.6 & 33.6 & $17.6-49.0$ & ACCEPT \\
\hline cis-1,2-Dichloroethylene & $\mu g / L$ & 38.2 & 33.6 & $19.2-48.3$ & ACCEPT \\
\hline trans-1,2-Dichloroethylene & $\mu g / L$ & 38.2 & 33.6 & $19.2-48.3$ & ACCEPT \\
\hline 1,2-Dichloropropane & $\mu \mathrm{g} / \mathrm{L}$ & 127 & 112 & $73.9-147.0$ & ACCEPT \\
\hline cis-1,3-Dichloropropylene & $\mu \mathrm{g} / \mathrm{L}$ & 38.4 & 36 & $25.2-46.8$ & ACCEPT \\
\hline trans-1,3-Dichloropropylene & $\mu \mathrm{g} / \mathrm{L}$ & 82.1 & 68 & $43.9-92.2$ & ACCEPT \\
\hline Ethylbenzene & $\mu g / L$ & 42.3 & 38 & $26.0-48.7$ & ACCEPT \\
\hline 2-Hexanone & $\mu \mathrm{g} / \mathrm{L}$ & $\mathrm{N} / \mathrm{A}$ & $\mathrm{N} / \mathrm{A}$ & $\mathrm{N} / \mathrm{A}$ & NOT REPORTED \\
\hline Methylene chloride & $\mu \mathrm{g} / \mathrm{L}$ & 34.3 & 33.6 & $20.4-47.7$ & ACCEPT \\
\hline 4-Methyl-2-pentanone (MIBK) & $\mu g / L$ & $<5.0$ & 0 & 0 & ACCEPT \\
\hline Styrene & $\mu g / L$ & 45.1 & 38 & $24.8-51.5$ & ACCEPT \\
\hline 1,1,1,2-Tetrachloroethane & $\mu \mathrm{g} / \mathrm{L}$ & 25.8 & 24 & $9.60-38.4$ & ACCEPT \\
\hline 1,1,2,2-Tetrachloroethane & $\mu \mathrm{g} / \mathrm{L}$ & 77.9 & 68 & $39.4-99.9$ & ACCEPT \\
\hline Tetrachloroethylene & $\mu \mathrm{g} / \mathrm{L}$ & 40.7 & 48 & $26.5-62.9$ & ACCEPT \\
\hline Toluene & $\mu g / L$ & 41.7 & 38 & $26.4-48.0$ & ACCEPT \\
\hline 1,1,1-Trichloroethane & $\mu g / L$ & 52.3 & 48 & $30.0-63.4$ & ACCEPT \\
\hline 1,1,2-Trichloroethane & $\mu \mathrm{g} / \mathrm{L}$ & 37.6 & 31.6 & $22.1-41.9$ & ACCEPT \\
\hline Trichloroethylene & $\mu g / L$ & 61.3 & 60 & $38.1-78.4$ & ACCEPT \\
\hline Trichlorofluoromethane & $\mu g / L$ & $<1.0$ & 0 & 0 & ACCEPT \\
\hline 1,2,3-Trichloropropane & $\mu g / L$ & 31.1 & 35.2 & $14.1-56.3$ & ACCEPT \\
\hline Vinyl acetate & $\mu g / L$ & N/A & $\mathrm{N} / \mathrm{A}$ & $\mathrm{N} / \mathrm{A}$ & NOT REPORTED \\
\hline Vinyl chloride & $\mu \mathrm{g} / \mathrm{L}$ & 45.9 & 40.1 & $16.1-64.2$ & ACCEPT \\
\hline Xylenes, total & $\mu g / L$ & 140 & 126 & $72.1-170.0$ & ACCEPT \\
\hline \multicolumn{6}{|l|}{ SVOCs-Acids } \\
\hline Benzoic acid & $\mu g / L$ & $\mathrm{~N} / \mathrm{A}$ & $\mathrm{N} / \mathrm{A}$ & $\mathrm{N} / \mathrm{A}$ & NOT REPORTED \\
\hline 4-Chloro-3-methylphenol & $\mu g / L$ & 144 & 186 & $73.5-239.0$ & ACCEPT \\
\hline 2-Chlorophenol. & $\mu g / L$ & 77 & 136 & $38.7-170.0$ & ACCEPT \\
\hline 2,4-Dichlorophenol & $\mu g / L$ & 64.2 & 106 & $34.0-131.0$ & ACCEPT \\
\hline 2,6-Dichlorophenol & $\mu g / L$ & $N / A$ & $\mathrm{~N} / \mathrm{A}$ & $\mathrm{N} / \mathrm{A}$ & NOT REPORTED \\
\hline 2,4-Dimethylphenol & $\mu g / L$ & 54.3 & 86.1 & $17.4-114.0$ & ACCEPT \\
\hline 4,6-Dinitro-2-methylphenol & $\mu g / L$ & 41.4 & 122 & $40.8-172.0$ & CK FOR ERROR \\
\hline 2,4-Dinitrophenol & $\mu g / L$ & $<5.0$ & 166 & $16.6-222.0$ & NOT ACCEPT \\
\hline 2-Methlyphenol & $\mu g / L$ & $\mathrm{~N} / \mathrm{A}$ & $\mathrm{N} / \mathrm{A}$ & $\mathrm{N} / \mathrm{A}$ & NOT REPORTED \\
\hline 3-Methylphenol & $\mu g / L$ & $\mathrm{~N} / \mathrm{A}$ & $\mathrm{N} / \mathrm{A}$ & $\mathrm{N} / \mathrm{A}$ & NOT REPORTED \\
\hline 4-Methylphenol & $\mu \mathrm{g} / \mathrm{L}$ & $\mathrm{N} / \mathrm{A}$ & N/A & $\mathrm{N} / \mathrm{A}$ & NOT REPORTED \\
\hline 2-Nitrophenol & $\mu g / L$ & 101 & 164 & $36.9-216.0$ & ACCEPT \\
\hline 3-Nitrophenol & $\mu g / L$ & N/A & $\mathrm{N} / \mathrm{A}$ & $\mathrm{N} / \mathrm{A}$ & NOT REPORTED \\
\hline 4-Nitrophenol & $\mu g / L$ & $<5.0$ & 119 & $11.9-161.0$ & NOT ACCEPT \\
\hline Pentachlorophenol & $\mu g / L$ & 66.1 & 169 & $47.0-234.0$ & CK FOR ERROR \\
\hline Phenol & $\mu g / L$ & 37.3 & 135 & $13.5-181.0$ & ACCEPT \\
\hline 2,4,5-Trichlorophenol & $\mu \mathrm{g} / \mathrm{L}$ & $<5.0$ & 0 & 0 & ACCEPT \\
\hline
\end{tabular}


Table 7.4 - Absolute Grade PT Program Assessment of Trace Analysis, Inc. October - November, 2005

\begin{tabular}{|c|c|c|c|c|c|}
\hline Parameter & Units & $\begin{array}{c}\text { Reported } \\
\text { Value }\end{array}$ & $\begin{array}{l}\text { Assigned } \\
\text { Value }\end{array}$ & $\begin{array}{c}\text { Acceptance } \\
\text { Limits }\end{array}$ & $\begin{array}{l}\text { Performance } \\
\text { Evaluation }^{\mathrm{b}}\end{array}$ \\
\hline 2,4,6-Trichlorophenol & $\mu \mathrm{g} / \mathrm{L}$ & $<5.0$ & 0 & 0 & ACCEPT \\
\hline \multicolumn{6}{|l|}{ SVOCs Base Neturals } \\
\hline Acenaphthene & $\mu \mathrm{g} / \mathrm{L}$ & 51.6 & 68.6 & $27.8-82.5$ & ACCEPT \\
\hline Acenaphthylene & $\mu \mathrm{g} / \mathrm{L}$ & 187 & 174 & $70.1-210.0$ & CK FOR ERROR \\
\hline Aniline & $\mu \mathrm{g} / \mathrm{L}$ & 83.9 & 0 & 0 & NOT ACCEPT \\
\hline Anthracene & $\mu \mathrm{g} / \mathrm{L}$ & 122 & 70.1 & $29.8-88.2$ & NOT ACCEPT \\
\hline Benzidine & $\mu \mathrm{g} / \mathrm{L}$ & $<5.0$ & 0 & 0 & ACCEPT \\
\hline Benzo(a)anthracene & $\mu \mathrm{g} / \mathrm{L}$ & 69.9 & 57.7 & 25.7-73.8 & CK FOR ERROR \\
\hline Benzo(b)fluoranthene & $\mu \mathrm{g} / \mathrm{L}$ & 203 & 54 & 19.6-73.3 & NOT ACCEPT \\
\hline Benzo(k)fluoranthene & $\mu g / L$ & $<5.0$ & 134 & $33.9-190.0$ & NOT ACCEPT \\
\hline Benzo(g,h,i)perylene & $\mu g / L$ & 138 & 142 & $57.6-188.0$ & ACCEPT \\
\hline Benzo(a)pyrene & $\mu g / L$ & 31 & 40.9 & $12.5-53.6$ & ACCEPT \\
\hline Benzyl alcohol & $\mu g / L$ & $<5.0$ & 47.5 & $0.0-146$ & ACCEPT \\
\hline 4-Bromophenyl-phenylether & $\mu \mathrm{g} / \mathrm{L}$ & 131 & 127 & $40.9-169.0$ & ACCEPT \\
\hline Butylbenzylphthalate & $\mu g / L$ & 96.6 & 119 & $22.7-170.0$ & ACCEPT \\
\hline Carbazole & $\mu g / L$ & $\mathrm{~N} / \mathrm{A}$ & $\mathrm{N} / \mathrm{A}$ & N/A & NOT REPORTED \\
\hline 4-Chloroaniline & $\mu \mathrm{g} / \mathrm{L}$ & $<0.5$ & 0 & 0 & ACCEPT \\
\hline bis(2-Chloroethoxy)methane & $\mu g / L$ & 42.4 & 66.1 & $26.0-79.4$ & ACCEPT \\
\hline bis(2-Chloroethyl)ether & $\mu \mathrm{g} / \mathrm{L}$ & 97.2 & 180 & $47.4-217.0$ & ACCEPT \\
\hline bis(2-Chloroisopropyl)ether & $\mu g / L$ & 54.1 & 91.7 & $23.1-113.0$ & ACCEPT \\
\hline 1-Chloronaphthalene & $\mu \mathrm{g} / \mathrm{L}$ & 41.5 & 0 & 0 & NOT ACCEPT \\
\hline 2-Chloronaphthalene & $\mu \mathrm{g} / \mathrm{L}$ & 35.5 & 56.9 & $17.0-69.6$ & ACCEPT \\
\hline 4-Chlorophenyl-phenylether & $\mu g / L$ & 168 & 150 & $55.8-185.0$ & CK FOR ERROR \\
\hline Chrysene & $\mu \mathrm{g} / \mathrm{L}$ & 156 & 169 & $65.3-215.0$ & ACCEPT \\
\hline Dibenz(a,h)anthracene & $\mu \mathrm{g} / \mathrm{L}$ & $<5.0$ & 55.7 & $15.3-79.0$ & NOT ACCEPT \\
\hline Dibenzofuran & $\mu g / L$ & 44.3 & 58.8 & $21.4-75.3$ & ACCEPT \\
\hline Di-n-butylphthalate & $\mu g / L$ & 175 & 154 & $49.7-197.0$ & CK FOR ERROR \\
\hline 1,2-Dichlorobenzene & $\mu g / L$ & 79.2 & 129 & $16.3-152.0$ & ACCEPT \\
\hline 1,3-Dichlorobenzene & $\mu g / L$ & 30.5 & 56.1 & $7.42-67.1$ & ACCEPT \\
\hline 1,4-Dichlorobenzene & $\mu g / L$ & 48.9 & 86.8 & $8.68-105.0$ & ACCEPT \\
\hline 3,3'-Dichlorobenzidine & $\mu g / L$ & $<5.0$ & 0 & 0 & ACCEPT \\
\hline Diethylphthalate & $\mu g / L$ & 136 & 122 & $22.6-167.0$ & ACCEPT \\
\hline Dimethlyphthalate & $\mu g / L$ & 113 & 110 & $11.0-159.0$ & ACCEPT \\
\hline 2,4-Dinitrotoluene & $\mu g / L$ & 95 & 106 & $39.4-131.0$ & ACCEPT \\
\hline 2,6-Dinitrotoulene & $\mu g / L$ & 99.1 & 108 & $44.7-135.0$ & ACCEPT \\
\hline Di-n-octylphthalate & $\mu g / L$ & 45.3 & 55.2 & $16.0-83.7$ & ACCEPT \\
\hline bis(2-ethylhexyl)phthalate & $\mu g / L$ & 329 & 163 & $47.6-220.0$ & NOT ACCEPT \\
\hline Fluoranthene & $\mu g / L$ & 147 & 139 & $60.8-165.0$ & ACCEPT \\
\hline Fluorene & $\mu g / L$ & 86.5 & 79.9 & $33.8-96.6$ & CK FOR ERROR \\
\hline Hexachlorobenzene & $\mu g / L$ & 18.2 & 25 & $9.94-33.9$ & ACCEPT \\
\hline Hexachlorobutadiene & $\mu \mathrm{g} / \mathrm{L}$ & 38.6 & 64.4 & $6.44-80.1$ & ACCEPT \\
\hline Hexachlorocyclopentadiene & $\mu g / L$ & 61.1 & 191 & $19.1-245.0$ & ACCEPT \\
\hline Hexachloroethane & $\mu g / L$ & 48.3 & 87.4 & $9.05-103.0$ & ACCEPT \\
\hline Indeno(1,2,3-cd)pyrene & $\mu g / L$ & 77.5 & 94.7 & $27.1-120.0$ & ACCEPT \\
\hline Isophorone & $\mu \mathrm{g} / \mathrm{L}$ & 54.5 & 65.5 & $26.2-85.1$ & ACCEPT \\
\hline
\end{tabular}


Table 7.4 - Absolute Grade PT Program Assessment of Trace Analysis, Inc. October - November, 2005

\begin{tabular}{llcccc}
\hline \multicolumn{1}{c}{ Parameter } & Units & $\begin{array}{c}\text { Reported } \\
\text { Value }\end{array}$ & $\begin{array}{c}\text { Assigned } \\
\text { Value }\end{array}$ & $\begin{array}{c}\text { Acceptance } \\
\text { Limits }\end{array}$ & $\begin{array}{c}\text { Performance } \\
\text { Evaluation }^{\mathbf{b}}\end{array}$ \\
\hline 1-Methylnaphthalene & $\mu \mathrm{g} / \mathrm{L}$ & $\mathrm{N} / \mathrm{A}$ & $\mathrm{N} / \mathrm{A}$ & $\mathrm{N} / \mathrm{A}$ & NOT REPORTED \\
2-Methylnaphthalene & $\mu \mathrm{g} / \mathrm{L}$ & 66.8 & 91.1 & $17.5-107.0$ & ACCEPT \\
Naphthalene & $\mu \mathrm{g} / \mathrm{L}$ & 93.6 & 136 & $35.2-160.0$ & ACCEPT \\
2-Nitroaniline & $\mu \mathrm{g} / \mathrm{L}$ & 64.9 & 72.4 & $48.7-96.1$ & ACCEPT \\
3-Nitroaniline & $\mu \mathrm{g} / \mathrm{L}$ & $<5.0$ & 36.5 & $0.0-107.0$ & ACCEPT \\
4-Nitroaniline & $\mu \mathrm{g} / \mathrm{L}$ & 54.7 & 75.6 & $37.9-113.0$ & ACCEPT \\
Nitrobenzene & $\mu \mathrm{g} / \mathrm{L}$ & 34.9 & 56.2 & $18.1-70.1$ & ACCEPT \\
N-Nitrosodiethylamine & $\mu \mathrm{g} / \mathrm{L}$ & $\mathrm{N} / \mathrm{A}$ & $\mathrm{N} / \mathrm{A}$ & $\mathrm{N} / \mathrm{A}$ & NOT REPORTED \\
N-Nitrosodimethylamine & $\mu \mathrm{g} / \mathrm{L}$ & 50.1 & 115 & $11.5-136.0$ & ACCEPT \\
N-Nitrosodiphenylamine & $\mu \mathrm{g} / \mathrm{L}$ & $<5.0$ & 0 & 0 & ACCEPT \\
N-Nitroso-di-n-propylamine & $\mu \mathrm{g} / \mathrm{L}$ & 88.2 & 111 & $33.5-141.5$ & ACCEPT \\
Phenanthrene & $\mu \mathrm{g} / \mathrm{L}$ & 58.6 & 122 & $55.9-146.0$ & CK FOR ERROR \\
Pyrene & $\mu \mathrm{g} / \mathrm{L}$ & 100 & 124 & $41.4-168.0$ & ACCEPT \\
Pyridine & $\mu \mathrm{g} / \mathrm{L}$ & $<5.0$ & 0 & 0 & ACCEPT \\
1,2,4-Trichlorobenzene & $\mu \mathrm{g} / \mathrm{L}$ & 102 & 149 & $34.0-176.0$ & ACCEPT \\
\hline
\end{tabular}

a Standard Unit

${ }^{\mathrm{b}}$ Check for Error indicates result is above the warning limit, but within the acceptance limit.

N/A - Not Applicable

Not Reported - Parameter not analyzed

\begin{tabular}{|c|c|c|c|c|c|}
\hline Parameter & Units & $\begin{array}{c}\text { Reported } \\
\text { Value }\end{array}$ & $\begin{array}{c}\text { Assigned } \\
\text { Value }\end{array}$ & $\begin{array}{l}\text { Acceptance } \\
\text { Limits }\end{array}$ & Performance Evaluation \\
\hline \multicolumn{6}{|l|}{ Gasoline in Water } \\
\hline Unleaded Gasoline & $\mu g / L$ & 1810 & 1945 & $758.0-3440.0$ & ACCEPT \\
\hline Benzene & $\mu \mathrm{g} / \mathrm{L}$ & 98.8 & 96 & $70.2-121.0$ & ACCEPT \\
\hline Ethylbenzene & $\mu \mathrm{g} / \mathrm{L}$ & 28.1 & 31.6 & $21.6-40.7$ & ACCEPT \\
\hline Toluene & $\mu g / L$ & 83.6 & 84 & $58.3-105.0$ & ACCEPT \\
\hline Xylenes, M/P & $\mu \mathrm{g} / \mathrm{L}$ & 132 & 141 & $80.9-190.0$ & ACCEPT \\
\hline \multicolumn{6}{|l|}{ Diesel in Water } \\
\hline No. 2 Diesel & $\mu g / L$ & 852 & 2852 & $684.0-3691.0$ & CK FOR ERROR \\
\hline \multicolumn{6}{|l|}{$\underline{\mathrm{TPH}}$ in Water } \\
\hline TPH (gravimetric) & $\mathrm{mg} / \mathrm{bttl}$ & $N / A$ & $\mathrm{~N} / \mathrm{A}$ & $N / A$ & NOT REPORTED \\
\hline TPH (IR) & $\mathrm{mg} / \mathrm{bttl}$ & $N / A$ & $N / A$ & $N / A$ & NOT REPORTED \\
\hline
\end{tabular}


Waste Isolation Pilot Plant Annual Site Environmental Report for 2005 DOE/WIPP-06-2225

\begin{tabular}{lccccc}
\hline Table 7.6 - $\begin{array}{c}\text { Absolute Grade PT Program Assessment of Trace Analysis, Inc., } \\
\text { Pesticides - October - November, 2005 }\end{array}$ \\
\hline \multicolumn{1}{c}{ Parameter } & Units & $\begin{array}{c}\text { Reported } \\
\text { Value }\end{array}$ & $\begin{array}{c}\text { Assigned } \\
\text { Value }\end{array}$ & $\begin{array}{c}\text { Acceptance } \\
\text { Limits }\end{array}$ & $\begin{array}{c}\text { Performance } \\
\text { Evaluation }\end{array}$ \\
\hline Aldrin & $\mu \mathrm{g} / \mathrm{L}$ & 2.8 & 4.01 & $1.14-5.54$ & ACCEPT \\
alpha-BHC & $\mu \mathrm{g} / \mathrm{L}$ & 5.1 & 7.41 & $3.22-10.1$ & ACCEPT \\
beta-BHC & $\mu \mathrm{g} / \mathrm{L}$ & 2.9 & 3.91 & $1.59-5.45$ & ACCEPT \\
delta-BHC & $\mu \mathrm{g} / \mathrm{L}$ & 9.3 & 14 & $5.40-19.5$ & ACCEPT \\
gamma-BHC (Lindane) & $\mu \mathrm{g} / \mathrm{L}$ & 4.3 & 6.51 & $2.65-8.99$ & ACCEPT \\
alpha-Chlordane & $\mu \mathrm{g} / \mathrm{L}$ & 6.9 & 8.61 & $3.88-11.5$ & ACCEPT \\
gamma-Chlordane & $\mu \mathrm{g} / \mathrm{L}$ & 18.7 & 7.01 & $2.87-9.50$ & NOT ACCEPT \\
Chlordane, total & $\mu \mathrm{g} / \mathrm{L}$ & $\mathrm{N} / \mathrm{A}$ & $\mathrm{N} / \mathrm{A}$ & $\mathrm{N} / \mathrm{A}$ & NOT REPORTED \\
4,4'-DDD & $\mu \mathrm{g} / \mathrm{L}$ & 5.8 & 6.91 & $2.55-9.86$ & ACCEPT \\
4,4'-DDE & $\mu \mathrm{g} / \mathrm{L}$ & 4.3 & 5.71 & $2.53-7.42$ & ACCEPT \\
4,4'-DDT & $\mu \mathrm{g} / \mathrm{L}$ & 4.4 & 6.11 & $2.28-8.68$ & ACCEPT \\
Dieldrin & $\mu \mathrm{g} / \mathrm{L}$ & 7.4 & 10 & $4.92-13.6$ & ACCEPT \\
Endrin & $\mu \mathrm{g} / \mathrm{L}$ & 13.5 & 18 & $6.22-26.6$ & ACCEPT \\
Endrin aldehyde & $\mu \mathrm{g} / \mathrm{L}$ & 8.1 & 12 & $3.61-17.9$ & ACCEPT \\
Endrin ketone & $\mu \mathrm{g} / \mathrm{L}$ & 4.5 & 10 & $5.5-14.5$ & NOT ACCEPT \\
Endosulfan I & $\mu \mathrm{g} / \mathrm{L}$ & 11.4 & 15 & $4.65-22.0$ & ACCEPT \\
Endosulfan II & $\mu \mathrm{g} / \mathrm{L}$ & 6.8 & 11 & $3.45-14.7$ & ACCEPT \\
Endosulfan sulfate & $\mu \mathrm{g} / \mathrm{L}$ & 8.4 & 13 & $4.93-19.0$ & ACCEPT \\
Heptachlor & $\mu \mathrm{g} / \mathrm{L}$ & 5.4 & 7.11 & $2.3-9.7$ & ACCEPT \\
Heptachlor epoxide & $\mu \mathrm{g} / \mathrm{L}$ & 3.4 & 4.71 & $2.32-6.61$ & ACCEPT \\
Methoxychlor & $\mu \mathrm{g} / \mathrm{L}$ & 4.8 & 7.92 & $2.08-12.6$ & ACCEPT \\
Toxaphene & $\mu \mathrm{g} / \mathrm{L}$ & 34.3 & 36 & $0.0-65.1$ & ACCEPT \\
\hline & & & & &
\end{tabular}


Waste Isolation Pilot Plant Annual Site Environmental Report for 2005

DOE/WIPP-06-2225

This page intentionally left blank 


\section{Appendix A}

References

10 CFR Part 50, Appendix B. "Quality Assurance Criteria for Nuclear Power Plants and Fuel Reprocessing Plants." Code of Federal Regulations. Office of the Federal Register, National Archives and Records Administration, Washington, D.C.

10 CFR Part 61. "Licensing Requirements for Land Disposal of Radioactive Waste." Code of Federal Regulations. Office of the Federal Register, National Archives and Records Administration, Washington, D.C.

10 CFR Part 71. "Packaging and Transportation of Radioactive Material." Code of Federal Regulations. Office of the Federal Register, National Archives and Records Administration, Washington, D.C.

10 CFR Part 834. "Radiation Protection of the Public and the Environment"; Proposed Rule. Code of Federal Regulations. Office of the Federal Register, National Archives and Records Administration, Washington, D.C.

10 CFR Part 835. "Occupational Radiation Protection." Code of Federal Regulations. Office of the Federal Register, National Archives and Records Administration, Washington, D.C.

10 CFR Part 1021. "National Environmental Policy Act Implementing Procedures." Code of Federal Regulations. Office of the Federal Register, National Archives and Records Administration, Washington, D.C.

40 CFR Part 61. "National Emission Standards for Hazardous Air Pollutants." Code of Federal Regulations. Office of the Federal Register, National Archives and Records Administration, Washington, D.C.

40 CFR Part 122. "EPA Administered Permit Programs: the National Pollutant Discharge Elimination System." Code of Federal Regulations. Office of the Federal Register, National Archives and Records Administration, Washington, D.C.

40 CFR Part 141. "National Primary Drinking Water Regulations." Code of Federal Regulations. Office of the Federal Register, National Archives and Records Administration, Washington, D.C.

40 CFR Part 143. "National Secondary Drinking Water Regulations." Code of Federal Regulations. Office of the Federal Register, National Archives and Records Administration, Washington, D.C. 
40 CFR Part 191. "Environmental Radiation Protection Standards for Management and Disposal of Spent Nuclear Fuel, High-Level and Transuranic Radioactive Wastes." Code of Federal Regulations. Office of the Federal Register, National Archives and Records Administration, Washington, D.C.

40 CFR Part 194. "Criteria for the Certification and Re-Certification of the Waste Isolation Pilot Plant's Compliance With the 40 CFR Part 191 Disposal Regulations." Code of Federal Regulations. Office of the Federal Register, National Archives and Records Administration, Washington, D.C.

40 CFR Part 247. "Comprehensive Procurement Guideline for Products Containing Recovered Materials." Code of Federal Regulations. Office of the Federal Register, National Archives and Records Administration, Washington, D.C.

40 CFR Part 262. "Standards Applicable to Generators of Hazardous Waste." Code of Federal Regulations. Office of the Federal Register, National Archives and Records Administration, Washington, D.C.

40 CFR Part 264. "Standards for Owners and Operators of Hazardous Waste Treatment, Storage, and Disposal Facilities." Code of Federal Regulations. Office of the Federal Register, National Archives and Records Administration, Washington, D.C.

40 CFR Part 270, "EPA Administered Permit Programs: the Hazardous Waste Permit Program." Code of Federal Regulations. Office of the Federal Register, National Archives and Records Administration, Washington, D.C.

40 CFR Part 280, "Technical Standards and Corrective Action Requirements for Owners and Operators of Underground Storage Tanks (UST)." Code of Federal Regulations. Office of the Federal Register, National Archives and Records Administration, Washington, D.C.

40 CFR Part 281, "Approval of State Underground Storage Tank Programs." Code of Federal Regulations. Office of the Federal Register, National Archives and Records Administration, Washington, D.C.

40 CFR Part 300, "National Oil and Hazardous Substances Pollution Contingency Plan." Code of Federal Regulations. Office of the Federal Register, National Archives and Records Administration, Washington, D.C.

40 CFR Part 302. "Designation, Reportable Quantities, and Notification." Code of Federal Regulations. Office of the Federal Register, National Archives and Records Administration, Washington, D.C.

40 CFR Part 503. "Standards for the Use or Disposal of Sewage Sludge." Code of Federal Regulations. Office of the Federal Register, National Archives and Records Administration, Washington, D.C. 
40 CFR Part 761. "Polychlorinated Biphenyls (PCBs) Manufacturing, Processing, Distribution in Commerce, and Use Prohibitions." Code of Federal Regulations. Office of the Federal Register, National Archives and Records Administration, Washington, D.C.

40 CFR Parts 1500-1517. "Council on Environmental Quality." Code of Federal Regulations. Office of the Federal Register, National Archives and Records Administration, Washington, D.C.

43 CFR Part 2800. "Rights-of-Way, Principles and Procedures." Code of Federal Regulations. Office of the Federal Register, National Archives and Records Administration, Washington, D.C.

50 CFR §21.11, "General Permit Requirements." Code of Federal Regulations. Office of the Federal Register, National Archives and Records Administration, Washington, D.C.

20.2.72 NMAC. "Construction Permits." Title 20, New Mexico Administrative Code. (Air Quality Control Regulation 702). Santa Fe, NM.

20.4.1 NMAC. "Hazardous Waste Management." Title 20, New Mexico Administrative Code. Santa Fe, NM.

20.6.2 NMAC. "Ground and Surface Water Protection." Title 20, New Mexico Administrative Code. Santa Fe, NM.

20.7.10 NMAC. "Drinking Water." Title 20 New Mexico Administrative Code. Santa Fe, NM.

20.9.1 NMAC. "New Mexico Solid Waste Management Regulations."

Title 20 New Mexico Administrative Code. Santa Fe, NM.

15 U.S.C. §2301, et seq. Toxic Substances Control Act. U.S. Government Printing Office, Washington, D.C.

16 U.S.C. \$470, et seq. National Historic Preservation Act. United States Code. U.S. Government Printing Office, Washington, D.C.

16 U.S.C. \$1531-1544. Endangered Species Act of 1973. United States Code. U.S. Government Printing Office, Washington, D.C.

16 U.S.C. $§ \S 703$ through 712. Migratory Bird Treaty Act. United States Code. U.S. Government Printing Office, Washington, D.C.

33 U.S.C. §1251-1376. Federal Water Pollution Control Act of 1948 (Clean Water Act), Section 402. United States Code. U.S. Government Printing Office, Washington, D.C. 
42 U.S.C. $\S 300 f$ et seq. Safe Drinking Water Act. United States Code.

U.S. Government Printing Office, Washington, D.C.

42 U.S.C. §2011. Atomic Energy Act of 1954. United States Code. U.S. Government Printing Office, Washington, D.C.

42 U.S.C. §§4321-4345. National Environmental Policy Act. United States Code. U.S. Government Printing Office, Washington, D.C.

42 U.S.C. $\$ 6901$, et seq. Resource Conservation and Recovery Act. United States Code. U.S. Government Printing Office, Washington, D.C.

42 U.S.C. $\S \S 6912,6939 \mathrm{c}$ and 6961. Federal Facilities Compliance Act of 1992. United States Code. U.S. Government Printing Office, Washington, D.C.

42 U.S.C. §7112. Department of Energy Organization Act. United States Code. U.S. Government Printing Office, Washington, D.C.

42 U.S.C. $§ 7401$, et seq. Clean Air Act. United States Code. U.S. Government Printing Office, Washington, D.C.

42 U.S.C. $\$ 9601$, et seq. Comprehensive Environmental Response, Compensation, and Liability Act (including the Superfund Amendments and Reauthorization Act of 1986). United States Code. U.S. Government Printing Office, Washington, D.C.

42 U.S.C. §10101. Nuclear Waste Policy Act of 1982. United States Code.

U.S. Government Printing Office, Washington, D.C.

43 U.S.C. §§1701-1785. Federal Land Policy and Management Act. United States Code. U.S. Government Printing Office, Washington, D.C.

49 U.S.C. $§ 5101$, et seq.; 49 CFR Parts 105-179. Hazardous Materials Transportation Act. United States Code. U.S. Government Printing Office, Washington, D.C.

ANSI/ASQC - E4. Proposed. Quality Assurance Program Requirements for Environmental Programs. American National Standards Institute/American Society for Quality Control, Washington, D.C.

ASME NQA-1-1989 and Supplementary Requirements, Quality Assurance Program Requirements for Nuclear Facilities

ASME NQA-2a-1990 addenda, Part 2.7, Quality Assurance Requirements of Computer Software for Nuclear Facility Applications 
ASME NQA-3-1989 (excluding Section 2.1(b) and (c), and Section 17.1), Quality Assurance Program Requirements for the Collection of Scientific and Technical Information for Site Characterization of High-Level Nuclear Waste

Beauheim, R. L. 1986. Analysis of Pumping Tests of the Culebra Dolomite Conducted at the H-3 Hydropad at the Waste Isolation Pilot Plant (WIPP) Site, SAND86-2311, Sandia National Laboratories, Albuquerque, NM.

Beauheim, R. L. 1987. Interpretations of Single-Well Hydraulic Tests Conducted at and Near the Waste Isolation Pilot Plant (WIPP) Site, 1983-1987, SAND 87-0039, Sandia National Laboratories, Albuquerque, NM.

Beauheim, R. L., T. F. Dale, and J. F. Pickens. 1991. Interpretations of Single-Well Hydraulic Tests of the Rustler Formation Conducted in the Vicinity of the Waste Isolation Pilot Plant Site, 1988-1989. SAND-890869, Sandia National Laboratories, Albuquerque, NM.

Beauheim, R. L., and G. J. Ruskauff. 1998. Analysis of Hydraulic Tests of the Culebra and Magenta Dolomites and Dewey Lake Redbeds Conducted at the Waste Isolation Pilot Plant Site, SAND 98-0049, Sandia National Laboratories, Albuquerque, NM.

Beauheim, R. L., and R. M. Roberts. 2002. "Hydrology and Hydraulic Properties of a Bedded Evaporite Formation." Journal of Hydrology, v. 259, pp. 66-88

Beck, Harold L. and Burton G. Bennet. 2002. Historical Overview of Atmospheric Nuclear Weapon Testing and Estimates of Fallout in the Continental United States. Health Phys 82:591-608.

CEMRC. 2004. Plutonium in the 2003 Second Quarter FAS Composite (Revised). Carlsbad Environmental Research Monitoring and Research Center. Carlsbad, NM.

Cooper, J. B., and V. M. Glanzman. 1971. "Geohydrology of Project Gnome Site, Eddy County, New Mexico." Professional Paper 712-A, U.S. Geological Survey, Washington, DC.

Daniel B. Stephens \& Associates, Inc. 2003. Water Budget Analysis of the Shallow Subsurface Water at the Waste Isolation Pilot Plant, Carlsbad, NM.

DOE/CAO 96-2184. 1996. 40 CFR Part 191 Compliance Certification Application for the Waste Isolation Pilot Plant. U.S. Department of Energy, Carlsbad Field Office. Carlsbad, NM.

DOE/EH-0173T. 1991. Environmental Regulatory Guide for Radiological Effluent Monitoring and Environmental Surveillance, Department of Environment, Safety, and Health, U.S. Department of Energy, Washington, D.C. 
DOE. 2005. Guidance for the Preparation of DOE Annual Site Environmental Reports (ASERs) for Calendar Year 2005. Department of Environment, Safety, and Health, U.S. Department of Energy, Washington, D.C.

DOE/EIS-0026. 1980. Final Environmental Impact Statement, Waste Isolation Pilot Plant. Volumes 1 and 2. U.S. Department of Energy, Washington, D.C.

DOE/EIS-0026-FS. 1990. Final Supplement Environmental Impact Statement for the Waste Isolation Pilot Plant, Waste Isolation Pilot Plant, Volumes 1 through 3. U.S. Department of Energy, Washington, D.C.

DOE/EIS-0026-S-2. 1997. Waste Isolation Pilot Plant Disposal Phase Final Supplemental Environmental Impact Statement, (SEIS-II). Volumes 1 through 3. U.S. Department of Energy, Washington, D.C.

DOE/EIS-0026-SA05, Supplement Analysis for the Waste Isolation Pilot Plant Site Wide Operations, April 2005.

DOE Order 151.1C. 2005. Comprehensive Emergency Management System. U.S. Department of Energy, Washington, D.C.

DOE Order 225.1A. 1997. Accident Investigation. U.S. Department of Energy, Washington, D.C.

DOE Order 231.1A. 2003. Environmental, Safety, and Health Reporting. U.S. Department of Energy, Washington, D.C.

DOE Order 414.1C. 2005. Quality Assurance. U.S. Department of Energy, Washington, D.C.

DOE Order 435.1. 1999. Radioactive Waste Management. U.S. Department of Energy, Washington, D.C.

DOE Order 450.1. 2003. Environmental Protection Program. U.S. Department of Energy, Washington D.C.

DOE Order 451.1B. 2001. National Environmental Compliance Policy Act Compliance Program. U.S. Department of Energy, Washington, D.C.

DOE-STD-1153-2002. 2003. A Graded Approach for Evaluating Radiation Doses to Aquatic and Terrestrial Biota. National Technical Information Service, Washington, D.C.

DOE/CBFO-94-1012. 1994. Quality Assurance Program Document. Waste Isolation Pilot Plant, Carlsbad, NM. 
DOE/WIPP. 2002. Base Contract Statement of Work for Subcontractor Analytical Laboratories, Waste Isolation Pilot Plant, Revision 2.

DOE/WIPP 92-037. 1992. Statistical Summary of the Radiological Baseline for the Waste Isolation Pilot Plant. Waste Isolation Pilot Plant, Carlsbad, NM.

DOE/WIPP 93-004. 2002. Waste Isolation Pilot Plant Land Management Plan. Waste Isolation Pilot Plant, Carlsbad, NM.

DOE/WIPP 95-2065. 2004. Waste Isolated Pilot Plant Contact Handled (CH) Documented Safety Analysis. Waste Isolation Pilot Plant, Carlsbad, NM.

DOE/WIPP 97-2219. 1997. Exhaust Shaft Hydraulic Assessment Data Report. Waste Isolation Pilot Plant. Carlsbad, NM.

DOE/WIPP 98-2285. 1998. Waste Isolation Pilot Plant RCRA Background Groundwater Quality Baseline Report. Waste Isolation Pilot Plant, Carlsbad, NM.

DOE/WIPP 99-2194. 2004. Waste Isolation Pilot Plant Environmental Monitoring Plan. Waste Isolation Pilot Plant, Carlsbad, NM.

DOE/WIPP 00-2014. 2000. WIPP Sampling and Analysis Plan for Solid Waste Management Units. Waste Isolation Pilot Plant, Carlsbad, NM.

DOE/WIPP 06-2171. 2006. Waste Isolation Pilot Plant Biennial Environmental Compliance Report. Waste Isolation Pilot Plant, Carlsbad, NM.

DOE/WIPP 03-2225. 2003. Waste Isolation Pilot Plant 2002 Site Environmental Report. Waste Isolation Pilot Plant, Carlsbad, NM.

DOE/WIPP-02-3286. 2002. Waste Isolation Pilot Plant Contact-Handled Waste Handling Emergency Planning Hazards Assessment. Waste Isolation Pilot Plant, Carlsbad, NM.

DOE/WIPP 05-3319. 2005. Basic Data Report for Drillhole SNL-13 (C-3139). Waste Isolation Pilot Plant, Carlsbad, NM.

DOE/WIPP 05-3320. 2005. Basic Data Report for Drillhole SNL-14 (C-3152). Waste Isolation Pilot Plant, Carlsbad, NM.

DOE/WIPP 05-3325. 2005. Basic Data Report for Drillhole SNL-15 (C-3152). Waste Isolation Pilot Plant, Carlsbad, NM.

DOE/WIPP 05-3324. 2005. Basic Data Report for Drillhole SNL-8 (C-3150). Waste Isolation Pilot Plant, Carlsbad, NM. 
DOE/WIPP 05-3323. 2005. Basic Data Report for Drillhole SNL-6 (C-3151). Waste Isolation Pilot Plant, Carlsbad, NM.

DOE/WIPP 04-3310. 2004. CBFO/WTS Environmental Policy Statement

DOE/WIPP 05-3318. 2005. Waste Isolation Pilot Plant Environmental Management System Description. Waste Isolation Pilot Plant, Carlsbad, NM.

DOI/BLM. 1997. Carlsbad Approved Resource Management Plan Amendment and Record of Decision. United States Department of the Interior Bureau of Land Management, Roswell, NM.

DP-831. 2003. WIPP Discharge Permit. New Mexico Environment Department, Santa Fe, NM.

EPA. 1994. EPA Contract Laboratory Program Volatile Organics Analysis of Ambient Air in Canisters (draft). U.S. Environmental Protection Agency, Washington, D.C.

EPA. 2005a. EPA letter from Bonnie C. Gitlin, Acting Director, Radiation Protection Division, U.S. Environmental Protection Agency, to Dr. Ines Triay, Acting Manager, Carlsbad Field Office. April 15, 2005.

EPA. 2005b. EPA letter from Bonnie C. Gitlin, Acting Director, Radiation Protection Division, U.S. Environmental Protection Agency, to Dr. Ines Triay, Acting Manager, Carlsbad Field Office. July 8, 2005.

EPA. 2005c. EPA letter from Bonnie Gitlin, Acting Director, Radiation Protection Division, U.S. Environmental Protection Agency, to Lloyd L. Piper, Acting Manager, Carlsbad Field Office. August 31, 2005.

EPA. 2005d. EPA letter from Bonnie Gitlin, Acting Director, Radiation Protection Division, U.S. Environmental Protection Agency, to Lloyd L. Piper, Acting Manager, Carlsbad Field Office. September 23, 2005.

EPA TO-14A. 1999. Compendium of Methods for the Determination of Toxic Organic Compounds in Ambient Air. U.S. Environmental Protection Agency, Washington, D.C.

Executive Order 13101. 1998. Greening the Government Through Waste Prevention, Recycling, and Federal Acquisition. Office of the President, Washington, D.C.

Executive Order 13148. 1998. Greening the Government Through Leadership in Environmental Management. Office of the President, Washington, D.C.

HPS N13.30. 1996. Performance Criteria for Radiobioassay. Health Physics Society, Washington, D.C. 
Human Health Fact Sheet (Strontium), Argonne National Laboratory, EVS, August 2005.

ISO 14001. Environmental Management Systems - Specification with Guidance for Use. 1996. International Organizations for Standardization. Geneva, Switzerland.

IT Corporation. 2000. Waste Isolation Pilot Plant RCRA Background Groundwater Quality Baseline Update Report. Albuquerque, NM.

Mercer, J. W. 1983. Geohydrology of the Proposed Waste Isolation Pilot Plant Site, Los Medaños Area, Southeastern New Mexico, Water Resources investigations, Report 83-4016, U.S. Geological Survey.

Mercer, J. W. and B. R. Orr. 1977. Review and Analysis of Geologic Conditions Near the Site of a Potential Nuclear Waste Repository Eddy and Lea Counties, New Mexico, U.S. Geological Survey Open-File Rept., 77-123.

Minnema, D. M. and L. W. Brewer. 1983. Background Radiation Measurements at Waste Isolation Pilot Plant Site, Carlsbad, New Mexico. SAND83-1296.

MP 1.2, Work Suspension and Stop-Work Direction. Washington TRU Solutions LLC, Waste Isolation Pilot Plant, Carlsbad, NM.

MP 1.12, Worker Protection Policy. Washington TRU Solutions LLC, Waste Isolation Pilot Plant, Carlsbad, NM.

MP 1.14, Environmental Management. Washington TRU Solutions LLC, Waste Isolation Pilot Plant, Carlsbad, NM.

MP 1.28, Integrated Safety Management. Washington TRU Solutions LLC, Waste Isolation Pilot Plant, Carlsbad, NM.

NCRP. 1976. Environmental Radiation Measurements. Report Number 50. National Council on Radiation and Measurements. Bethesda, MD.

NCRP. 1987a. Report No. 94, Exposure of the Population in the United States and Canada from Natural Background Radiation. National Council on Radiation Protection and Measurements. Bethesda, MD.

NCRP. 1987b. Use of Bioassay Procedures for Assessment of Internal Radionuclide Deposition. National Council on Radiation Protection and Measurements. Bethesda, MD.

NCRP. 1991. Report No. 109, Effects of lonizing Radiation on Aquatic Organisms. National Council on Radiation Protection and Measurements. Bethesda, MD. 
NM4890139088-TSDF. 1999. Waste Isolation Pilot Plant Hazardous Waste Facility Permit. New Mexico Environment Department, Santa Fe, NM.

NMR05A823. 2001. New Mexico NPDES Multi-Sector General Permit. New Mexico Environment Department, Santa Fe, NM.

NMSA 1978. §74-2. New Mexico Air Quality Control Act. New Mexico Statutes Annotated 1978. State of New Mexico, Santa Fe, NM.

NMSA 1978. §74-4-1. New Mexico Hazardous Waste Act. New Mexico Statutes Annotated 1978. State of New Mexico, Santa Fe, NM.

NMSA 1978. §74-6-1. New Mexico Water Quality Act. New Mexico Statutes Annotated. State of New Mexico, Santa Fe, NM.

NRC-Docket-71-9218. TRUPACT-II Safety Analysis Report for Packaging. Nuclear Regulator Commission, Washington, D.C.

Pacific Northwest National Laboratory. 1999. Hanford Decision Level for Alpha Spectrometry Bioassay Analyses Based on the Sample Specific Total Propagated Uncertainty (99352). J. A. MacLellan, Radiation and Health Technology. Richland, WA.

Public Law 96-164. National Security and Military Applications of Nuclear Energy Authorization Act of 1980.

Public Law 102-579. Waste Isolation Pilot Plant Land Withdrawal Act. October 1992, as amended October 1996 by Public Law 104-201.

EPA QA/R-5. 2001. EPA Requirements for Quality Assurance Project Plans, U.S. Environmental Protection Agency, Washington, D.C.

Regulatory Guide 4.15, Rev. 1. 1979. Quality Assurance for Radiological Monitoring Programs-Effluent Streams and the Environment. U.S. Nuclear Regulatory Commission, Washington, D.C.

Rosman, K. J. R. and P. D. P Taylor. 1998. Isotopic Compositions of the Elements. Pure Applied Chemistry. 70(1):217-236.

Stormont, J. C., C. L. Howard, and J. J. K. Daemen. 1991. Changes in Rock Salt Permeability Due to Nearby Excavation. In: Roegiers, J. C. (Ed.), Rock Mechanics as a Multidisciplinary Science. Proceedings of the $32^{\text {nd }}$ U.S. Symposium, the University of Oklahoma, Norman, Oklahoma, July 10-12, 1991. A. A. Balkema, Brookfield, VT, pp. 899-907.

United Nations Scientific Community on the Effects of Atomic Radiation. 2002. Sources of Effects of lonizing Radiation. Publication EOO:IX.3. New York, NY. 
Ward, J. J. and G. Walter. 1983. Aquifer Tests to Determine the Principal Components of Transmissivity in the Culebra Dolomite at Hydropads $\mathrm{H}-4, \mathrm{H}-5$, and $\mathrm{H}-6$ : Waste Isolation Pilot Plant (WIPP), Southeastern New Mexico, SAND83-7009, Sandia National Laboratories, Albuquerque, NM.

WP 02-1, WIPP Groundwater Monitoring Program Plan. Washington TRU Solutions LLC. Waste Isolation Pilot Plant, Carlsbad, NM.

WP 02-EC.07, Waste Isolation Pilot Plant Affirmative Procurement Plan. Washington TRU Solutions LLC. Waste Isolation Pilot Plant, Carlsbad, NM.

WP 02-EC.08, National Environmental Policy Act Compliance Plan. Washington TRU Solutions LLC. Waste Isolation Pilot Plant, Carlsbad, NM.

WP 02-EC.11, Waste Isolation Pilot Plant Pollution Prevention Program Plan. Washington TRU Solutions LLC. Waste Isolation Pilot Plant, Carlsbad, NM.

WP 02-EC.13, Environmental Assessment Plan. Washington TRU Solutions LLC. Waste Isolation Pilot Plant, Carlsbad, NM.

WP 14-TR.01, WIPP Training Program. Washington TRU Solutions LLC. Waste Isolation Pilot Plant, Carlsbad, NM.

WP 12-VC.01, Confirmatory Volatile Organic Compound Monitoring Program. Washington TRU Solutions LLC. Waste Isolation Pilot Plant, Carlsbad, NM. 
Waste Isolation Pilot Plant Annual Site Environmental Report for 2005

DOE/WIPP-06-2225

This page intentionally left blank 


\section{Waste Isolation Pilot Plant Annual Site Environmental Report for 2005 DOE/WIPP-06-2225}

\section{Appendix B \\ Active Environmental Permits}

\begin{tabular}{|c|c|c|c|c|c|}
\hline & Granting Agency & Type of Permit & $\begin{array}{c}\text { Permit } \\
\text { Number }\end{array}$ & Granted & Expiration \\
\hline 1 & $\begin{array}{l}\text { Department of the Interior, } \\
\text { Bureau of Land Management }\end{array}$ & Right-of-Way for Water Pipeline & NM53809 & $8 / 17 / 83$ & None \\
\hline 2 & $\begin{array}{l}\text { Department of the Interior, } \\
\text { Bureau of Land Management }\end{array}$ & Right-of-Way for the North Access Road & NM55676 & $8 / 24 / 83$ & None \\
\hline 3 & $\begin{array}{l}\text { Department of the Interior, } \\
\text { Bureau of Land Management }\end{array}$ & Right-of-Way for Railroad & NM55699 & $9 / 27 / 83$ & None \\
\hline 4 & $\begin{array}{l}\text { Department of the Interior, } \\
\text { Bureau of Land Management }\end{array}$ & $\begin{array}{l}\text { Right-of-Way for Dosimetry and Aerosol } \\
\text { Sampling Sites }\end{array}$ & NM63136 & $7 / 31 / 86$ & $7 / 31 / 11$ \\
\hline 5 & \begin{tabular}{|l} 
Department of the Interior, \\
Bureau of Land Management
\end{tabular} & $\begin{array}{l}\text { Right-of-Way for Seven Subsidence } \\
\text { Monuments }\end{array}$ & NM65801 & $11 / 7 / 86$ & None \\
\hline 6 & $\begin{array}{l}\text { Department of the Interior, } \\
\text { Bureau of Land Management }\end{array}$ & Right-of-Way for Aerosol Sampling Site & NM77921 & $8 / 18 / 89$ & $8 / 18 / 19$ \\
\hline 7 & \begin{tabular}{|l} 
Department of the Interior, \\
Bureau of Land Management
\end{tabular} & Right-of-Way for 2 Survey Monuments & NM82245 & $12 / 13 / 89$ & $12 / 13 / 19$ \\
\hline 8 & $\begin{array}{l}\text { Department of the Interior, } \\
\text { Bureau of Land Management }\end{array}$ & Right-of-Way for telephone cable & NM46029 & $7 / 3 / 90$ & $9 / 4 / 11$ \\
\hline 9 & $\begin{array}{l}\text { Department of the Interior, } \\
\text { Bureau of Land Management }\end{array}$ & Right-of-Way for SPS Powerline & NM43203 & $2 / 20 / 96$ & $10 / 19 / 11$ \\
\hline 10 & $\begin{array}{l}\text { Department of the Interior, } \\
\text { Bureau of Land Management }\end{array}$ & Right-of-Way for South Access Road & NM46130 & $8 / 17 / 81$ & $8 / 17 / 31$ \\
\hline 11 & \begin{tabular}{|l} 
Department of the Interior, \\
Bureau of Land Management
\end{tabular} & Right-of-Way for South Access Road Fence & NM94304 & $3 / 15 / 95$ & none \\
\hline 12 & $\begin{array}{l}\text { Department of the Interior, } \\
\text { Bureau of Land Management }\end{array}$ & Right-of-Way for Duval telephone line & NM60174 & $11 / 6 / 96$ & $3 / 8 / 15$ \\
\hline 13 & $\begin{array}{l}\text { Department of the Interior, } \\
\text { Bureau of Land Management }\end{array}$ & Right-of-Way for Wells AEC-7 \& AEC-8 & NM108365 & $8 / 30 / 02$ & $8 / 30 / 32$ \\
\hline 14 & $\begin{array}{l}\text { Department of the Interior, } \\
\text { Bureau of Land Management }\end{array}$ & Right-of-Way for ERDA-6 & NM108365 & $8 / 30 / 02$ & $8 / 30 / 32$ \\
\hline 15 & $\begin{array}{l}\text { Department of the Interior, } \\
\text { Bureau of Land Management }\end{array}$ & $\begin{array}{l}\text { Right-of-Way for Monitoring Well C-2756 } \\
\text { (P-18) }\end{array}$ & NM108365 & $8 / 30 / 02$ & $8 / 30 / 32$ \\
\hline 16 & \begin{tabular}{|l} 
Department of the Interior, \\
Bureau of Land Management
\end{tabular} & $\begin{array}{l}\text { Right-of-way for Monitoring Well C-2664 } \\
\text { (Cabin Baby) }\end{array}$ & NM107944 & $4 / 23 / 02$ & $4 / 23 / 32$ \\
\hline 17 & \begin{tabular}{|l} 
Department of the Interior, \\
Bureau of Land Management
\end{tabular} & Right-of-Way for Seismic Monitoring Station & NM85426 & $9 / 23 / 91$ & None \\
\hline 18 & \begin{tabular}{|l} 
Department of the Interior, \\
Bureau of Land Management
\end{tabular} & $\begin{array}{l}\text { Right-of-Way for Wells C-2725 (H-4A), } \\
\text { C-2775 (H-4B), \& C-2776 (H-4C) }\end{array}$ & NM108365 & $8 / 30 / 02$ & $8 / 30 / 32$ \\
\hline 19 & $\begin{array}{l}\text { Department of the Interior, } \\
\text { Bureau of Land Management }\end{array}$ & $\begin{array}{l}\text { Right-of-Way for Monitoring Wells C-2723 } \\
\text { (WIPP-25), C-2724 (WIPP-26), C-2722 } \\
\text { (WIPP-27), C-2636 (WIPP-28), C-2743 } \\
\text { (WIPP-29), \& C-2727 (WIPP-30) }\end{array}$ & NM108365 & $8 / 30 / 02$ & $8 / 30 / 32$ \\
\hline 20 & $\begin{array}{l}\text { Department of the Interior, } \\
\text { Bureau of Land Management }\end{array}$ & Right-of-Way for Monitoring Well WIPP-11 & NM108365 & $9 / 15 / 04$ & $9 / 20 / 34$ \\
\hline 21 & $\begin{array}{l}\text { Department of the Interior, } \\
\text { Bureau of Land Management }\end{array}$ & $\begin{array}{l}\text { Right-of-Way easement for WIPP well bore } \\
\text { SNL-2 }\end{array}$ & 109174 & $4 / 15 / 03$ & $4 / 15 / 33$ \\
\hline 22 & $\begin{array}{l}\text { Department of the Interior, } \\
\text { Bureau of Land Management }\end{array}$ & $\begin{array}{l}\text { Right-of-Way easement for WIPP well bore } \\
\text { SNL-9 }\end{array}$ & 109175 & $4 / 15 / 03$ & $4 / 15 / 33$ \\
\hline 23 & $\begin{array}{l}\text { Department of the Interior, } \\
\text { Bureau of Land Management }\end{array}$ & $\begin{array}{l}\text { Right-of-Way easement for WIPP well bore } \\
\text { SNL-12 }\end{array}$ & 109176 & $4 / 15 / 03$ & $4 / 15 / 33$ \\
\hline
\end{tabular}




\section{Waste Isolation Pilot Plant Annual Site Environmental Report for 2005 DOE/WIPP-06-2225}

\begin{tabular}{|c|c|c|c|c|c|}
\hline & Granting Agency & Type of Permit & \begin{tabular}{|c} 
Permit \\
Number
\end{tabular} & Granted & Expiration \\
\hline 24 & $\begin{array}{l}\text { Department of the Interior, } \\
\text { Bureau of Land Management }\end{array}$ & $\begin{array}{l}\text { Right-of-Way easement for WIPP well bore } \\
\text { SNL-1 (access road) }\end{array}$ & 109177 & $6 / 17 / 03$ & $6 / 17 / 33$ \\
\hline 25 & $\begin{array}{l}\text { Department of the Interior, } \\
\text { Bureau of Land Management }\end{array}$ & $\begin{array}{l}\text { Right-of-Way easement for WIPP well bore } \\
\text { SNL-11 }\end{array}$ & 110735 & $10 / 17 / 03$ & $10 / 17 / 33$ \\
\hline 26 & $\begin{array}{l}\text { Department of the Interior, } \\
\text { Bureau of Land Management }\end{array}$ & $\begin{array}{l}\text { Right-of-Way easement for WIPP well bore } \\
\text { SNL-5 }\end{array}$ & 110735 & $10 / 17 / 03$ & $10 / 17 / 33$ \\
\hline 27 & $\begin{array}{l}\text { Department of the Interior, } \\
\text { Bureau of Land Management }\end{array}$ & Right-of-Way grant for SNL-16 and 17 & NM108365 & $12 / 21 / 05$ & $8 / 30 / 32$ \\
\hline 28 & $\begin{array}{l}\text { U.S. Department of the Interior, } \\
\text { Fish and Wildlife Service }\end{array}$ & $\begin{array}{l}\text { Concurrence that WIPP construction } \\
\text { activities will have no significant impact on } \\
\text { federally-listed threatened or endangered } \\
\text { species }\end{array}$ & None & $5 / 29 / 80$ & None \\
\hline 29 & $\begin{array}{l}\text { New Mexico Commissioner of } \\
\text { Public Lands }\end{array}$ & Right-of-Way for High Volume Air Sampler & RW-22789 & $10 / 3 / 85$ & $10 / 3 / 20$ \\
\hline 30 & $\begin{array}{l}\text { New Mexico Commissioner of } \\
\text { Public Lands }\end{array}$ & Monitoring Well SNL-3 & RW-28537 & $7 / 31 / 03$ & $7 / 31 / 38$ \\
\hline 31 & $\begin{array}{l}\text { New Mexico Commissioner of } \\
\text { Public Lands }\end{array}$ & Monitoring Well SNL-1 & RW-28535 & $8 / 27 / 03$ & $8 / 27 / 38$ \\
\hline 32 & $\begin{array}{l}\text { New Mexico Commissioner of } \\
\text { Public Lands }\end{array}$ & $\begin{array}{l}\text { Right-of-Way Easement for Accessing State } \\
\text { Trust Lands in Eddy \& Lea Counties }\end{array}$ & RW-25430 & $9 / 28 / 04$ & $9 / 28 / 14$ \\
\hline 33 & $\begin{array}{l}\text { New Mexico Environment } \\
\text { Department Air Quality Bureau }\end{array}$ & $\begin{array}{l}\text { Operating Permit for two backup diesel } \\
\text { generators }\end{array}$ & $310-\mathrm{M}-2$ & $12 / 7 / 93$ & None \\
\hline 34 & $\begin{array}{l}\text { New Mexico Department of Game } \\
\text { and Fish }\end{array}$ & $\begin{array}{l}\text { Concurrence that WIPP construction } \\
\text { activities will have no significant impact on } \\
\text { state-listed threatened or endangered } \\
\text { species }\end{array}$ & None & $5 / 26 / 89$ & None \\
\hline 35 & \begin{tabular}{|l} 
New Mexico Environment \\
Department-UST Bureau
\end{tabular} & Underground Storage Tanks & \begin{tabular}{|c|} 
Facility No. \\
31539 \\
\end{tabular} & $7 / 1 / 05$ & $6 / 30 / 06$ \\
\hline 36 & New Mexico State Engineer Office & $\begin{array}{l}\text { Monitoring Well Exhaust Shaft Exploratory } \\
\text { Borehole }\end{array}$ & C-2801 & $2 / 23 / 01$ & None \\
\hline 37 & New Mexico State Engineer Office & Monitoring Well & $\mathrm{C}-2811$ & $3 / 2 / 02$ & None \\
\hline 38 & New Mexico State Engineer Office & $\begin{array}{l}\text { Monitoring Well Exhaust Shaft Exploratory } \\
\text { Borehole }\end{array}$ & C-2802 & $2 / 23 / 01$ & None \\
\hline 39 & New Mexico State Engineer Office & $\begin{array}{l}\text { Monitoring Well Exhaust Shaft Exploratory } \\
\text { Borehole }\end{array}$ & C-2803 & $2 / 23 / 01$ & None \\
\hline 40 & New Mexico State Engineer Office & Appropriation: WQSP-1 Well & C-2413 & $10 / 21 / 96$ & None \\
\hline 41 & New Mexico State Engineer Office & Appropriation: WQSP-2 Well & C-2414 & $10 / 21 / 96$ & None \\
\hline 42 & New Mexico State Engineer Office & Appropriation: WQSP-3 Well & C-2415 & $10 / 21 / 96$ & None \\
\hline 43 & New Mexico State Engineer Office & Appropriation: WQSP-4 Well & C-2416 & $10 / 21 / 96$ & None \\
\hline 44 & New Mexico State Engineer Office & Appropriation: WQSP-5 Well & C-2417 & $10 / 21 / 96$ & None \\
\hline 45 & New Mexico State Engineer Office & Appropriation: WQSP-6 Well & C-2418 & $10 / 21 / 96$ & None \\
\hline 46 & New Mexico State Engineer Office & Appropriation: WQSP-6a Well & C-2419 & $10 / 21 / 96$ & None \\
\hline 47 & New Mexico State Engineer Office & Monitoring Well AEC-7 & C-2742 & $11 / 6 / 00$ & None \\
\hline 48 & New Mexico State Engineer Office & Monitoring Well AEC-8 & C-2744 & $11 / 6 / 00$ & None \\
\hline 49 & New Mexico State Engineer Office & Monitoring Well Cabin Baby & C-2664 & $7 / 30 / 99$ & None \\
\hline 50 & New Mexico State Engineer Office & Monitoring Well DOE-1 & C-2757 & $11 / 6 / 00$ & None \\
\hline 51 & New Mexico State Engineer Office & Monitoring Well DOE-2 & C-2682 & $4 / 17 / 00$ & None \\
\hline 52 & New Mexico State Engineer Office & Monitoring Well ERDA-9 & C-2752 & $11 / 6 / 00$ & None \\
\hline 53 & New Mexico State Engineer Office & Monitoring Well $\mathrm{H}-1$ & C-2765 & $11 / 6 / 00$ & None \\
\hline 54 & New Mexico State Engineer Office & Monitoring Well H-2A & C-2762 & $11 / 6 / 00$ & None \\
\hline
\end{tabular}




\section{Waste Isolation Pilot Plant Annual Site Environmental Report for 2005 DOE/WIPP-06-2225}

\section{Table B.1 - Active Environmental Permits for the Waste Isolation Pilot Plant - Calendar Year 2005 (Does Not Include Hazardous Waste Facility Permit)}

\begin{tabular}{|c|c|c|c|c|c|}
\hline & Granting Agency & Type of Permit & $\begin{array}{l}\text { Permit } \\
\text { Number }\end{array}$ & Granted & Expiration \\
\hline 55 & New Mexico State Engineer Office & Monitoring Well H-2B1 & C-2758 & $11 / 6 / 00$ & None \\
\hline 56 & New Mexico State Engineer Office & Monitoring Well H-2B2 & C-2763 & $11 / 6 / 00$ & None \\
\hline 57 & New Mexico State Engineer Office & Monitoring Well $\mathrm{H}-2 \mathrm{C}$ & C-2759 & $11 / 6 / 00$ & None \\
\hline 58 & New Mexico State Engineer Office & Monitoring Well H-3B1 & C-2764 & $11 / 6 / 00$ & None \\
\hline 59 & New Mexico State Engineer Office & Monitoring Well H-3B2 & C-2760 & $11 / 6 / 00$ & None \\
\hline 60 & New Mexico State Engineer Office & Monitoring Well H-3B3 & C-2761 & $11 / 6 / 00$ & None \\
\hline 61 & New Mexico State Engineer Office & Monitoring Well H-3D & C-3207 & $11 / 6 / 00$ & None \\
\hline 62 & New Mexico State Engineer Office & Monitoring Well H-4A & C-2725 & $11 / 6 / 00$ & None \\
\hline 63 & New Mexico State Engineer Office & Monitoring Well H-4B & C-2775 & $11 / 6 / 00$ & None \\
\hline 64 & New Mexico State Engineer Office & Monitoring Well $\mathrm{H}-4 \mathrm{C}$ & C-2776 & $11 / 6 / 00$ & None \\
\hline 65 & New Mexico State Engineer Office & Monitoring Well H-5A & C-2746 & $11 / 6 / 00$ & None \\
\hline 66 & New Mexico State Engineer Office & Monitoring Well H-5B & C-2745 & $11 / 6 / 00$ & None \\
\hline 67 & New Mexico State Engineer Office & Monitoring Well H-5C & C-2747 & $11 / 6 / 00$ & None \\
\hline 68 & New Mexico State Engineer Office & Monitoring Well $\mathrm{H}-6 \mathrm{~A}$ & C-2751 & $11 / 6 / 00$ & None \\
\hline 69 & New Mexico State Engineer Office & Monitoring Well H-6B & C-2749 & $11 / 6 / 00$ & None \\
\hline 70 & New Mexico State Engineer Office & Monitoring Well H-6C & C-2750 & $11 / 6 / 00$ & None \\
\hline 71 & New Mexico State Engineer Office & Monitoring Well H-7A & C-2694 & $4 / 17 / 00$ & None \\
\hline 72 & New Mexico State Engineer Office & Monitoring Well H-7B1 & C-2770 & $11 / 6 / 00$ & None \\
\hline 73 & New Mexico State Engineer Office & Monitoring Well H-7B2 & C-2771 & $11 / 6 / 00$ & None \\
\hline 74 & New Mexico State Engineer Office & Monitoring Well H-7C & C-2772 & $11 / 6 / 00$ & None \\
\hline 75 & New Mexico State Engineer Office & Monitoring Well $\mathrm{H}-8 \mathrm{~A}$ & C-2780 & $11 / 6 / 00$ & None \\
\hline 76 & New Mexico State Engineer Office & Monitoring Well H-8B & C-2781 & $11 / 6 / 00$ & None \\
\hline 77 & New Mexico State Engineer Office & Monitoring Well H-8C & C-2782 & $11 / 6 / 00$ & None \\
\hline 78 & New Mexico State Engineer Office & Monitoring Well H-9A & C-2785 & $11 / 6 / 00$ & None \\
\hline 79 & New Mexico State Engineer Office & Monitoring Well H-9B & C-2783 & $11 / 6 / 00$ & None \\
\hline 80 & New Mexico State Engineer Office & Monitoring Well H-9C & C-2784 & $11 / 6 / 00$ & None \\
\hline 81 & New Mexico State Engineer Office & Monitoring Well $\mathrm{H}-10 \mathrm{~A}$ & C-2779 & $11 / 6 / 00$ & None \\
\hline 82 & New Mexico State Engineer Office & Monitoring Well $\mathrm{H}-10 \mathrm{~B}$ & C-2778 & $11 / 6 / 00$ & None \\
\hline 83 & New Mexico State Engineer Office & Monitoring Well $\mathrm{H}-10 \mathrm{C}$ & C-2695 & $4 / 17 / 00$ & None \\
\hline 84 & New Mexico State Engineer Office & Monitoring Well H-11B1 & C-2767 & $11 / 6 / 00$ & None \\
\hline 85 & New Mexico State Engineer Office & Monitoring Well H-11B2 & C-2687 & $4 / 17 / 00$ & None \\
\hline 86 & New Mexico State Engineer Office & Monitoring Well H-11B3 & C-2768 & $11 / 6 / 00$ & None \\
\hline 87 & New Mexico State Engineer Office & Monitoring Well H-11B4 & C-2769 & $11 / 6 / 00$ & None \\
\hline 88 & New Mexico State Engineer Office & Monitoring Well $\mathrm{H}-12$ & C-2777 & $11 / 6 / 00$ & None \\
\hline 89 & New Mexico State Engineer Office & Monitoring Well H-14 & C-2766 & $11 / 6 / 00$ & None \\
\hline 90 & New Mexico State Engineer Office & Monitoring Well $\mathrm{H}-15$ & C-2685 & $4 / 17 / 00$ & None \\
\hline 91 & New Mexico State Engineer Office & Monitoring Well H-16 & C-2753 & $11 / 6 / 00$ & None \\
\hline 92 & New Mexico State Engineer Office & Monitoring Well H-17 & C-2773 & $11 / 6 / 00$ & None \\
\hline 93 & New Mexico State Engineer Office & Monitoring Well $\mathrm{H}-18$ & C-2683 & $4 / 17 / 00$ & None \\
\hline 94 & New Mexico State Engineer Office & Monitoring Well P-17 & C-2774 & $11 / 6 / 00$ & None \\
\hline 95 & New Mexico State Engineer Office & Monitoring Well WIPP-11 & C03112 & $8 / 25 / 04$ & $8 / 31 / 05$ \\
\hline 96 & New Mexico State Engineer Office & Monitoring Well WIPP-12 & C-2639 & $1 / 12 / 99$ & None \\
\hline 97 & New Mexico State Engineer Office & Monitoring Well WIPP-13 & C-2748 & $11 / 6 / 00$ & None \\
\hline 98 & New Mexico State Engineer Office & Monitoring Well WIPP-18 & C-2684 & $4 / 17 / 00$ & None \\
\hline
\end{tabular}


Waste Isolation Pilot Plant Annual Site Environmental Report for 2005 DOE/WIPP-06-2225

\begin{tabular}{|c|c|c|c|c|c|}
\hline & Granting Agency & Type of Permit & $\begin{array}{l}\text { Permit } \\
\text { Number }\end{array}$ & Granted & Expiration \\
\hline 99 & New Mexico State Engineer Office & Monitoring Well WIPP-19 & C-2755 & $11 / 6 / 00$ & None \\
\hline 100 & New Mexico State Engineer Office & Monitoring Well WIPP-21 & C-2754 & $11 / 6 / 00$ & None \\
\hline 101 & New Mexico State Engineer Office & Monitoring Well WIPP-25 & C-2723 & $7 / 26 / 00$ & None \\
\hline 102 & New Mexico State Engineer Office & Monitoring Well WIPP-26 & C-2724 & $11 / 6 / 00$ & None \\
\hline 103 & New Mexico State Engineer Office & Monitoring Well WIPP-27 & C-2722 & $11 / 6 / 00$ & None \\
\hline 104 & New Mexico State Engineer Office & Monitoring Well WIPP-28 & C-2636 & $1 / 12 / 99$ & None \\
\hline 105 & New Mexico State Engineer Office & Monitoring Well WIPP-29 & C-2743 & $11 / 6 / 00$ & None \\
\hline 106 & New Mexico State Engineer Office & Monitoring Well WIPP-30 & C-2727 & $8 / 4 / 00$ & None \\
\hline 107 & New Mexico State Engineer Office & Monitoring Well SNL-2 & C-2948 & $2 / 14 / 03$ & None \\
\hline 108 & New Mexico State Engineer Office & Monitoring Well SNL-9 & C-2950 & $2 / 14 / 03$ & None \\
\hline 109 & New Mexico State Engineer Office & Monitoring Well SNL-12 & C-2954 & $2 / 25 / 03$ & None \\
\hline 110 & New Mexico State Engineer Office & Monitoring Well SNL-1 & C-2953 & $2 / 25 / 03$ & None \\
\hline 111 & New Mexico State Engineer Office & Monitoring Well SNL-3 & C-2949 & $2 / 14 / 03$ & None \\
\hline 112 & New Mexico State Engineer Office & Monitoring Well WTS-4 & C-2960 & $3 / 18 / 03$ & None \\
\hline 113 & New Mexico State Engineer Office & Monitoring Well SNL-5 & C-3002 & $10 / 1 / 03$ & None \\
\hline 114 & New Mexico State Engineer Office & Monitoring Well IMC-461 & C-3015 & $11 / 25 / 03$ & None \\
\hline 115 & New Mexico State Engineer Office & Monitoring Well SNL-11 & C-3003 & $10 / 1 / 03$ & None \\
\hline 116 & New Mexico State Engineer Office & Monitoring Well SNL10 & C03221 & $7 / 26 / 05$ & 7/31/07 \\
\hline 117 & New Mexico State Engineer Office & Monitoring Well SNL16 & C03220 & $7 / 26 / 05$ & $7 / 31 / 07$ \\
\hline 118 & New Mexico State Engineer Office & Monitoring Well SNL17 & $\mathrm{C} 03222$ & $7 / 26 / 05$ & $7 / 31 / 07$ \\
\hline 119 & New Mexico State Engineer Office & Monitoring Well SNL18 & C03233 & $10 / 6 / 05$ & $10 / 31 / 06$ \\
\hline 120 & New Mexico State Engineer Office & Monitoring Well SNL19 & $\mathrm{C} 03234$ & $10 / 6 / 05$ & $10 / 31 / 06$ \\
\hline
\end{tabular}




\section{Appendix C \\ Location Codes}

Table C.1 - Codes Used to Identify the Sites from Which Samples Were Collected

\begin{tabular}{llll}
\hline Code & \multicolumn{1}{c}{ Location } & Code & \multicolumn{1}{c}{ Location } \\
\hline BHT & Bottom of the Hill Tank & RCP1 & Rainwater Catchment Pond (1) \\
BRA & Brantley Lake & RCP2 & Rainwater Catchment Pond (2) \\
CBD & Carlsbad & RED & Red Tank \\
COW & Coyote Well (deionized water blank) & SEC & South East Control \\
FWT & Fresh Water Tank & SMR & Smith Ranch \\
HIL & Hill Tank & SOO & Sample of Opportunity* \\
IDN & Indian Tank & SWL & Sewage Lagoons \\
LST & Lost Tank & TUT & Tut Tank \\
MLR & Mills Ranch & UPR & Upper Pecos River \\
NOY & Noya Tank & WAB & WIPP Air Blank \\
PCN & Pierce Canyon & WEE & WIPP East \\
PEC & Pecos River & WFF & WIPP Far Field \\
PKT & Poker Trap & WQSP & Water Quality Sample Program \\
& & WSS & WIPP South \\
\hline
\end{tabular}

* Sample taken where found 
Waste Isolation Pilot Plant Annual Site Environmental Report for 2005

DOE/WIPP-06-2225

This page intentionally left blank 


\section{Appendix D Equations}

\section{Detection}

All radionuclides with the exception of ${ }^{137} \mathrm{Cs},{ }^{60} \mathrm{Co}$, and ${ }^{40} \mathrm{~K}$ are considered "detected" if the radionuclide concentration is greater than the minimum detectable concentration and the total propagated uncertainty at the two sigma level. For the exceptions noted, these radionuclides are considered detected if they meet the criteria listed above and the confidence level from which the peak or peaks associated with them can be identified by the gamma spectroscopy software at a confidence level of 90 percent or greater.

\section{Minimum Detectable Concentration (MDC)}

The MDC is the smallest amount (activity or mass) of an analyte in a sample that will be detected with a 5 percent probability of non-detection while accepting a 5 percent probability of erroneously deciding that a positive quantity of analyte is present in an appropriate blank sample. This method assures that any claimed MDC has at least a 95 percent chance of being detected. It is possible to achieve a very low level of detection by analyzing a large sample size and counting for a very long time.

The WIPP Laboratories used the following equation for calculating the MDCs for each radionuclide in various sample matrices:

$$
M D C=\frac{4.66 \sqrt{S}}{K T}+\frac{3.00}{K T}
$$

Where:

$$
\begin{aligned}
& S=\begin{array}{l}
\text { Net method blank counts; when method blank counts }=0 \text {, average } \\
\text { of the last } 30 \text { blanks analyzed are substituted }
\end{array} \\
& K=\quad \begin{array}{l}
\text { A correction factor that includes items such as unit conversions, } \\
\text { sample volume/weight, decay correction, detector efficiency, } \\
\text { chemical recovery and abundance correction, etc. }
\end{array} \\
& T=\begin{array}{l}
\text { Counting time where the background and sample counting time are } \\
\text { identical }
\end{array}
\end{aligned}
$$

For further evaluation of the MDC, refer to HPS N13.30 - 1996, Performance Criteria for Radiobioassay.

\section{Total Propagated Uncertainty (TPU)}

The TPU is an estimate of the uncertainty in the measurement due to all sources, including counting error, measurement error, chemical recovery error, detector efficiency, randomness of radioactive decay, and any other sources of uncertainty. 
The total propagated uncertainty for each data point must be reported at $2 \sigma$ level. The TPU was calculated by using the following equation:

$$
T P U_{1 \sigma}=\sigma_{A C T}=\frac{\sqrt{\sigma_{N C R}^{2}+(N C R)^{2} *\left(R E_{E F F}^{2}+R E_{A L I}^{2}+R E_{R}^{2}+\Sigma R E_{C F}^{2}\right)}}{2.22 * E F F * A L I * R * A B N_{S} * e^{-\lambda \Delta t} * C F}
$$

Where:

$$
\begin{aligned}
& \mathrm{EFF}=\text { Detector Efficiency } \\
& \mathrm{ALI}=\text { Sample Aliquot Volume or Mass } \\
& \mathrm{R} \quad=\text { Sample Tracer/Carrier Recovery } \\
& A B N_{s}=\text { Abundance Fraction of the Emissions Used for } \\
& \text { Identification/Quantification } \\
& \sigma^{2}{ }_{\text {NCR }}=\text { Variance of the Net Sample Count Rate } \\
& \text { NCR = Net Sample Count Rate } \\
& \mathrm{RE}_{\mathrm{EFF}}^{2}=\text { Square of the Relative Error of the Efficiency Term } \\
& \mathrm{RE}^{2}{ }_{\mathrm{ALI}}=\text { Square of the Relative Error of the Aliquot } \\
& \mathrm{RE}^{2}{ }_{\mathrm{R}}=\text { Square of the Relative Error of the Sample Recovery } \\
& \mathrm{RE}^{2}{ }_{\mathrm{CF}}=\text { Square of the Relative Error of Other Correction Factors } \\
& \lambda=\text { Analyte Decay Constant }=\ln 2 / \text { (half-life) [Same units as the } \\
& \text { half-life used to compute } \lambda \text { ] } \\
& \Delta \mathrm{t} \quad=\text { Time from Sample Collection to Radionuclide Separation or } \\
& \text { Mid-Point of Count Time (Same units as half-life) } \\
& \mathrm{CF}=\text { Other Correction Factors as Appropriate (i.e., ingrowth factor, } \\
& \text { self-absorption factor, etc.). }
\end{aligned}
$$

For further discussion of TPU, refer to HPS N13.30-1996, Performance Criteria for Radiobioassay, and/or Waste Acceptance Criteria for Off-Site Generators, Fernald Environmental Management Project (DOE, 1994).

\section{Relative Error Ratio (RER)}

The Relative Error Ratio is a method, similar to a t-test, with which to compare duplicate results (see Chapters 4 and 8; WP 02-EM3004).

$$
R E R=\frac{\left|x_{A}-x_{B}\right|}{\sqrt{\left(2 \sigma_{A}\right)^{2}+\left(2 \sigma_{R}\right)^{2}}}
$$

Where:

$$
\begin{array}{ll}
\overline{X_{A}} & =\text { Mean Activity of Population A } \\
\overline{X_{B}} & =\text { Mean Activity of Population B } \\
\sigma_{A} & =\text { Standard Deviation of Population A } \\
\sigma_{B} & =\text { Standard Deviation of Population B }
\end{array}
$$




\section{Percent Bias (\% Bias)}

The percent bias is a measure of the accuracy of radiochemical separation methods and counting instruments; that is, a measure of how reliable the results of analyses are when compared to the actual values.

$$
\% B I A S=\left[\frac{A_{m}-A_{k}}{A_{k}}\right] * 100 \%
$$

Where:

$\begin{array}{lll}\% \text { BIAS } & =\text { Percent Bias } \\ A_{m} & =\text { Measured Sample Activity } \\ A_{k} & =\quad \text { Known Sample Activity }\end{array}$


Waste Isolation Pilot Plant Annual Site Environmental Report for 2005

DOE/WIPP-06-2225

This page intentionally left blank 


\section{Appendix E \\ Time Trend Plots for Detectable Constituents in Groundwater}

The figures in this appendix show the concentrations of various groundwater constituents relative to a baseline concentration, and are in a form required by the NMED and the HWFP. Baseline concentrations were measured from 1995 through 2000. These plots indicate the sample and duplicate concentration values with respect to sample round. Sampling Round 20 occurred March through May 2005 and sampling Round 21 occurred September through November 2005. See Appendix F for specific concentration information on the groundwater wells. Total suspended solids (TSS) concentrations shown in the time-trend graphs in this appendix appear to exhibit a major change from the early sampling rounds to latter rounds. Early round analyses were performed by different subcontract laboratories than those since Round 7 . In many cases, the laboratories that performed TSS analyses prior to Round 7 had higher minimum detection levels than the current laboratory. Those higher detection levels appear as higher concentrations for TSS during early sampling rounds. Also, some of the higher reported concentrations for early sampling rounds were the result of the wells being newly drilled and the formation and gravel pack having some fine grained material that was eventually removed by pumping and sampling. Other observations worth noting include:

$\cdot$

The potassium concentrations reported for several wells over the last three to four sampling rounds appear to be higher or on a slightly increasing trend. However the contract laboratory has reported unusually high potassium concentrations during earlier rounds and this may be a laboratory analytical problem with this constituent.

Total Organic Halogens (TOH) had been reported at relatively high and highly variable concentrations during rounds prior to Round 19 (wells WQSP-6 and $6 \mathrm{~A}$, for example). A new contract laboratory began performing $\mathrm{TOH}$ analyses with Round 19. The previous laboratory reported having great difficulty with TOH analyses for WIPP brines due to the great concentrations of inorganic halogens interfering with the analysis. The new laboratory has reported lower and consistent concentrations for TOH since Round 19.

- Well WQSP-6A has shown a fairly clear trend of decreasing concentrations for sodium and chloride since the early sampling rounds. This is attributed to removing original drilling fluid artifacts as pumping and sampling has progressed (the well has basically been cleaning up with time). This trend appears to have leveled off over the past few sampling rounds. 


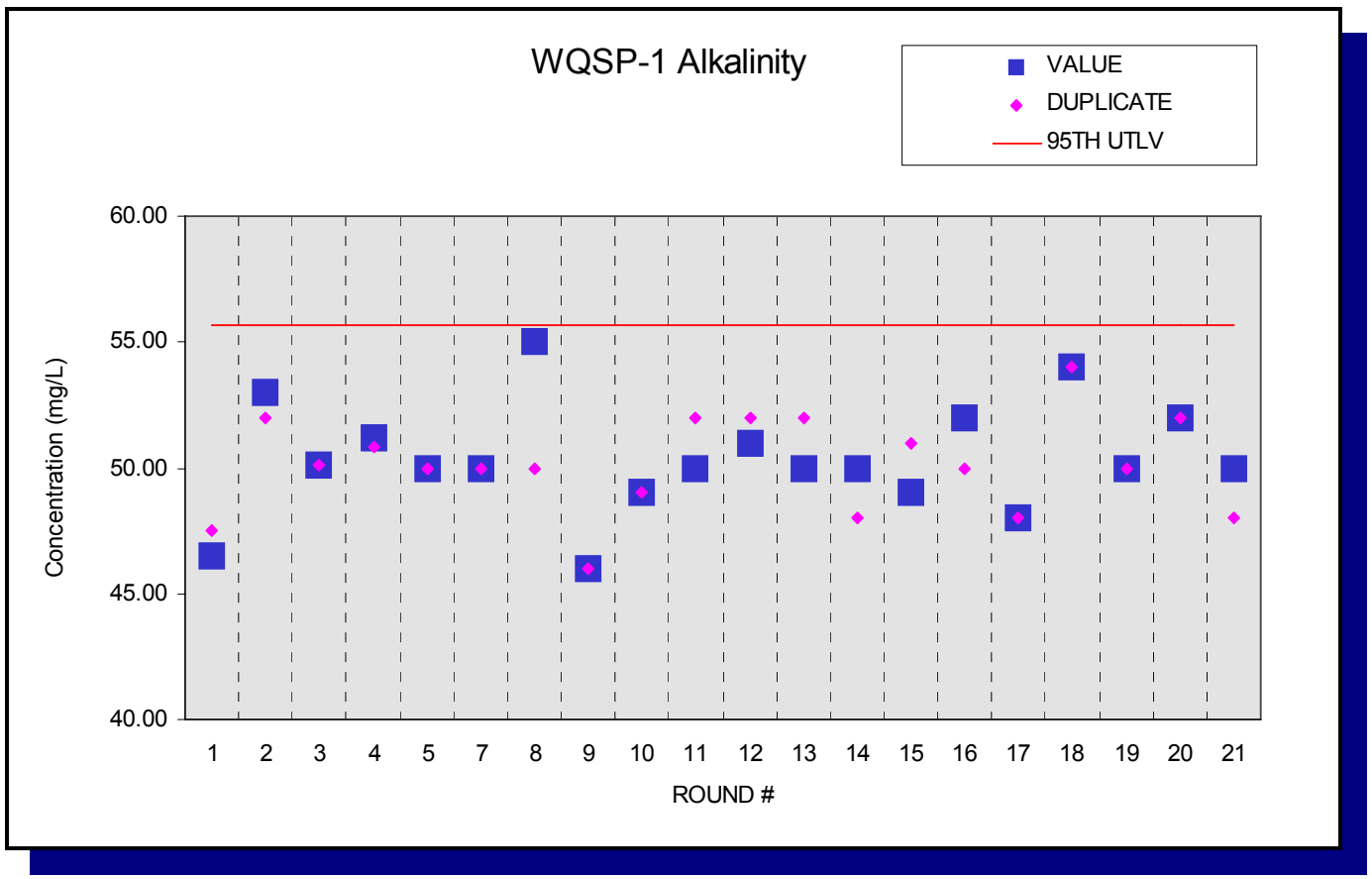

Figure E.1 - Time Trend Plot for Alkalinity at WQSP-1

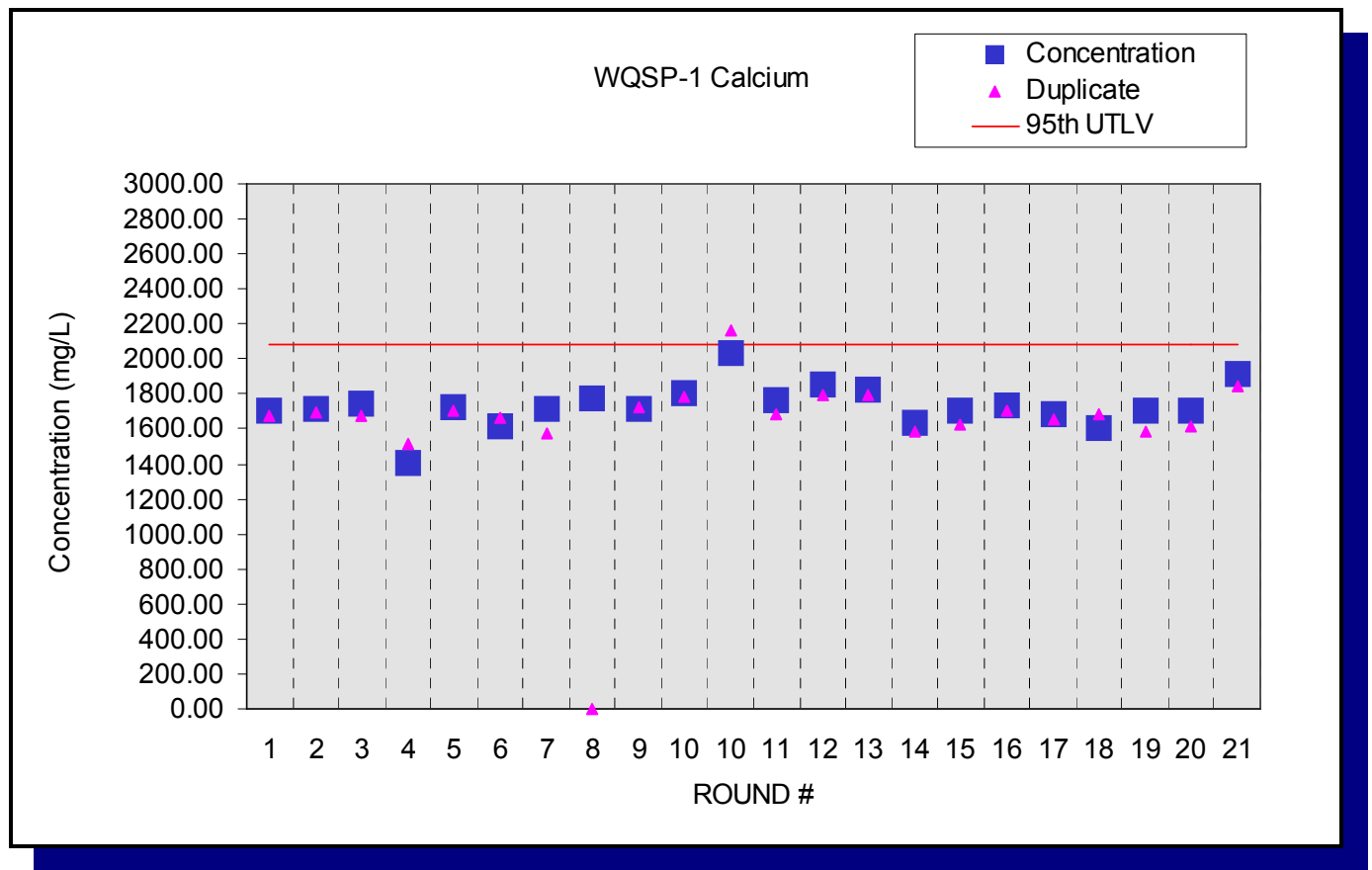

Figure E.2 - Time Trend Plot for Calcium at WQSP-1 


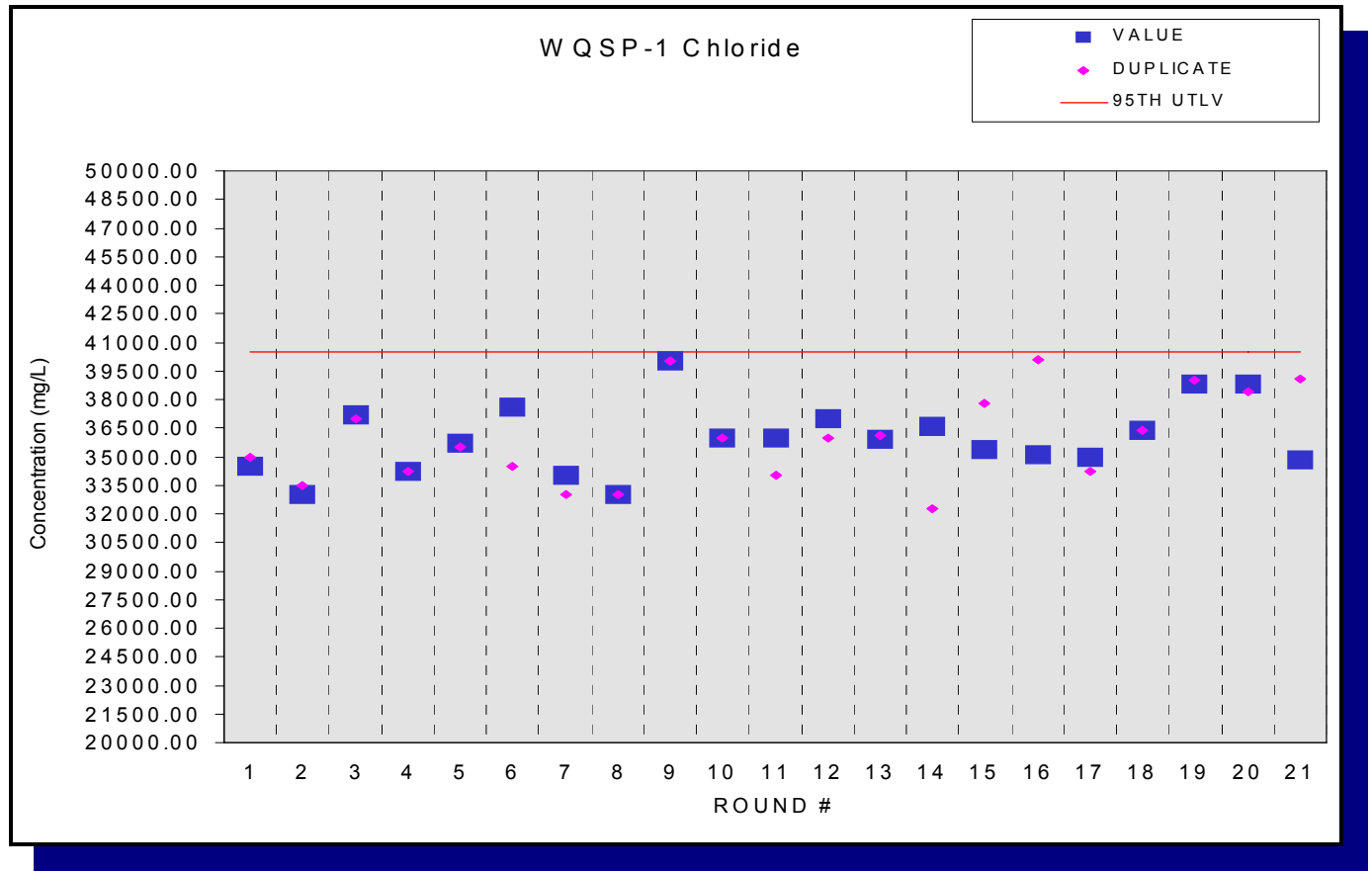

Figure E.3 - Time Trend Plot for Chloride at WQSP-1

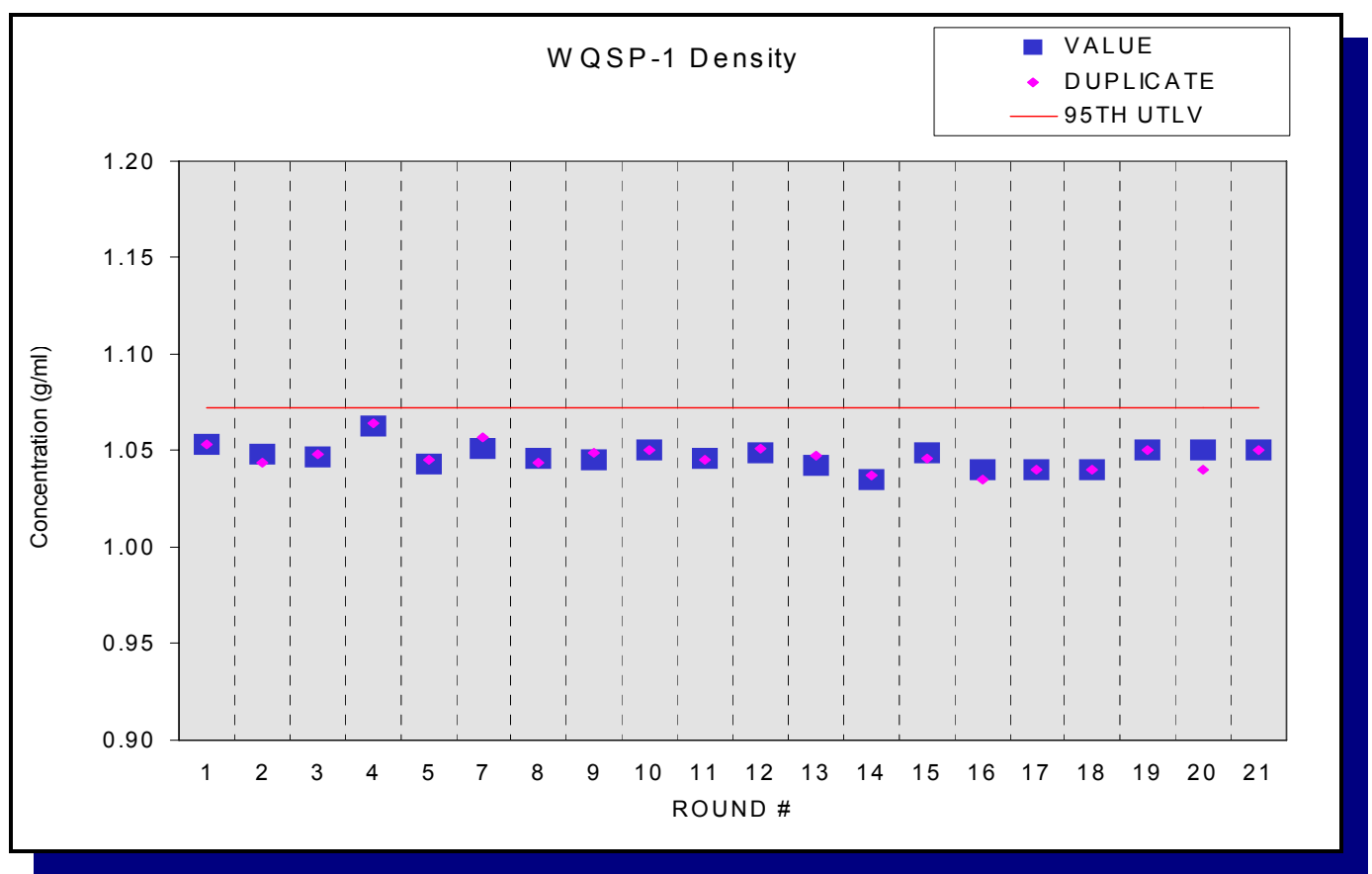

Figure E.4 - Time Trend Plot for Density at WQSP-1 


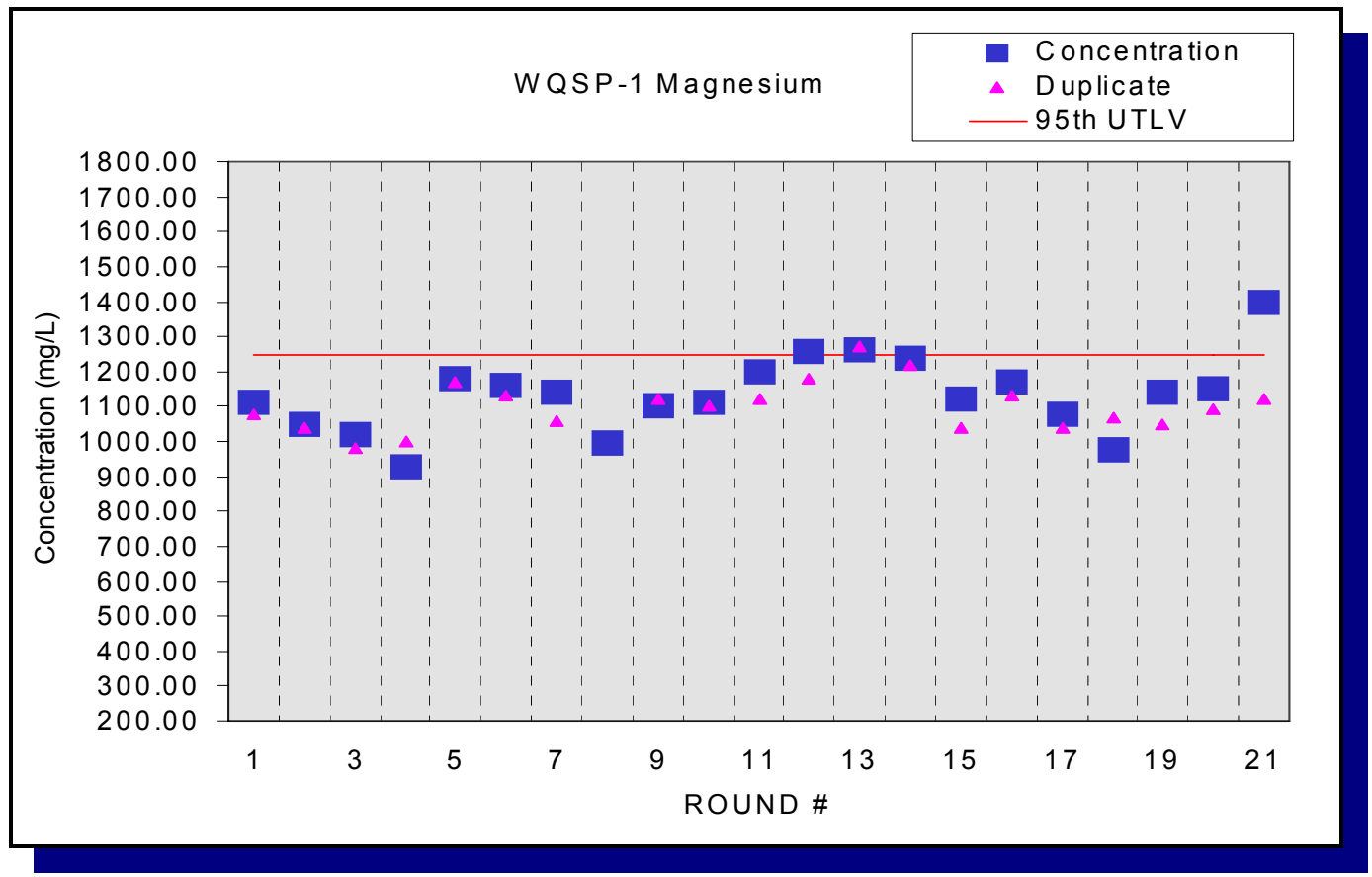

Figure E.5 - Time Trend Plot for Magnesium at WQSP-1

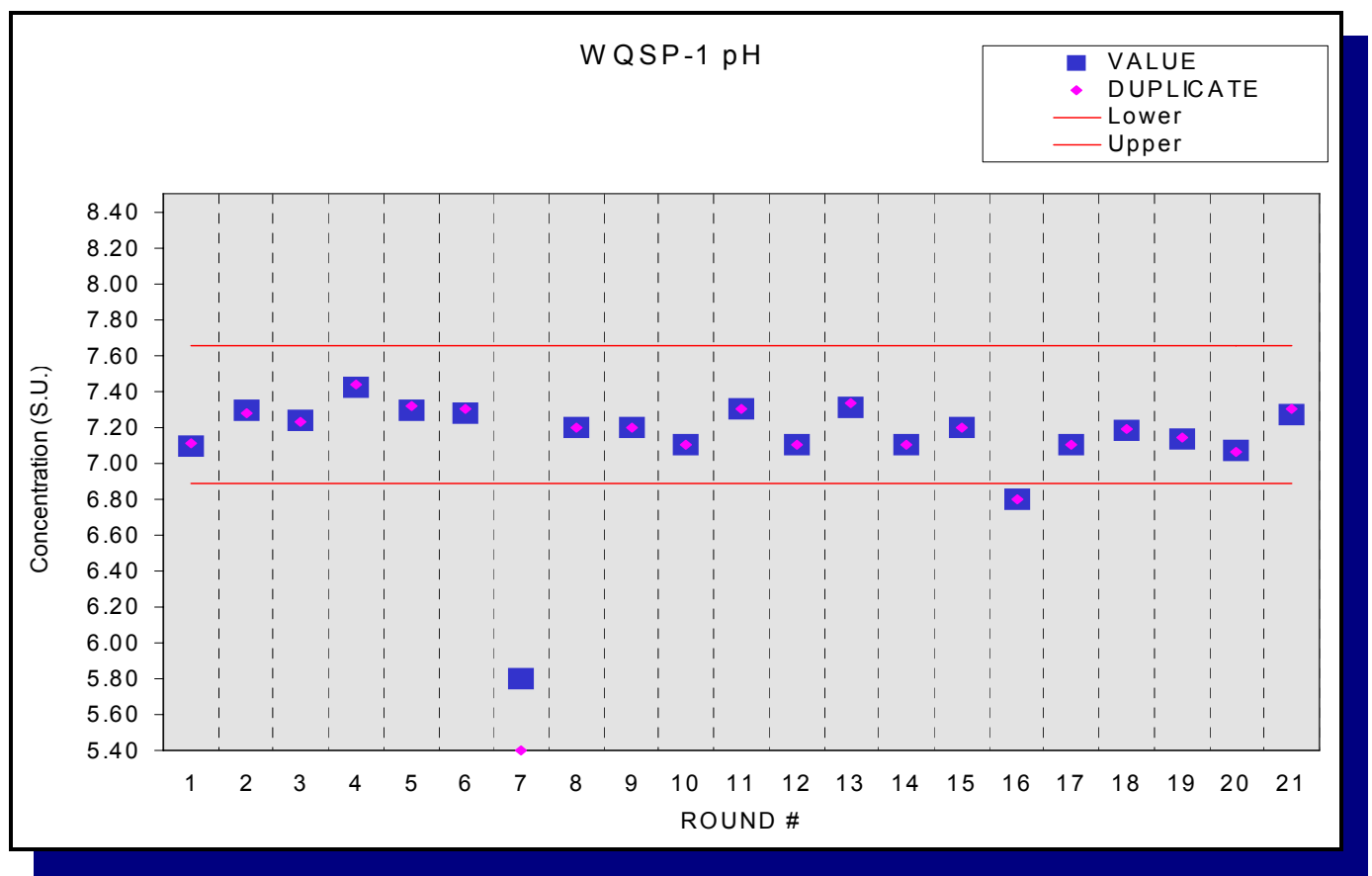

Figure E.6 - Time Trend Plot for $\mathrm{pH}$ at WQSP-1 


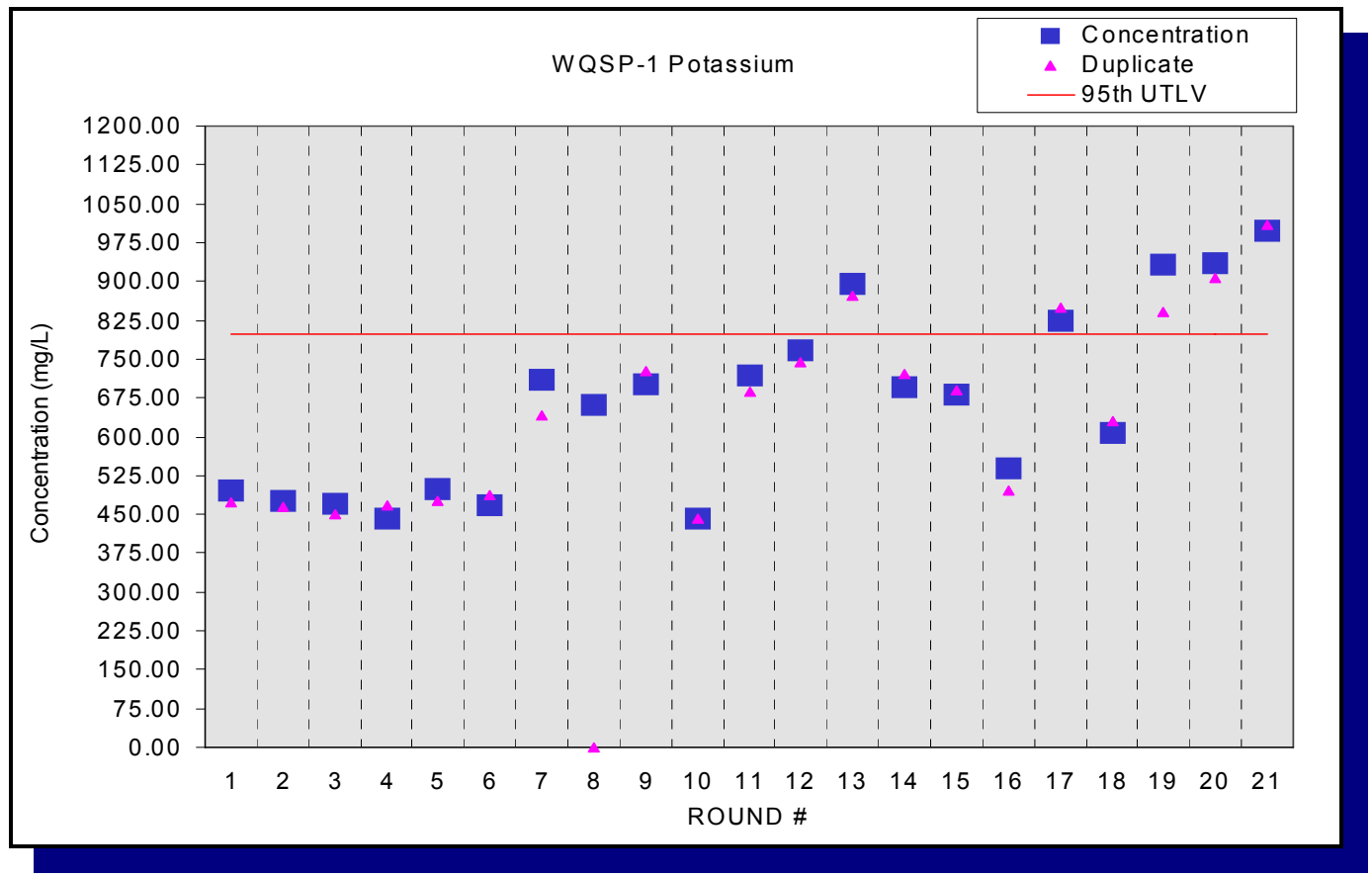

Figure E.7 - Time Trend Plot for Potassium at WQSP-1

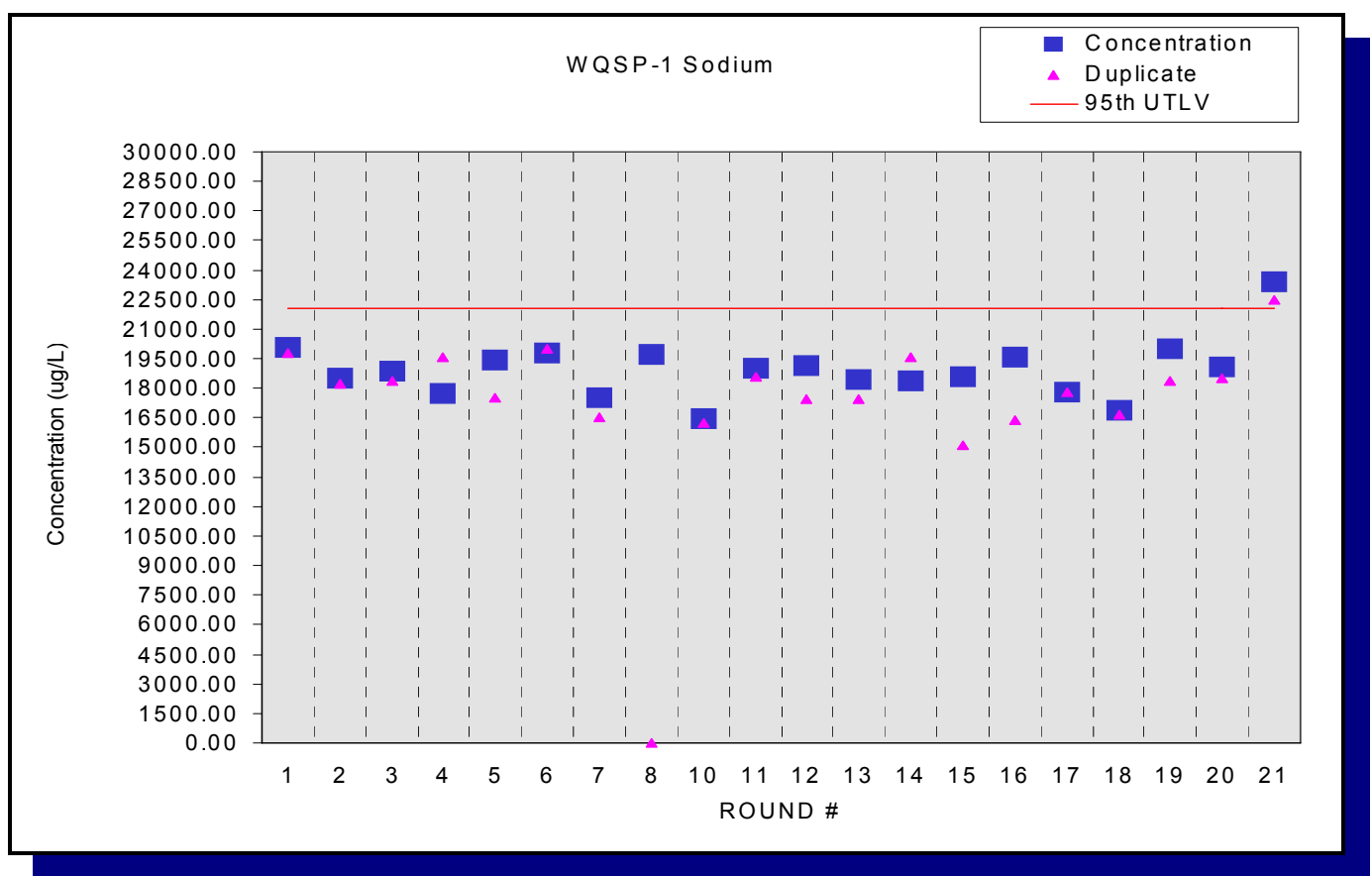

Figure E.8 - Time Trend Plot for Sodium at WQSP-1 


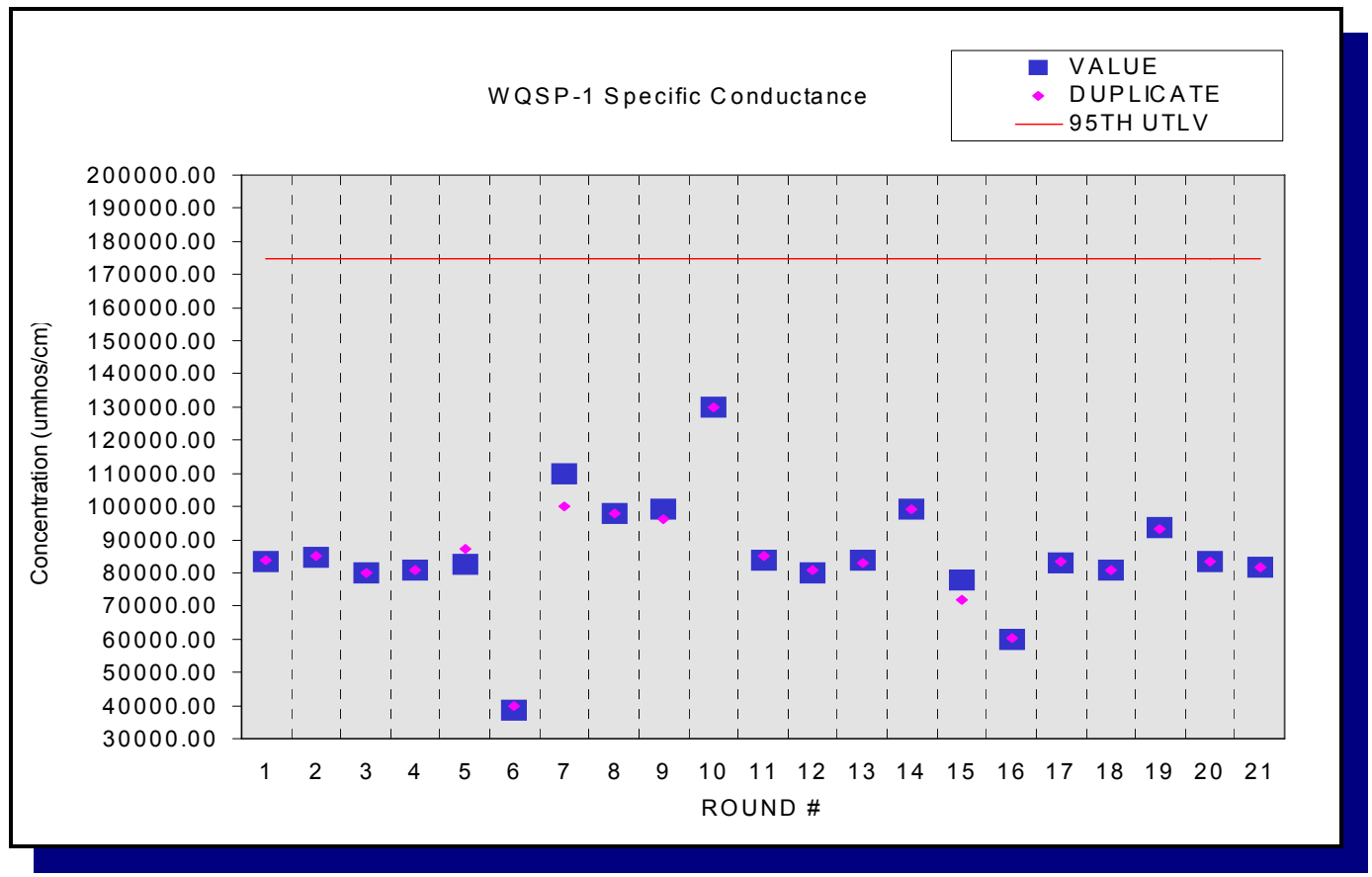

Figure E.9 - Time Trend Plot for Specific Conductance at WQSP-1

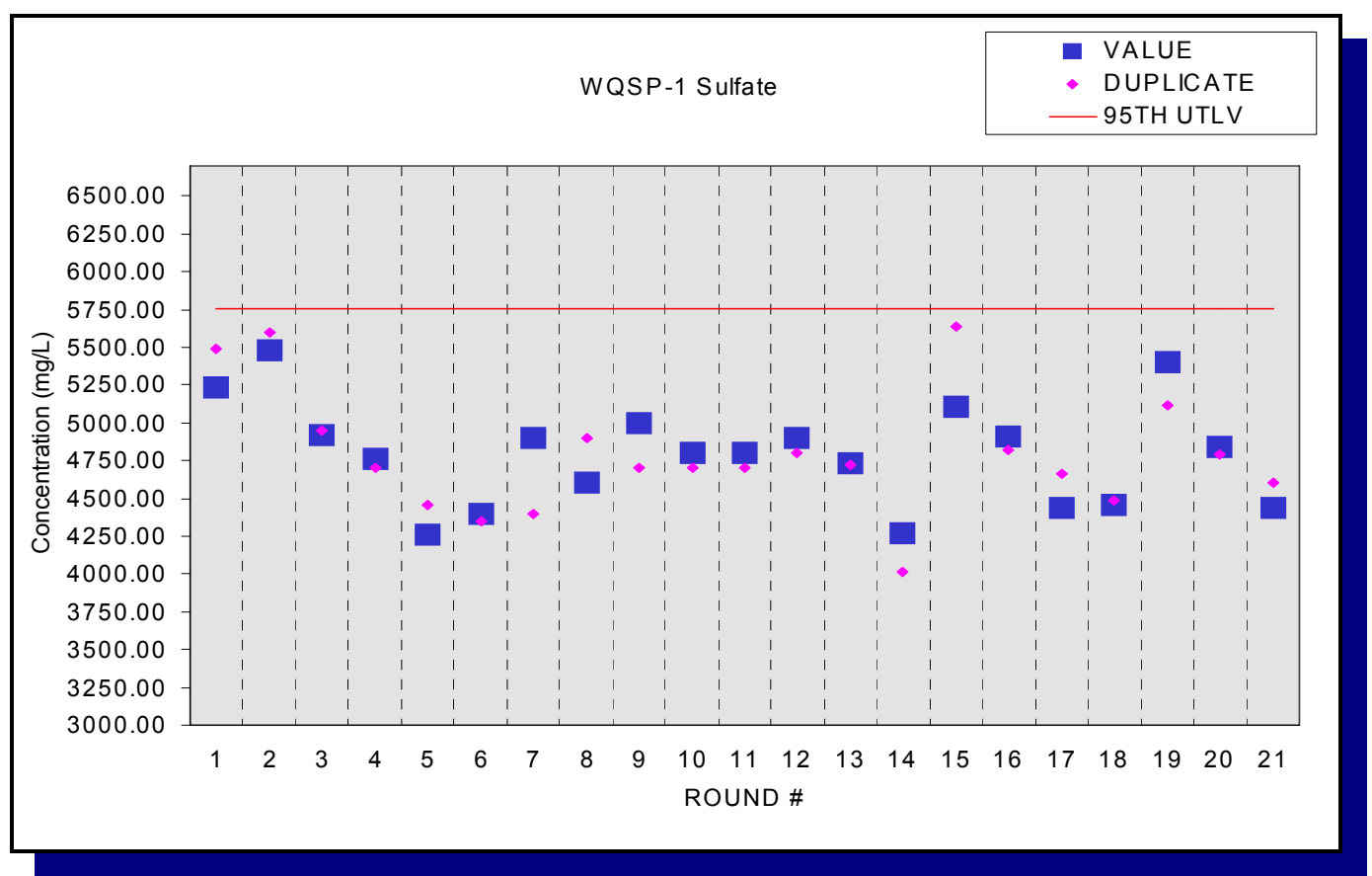

Figure E.10 - Time Trend Plot for Sulfate at WQSP-1 


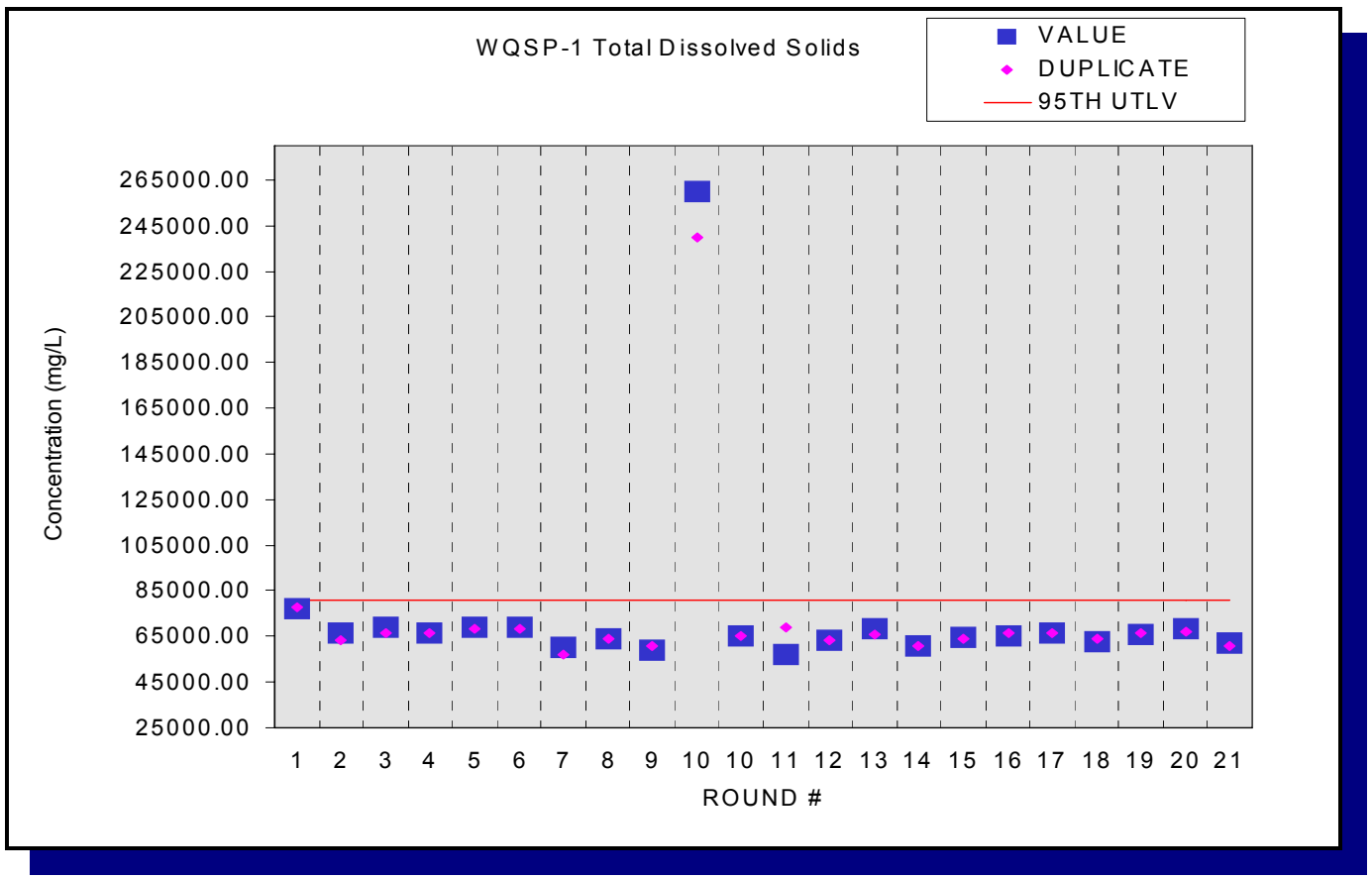

Figure E.11 - Time Trend Plot for Total Dissolved Solids at WQSP-1

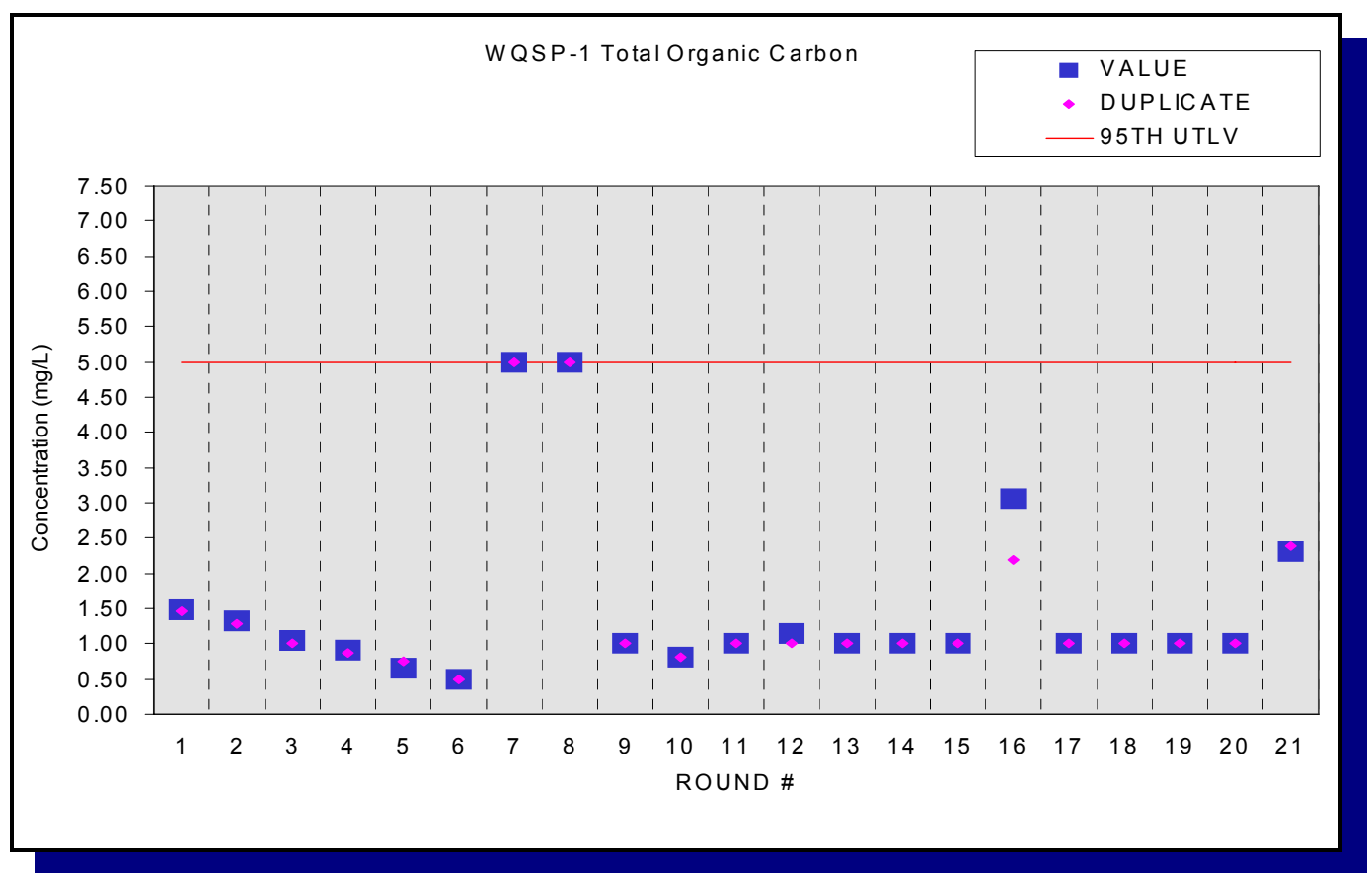

Figure E.12 - Time Trend Plot for Total Organic Carbon at WQSP-1 


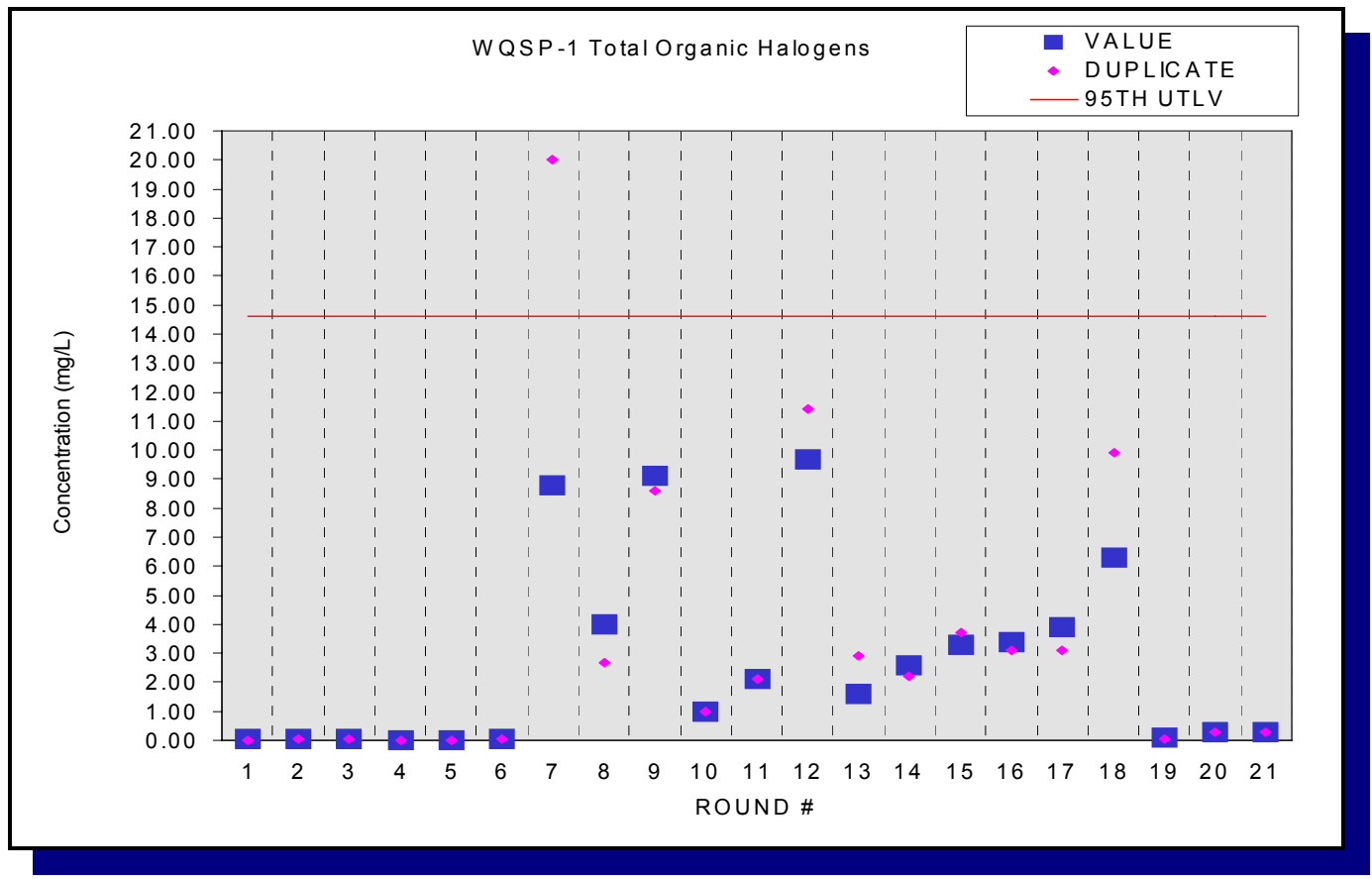

Figure E.13 - Time Trend Plot for Total Organic Halogens at WQSP-1

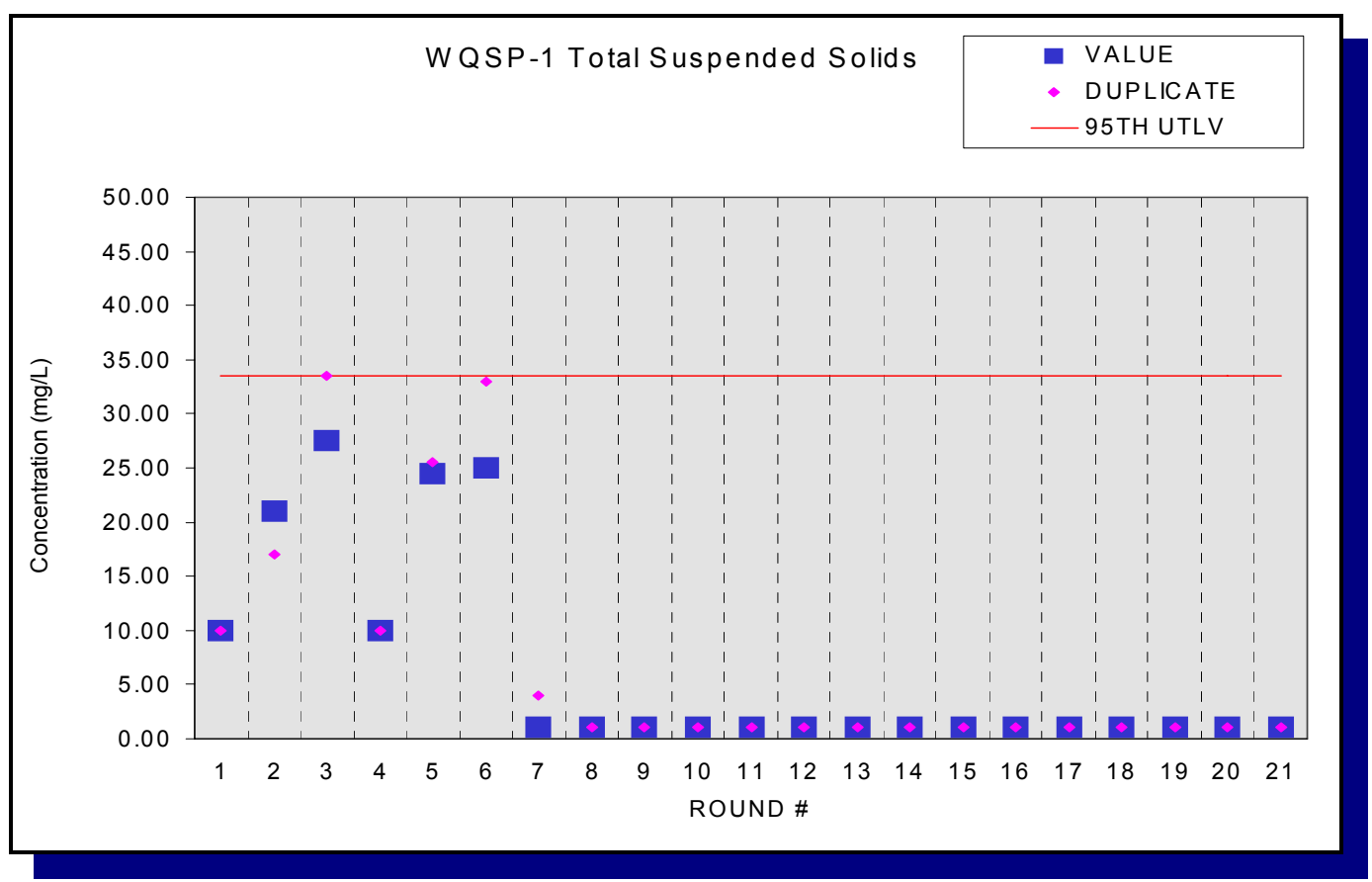

Figure E.14 - Time Trend Plot for Total Suspended Solids at WQSP-1 


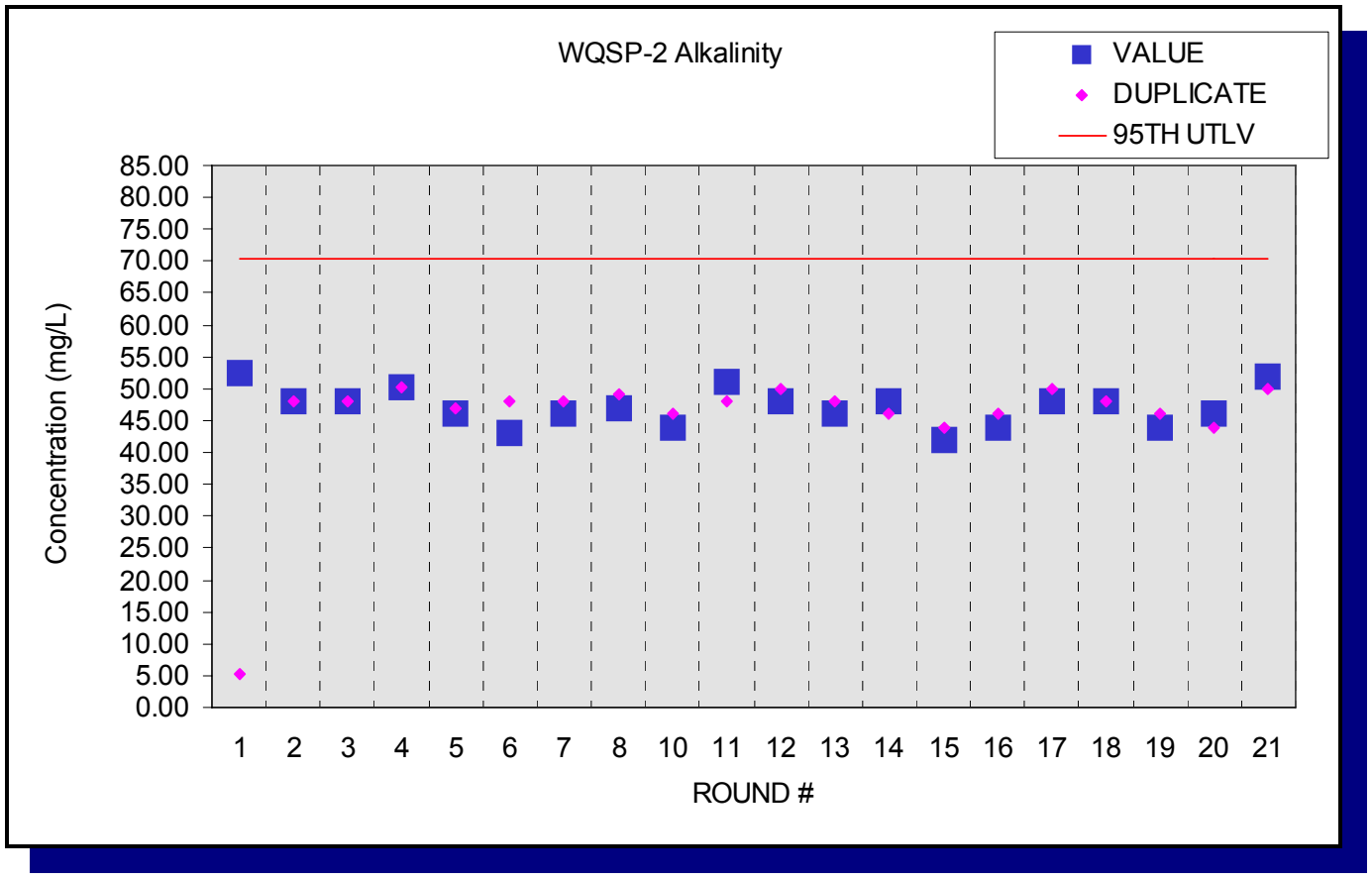

Figure E.15 - Time Trend Plot for Alkalinity at WQSP-2

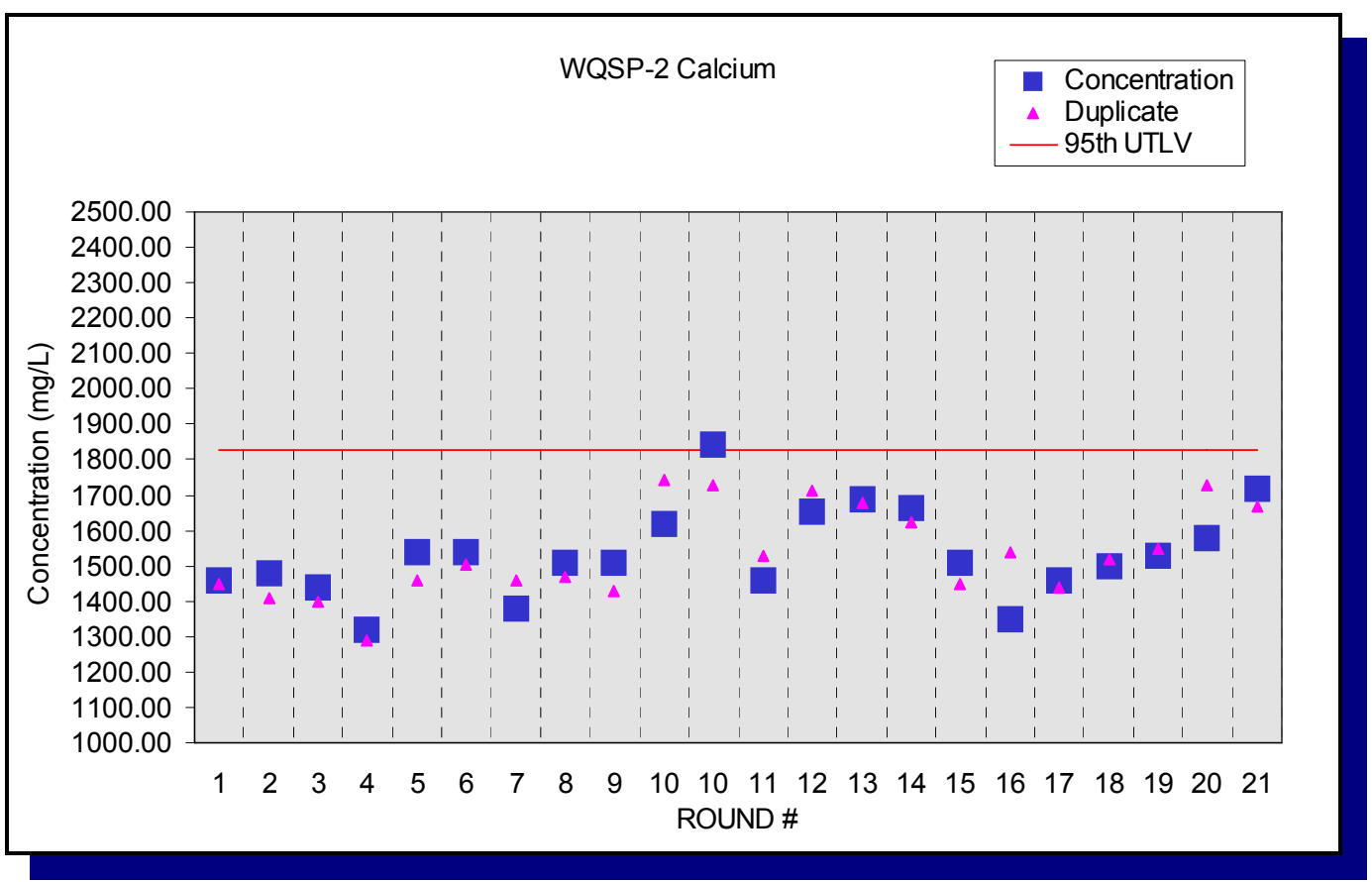

Figure E.16 - Time Trend Plot for Calcium at WQSP-2 


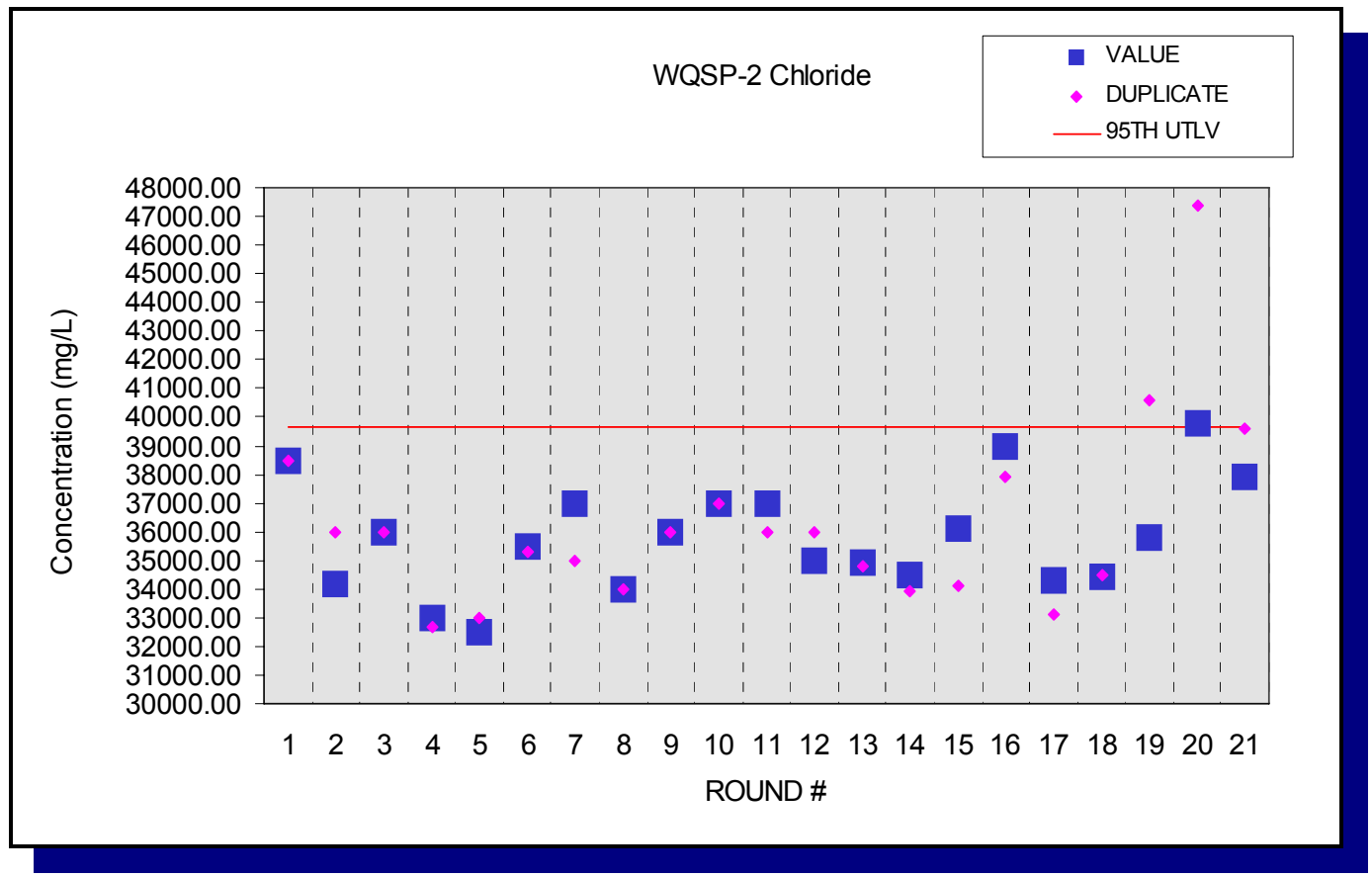

Figure E.17 - Time Trend Plot for Chloride at WQSP-2

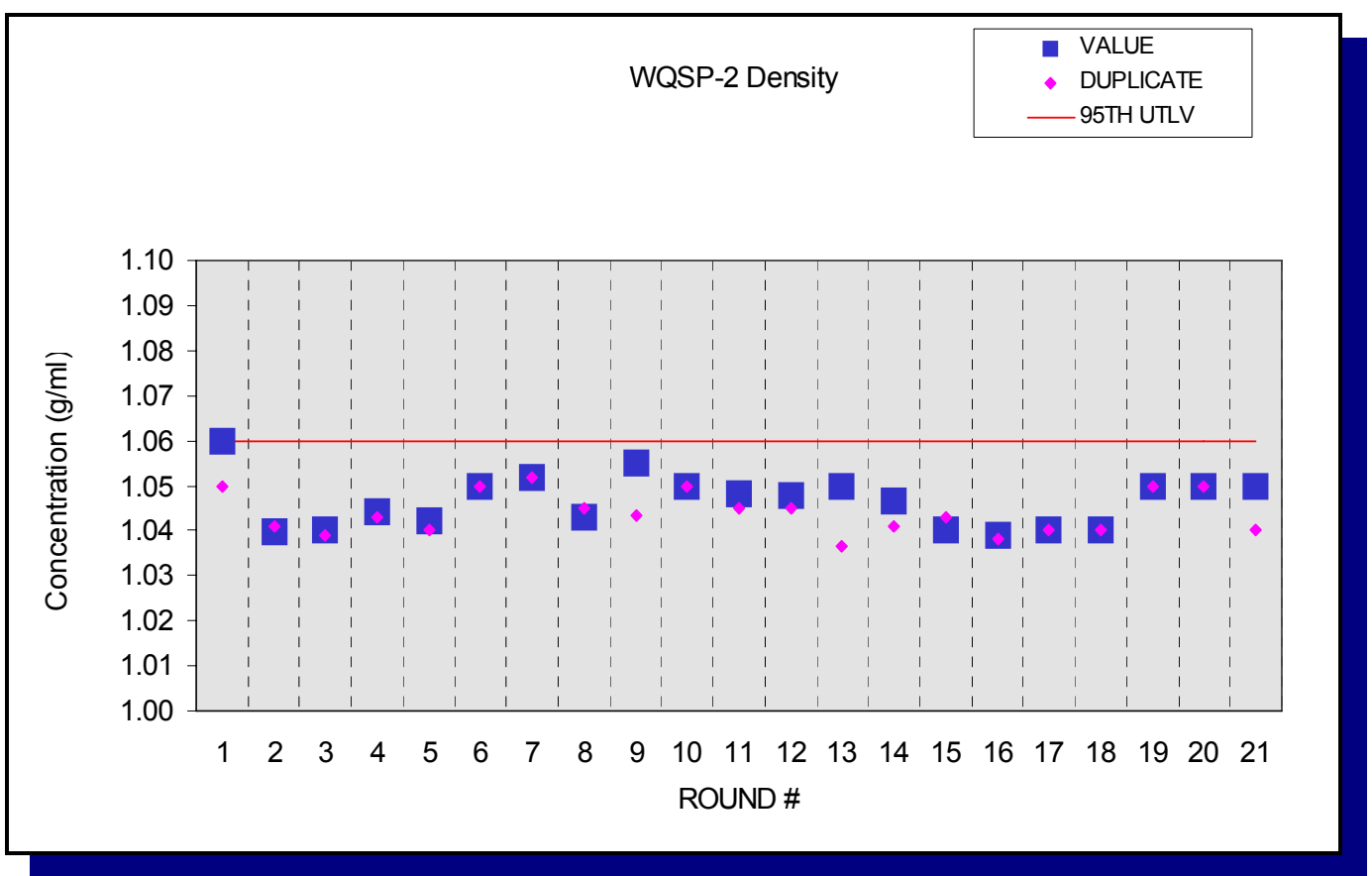

Figure E.18 - Time Trend Plot for Density at WQSP-2 


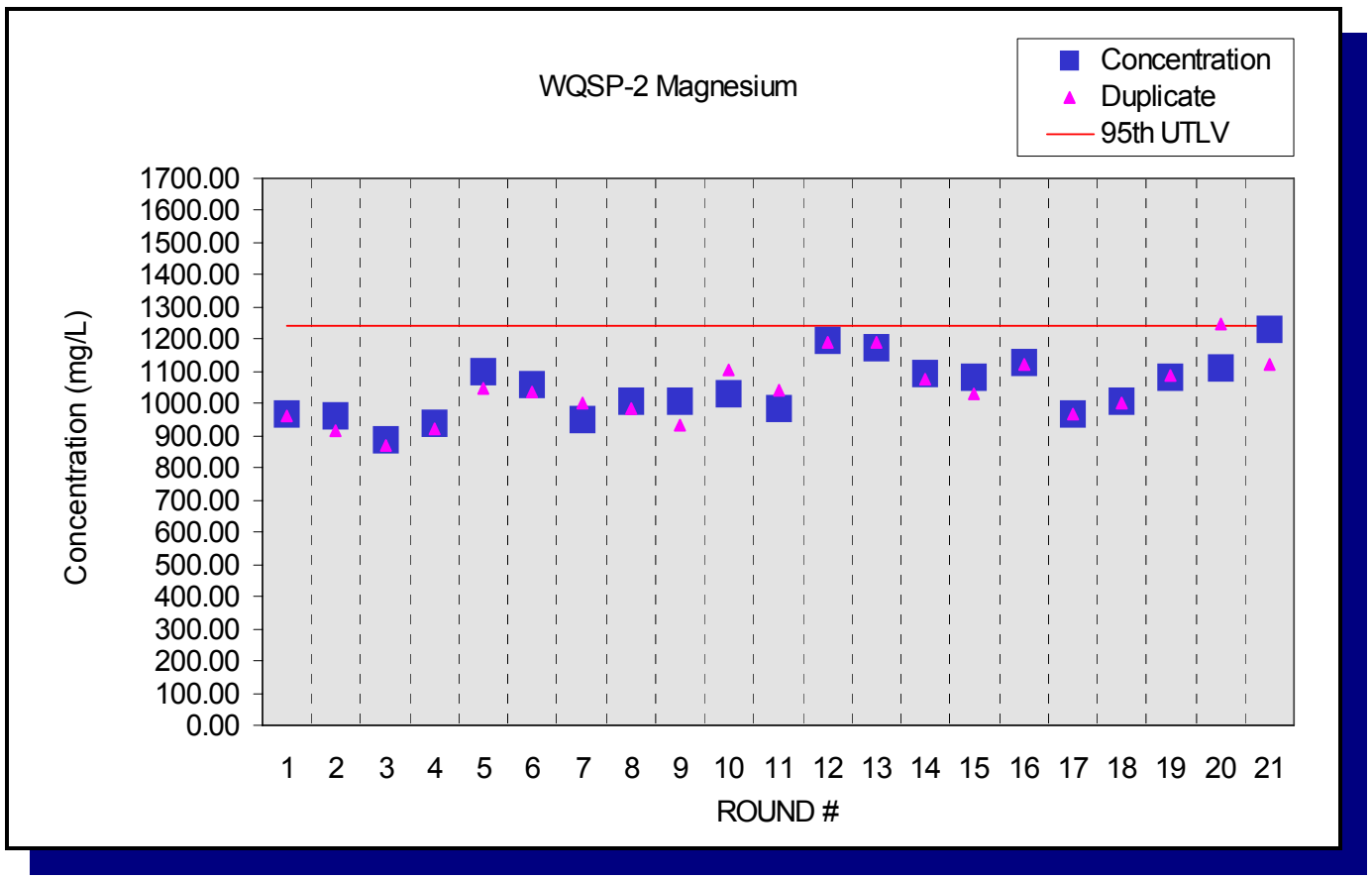

Figure E.19 - Time Trend Plot for Magnesium at WQSP-2

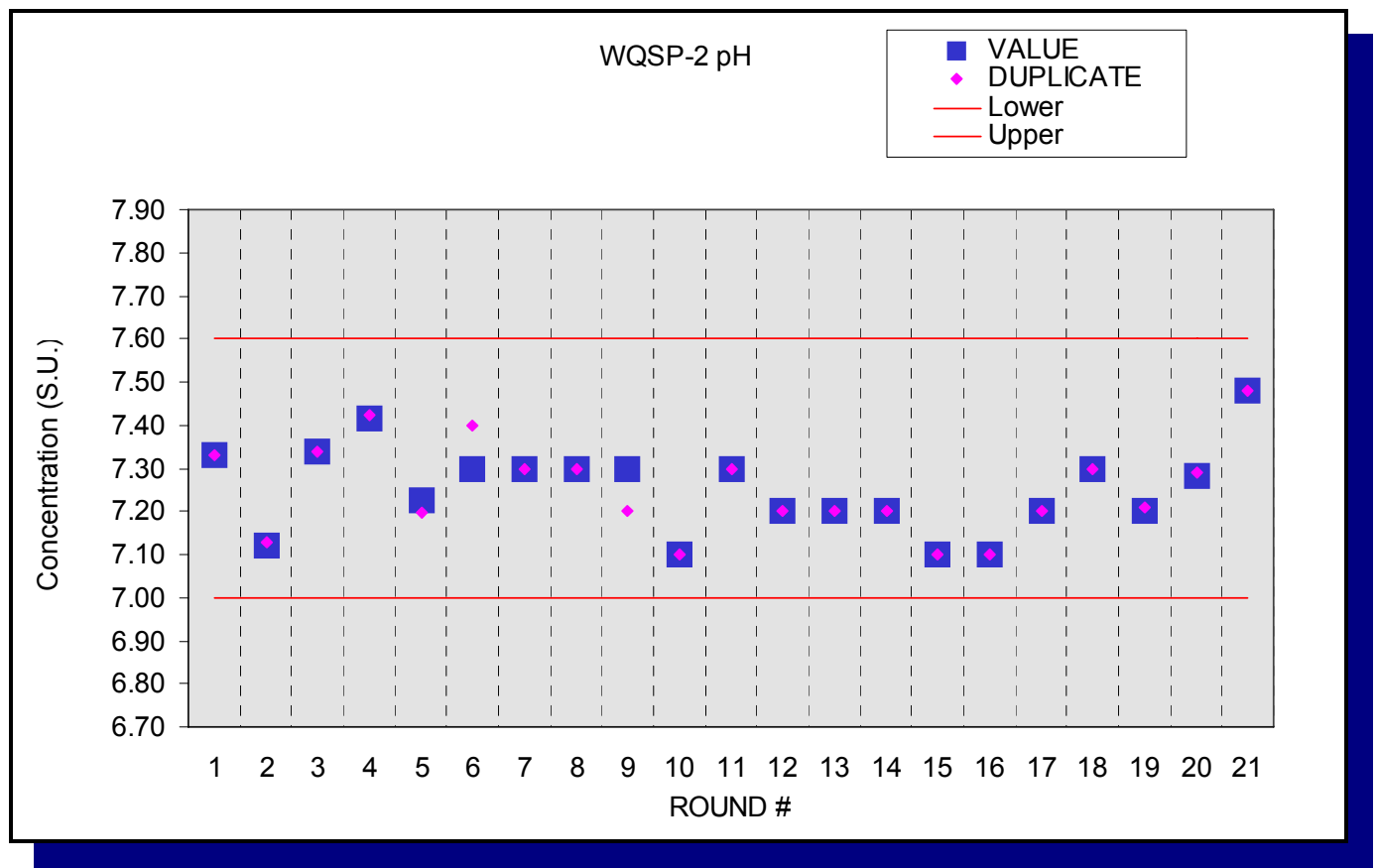

Figure E-20 - Time Trend Plot for pH at WQSP-2 


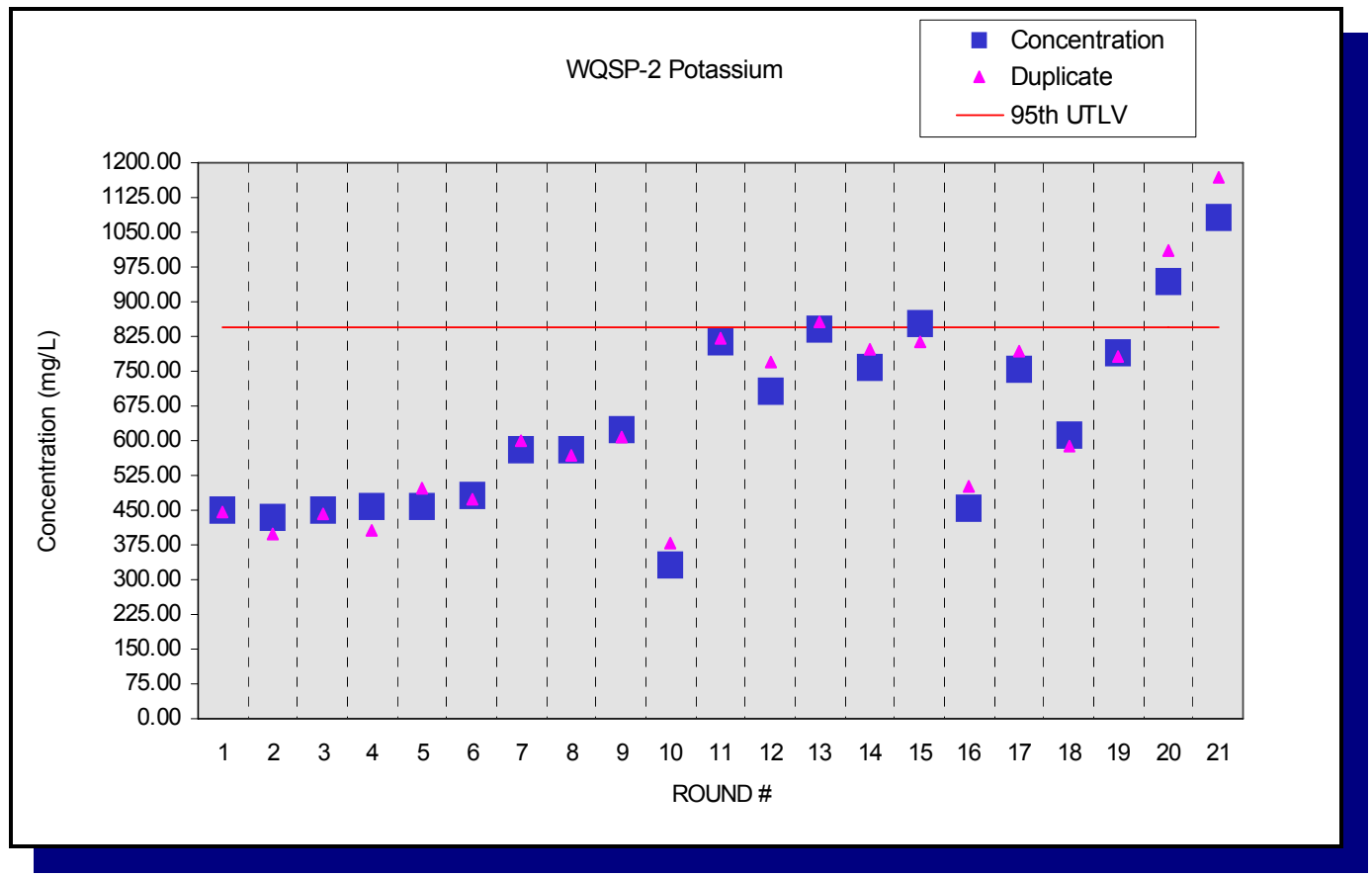

Figure E.21 - Time Trend Plot for Potassium at WQSP-2

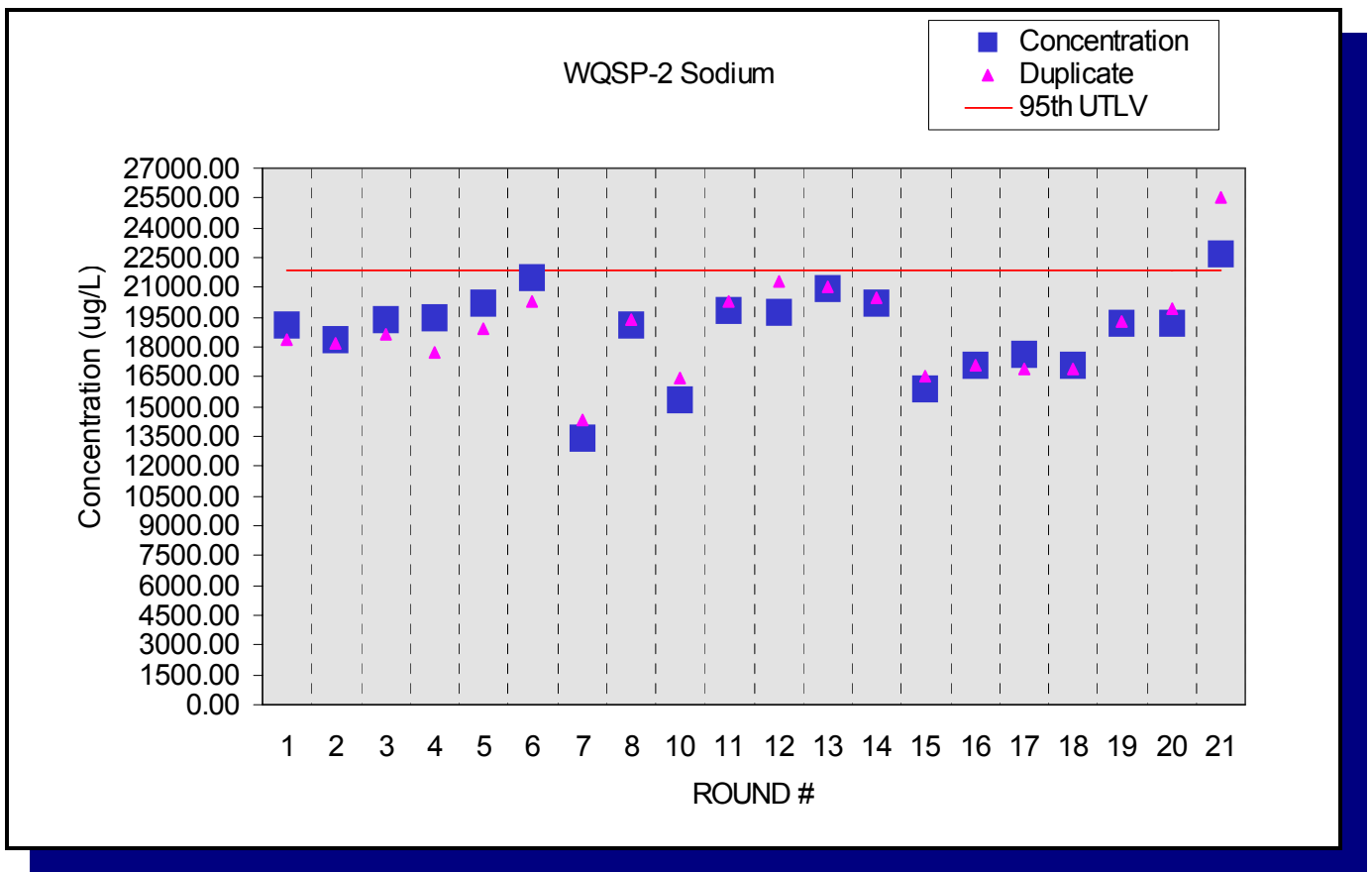

Figure E.22 - Time Trend Plot for Sodium at WQSP-2 


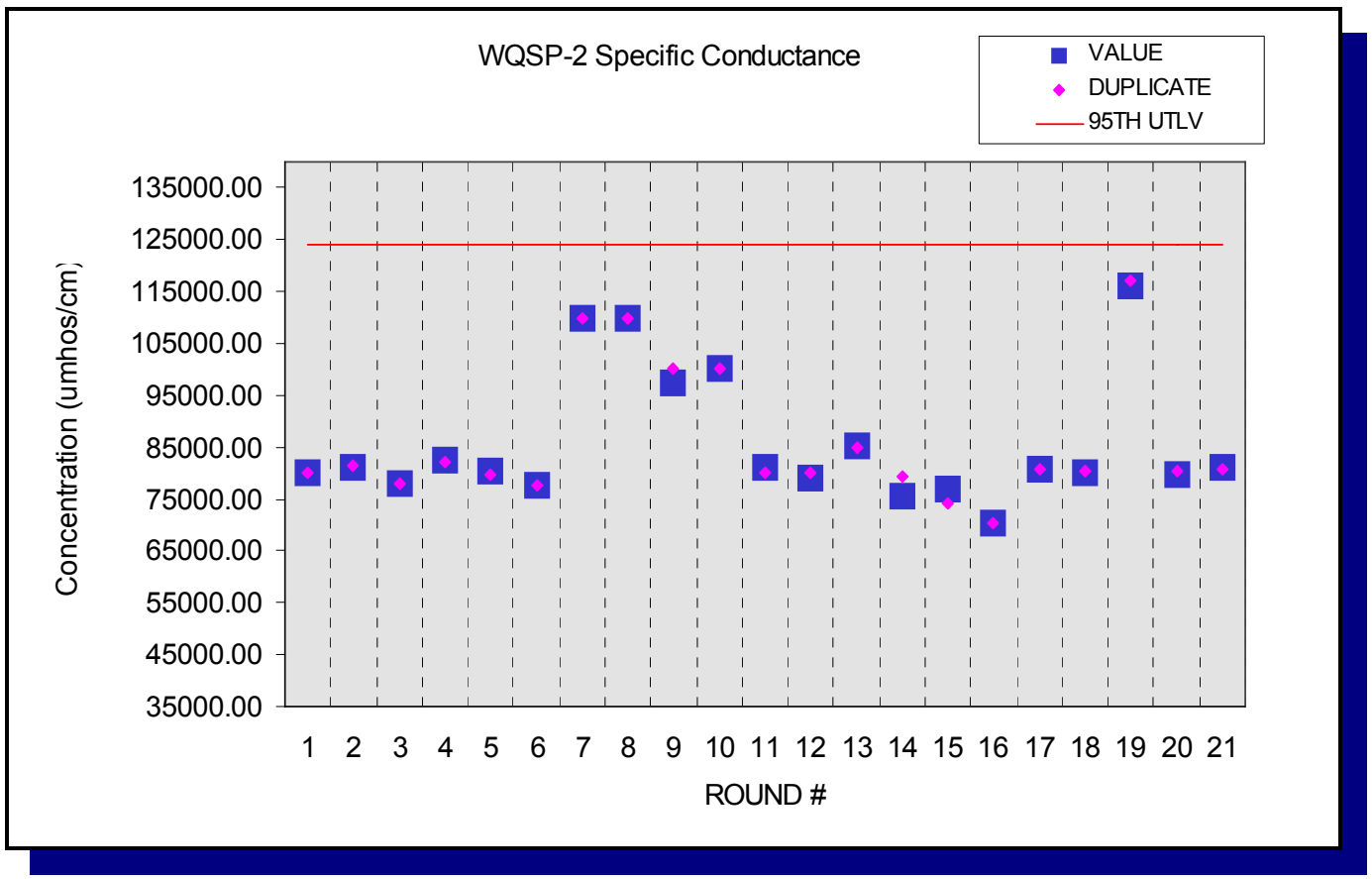

Figure E.23 - Time Trend Plot for Specific Conductance at WQSP-2

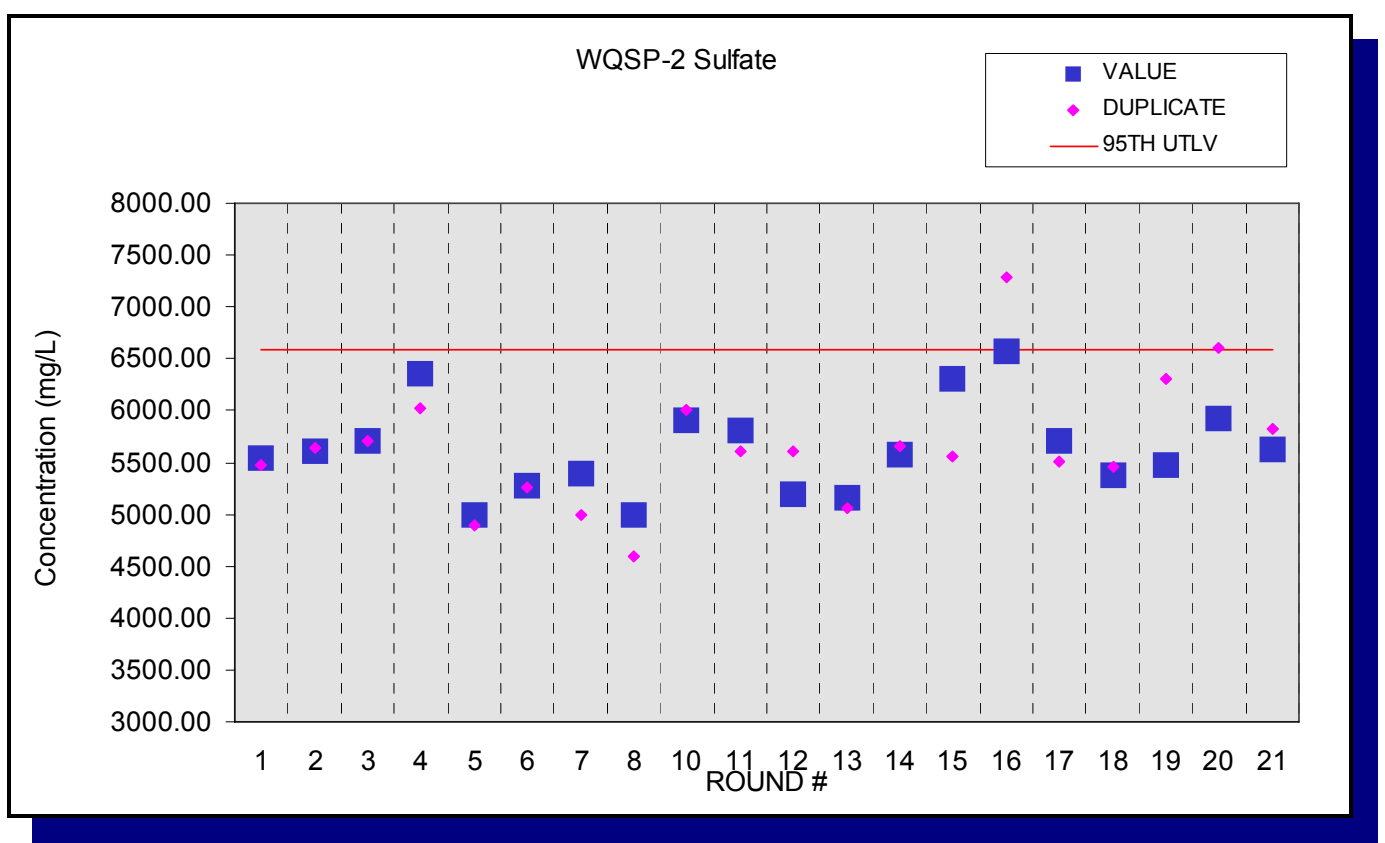

Figure E.24 - Time Trend Plot for Sulfate at WQSP-2 


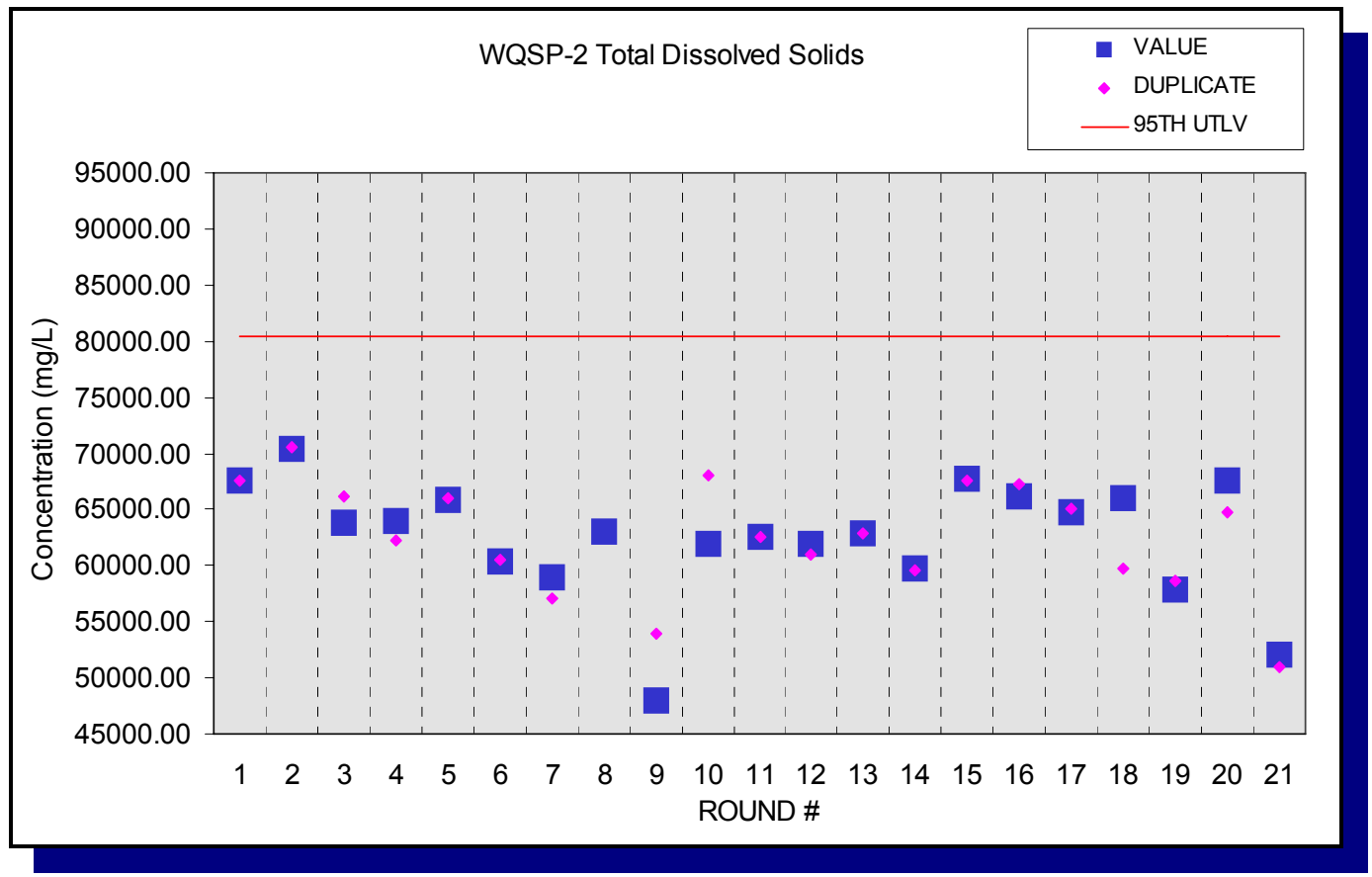

Figure E.25 - Time Trend Plot for Total Dissolved Solids at WQSP-2

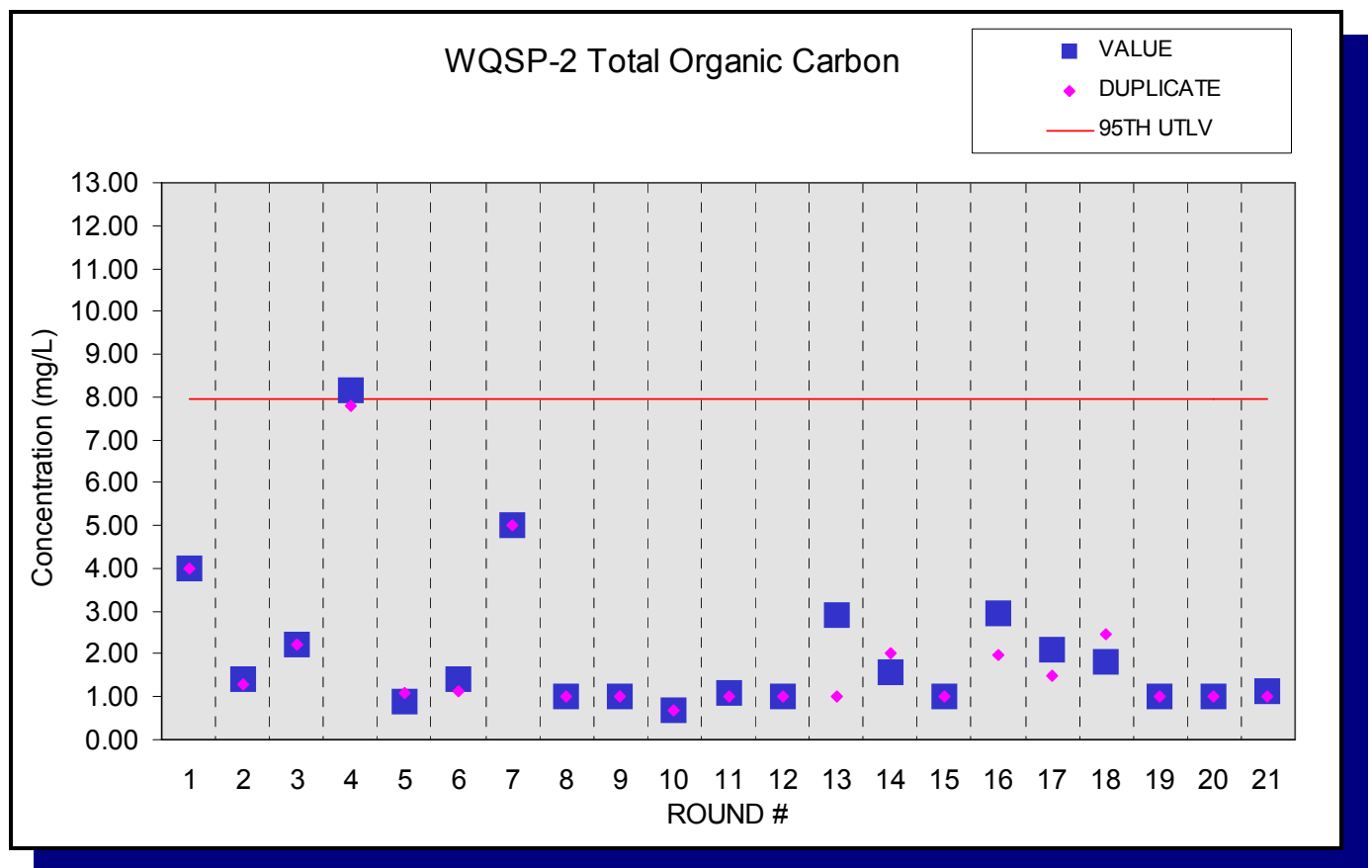

Figure E.26 - Time Trend Plot for Total Organic Carbon at WQSP-2 


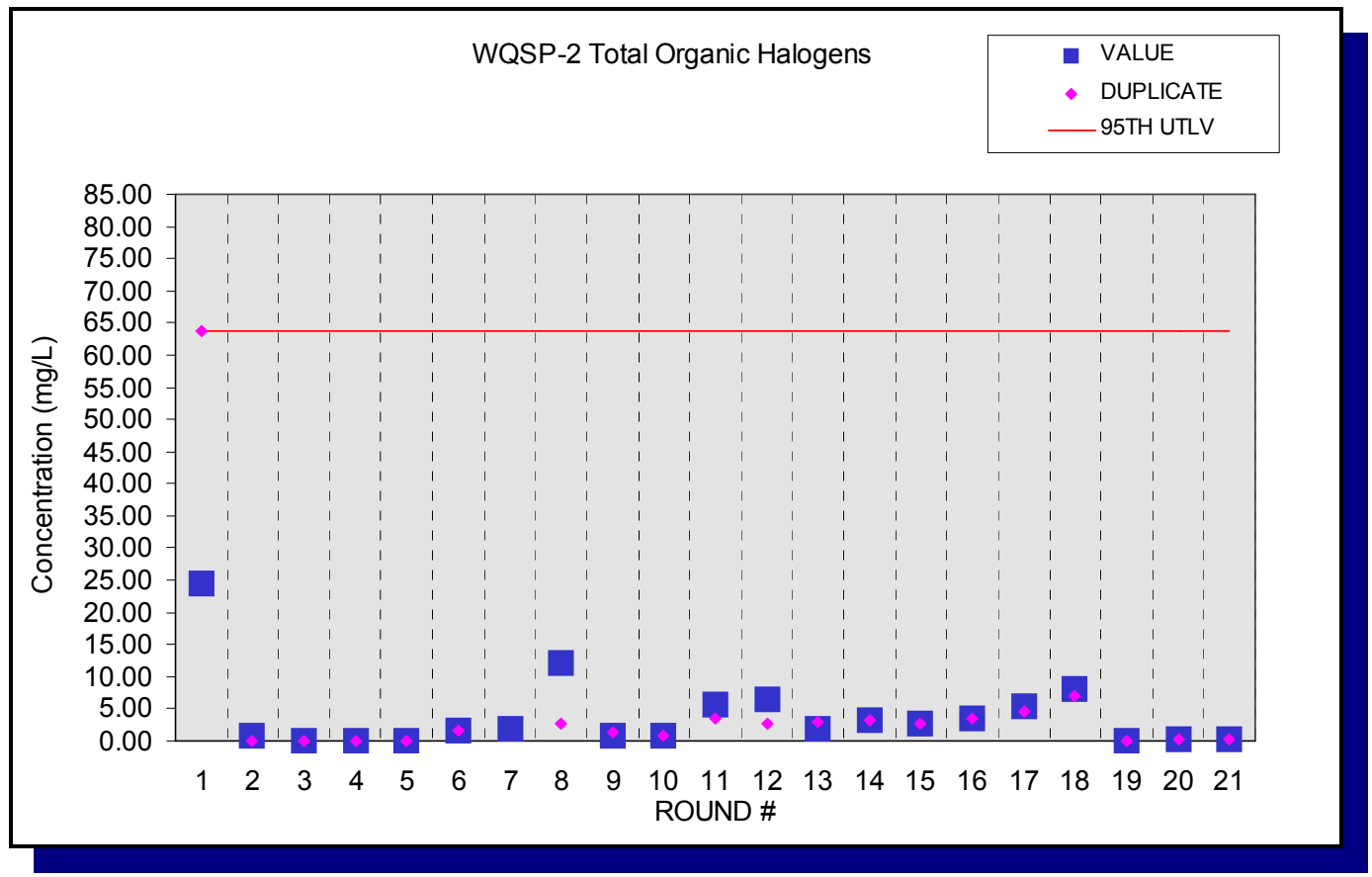

Figure E.27 - Time Trend Plot for Total Organic Halogens at WQSP-2

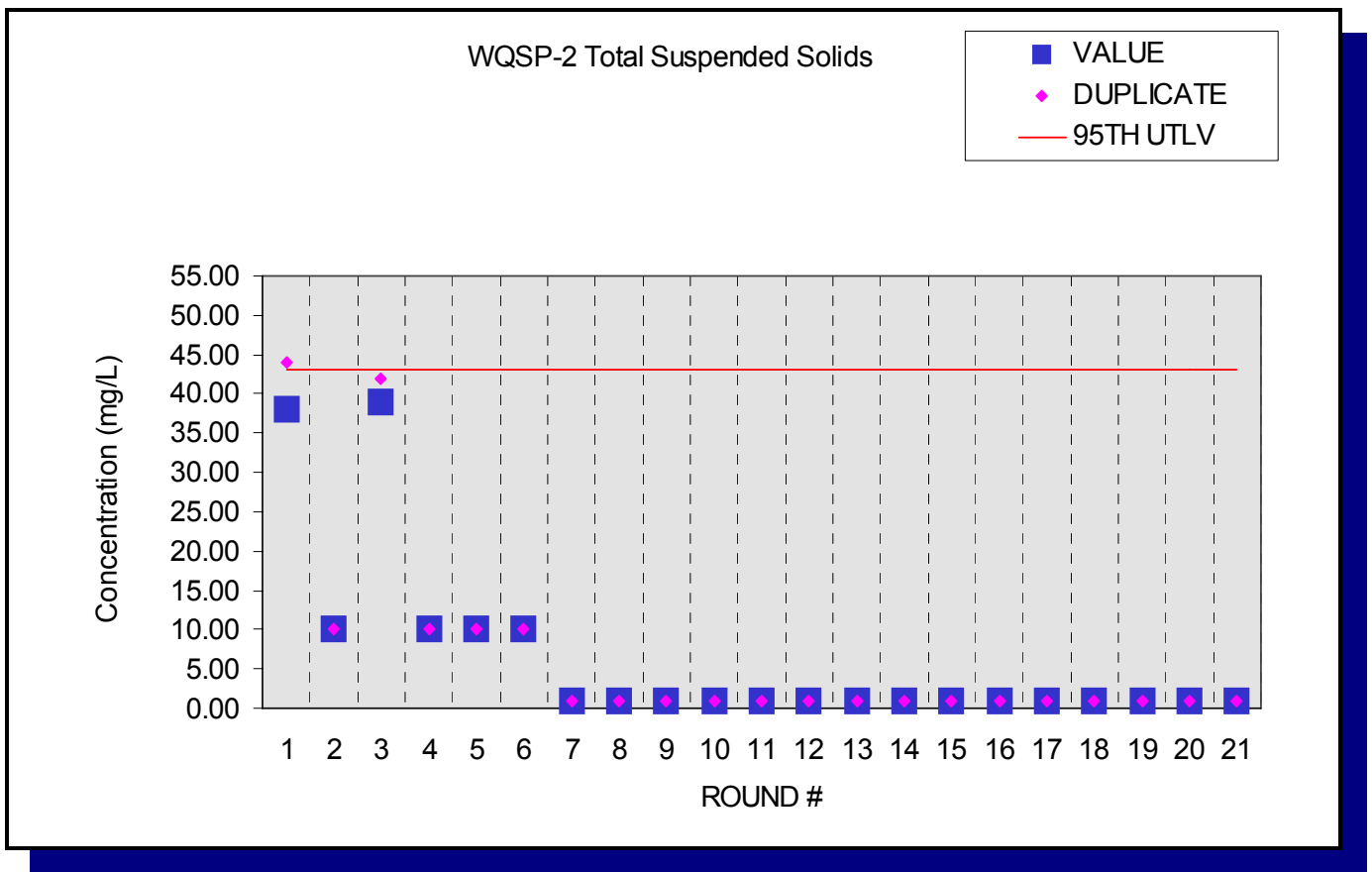

Figure E.28 - Time Trend Plot for Total Suspended Solids at WQSP-2 


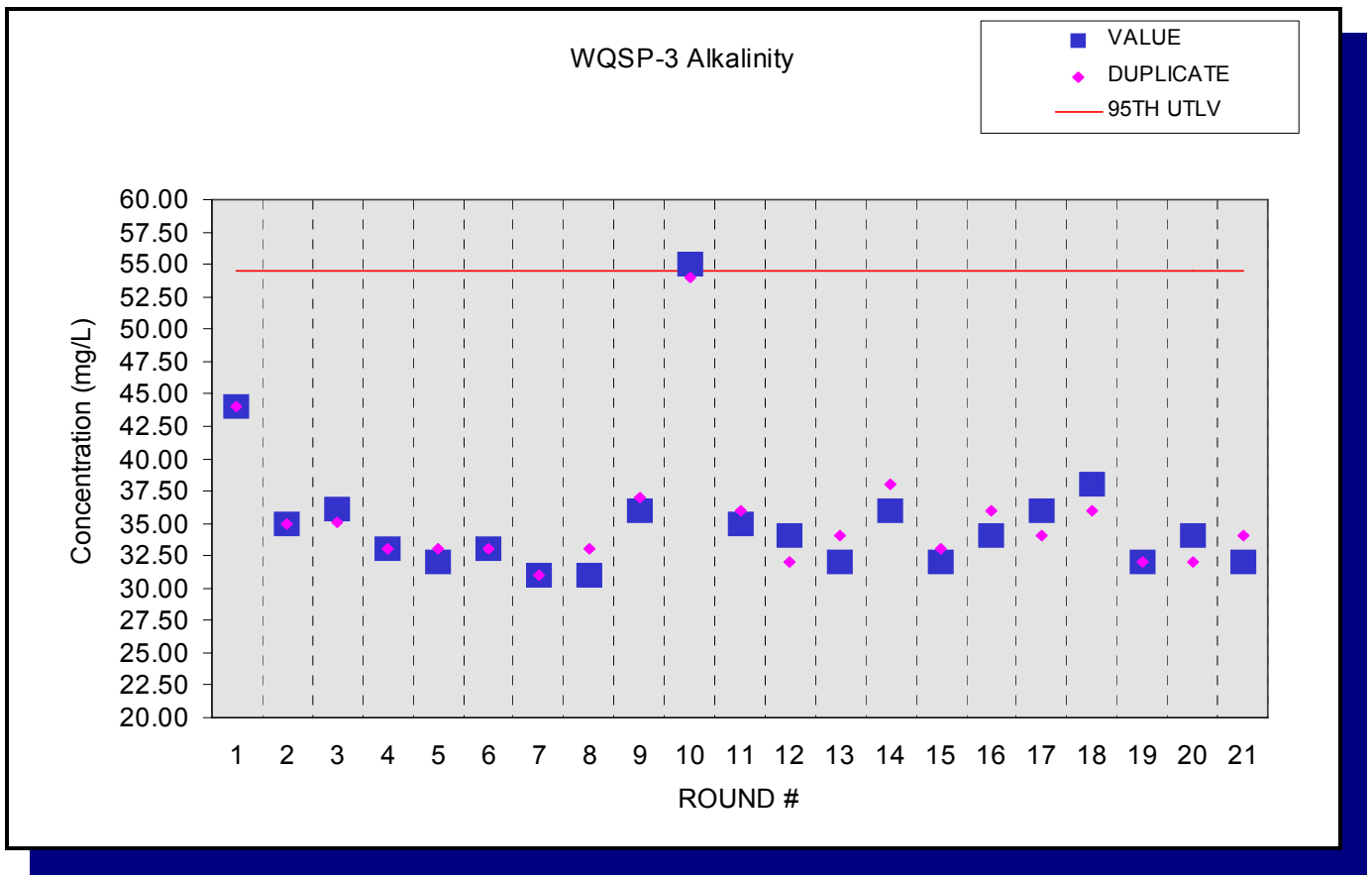

Figure E.29 - Time Trend Plot for Alkalinity at WQSP-3

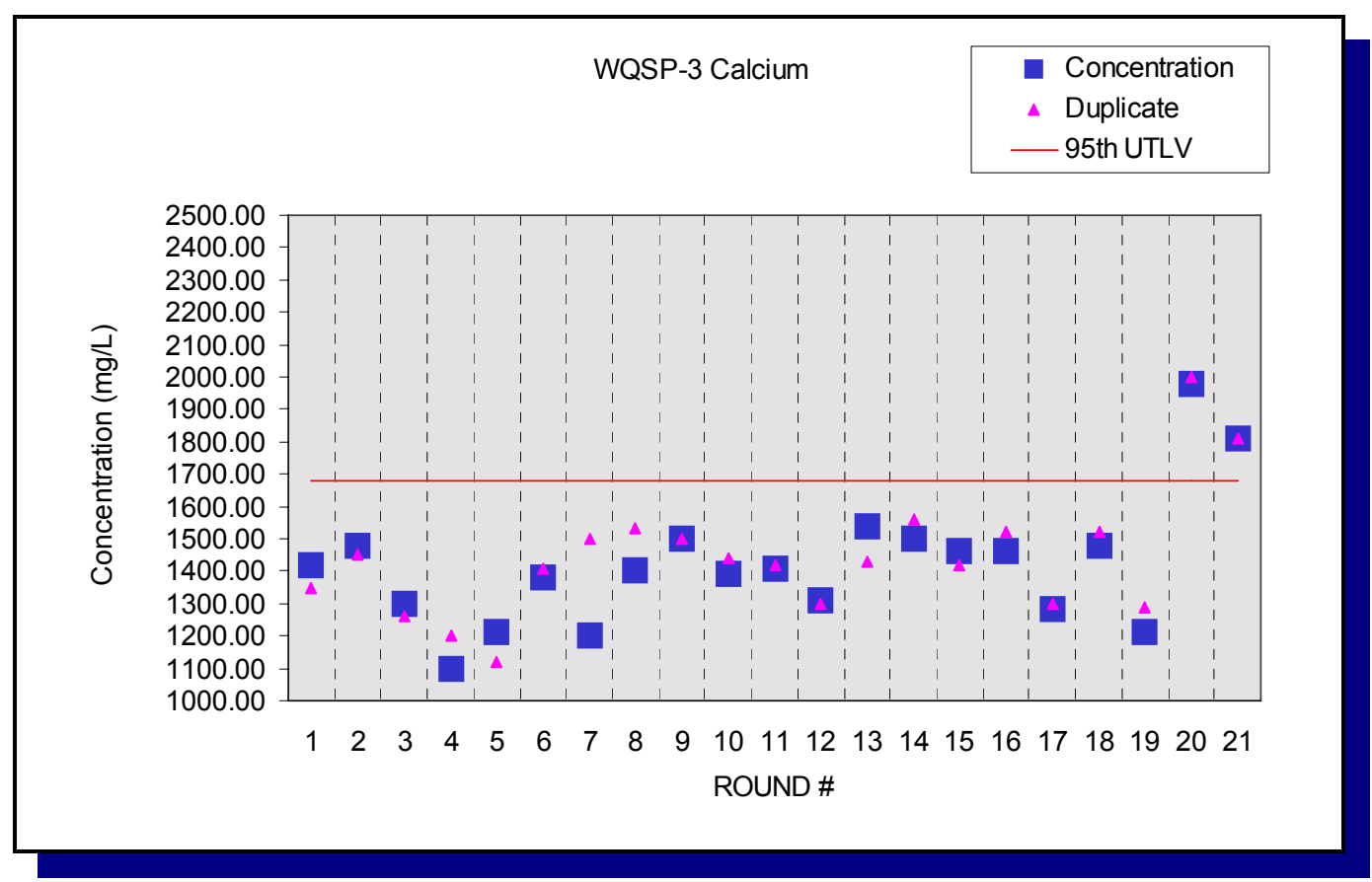

Figure E.30 - Time Trend Plot for Calcium at WQSP-3 


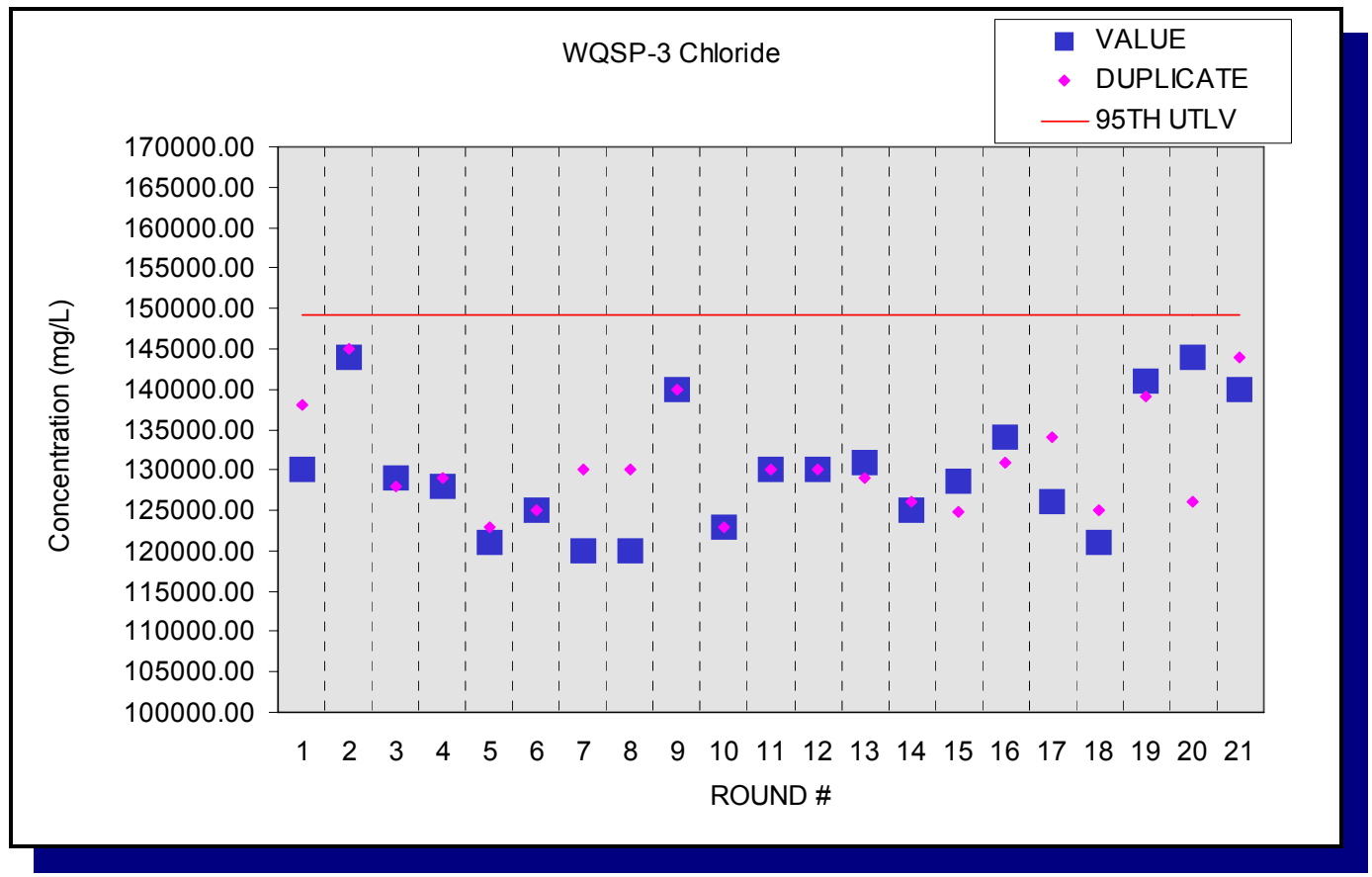

Figure E.31 - Time Trend Plot for Chloride at WQSP-3

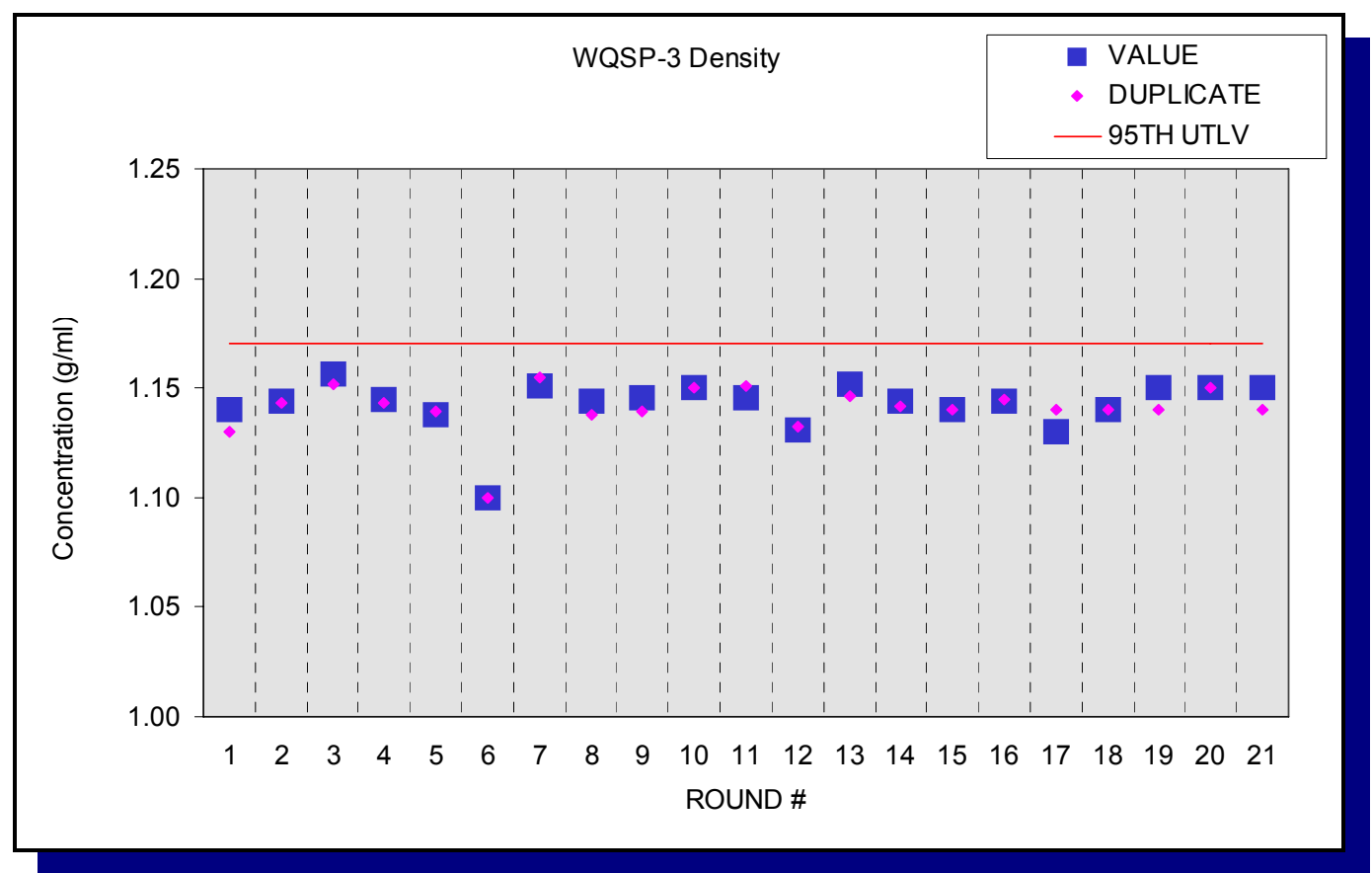

Figure E.32 - Time Trend Plot for Density at WQSP-3 


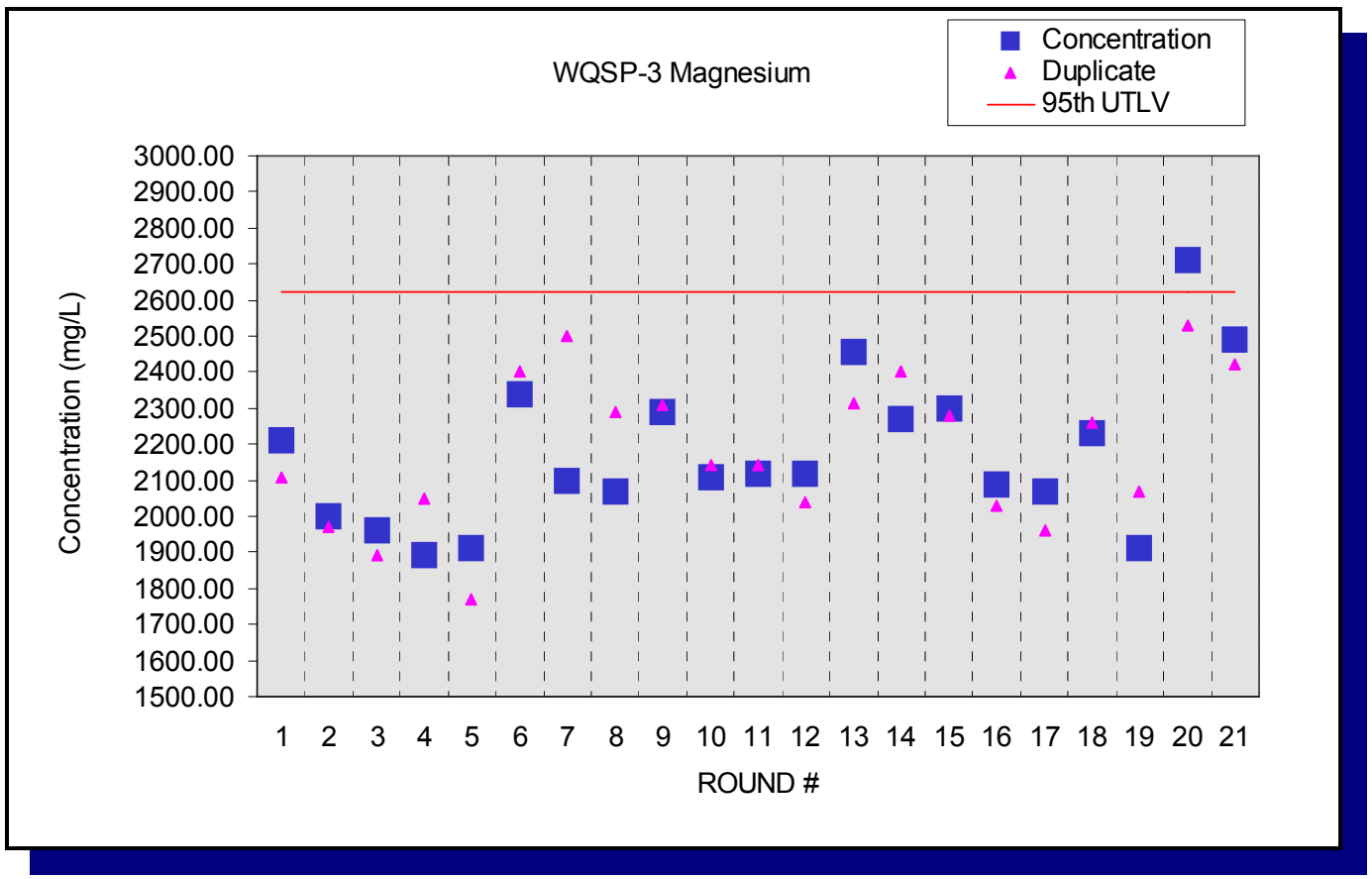

Figure E.33 - Time Trend Plot for Magnesium at WQSP-3

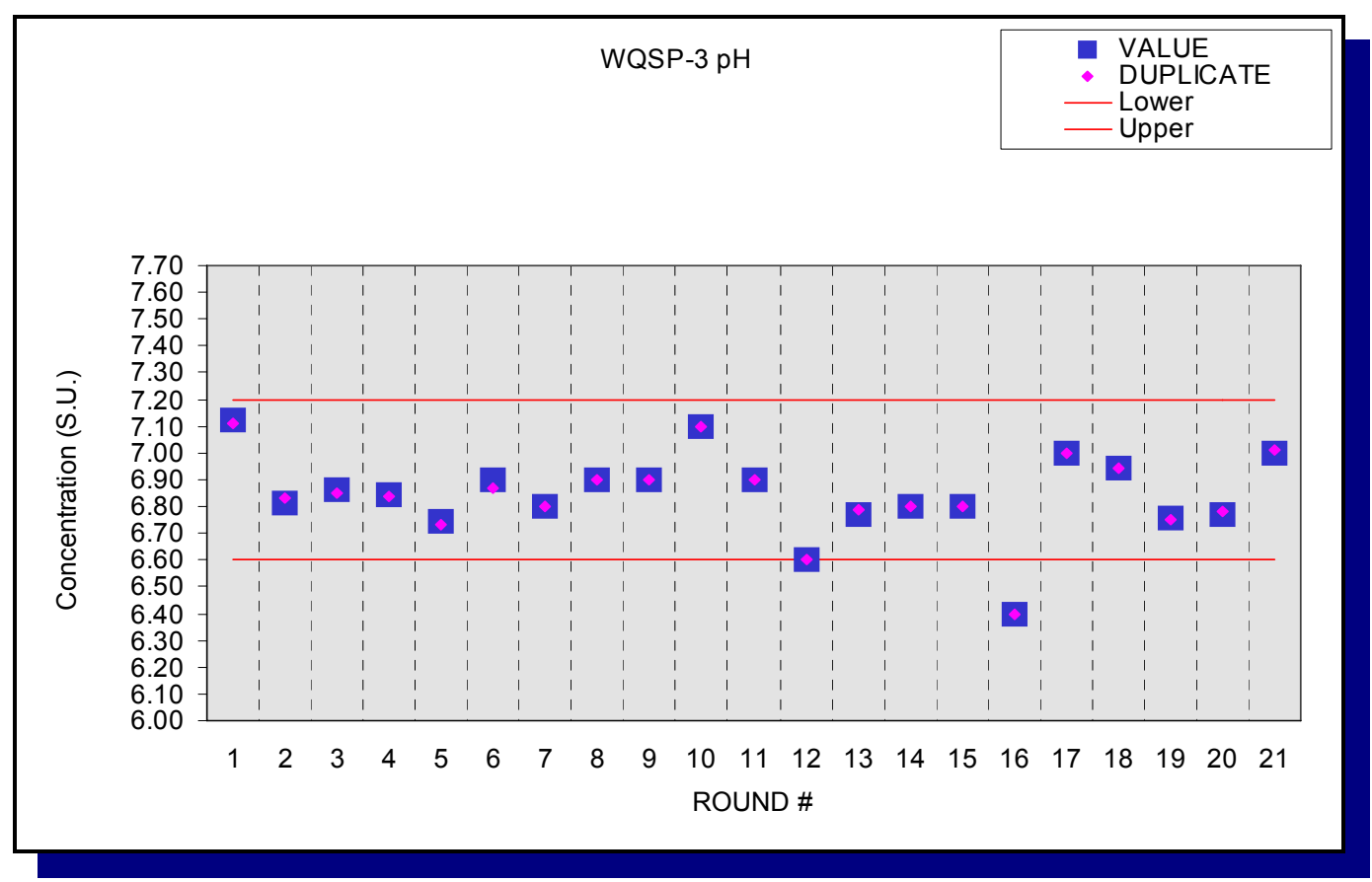

Figure E.34 - Time Trend Plot for $\mathrm{pH}$ at WQSP-3 


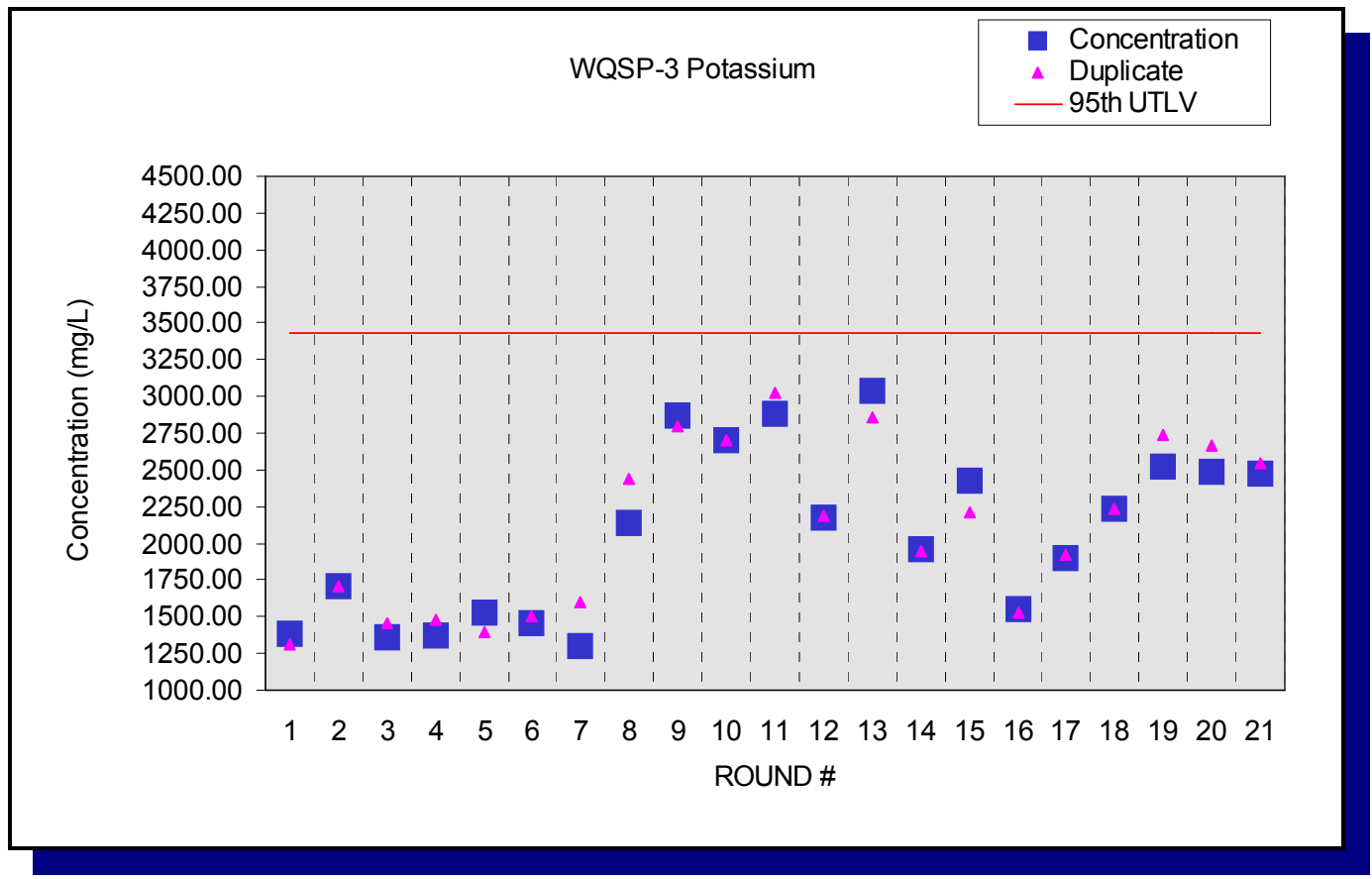

Figure E.35 - Time Trend Plot for Potassium at WQSP-3

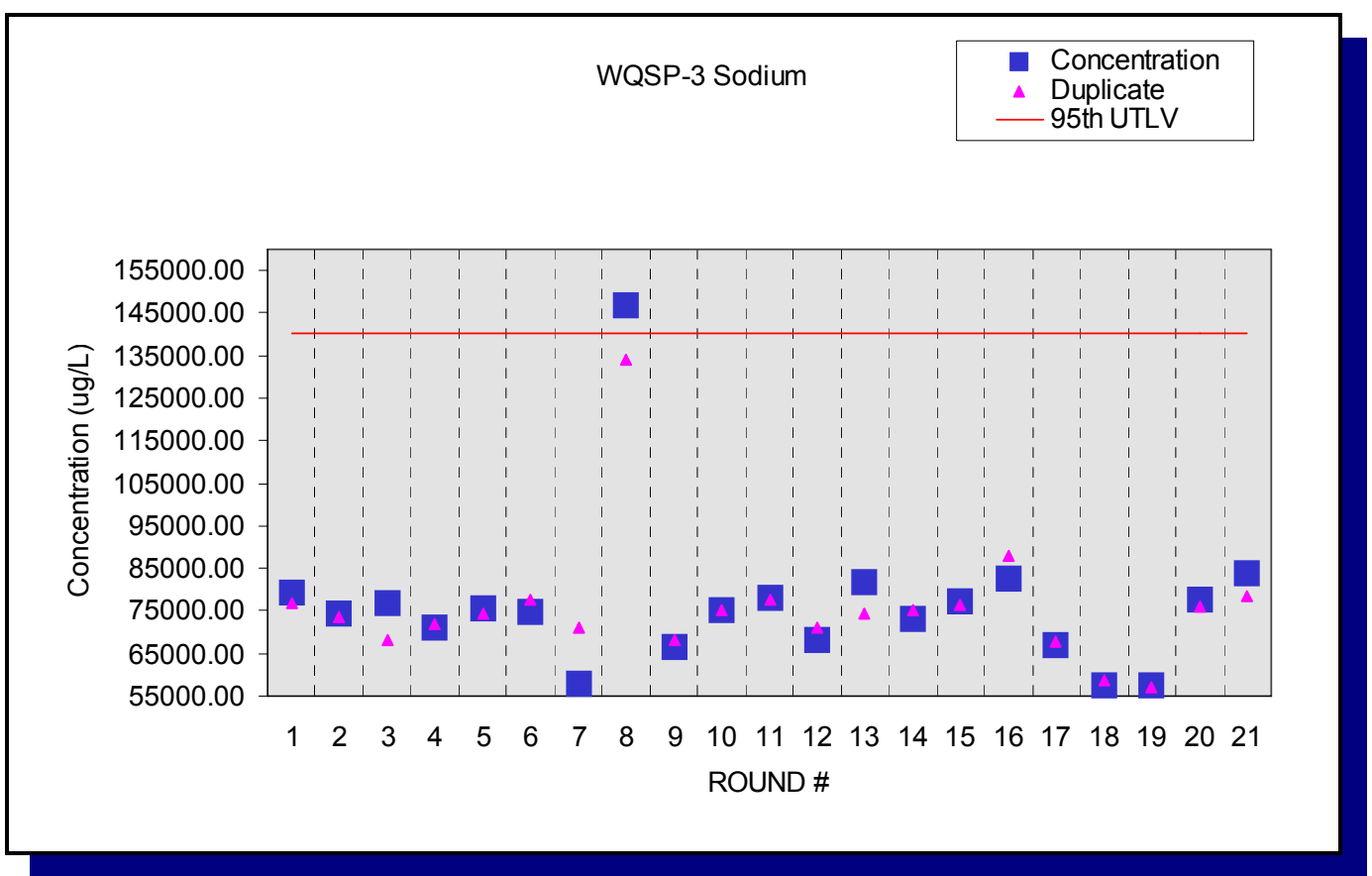

Figure E.36 - Time Trend Plot for Sodium at WQSP-3 


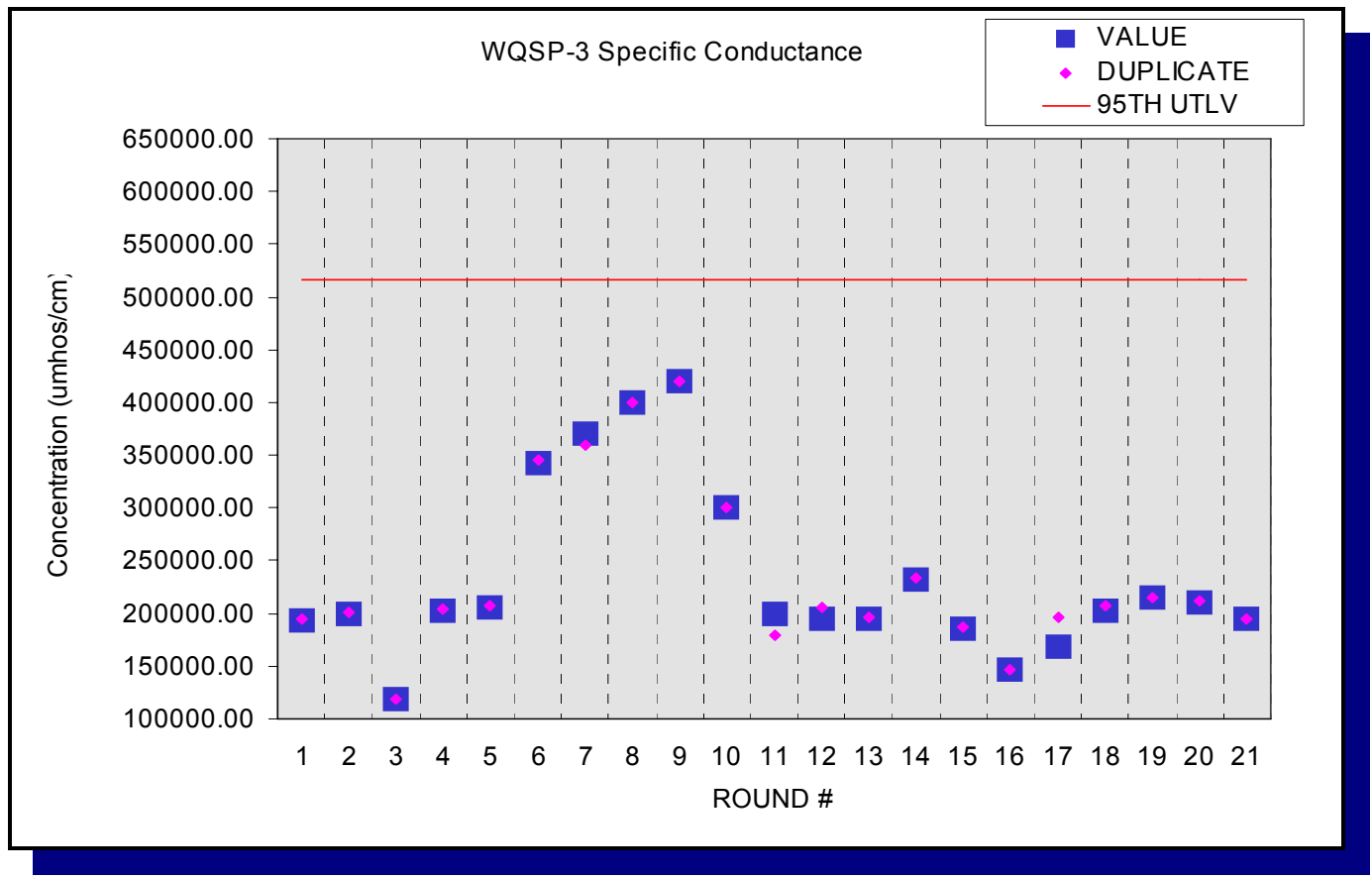

Figure E.37 - Time Trend Plot for Specific Conductance at WQSP-3

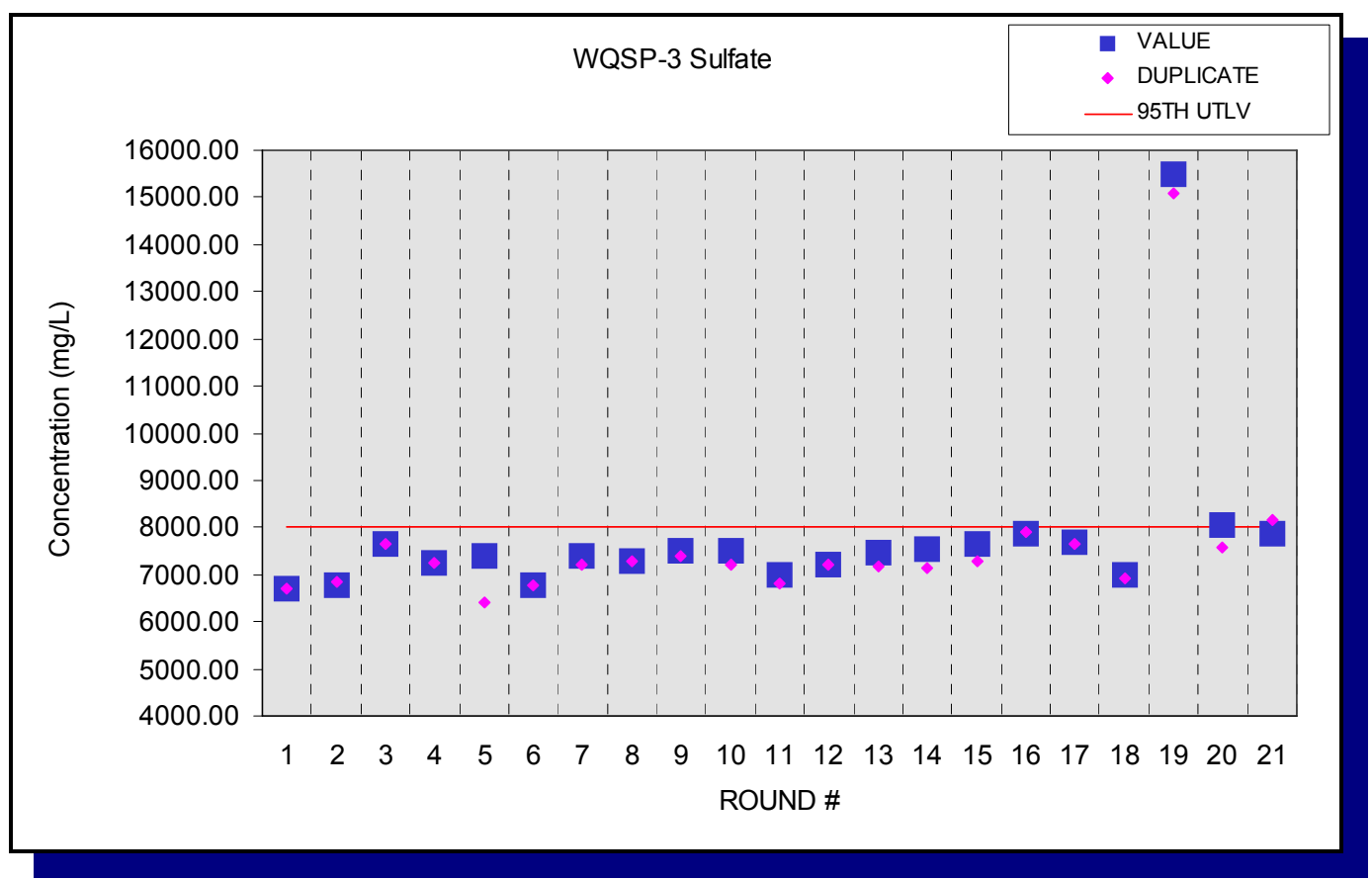

Figure E.38 - Time Trend Plot for Sulfate at WQSP-3 


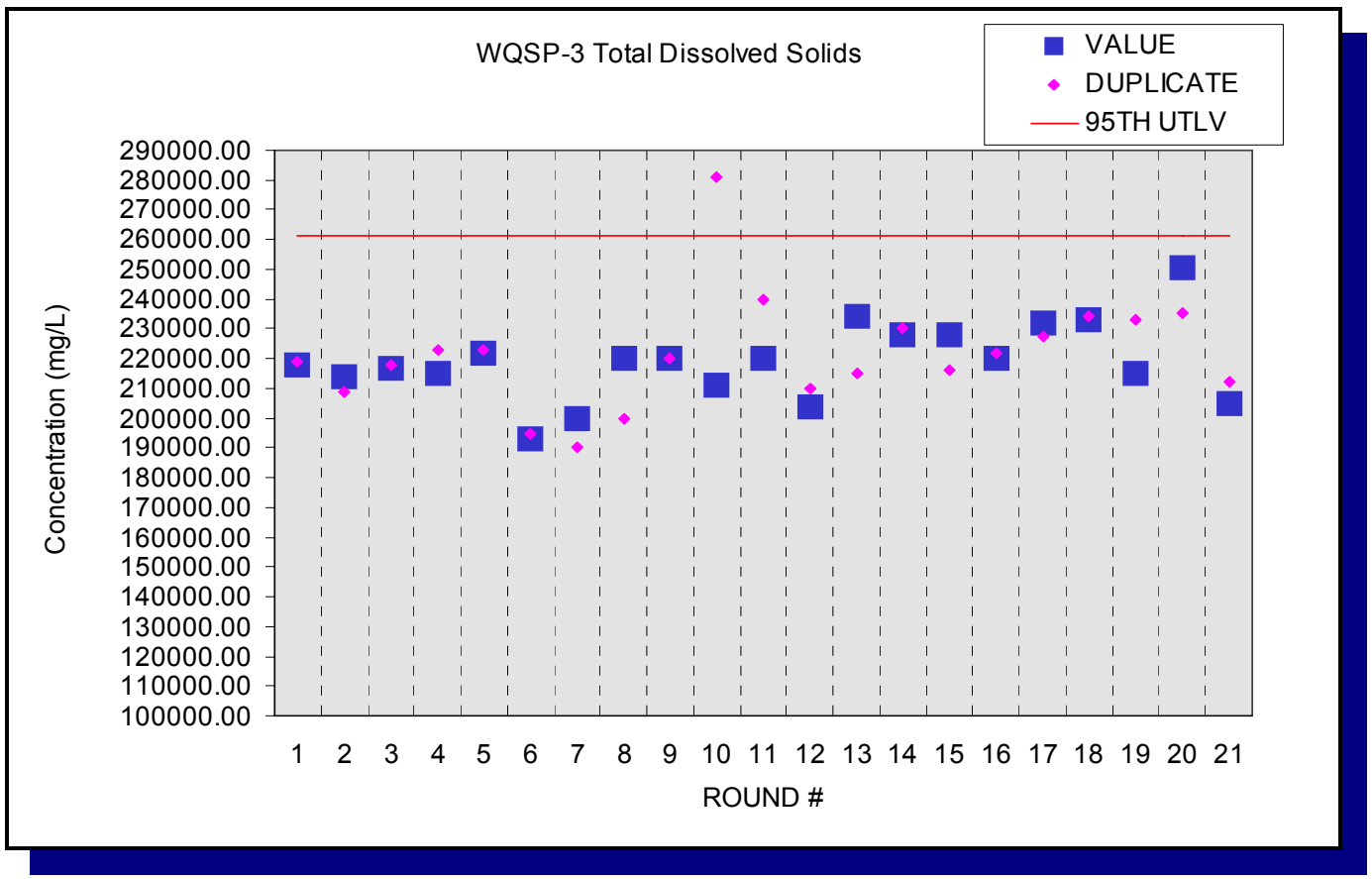

Figure E.39 - Time Trend Plot for Total Dissolved Solids at WQSP-3

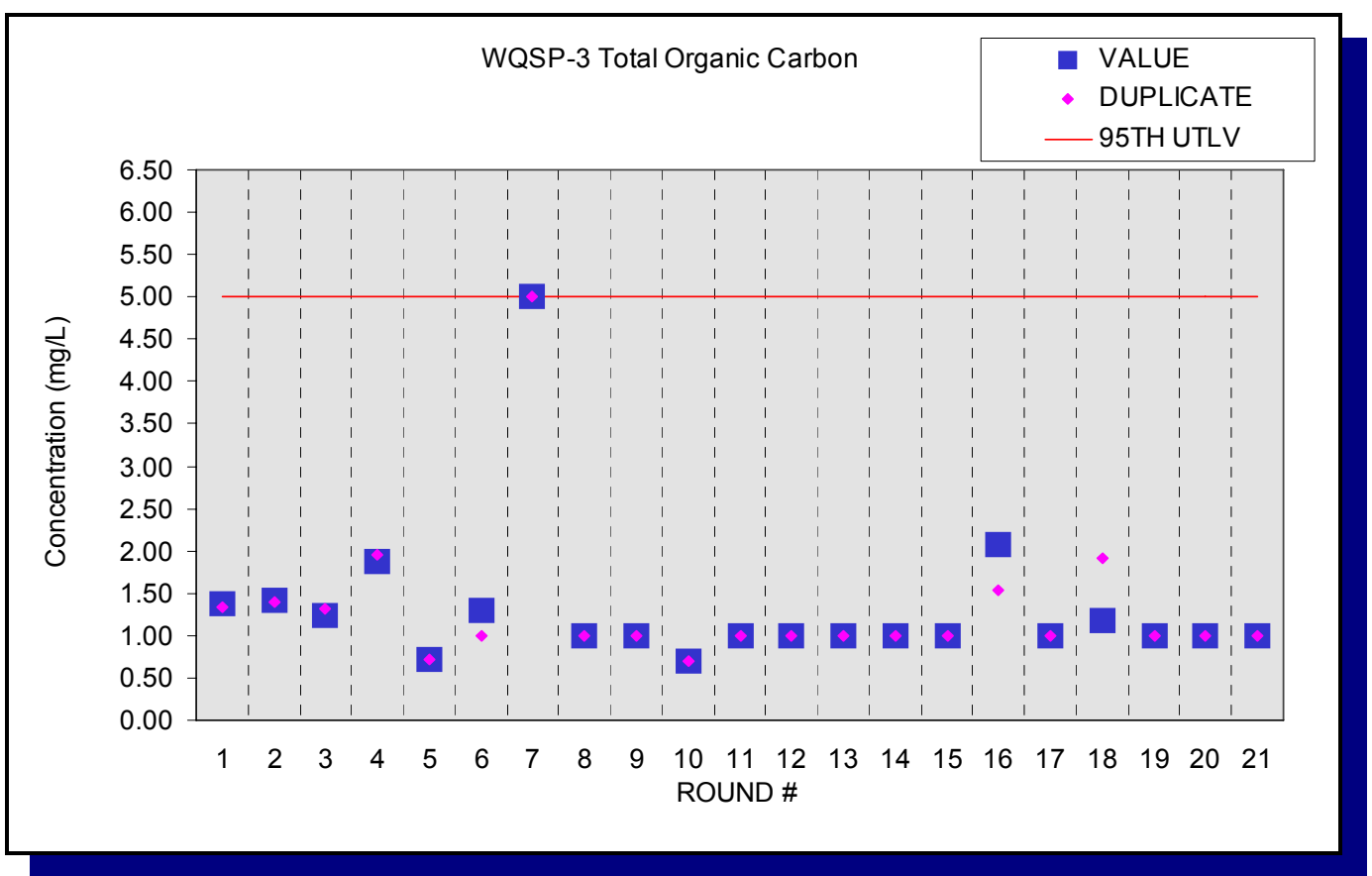

Figure E.40 - Time Trend Plot for Total Organic Carbon at WQSP-3 


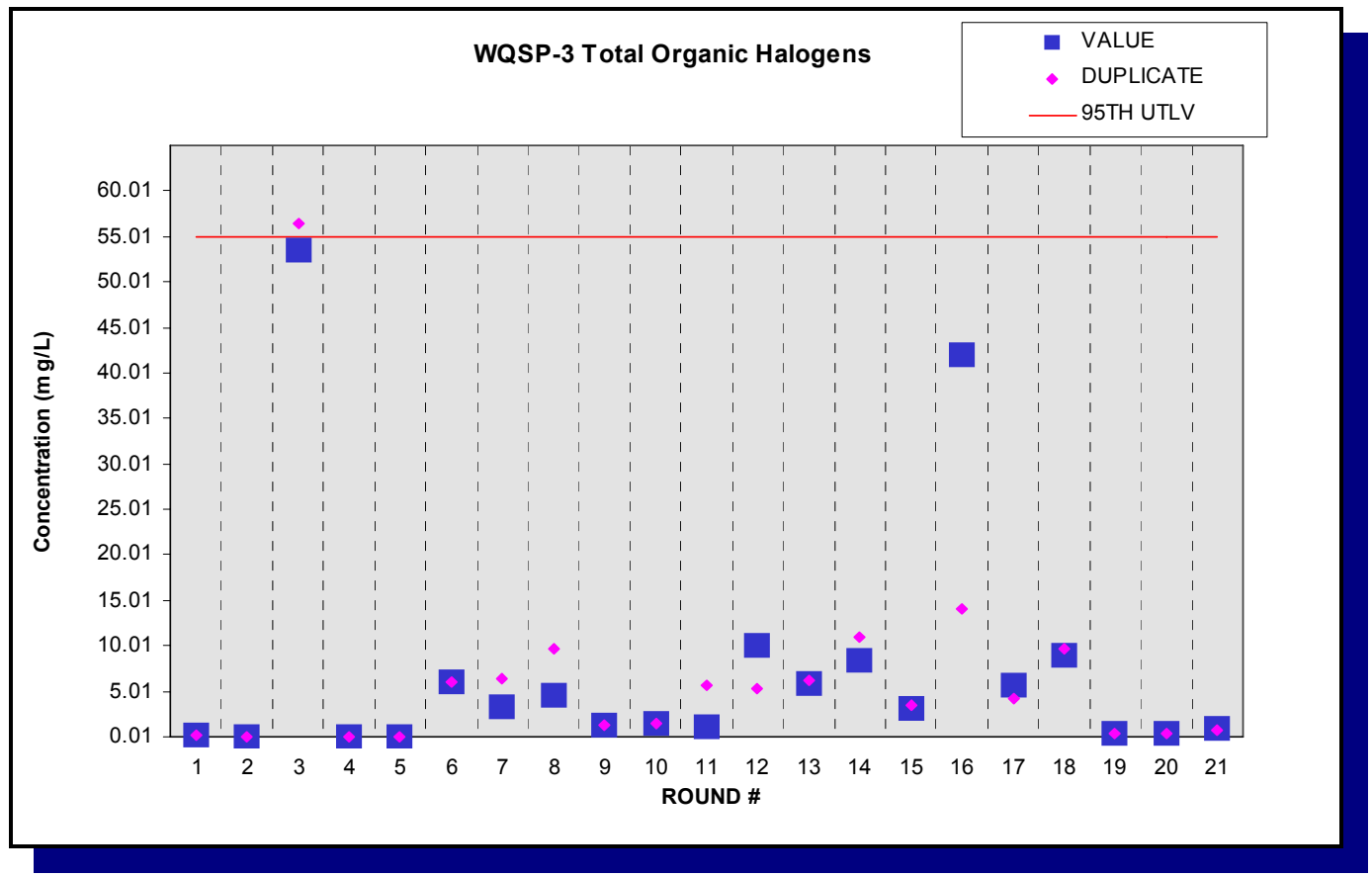

Figure E.41 - Time Trend Plot for Total Organic Halogens at WQSP-3

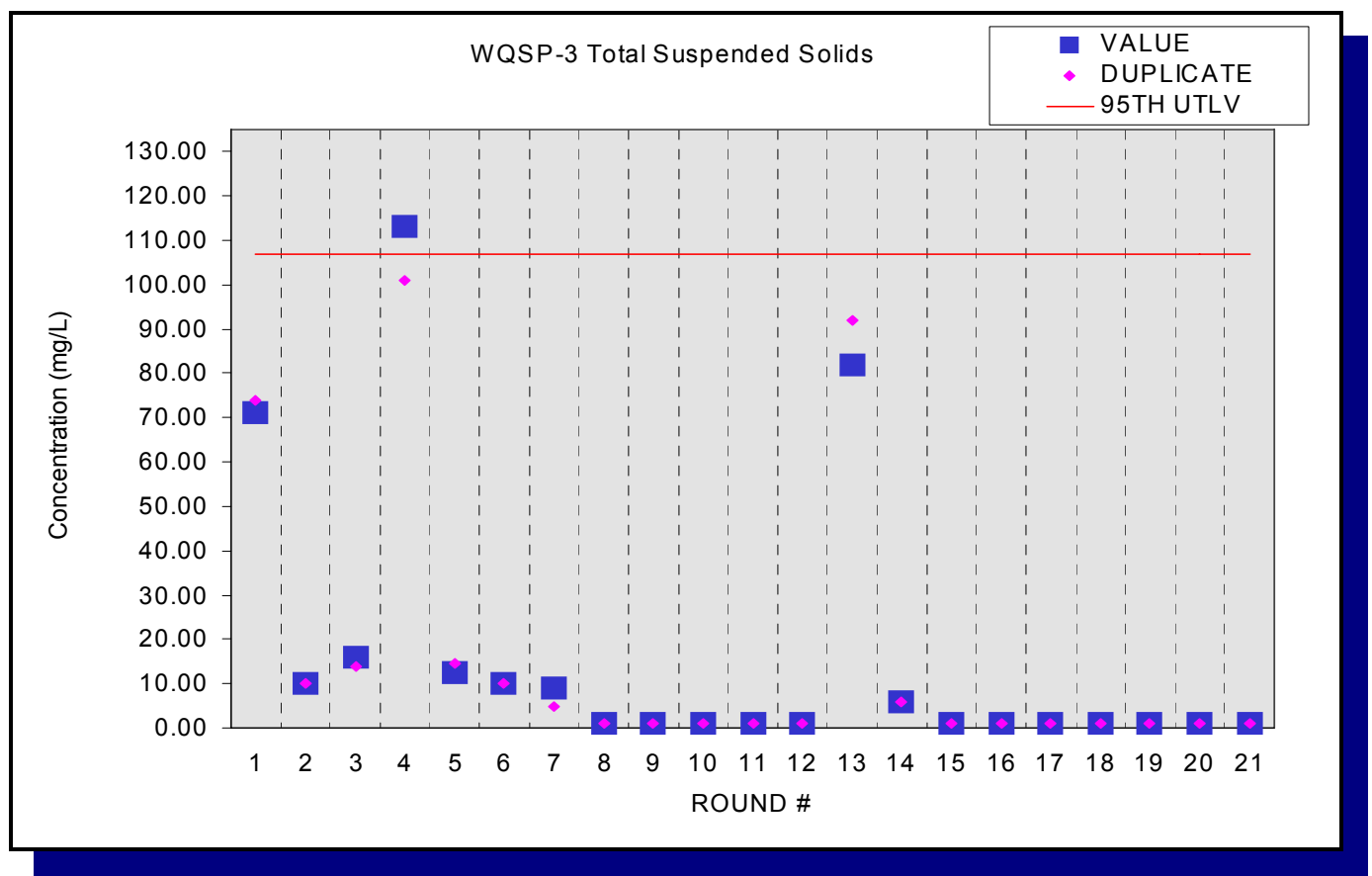

Figure E.42 - Time Trend Plot for Total Suspended Solids at WQSP-3 


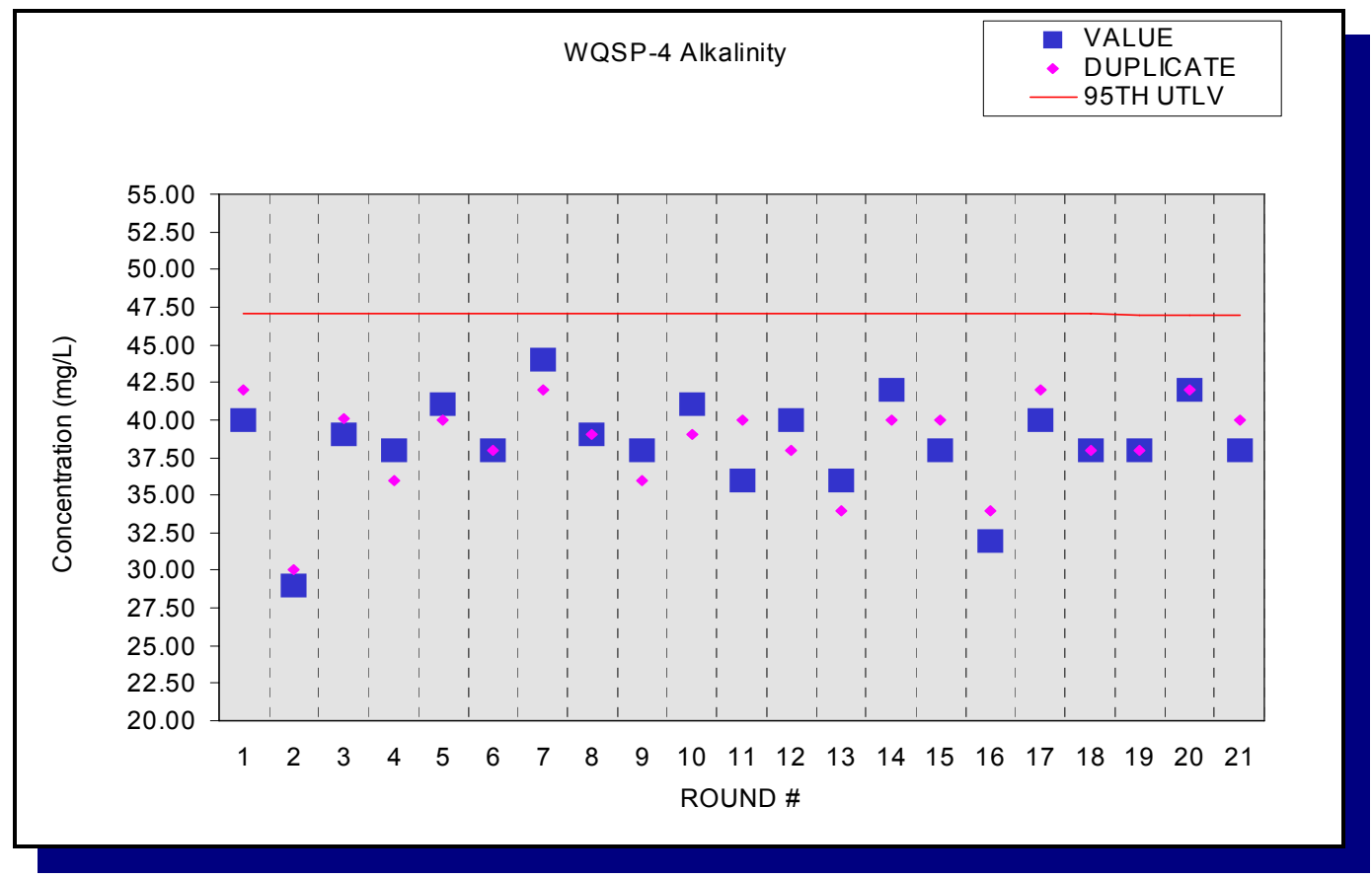

Figure E.43 - Time Trend Plot for Alkalinity at WQSP-4

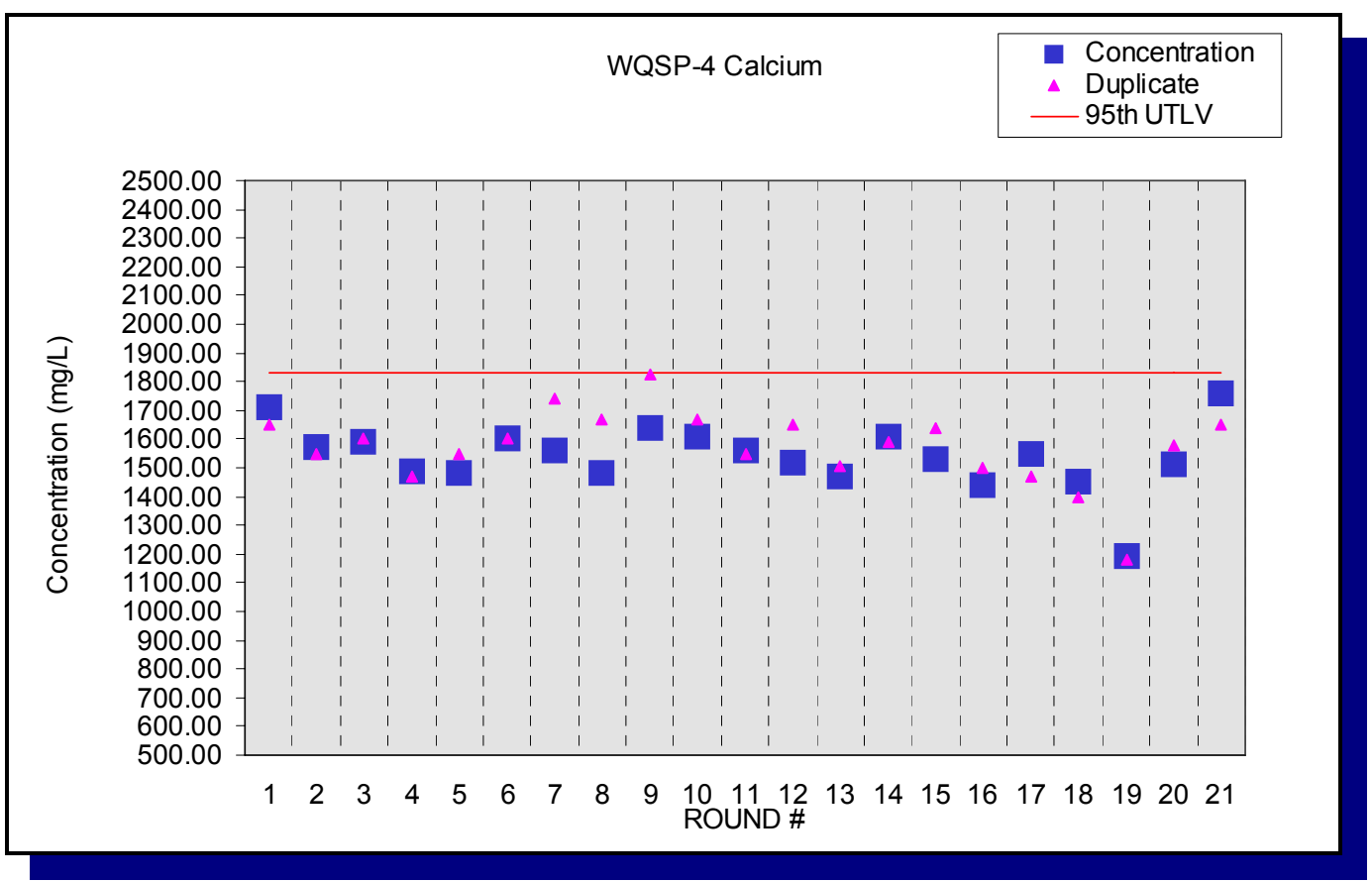

Figure E.44 - Time Trend Plot for Calcium at WQSP-4 


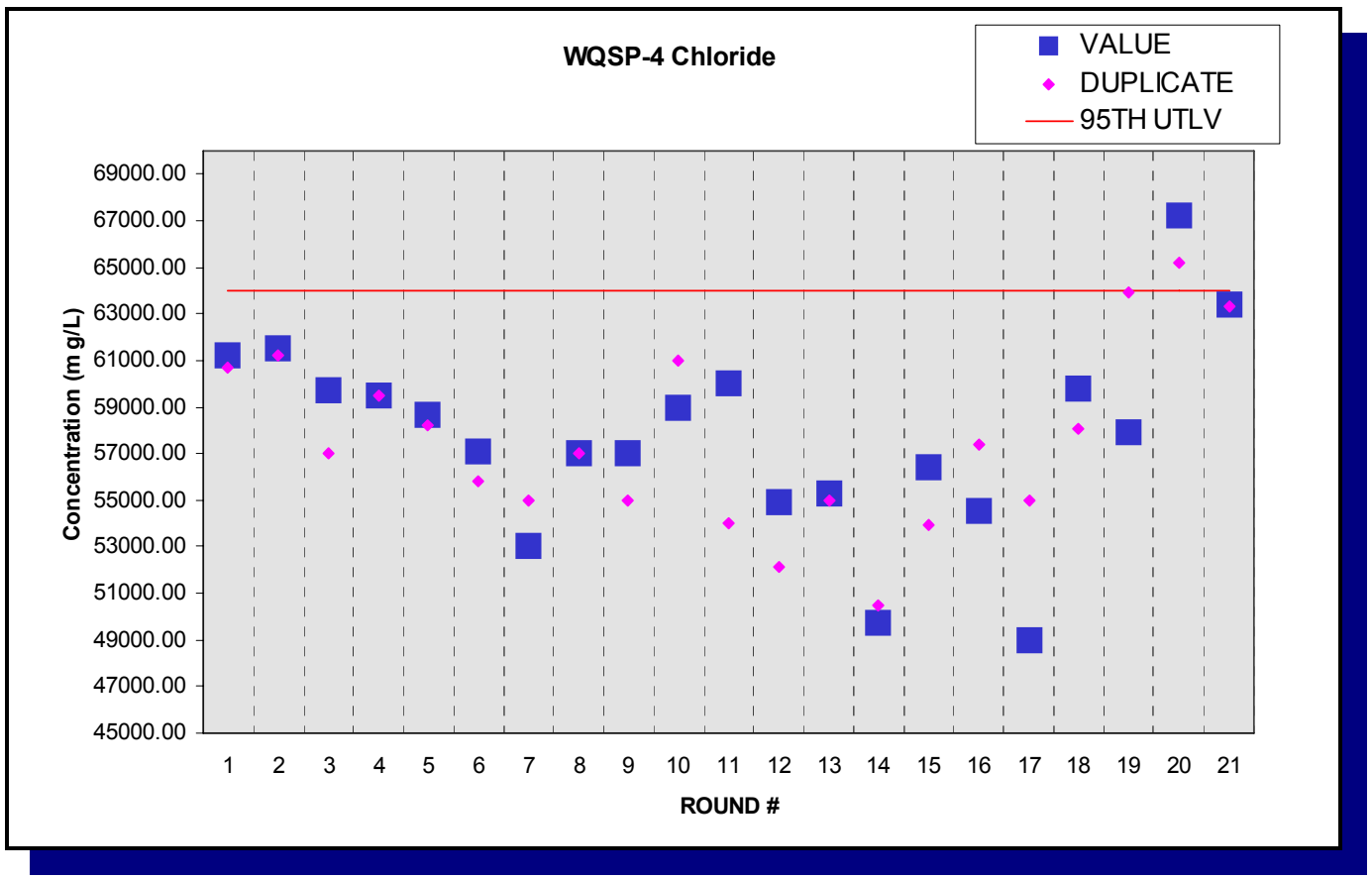

Figure E.45 - Time Trend Plot for Chloride at WQSP-4

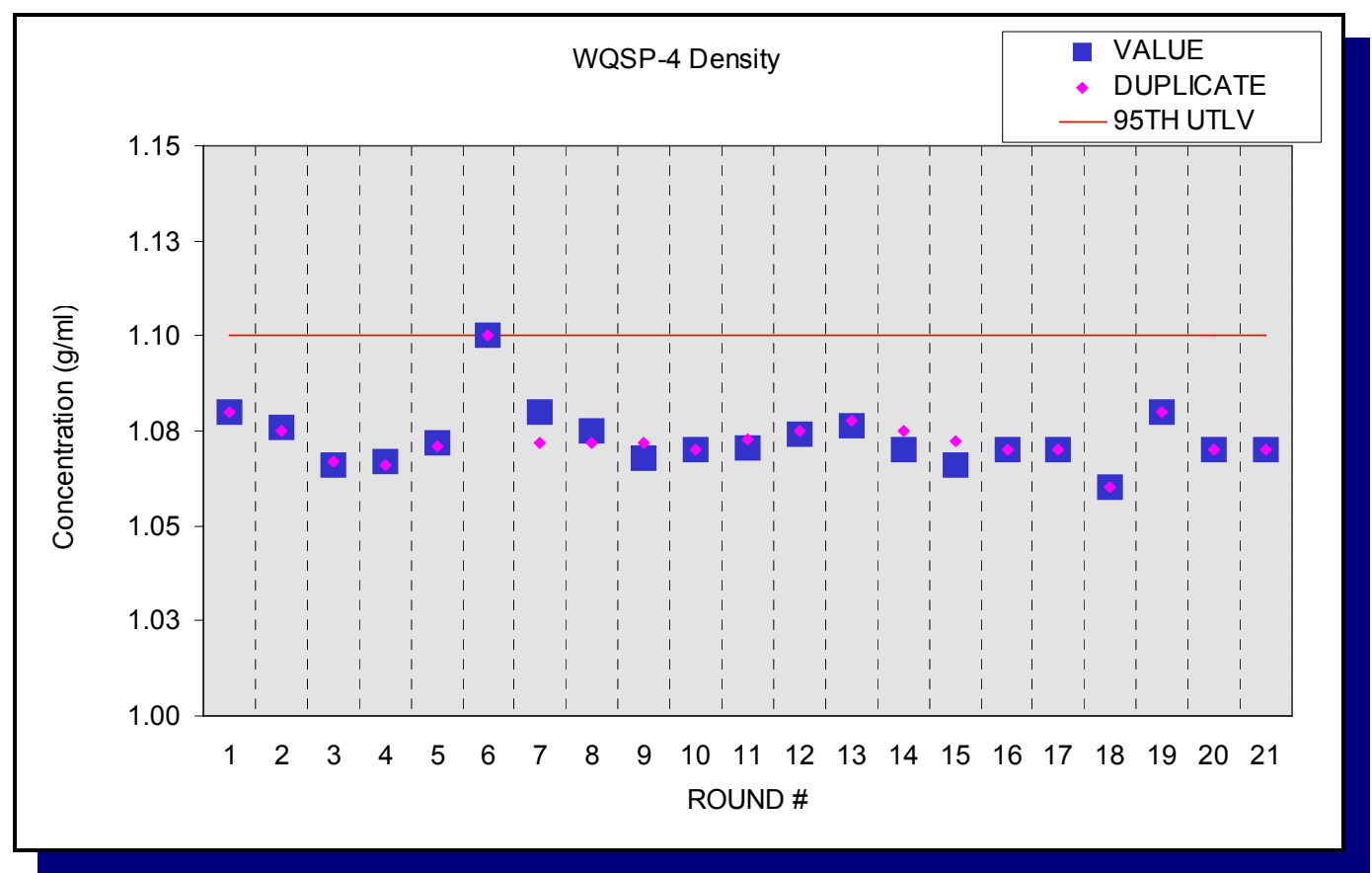

Figure E.46 - Time Trend Plot for Density at WQSP-4 


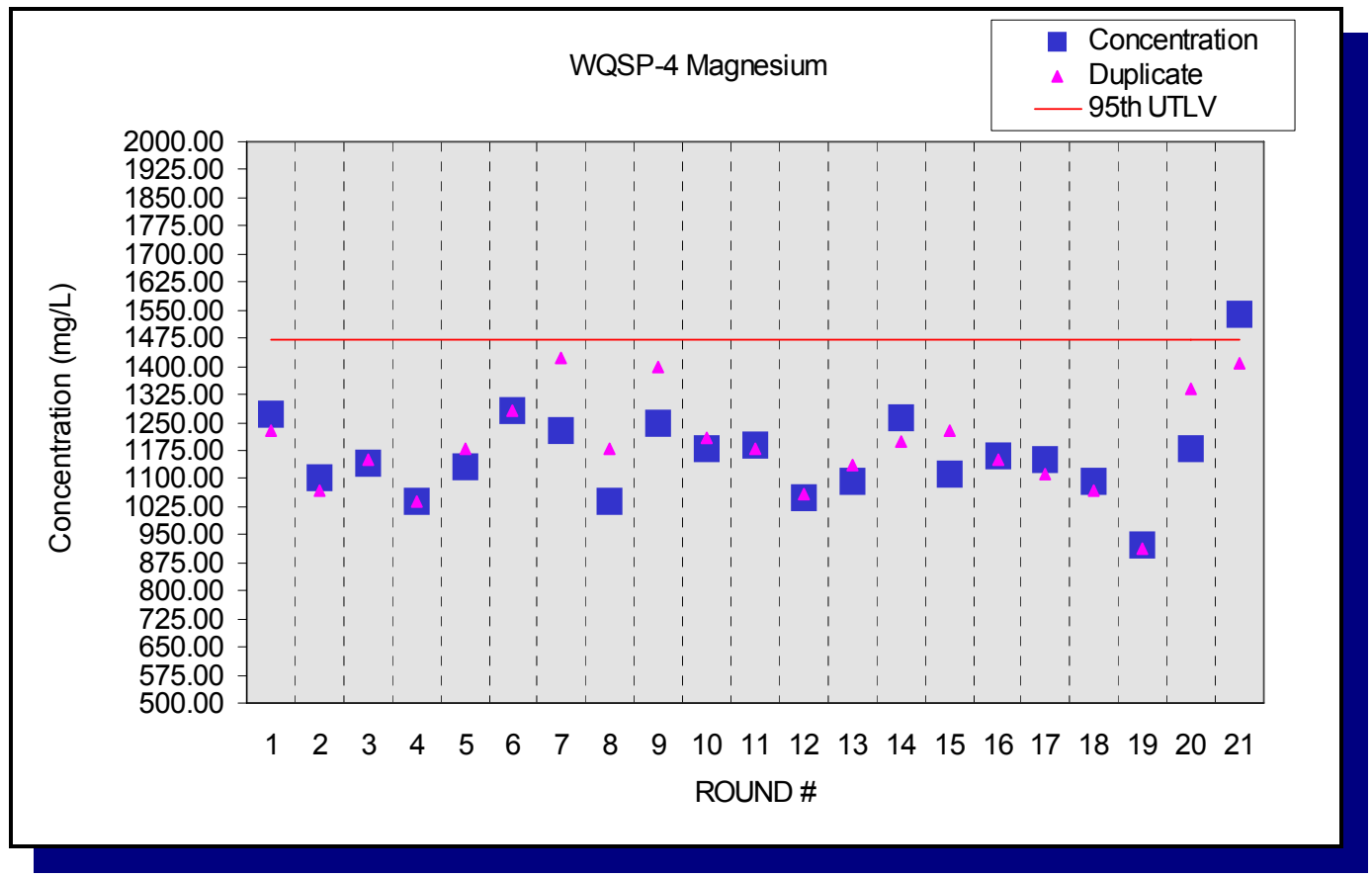

Figure E.47 - Time Trend Plot for Magnesium at WQSP-4

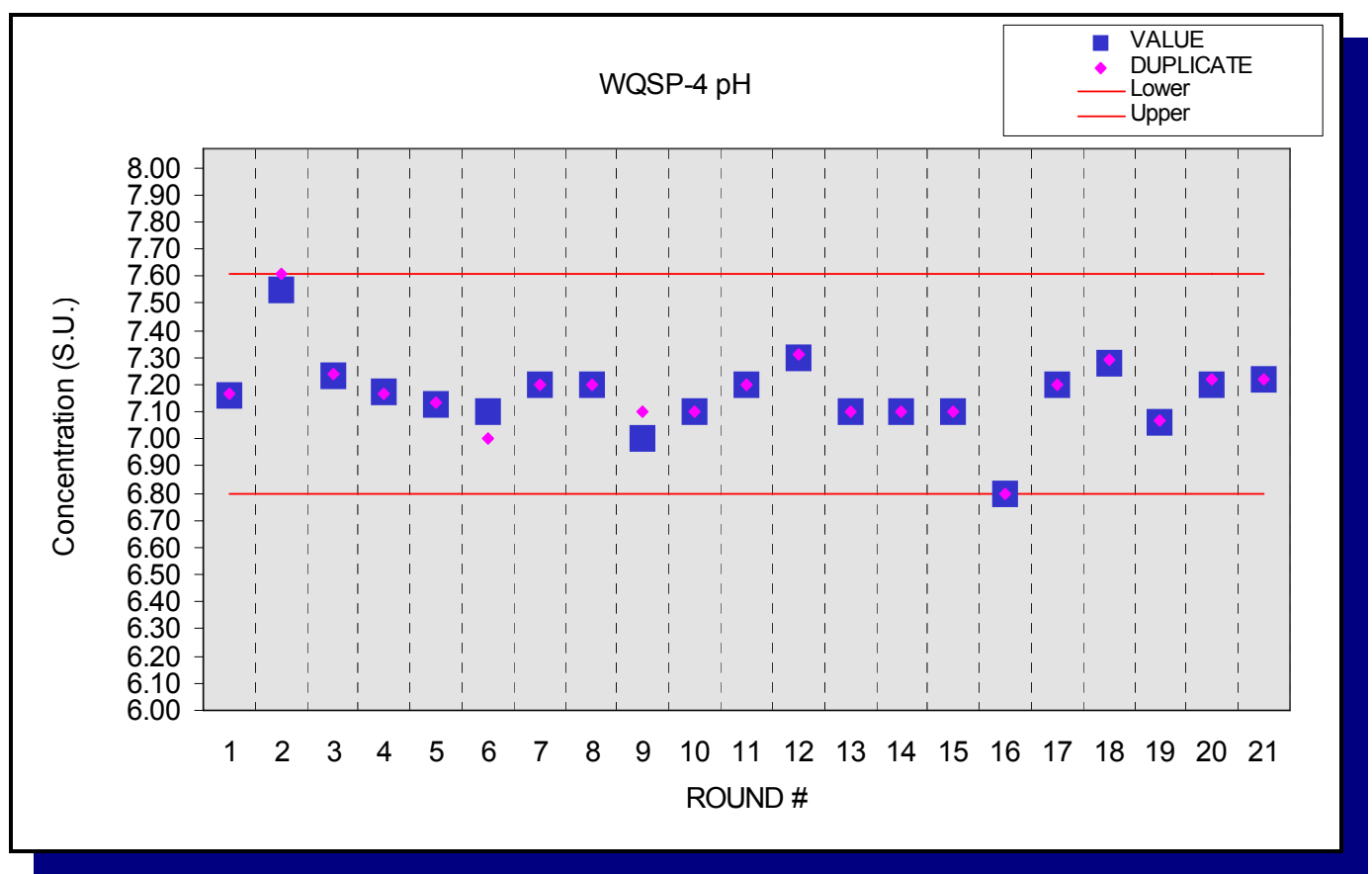

Figure E.48 - Time Trend Plot for $\mathrm{pH}$ at WQSP-4 


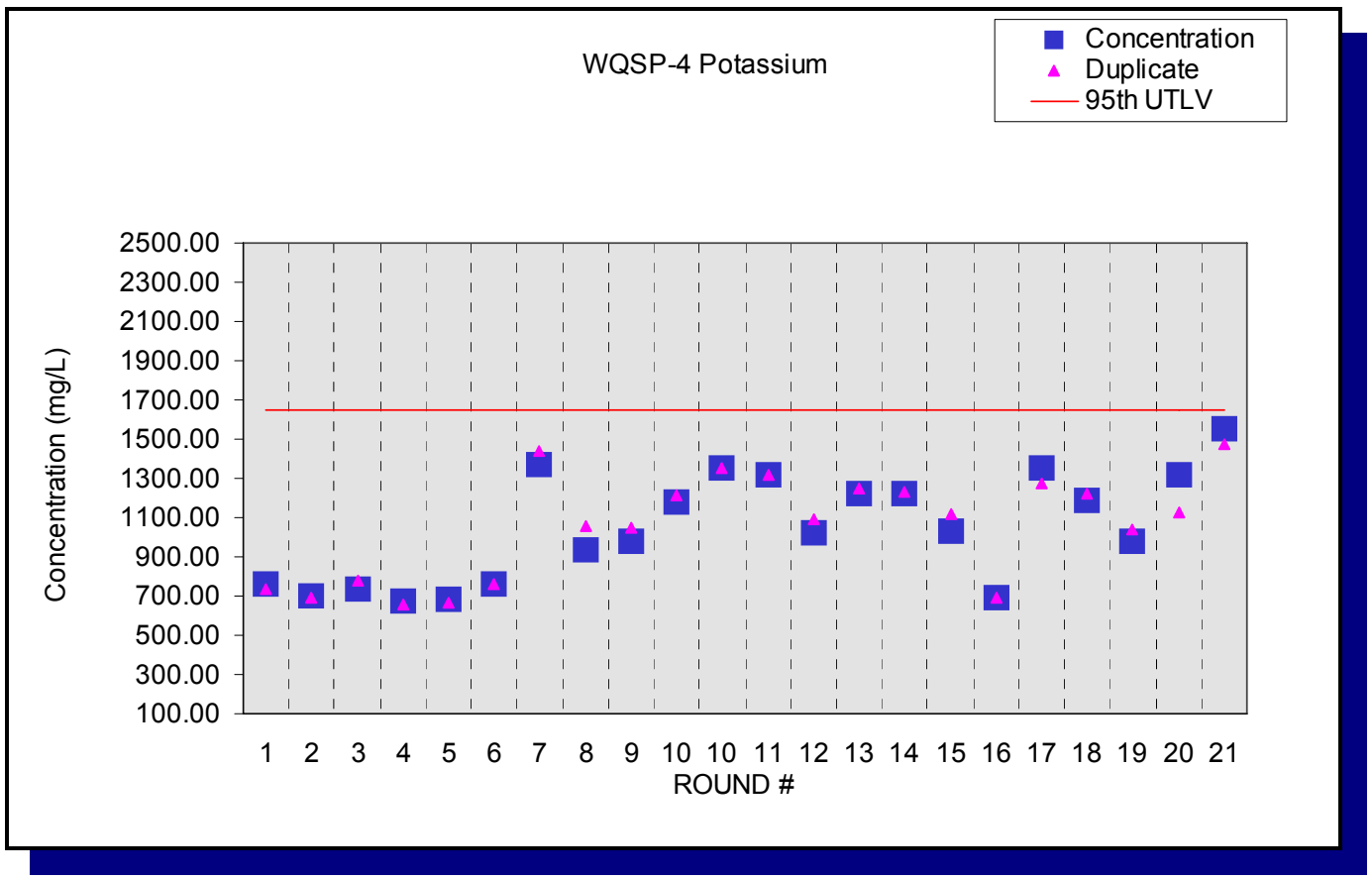

Figure E.49 - Time Trend Plot for Potassium at WQSP-4

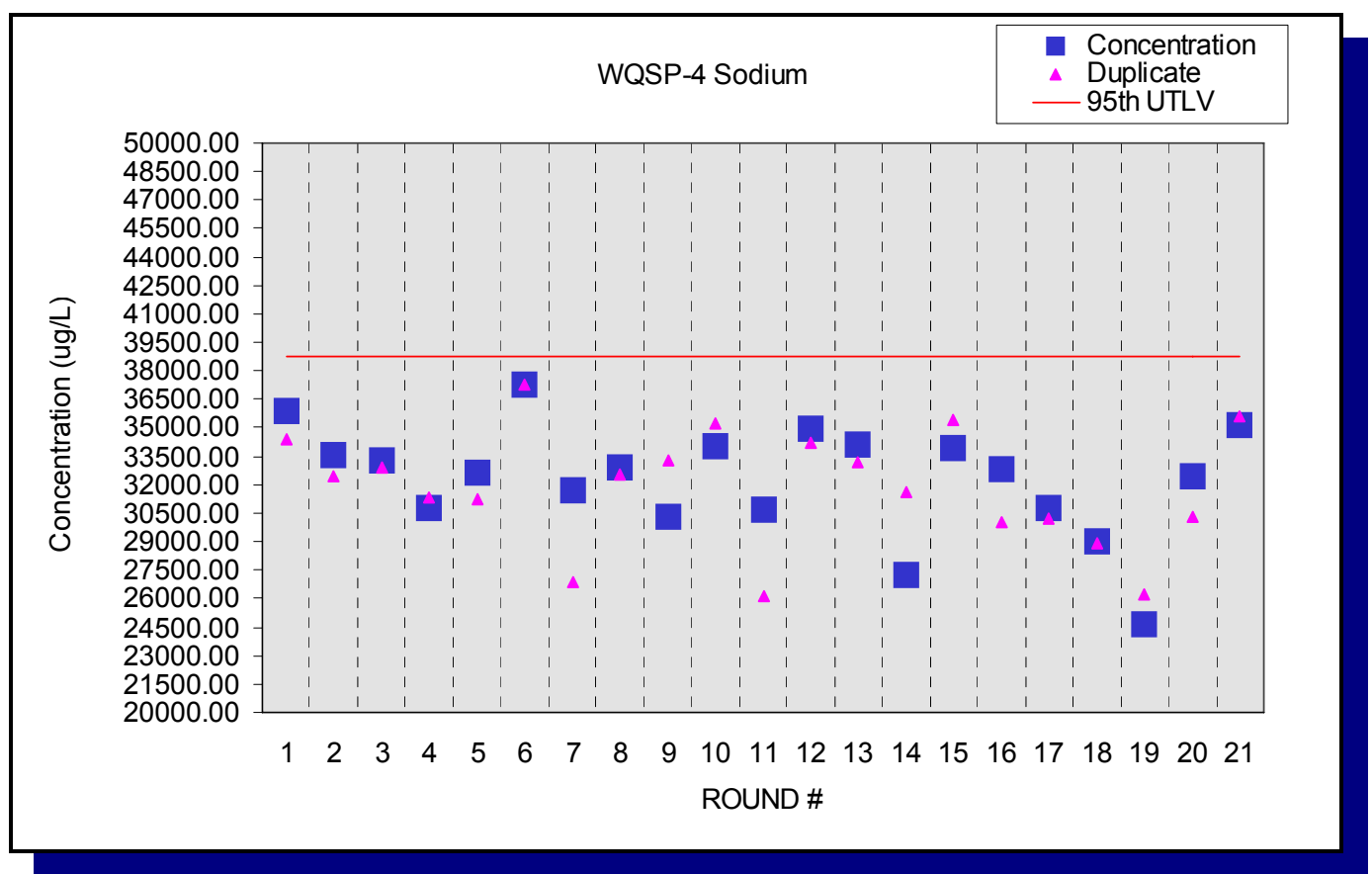

Figure E.50 - Time Trend Plot for Sodium at WQSP-4 


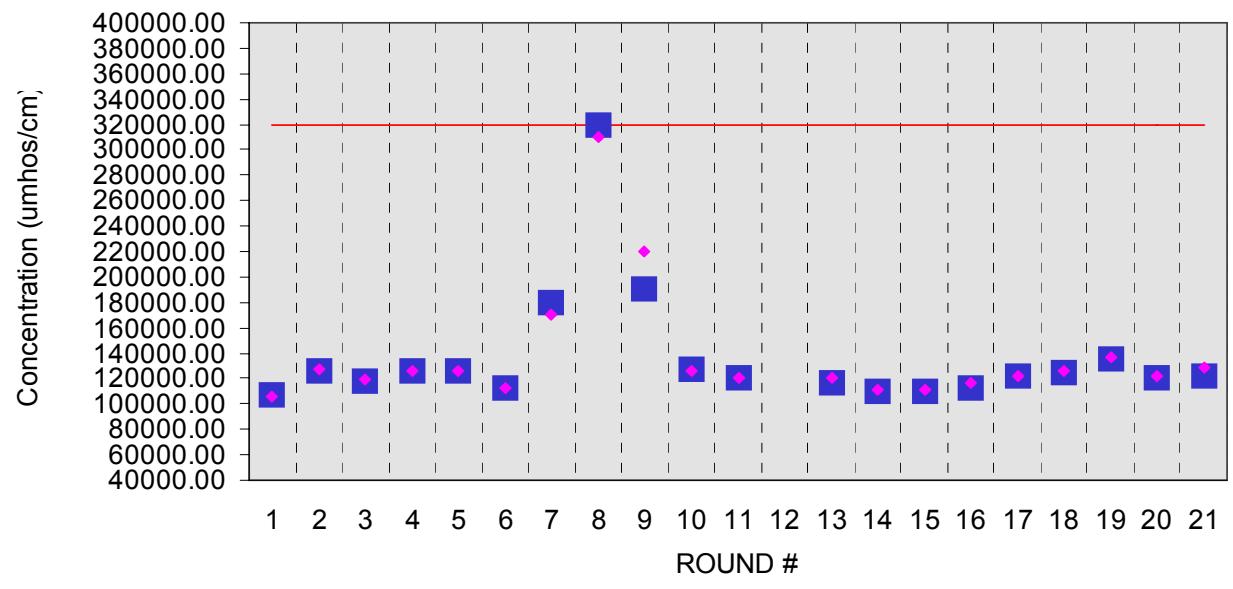

Figure E.51 - Time Trend Plot for Specific Conductance at WQSP-4

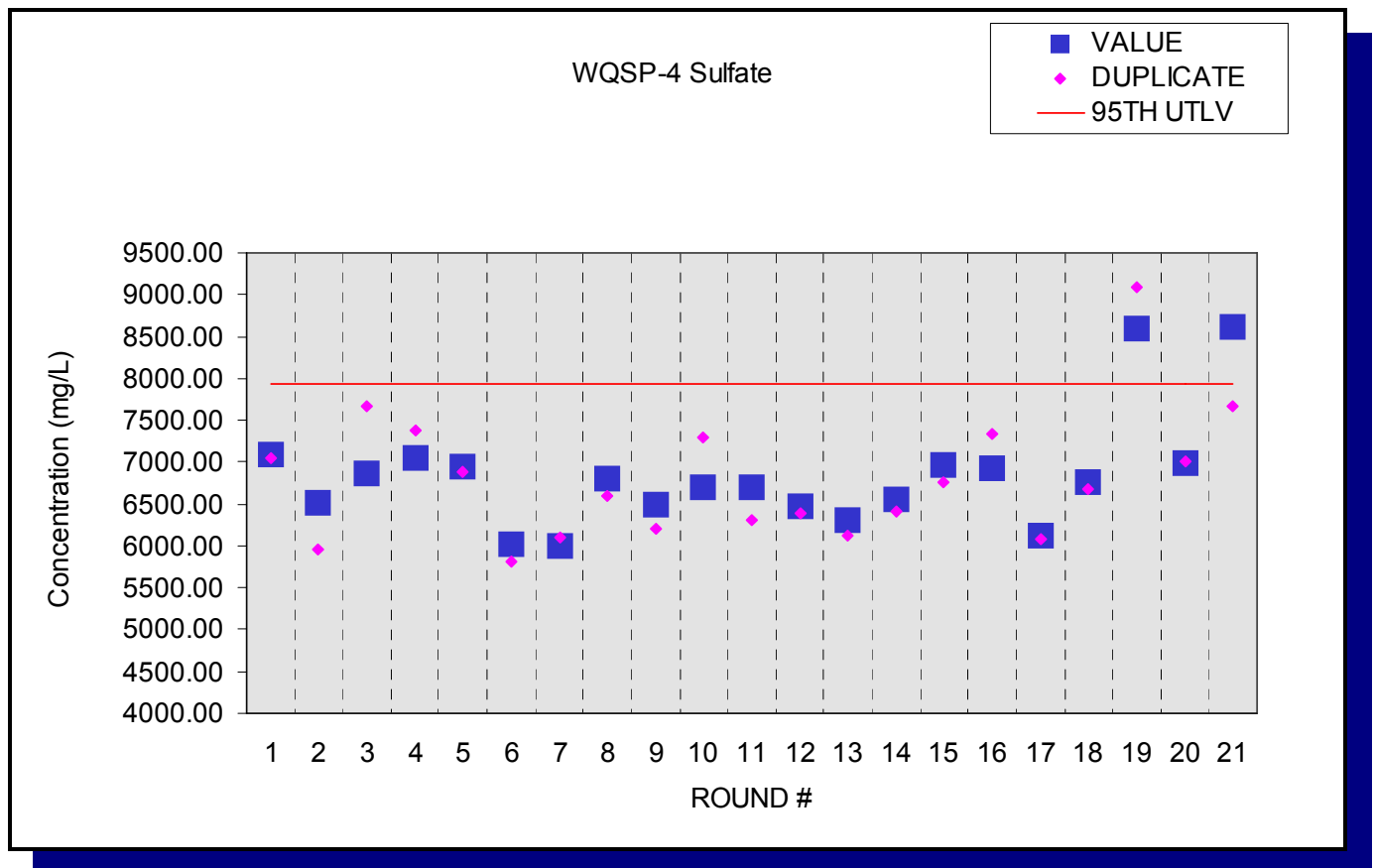

Figure E.52 - Time Trend Plot for Sulfate at WQSP-4 


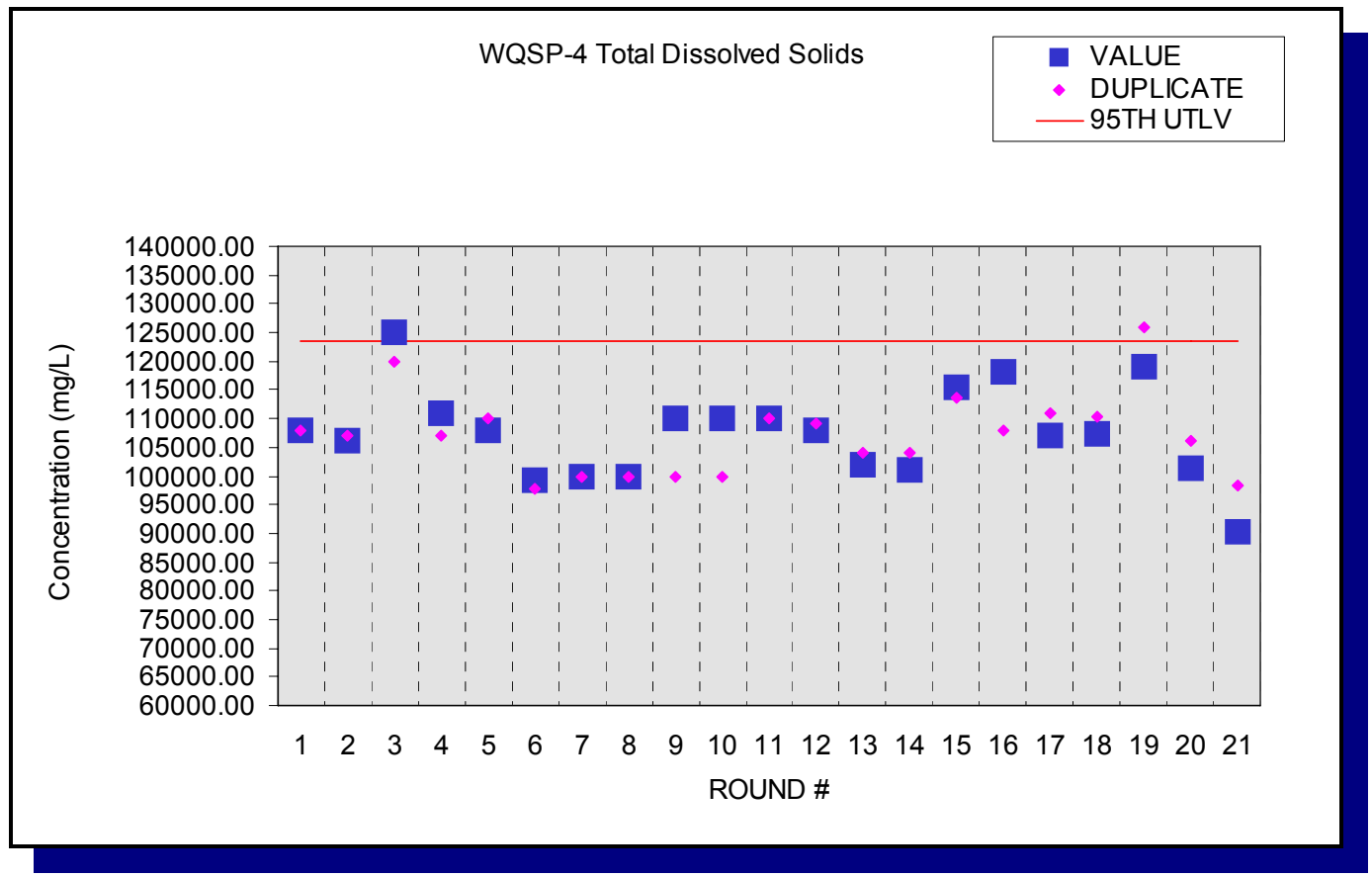

Figure E.53 - Time Trend Plot for Total Dissolved Solids at WQSP-4

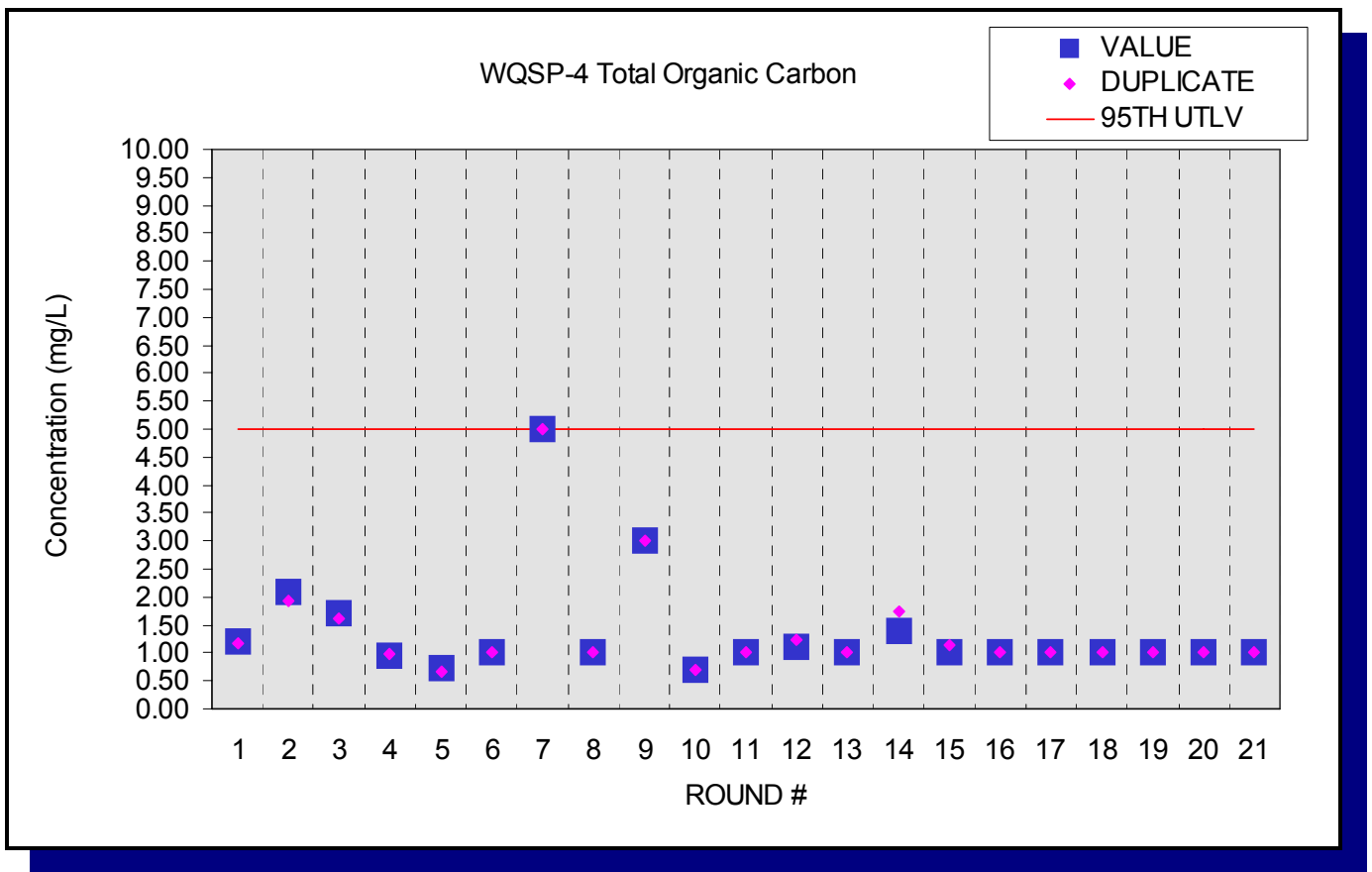

Figure E.54 - Time Trend Plot for Total Organic Carbon at WQSP-4 


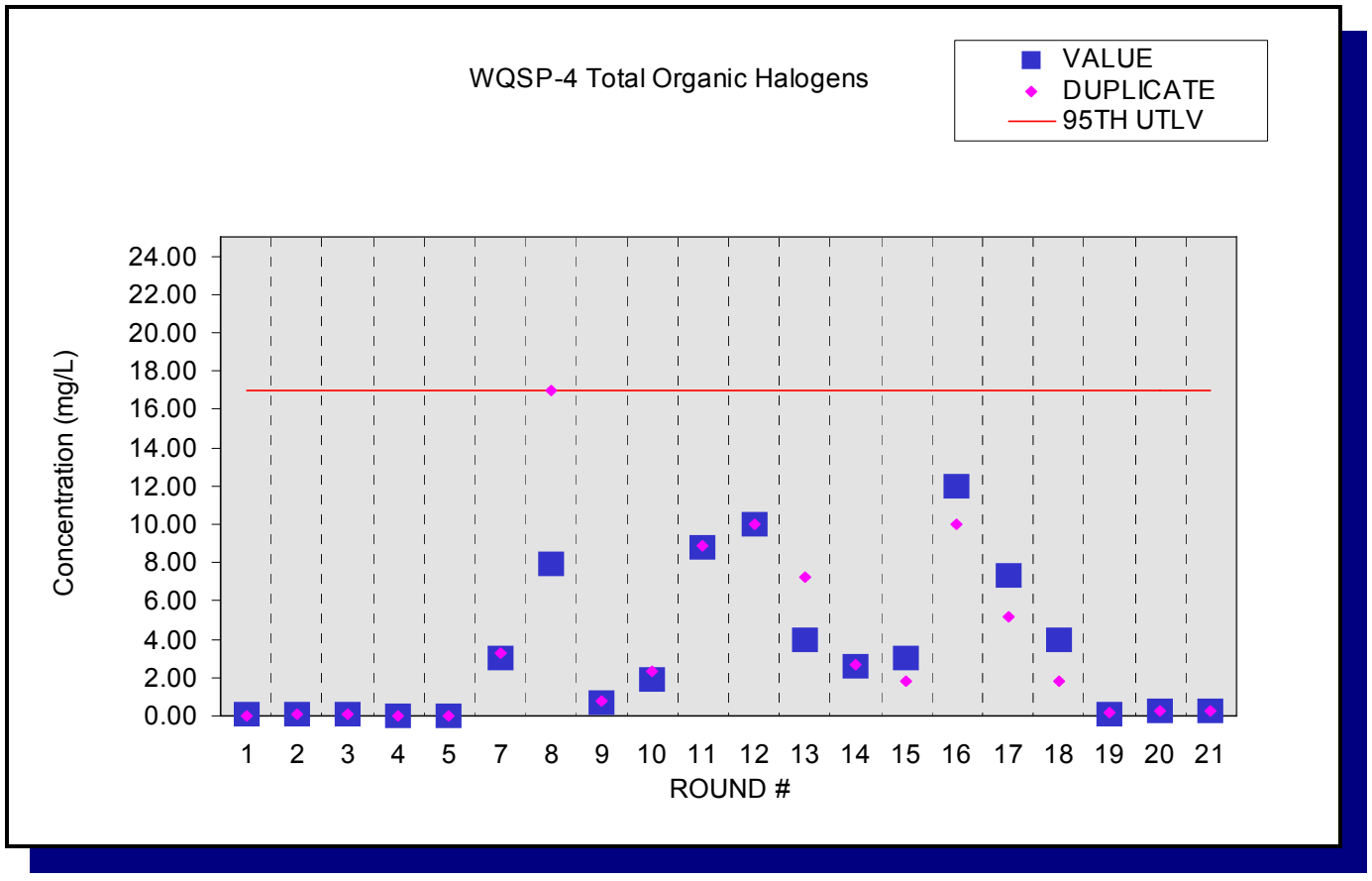

Figure E.55 - Time Trend Plot for Total Organic Halogens at WQSP-4

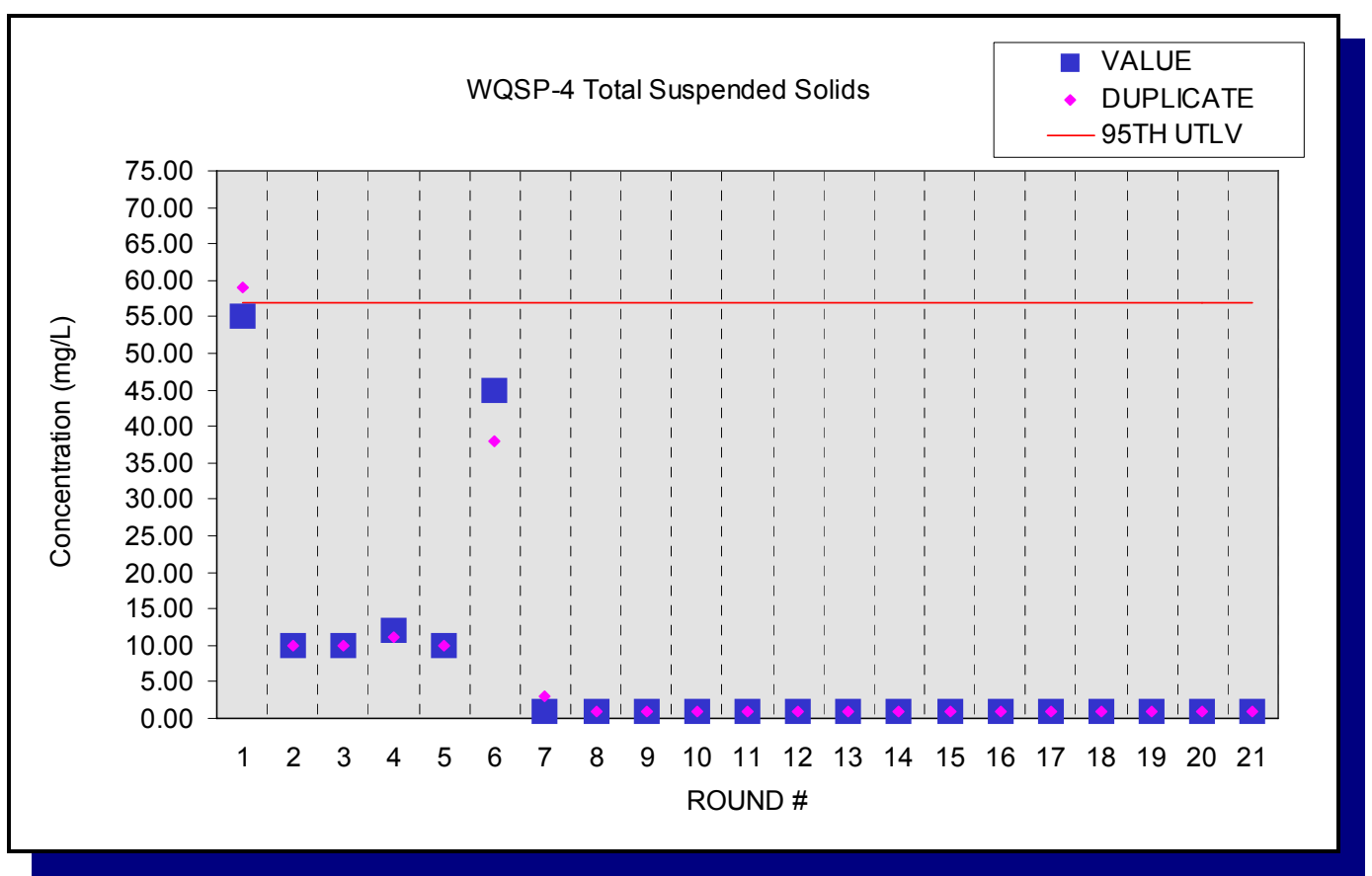

Figure E.56 - Time Trend Plot for Total Suspended Solids at WQSP-4 


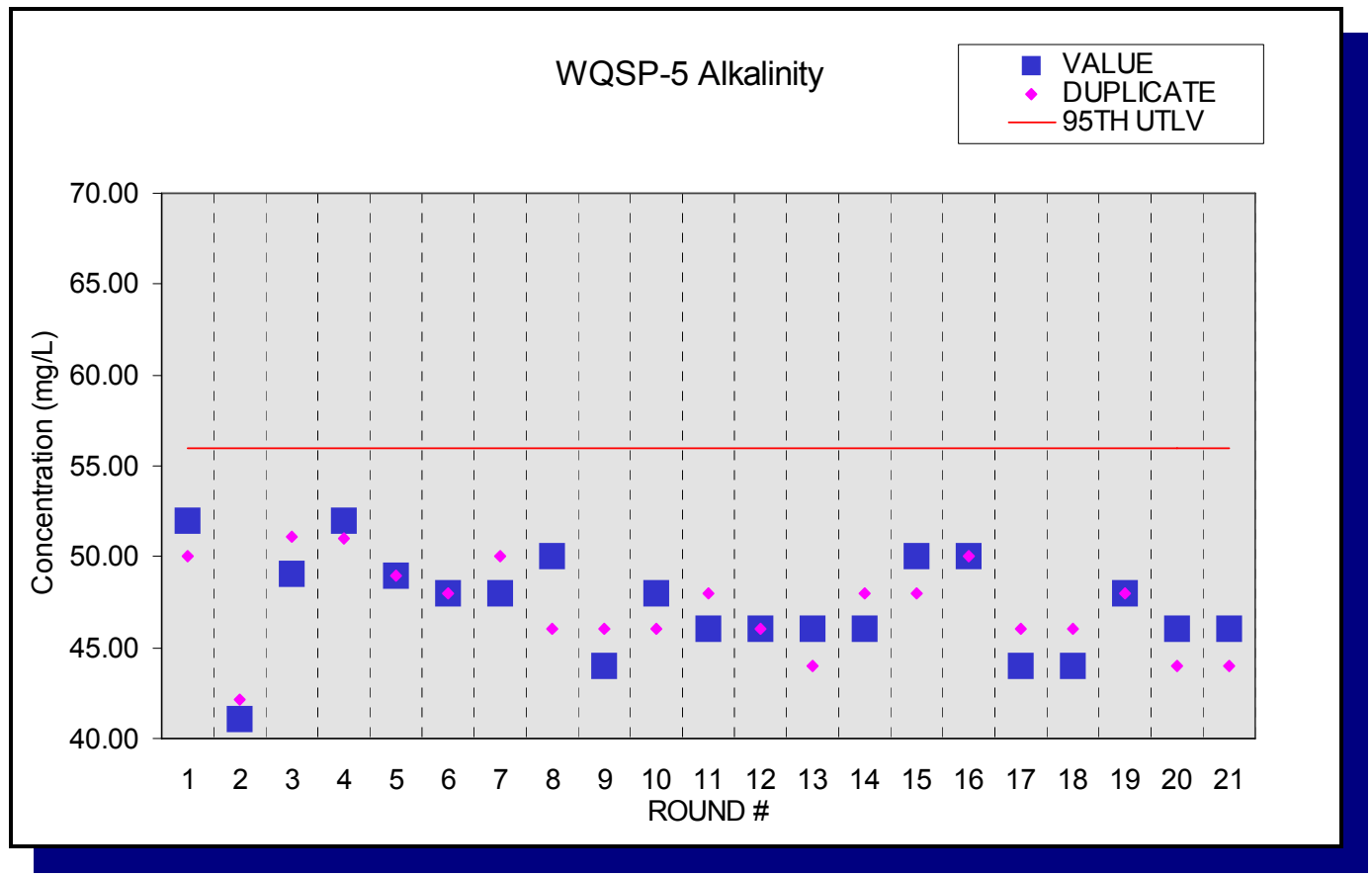

Figure E.57 - Time Trend Plot for Alkalinity at WQSP-5

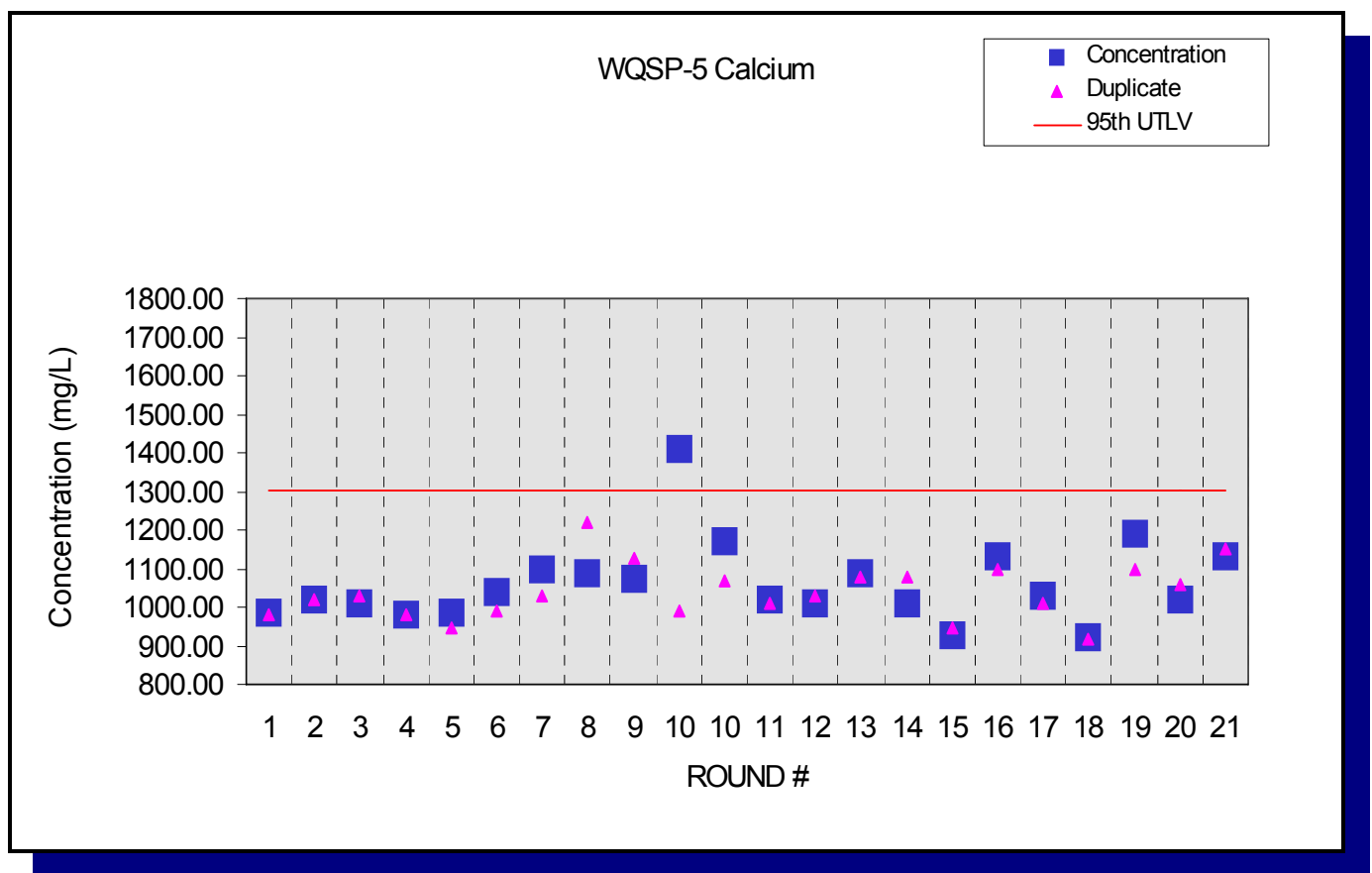

Figure E.58 - Time Trend Plot for Calcium at WQSP-5 


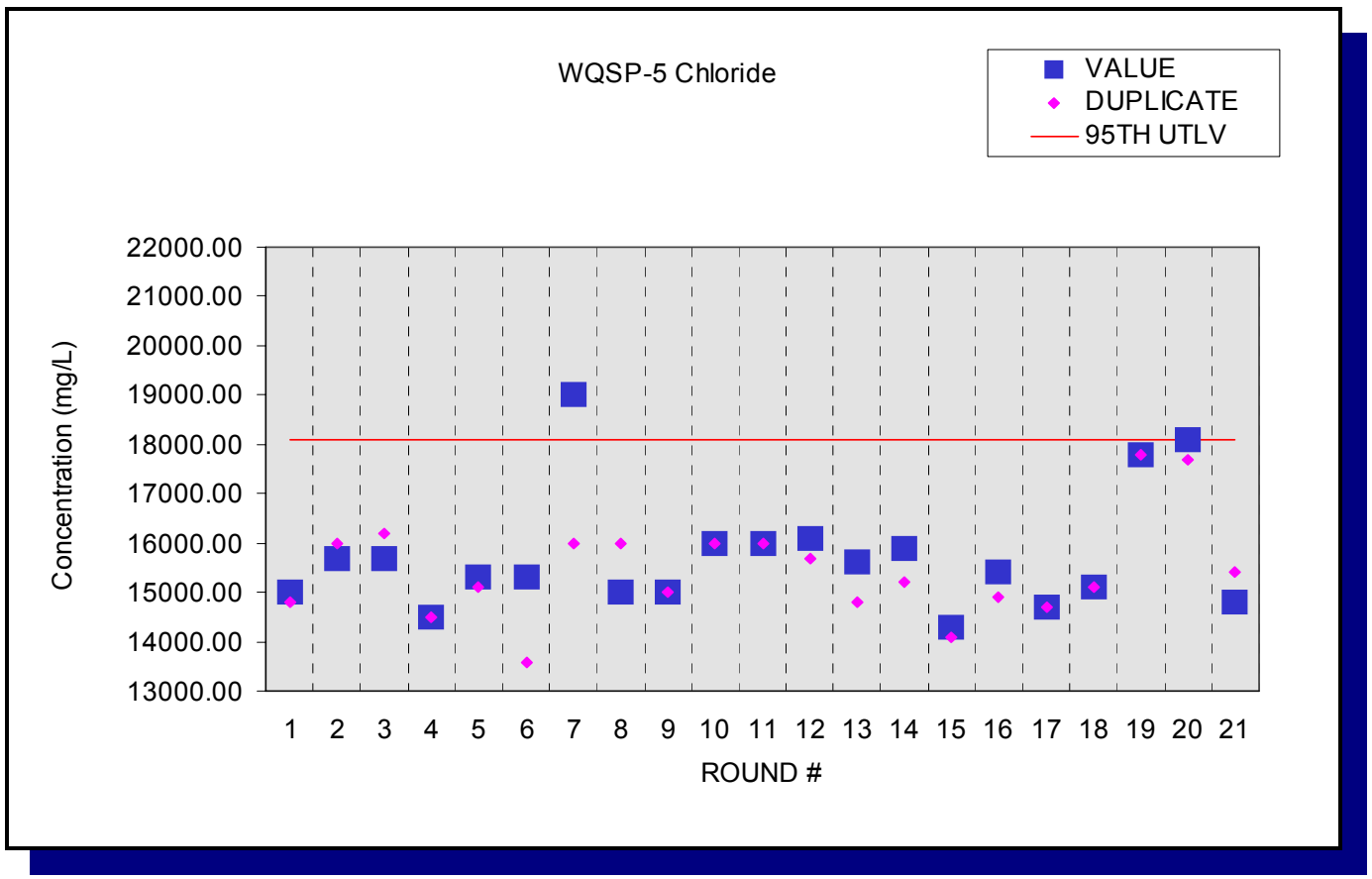

Figure E.59 - Time Trend Plot for Chloride at WQSP-5

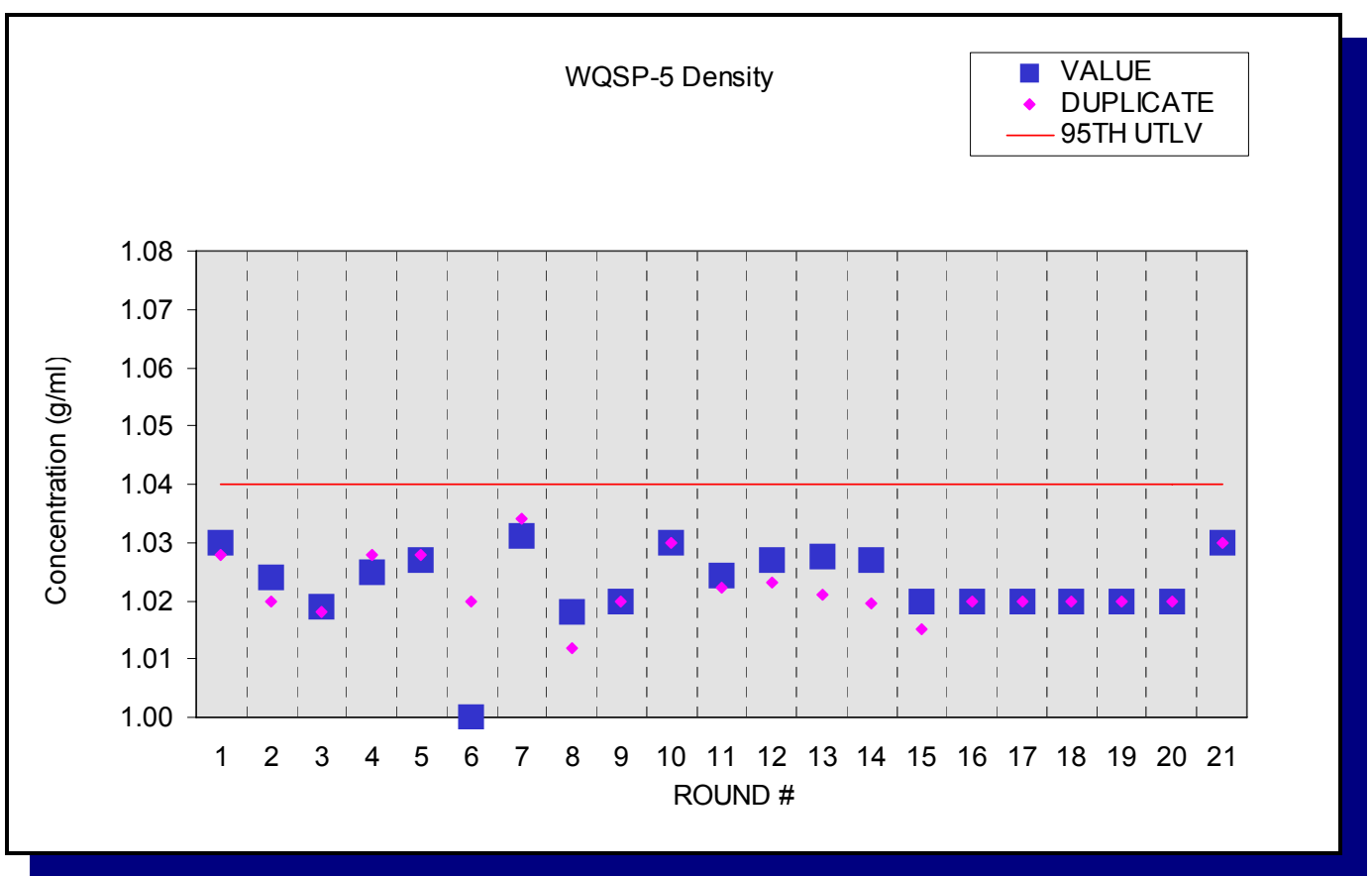

Figure E.60 - Time Trend Plot for Density at WQSP-5 


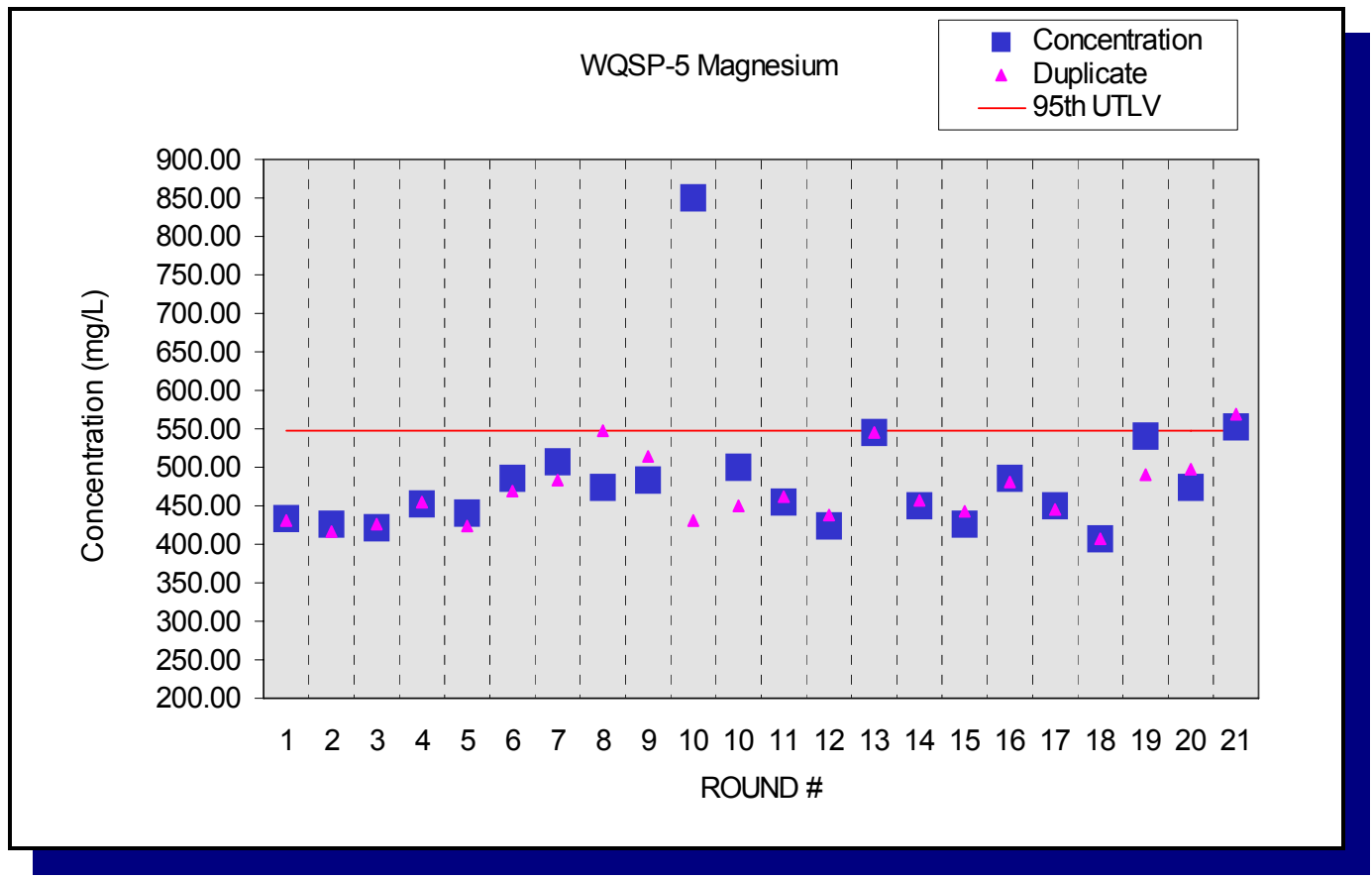

Figure E.61 - Time Trend Plot for Magnesium at WQSP-5

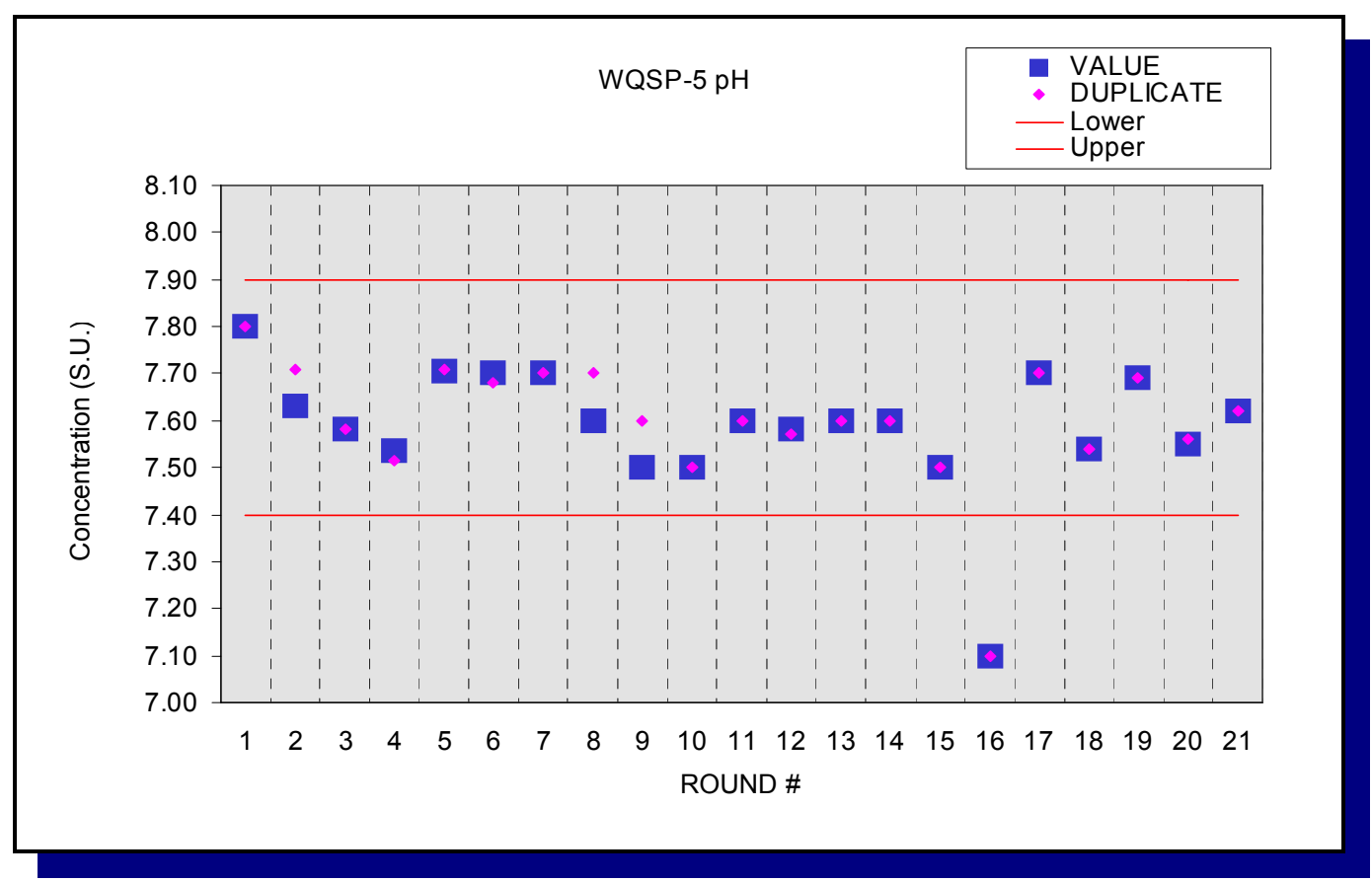

Figure E.62 - Time Trend Plot for pH at WQSP-5 


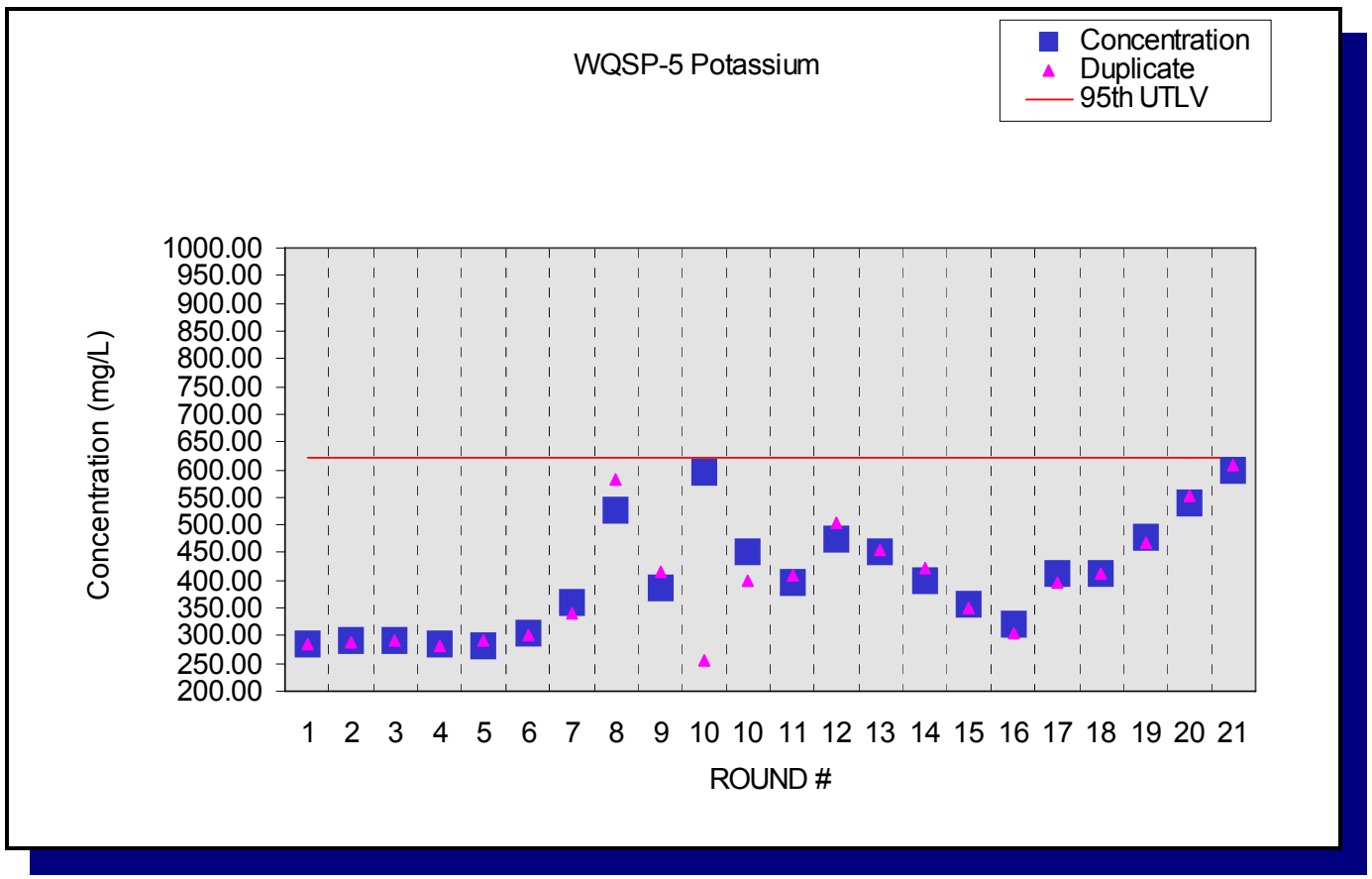

Figure E.63 - Time Trend Plot for Potassium at WQSP-5

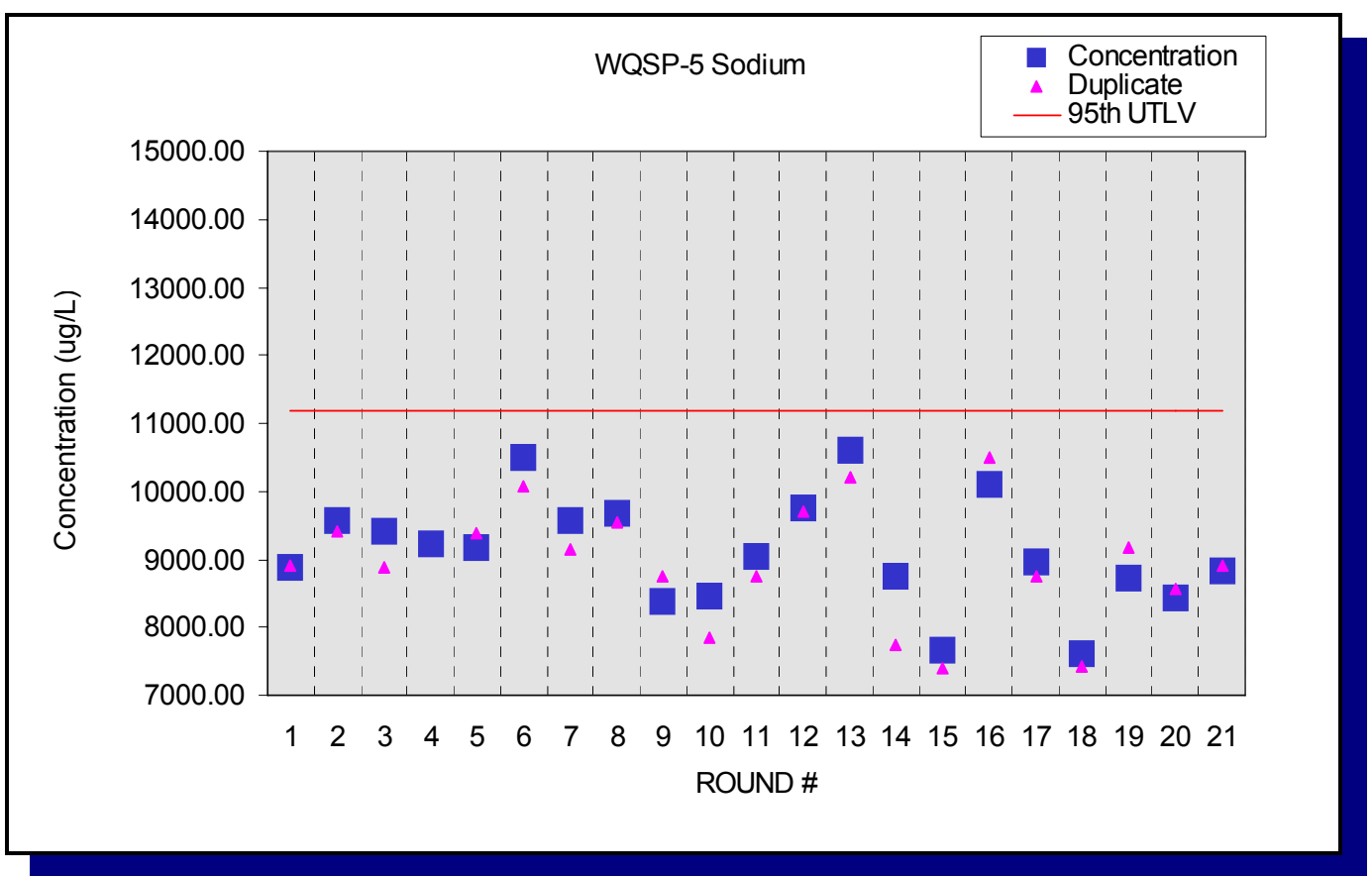

Figure E.64 - Time Trend Plot for Sodium at WQSP-5 


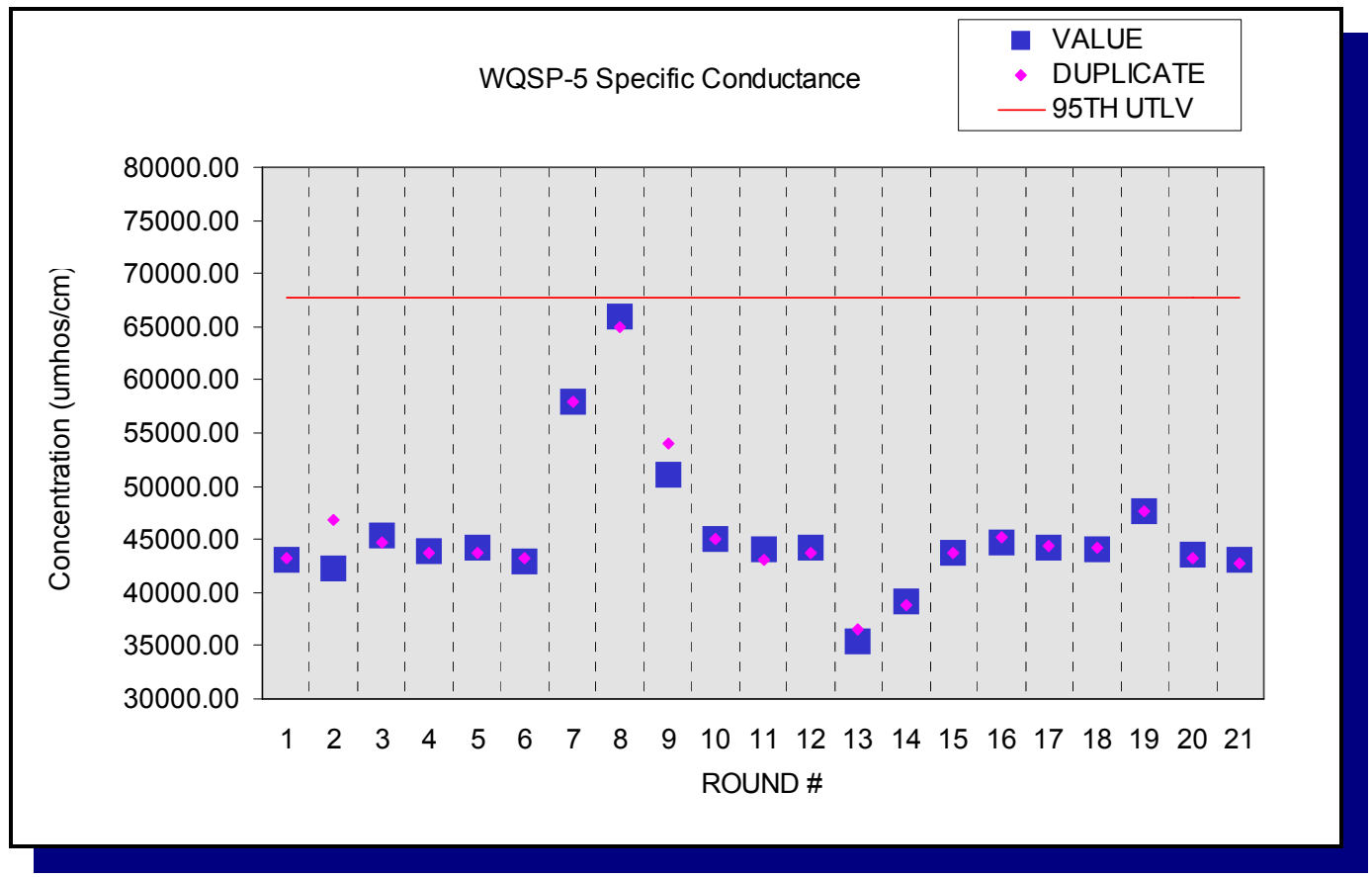

Figure E.65 - Time Trend Plot for Specific Conductance at WQSP-5

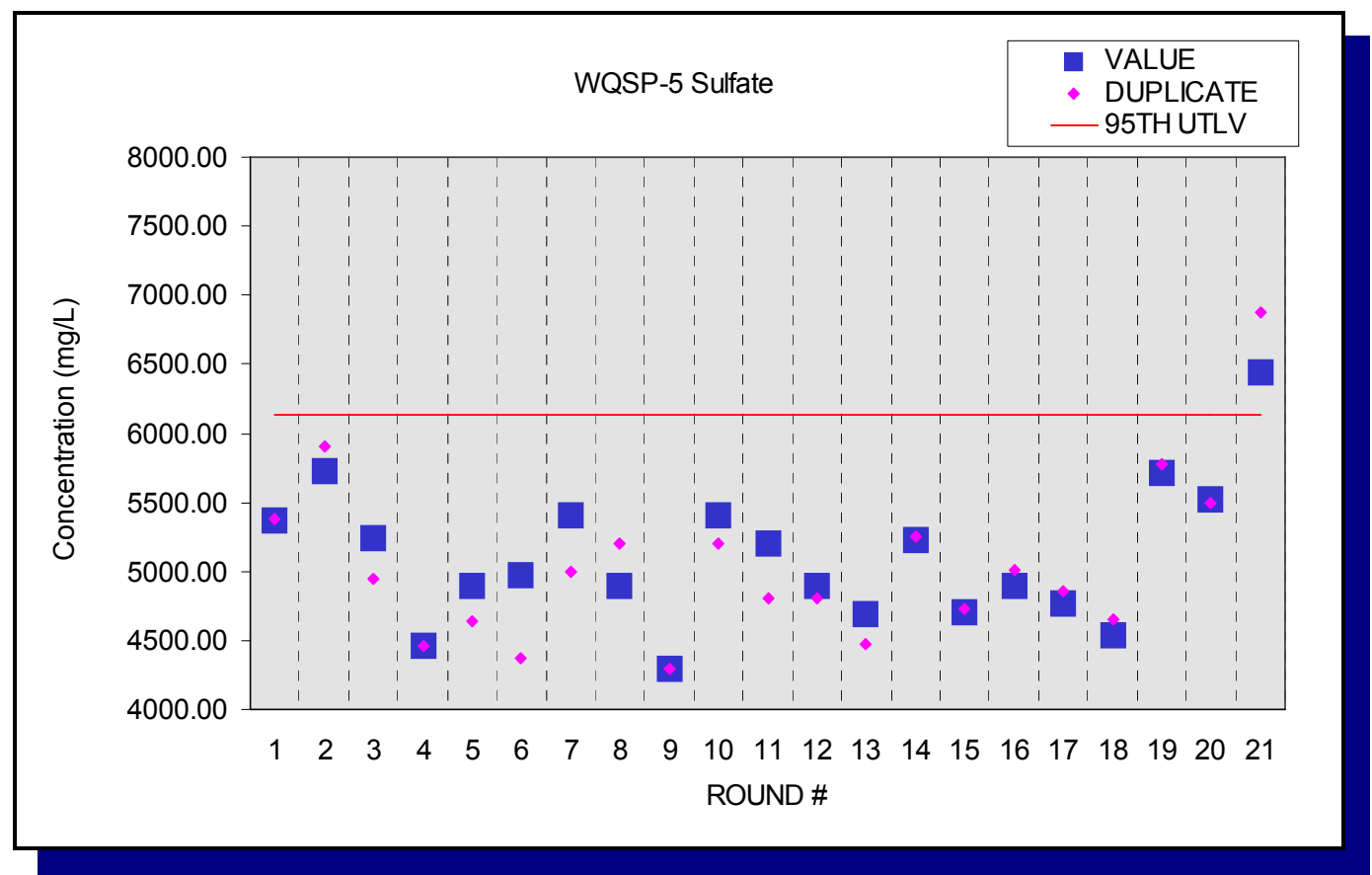

Figure E.66 - Time Trend Plot for Sulfate at WQSP-5 


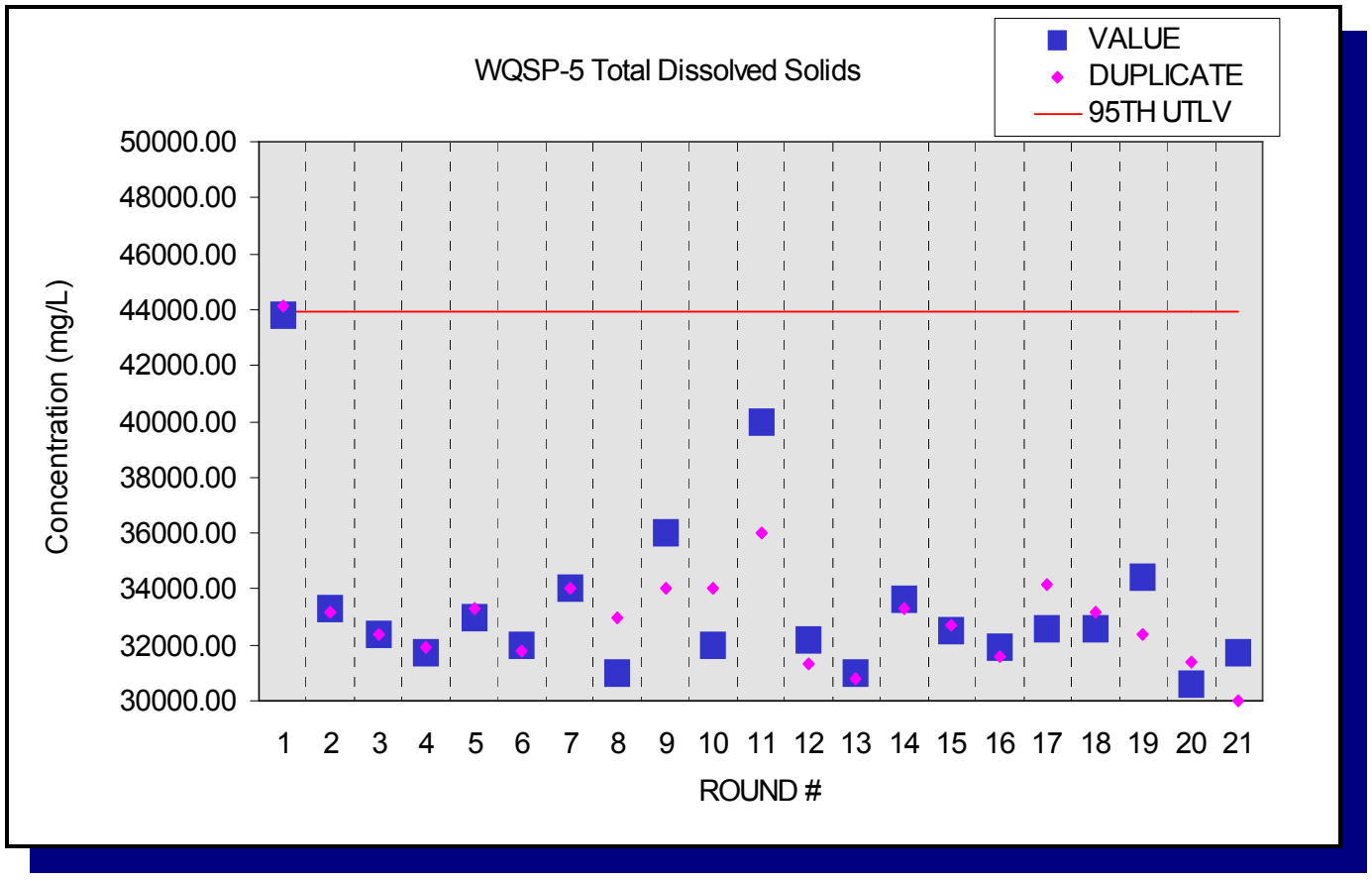

Figure E.67 - Time Trend Plot for Total Dissolved Solids at WQSP-5

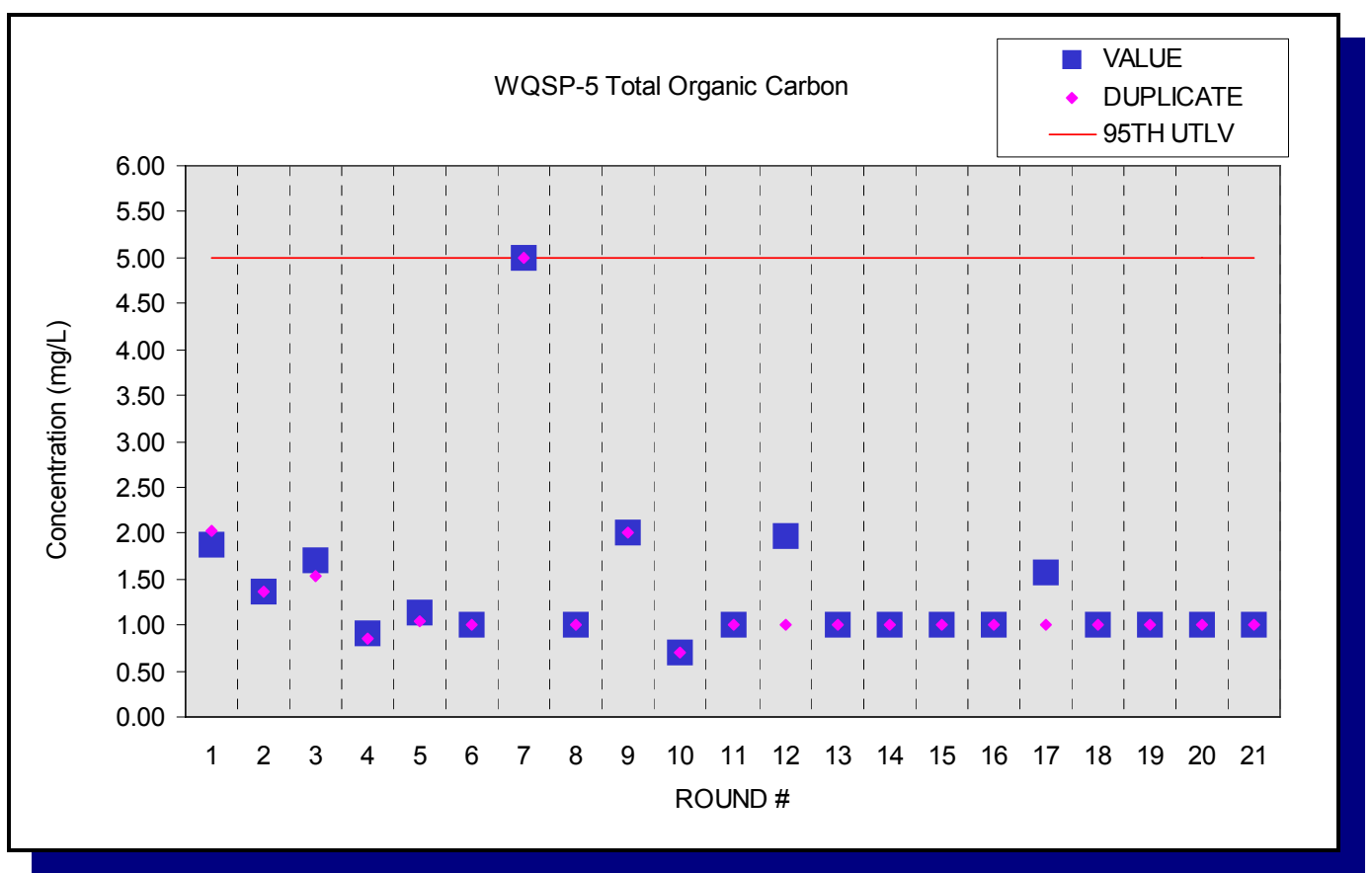

Figure E.68 - Time Trend Plot for Total Organic Carbon at WQSP-5 


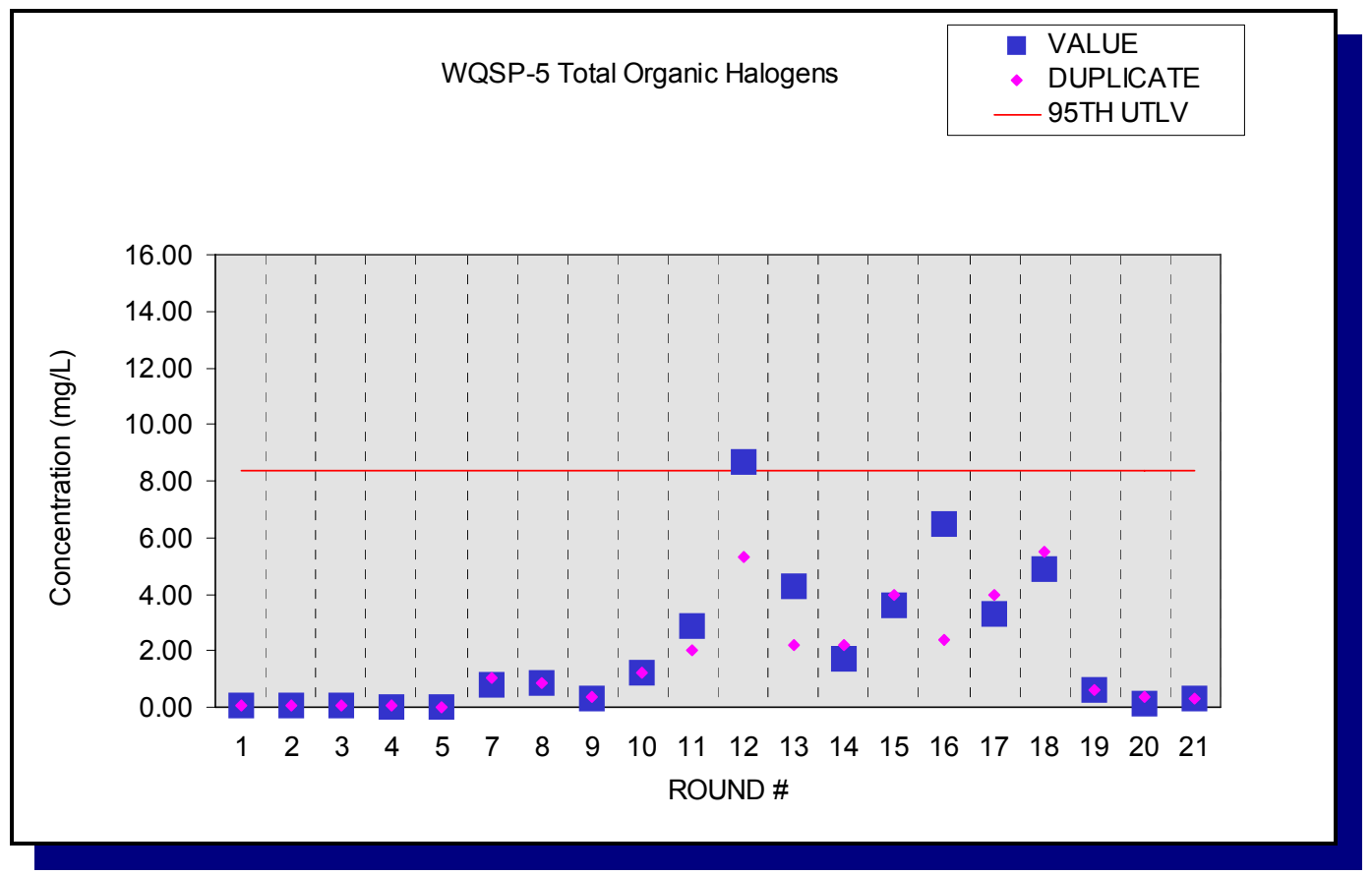

Figure E.69 - Time Trend Plot for Total Organic Halogens at WQSP-5

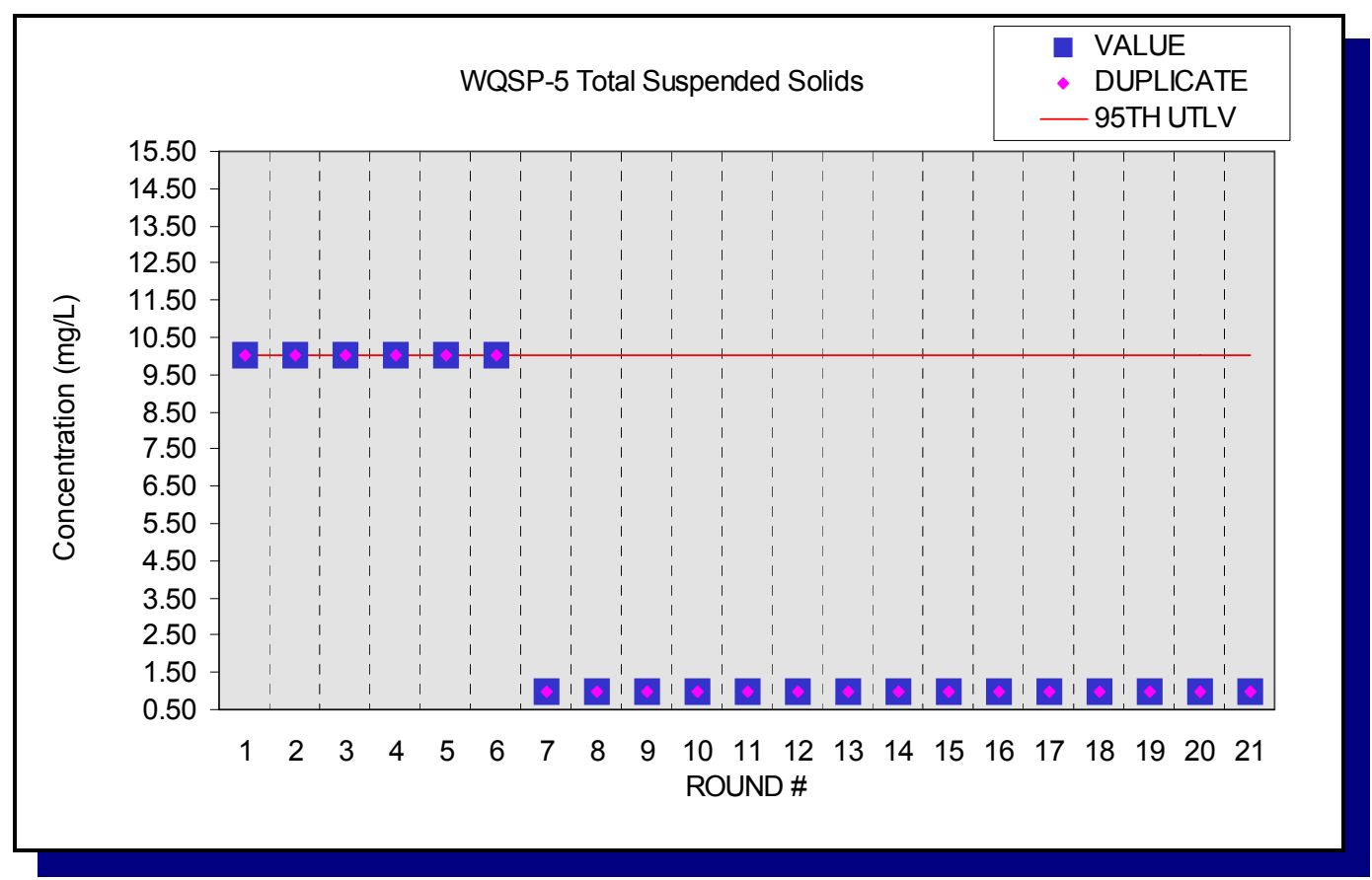

Figure E.70 - Time Trend Plot for Total Suspended Solids at WQSP-5 


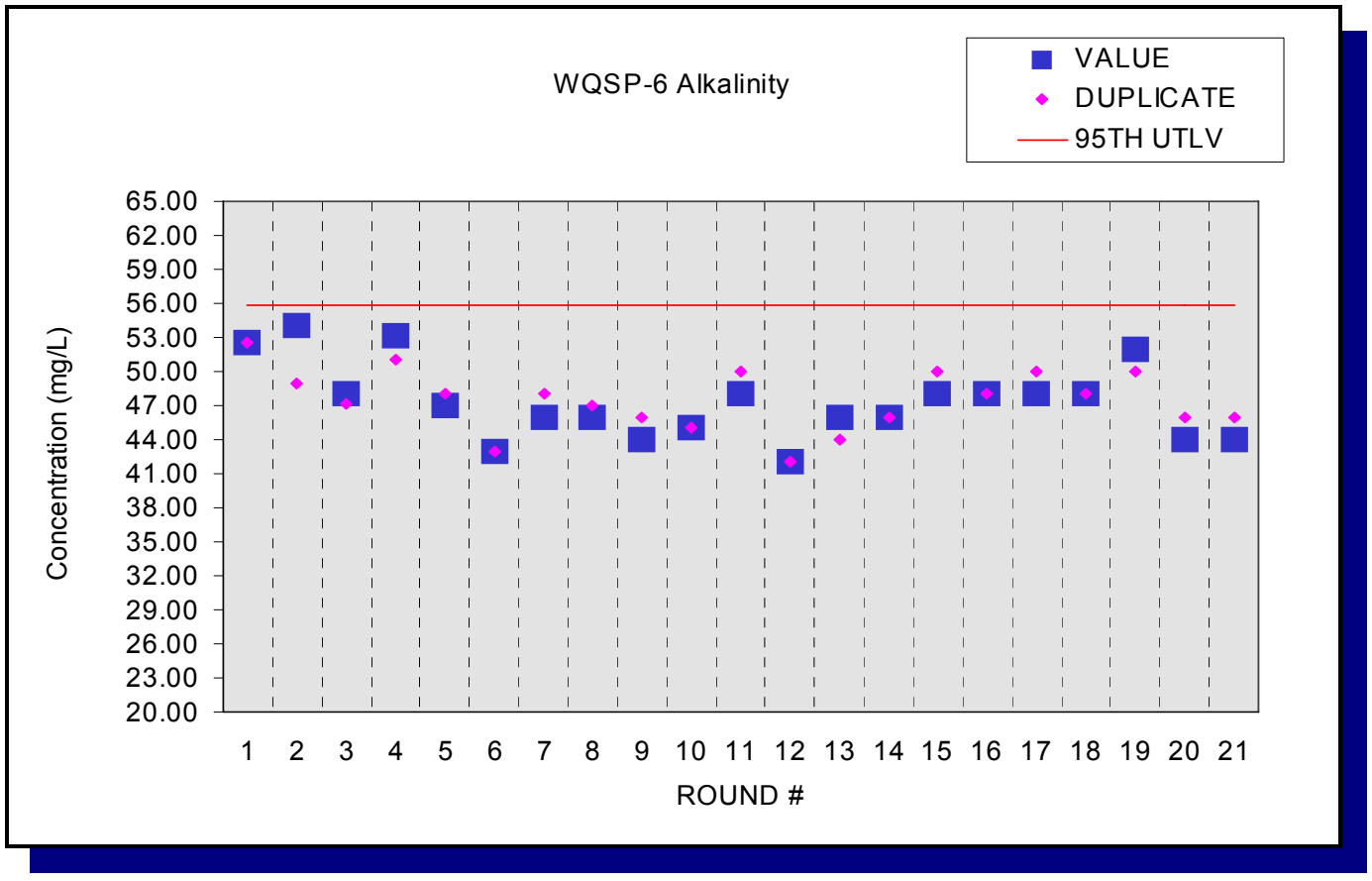

Figure E.71 - Time Trend Plot for Alkalinity at WQSP-6

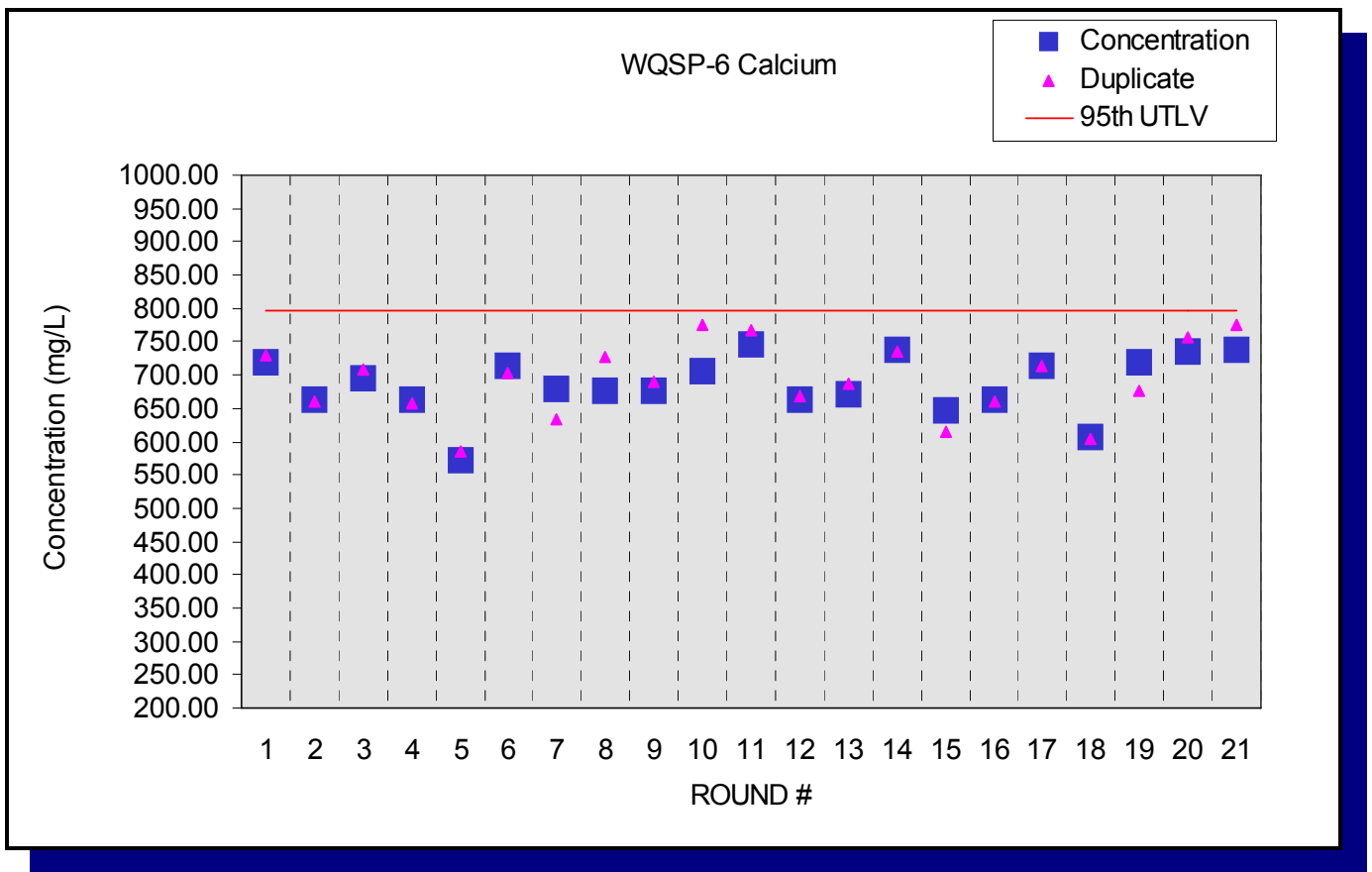

Figure E.72 - Time Trend Plot for Calcium at WQSP-6 


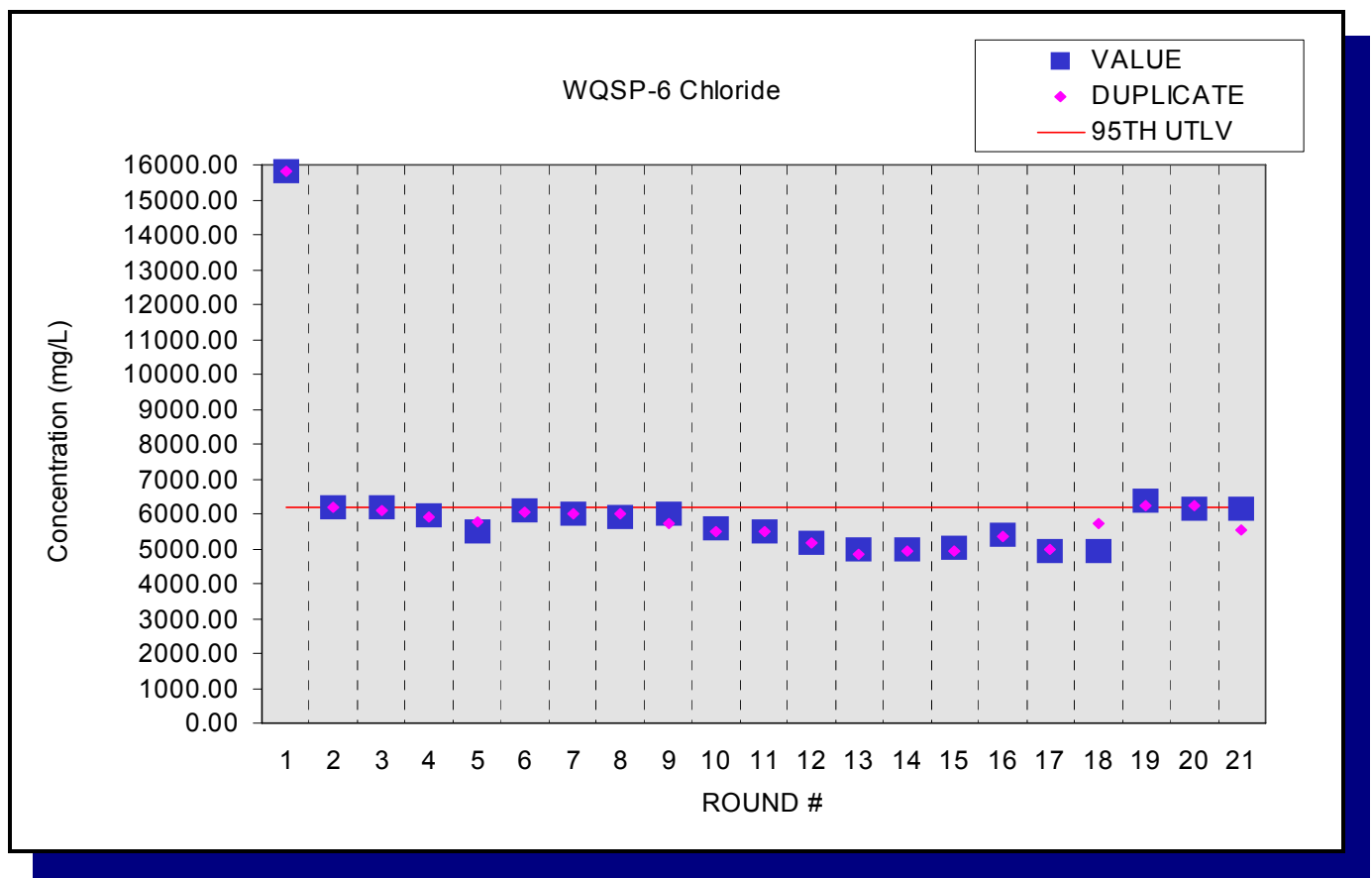

Figure E.73 - Time Trend Plot for Chloride at WQSP-6

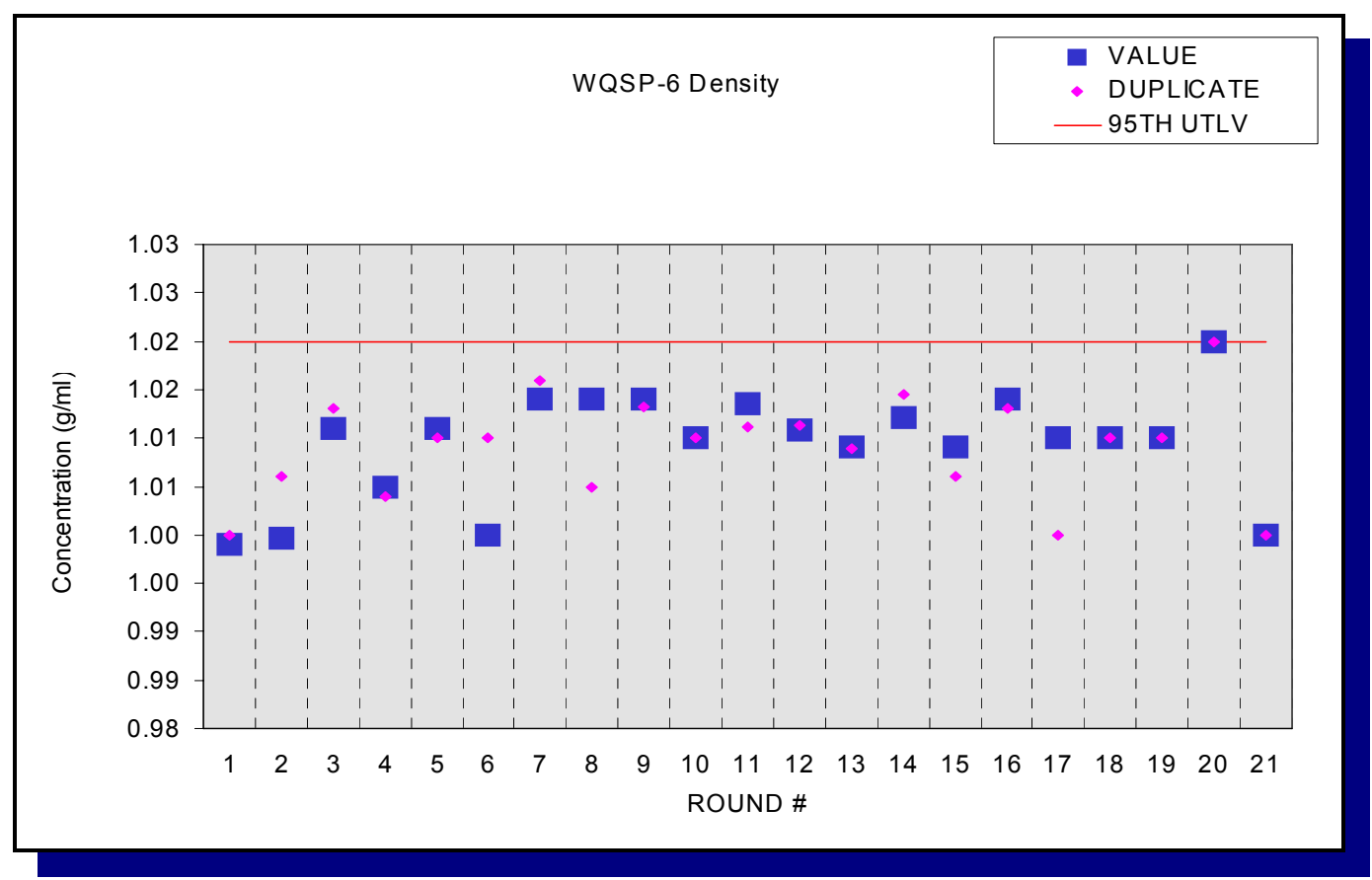

Figure E.74 - Time Trend Plot for Density at WQSP-6 


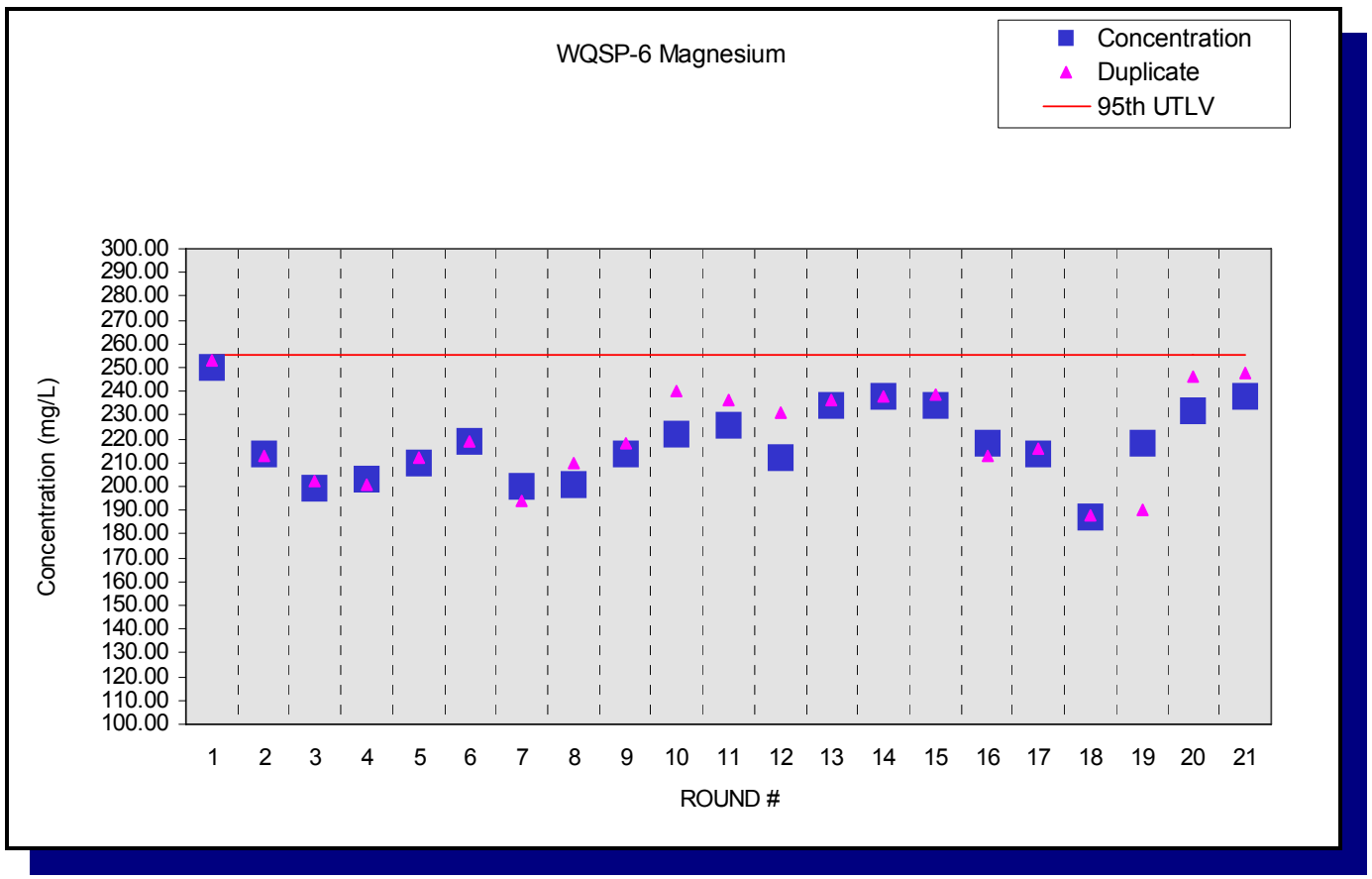

Figure E.75 - Time Trend Plot for Magnesium at WQSP-6

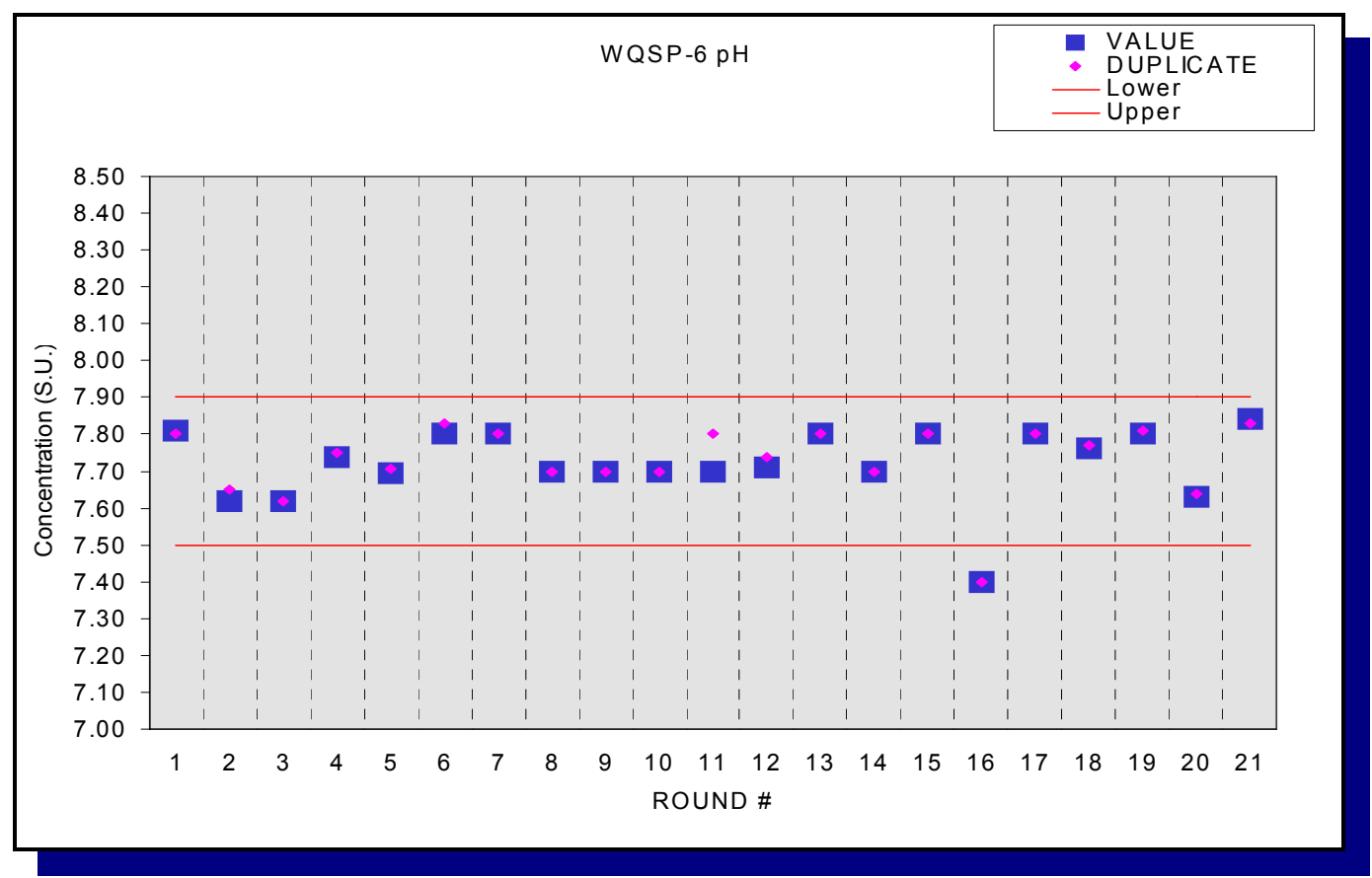

Figure E.76 - Time Trend Plot for pH at WQSP-6 


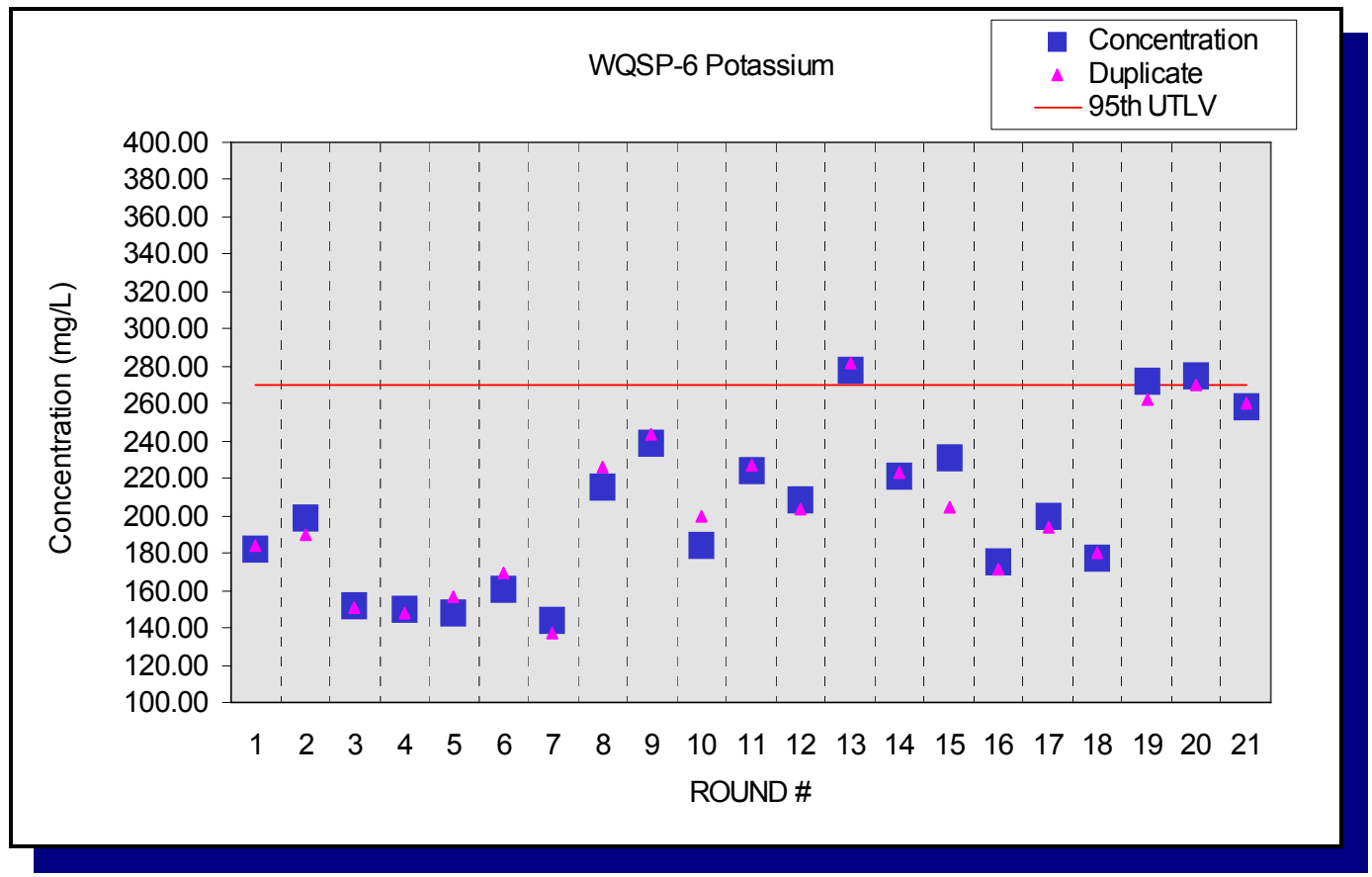

Figure E.77 - Time Trend Plot for Potassium at WQSP-6

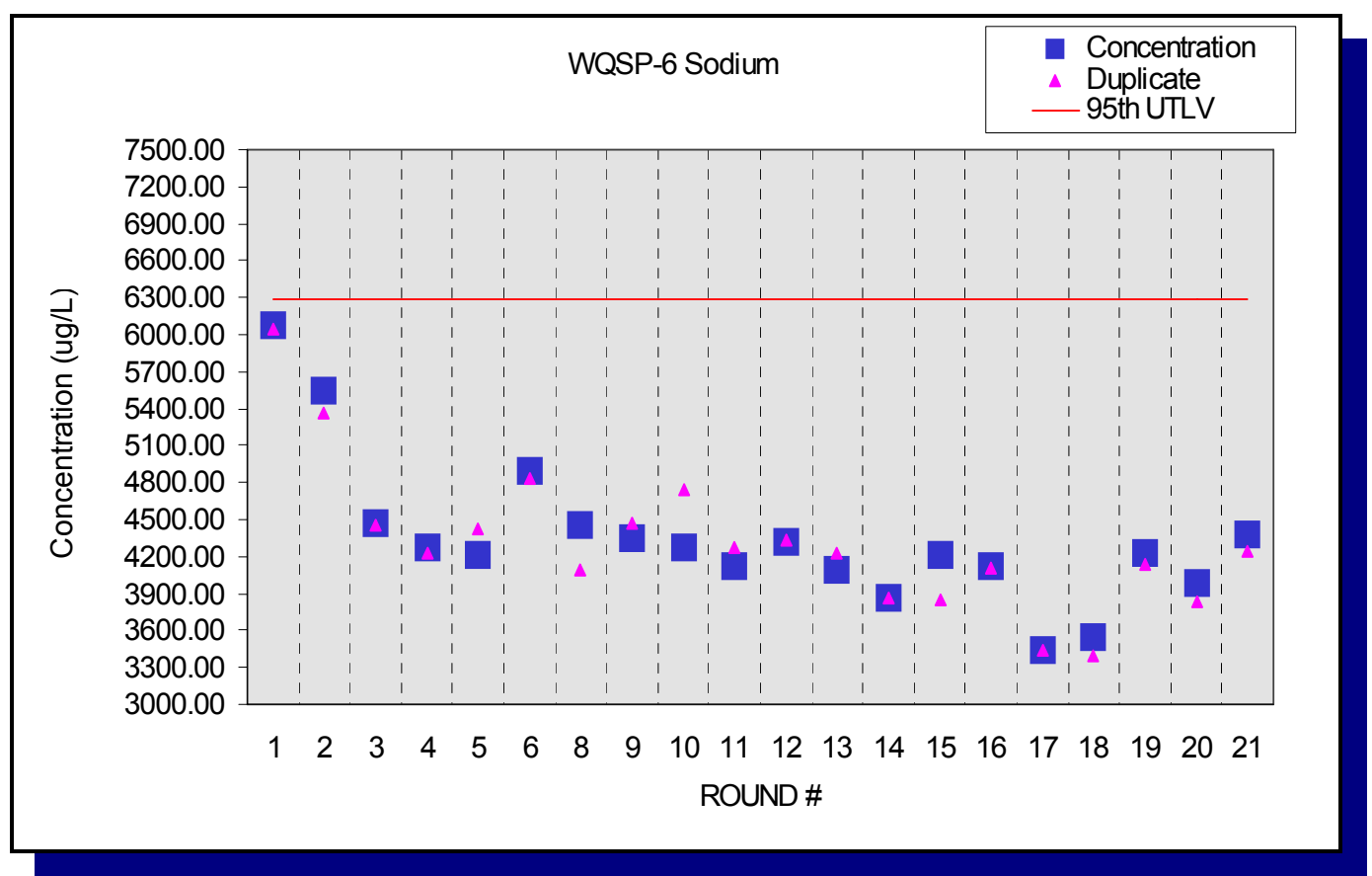

Figure E.78 - Time Trend Plot for Sodium at WQSP-6 


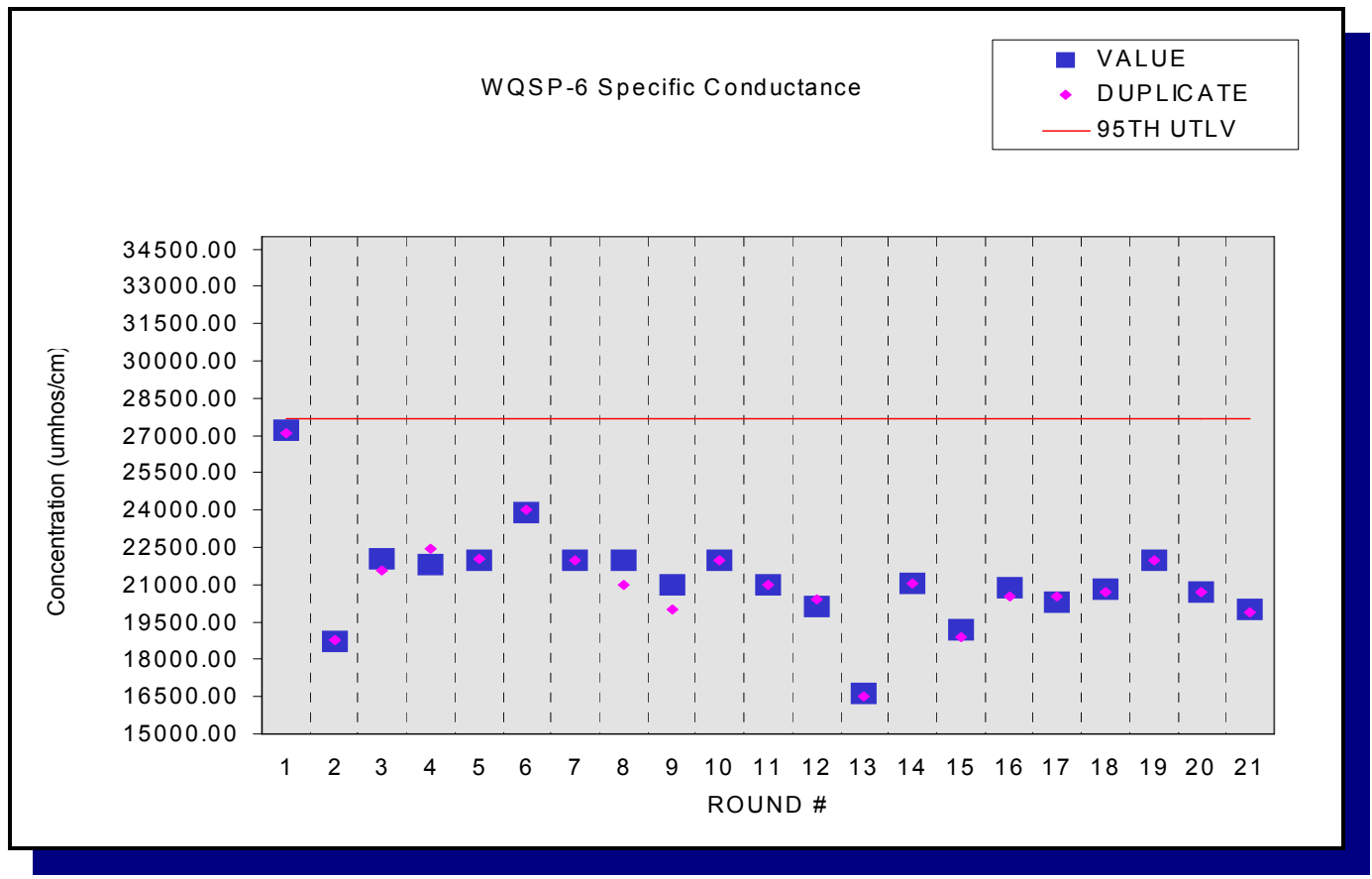

Figure E.79 - Time Trend Plot for Specific Conductance at WQSP-6

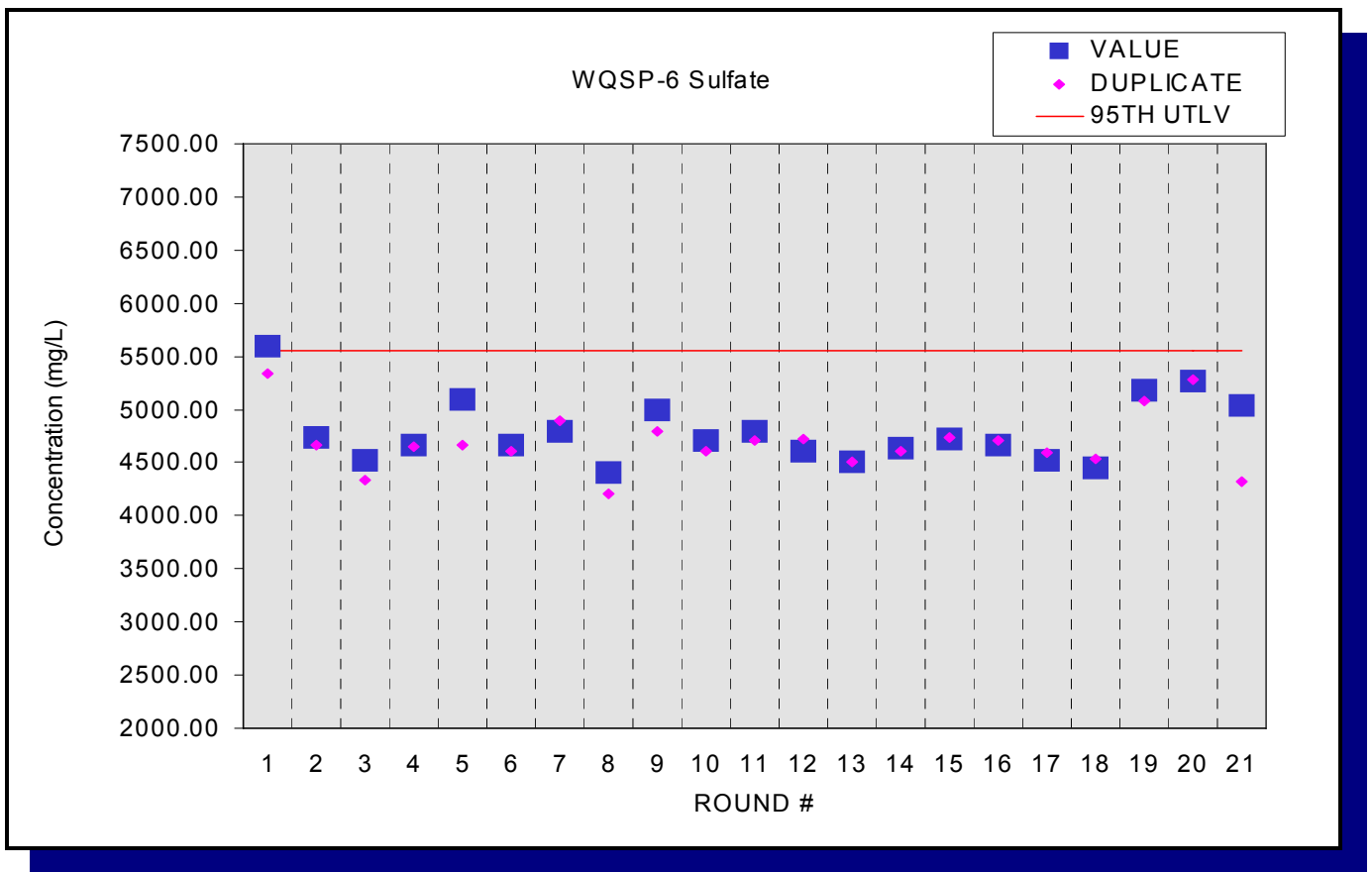

Figure E.80 - Time Trend Plot for Sulfate at WQSP-6 


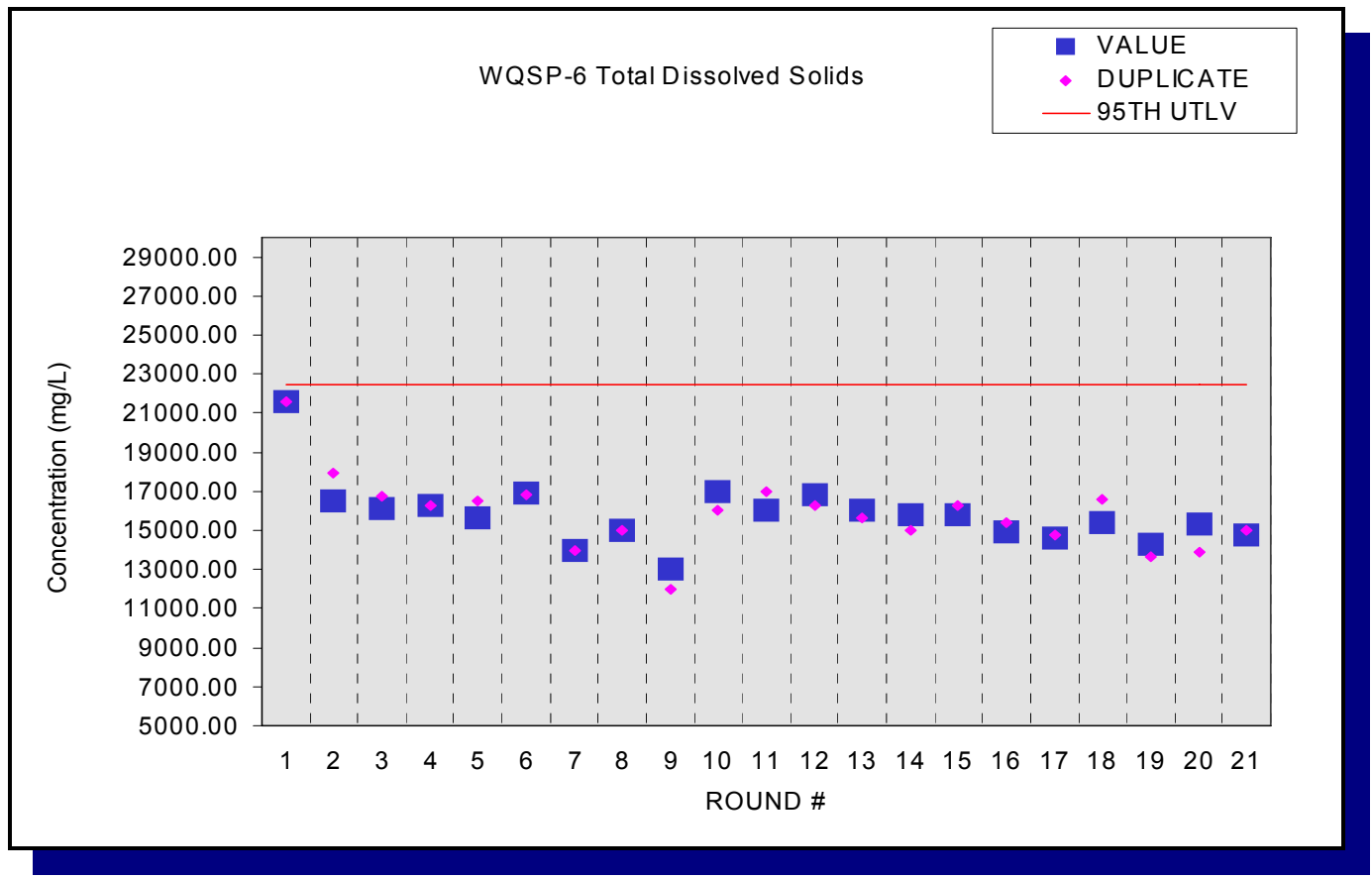

Figure E.81 - Time Trend Plot for Total Dissolved Solids at WQSP-6

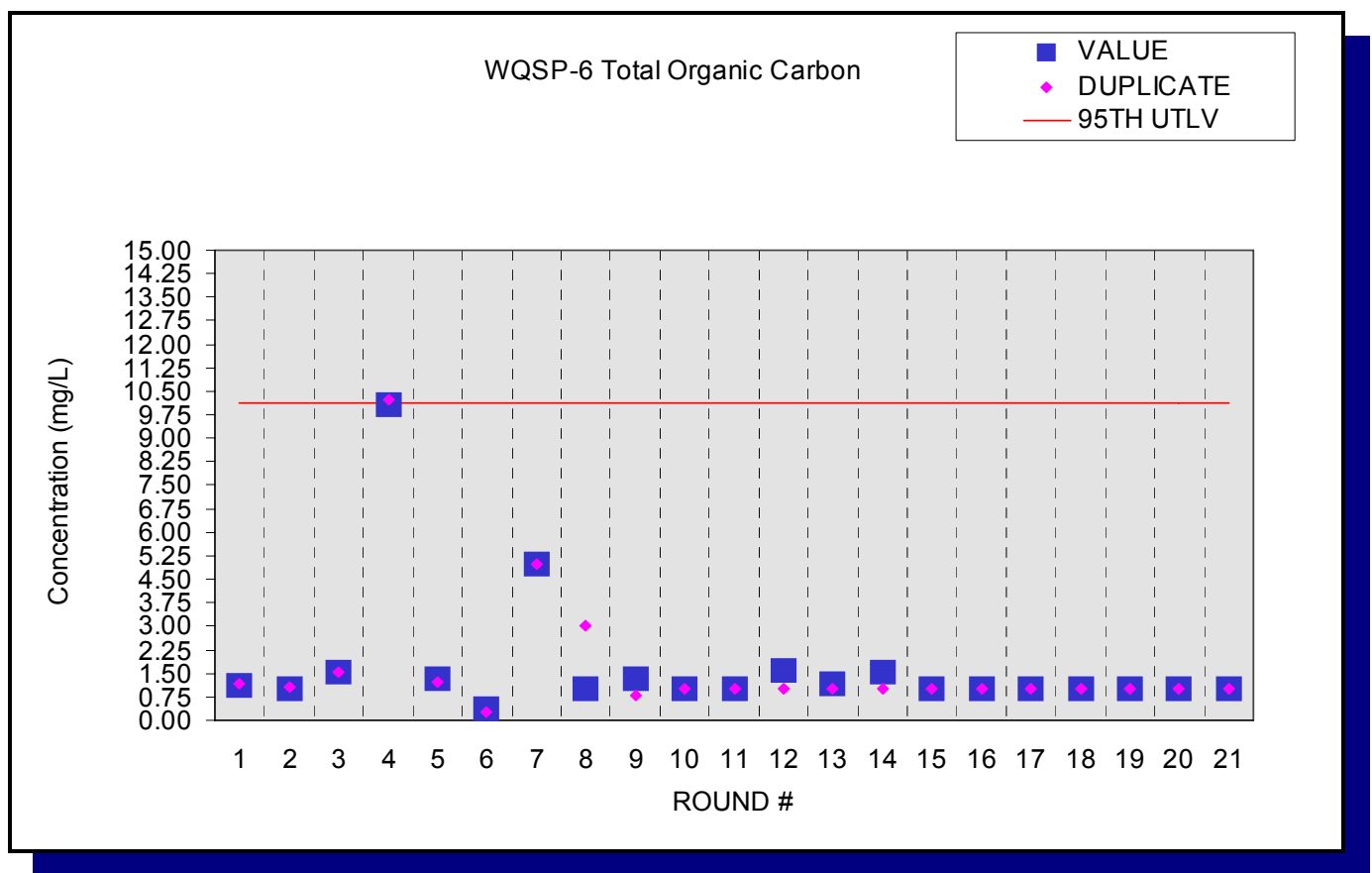

Figure E.82 - Time Trend Plot for Total Organic Carbon at WQSP-6 


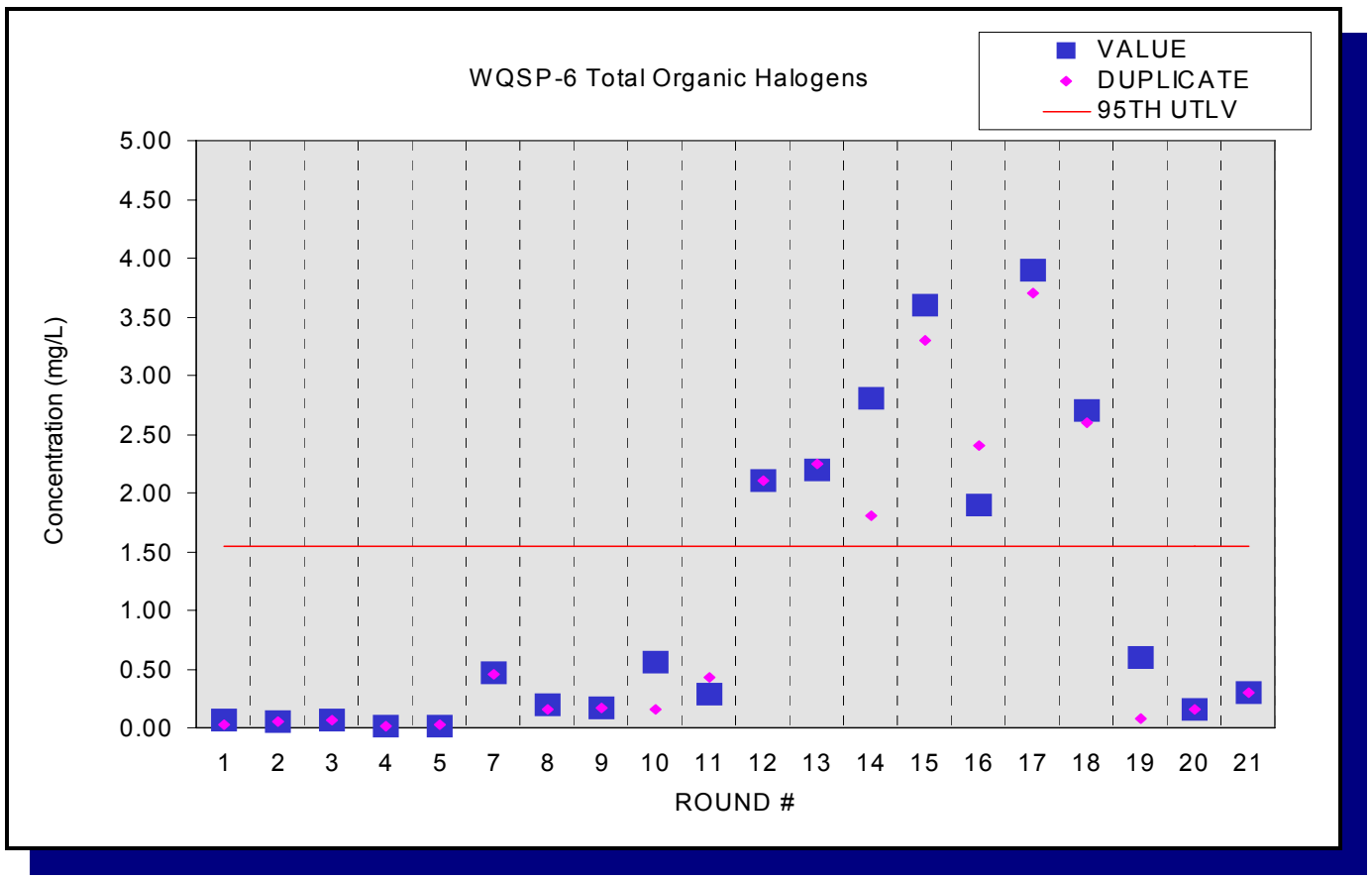

Figure E.83 - Time Trend Plot for Total Organic Halogens at WQSP-6

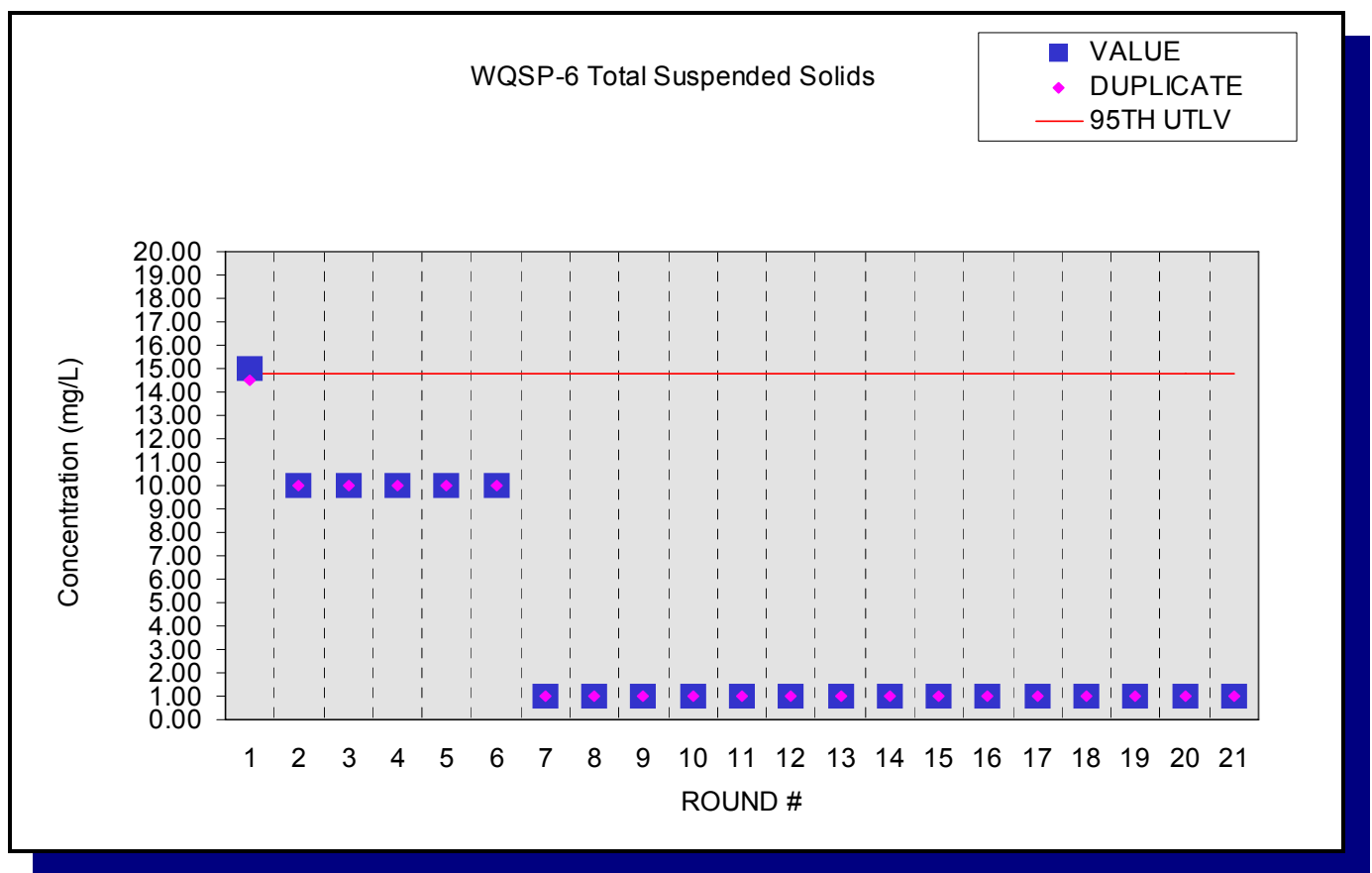

Figure E.84 - Time Trend Plot for Total Suspended Solids at WQSP-6 


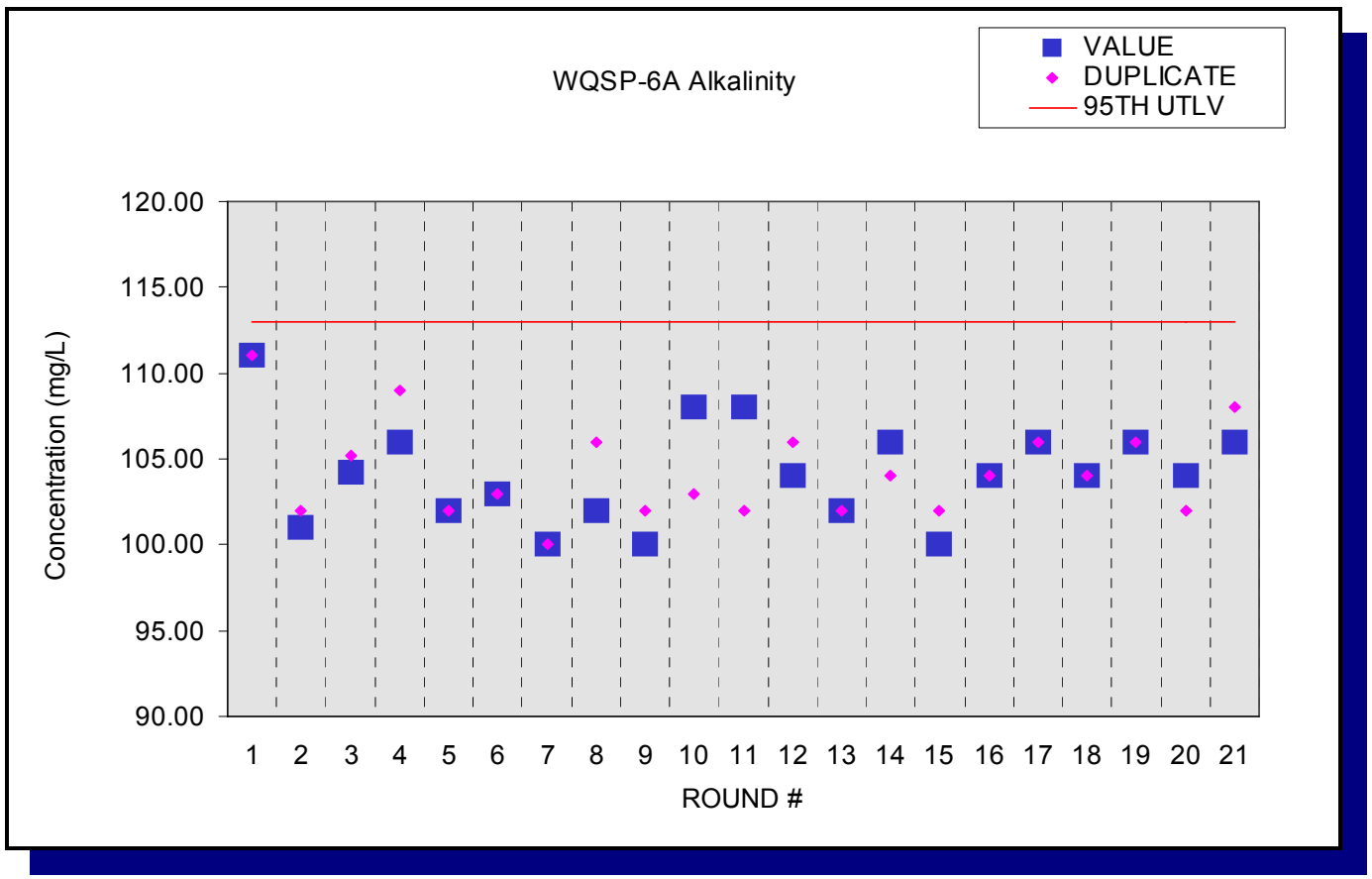

Figure E.85 - Time Trend Plot for Alkalinity at WQSP-6A

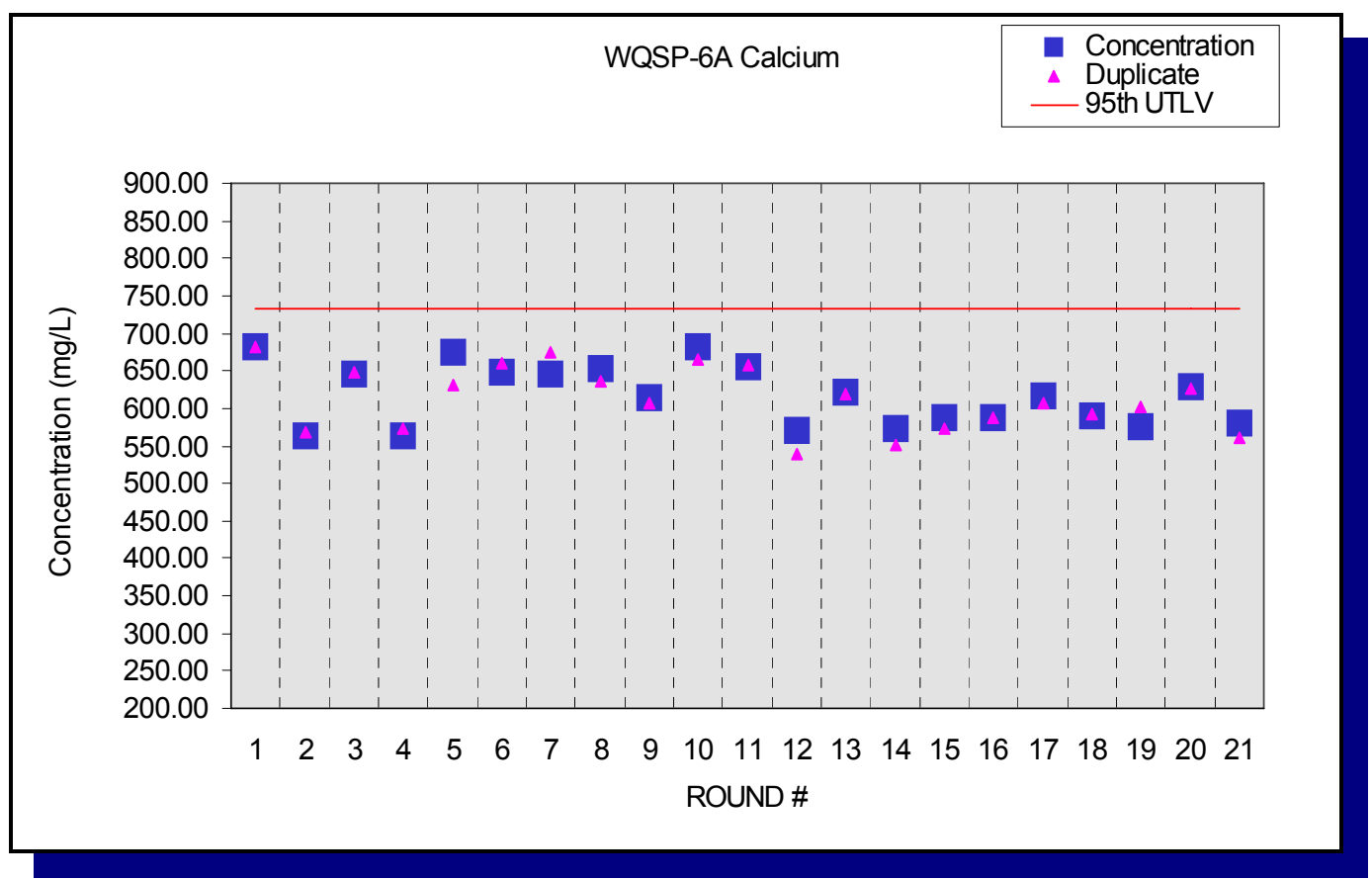

Figure E.86 - Time Trend Plot for Calcium at WQSP-6A 


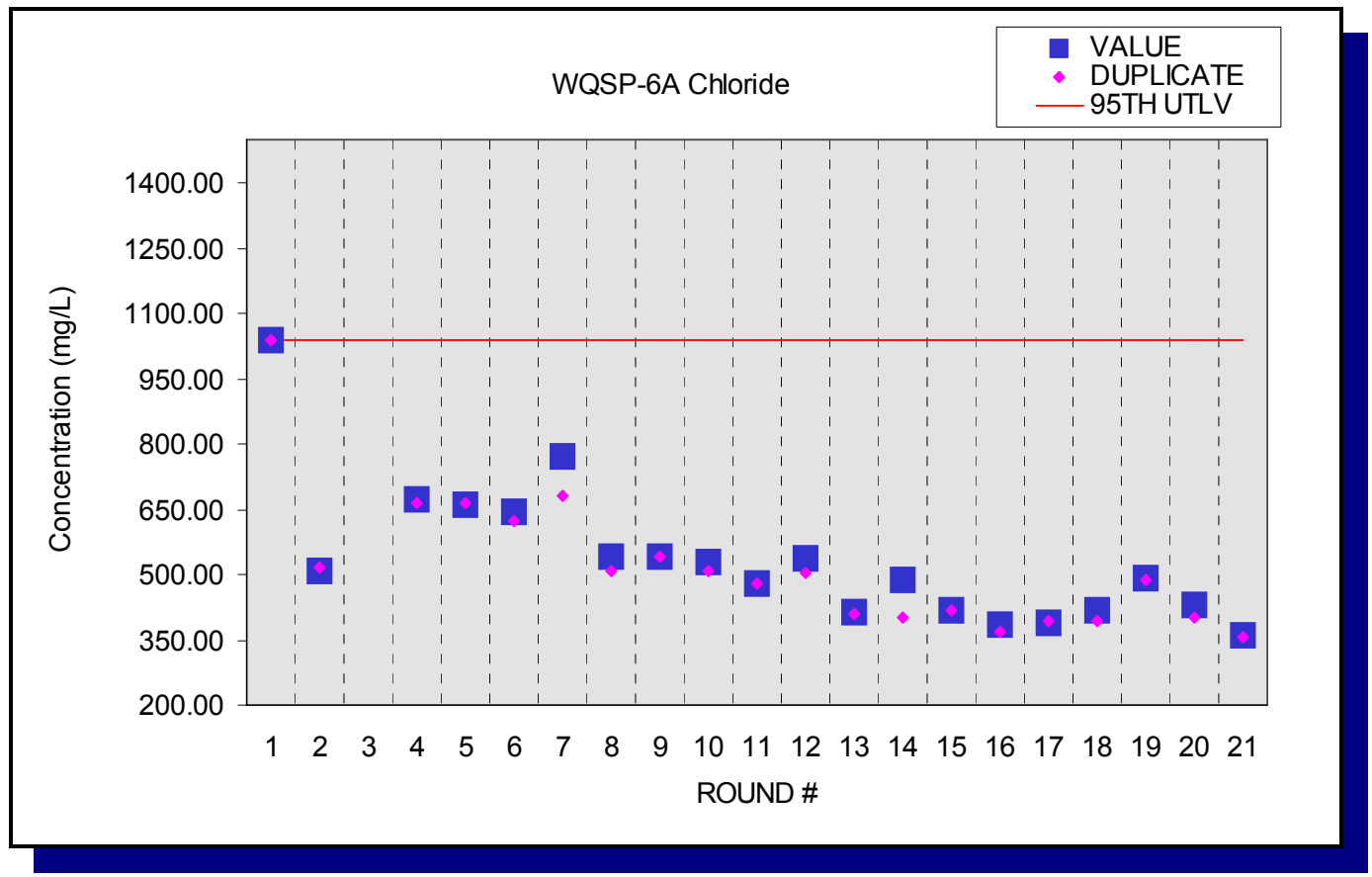

Figure E.87 - Time Trend Plot for Chloride at WQSP-6A

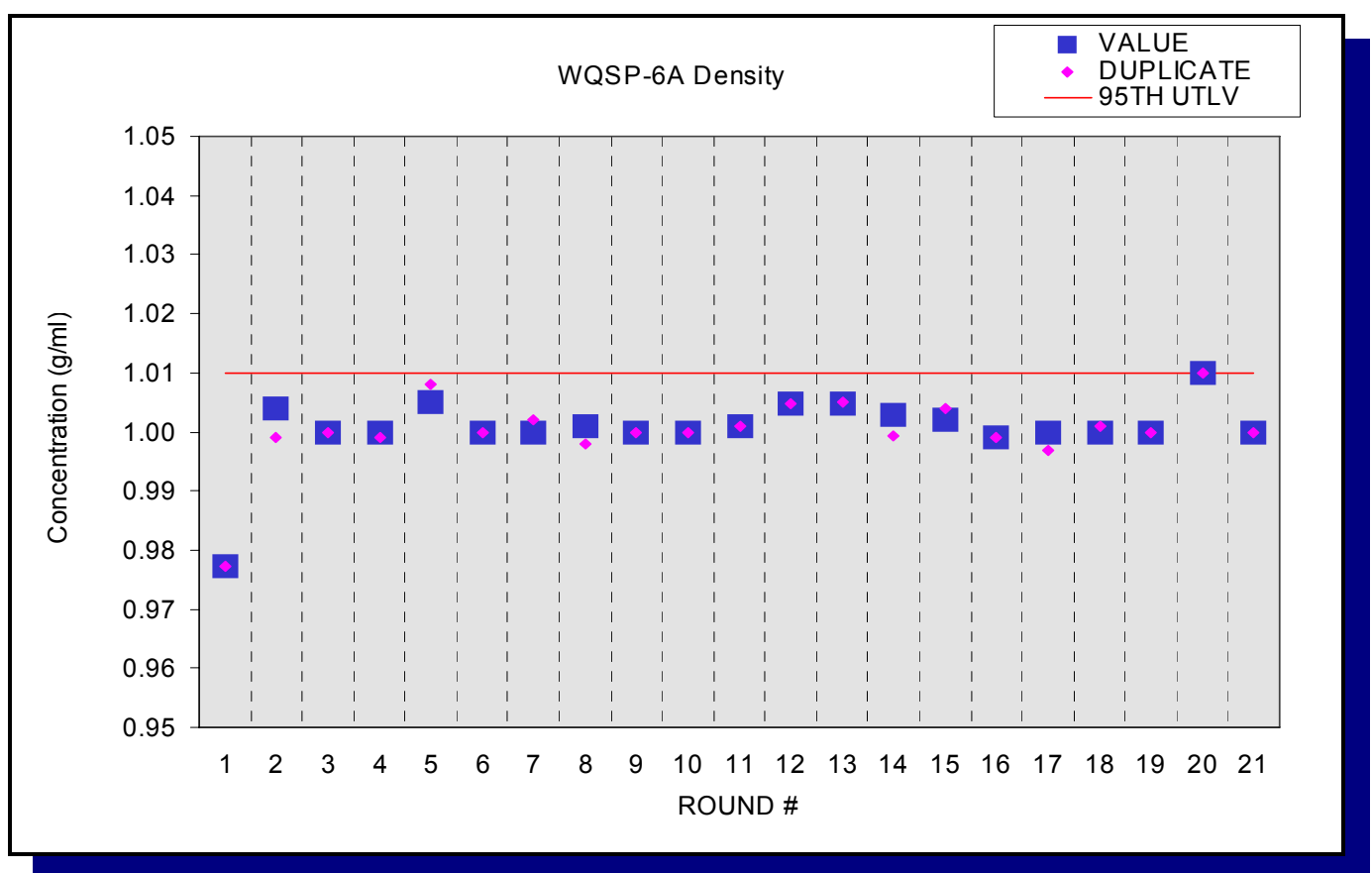

Figure E.88 - Time Trend Plot for Density at WQSP-6A 


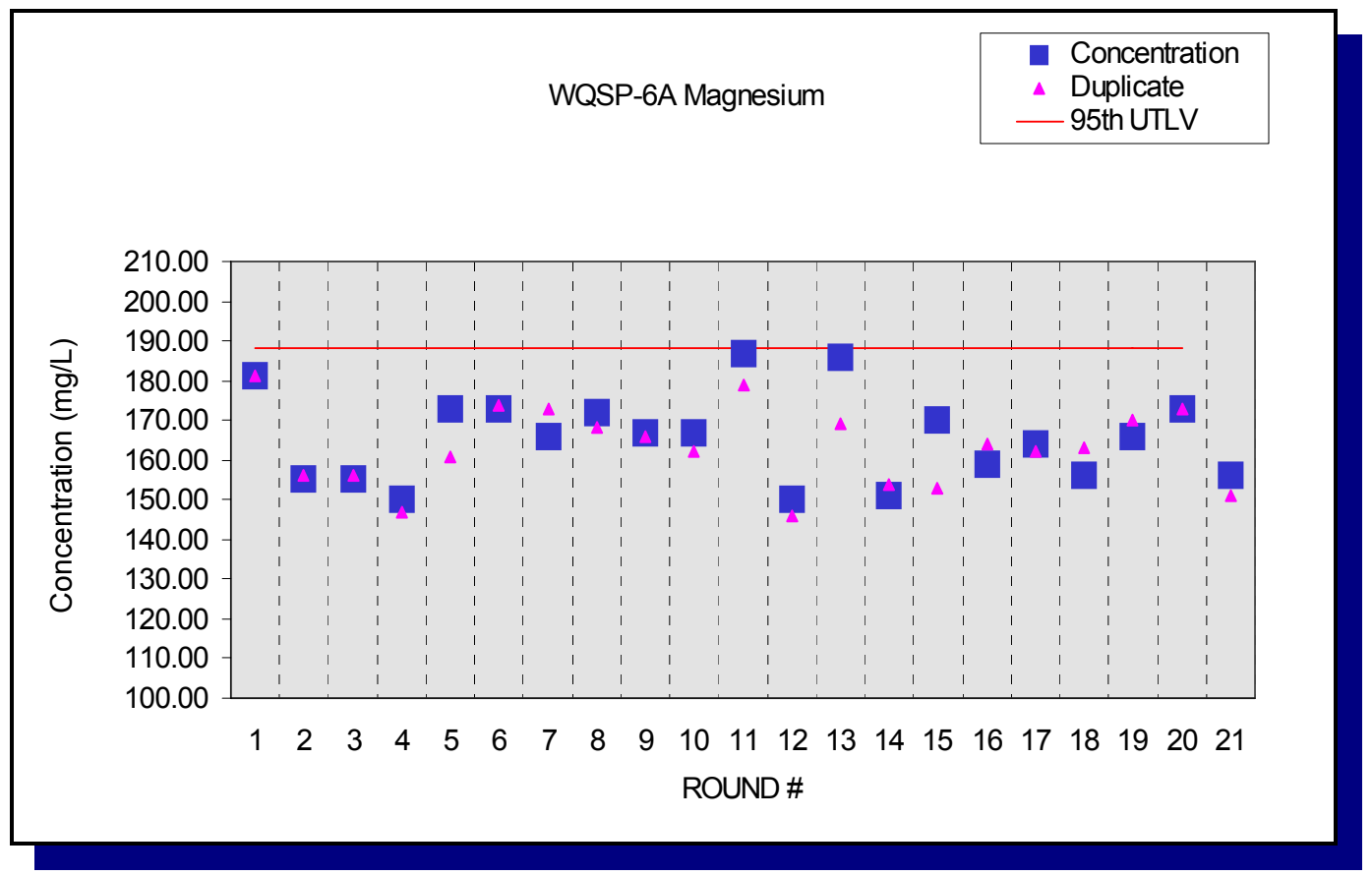

Figure E.89 - Time Trend Plot for Magnesium at WQSP-6A

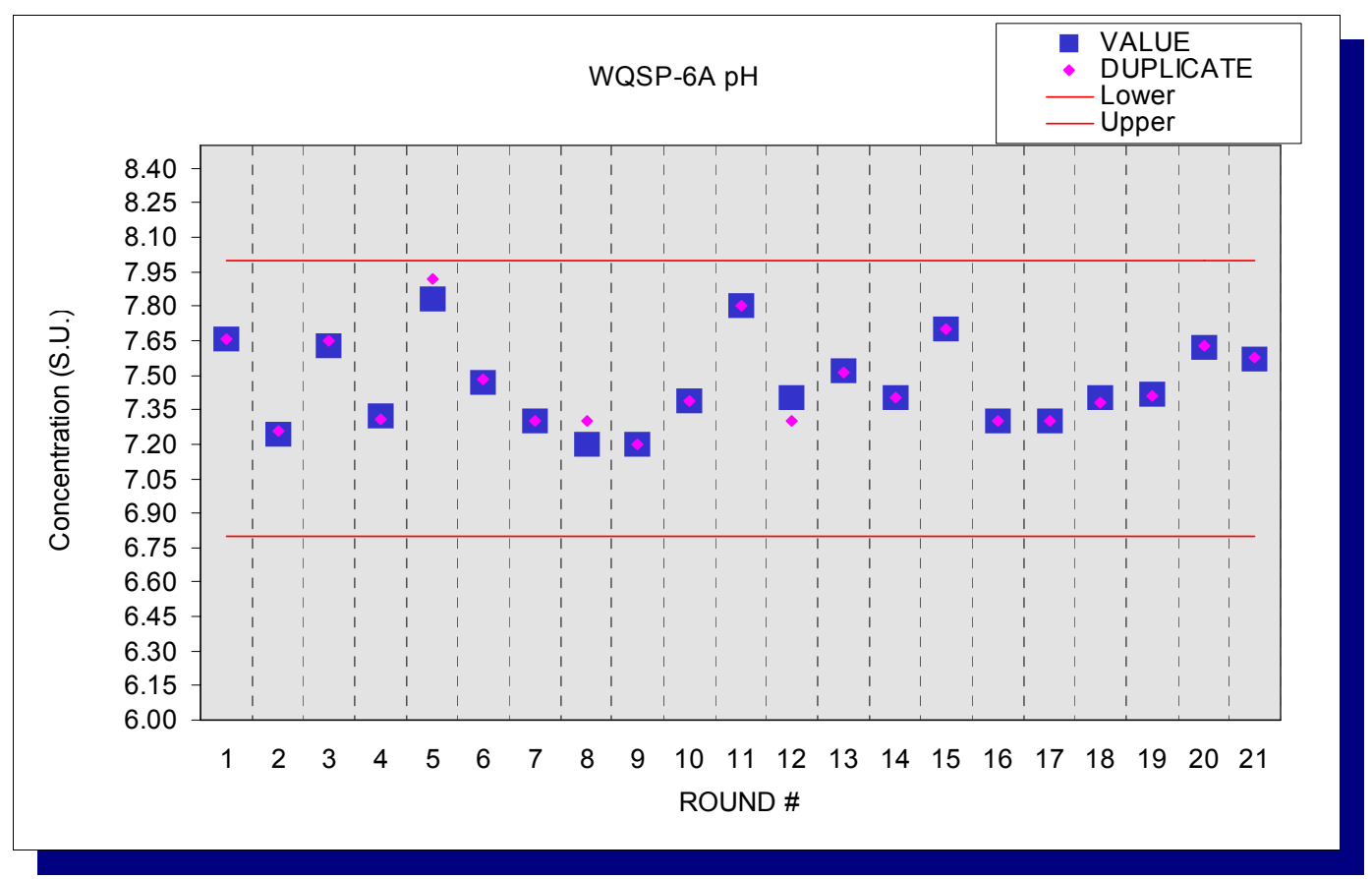

Figure E.90 - Time Trend Plot for $\mathrm{pH}$ at WQSP-6A 


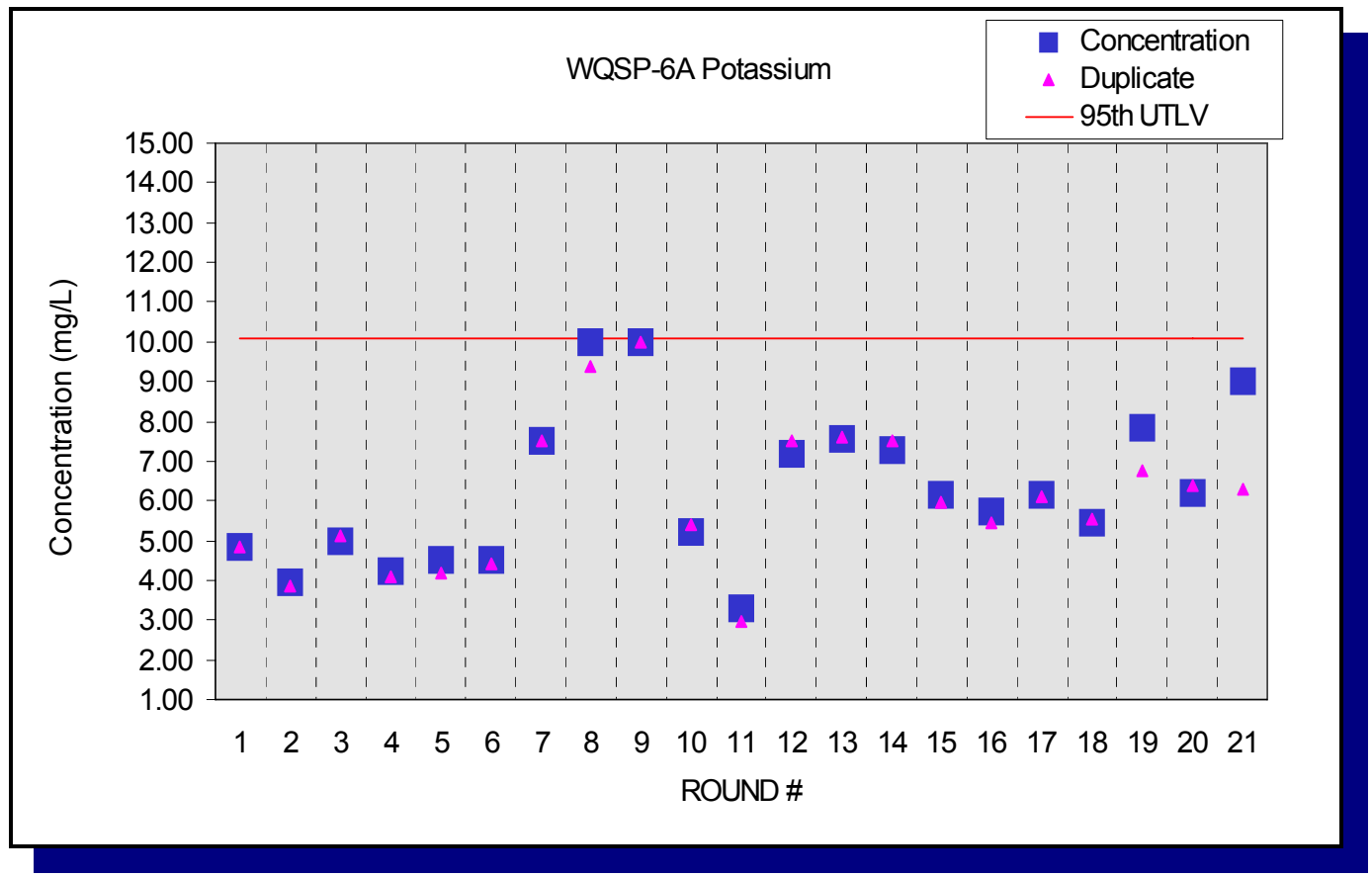

Figure E.91 - Time Trend Plot for Potassium at WQSP-6A

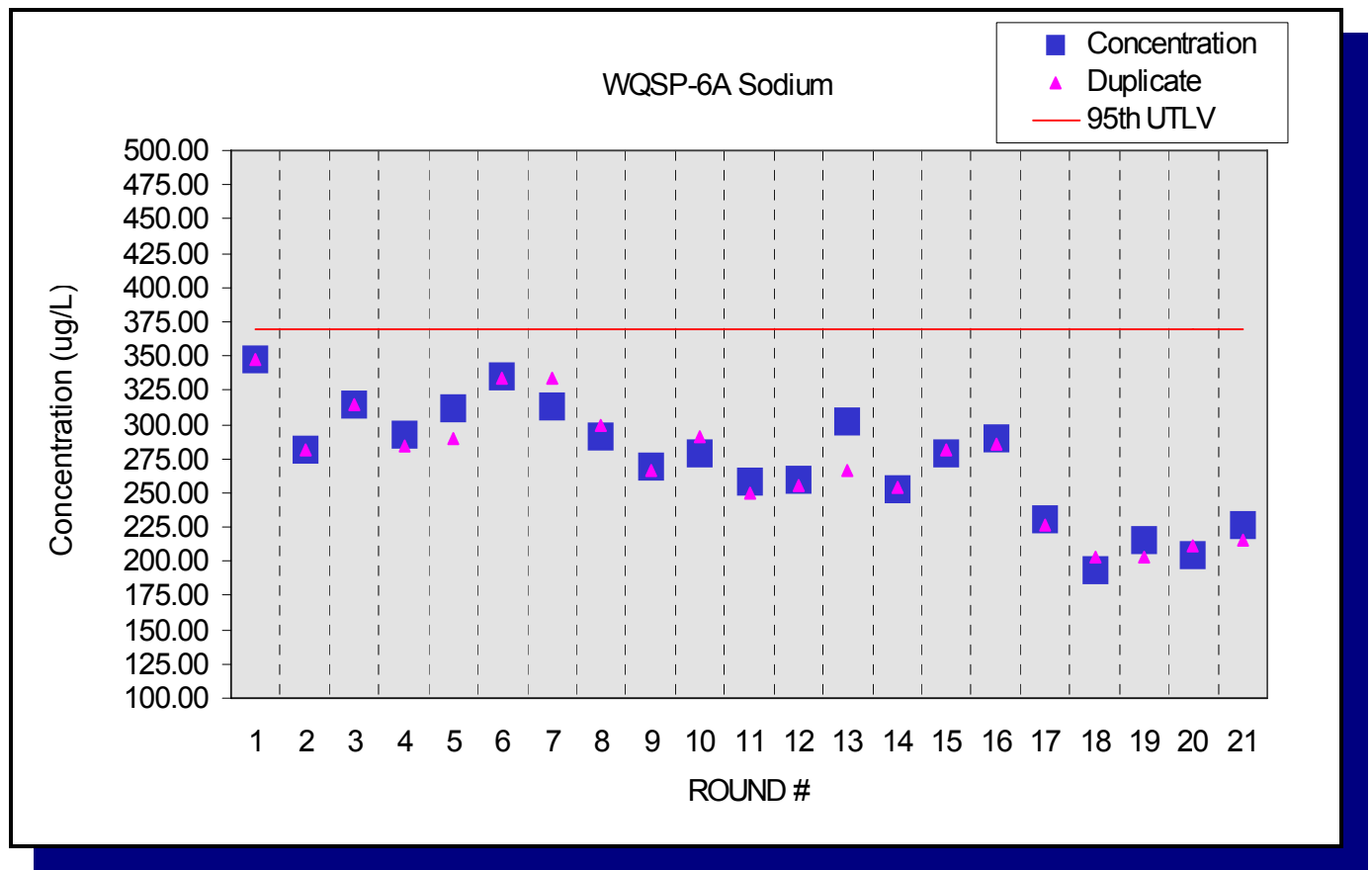

Figure E.92 - Time Trend Plot for Sodium at WQSP-6A 


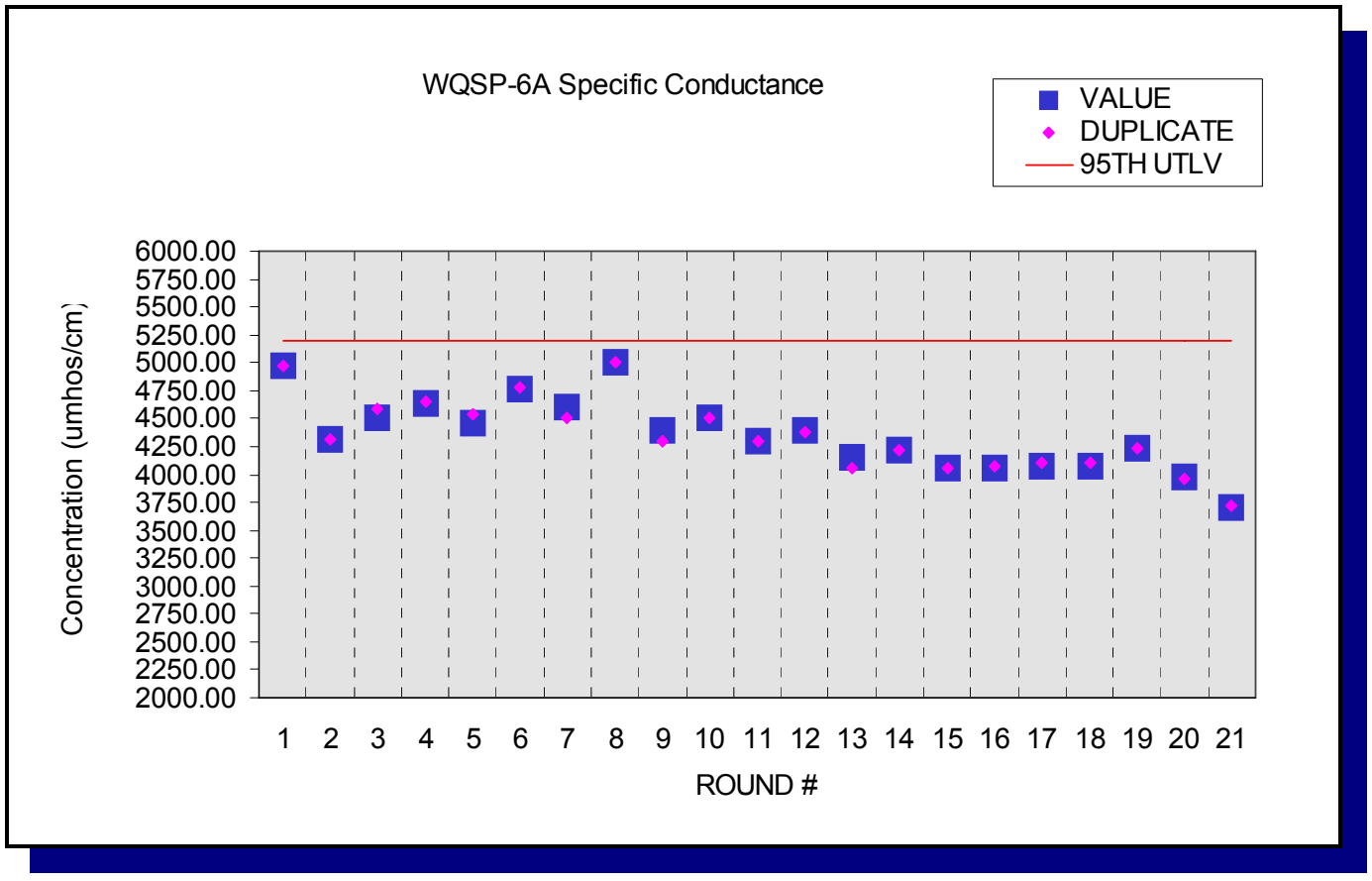

Figure E.93 - Time Trend Plot for Specific Conductance at WQSP-6A

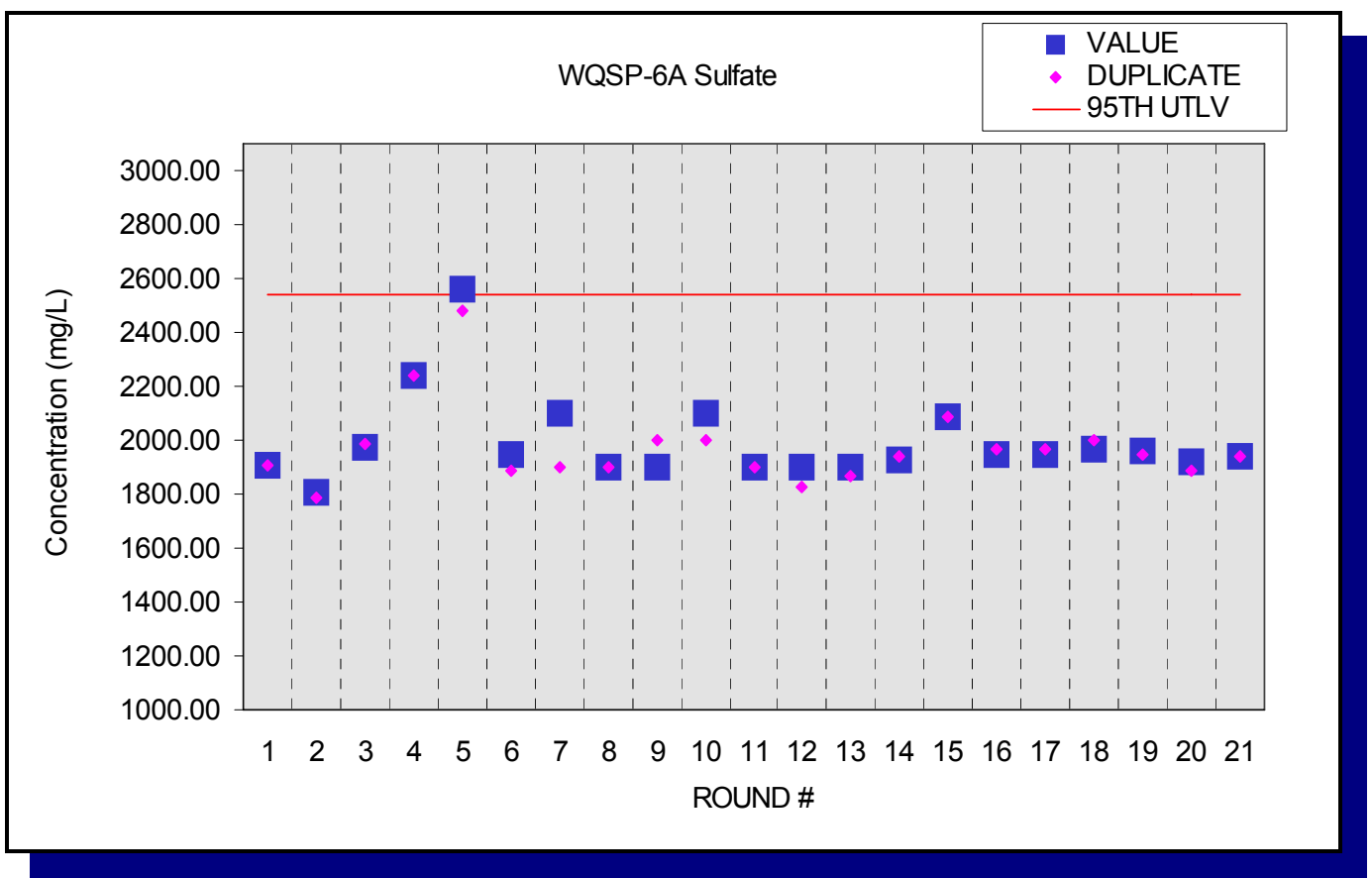

Figure E.94 - Time Trend Plot for Sulfate at WQSP-6A 


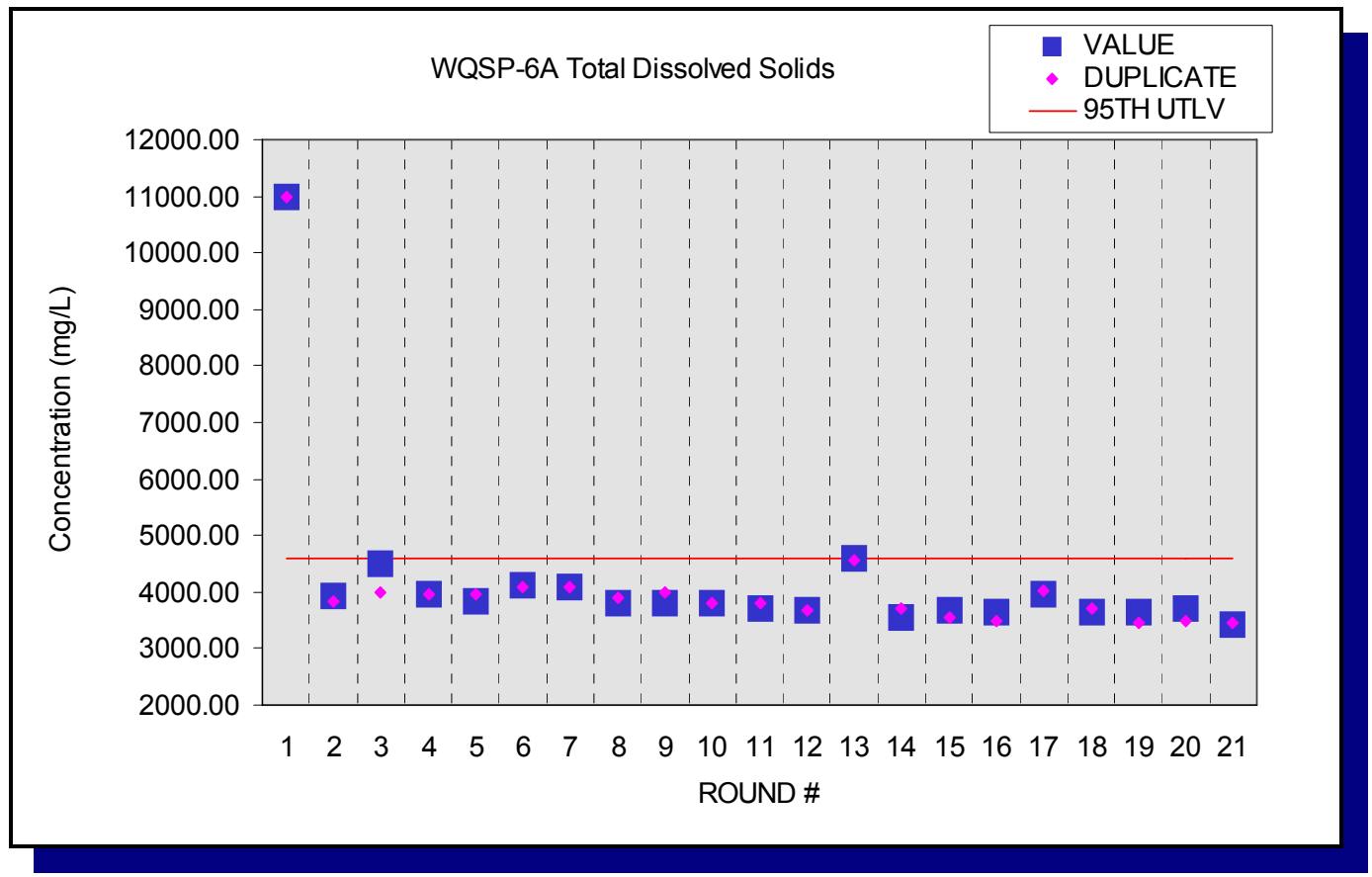

Figure E.95 - Time Trend Plot for Total Dissolved Solids at WQSP-6A

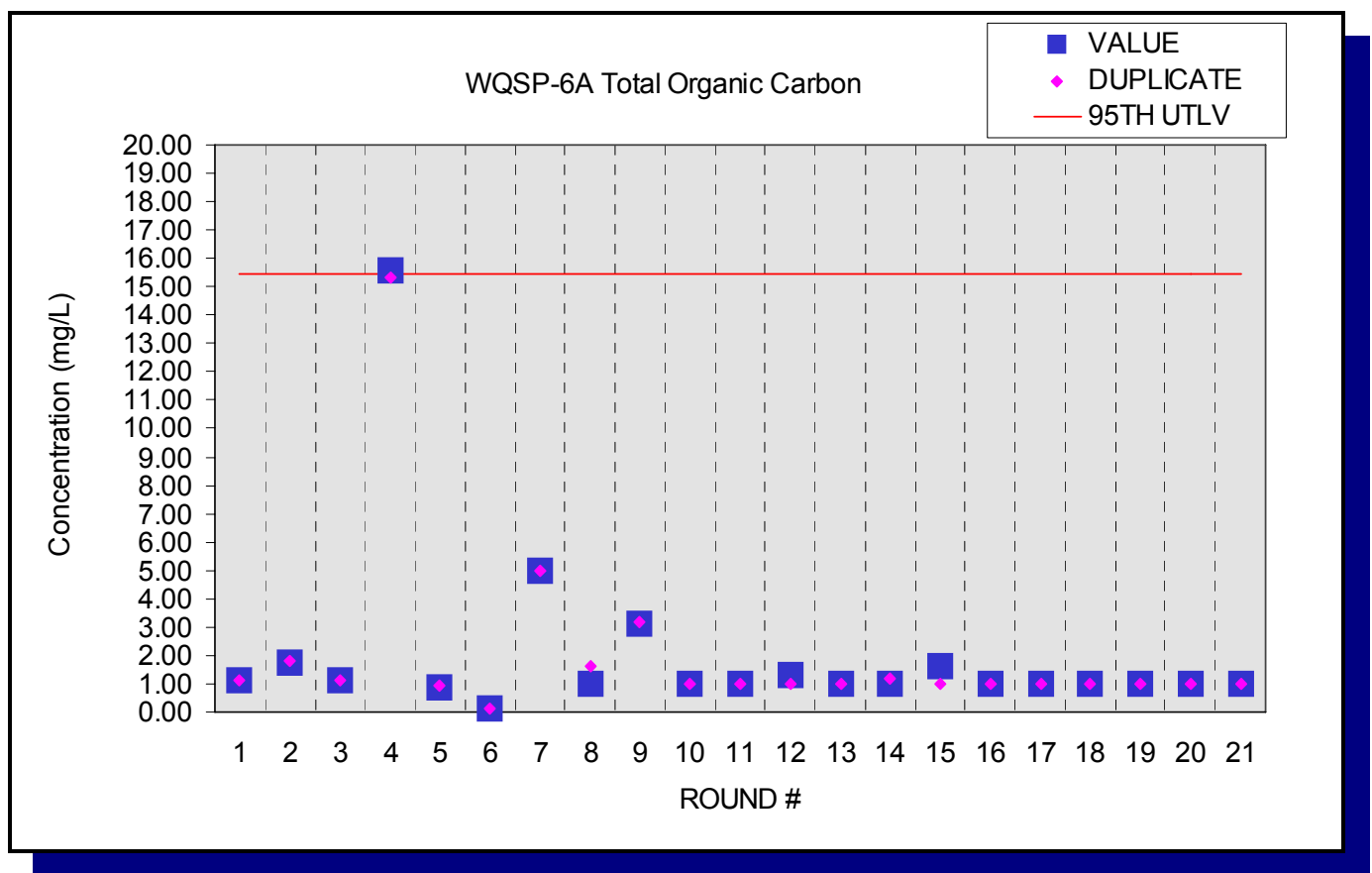

Figure E.96 - Time Trend Plot for Total Organic Carbon at WQSP-6A 


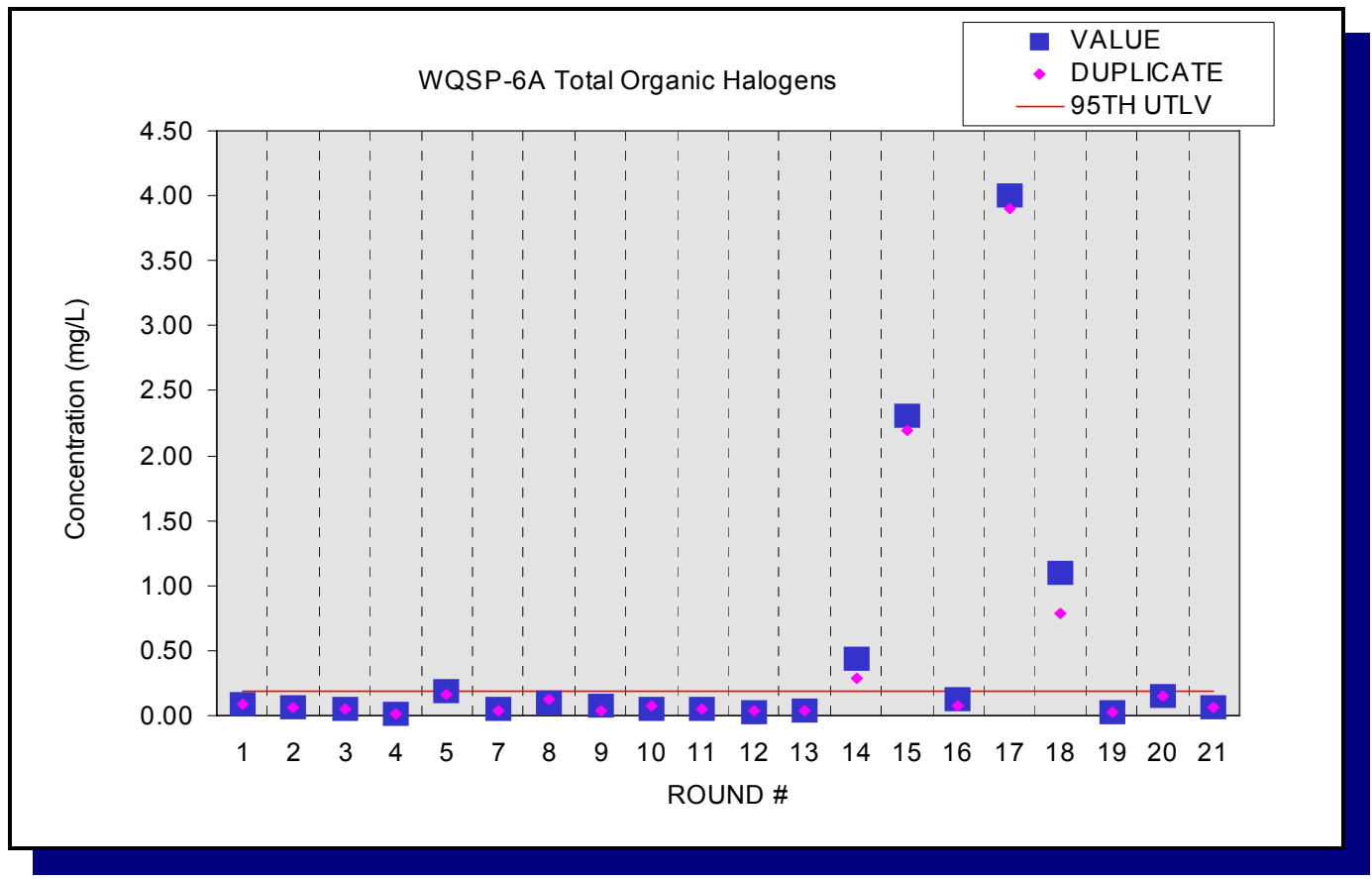

Figure E.97 - Time Trend Plot for Total Organic Halogens at WQSP-6A

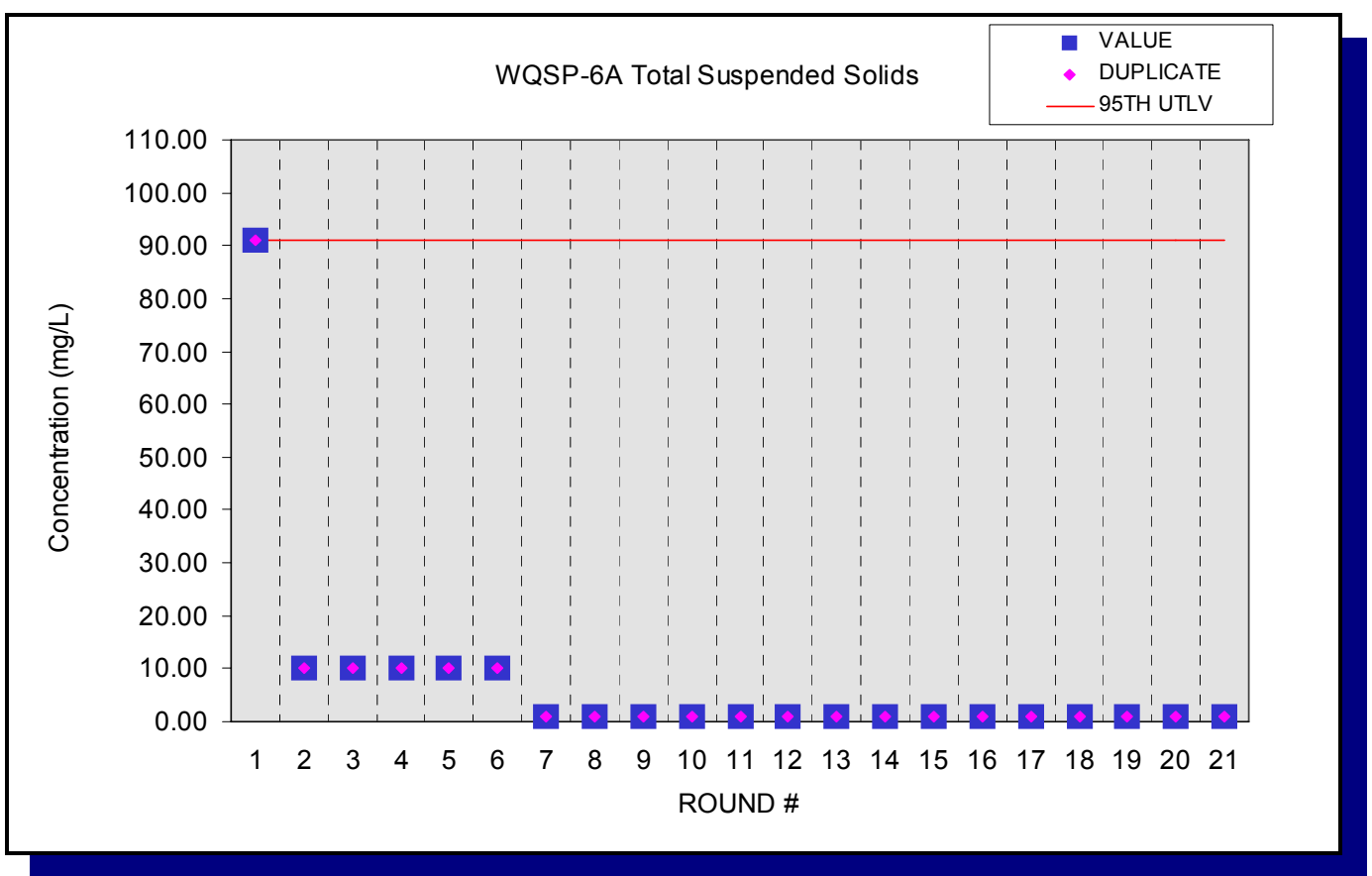

Figure E.98 - Time Trend Plot for Total Suspended Solids at WQSP-6A 


\section{Appendix $F$ \\ Groundwater Data Tables}

\begin{tabular}{|c|c|c|c|c|c|c|c|c|}
\hline \multirow[b]{3}{*}{ Parameter } & \multicolumn{4}{|c|}{ Concentration } & \multirow[b]{3}{*}{ Units } & \multirow{2}{*}{\multicolumn{2}{|c|}{ Reporting Limit }} & \multirow[b]{3}{*}{$\begin{array}{l}95^{\text {th }} \\
\text { UTLV }^{\text {a }}\end{array}$} \\
\hline & \multicolumn{2}{|c|}{ Round 20} & \multicolumn{2}{|c|}{ Round 21} & & & & \\
\hline & Sample & Dup. & Sample & Dup. & & $\begin{array}{l}\text { Round } \\
20\end{array}$ & $\begin{array}{l}\text { Round } \\
21\end{array}$ & \\
\hline 1,1,1-Trichloroethane & $<1$ & $<1$ & $<1$ & $<1$ & $\mu \mathrm{g} / \mathrm{L}$ & 1 & 1 & $<\mathrm{RL}^{\mathrm{b}}$ \\
\hline 1,1,2,2-Tetrachloroethane & $<1$ & $<1$ & $<1$ & $<1$ & $\mu \mathrm{g} / \mathrm{L}$ & 1 & 1 & $<\mathrm{RL}$ \\
\hline 1,1,2-Trichloroethane & $<1$ & $<1$ & $<1$ & $<1$ & $\mu \mathrm{g} / \mathrm{L}$ & 1 & 1 & $<R L$ \\
\hline 1,1-Dichloroethane & $<1$ & $<1$ & $<1$ & $<1$ & $\mu \mathrm{g} / \mathrm{L}$ & 1 & 1 & $<\mathrm{RL}$ \\
\hline 1,1-Dichloroethylene & $<1$ & $<1$ & $<1$ & $<1$ & $\mu \mathrm{g} / \mathrm{L}$ & 1 & 1 & $<\mathrm{RL}$ \\
\hline 1,2-Dichloroethane & $<1$ & $<1$ & $<1$ & $<1$ & $\mu \mathrm{g} / \mathrm{L}$ & 1 & 1 & $<\mathrm{RL}$ \\
\hline Carbon tetrachloride & $<1$ & $<1$ & $<1$ & $<1$ & $\mu \mathrm{g} / \mathrm{L}$ & 1 & 1 & $<\mathrm{RL}$ \\
\hline Chlorobenzene & $<1$ & $<1$ & $<1$ & $<1$ & $\mu \mathrm{g} / \mathrm{L}$ & 1 & 1 & $<\mathrm{RL}$ \\
\hline Chloroform & $<1$ & $<1$ & $<1$ & $<1$ & $\mu \mathrm{g} / \mathrm{L}$ & 1 & 1 & $<\mathrm{RL}$ \\
\hline cis-1,2-Dichloroethylene & $<1$ & $<1$ & $<1$ & $<1$ & $\mu \mathrm{g} / \mathrm{L}$ & 1 & 1 & $<\mathrm{RL}$ \\
\hline trans-1, 2-Dichloroethylene & $<1$ & $<1$ & $<1$ & $<1$ & $\mu \mathrm{g} / \mathrm{L}$ & 1 & 1 & $<R L$ \\
\hline Methyl ethyl ketone & $<5$ & $<5$ & $<5$ & $<5$ & $\mu \mathrm{g} / \mathrm{L}$ & 5 & 5 & $<\mathrm{RL}$ \\
\hline Methylene chloride & $<5$ & $<5$ & $<5$ & $<5$ & $\mu \mathrm{g} / \mathrm{L}$ & 5 & 5 & $<R L$ \\
\hline Tetrachloroethylene & $<1$ & $<1$ & $<1$ & $<1$ & $\mu \mathrm{g} / \mathrm{L}$ & 1 & 1 & $<\mathrm{RL}$ \\
\hline Toluene & $<1$ & $<1$ & $<1$ & $<1$ & $\mu \mathrm{g} / \mathrm{L}$ & 1 & 1 & $<R L$ \\
\hline Trichloroethylene & $<1$ & $<1$ & $<1$ & $<1$ & $\mu \mathrm{g} / \mathrm{L}$ & 1 & 1 & $<\mathrm{RL}$ \\
\hline Trichlorofluoromethane & $<1$ & $<1$ & $<1$ & $<1$ & $\mu \mathrm{g} / \mathrm{L}$ & 1 & 1 & $<\mathrm{RL}$ \\
\hline Vinyl chloride & $<1$ & $<1$ & $<1$ & $<1$ & $\mu \mathrm{g} / \mathrm{L}$ & 1 & 1 & $<\mathrm{RL}$ \\
\hline Xylene & $<1$ & $<1$ & $<1$ & $<1$ & $\mu \mathrm{g} / \mathrm{L}$ & 1 & 1 & $<R L$ \\
\hline 1,2-Dichlorobenzene & $<5$ & $<5$ & $<5$ & $<5$ & $\mu \mathrm{g} / \mathrm{L}$ & 5 & 5 & $<R L$ \\
\hline 1,4-Dichlorobenzene & $<5$ & $<5$ & $<5$ & $<5$ & $\mu \mathrm{g} / \mathrm{L}$ & 5 & 5 & $<\mathrm{RL}$ \\
\hline 2,4-Dinitrophenol & $<20$ & $<20$ & $<20$ & $<20$ & $\mu \mathrm{g} / \mathrm{L}$ & 20 & 20 & $<\mathrm{RL}$ \\
\hline 2,4-Dinitrotoluene & $<20$ & $<20$ & $<5$ & $<5$ & $\mu \mathrm{g} / \mathrm{L}$ & 20 & 5 & $<R L$ \\
\hline 2-Methylphenol & $<5$ & $<5$ & $<5$ & $<5$ & $\mu \mathrm{g} / \mathrm{L}$ & 5 & 5 & $<\mathrm{RL}$ \\
\hline $\begin{array}{l}\text { 3-Methylphenol/ } \\
\text { 4-Methylphenol }\end{array}$ & $<5$ & $<5$ & $<5$ & $<5$ & $\mu \mathrm{g} / \mathrm{L}$ & 5 & 5 & $<\mathrm{RL}$ \\
\hline Hexachlorobenzene & $<5$ & $<5$ & $<5$ & $<5$ & $\mu \mathrm{g} / \mathrm{L}$ & 5 & 5 & $<\mathrm{RL}$ \\
\hline Hexachloroethane & $<5$ & $<5$ & $<5$ & $<5$ & $\mu \mathrm{g} / \mathrm{L}$ & 5 & 5 & $<\mathrm{RL}$ \\
\hline Nitrobenzene & $<5$ & $<5$ & $<5$ & $<5$ & $\mu \mathrm{g} / \mathrm{L}$ & 5 & 5 & $<\mathrm{RL}$ \\
\hline Pentachlorophenol & $<5$ & $<5$ & $<20$ & $<20$ & $\mu \mathrm{g} / \mathrm{L}$ & 5 & 20 & $<\mathrm{RL}$ \\
\hline Pyridine & $<5$ & $<5$ & $<5$ & $<5$ & $\mu \mathrm{g} / \mathrm{L}$ & 5 & 5 & $<\mathrm{RL}$ \\
\hline Isobutanol & $<5$ & $<5$ & $<5$ & $<5$ & $\mu \mathrm{g} / \mathrm{L}$ & 5 & 5 & $<R L$ \\
\hline Alkalinity & 52 & 52 & 50 & 48 & $\mathrm{mg} / \mathrm{L}$ & 4 & 4 & 55.7 \\
\hline Chloride & 38,800 & 38,400 & 34,800 & 39,100 & $\mathrm{mg} / \mathrm{L}$ & 2 & 2 & 40,472 \\
\hline Density & 1.05 & 1.04 & 1.05 & 1.05 & $\mathrm{~g} / \mathrm{ml}$ & $N / A^{d}$ & $N / A^{d}$ & 1.072 \\
\hline Nitrate (as N) & $<0.10$ & $<0.10$ & $<0.10$ & $<0.10$ & $\mathrm{mg} / \mathrm{L}$ & 0.1 & 0.1 & $<10$ \\
\hline $\mathrm{pH}$ & 7.07 & 7.06 & 7.27 & 7.30 & $S U^{c}$ & $N / A^{d}$ & $N / A^{d}$ & $6.89-7.65$ \\
\hline Specific conductance & 83,400 & 83,600 & 81,700 & 81,600 & $\mu \mathrm{mhos} / \mathrm{cm}$ & $N / A$ & $\mathrm{~N} / \mathrm{A}$ & 175,000 \\
\hline Sulfate & 4,840 & 4,790 & 4,440 & 4,600 & $\mathrm{mg} / \mathrm{L}$ & 2 & 2 & 5,757 \\
\hline Total dissolved solids & 68,600 & 67,000 & 62,300 & 61,000 & $\mathrm{mg} / \mathrm{L}$ & 10 & 10 & 80,700 \\
\hline Total organic carbon & $<1.0$ & $<1.0$ & 2.30 & 2.30 & $\mathrm{mg} / \mathrm{L}$ & 1 & 1 & 5 \\
\hline
\end{tabular}


Waste Isolation Pilot Plant Annual Site Environmental Report for 2005 DOE/WIPP-06-2225

\begin{tabular}{|c|c|c|c|c|c|c|c|c|}
\hline \multirow[b]{3}{*}{ Parameter } & \multicolumn{4}{|c|}{ Concentration } & \multirow[b]{3}{*}{ Units } & & & \multirow[b]{3}{*}{$\begin{array}{l}9^{\text {th }} \\
\text { UTLV }^{\mathrm{a}}\end{array}$} \\
\hline & \multicolumn{2}{|c|}{ Round 20} & \multicolumn{2}{|c|}{ Round 21} & & \multicolumn{2}{|c|}{ Reporting Limit } & \\
\hline & Sample & Dup. & Sample & Dup. & & $\begin{array}{c}\text { Round } \\
20\end{array}$ & $\begin{array}{c}\text { Round } \\
21\end{array}$ & \\
\hline Total organic halogen & $<0.30$ & $<0.30$ & $<0.30$ & $<0.03$ & $\mathrm{mg} / \mathrm{L}$ & 0.30 & 0.30 & 14.6 \\
\hline Total suspended solids & $<1.0$ & $<1.0$ & $<1.0$ & $<1.0$ & $\mathrm{mg} / \mathrm{L}$ & 1 & 1 & 33.5 \\
\hline Antimony & $<0.025$ & $<0.025$ & $<0.025$ & $<0.025$ & $\mathrm{mg} / \mathrm{L}$ & 0.025 & 0.025 & 0.33 \\
\hline Arsenic & $<0.05$ & $<0.05$ & $<0.05$ & $<0.05$ & $\mathrm{mg} / \mathrm{L}$ & 0.05 & 0.05 & $<0.1$ \\
\hline Barium & 0.025 & 0.025 & 0.036 & 0.038 & $\mathrm{mg} / \mathrm{L}$ & 0.02 & 0.02 & $<1.0$ \\
\hline Beryllium & $<0.01$ & $<0.01$ & $<0.01$ & $<0.01$ & $\mathrm{mg} / \mathrm{L}$ & 0.01 & 0.01 & $<0.02$ \\
\hline Cadmium & $<0.01$ & $<0.01$ & $<0.01$ & $<0.01$ & $\mathrm{mg} / \mathrm{L}$ & 0.01 & 0.01 & $<0.2$ \\
\hline Calcium & 1,700 & 1,610 & 1,910 & 1,840 & $\mathrm{mg} / \mathrm{L}$ & 0.5 & 0.5 & 2,087 \\
\hline Chromium & 0.082 & 0.084 & $<0.025$ & $<0.025$ & $\mathrm{mg} / \mathrm{L}$ & 0.025 & 0.025 & $<0.5$ \\
\hline Iron & $<0.50$ & $<0.50$ & $<0.50$ & $<0.50$ & $\mathrm{mg} / \mathrm{L}$ & 0.50 & 0.50 & 1.32 \\
\hline Lead & $<0.02$ & $<0.02$ & $<0.02$ & $<0.02$ & $\mathrm{mg} / \mathrm{L}$ & 0.02 & 0.02 & 0.105 \\
\hline Magnesium & 1,150 & 1,090 & 1,400 & 1,120 & $\mathrm{mg} / \mathrm{L}$ & 0.5 & 0.5 & 1,247 \\
\hline Mercury & $<0.0002$ & $<0.0002$ & $<0.0002$ & $<0.0002$ & $\mathrm{mg} / \mathrm{L}$ & 0 & 0 & $<0.002$ \\
\hline Nickel & $<0.025$ & $<0.025$ & $<0.025$ & $<0.025$ & $\mathrm{mg} / \mathrm{L}$ & 0.025 & 0.025 & 0.490 \\
\hline Potassium & 934 & 907 & 998 & 1,010 & $\mathrm{mg} / \mathrm{L}$ & 0.5 & 0.5 & 799 \\
\hline Selenium & $<0.025$ & $<0.025$ & $<0.025$ & $<0.025$ & $\mathrm{mg} / \mathrm{L}$ & 0.025 & 0.025 & 0.15 \\
\hline Silver & $<0.013$ & $<0.013$ & $<0.013$ & $<0.013$ & $\mathrm{mg} / \mathrm{L}$ & 0.013 & 0.013 & $<0.50$ \\
\hline Sodium & 19,100 & 18,500 & 23,400 & 22,500 & $\mathrm{mg} / \mathrm{L}$ & 0.5 & 0.5 & 22,090 \\
\hline Thallium & $<0.025$ & $<0.025$ & $<0.025$ & $<0.025$ & $\mathrm{mg} / \mathrm{L}$ & 0.025 & 0.025 & 0.980 \\
\hline Vanadium & $<0.025$ & $<0.025$ & $<0.025$ & $<0.025$ & $\mathrm{mg} / \mathrm{L}$ & 0.025 & 0.025 & $<0.1$ \\
\hline
\end{tabular}

Table F.2 - Analytical Results for Groundwater Sampled from Well WQSP-2

\begin{tabular}{|c|c|c|c|c|c|c|c|c|}
\hline \multirow[b]{3}{*}{ Parameter } & \multicolumn{4}{|c|}{ Concentration } & \multirow[b]{3}{*}{ Units } & & & \multirow[b]{3}{*}{$\begin{array}{l}95^{\text {th }} \\
\text { UTLV }^{\mathrm{a}}\end{array}$} \\
\hline & \multicolumn{2}{|c|}{ Round 20} & \multicolumn{2}{|c|}{ Round 21} & & \multicolumn{2}{|c|}{ Reporting Limit } & \\
\hline & Sample & Dup. & Sample & Dup. & & $\begin{array}{c}\text { Round } \\
20\end{array}$ & $\begin{array}{c}\text { Round } \\
21\end{array}$ & \\
\hline 1,1,1-Trichloroethane & $<1$ & $<1$ & $<1$ & $<1$ & $\mu \mathrm{g} / \mathrm{L}$ & 1 & 1 & $<\mathrm{RL}^{\mathrm{b}}$ \\
\hline 1,1,2,2-Tetrachloroethane & $<1$ & $<1$ & $<1$ & $<1$ & $\mu \mathrm{g} / \mathrm{L}$ & 1 & 1 & $<\mathrm{RL}$ \\
\hline 1,1,2-Trichloroethane & $<1$ & $<1$ & $<1$ & $<1$ & $\mu \mathrm{g} / \mathrm{L}$ & 1 & 1 & $<R L$ \\
\hline 1,1-Dichloroethane & $<1$ & $<1$ & $<1$ & $<1$ & $\mu g / L$ & 1 & 1 & $<R L$ \\
\hline 1,1-Dichloroethylene & $<1$ & $<1$ & $<1$ & $<1$ & $\mu \mathrm{g} / \mathrm{L}$ & 1 & 1 & $<R L$ \\
\hline 1,2-Dichloroethane & $<1$ & $<1$ & $<1$ & $<1$ & $\mu \mathrm{g} / \mathrm{L}$ & 1 & 1 & $<R L$ \\
\hline Carbon tetrachloride & $<1$ & $<1$ & $<1$ & $<1$ & $\mu \mathrm{g} / \mathrm{L}$ & 1 & 1 & $<R L$ \\
\hline Chlorobenzene & $<1$ & $<1$ & $<1$ & $<1$ & $\mu \mathrm{g} / \mathrm{L}$ & 1 & 1 & $<R L$ \\
\hline Chloroform & $<1$ & $<1$ & $<1$ & $<1$ & $\mu \mathrm{g} / \mathrm{L}$ & 1 & 1 & $<R L$ \\
\hline cis-1,2-Dichloroethylene & $<1$ & $<1$ & $<1$ & $<1$ & $\mu \mathrm{g} / \mathrm{L}$ & 1 & 1 & $<R L$ \\
\hline trans-1,2-Dichloroethylene & $<1$ & $<1$ & $<1$ & $<1$ & $\mu \mathrm{g} / \mathrm{L}$ & 1 & 1 & $<\mathrm{RL}$ \\
\hline Methyl ethyl ketone & $<5$ & $<5$ & $<5$ & $<5$ & $\mu \mathrm{g} / \mathrm{L}$ & 5 & 5 & $<R L$ \\
\hline Methylene chloride & $<5$ & $<5$ & $<5$ & $<5$ & $\mu g / L$ & 5 & 5 & $<R L$ \\
\hline Tetrachloroethylene & $<1$ & $<1$ & $<1$ & $<1$ & $\mu \mathrm{g} / \mathrm{L}$ & 1 & 1 & $<R L$ \\
\hline
\end{tabular}




\begin{tabular}{|c|c|c|c|c|c|c|c|c|}
\hline \multirow[b]{3}{*}{ Parameter } & \multicolumn{4}{|c|}{ Concentration } & \multirow[b]{3}{*}{ Units } & \multirow{2}{*}{\multicolumn{2}{|c|}{ Reporting Limit }} & \multirow[b]{3}{*}{$\begin{array}{c}95^{\text {th }} \\
\text { UTLV }^{\mathrm{a}}\end{array}$} \\
\hline & \multicolumn{2}{|c|}{ Round 20} & \multicolumn{2}{|c|}{ Round 21} & & & & \\
\hline & Sample & Dup. & Sample & Dup. & & $\begin{array}{c}\text { Round } \\
20\end{array}$ & $\begin{array}{c}\text { Round } \\
21\end{array}$ & \\
\hline Toluene & $<1$ & $<1$ & $<1$ & $<1$ & $\mu \mathrm{g} / \mathrm{L}$ & 1 & 1 & $<\mathrm{RL}$ \\
\hline Trichloroethylene & $<1$ & $<1$ & $<1$ & $<1$ & $\mu \mathrm{g} / \mathrm{L}$ & 1 & 1 & $<\mathrm{RL}$ \\
\hline Trichlorofluoromethane & $<1$ & $<1$ & $<1$ & $<1$ & $\mu g / L$ & 1 & 1 & $<\mathrm{RL}$ \\
\hline Vinyl chloride & $<1$ & $<1$ & $<1$ & $<1$ & $\mu \mathrm{g} / \mathrm{L}$ & 1 & 1 & $<R L$ \\
\hline Xylene & $<1$ & $<1$ & $<1$ & $<1$ & $\mu g / L$ & 1 & 1 & $<\mathrm{RL}$ \\
\hline 1,2-Dichlorobenzene & $<5$ & $<5$ & $<5$ & $<5$ & $\mu g / L$ & 5 & 5 & $<\mathrm{RL}$ \\
\hline 1,4-Dichlorobenzene & $<5$ & $<5$ & $<5$ & $<5$ & $\mu g / L$ & 5 & 5 & $<\mathrm{RL}$ \\
\hline 2,4-Dinitrophenol & $<20$ & $<20$ & $<5$ & $<5$ & $\mu g / L$ & 20 & 5 & $<R L$ \\
\hline 2,4-Dinitrotoluene & $<20$ & $<20$ & $<5$ & $<5$ & $\mu \mathrm{g} / \mathrm{L}$ & 20 & 5 & $<\mathrm{RL}$ \\
\hline 2-Methylphenol & $<5$ & $<5$ & $<5$ & $<5$ & $\mu \mathrm{g} / \mathrm{L}$ & 5 & 5 & $<\mathrm{RL}$ \\
\hline $\begin{array}{l}\text { 3-Methylphenol/ } \\
\text { 4-Methylphenol }\end{array}$ & $<5$ & $<5$ & $<5$ & $<5$ & $\mu g / L$ & 5 & 5 & $<\mathrm{RL}$ \\
\hline Hexachlorobenzene & $<5$ & $<5$ & $<5$ & $<5$ & $\mu g / L$ & 5 & 5 & $<\mathrm{RL}$ \\
\hline Hexachloroethane & $<5$ & $<5$ & $<5$ & $<5$ & $\mu \mathrm{g} / \mathrm{L}$ & 5 & 5 & $<R L$ \\
\hline Nitrobenzene & $<5$ & $<5$ & $<5$ & $<5$ & $\mu g / L$ & 5 & 5 & $<\mathrm{RL}$ \\
\hline Pentachlorophenol & $<5$ & $<5$ & $<5$ & $<5$ & $\mu g / L$ & 5 & 5 & $<\mathrm{RL}$ \\
\hline Pyridine & $<5$ & $<5$ & $<5$ & $<5$ & $\mu g / L$ & 5 & 5 & $<\mathrm{RL}$ \\
\hline Isobutanol & $<5$ & $<5$ & $<5$ & $<5$ & $\mu g / L$ & 5 & 5 & $<\mathrm{RL}$ \\
\hline Alkalinity & 46 & 44 & 52 & 50 & $\mathrm{mg} / \mathrm{L}$ & 4 & 4 & 70.3 \\
\hline Chloride & 39,800 & 47,400 & 37,900 & 39,600 & $\mathrm{mg} / \mathrm{L}$ & 2 & 2 & 39,670 \\
\hline Density & 1.05 & 1.05 & 1.05 & 1.04 & $\mathrm{~g} / \mathrm{ml}$ & $N / A^{c}$ & $N / A^{c}$ & 1.06 \\
\hline Nitrate (as N) & $<0.1$ & $<0.1$ & $<0.1$ & $<0.1$ & $\mathrm{mg} / \mathrm{L}$ & 0.1 & 0.1 & $<10$ \\
\hline $\mathrm{pH}$ & 7.28 & 7.29 & 7.48 & 7.48 & $S U^{d}$ & $N / A^{c}$ & $N / A^{c}$ & $7.00-7.60$ \\
\hline Specific conductance & 79,800 & 80,300 & 81,000 & 80,600 & $\mu \mathrm{mhos} / \mathrm{cm}$ & $N / A^{c}$ & $N / A^{c}$ & 124,000 \\
\hline Sulfate & 5,920 & 6,610 & 5,630 & 5830 & $\mathrm{mg} / \mathrm{L}$ & 2 & 2 & 6,590 \\
\hline Total dissolved solids & 67,600 & 64,800 & 52,000 & 51,000 & $\mathrm{mg} / \mathrm{L}$ & 10 & 10 & 80,500 \\
\hline Total organic carbon & $<1.0$ & $<1.0$ & 1.12 & $<1.0$ & $\mathrm{mg} / \mathrm{L}$ & 1 & 1 & 7.97 \\
\hline Total organic halogen & $<0.30$ & $<0.30$ & $<0.30$ & $<0.30$ & $\mathrm{mg} / \mathrm{L}$ & 0.30 & 0.30 & 63.8 \\
\hline Total suspended solids & $<1.0$ & $<1.0$ & $<1.0$ & $<1.0$ & $\mathrm{mg} / \mathrm{L}$ & 1 & 1 & 43 \\
\hline Antimony & $<0.025$ & $<0.025$ & $<0.025$ & $<0.025$ & $\mathrm{mg} / \mathrm{L}$ & 0.025 & 0.025 & $<0.50$ \\
\hline Arsenic & $<0.05$ & $<0.05$ & $<0.05$ & $<0.05$ & $\mathrm{mg} / \mathrm{L}$ & 0.05 & 0.05 & 0.062 \\
\hline Barium & $<0.02$ & $<0.02$ & $<0.05$ & $<0.05$ & $\mathrm{mg} / \mathrm{L}$ & 0.02 & 0.05 & $<1.0$ \\
\hline Beryllium & $<0.01$ & $<0.01$ & 0.013 & 0.013 & $\mathrm{mg} / \mathrm{L}$ & 0.01 & 0.01 & $<1.0$ \\
\hline Cadmium & $<0.01$ & $<0.01$ & $<0.01$ & $<0.01$ & $\mathrm{mg} / \mathrm{L}$ & 0.01 & 0.01 & $<0.5$ \\
\hline Calcium & 1580 & 1730 & 1720 & 1670 & $\mathrm{mg} / \mathrm{L}$ & 0.5 & 0.5 & 1,827 \\
\hline Chromium & $<0.05$ & $<0.05$ & $<0.05$ & $<0.05$ & $\mathrm{mg} / \mathrm{L}$ & 0.05 & 0.05 & $<0.5$ \\
\hline Iron & $<0.50$ & $<0.50$ & $<0.50$ & $<0.50$ & $\mathrm{mg} / \mathrm{L}$ & 0.50 & 0.50 & 1.32 \\
\hline Lead & $<0.05$ & $<0.05$ & $<0.05$ & $<0.05$ & $\mathrm{mg} / \mathrm{L}$ & 0.05 & 0.05 & 0.163 \\
\hline Magnesium & 1110 & 1250 & 1230 & 1120 & $\mathrm{mg} / \mathrm{L}$ & 0.5 & 0.5 & 1,244 \\
\hline Mercury & $<0.0002$ & $<0.0002$ & $<0.0002$ & $<0.0002$ & $\mathrm{mg} / \mathrm{L}$ & 0 & 0 & $<0.002$ \\
\hline Nickel & $<0.05$ & $<0.05$ & $<0.05$ & $<0.05$ & $\mathrm{mg} / \mathrm{L}$ & 0.05 & 0.05 & 0.490 \\
\hline Potassium & 944 & 1,010 & 1,080 & 1,170 & $\mathrm{mg} / \mathrm{L}$ & 0.5 & 0.5 & 845 \\
\hline Selenium & $<0.025$ & $<0.025$ & $<0.025$ & $<0.025$ & $\mathrm{mg} / \mathrm{L}$ & 0.025 & 0.025 & 0.150 \\
\hline Silver & $<0.025$ & $<0.025$ & $<0.025$ & $<0.025$ & $\mathrm{mg} / \mathrm{L}$ & 0.025 & 0.025 & $<0.50$ \\
\hline
\end{tabular}


Table F.2 - Analytical Results for Groundwater Sampled from Well WQSP-2

Concentration

\begin{tabular}{|c|c|c|c|c|c|c|c|c|}
\hline \multirow[b]{2}{*}{ Parameter } & \multicolumn{2}{|c|}{ Round 20} & \multicolumn{2}{|c|}{ Round 21} & \multirow[b]{2}{*}{ Units } & \multicolumn{2}{|c|}{ Reporting Limit } & \multirow[b]{2}{*}{$\begin{array}{l}9^{\text {th }} \\
\text { UTLV }^{\mathrm{a}}\end{array}$} \\
\hline & Sample & Dup. & Sample & Dup. & & $\begin{array}{c}\text { Round } \\
20\end{array}$ & $\begin{array}{c}\text { Round } \\
21\end{array}$ & \\
\hline Sodium & 19,200 & 19,900 & 22,700 & 25,500 & $\mathrm{mg} / \mathrm{L}$ & 0.5 & 0.5 & 21,900 \\
\hline Thallium & $<0.025$ & $<0.025$ & $<0.025$ & $<0.025$ & $\mathrm{mg} / \mathrm{L}$ & 0.025 & 0.025 & 0.98 \\
\hline Vanadium & $<0.025$ & $<0.025$ & $<0.025$ & $<0.025$ & $\mathrm{mg} / \mathrm{L}$ & 0.025 & 0.025 & $<0.1$ \\
\hline $\begin{array}{l}{ }^{\mathrm{A}} 95^{\text {th }} \text { Upper tolerance I } \\
{ }^{\mathrm{b}} \text { Reporting limit } \\
{ }^{\mathrm{C}} \text { Not applicable } \\
{ }^{\mathrm{d}} \text { Standard unit }\end{array}$ & , equivale & to $95 \% \mathrm{C}$ & idence lim & & & & & \\
\hline
\end{tabular}

Table F.3 - Analytical Results for Groundwater Sampled from Well WQSP-3

\begin{tabular}{|c|c|c|c|c|c|c|c|c|}
\hline \multirow[b]{3}{*}{ Parameter } & \multicolumn{4}{|c|}{ Concentration } & \multirow[b]{3}{*}{ Units } & \multirow{2}{*}{\multicolumn{2}{|c|}{ Reporting Limit }} & \multirow[b]{3}{*}{$\begin{array}{l}9^{\text {th }} \\
\text { UTLV }^{\mathrm{a}}\end{array}$} \\
\hline & \multicolumn{2}{|c|}{ Round 20} & \multicolumn{2}{|c|}{ Round 21} & & & & \\
\hline & Sample & Dup. & Sample & Dup. & & $\begin{array}{c}\text { Round } \\
20\end{array}$ & $\begin{array}{c}\text { Round } \\
21\end{array}$ & \\
\hline 1,1,1-Trichloroethane & $<1$ & $<1$ & $<1$ & $<1$ & $\mu \mathrm{g} / \mathrm{L}$ & 1 & 1 & $<\mathrm{RL}^{\mathrm{b}}$ \\
\hline 1,1,2,2-Tetrachloroethane & $<1$ & $<1$ & $<1$ & $<1$ & $\mu \mathrm{g} / \mathrm{L}$ & 1 & 1 & $<\mathrm{RL}$ \\
\hline 1,1,2-Trichloroethane & $<1$ & $<1$ & $<1$ & $<1$ & $\mu g / L$ & 1 & 1 & $<\mathrm{RL}$ \\
\hline 1,1-Dichloroethane & $<1$ & $<1$ & $<1$ & $<1$ & $\mu g / L$ & 1 & 1 & $<\mathrm{RL}$ \\
\hline 1,1-Dichloroethylene & $<1$ & $<1$ & $<1$ & $<1$ & $\mu \mathrm{g} / \mathrm{L}$ & 1 & 1 & $<\mathrm{RL}$ \\
\hline 1,2-Dichloroethane & $<1$ & $<1$ & $<1$ & $<1$ & $\mu g / L$ & 1 & 1 & $<\mathrm{RL}$ \\
\hline Carbon tetrachloride & $<1$ & $<1$ & $<1$ & $<1$ & $\mu \mathrm{g} / \mathrm{L}$ & 1 & 1 & $<\mathrm{RL}$ \\
\hline Chlorobenzene & $<1$ & $<1$ & $<1$ & $<1$ & $\mu \mathrm{g} / \mathrm{L}$ & 1 & 1 & $<R L$ \\
\hline Chloroform & $<1$ & $<1$ & $<1$ & $<1$ & $\mu \mathrm{g} / \mathrm{L}$ & 1 & 1 & $<\mathrm{RL}$ \\
\hline cis-1,2-Dichloroethylene & $<1$ & $<1$ & $<1$ & $<1$ & $\mu g / L$ & 1 & 1 & $<\mathrm{RL}$ \\
\hline trans-1,2-Dichloroethylene & $<1$ & $<1$ & $<1$ & $<1$ & $\mu g / L$ & 1 & 1 & $<\mathrm{RL}$ \\
\hline Methyl ethyl ketone & $<5$ & $<5$ & $<5$ & $<5$ & $\mu \mathrm{g} / \mathrm{L}$ & 5 & 5 & $<\mathrm{RL}$ \\
\hline Methylene chloride & $<5$ & $<5$ & $<5$ & $<5$ & $\mu g / L$ & 5 & 5 & $<\mathrm{RL}$ \\
\hline Tetrachloroethylene & $<1$ & $<1$ & $<1$ & $<1$ & $\mu g / L$ & 1 & 1 & $<\mathrm{RL}$ \\
\hline Toluene & $<1$ & $<1$ & $<1$ & $<1$ & $\mu g / L$ & 1 & 1 & $<\mathrm{RL}$ \\
\hline Trichloroethylene & $<1$ & $<1$ & $<1$ & $<1$ & $\mu g / L$ & 1 & 1 & $<R L$ \\
\hline Trichlorofluoromethane & $<1$ & $<1$ & $<1$ & $<1$ & $\mu g / L$ & 1 & 1 & $<\mathrm{RL}$ \\
\hline Vinyl chloride & $<1$ & $<1$ & $<1$ & $<1$ & $\mu g / L$ & 1 & 1 & $<\mathrm{RL}$ \\
\hline Xylene & $<1$ & $<1$ & $<1$ & $<1$ & $\mu \mathrm{g} / \mathrm{L}$ & 1 & 1 & $<\mathrm{RL}$ \\
\hline 1,2-Dichlorobenzene & $<5$ & $<5$ & $<5$ & $<5$ & $\mu g / L$ & 5 & 5 & $<\mathrm{RL}$ \\
\hline 1,4-Dichlorobenzene & $<5$ & $<5$ & $<5$ & $<5$ & $\mu g / L$ & 5 & 5 & $<R L$ \\
\hline 2,4-Dinitrophenol & $<20$ & $<20$ & $<20$ & $<20$ & $\mu g / L$ & 20 & 20 & $<\mathrm{RL}$ \\
\hline 2,4-Dinitrotoluene & $<20$ & $<20$ & $<5$ & $<5$ & $\mu \mathrm{g} / \mathrm{L}$ & 20 & 5 & $<\mathrm{RL}$ \\
\hline 2-Methylphenol & $<5$ & $<5$ & $<5$ & $<5$ & $\mu \mathrm{g} / \mathrm{L}$ & 5 & 5 & $<\mathrm{RL}$ \\
\hline $\begin{array}{l}\text { 3-Methylphenol/ } \\
\text { 4-Methylphenol }\end{array}$ & $<5$ & $<5$ & $<5$ & $<5$ & $\mu \mathrm{g} / \mathrm{L}$ & 5 & 5 & $<\mathrm{RL}$ \\
\hline Hexachlorobenzene & $<5$ & $<5$ & $<20$ & $<20$ & $\mu g / L$ & 5 & 20 & $<\mathrm{RL}$ \\
\hline Hexachloroethane & $<5$ & $<5$ & $<5$ & $<5$ & $\mu \mathrm{g} / \mathrm{L}$ & 5 & 5 & $<\mathrm{RL}$ \\
\hline Nitrobenzene & $<5$ & $<5$ & $<5$ & $<5$ & $\mu g / L$ & 5 & 5 & $<\mathrm{RL}$ \\
\hline Pentachlorophenol & $<5$ & $<5$ & $<20$ & $<20$ & $\mu g / L$ & 5 & 20 & $<R L$ \\
\hline Pyridine & $<5$ & $<5$ & $<5$ & $<5$ & $\mu \mathrm{g} / \mathrm{L}$ & 5 & 5 & $<\mathrm{RL}$ \\
\hline Isobutanol & $<5$ & $<5$ & $<5$ & $<5$ & $\mu g / L$ & 5 & 5 & $<\mathrm{RL}$ \\
\hline
\end{tabular}


Waste Isolation Pilot Plant Annual Site Environmental Report for 2005 DOE/WIPP-06-2225

\begin{tabular}{|c|c|c|c|c|c|c|c|c|}
\hline \multirow[b]{3}{*}{ Parameter } & \multicolumn{4}{|c|}{ Concentration } & \multirow[b]{3}{*}{ Units } & & & \multirow[b]{3}{*}{$\begin{array}{c}\text { 95 } \\
\text { UTLV } \\
\text { UT }\end{array}$} \\
\hline & \multicolumn{2}{|c|}{ Round 20} & \multicolumn{2}{|c|}{ Round 21} & & \multicolumn{2}{|c|}{ Reporting Limit } & \\
\hline & Sample & Dup. & Sample & Dup. & & $\begin{array}{c}\text { Round } \\
20\end{array}$ & $\begin{array}{c}\text { Round } \\
21\end{array}$ & \\
\hline Alkalinity & 34 & 32 & 32 & 34 & $\mathrm{mg} / \mathrm{L}$ & 4 & 4 & 54.5 \\
\hline Chloride & 144,000 & 126,000 & 140,000 & 144,000 & $\mathrm{mg} / \mathrm{L}$ & 2 & 2 & 149,100 \\
\hline Density & 1.15 & 1.15 & 1.15 & 1.14 & $\mathrm{~g} / \mathrm{ml}$ & $N / A^{c}$ & $N / A^{c}$ & 1.17 \\
\hline Nitrate (as N) & $<0.10$ & $<0.10$ & $<0.10$ & $<0.10$ & $\mathrm{mg} / \mathrm{L}$ & 0.1 & 0.1 & 12 \\
\hline $\mathrm{pH}$ & 6.77 & 6.78 & 6.70 & 7.01 & $S U^{d}$ & $N / A^{c}$ & $N / A^{c}$ & $6.6-7.2$ \\
\hline Specific conductance & 210,000 & 212,000 & 194,000 & 194,000 & $\mu \mathrm{mhos} / \mathrm{cm}$ & $N / A^{c}$ & $N / A^{c}$ & 517,000 \\
\hline Sulfate & 8,060 & 7,560 & 7,860 & 8,160 & $\mathrm{mg} / \mathrm{L}$ & 2 & 2 & 8,015 \\
\hline Total dissolved solids & 250,500 & 235,500 & 205,000 & 212,000 & $\mathrm{mg} / \mathrm{L}$ & 10 & 10 & 261,000 \\
\hline Total organic carbon & $<1.0$ & $<1.0$ & $<1.0$ & $<1.0$ & $\mathrm{mg} / \mathrm{L}$ & 1 & 1 & 5 \\
\hline Total organic halogen & 0.32 & 0.35 & 0.86 & 0.75 & $\mathrm{mg} / \mathrm{L}$ & 0.30 & 0.30 & 55 \\
\hline Total suspended solids & $<1.0$ & $<1.0$ & $<1.0$ & $<1.0$ & $\mathrm{mg} / \mathrm{L}$ & 1 & 1 & 107 \\
\hline Antimony & $<0.250$ & $<0.250$ & $<0.250$ & $<0.250$ & $\mathrm{mg} / \mathrm{L}$ & 0.25 & 0.25 & $<1.0$ \\
\hline Arsenic & $<0.250$ & $<0.250$ & $<0.250$ & $<0.250$ & $\mathrm{mg} / \mathrm{L}$ & 0.25 & 0.25 & 0.207 \\
\hline Barium & $<0.02$ & $<0.02$ & 0.051 & 0.041 & $\mathrm{mg} / \mathrm{L}$ & 0.02 & 0.02 & $<1.0$ \\
\hline Beryllium & $<0.01$ & $<0.01$ & $<0.01$ & $<0.01$ & $\mathrm{mg} / \mathrm{L}$ & 0.01 & 0.01 & $<0.1$ \\
\hline Cadmium & $<0.025$ & $<0.025$ & $<0.025$ & $<0.025$ & $\mathrm{mg} / \mathrm{L}$ & 0.025 & 0.025 & $<0.5$ \\
\hline Calcium & 1,980 & 2,000 & 1,810 & 1,810 & $\mathrm{mg} / \mathrm{L}$ & 0.5 & 0.5 & 1,680 \\
\hline Chromium & $<0.025$ & $<0.025$ & $<0.025$ & $<0.025$ & $\mathrm{mg} / \mathrm{L}$ & 0.025 & 0.025 & $<2.0$ \\
\hline Iron & 1.72 & $<0.5$ & $<0.5$ & 2.19 & $\mathrm{mg} / \mathrm{L}$ & 0.5 & 0.5 & $<1.0$ \\
\hline Lead & $<0.10$ & $<0.10$ & $<0.10$ & $<0.10$ & $\mathrm{mg} / \mathrm{L}$ & 0.10 & 0.10 & 0.80 \\
\hline Magnesium & 2,710 & 2,530 & 2,490 & 2,420 & $\mathrm{mg} / \mathrm{L}$ & 0.5 & 0.5 & 2,625 \\
\hline Mercury & $<0.0002$ & $<0.0002$ & $<0.0002$ & $<0.0002$ & $\mathrm{mg} / \mathrm{L}$ & 0 & 0 & $<0.002$ \\
\hline Nickel & $<0.05$ & $<0.05$ & $<0.05$ & $<0.05$ & $\mathrm{mg} / \mathrm{L}$ & 0.05 & 0.05 & $<5.00$ \\
\hline Potassium & 2,490 & 2,670 & 2,480 & 2,550 & $\mathrm{mg} / \mathrm{L}$ & 0.5 & 0.5 & 3,438 \\
\hline Selenium & $<0.25$ & $<0.25$ & $<0.25$ & $<0.25$ & $\mathrm{mg} / \mathrm{L}$ & 0.25 & 0.25 & $<2.00$ \\
\hline Silver & $<0.013$ & $<0.013$ & $<0.013$ & $<0.013$ & $\mathrm{mg} / \mathrm{L}$ & 0.013 & 0.013 & 0.31 \\
\hline Sodium & 77,500 & 75,900 & 83,700 & 78,300 & $\mathrm{mg} / \mathrm{L}$ & 0.5 & 0.5 & 140,400 \\
\hline Thallium & $<0.025$ & $<0.025$ & $<0.025$ & $<0.025$ & $\mathrm{mg} / \mathrm{L}$ & 0.025 & 0.025 & 5.800 \\
\hline Vanadium & $<0.05$ & $<0.05$ & $<0.05$ & $<0.05$ & $\mathrm{mg} / \mathrm{L}$ & 0.05 & 0.05 & $<5.00$ \\
\hline
\end{tabular}




\section{Waste Isolation Pilot Plant Annual Site Environmental Report for 2005 DOE/WIPP-06-2225}

\begin{tabular}{|c|c|c|c|c|c|c|c|c|}
\hline \multirow[b]{3}{*}{ Parameter } & \multicolumn{4}{|c|}{ Concentration } & \multirow[b]{3}{*}{ Units } & \multirow{2}{*}{\multicolumn{2}{|c|}{ Reporting Limit }} & \multirow[b]{3}{*}{$\begin{array}{c}9^{\text {th }} \\
\text { UTLV }^{\text {a }}\end{array}$} \\
\hline & \multicolumn{2}{|c|}{ Round 20} & \multicolumn{2}{|c|}{ Round 21} & & & & \\
\hline & Sample & Dup. & Sample & Dup. & & $\begin{array}{l}\text { Round } \\
20\end{array}$ & $\begin{array}{l}\text { Round } \\
21\end{array}$ & \\
\hline 1,1,1-Trichloroethane & $<1$ & $<1$ & $<1$ & $<1$ & $\mu \mathrm{g} / \mathrm{L}$ & 1 & 1 & $<\mathrm{RL}^{\mathrm{b}}$ \\
\hline 1,1,2,2-Tetrachloroethane & $<1$ & $<1$ & $<1$ & $<1$ & $\mu \mathrm{g} / \mathrm{L}$ & 1 & 1 & $<\mathrm{RL}$ \\
\hline 1,1,2-Trichloroethane & $<1$ & $<1$ & $<1$ & $<1$ & $\mu \mathrm{g} / \mathrm{L}$ & 1 & 1 & $<R L$ \\
\hline 1,1-Dichloroethane & $<1$ & $<1$ & $<1$ & $<1$ & $\mu \mathrm{g} / \mathrm{L}$ & 1 & 1 & $<R L$ \\
\hline 1,1-Dichloroethylene & $<1$ & $<1$ & $<1$ & $<1$ & $\mu \mathrm{g} / \mathrm{L}$ & 1 & 1 & $<\mathrm{RL}$ \\
\hline 1,2-Dichloroethane & $<1$ & $<1$ & $<1$ & $<1$ & $\mu \mathrm{g} / \mathrm{L}$ & 1 & 1 & $<\mathrm{RL}$ \\
\hline Carbon tetrachloride & $<1$ & $<1$ & $<1$ & $<1$ & $\mu \mathrm{g} / \mathrm{L}$ & 1 & 1 & $<\mathrm{RL}$ \\
\hline Chlorobenzene & $<1$ & $<1$ & $<1$ & $<1$ & $\mu \mathrm{g} / \mathrm{L}$ & 1 & 1 & $<R L$ \\
\hline Chloroform & $<1$ & $<1$ & $<1$ & $<1$ & $\mu \mathrm{g} / \mathrm{L}$ & 1 & 1 & $<\mathrm{RL}$ \\
\hline cis-1,2-Dichloroethylene & $<1$ & $<1$ & $<1$ & $<1$ & $\mu \mathrm{g} / \mathrm{L}$ & 1 & 1 & $<\mathrm{RL}$ \\
\hline trans-1,2-Dichloroethylene & $<1$ & $<1$ & $<1$ & $<1$ & $\mu \mathrm{g} / \mathrm{L}$ & 1 & 1 & $<\mathrm{RL}$ \\
\hline Methyl ethyl ketone & $<5$ & $<5$ & $<5$ & $<5$ & $\mu \mathrm{g} / \mathrm{L}$ & 5 & 5 & $<\mathrm{RL}$ \\
\hline Methylene chloride & $<5$ & $<5$ & $<5$ & $<5$ & $\mu \mathrm{g} / \mathrm{L}$ & 5 & 5 & $<R L$ \\
\hline Tetrachloroethylene & $<1$ & $<1$ & $<1$ & $<1$ & $\mu \mathrm{g} / \mathrm{L}$ & 1 & 1 & $<\mathrm{RL}$ \\
\hline Toluene & $<1$ & $<1$ & $<1$ & $<1$ & $\mu \mathrm{g} / \mathrm{L}$ & 1 & 1 & $<R L$ \\
\hline Trichloroethylene & $<1$ & $<1$ & $<1$ & $<1$ & $\mu \mathrm{g} / \mathrm{L}$ & 1 & 1 & $<R L$ \\
\hline Trichlorofluoromethane & $<1$ & $<1$ & $<1$ & $<1$ & $\mu \mathrm{g} / \mathrm{L}$ & 1 & 1 & $<R L$ \\
\hline Vinyl chloride & $<1$ & $<1$ & $<1$ & $<1$ & $\mu \mathrm{g} / \mathrm{L}$ & 1 & 1 & $<\mathrm{RL}$ \\
\hline Xylene & $<1$ & $<1$ & $<1$ & $<1$ & $\mu \mathrm{g} / \mathrm{L}$ & 1 & 1 & $<R L$ \\
\hline 1,2-Dichlorobenzene & $<5$ & $<5$ & $<5$ & $<5$ & $\mu \mathrm{g} / \mathrm{L}$ & 5 & 5 & $<\mathrm{RL}$ \\
\hline 1,4-Dichlorobenzene & $<5$ & $<5$ & $<5$ & $<5$ & $\mu \mathrm{g} / \mathrm{L}$ & 5 & 5 & $<R L$ \\
\hline 2,4-Dinitrophenol & $<20$ & $<20$ & $<20$ & $<20$ & $\mu \mathrm{g} / \mathrm{L}$ & 20 & 20 & $<\mathrm{RL}$ \\
\hline 2,4-Dinitrotoluene & $<5$ & $<5$ & $<5$ & $<5$ & $\mu \mathrm{g} / \mathrm{L}$ & 5 & 5 & $<\mathrm{RL}$ \\
\hline 2-Methylphenol & $<5$ & $<5$ & $<5$ & $<5$ & $\mu \mathrm{g} / \mathrm{L}$ & 5 & 5 & $<\mathrm{RL}$ \\
\hline $\begin{array}{l}\text { 3-Methylphenol/ } \\
\text { 4-Methylphenol }\end{array}$ & $<5$ & $<5$ & $<5$ & $<5$ & $\mu \mathrm{g} / \mathrm{L}$ & 5 & 5 & $<R L$ \\
\hline Hexachlorobenzene & $<5$ & $<5$ & $<5$ & $<5$ & $\mu \mathrm{g} / \mathrm{L}$ & 5 & 5 & $<R L$ \\
\hline Hexachloroethane & $<5$ & $<5$ & $<5$ & $<5$ & $\mu \mathrm{g} / \mathrm{L}$ & 5 & 5 & $<\mathrm{RL}$ \\
\hline Nitrobenzene & $<5$ & $<5$ & $<5$ & $<5$ & $\mu \mathrm{g} / \mathrm{L}$ & 5 & 5 & $<\mathrm{RL}$ \\
\hline Pentachlorophenol & $<20$ & $<20$ & $<20$ & $<20$ & $\mu \mathrm{g} / \mathrm{L}$ & 20 & 20 & $<\mathrm{RL}$ \\
\hline Pyridine & $<5$ & $<5$ & $<5$ & $<5$ & $\mu g / L$ & 5 & 5 & $<R L$ \\
\hline Isobutanol & $<5$ & $<5$ & $<5$ & $<5$ & $\mu g / L$ & 5 & 5 & $<\mathrm{RL}$ \\
\hline Alkalinity & 42 & 42 & 38 & 40 & $\mathrm{mg} / \mathrm{L}$ & 4 & 4 & 47.1 \\
\hline Chloride & 67,200 & 65,200 & 63,400 & 63,300 & $\mathrm{mg} / \mathrm{L}$ & 2 & 2 & 63,960 \\
\hline Density & 1.07 & 1.07 & 1.07 & 1.07 & $\mathrm{~g} / \mathrm{ml}$ & $N / A^{c}$ & $N / A^{c}$ & 1.1 \\
\hline Nitrate (as N) & $<0.10$ & $<0.10$ & $<0.10$ & $<0.10$ & $\mathrm{mg} / \mathrm{L}$ & 0.1 & 0.1 & 10 \\
\hline $\mathrm{pH}$ & 7.20 & 7.22 & 7.22 & 7.22 & $S U^{d}$ & $N / A^{c}$ & $N / A^{c}$ & $6.80-7.61$ \\
\hline Specific conductance & 121,000 & 122,000 & 122,000 & 128,000 & $\mu \mathrm{mhos} / \mathrm{cm}$ & $N / A^{c}$ & $N / A^{c}$ & 319,800 \\
\hline Sulfate & 6,980 & 7,010 & 8,610 & 7,660 & $\mathrm{mg} / \mathrm{L}$ & 2 & 2 & 7,927 \\
\hline Total dissolved solids & 101,200 & 106,100 & 90,200 & 98,400 & $\mathrm{mg} / \mathrm{L}$ & 10 & 10 & 123,500 \\
\hline Total organic carbon & $<1.0$ & $<1.0$ & $<1.0$ & $<1.0$ & $\mathrm{mg} / \mathrm{L}$ & 1 & 1 & 5 \\
\hline Total organic halogen & $<0.30$ & $<0.30$ & $<0.30$ & $<0.30$ & $\mathrm{mg} / \mathrm{L}$ & 0.30 & 0.30 & 17 \\
\hline Total suspended solids & $<1.0$ & $<1.0$ & $<1.0$ & $<1.0$ & $\mathrm{mg} / \mathrm{L}$ & 1 & 1 & 57 \\
\hline Antimony & $<0.05$ & $<0.05$ & $<0.05$ & $<0.05$ & $\mathrm{mg} / \mathrm{L}$ & 0.05 & 0.05 & 0.8 \\
\hline
\end{tabular}


Waste Isolation Pilot Plant Annual Site Environmental Report for 2005 DOE/WIPP-06-2225

\begin{tabular}{|c|c|c|c|c|c|c|c|c|}
\hline \multirow[b]{3}{*}{ Parameter } & \multicolumn{4}{|c|}{ Concentration } & \multirow[b]{3}{*}{ Units } & \multirow{2}{*}{\multicolumn{2}{|c|}{ Reporting Limit }} & \multirow[b]{3}{*}{$\begin{array}{l}9^{\text {th }} \\
\text { UTLV }^{\mathrm{a}}\end{array}$} \\
\hline & \multicolumn{2}{|c|}{ Round 20} & \multicolumn{2}{|c|}{ Round 21} & & & & \\
\hline & Sample & Dup. & Sample & Dup. & & $\begin{array}{c}\text { Round } \\
20\end{array}$ & $\begin{array}{c}\text { Round } \\
21\end{array}$ & \\
\hline Arsenic & $<0.05$ & $<0.05$ & $<0.05$ & $<0.05$ & $\mathrm{mg} / \mathrm{L}$ & 0.05 & 0.05 & $<0.50$ \\
\hline Barium & 0.034 & 0.034 & 0.047 & $<0.049$ & $\mathrm{mg} / \mathrm{L}$ & 0.20 & 0.02 & $<1.0$ \\
\hline Beryllium & 0.028 & 0.028 & $<0.01$ & $<0.01$ & $\mathrm{mg} / \mathrm{L}$ & 0.01 & 0.01 & 0.25 \\
\hline Cadmium & $<0.01$ & $<0.01$ & $<0.01$ & $<0.01$ & $\mathrm{mg} / \mathrm{L}$ & 0.01 & 0.01 & $<0.50$ \\
\hline Calcium & 1510 & 1580 & 1760 & 1650 & $\mathrm{mg} / \mathrm{L}$ & 0.5 & 0.5 & 1,834 \\
\hline Chromium & $<0.10$ & $<0.10$ & $<0.10$ & $<0.10$ & $\mathrm{mg} / \mathrm{L}$ & 0.10 & 0.10 & $<2.0$ \\
\hline Iron & $<0.50$ & 3.16 & $<0.50$ & $<0.50$ & $\mathrm{mg} / \mathrm{L}$ & 0.5 & 0.5 & $<4.0$ \\
\hline Lead & $<0.05$ & $<0.05$ & $<0.05$ & $<0.05$ & $\mathrm{mg} / \mathrm{L}$ & 0.05 & 0.05 & 0.525 \\
\hline Magnesium & 1,180 & 1,340 & 1,540 & 1,410 & $\mathrm{mg} / \mathrm{L}$ & 0.5 & 0.5 & 1,472 \\
\hline Mercury & $<0.0002$ & $<0.0002$ & $<0.0002$ & $<0.0002$ & $\mathrm{mg} / \mathrm{L}$ & 0 & 0 & $<0.002$ \\
\hline Nickel & $<0.025$ & $<0.025$ & $<0.025$ & $<0.025$ & $\mathrm{mg} / \mathrm{L}$ & 0.025 & 0.025 & $<5.00$ \\
\hline Potassium & 1320 & 1130 & 1550 & 1470 & $\mathrm{mg} / \mathrm{L}$ & 0.5 & 0.5 & 1,648 \\
\hline Selenium & $<0.10$ & $<0.10$ & $<0.10$ & $<0.10$ & $\mathrm{mg} / \mathrm{L}$ & 0.10 & 0.10 & 2.009 \\
\hline Silver & $<0.05$ & $<0.05$ & $<0.05$ & $<0.05$ & $\mathrm{mg} / \mathrm{L}$ & 0.05 & 0.05 & 0.519 \\
\hline Sodium & 32,400 & 30,300 & 35,100 & 35,600 & $\mathrm{mg} / \mathrm{L}$ & 0.5 & 0.5 & 38,790 \\
\hline Thallium & $<0.05$ & $<0.05$ & $<0.05$ & $<0.05$ & $\mathrm{mg} / \mathrm{L}$ & 0.05 & 0.05 & 1.00 \\
\hline Vanadium & 0.051 & 0.045 & $<0.025$ & $<0.025$ & $\mathrm{mg} / \mathrm{L}$ & 0.05 & 0.025 & $<5.00$ \\
\hline
\end{tabular}

Table F.5 - Analytical Results for Groundwater Sampled from Well WQSP-5

\begin{tabular}{|c|c|c|c|c|c|c|c|c|}
\hline \multirow[b]{3}{*}{ Parameter } & \multicolumn{4}{|c|}{ Concentration } & \multirow[b]{3}{*}{ Units } & \multirow{2}{*}{\multicolumn{2}{|c|}{ Reporting Limit }} & \multirow[b]{3}{*}{$\begin{array}{c}95^{\text {th }} \\
\text { UTLV }^{\mathrm{a}}\end{array}$} \\
\hline & \multicolumn{2}{|c|}{ Round 20} & \multicolumn{2}{|c|}{ Round 21} & & & & \\
\hline & Sample & Dup. & Sample & Dup. & & $\begin{array}{c}\text { Round } \\
20\end{array}$ & $\begin{array}{c}\text { Round } \\
21\end{array}$ & \\
\hline 1,1,1-Trichloroethane & $<1$ & $<1$ & $<1$ & $<1$ & $\mu \mathrm{g} / \mathrm{L}$ & 1 & 1 & $<\mathrm{RL}^{\mathrm{b}}$ \\
\hline 1,1,2,2-Tetrachloroethane & $<1$ & $<1$ & $<1$ & $<1$ & $\mu \mathrm{g} / \mathrm{L}$ & 1 & 1 & $<\mathrm{RL}$ \\
\hline 1,1,2-Trichloroethane & $<1$ & $<1$ & $<1$ & $<1$ & $\mu \mathrm{g} / \mathrm{L}$ & 1 & 1 & $<R L$ \\
\hline 1,1-Dichloroethane & $<1$ & $<1$ & $<1$ & $<1$ & $\mu \mathrm{g} / \mathrm{L}$ & 1 & 1 & $<\mathrm{RL}$ \\
\hline 1,1-Dichloroethylene & $<1$ & $<1$ & $<1$ & $<1$ & $\mu \mathrm{g} / \mathrm{L}$ & 1 & 1 & $<R L$ \\
\hline 1,2-Dichloroethane & $<1$ & $<1$ & $<1$ & $<1$ & $\mu \mathrm{g} / \mathrm{L}$ & 1 & 1 & $<\mathrm{RL}$ \\
\hline Carbon tetrachloride & $<1$ & $<1$ & $<1$ & $<1$ & $\mu \mathrm{g} / \mathrm{L}$ & 1 & 1 & $<R L$ \\
\hline Chlorobenzene & $<1$ & $<1$ & $<1$ & $<1$ & $\mu \mathrm{g} / \mathrm{L}$ & 1 & 1 & $<R L$ \\
\hline Chloroform & $<1$ & $<1$ & $<1$ & $<1$ & $\mu \mathrm{g} / \mathrm{L}$ & 1 & 1 & $<R L$ \\
\hline cis-1,2-Dichloroethylene & $<1$ & $<1$ & $<1$ & $<1$ & $\mu \mathrm{g} / \mathrm{L}$ & 1 & 1 & $<R L$ \\
\hline trans-1,2-Dichloroethylene & $<1$ & $<1$ & $<1$ & $<1$ & $\mu g / L$ & 1 & 1 & $<\mathrm{RL}$ \\
\hline Methyl ethyl ketone & $<5$ & $<5$ & $<5$ & $<5$ & $\mu \mathrm{g} / \mathrm{L}$ & 5 & 5 & $<\mathrm{RL}$ \\
\hline Methylene chloride & $<5$ & $<5$ & $<5$ & $<5$ & $\mu \mathrm{g} / \mathrm{L}$ & 5 & 5 & $<R L$ \\
\hline Tetrachloroethylene & $<1$ & $<1$ & $<1$ & $<1$ & $\mu g / L$ & 1 & 1 & $<R L$ \\
\hline Toluene & $<1$ & $<1$ & $<1$ & $<1$ & $\mu \mathrm{g} / \mathrm{L}$ & 1 & 1 & $<R L$ \\
\hline Trichloroethylene & $<1$ & $<1$ & $<1$ & $<1$ & $\mu \mathrm{g} / \mathrm{L}$ & 1 & 1 & $<R L$ \\
\hline Trichlorofluoromethane & $<1$ & $<1$ & $<1$ & $<1$ & $\mu \mathrm{g} / \mathrm{L}$ & 1 & 1 & $<R L$ \\
\hline
\end{tabular}




\begin{tabular}{|c|c|c|c|c|c|c|c|c|}
\hline \multirow[b]{3}{*}{ Parameter } & \multicolumn{4}{|c|}{ Concentration } & \multirow[b]{3}{*}{ Units } & & & \multirow[b]{3}{*}{$\begin{array}{c}\mathbf{9 5}^{\text {th }} \\
\text { UTLVV }^{\text {a }}\end{array}$} \\
\hline & \multicolumn{2}{|c|}{ Round 20} & \multicolumn{2}{|c|}{ Round 21} & & \multicolumn{2}{|c|}{ Reporting Limit } & \\
\hline & Sample & Dup. & Sample & Dup. & & $\begin{array}{c}\text { Round } \\
20\end{array}$ & $\begin{array}{c}\text { Round } \\
21\end{array}$ & \\
\hline Vinyl chloride & $<1$ & $<1$ & $<1$ & $<1$ & $\mu \mathrm{g} / \mathrm{L}$ & 1 & 1 & $<\mathrm{RL}$ \\
\hline Xylene & $<1$ & $<1$ & $<1$ & $<1$ & $\mu \mathrm{g} / \mathrm{L}$ & 1 & 1 & $<\mathrm{RL}$ \\
\hline 1,2-Dichlorobenzene & $<5$ & $<5$ & $<5$ & $<5$ & $\mu g / L$ & 5 & 5 & $<R L$ \\
\hline 1,4-Dichlorobenzene & $<5$ & $<5$ & $<5$ & $<5$ & $\mu g / L$ & 5 & 5 & $<\mathrm{RL}$ \\
\hline 2,4-Dinitrophenol & $<20$ & $<20$ & $<20$ & $<20$ & $\mu \mathrm{g} / \mathrm{L}$ & 20 & 20 & $<\mathrm{RL}$ \\
\hline 2,4-Dinitrotoluene & $<5$ & $<5$ & $<5$ & $<5$ & $\mu g / L$ & 5 & 5 & $<R L$ \\
\hline 2-Methylphenol & $<5$ & $<5$ & $<5$ & $<5$ & $\mu \mathrm{g} / \mathrm{L}$ & 5 & 5 & $<R L$ \\
\hline $\begin{array}{l}\text { 3-Methylphenol/ } \\
\text { 4-Methylphenol }\end{array}$ & $<5$ & $<5$ & $<5$ & $<5$ & $\mu \mathrm{g} / \mathrm{L}$ & 5 & 5 & $<R L$ \\
\hline Hexachlorobenzene & $<5$ & $<5$ & $<5$ & $<5$ & $\mu \mathrm{g} / \mathrm{L}$ & 5 & 5 & $<R L$ \\
\hline Hexachloroethane & $<5$ & $<5$ & $<5$ & $<5$ & $\mu \mathrm{g} / \mathrm{L}$ & 5 & 5 & $<\mathrm{RL}$ \\
\hline Nitrobenzene & $<5$ & $<5$ & $<5$ & $<5$ & $\mu g / L$ & 5 & 5 & $<\mathrm{RL}$ \\
\hline Pentachlorophenol & $<5$ & $<5$ & $<5$ & $<5$ & $\mu \mathrm{g} / \mathrm{L}$ & 5 & 5 & $<\mathrm{RL}$ \\
\hline Pyridine & $<5$ & $<5$ & $<5$ & $<5$ & $\mu \mathrm{g} / \mathrm{L}$ & 5 & 5 & $<\mathrm{RL}$ \\
\hline Isobutanol & $<5$ & $<5$ & $<5$ & $<5$ & $\mu \mathrm{g} / \mathrm{L}$ & 5 & 5 & $<\mathrm{RL}$ \\
\hline Alkalinity & 46 & 44 & 46 & 44 & $\mathrm{mg} / \mathrm{L}$ & 4 & 4 & 56 \\
\hline Chloride & 18,100 & 17,700 & 14,800 & 15,400 & $\mathrm{mg} / \mathrm{L}$ & 2 & 2 & 18,100 \\
\hline Density & 1.02 & 1.02 & 1.03 & 1.03 & $\mathrm{~g} / \mathrm{ml}$ & $N / A^{c}$ & $N / A^{c}$ & 1.04 \\
\hline Nitrate (as N) & $<0.10$ & $<0.10$ & $<0.10$ & $<0.10$ & $\mathrm{mg} / \mathrm{L}$ & 0.1 & 0.1 & 10 \\
\hline $\mathrm{pH}$ & 7.55 & 7.56 & 7.62 & 7.62 & $S U^{d}$ & $N / A^{c}$ & $N / A^{c}$ & $7.40-7.90$ \\
\hline Specific conductance & 43,500 & 43,200 & 43,000 & 42,700 & $\mu \mathrm{mhos} / \mathrm{cm}$ & $N / A^{c}$ & $N / A^{c}$ & 67,700 \\
\hline Sulfate & 5,520 & 5,500 & 6,440 & 6,870 & $\mathrm{mg} / \mathrm{L}$ & 2 & 2 & 6,129 \\
\hline Total dissolved solids & 30,600 & 31,400 & 31,700 & 30,000 & $\mathrm{mg} / \mathrm{L}$ & 10 & 10 & 43,950 \\
\hline Total organic carbon & $<1.0$ & $<1.0$ & $<1.0$ & $<1.0$ & $\mathrm{mg} / \mathrm{L}$ & 1 & 1 & 5 \\
\hline Total organic halogen & $<0.15$ & 0.37 & $<0.30$ & $<0.30$ & $\mathrm{mg} / \mathrm{L}$ & 0.15 & 0.30 & 8.37 \\
\hline Total suspended solids & $<1.0$ & $<1.0$ & $<1.0$ & $<1.0$ & $\mathrm{mg} / \mathrm{L}$ & 1 & 1 & 10 \\
\hline Antimony & $<0.05$ & $<0.05$ & $<0.05$ & $<0.05$ & $\mathrm{mg} / \mathrm{L}$ & 0.05 & 0.05 & 0.073 \\
\hline Arsenic & $<0.10$ & $<0.10$ & $<0.10$ & $<0.10$ & $\mathrm{mg} / \mathrm{L}$ & 0.10 & 0.10 & 0.5 \\
\hline Barium & 0.027 & 0.028 & $<0.02$ & $<0.02$ & $\mathrm{mg} / \mathrm{L}$ & 0.02 & 0.02 & 1 \\
\hline Beryllium & $<0.01$ & $<0.01$ & $<0.025$ & $<0.025$ & $\mathrm{mg} / \mathrm{L}$ & 0.01 & 0.025 & 0.02 \\
\hline Cadmium & $<0.01$ & $<0.01$ & $<0.01$ & $<0.01$ & $\mathrm{mg} / \mathrm{L}$ & 0.01 & 0.01 & 0.05 \\
\hline Calcium & 1020 & 1060 & 1130 & 1150 & $\mathrm{mg} / \mathrm{L}$ & 0.5 & 0.5 & 1,303 \\
\hline Chromium & $<0.025$ & $<0.025$ & $<0.250$ & $<0.250$ & $\mathrm{mg} / \mathrm{L}$ & 0.025 & 0.025 & 0.50 \\
\hline Iron & 2.64 & 2.71 & $<0.50$ & $<0.50$ & $\mathrm{mg} / \mathrm{L}$ & 0.5 & 0.5 & 0.795 \\
\hline Lead & $<0.05$ & $<0.05$ & $<0.05$ & $<0.05$ & $\mathrm{mg} / \mathrm{L}$ & 0.05 & 0.05 & 0.05 \\
\hline Magnesium & 474 & 497 & 553 & 568 & $\mathrm{mg} / \mathrm{L}$ & 0.5 & 0.5 & 547.0 \\
\hline Mercury & $<0.0002$ & $<0.0002$ & $<0.0002$ & $<0.0002$ & $\mathrm{mg} / \mathrm{L}$ & 0 & 0 & 0.002 \\
\hline Nickel & $<0.025$ & $<0.025$ & $<0.025$ & $<0.025$ & $\mathrm{mg} / \mathrm{L}$ & 0.025 & 0.025 & 0.10 \\
\hline Potassium & 539 & 553 & 598 & 608 & $\mathrm{mg} / \mathrm{L}$ & 0.5 & 0.5 & 622.0 \\
\hline Selenium & $<0.05$ & $<0.05$ & $<0.05$ & $<0.05$ & $\mathrm{mg} / \mathrm{L}$ & 0.05 & 0.05 & 0.10 \\
\hline Silver & $<0.013$ & $<0.013$ & $<0.013$ & $<0.013$ & $\mathrm{mg} / \mathrm{L}$ & 0.013 & 0.013 & 0.50 \\
\hline
\end{tabular}


Table F.5 - Analytical Results for Groundwater Sampled from Well WQSP-5

\begin{tabular}{|c|c|c|c|c|c|c|c|c|}
\hline \multirow[b]{3}{*}{ Parameter } & \multicolumn{4}{|c|}{ Concentration } & \multirow[b]{3}{*}{ Units } & \multirow{2}{*}{\multicolumn{2}{|c|}{ Reporting Limit }} & \multirow[b]{3}{*}{$\begin{array}{c}9^{\text {th }} \\
\text { UTLV }^{\mathrm{a}}\end{array}$} \\
\hline & \multicolumn{2}{|c|}{ Round 20} & \multicolumn{2}{|c|}{ Round 21} & & & & \\
\hline & Sample & Dup. & Sample & Dup. & & $\begin{array}{c}\text { Round } \\
20\end{array}$ & $\begin{array}{c}\text { Round } \\
21\end{array}$ & \\
\hline Sodium & 8,420 & 8,550 & 8,820 & 8,920 & $\mathrm{mg} / \mathrm{L}$ & 0.5 & 0.5 & 11,190 \\
\hline Thallium & $<0.10$ & $<0.10$ & $<0.10$ & $<0.10$ & $\mathrm{mg} / \mathrm{L}$ & 0.10 & 0.10 & 0.209 \\
\hline Vanadium & 0.055 & 0.047 & $<0.025$ & $<0.025$ & $\mathrm{mg} / \mathrm{L}$ & 0.025 & 0.025 & 2.70 \\
\hline
\end{tabular}

Table F.6 - Analytical Results for Groundwater Sampled from Well WQSP-6

Concentration

\begin{tabular}{|c|c|c|c|c|c|c|c|c|}
\hline \multirow[b]{2}{*}{ Parameter } & \multicolumn{2}{|c|}{ Round 20} & \multicolumn{2}{|c|}{ Round 21} & \multirow[b]{2}{*}{ Units } & \multicolumn{2}{|c|}{ Reporting LIMIT } & \multirow[b]{2}{*}{$\begin{array}{l}95^{\text {th }} \\
\text { UTLV }\end{array}$} \\
\hline & Sample & Dup. & Sample & Dup. & & $\begin{array}{c}\text { Round } \\
20\end{array}$ & $\begin{array}{c}\text { Round } \\
21\end{array}$ & \\
\hline 1,1,1-Trichloroethane & $<1$ & $<1$ & $<1$ & $<1$ & $\mu \mathrm{g} / \mathrm{L}$ & 1 & 1 & $<\mathrm{RL}^{\mathrm{b}}$ \\
\hline 1,1,2,2-Tetrachloroethane & $<1$ & $<1$ & $<1$ & $<1$ & $\mu g / L$ & 1 & 1 & $<\mathrm{RL}$ \\
\hline 1,1,2-Trichloroethane & $<1$ & $<1$ & $<1$ & $<1$ & $\mu g / L$ & 1 & 1 & $<R L$ \\
\hline 1,1-Dichloroethane & $<1$ & $<1$ & $<1$ & $<1$ & $\mu \mathrm{g} / \mathrm{L}$ & 1 & 1 & $<R L$ \\
\hline 1,1-Dichloroethylene & $<1$ & $<1$ & $<1$ & $<1$ & $\mu g / L$ & 1 & 1 & $<R L$ \\
\hline 1,2-Dichloroethane & $<1$ & $<1$ & $<1$ & $<1$ & $\mu \mathrm{g} / \mathrm{L}$ & 1 & 1 & $<R L$ \\
\hline Carbon tetrachloride & $<1$ & $<1$ & $<1$ & $<1$ & $\mu g / L$ & 1 & 1 & $<\mathrm{RL}$ \\
\hline Chlorobenzene & $<1$ & $<1$ & $<1$ & $<1$ & $\mu g / L$ & 1 & 1 & $<\mathrm{RL}$ \\
\hline Chloroform & $<1$ & $<1$ & $<1$ & $<1$ & $\mu \mathrm{g} / \mathrm{L}$ & 1 & 1 & $<\mathrm{RL}$ \\
\hline cis-1,2-Dichloroethylene & $<1$ & $<1$ & $<1$ & $<1$ & $\mu g / L$ & 1 & 1 & $<\mathrm{RL}$ \\
\hline trans-1,2-Dichloroethylene & $<1$ & $<1$ & $<1$ & $<1$ & $\mu g / L$ & 1 & 1 & $<\mathrm{RL}$ \\
\hline Methyl ethyl ketone & $<5$ & $<5$ & $<5$ & $<5$ & $\mu g / L$ & 5 & 5 & $<R L$ \\
\hline Methylene chloride & $<5$ & $<5$ & $<5$ & $<5$ & $\mu g / L$ & 5 & 5 & $<\mathrm{RL}$ \\
\hline Tetrachloroethylene & $<1$ & $<1$ & $<1$ & $<1$ & $\mu g / L$ & 1 & 1 & $<R L$ \\
\hline Toluene & $<1$ & $<1$ & $<1$ & $<1$ & $\mu g / L$ & 1 & 1 & $<R L$ \\
\hline Trichloroethylene & $<1$ & $<1$ & $<1$ & $<1$ & $\mu g / L$ & 1 & 1 & $<R L$ \\
\hline Trichlorofluoromethane & $<1$ & $<1$ & $<1$ & $<1$ & $\mu g / L$ & 1 & 1 & $<R L$ \\
\hline Vinyl chloride & $<1$ & $<1$ & $<1$ & $<1$ & $\mu \mathrm{g} / \mathrm{L}$ & 1 & 1 & $<R L$ \\
\hline Xylene & $<1$ & $<1$ & $<1$ & $<1$ & $\mu \mathrm{g} / \mathrm{L}$ & 1 & 1 & $<\mathrm{RL}$ \\
\hline 1,2-Dichlorobenzene & $<5$ & $<5$ & $<5$ & $<5$ & $\mu g / L$ & 5 & 5 & $<\mathrm{RL}$ \\
\hline 1,4-Dichlorobenzene & $<5$ & $<5$ & $<5$ & $<5$ & $\mu g / L$ & 5 & 5 & $<R L$ \\
\hline 2,4-Dinitrophenol & $<5$ & $<5$ & $<20$ & $<20$ & $\mu g / L$ & 5 & 20 & $<R L$ \\
\hline 2,4-Dinitrotoluene & $<5$ & $<5$ & $<5$ & $<5$ & $\mu \mathrm{g} / \mathrm{L}$ & 5 & 5 & $<R L$ \\
\hline 2-Methylphenol & $<5$ & $<5$ & $<5$ & $<5$ & $\mu g / L$ & 5 & 5 & $<R L$ \\
\hline $\begin{array}{l}\text { 3-Methylphenol } \\
\text { 4-Methylphenol }\end{array}$ & $<5$ & $<5$ & $<5$ & $<5$ & $\mu g / L$ & 5 & 5 & $<R L$ \\
\hline Hexachlorobenzene & $<5$ & $<5$ & $<5$ & $<5$ & $\mu \mathrm{g} / \mathrm{L}$ & 5 & 5 & $<\mathrm{RL}$ \\
\hline Hexachloroethane & $<5$ & $<5$ & $<5$ & $<5$ & $\mu g / L$ & 5 & 5 & $<\mathrm{RL}$ \\
\hline Nitrobenzene & $<5$ & $<5$ & $<5$ & $<5$ & $\mu g / L$ & 5 & 5 & $<R L$ \\
\hline Pentachlorophenol & $<5$ & $<5$ & $<5$ & $<5$ & $\mu g / L$ & 5 & 5 & $<R L$ \\
\hline Pyridine & $<5$ & $<5$ & $<5$ & $<5$ & $\mu g / L$ & 5 & 5 & $<\mathrm{RL}$ \\
\hline
\end{tabular}


Waste Isolation Pilot Plant Annual Site Environmental Report for 2005 DOE/WIPP-06-2225

\begin{tabular}{|c|c|c|c|c|c|c|c|c|}
\hline \multirow[b]{3}{*}{ Parameter } & \multicolumn{4}{|c|}{ Concentration } & \multirow[b]{3}{*}{ Units } & & & \multirow[b]{3}{*}{$\begin{array}{l}\text { 95 }^{\text {th }} \\
\text { UTLV }^{\text {a }}\end{array}$} \\
\hline & \multicolumn{2}{|c|}{ Round 20} & \multicolumn{2}{|c|}{ Round 21} & & \multicolumn{2}{|c|}{ Reporting LIMIT } & \\
\hline & Sample & Dup. & Sample & Dup. & & $\begin{array}{c}\text { Round } \\
20\end{array}$ & $\begin{array}{c}\text { Round } \\
21 \\
\end{array}$ & \\
\hline Isobutanol & $<5$ & $<5$ & $<5$ & $<5$ & $\mu \mathrm{g} / \mathrm{L}$ & 5 & 5 & $<R L$ \\
\hline Alkalinity & 44 & 46 & 44 & 46 & $\mathrm{mg} / \mathrm{L}$ & 4 & 4 & 55.8 \\
\hline Chloride & 6,140 & 6,220 & 6,120 & 5,540 & $\mathrm{mg} / \mathrm{L}$ & 2 & 2 & 6,200 \\
\hline Density & 1.02 & 1.02 & 1.00 & 1.00 & $\mathrm{~g} / \mathrm{ml}$ & $N / A^{c}$ & $N / A^{c}$ & 1.02 \\
\hline Nitrate (as $\mathrm{N}$ ) & $<0.10$ & $<0.10$ & $<0.10$ & $<0.10$ & $\mathrm{mg} / \mathrm{L}$ & 0.1 & 0.1 & 7.45 \\
\hline $\mathrm{pH}$ & 7.63 & 7.64 & 7.84 & 7.83 & $S U^{d}$ & $N / A^{c}$ & $N / A^{c}$ & $7.50-7.90$ \\
\hline Specific conductance & 20,700 & 20,700 & 20,000 & 19,900 & $\mu \mathrm{mhos} / \mathrm{cm}$ & $N / A^{c}$ & $N / A^{c}$ & 27,660 \\
\hline Sulfate & 5,260 & 5,280 & 5,030 & 4,320 & $\mathrm{mg} / \mathrm{L}$ & 2 & 2 & 5,557 \\
\hline Total dissolved solids & 15,300 & 13,900 & 14,800 & 15,000 & $\mathrm{mg} / \mathrm{L}$ & 10 & 10 & 22,500 \\
\hline Total organic carbon & $<1.0$ & $<1.0$ & $<1.0$ & $<1.0$ & $\mathrm{mg} / \mathrm{L}$ & 1 & 1 & 10.14 \\
\hline Total organic halogen & $<0.15$ & $<0.15$ & $<0.30$ & $<0.30$ & $\mathrm{mg} / \mathrm{L}$ & 0.15 & 0.30 & 1.54 \\
\hline Total suspended solids & $<1.0$ & $<1.0$ & $<1.0$ & $<1.0$ & $\mathrm{mg} / \mathrm{L}$ & 1 & 1 & 14.8 \\
\hline Antimony & $<0.025$ & $<0.025$ & $<0.025$ & $<0.025$ & $\mathrm{mg} / \mathrm{L}$ & 0.025 & 0.025 & 0.14 \\
\hline Arsenic & $<0.10$ & $<0.10$ & $<0.10$ & $<0.10$ & $\mathrm{mg} / \mathrm{L}$ & 0.10 & 0.10 & $<0.50$ \\
\hline Barium & $<0.02$ & $<0.02$ & $<0.02$ & $<0.02$ & $\mathrm{mg} / \mathrm{L}$ & 0.02 & 0.02 & $<1.0$ \\
\hline Beryllium & $<0.01$ & $<0.01$ & 0.028 & 0.028 & $\mathrm{mg} / \mathrm{L}$ & 0.01 & 0.01 & $<0.020$ \\
\hline Cadmium & $<0.01$ & $<0.01$ & $<0.01$ & $<0.01$ & $\mathrm{mg} / \mathrm{L}$ & 0.01 & 0.01 & $<0.050$ \\
\hline Calcium & 736 & 756 & 739 & 776 & $\mathrm{mg} / \mathrm{L}$ & 0.5 & 0.5 & 796 \\
\hline Chromium & $<0.025$ & $<0.025$ & $<0.025$ & $<0.025$ & $\mathrm{mg} / \mathrm{L}$ & 0.025 & 0.025 & $<0.50$ \\
\hline Iron & $<0.50$ & $<0.5$ & $<0.50$ & $<0.50$ & $\mathrm{mg} / \mathrm{L}$ & 0.5 & 0.5 & 3.105 \\
\hline Lead & $<0.02$ & $<0.02$ & $<0.02$ & $<0.02$ & $\mathrm{mg} / \mathrm{L}$ & 0.02 & 0.02 & 0.150 \\
\hline Magnesium & 232 & 246 & 238 & 248 & $\mathrm{mg} / \mathrm{L}$ & 0.5 & 0.5 & 255 \\
\hline Mercury & $<0.0002$ & $<0.0002$ & $<0.0002$ & $<0.0002$ & $\mathrm{mg} / \mathrm{L}$ & 0 & 0 & $<0.002$ \\
\hline Nickel & $<0.025$ & $<0.03$ & $<0.03$ & $<0.03$ & $\mathrm{mg} / \mathrm{L}$ & 0.025 & 0.03 & $<0.50$ \\
\hline Potassium & 275 & 270 & 258 & 260 & $\mathrm{mg} / \mathrm{L}$ & 0.5 & 0.5 & 270 \\
\hline Selenium & 0.078 & 0.059 & $<0.025$ & $<0.025$ & $\mathrm{mg} / \mathrm{L}$ & 0.025 & 0.025 & $<0.10$ \\
\hline Silver & $<0.013$ & $<0.013$ & $<0.013$ & $<0.013$ & $\mathrm{mg} / \mathrm{L}$ & 0.013 & 0.013 & $<0.50$ \\
\hline Sodium & 3,980 & 3,840 & 4,380 & 4,250 & $\mathrm{mg} / \mathrm{L}$ & 0.5 & 0.5 & 6,290 \\
\hline Thallium & $<0.075$ & $<0.075$ & $<0.075$ & $<0.075$ & $\mathrm{mg} / \mathrm{L}$ & 0.075 & 0.075 & 0.560 \\
\hline Vanadium & $<0.025$ & $<0.025$ & $<0.025$ & $<0.025$ & $\mathrm{mg} / \mathrm{L}$ & 0.025 & 0.025 & $<0.10$ \\
\hline
\end{tabular}

A $95^{\text {th }}$ Upper tolerance limit value, equivalent to $95 \%$ confidence limit

${ }^{\mathrm{b}}$ Reporting limit

c Not applicable

d Standard unit 


\begin{tabular}{|c|c|c|c|c|c|c|c|c|}
\hline \multirow[b]{3}{*}{ Parameter } & \multicolumn{4}{|c|}{ Concentration } & \multirow[b]{3}{*}{ Units } & & & \multirow[b]{3}{*}{$\begin{array}{c}95^{\text {th }} \\
\text { UTLV }^{\mathrm{a}}\end{array}$} \\
\hline & \multicolumn{2}{|c|}{ Round 20} & \multicolumn{2}{|c|}{ Round 21} & & \multicolumn{2}{|c|}{ Reporting LIMIT } & \\
\hline & Sample & Dup. & Sample & Dup. & & $\begin{array}{c}\text { Round } \\
20\end{array}$ & $\begin{array}{c}\text { Round } \\
21\end{array}$ & \\
\hline 1,1,1-Trichloroethane & $<1$ & $<1$ & $<1$ & $<1$ & $\mu \mathrm{g} / \mathrm{L}$ & 1 & 1 & $<\mathrm{RL}^{\mathrm{b}}$ \\
\hline $1,1,2,2$-Tetrachloroethane & $<1$ & $<1$ & $<1$ & $<1$ & $\mu g / L$ & 1 & 1 & $<\mathrm{RL}$ \\
\hline 1,1,2-Trichloroethane & $<1$ & $<1$ & $<1$ & $<1$ & $\mu g / L$ & 1 & 1 & $<\mathrm{RL}$ \\
\hline 1,1-Dichloroethane & $<1$ & $<1$ & $<1$ & $<1$ & $\mu g / L$ & 1 & 1 & $<\mathrm{RL}$ \\
\hline 1,1-Dichloroethylene & $<1$ & $<1$ & $<1$ & $<1$ & $\mu g / L$ & 1 & 1 & $<\mathrm{RL}$ \\
\hline 1,2-Dichloroethane & $<1$ & $<1$ & $<1$ & $<1$ & $\mu g / L$ & 1 & 1 & $<\mathrm{RL}$ \\
\hline Carbon tetrachloride & $<1$ & $<1$ & $<1$ & $<1$ & $\mu g / L$ & 1 & 1 & $<\mathrm{RL}$ \\
\hline Chlorobenzene & $<1$ & $<1$ & $<1$ & $<1$ & $\mu \mathrm{g} / \mathrm{L}$ & 1 & 1 & $<\mathrm{RL}$ \\
\hline Chloroform & $<1$ & $<1$ & $<1$ & $<1$ & $\mu g / L$ & 1 & 1 & $<\mathrm{RL}$ \\
\hline cis-1,2-Dichloroethylene & $<1$ & $<1$ & $<1$ & $<1$ & $\mu \mathrm{g} / \mathrm{L}$ & 1 & 1 & $<\mathrm{RL}$ \\
\hline trans-1,2-Dichloroethylene & $<1$ & $<1$ & $<1$ & $<1$ & $\mu g / L$ & 1 & 1 & $<\mathrm{RL}$ \\
\hline Methyl ethyl ketone & $<5$ & $<5$ & $<5$ & $<5$ & $\mu g / L$ & 5 & 5 & $<\mathrm{RL}$ \\
\hline Methylene chloride & $<5$ & $<5$ & $<5$ & $<5$ & $\mu g / L$ & 5 & 5 & $<\mathrm{RL}$ \\
\hline Tetrachloroethylene & $<1$ & $<1$ & $<1$ & $<1$ & $\mu g / L$ & 1 & 1 & $<\mathrm{RL}$ \\
\hline Toluene & $<1$ & $<1$ & $<1$ & $<1$ & $\mu g / L$ & 1 & 1 & $<\mathrm{RL}$ \\
\hline Trichloroethylene & $<1$ & $<1$ & $<1$ & $<1$ & $\mu g / L$ & 1 & 1 & $<\mathrm{RL}$ \\
\hline Trichlorofluoromethane & $<1$ & $<1$ & $<1$ & $<1$ & $\mu g / L$ & 1 & 1 & $<\mathrm{RL}$ \\
\hline Vinyl chloride & $<1$ & $<1$ & $<1$ & $<1$ & $\mu g / L$ & 1 & 1 & $<\mathrm{RL}$ \\
\hline Xylene & $<1$ & $<1$ & $<1$ & $<1$ & $\mu g / L$ & 1 & 1 & $<\mathrm{RL}$ \\
\hline 1,2-Dichlorobenzene & $<5$ & $<5$ & $<5$ & $<5$ & $\mu g / L$ & 5 & 5 & $<\mathrm{RL}$ \\
\hline 1,4-Dichlorobenzene & $<5$ & $<5$ & $<5$ & $<5$ & $\mu g / L$ & 5 & 5 & $<\mathrm{RL}$ \\
\hline 2,4-Dinitrophenol & $<20$ & $<20$ & $<20$ & $<20$ & $\mu g / L$ & 20 & 20 & $<\mathrm{RL}$ \\
\hline 2,4-Dinitrotoluene & $<5$ & $<5$ & $<5$ & $<5$ & $\mu g / L$ & 5 & 5 & $<\mathrm{RL}$ \\
\hline 2-Methylphenol & $<5$ & $<5$ & $<5$ & $<5$ & $\mu g / L$ & 5 & 5 & $<R L$ \\
\hline $\begin{array}{l}\text { 3-Methylphenol/ } \\
\text { 4-Methylphenol }\end{array}$ & $<5$ & $<5$ & $<5$ & $<5$ & $\mu \mathrm{g} / \mathrm{L}$ & 5 & 5 & $<\mathrm{RL}$ \\
\hline Hexachlorobenzene & $<5$ & $<5$ & $<5$ & $<5$ & $\mu g / L$ & 5 & 5 & $<\mathrm{RL}$ \\
\hline Hexachloroethane & $<5$ & $<5$ & $<5$ & $<5$ & $\mu g / L$ & 5 & 5 & $<\mathrm{RL}$ \\
\hline Nitrobenzene & $<5$ & $<5$ & $<5$ & $<5$ & $\mu g / L$ & 5 & 5 & $<\mathrm{RL}$ \\
\hline Pentachlorophenol & $<5$ & $<5$ & $<20$ & $<20$ & $\mu g / L$ & 5 & 20 & $<\mathrm{RL}$ \\
\hline Pyridine & $<5$ & $<5$ & $<5$ & $<5$ & $\mu \mathrm{g} / \mathrm{L}$ & 5 & 5 & $<\mathrm{RL}$ \\
\hline Isobutanol & $<5$ & $<5$ & $<5$ & $<5$ & $\mathrm{mg} / \mathrm{L}$ & 5 & 5 & $<\mathrm{RL}$ \\
\hline Alkalinity & 104 & 102 & 106 & 108 & $\mathrm{mg} / \mathrm{L}$ & 4 & 4 & 113 \\
\hline Chloride & 432 & 401 & 360 & 357 & $\mathrm{mg} / \mathrm{L}$ & 2 & 2 & 1040 \\
\hline Density & 1.00 & 1.00 & 1.00 & 1.00 & $\mathrm{~g} / \mathrm{ml}$ & $N / A^{c}$ & $N / A^{c}$ & 1.01 \\
\hline Nitrate (as N) & 5.98 & 5.86 & $<0.01$ & $<0.01$ & $\mathrm{mg} / \mathrm{L}$ & 0.1 & 0.01 & 12.2 \\
\hline $\mathrm{pH}$ & 7.62 & 7.63 & 7.57 & 7.58 & $S U^{d}$ & $N / A^{c}$ & $N / A^{c}$ & $6.80-8.00$ \\
\hline Specific conductance & 3,372 & 3,960 & 3,710 & 3,720 & $\mu \mathrm{mhos} / \mathrm{cm}$ & $N / A^{c}$ & $N / A^{c}$ & 5,192 \\
\hline Sulfate & 1,920 & 1,890 & 1,940 & 1,940 & $\mathrm{mg} / \mathrm{L}$ & 2 & 2 & 2,543 \\
\hline Total dissolved solids & 3,700 & 3,500 & 3,430 & 3,460 & $\mathrm{mg} / \mathrm{L}$ & 10 & 10 & 4,600 \\
\hline Total organic carbon & $<1.0$ & $<1.0$ & $<1.0$ & $<1.0$ & $\mathrm{mg} / \mathrm{L}$ & 1 & 1 & 15.45 \\
\hline Total organic halogen & $<0.15$ & $<0.15$ & $<0.06$ & $<0.06$ & $\mathrm{mg} / \mathrm{L}$ & 0.15 & 0.06 & 0.19 \\
\hline Total suspended solids & $<1.0$ & $<1.0$ & $<1.0$ & $<1.0$ & $\mathrm{mg} / \mathrm{L}$ & 1.0 & 1.0 & 91 \\
\hline
\end{tabular}




\section{Waste Isolation Pilot Plant Annual Site Environmental Report for 2005 DOE/WIPP-06-2225}

\section{Table F.7 - Analytical Results for Groundwater Sampled from Well WQSP-6A}

\section{Concentration}

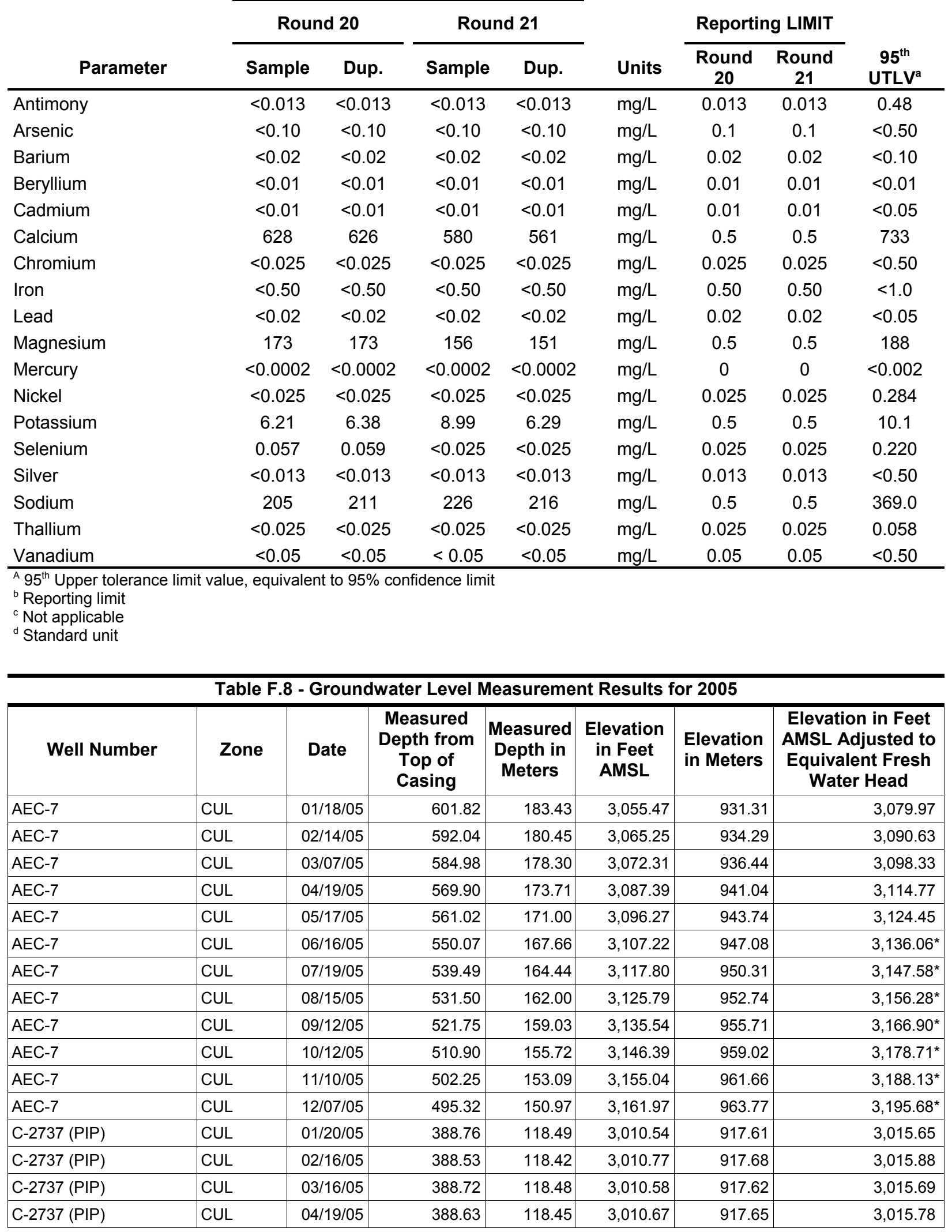




\section{Waste Isolation Pilot Plant Annual Site Environmental Report for 2005 DOE/WIPP-06-2225}

\begin{tabular}{|c|c|c|c|c|c|c|c|}
\hline Well Number & Zone & Date & $\begin{array}{l}\text { Measured } \\
\text { Depth from } \\
\text { Top of } \\
\text { Casing }\end{array}$ & $\begin{array}{c}\text { Measured } \\
\text { Depth in } \\
\text { Meters }\end{array}$ & $\begin{array}{c}\text { Elevation } \\
\text { in Feet } \\
\text { AMSL }\end{array}$ & $\begin{array}{l}\text { Elevation } \\
\text { in Meters }\end{array}$ & $\begin{array}{l}\text { Elevation in Feet } \\
\text { AMSL Adjusted to } \\
\text { Equivalent Fresh } \\
\text { Water Head }\end{array}$ \\
\hline C-2737 (PIP) & CUL & 05/18/05 & 388.24 & 118.34 & $3,011.06$ & 917.77 & $3,016.18^{*}$ \\
\hline C-2737 (PIP) & CUL & 06/21/05 & 388.05 & 118.28 & $3,011.25$ & 917.83 & $3,014.26^{*}$ \\
\hline C-2737 (PIP) & CUL & 07/19/05 & 387.75 & 118.19 & $3,011.55$ & 917.92 & $3,014.56^{*}$ \\
\hline C-2737 (PIP) & CUL & 08/15/05 & 387.77 & 118.19 & $3,011.53$ & 917.91 & $3,014.54^{*}$ \\
\hline C-2737 (PIP) & CUL & 09/14/05 & 391.45 & 119.31 & $3,007.85$ & 916.79 & $3,010.83^{*}$ \\
\hline C-2737 (PIP) & CUL & $10 / 12 / 05$ & 392.15 & 119.53 & $3,007.15$ & 916.58 & $3,010.12^{*}$ \\
\hline C-2737 (PIP) & CUL & $11 / 07 / 05$ & 391.51 & 119.33 & $3,007.79$ & 916.77 & $3,010.77^{*}$ \\
\hline C-2737 (PIP) & CUL & $12 / 07 / 05$ & 391.07 & 119.20 & $3,008.23$ & 916.91 & $3,011.21^{*}$ \\
\hline DOE-1 & CUL & 01/19/05 & 477.82 & 145.64 & $2,988.22$ & 910.81 & $3,017.65$ \\
\hline DOE-1 & CUL & $02 / 14 / 05$ & 477.16 & 145.44 & $2,988.88$ & 911.01 & $3,018.37$ \\
\hline DOE-1 & CUL & 03/10/05 & 476.56 & 145.26 & $2,989.48$ & 911.19 & $3,019.02$ \\
\hline DOE-1 & CUL & 04/19/05 & 475.62 & 144.97 & $2,990.42$ & 911.48 & $3,020.04$ \\
\hline DOE-1 & CUL & 05/16/05 & 474.87 & 144.74 & $2,991.17$ & 911.71 & $3,020.85$ \\
\hline DOE-1 & CUL & $06 / 20 / 05$ & 473.95 & 144.46 & $2,992.09$ & 911.99 & $3,027.58^{*}$ \\
\hline DOE-1 & CUL & 07/19/05 & 473.10 & 144.20 & $2,992.94$ & 912.25 & $3,028.52^{*}$ \\
\hline DOE-1 & CUL & $08 / 17 / 05$ & 473.90 & 144.44 & $2,992.14$ & 912.00 & $3,027.64^{*}$ \\
\hline DOE-1 & CUL & 09/13/05 & 477.43 & 145.52 & $2,988.61$ & 910.93 & $3,023.76^{*}$ \\
\hline DOE-1 & CUL & $10 / 10 / 05$ & 477.58 & 145.57 & $2,988.46$ & 910.88 & $3,023.59^{*}$ \\
\hline DOE-1 & CUL & $11 / 07 / 05$ & 477.00 & 145.39 & $2,989.04$ & 911.06 & $3,024.23^{*}$ \\
\hline DOE-1 & CUL & $12 / 06 / 05$ & 476.21 & 145.15 & $2,989.83$ & 911.30 & $3,025.10^{*}$ \\
\hline ERDA-9 & CUL & $01 / 20 / 05$ & 400.35 & 122.03 & $3,009.75$ & 917.37 & $3,025.26$ \\
\hline ERDA-9 & CUL & $02 / 17 / 05$ & 400.15 & 121.97 & $3,009.95$ & 917.43 & $3,025.47$ \\
\hline ERDA-9 & CUL & 03/16/05 & 400.99 & 122.22 & $3,009.11$ & 917.18 & $3,024.58$ \\
\hline ERDA-9 & CUL & $04 / 19 / 05$ & 400.88 & 122.19 & $3,009.22$ & 917.21 & $3,024.70$ \\
\hline ERDA-9 & CUL & 05/16/05 & 400.24 & 121.99 & $3,009.86$ & 917.41 & $3,025.37$ \\
\hline ERDA-9 & CUL & $06 / 20 / 05$ & 399.37 & 121.73 & $3,010.73$ & 917.67 & $3,032.00^{*}$ \\
\hline ERDA-9 & CUL & 07/19/05 & 399.09 & 121.64 & $3,011.01$ & 917.76 & $3,032.30^{*}$ \\
\hline ERDA-9 & CUL & 08/15/05 & 398.91 & 121.59 & $3,011.19$ & 917.81 & $3,032.49^{*}$ \\
\hline ERDA-9 & CUL & 09/13/05 & 401.11 & 122.26 & $3,008.99$ & 917.14 & $3,030.14^{*}$ \\
\hline ERDA-9 & CUL & $10 / 10 / 05$ & 401.74 & 122.45 & $3,008.36$ & 916.95 & $3,029.47^{*}$ \\
\hline ERDA-9 & CUL & $11 / 07 / 05$ & 401.55 & 122.39 & $3,008.55$ & 917.01 & $3,029.67^{*}$ \\
\hline ERDA-9 & CUL & $12 / 05 / 05$ & 401.26 & 122.30 & $3,008.84$ & 917.09 & $3,029.98^{*}$ \\
\hline $\mathrm{H}-02 \mathrm{~b} 2$ & CUL & $01 / 20 / 05$ & 339.96 & 103.62 & $3,038.35$ & 926.09 & $3,040.71$ \\
\hline $\mathrm{H}-02 \mathrm{~b} 2$ & CUL & $02 / 16 / 05$ & 339.56 & 103.50 & $3,038.75$ & 926.21 & $3,041.11$ \\
\hline $\mathrm{H}-02 \mathrm{~b} 2$ & CUL & 03/08/05 & 339.71 & 103.54 & $3,038.60$ & 926.17 & $3,040.96$ \\
\hline $\mathrm{H}-02 \mathrm{~b} 2$ & CUL & $04 / 25 / 05$ & 333.51 & 101.65 & $3,044.80$ & 928.06 & $3,047.21$ \\
\hline $\mathrm{H}-02 \mathrm{~b} 2$ & CUL & 05/16/05 & 336.25 & 102.49 & $3,042.06$ & 927.22 & $3,044.45$ \\
\hline $\mathrm{H}-02 \mathrm{~b} 2$ & CUL & 06/20/05 & 336.26 & 102.49 & $3,042.05$ & 927.22 & $3,045.93^{*}$ \\
\hline $\mathrm{H}-02 \mathrm{~b} 2$ & CUL & $07 / 19 / 05$ & 336.01 & 102.42 & $3,042.30$ & 927.29 & $3,046.18^{*}$ \\
\hline $\mathrm{H}-02 \mathrm{~b} 2$ & CUL & 08/15/05 & 335.88 & 102.38 & $3,042.43$ & 927.33 & $3,046.31^{*}$ \\
\hline $\mathrm{H}-02 \mathrm{~b} 2$ & CUL & $09 / 13 / 05$ & 335.56 & 102.28 & $3,042.75$ & 927.43 & $3,046.64^{*}$ \\
\hline $\mathrm{H}-02 \mathrm{~b} 2$ & CUL & $10 / 12 / 05$ & 335.82 & 102.36 & $3,042.49$ & 927.35 & $3,046.38^{*}$ \\
\hline $\mathrm{H}-02 \mathrm{~b} 2$ & CUL & $11 / 08 / 05$ & 335.93 & 102.39 & $3,042.38$ & 927.32 & $3,046.26^{*}$ \\
\hline
\end{tabular}


Waste Isolation Pilot Plant Annual Site Environmental Report for 2005 DOE/WIPP-06-2225

\begin{tabular}{|c|c|c|c|c|c|c|c|}
\hline Well Number & Zone & Date & $\begin{array}{c}\text { Measured } \\
\text { Depth from } \\
\text { Top of } \\
\text { Casing }\end{array}$ & $\begin{array}{c}\text { Measured } \\
\text { Depth in } \\
\text { Meters }\end{array}$ & $\begin{array}{l}\text { Elevation } \\
\text { in Feet } \\
\text { AMSL }\end{array}$ & $\begin{array}{l}\text { Elevation } \\
\text { in Meters }\end{array}$ & $\begin{array}{l}\text { Elevation in Feet } \\
\text { AMSL Adjusted to } \\
\text { Equivalent Fresh } \\
\text { Water Head }\end{array}$ \\
\hline $\mathrm{H}-02 \mathrm{~b} 2$ & CUL & $12 / 05 / 05$ & 336.08 & 102.44 & $3,042.23$ & 927.27 & $3,046.11^{*}$ \\
\hline $\mathrm{H}-03 \mathrm{~b} 2$ & CUL & $01 / 20 / 05$ & 389.71 & 118.78 & $3,000.32$ & 914.50 & $3,011.72$ \\
\hline $\mathrm{H}-03 \mathrm{~b} 2$ & CUL & $02 / 17 / 05$ & 389.51 & 118.72 & $3,000.52$ & 914.56 & $3,011.93$ \\
\hline $\mathrm{H}-03 \mathrm{~b} 2$ & CUL & 03/08/05 & 389.53 & 118.73 & $3,000.50$ & 914.55 & $3,011.91$ \\
\hline $\mathrm{H}-03 \mathrm{~b} 2$ & CUL & 04/19/05 & 389.32 & 118.66 & $3,000.71$ & 914.62 & $3,012.12$ \\
\hline $\mathrm{H}-03 \mathrm{~b} 2$ & CUL & $05 / 16 / 05$ & 389.10 & 118.60 & $3,000.93$ & 914.68 & $3,012.35$ \\
\hline $\mathrm{H}-03 \mathrm{~b} 2$ & CUL & 06/21/05 & 388.93 & 118.55 & $3,001.10$ & 914.74 & $3,011.93^{*}$ \\
\hline $\mathrm{H}-03 \mathrm{~b} 2$ & CUL & $07 / 19 / 05$ & 388.85 & 118.52 & $3,001.18$ & 914.76 & $3,012.01^{*}$ \\
\hline $\mathrm{H}-03 \mathrm{~b} 2$ & CUL & 08/15/05 & 389.91 & 118.84 & $3,000.12$ & 914.44 & $3,010.91^{*}$ \\
\hline $\mathrm{H}-03 \mathrm{~b} 2$ & CUL & $09 / 13 / 05$ & 396.35 & 120.81 & $2,993.68$ & 912.47 & $3,004.24^{*}$ \\
\hline $\mathrm{H}-03 \mathrm{~b} 2$ & CUL & $10 / 10 / 05$ & 395.06 & 120.41 & $2,994.97$ & 912.87 & $3,005.58^{*}$ \\
\hline $\mathrm{H}-03 \mathrm{~b} 2$ & CUL & $11 / 07 / 05$ & 393.76 & 120.02 & $2,996.27$ & 913.26 & $3,006.92^{*}$ \\
\hline $\mathrm{H}-03 \mathrm{~b} 2$ & CUL & $12 / 05 / 05$ & 393.16 & 119.84 & $2,996.87$ & 913.45 & $3,007.55^{*}$ \\
\hline $\mathrm{H}-04 \mathrm{~b}$ & CUL & 01/19/05 & 330.32 & 100.68 & $3,003.03$ & 915.32 & $3,006.66$ \\
\hline $\mathrm{H}-04 \mathrm{~b}$ & CUL & $02 / 14 / 05$ & 329.54 & 100.44 & $3,003.81$ & 915.56 & $3,007.45$ \\
\hline $\mathrm{H}-04 \mathrm{~b}$ & CUL & 03/08/05 & 329.35 & 100.39 & $3,004.00$ & 915.62 & $3,007.65$ \\
\hline $\mathrm{H}-04 \mathrm{~b}$ & CUL & $04 / 19 / 05$ & 329.05 & 100.29 & $3,004.30$ & 915.71 & $3,007.95$ \\
\hline $\mathrm{H}-04 \mathrm{~b}$ & CUL & 05/16/05 & 329.10 & 100.31 & $3,004.25$ & 915.70 & $3,007.90$ \\
\hline $\mathrm{H}-04 \mathrm{~b}$ & CUL & 06/20/05 & 329.20 & 100.34 & $3,004.15$ & 915.66 & $3,006.06^{*}$ \\
\hline $\mathrm{H}-04 \mathrm{~b}$ & CUL & $07 / 19 / 05$ & 329.18 & 100.33 & $3,004.17$ & 915.67 & $3,006.08^{*}$ \\
\hline $\mathrm{H}-04 \mathrm{~b}$ & CUL & 08/15/05 & 330.41 & 100.71 & $3,002.94$ & 915.30 & $3,004.84^{*}$ \\
\hline $\mathrm{H}-04 \mathrm{~b}$ & CUL & 09/13/05 & 333.65 & 101.70 & $2,999.70$ & 914.31 & $3,001.56^{*}$ \\
\hline $\mathrm{H}-04 \mathrm{~b}$ & CUL & $10 / 10 / 05$ & 331.91 & 101.17 & $3,001.44$ & 914.84 & $3,003.32^{*}$ \\
\hline $\mathrm{H}-04 \mathrm{~b}$ & CUL & $11 / 07 / 05$ & 331.03 & 100.90 & $3,002.32$ & 915.11 & $3,004.21^{*}$ \\
\hline $\mathrm{H}-04 \mathrm{~b}$ & CUL & $12 / 05 / 05$ & 330.55 & 100.75 & $3,002.80$ & 915.25 & $3,004.70^{*}$ \\
\hline $\mathrm{H}-05 \mathrm{~b}$ & CUL & $01 / 18 / 05$ & 476.64 & 145.28 & $3,029.40$ & 923.36 & $3,074.38$ \\
\hline$H-05 b$ & CUL & $02 / 16 / 05$ & 476.42 & 145.21 & $3,029.62$ & 923.43 & $3,074.62$ \\
\hline $\mathrm{H}-05 \mathrm{~b}$ & CUL & 03/10/05 & 476.43 & 145.22 & $3,029.61$ & 923.43 & $3,074.61$ \\
\hline $\mathrm{H}-05 \mathrm{~b}$ & CUL & $04 / 19 / 05$ & 476.55 & 145.25 & $3,029.49$ & 923.39 & $3,074.48$ \\
\hline $\mathrm{H}-05 \mathrm{~b}$ & CUL & $05 / 18 / 05$ & 476.69 & 145.30 & $3,029.35$ & 923.35 & $3,074.33$ \\
\hline $\mathrm{H}-05 \mathrm{~b}$ & CUL & 06/16/05 & 470.18 & 143.31 & $3,035.86$ & 925.33 & $3,079.32^{*}$ \\
\hline $\mathrm{H}-05 \mathrm{~b}$ & CUL & $07 / 19 / 05$ & 470.78 & 143.49 & $3,035.26$ & 925.15 & $3,078.66^{*}$ \\
\hline $\mathrm{H}-05 \mathrm{~b}$ & CUL & 08/15/05 & 470.55 & 143.42 & $3,035.49$ & 925.22 & $3,078.91^{*}$ \\
\hline $\mathrm{H}-05 \mathrm{~b}$ & CUL & $09 / 12 / 05$ & 470.27 & 143.34 & $3,035.77$ & 925.30 & $3,079.22^{*}$ \\
\hline $\mathrm{H}-05 \mathrm{~b}$ & CUL & $10 / 12 / 05$ & 470.00 & 143.26 & $3,036.04$ & 925.38 & $3,079.52^{*}$ \\
\hline $\mathrm{H}-05 \mathrm{~b}$ & CUL & $11 / 10 / 05$ & 469.89 & 143.22 & $3,036.15$ & 925.42 & $3,079.64^{*}$ \\
\hline $\mathrm{H}-05 \mathrm{~b}$ & CUL & $12 / 07 / 05$ & 469.78 & 143.19 & $3,036.26$ & 925.45 & $3,079.76^{*}$ \\
\hline$H-06 b$ & CUL & 01/18/05 & 292.95 & 89.29 & $3,055.30$ & 931.26 & $3,067.58$ \\
\hline $\mathrm{H}-06 \mathrm{~b}$ & CUL & $02 / 15 / 05$ & 301.48 & 91.89 & $3,046.77$ & 928.66 & $3,058.73$ \\
\hline $\mathrm{H}-06 \mathrm{~b}$ & CUL & 03/07/05 & 296.78 & 90.46 & $3,051.47$ & 930.09 & $3,063.61$ \\
\hline $\mathrm{H}-06 \mathrm{~b}$ & CUL & $04 / 18 / 05$ & 292.60 & 89.18 & $3,055.65$ & 931.36 & $3,067.95$ \\
\hline $\mathrm{H}-06 \mathrm{~b}$ & CUL & $05 / 17 / 05$ & 291.87 & 88.96 & $3,056.38$ & 931.58 & $3,068.70$ \\
\hline $\mathrm{H}-06 \mathrm{~b}$ & CUL & 06/13/05 & 291.68 & 88.90 & $3,056.57$ & 931.64 & $3,069.87^{*}$ \\
\hline
\end{tabular}




\section{Waste Isolation Pilot Plant Annual Site Environmental Report for 2005 DOE/WIPP-06-2225}

\begin{tabular}{|c|c|c|c|c|c|c|c|}
\hline Well Number & Zone & Date & $\begin{array}{l}\text { Measured } \\
\text { Depth from } \\
\text { Top of } \\
\text { Casing }\end{array}$ & $\begin{array}{c}\text { Measured } \\
\text { Depth in } \\
\text { Meters }\end{array}$ & $\begin{array}{l}\text { Elevation } \\
\text { in Feet } \\
\text { AMSL }\end{array}$ & $\begin{array}{l}\text { Elevation } \\
\text { in Meters }\end{array}$ & $\begin{array}{l}\text { Elevation in Feet } \\
\text { AMSL Adjusted to } \\
\text { Equivalent Fresh } \\
\text { Water Head }\end{array}$ \\
\hline $\mathrm{H}-06 \mathrm{~b}$ & CUL & $07 / 18 / 05$ & 291.68 & 88.90 & $3,056.57$ & 931.64 & $3,069.87^{*}$ \\
\hline $\mathrm{H}-06 \mathrm{~b}$ & CUL & 08/16/05 & 291.45 & 88.83 & $3,056.80$ & 931.71 & $3,070.11^{*}$ \\
\hline $\mathrm{H}-06 \mathrm{~b}$ & CUL & $09 / 13 / 05$ & 290.96 & 88.68 & $3,057.29$ & 931.86 & $3,070.62^{*}$ \\
\hline $\mathrm{H}-06 \mathrm{~b}$ & CUL & $10 / 11 / 05$ & 290.75 & 88.62 & $3,057.50$ & 931.93 & $3,070.84^{*}$ \\
\hline $\mathrm{H}-06 \mathrm{~b}$ & CUL & $11 / 08 / 05$ & 290.32 & 88.49 & $3,057.93$ & 932.06 & $3,071.29^{*}$ \\
\hline $\mathrm{H}-06 \mathrm{~b}$ & CUL & $12 / 06 / 05$ & 289.97 & 88.38 & $3,058.28$ & 932.16 & $3,071.65^{*}$ \\
\hline $\mathrm{H}-07 \mathrm{~b} 1$ & CUL & $03 / 07 / 05$ & 162.90 & 49.65 & $3,001.27$ & 914.79 & $3,001.74$ \\
\hline $\mathrm{H}-07 \mathrm{~b} 1$ & CUL & $05 / 17 / 05$ & 162.97 & 499.67 & $3,001.20$ & 914.77 & $3,001.67$ \\
\hline $\mathrm{H}-07 \mathrm{~b} 1$ & CUL & $06 / 13 / 05$ & 163.18 & 49.74 & $3,000.99$ & 914.70 & $3,001.18^{*}$ \\
\hline $\mathrm{H}-07 \mathrm{~b} 1$ & CUL & 07/18/05 & 163.09 & 49.71 & $3,001.08$ & 914.73 & $3,001.27^{*}$ \\
\hline $\mathrm{H}-07 \mathrm{~b} 1$ & CUL & 08/16/05 & 163.27 & 49.76 & $3,000.90$ & 914.67 & $3,001.09^{*}$ \\
\hline $\mathrm{H}-07 \mathrm{~b} 1$ & CUL & $09 / 14 / 05$ & 163.18 & 499.74 & $3,000.99$ & 914.70 & $3,001.18^{*}$ \\
\hline $\mathrm{H}-07 \mathrm{~b} 1$ & CUL & $10 / 11 / 05$ & 163.08 & 49.71 & $3,001.09$ & 914.73 & $3,001.28^{*}$ \\
\hline $\mathrm{H}-07 \mathrm{~b} 1$ & CUL & $11 / 10 / 05$ & 163.32 & 49.78 & $3,000.85$ & 914.66 & $3,001.04^{*}$ \\
\hline $\mathrm{H}-07 \mathrm{~b} 1$ & CUL & $12 / 06 / 05$ & 163.17 & 49.73 & $3,001.00$ & 914.70 & $3,001.19^{*}$ \\
\hline $\mathrm{H}-09 \mathrm{c}$ (PIP) & CUL & $01 / 19 / 05$ & 410.97 & 125.26 & $2,996.33$ & 913.28 & $2,996.58$ \\
\hline $\mathrm{H}-09 \mathrm{c}(\mathrm{PIP})$ & CUL & $02 / 16 / 05$ & 410.60 & 125.15 & $2,996.70$ & 913.39 & $2,996.95$ \\
\hline $\mathrm{H}-09 \mathrm{c}$ (PIP) & CUL & 03/10/05 & 410.05 & 124.98 & $2,997.25$ & 913.56 & $2,997.50$ \\
\hline $\mathrm{H}-09 \mathrm{c}$ (PIP) & CUL & $04 / 18 / 05$ & 410.05 & 124.98 & $2,997.25$ & 913.56 & $2,997.50$ \\
\hline $\mathrm{H}-09 \mathrm{c}(\mathrm{PIP})$ & CUL & $05 / 17 / 05$ & 409.94 & 124.95 & $2,997.36$ & 913.60 & $2,997.61$ \\
\hline $\mathrm{H}-09 \mathrm{c}$ (PIP) & CUL & $06 / 20 / 05$ & 410.16 & 125.02 & $2,997.14$ & 913.53 & $2,998.40^{*}$ \\
\hline H-09c (PIP) & CUL & $07 / 18 / 05$ & 409.95 & 124.95 & $2,997.35$ & 913.59 & $2,998.61^{*}$ \\
\hline $\mathrm{H}-09 \mathrm{c}$ (PIP) & CUL & $08 / 16 / 05$ & 411.27 & 125.36 & $2,996.03$ & 913.19 & $2,997.29^{*}$ \\
\hline $\mathrm{H}-09 \mathrm{c}$ (PIP) & CUL & $09 / 12 / 05$ & 412.61 & 125.76 & $2,994.69$ & 912.78 & $2,995.94^{*}$ \\
\hline $\mathrm{H}-09 \mathrm{c}$ (PIP) & CUL & $10 / 11 / 05$ & 411.48 & 125.42 & $2,995.82$ & 913.13 & $2,997.08^{*}$ \\
\hline H-09c (PIP) & CUL & $11 / 07 / 05$ & 410.82 & 125.22 & $2,996.48$ & 913.33 & $2,997.74^{*}$ \\
\hline $\mathrm{H}-09 \mathrm{c}$ (PIP) & CUL & $12 / 06 / 05$ & 410.50 & 125.12 & $2,996.80$ & 913.42 & $2,998.06^{*}$ \\
\hline $\mathrm{H}-10 \mathrm{c}$ & CUL & $01 / 19 / 05$ & 663.83 & 202.34 & $3,024.81$ & 921.96 & $3,024.81$ \\
\hline $\mathrm{H}-10 \mathrm{c}$ & CUL & $02 / 16 / 05$ & 663.80 & 202.33 & $3,024.84$ & 921.97 & $3,024.84$ \\
\hline $\mathrm{H}-10 \mathrm{c}$ & CUL & 03/10/05 & 663.90 & 202.36 & $3,024.74$ & 921.94 & $3,024.74$ \\
\hline $\mathrm{H}-10 \mathrm{c}$ & CUL & $04 / 19 / 05$ & 664.10 & 202.42 & $3,024.54$ & 921.88 & $3,024.54$ \\
\hline $\mathrm{H}-10 \mathrm{c}$ & CUL & $05 / 17 / 05$ & 664.18 & 202.44 & $3,024.46$ & 921.86 & $3,024.46$ \\
\hline $\mathrm{H}-10 \mathrm{c}$ & CUL & $06 / 20 / 05$ & 664.40 & 202.51 & $3,024.24$ & 921.79 & $3,030.64^{*}$ \\
\hline $\mathrm{H}-10 \mathrm{c}$ & CUL & 07/19/05 & 664.53 & 202.55 & $3,024.11$ & 921.75 & $3,030.51^{*}$ \\
\hline$H-10 c$ & CUL & 08/16/05 & 664.50 & 202.54 & $3,024.14$ & 921.76 & $3,030.54^{*}$ \\
\hline $\mathrm{H}-10 \mathrm{c}$ & CUL & $09 / 12 / 05$ & 661.58 & 201.65 & $3,027.06$ & 922.65 & $3,033.49^{*}$ \\
\hline $\mathrm{H}-10 \mathrm{c}$ & CUL & $10 / 12 / 05$ & 662.93 & 202.06 & $3,025.71$ & 922.24 & $3,032.13^{*}$ \\
\hline$H-10 c$ & CUL & $11 / 07 / 05$ & 663.58 & 202.26 & $3,025.06$ & 922.04 & $3,031.47^{*}$ \\
\hline $\mathrm{H}-10 \mathrm{c}$ & CUL & $12 / 06 / 05$ & 655.13 & 199.68 & $3,033.51$ & 924.61 & $3,040.00^{*}$ \\
\hline $\mathrm{H}-11 \mathrm{~b} 4$ & CUL & $01 / 19 / 05$ & 424.54 & 129.40 & $2,986.35$ & 910.24 & $3,006.57$ \\
\hline $\mathrm{H}-11 \mathrm{~b} 4$ & CUL & $02 / 14 / 05$ & 424.03 & 129.24 & $2,986.86$ & 910.39 & $3,007.11$ \\
\hline $\mathrm{H}-11 \mathrm{~b} 4$ & CUL & $03 / 10 / 05$ & 423.93 & 129.21 & $2,986.96$ & 910.43 & $3,007.21$ \\
\hline $\mathrm{H}-11 \mathrm{~b} 4$ & CUL & $04 / 19 / 05$ & 423.58 & 129.11 & $2,987.31$ & 910.53 & $3,007.59$ \\
\hline
\end{tabular}


Waste Isolation Pilot Plant Annual Site Environmental Report for 2005 DOE/WIPP-06-2225

\begin{tabular}{|c|c|c|c|c|c|c|c|}
\hline Well Number & Zone & Date & $\begin{array}{c}\text { Measured } \\
\text { Depth from } \\
\text { Top of } \\
\text { Casing }\end{array}$ & $\begin{array}{c}\text { Measured } \\
\text { Depth in } \\
\text { Meters }\end{array}$ & $\begin{array}{c}\text { Elevation } \\
\text { in Feet } \\
\text { AMSL }\end{array}$ & $\begin{array}{l}\text { Elevation } \\
\text { in Meters }\end{array}$ & $\begin{array}{l}\text { Elevation in Feet } \\
\text { AMSL Adjusted to } \\
\text { Equivalent Fresh } \\
\text { Water Head }\end{array}$ \\
\hline $\mathrm{H}-11 \mathrm{~b} 4$ & CUL & 05/16/05 & 423.54 & 129.09 & $2,987.35$ & 910.54 & $3,007.63$ \\
\hline $\mathrm{H}-11 \mathrm{~b} 4$ & CUL & $06 / 20 / 05$ & 423.73 & 129.15 & $2,987.16$ & 910.49 & $3,007.12^{*}$ \\
\hline $\mathrm{H}-11 \mathrm{~b} 4$ & CUL & 07/19/05 & 423.81 & 129.18 & $2,987.08$ & 910.46 & $3,007.03^{*}$ \\
\hline $\mathrm{H}-11 \mathrm{~b} 4$ & CUL & 08/16/05 & 458.11 & 139.63 & $2,952.78$ & 900.01 & $2,970.54^{*}$ \\
\hline $\mathrm{H}-11 \mathrm{~b} 4$ & CUL & $09 / 13 / 05$ & 437.18 & 133.25 & $2,973.71$ & 906.39 & $2,992.81^{*}$ \\
\hline $\mathrm{H}-11 \mathrm{~b} 4$ & CUL & $10 / 10 / 05$ & 430.14 & 131.11 & $2,980.75$ & 908.53 & $3,000.30^{*}$ \\
\hline $\mathrm{H}-11 \mathrm{~b} 4$ & CUL & $11 / 07 / 05$ & 427.75 & 130.38 & $2,983.14$ & 909.26 & $3,002.84^{*}$ \\
\hline $\mathrm{H}-11 \mathrm{~b} 4$ & CUL & $12 / 06 / 05$ & 426.44 & 129.98 & $2,984.45$ & 909.66 & $3,004.23^{*}$ \\
\hline $\mathrm{H}-12$ & CUL & $05 / 17 / 05$ & 459.55 & 140.07 & $2,967.64$ & 904.54 & $3,004.70$ \\
\hline $\mathrm{H}-12$ & CUL & 06/20/05 & 458.05 & 139.61 & $2,969.14$ & 904.99 & $3,000.65^{*}$ \\
\hline $\mathrm{H}-12$ & CUL & 07/19/05 & 457.68 & 139.50 & $2,969.51$ & 905.11 & $3,001.05^{*}$ \\
\hline $\mathrm{H}-12$ & CUL & 08/16/05 & 457.58 & 139.47 & $2,969.61$ & 905.14 & $3,001.16^{*}$ \\
\hline $\mathrm{H}-12$ & CUL & $09 / 12 / 05$ & 458.69 & 139.81 & $2,968.50$ & 904.80 & $2,999.96^{*}$ \\
\hline $\mathrm{H}-12$ & CUL & $10 / 12 / 05$ & 459.00 & 139.90 & $2,968.19$ & 904.70 & $2,999.62^{*}$ \\
\hline $\mathrm{H}-12$ & CUL & $11 / 07 / 05$ & 458.81 & 139.85 & $2,968.38$ & 904.76 & $2,999.83^{*}$ \\
\hline $\mathrm{H}-12$ & CUL & $12 / 06 / 05$ & 458.65 & 139.80 & $2,968.54$ & 904.81 & $3,000.00^{*}$ \\
\hline $\mathrm{H}-15$ & CUL & $02 / 17 / 05$ & 491.50 & 149.81 & $2,990.13$ & 911.39 & $3,047.59$ \\
\hline $\mathrm{H}-15$ & CUL & 03/16/05 & 491.30 & 149.75 & $2,990.33$ & 911.45 & $3,047.82$ \\
\hline $\mathrm{H}-15$ & CUL & $04 / 19 / 05$ & 490.97 & 149.65 & $2,990.66$ & 911.55 & $3,048.20$ \\
\hline $\mathrm{H}-15$ & CUL & 05/16/05 & 491.07 & 149.68 & $2,990.56$ & 911.52 & $3,048.08$ \\
\hline $\mathrm{H}-15$ & CUL & 06/20/05 & 491.03 & 149.67 & $2,990.60$ & 911.53 & $3,027.56^{*}$ \\
\hline $\mathrm{H}-15$ & CUL & $07 / 19 / 05$ & 490.92 & 149.63 & $2,990.71$ & 911.57 & $3,027.68^{*}$ \\
\hline $\mathrm{H}-15$ & CUL & 08/15/05 & 492.52 & 150.12 & $2,989.11$ & 911.08 & $3,025.92^{*}$ \\
\hline $\mathrm{H}-15$ & CUL & 09/13/05 & 501.72 & 152.92 & $2,979.91$ & 908.28 & $3,015.83^{*}$ \\
\hline $\mathrm{H}-15$ & CUL & $10 / 10 / 05$ & 498.15 & 151.84 & $2,983.48$ & 909.36 & $3,019.75^{*}$ \\
\hline $\mathrm{H}-15$ & CUL & $11 / 07 / 05$ & 496.22 & 151.25 & $2,985.41$ & 909.95 & $3,021.86^{*}$ \\
\hline $\mathrm{H}-15$ & CUL & $12 / 05 / 05$ & 495.05 & 150.89 & $2,986.58$ & 910.31 & $3,023.15^{*}$ \\
\hline $\mathrm{H}-17$ & CUL & $01 / 19 / 05$ & 420.26 & 128.10 & $2,965.05$ & 903.75 & $3,014.79$ \\
\hline $\mathrm{H}-17$ & CUL & $02 / 14 / 05$ & 419.75 & 127.94 & $2,965.56$ & 903.90 & $3,015.38$ \\
\hline $\mathrm{H}-17$ & CUL & 03/10/05 & 419.55 & 127.88 & $2,965.76$ & 903.96 & $3,015.62$ \\
\hline $\mathrm{H}-17$ & CUL & $04 / 19 / 05$ & 419.25 & 127.79 & $2,966.06$ & 904.06 & $3,015.97$ \\
\hline $\mathrm{H}-17$ & CUL & 05/16/05 & 419.20 & 127.77 & $2,966.11$ & 904.07 & $3,016.02$ \\
\hline $\mathrm{H}-17$ & CUL & 06/20/05 & 419.14 & 127.75 & $2,966.17$ & 904.09 & $3,007.07^{*}$ \\
\hline $\mathrm{H}-17$ & CUL & $07 / 19 / 05$ & 419.08 & 127.74 & $2,966.23$ & 904.11 & $3,007.14^{*}$ \\
\hline $\mathrm{H}-17$ & CUL & 08/16/05 & 433.60 & 132.16 & $2,951.71$ & 899.68 & $2,990.65^{*}$ \\
\hline $\mathrm{H}-17$ & CUL & 09/13/05 & 434.08 & 132.31 & $2,951.23$ & 899.53 & $2,990.10^{*}$ \\
\hline $\mathrm{H}-17$ & CUL & $10 / 10 / 05$ & 426.43 & 129.98 & $2,958.88$ & 901.87 & $2,998.79^{*}$ \\
\hline $\mathrm{H}-17$ & CUL & $11 / 07 / 05$ & 423.57 & 129.10 & $2,961.74$ & 902.74 & $3,002.04^{*}$ \\
\hline $\mathrm{H}-17$ & CUL & $12 / 06 / 05$ & 422.10 & 128.66 & $2,963.21$ & 903.19 & $3,003.71^{*}$ \\
\hline $\mathrm{H}-19 \mathrm{b0}$ & CUL & $01 / 19 / 05$ & 427.10 & 130.18 & $2,991.28$ & 911.74 & $3,013.15$ \\
\hline $\mathrm{H}-19 \mathrm{~b} 0$ & CUL & $02 / 14 / 05$ & 426.66 & 130.05 & $2,991.72$ & 911.88 & $3,013.62$ \\
\hline $\mathrm{H}-19 \mathrm{b0}$ & CUL & 03/08/05 & 426.93 & 130.13 & $2,991.45$ & 911.79 & $3,013.33$ \\
\hline $\mathrm{H}-19 \mathrm{b0}$ & CUL & $04 / 19 / 05$ & 426.50 & 130.00 & $2,991.88$ & 911.93 & $3,013.79$ \\
\hline
\end{tabular}


Waste Isolation Pilot Plant Annual Site Environmental Report for 2005 DOE/WIPP-06-2225

\begin{tabular}{|c|c|c|c|c|c|c|c|}
\hline Well Number & Zone & Date & $\begin{array}{c}\text { Measured } \\
\text { Depth from } \\
\text { Top of } \\
\text { Casing }\end{array}$ & $\begin{array}{c}\text { Measured } \\
\text { Depth in } \\
\text { Meters }\end{array}$ & $\begin{array}{l}\text { Elevation } \\
\text { in Feet } \\
\text { AMSL }\end{array}$ & $\begin{array}{l}\text { Elevation } \\
\text { in Meters }\end{array}$ & $\begin{array}{l}\text { Elevation in Feet } \\
\text { AMSL Adjusted to } \\
\text { Equivalent Fresh } \\
\text { Water Head }\end{array}$ \\
\hline $\mathrm{H}-19 \mathrm{~b} 0$ & CUL & 05/16/05 & 426.40 & 129.97 & $2,991.98$ & 911.96 & $3,013.90$ \\
\hline $\mathrm{H}-19 \mathrm{~b} 0$ & CUL & 06/20/05 & 426.20 & 129.91 & $2,992.18$ & 912.02 & $3,014.11$ \\
\hline $\mathrm{H}-19 \mathrm{~b} 0$ & CUL & 07/19/05 & 426.18 & 129.90 & $2,992.20$ & 912.02 & $3,014.13$ \\
\hline $\mathrm{H}-19 \mathrm{b0}$ & CUL & 08/15/05 & 429.48 & 130.91 & $2,988.90$ & 911.02 & $3,010.61$ \\
\hline $\mathrm{H}-19 \mathrm{~b} 0$ & CUL & 09/13/05 & 435.81 & 132.83 & $2,982.57$ & 909.09 & $3,003.86$ \\
\hline $\mathrm{H}-19 \mathrm{~b} 0$ & CUL & $10 / 10 / 05$ & 432.89 & 131.94 & $2,985.49$ & 909.98 & $3,006.97$ \\
\hline $\mathrm{H}-19 \mathrm{~b} 0$ & CUL & $11 / 07 / 05$ & 431.15 & 131.41 & $2,987.23$ & 910.51 & $3,008.83$ \\
\hline $\mathrm{H}-19 \mathrm{~b} 0$ & CUL & $12 / 05 / 05$ & 430.34 & 131.17 & $2,988.04$ & 910.75 & $3,009.69$ \\
\hline $\mathrm{H}-19 \mathrm{~b} 2$ & CUL & 03/08/05 & 428.28 & 130.54 & $2,990.73$ & 911.57 & $3,012.67$ \\
\hline $\mathrm{H}-19 \mathrm{~b} 2$ & CUL & $06 / 20 / 05$ & 427.56 & 130.32 & $2,991.45$ & 911.79 & $3,013.44$ \\
\hline $\mathrm{H}-19 \mathrm{~b} 2$ & CUL & 09/13/05 & 437.21 & 133.26 & $2,981.80$ & 908.85 & $3,003.14$ \\
\hline $\mathrm{H}-19 \mathrm{~b} 2$ & CUL & $12 / 05 / 05$ & 431.68 & 131.58 & $2,987.33$ & 910.54 & $3,009.04$ \\
\hline $\mathrm{H}-19 \mathrm{b3}$ & CUL & 03/08/05 & 428.48 & 130.60 & $2,990.61$ & 911.54 & $3,012.44$ \\
\hline $\mathrm{H}-19 \mathrm{b3}$ & CUL & 06/20/05 & 427.78 & 130.39 & $2,991.31$ & 911.75 & $3,013.19$ \\
\hline $\mathrm{H}-19 \mathrm{~b} 3$ & CUL & 09/13/05 & 437.40 & 133.32 & $2,981.69$ & 908.82 & $3,002.92$ \\
\hline $\mathrm{H}-19 \mathrm{~b} 3$ & CUL & $12 / 05 / 05$ & 431.89 & 131.64 & $2,987.20$ & 910.50 & $3,008.80$ \\
\hline $\mathrm{H}-19 \mathrm{~b} 4$ & CUL & 03/08/05 & 427.72 & 130.37 & 2,991.31 & 911.75 & $3,013.04$ \\
\hline $\mathrm{H}-19 \mathrm{~b} 4$ & CUL & $06 / 20 / 05$ & 427.02 & 130.16 & $2,992.01$ & 911.96 & $3,013.78$ \\
\hline $\mathrm{H}-19 \mathrm{~b} 4$ & CUL & $09 / 13 / 05$ & 436.54 & 133.06 & $2,982.49$ & 909.06 & $3,003.62$ \\
\hline $\mathrm{H}-19 \mathrm{~b} 4$ & CUL & $12 / 05 / 05$ & 431.15 & 131.41 & $2,987.88$ & 910.71 & $3,009.38$ \\
\hline $\mathrm{H}-19 \mathrm{~b} 5$ & CUL & 03/08/05 & 427.78 & 130.39 & $2,990.85$ & 911.61 & $3,012.48$ \\
\hline $\mathrm{H}-19 \mathrm{~b} 5$ & CUL & 06/20/05 & 427.04 & 130.16 & $2,991.59$ & 911.84 & $3,013.27$ \\
\hline $\mathrm{H}-19 \mathrm{~b} 5$ & CUL & 09/13/05 & 436.62 & 133.08 & $2,982.01$ & 908.92 & $3,003.05$ \\
\hline $\mathrm{H}-19 \mathrm{~b} 5$ & CUL & $12 / 05 / 05$ & 431.20 & 131.43 & $2,987.43$ & 910.57 & $3,008.84$ \\
\hline $\mathrm{H}-19 \mathrm{~b} 6$ & CUL & 03/08/05 & 428.38 & 130.57 & $2,990.69$ & 911.56 & $3,012.46$ \\
\hline $\mathrm{H}-19 \mathrm{~b} 6$ & CUL & 06/20/05 & 427.70 & 130.36 & $2,991.37$ & 911.77 & $3,013.18$ \\
\hline $\mathrm{H}-19 \mathrm{~b} 6$ & CUL & 09/13/05 & 437.29 & 133.29 & $2,981.78$ & 908.85 & $3,002.95$ \\
\hline $\mathrm{H}-19 \mathrm{~b} 6$ & CUL & $12 / 05 / 05$ & 431.80 & 131.61 & $2,987.27$ & 910.52 & $3,008.81$ \\
\hline $\mathrm{H}-19 \mathrm{~b} 7$ & CUL & 03/08/05 & 428.49 & 130.60 & $2,990.50$ & 911.50 & $3,012.30$ \\
\hline $\mathrm{H}-19 \mathrm{~b} 7$ & CUL & $06 / 20 / 05$ & 427.76 & 130.38 & $2,991.23$ & 911.73 & $3,013.08$ \\
\hline $\mathrm{H}-19 \mathrm{~b} 7$ & CUL & $09 / 13 / 05$ & 437.40 & 133.32 & $2,981.59$ & 908.79 & $3,002.79$ \\
\hline $\mathrm{H}-19 \mathrm{~b} 7$ & CUL & $12 / 05 / 05$ & 431.88 & 131.64 & $2,987.11$ & 910.47 & $3,008.68$ \\
\hline I-461 & CUL & $01 / 18 / 05$ & 240.05 & 73.17 & $3,049.43$ & 929.47 & $3,052.02$ \\
\hline I-461 & CUL & $02 / 15 / 05$ & 238.50 & 72.69 & $3,050.98$ & 929.94 & $3,053.60$ \\
\hline I-461 & CUL & 03/07/05 & 238.39 & 72.66 & $3,051.09$ & 929.97 & $3,053.71$ \\
\hline I-461 & CUL & $04 / 18 / 05$ & 238.73 & 72.76 & $3,050.75$ & 929.87 & $3,053.36$ \\
\hline I-461 & CUL & $05 / 17 / 05$ & 237.95 & 72.53 & $3,051.53$ & 930.11 & $3,054.16$ \\
\hline I-461 & CUL & $06 / 13 / 05$ & 237.82 & 72.49 & $3,051.66$ & 930.15 & $3,052.21^{*}$ \\
\hline I-461 & CUL & $07 / 18 / 05$ & 238.22 & 72.61 & $3,051.26$ & 930.02 & $3,051.81^{*}$ \\
\hline I-461 & CUL & 08/16/05 & 238.41 & 72.67 & $3,051.07$ & 929.97 & $3,051.62^{*}$ \\
\hline I-461 & CUL & $09 / 13 / 05$ & 237.88 & 72.51 & $3,051.60$ & 930.13 & $3,052.15^{\star}$ \\
\hline I-461 & CUL & $10 / 11 / 05$ & 237.91 & 72.51 & $3,051.57$ & 930.12 & $3,052.12^{*}$ \\
\hline |-461 & CUL & $11 / 08 / 05$ & 237.80 & 72.48 & $3,051.68$ & 930.15 & $3,052.23^{*}$ \\
\hline
\end{tabular}


Waste Isolation Pilot Plant Annual Site Environmental Report for 2005 DOE/WIPP-06-2225

\begin{tabular}{|c|c|c|c|c|c|c|c|}
\hline Well Number & Zone & Date & $\begin{array}{c}\text { Measured } \\
\text { Depth from } \\
\text { Top of } \\
\text { Casing }\end{array}$ & $\begin{array}{c}\text { Measured } \\
\text { Depth in } \\
\text { Meters }\end{array}$ & $\begin{array}{l}\text { Elevation } \\
\text { in Feet } \\
\text { AMSL }\end{array}$ & $\begin{array}{l}\text { Elevation } \\
\text { in Meters }\end{array}$ & $\begin{array}{l}\text { Elevation in Feet } \\
\text { AMSL Adjusted to } \\
\text { Equivalent Fresh } \\
\text { Water Head }\end{array}$ \\
\hline |-461 & CUL & $12 / 06 / 05$ & 237.65 & 72.44 & $3,051.83$ & 930.20 & $3,052.38^{*}$ \\
\hline P-17 & CUL & $01 / 19 / 05$ & 351.04 & 107.00 & $2,986.20$ & 910.19 & $3,000.56$ \\
\hline $\mathrm{P}-17$ & CUL & $02 / 14 / 05$ & 350.54 & 106.84 & $2,986.70$ & 910.35 & $3,001.09$ \\
\hline P-17 & CUL & 03/10/05 & 350.31 & 106.77 & $2,986.93$ & 910.42 & $3,001.34$ \\
\hline $\mathrm{P}-17$ & CUL & 04/19/05 & 349.95 & 106.66 & $2,987.29$ & 910.53 & $3,001.72$ \\
\hline P-17 & CUL & $05 / 16 / 05$ & 349.93 & 106.66 & $2,987.31$ & 910.53 & $3,001.74$ \\
\hline $\mathrm{P}-17$ & CUL & 06/20/05 & 345.88 & 105.42 & $2,991.36$ & 911.77 & $3,006.96^{*}$ \\
\hline P-17 & CUL & 07/19/05 & 346.26 & 105.54 & $2,990.98$ & 911.65 & $3,006.55^{*}$ \\
\hline P-17 & CUL & 08/16/05 & 348.79 & 106.31 & $2,988.45$ & 910.88 & $3,003.85^{*}$ \\
\hline P-17 & CUL & 09/13/05 & 354.20 & 107.96 & $2,983.04$ & 909.23 & $2,998.07^{*}$ \\
\hline $\mathrm{P}-17$ & CUL & $10 / 10 / 05$ & 351.73 & 107.21 & $2,985.51$ & 909.98 & $3,000.71^{*}$ \\
\hline P-17 & CUL & $11 / 07 / 05$ & 350.10 & 106.71 & $2,987.14$ & 910.48 & $3,002.45^{*}$ \\
\hline P-17 & CUL & $12 / 06 / 05$ & 349.03 & 106.38 & $2,988.21$ & 910.81 & $3,003.59^{*}$ \\
\hline SNL-01 & CUL & 01/18/05 & 437.70 & 133.41 & $3,075.14$ & 937.30 & $3,079.52$ \\
\hline SNL-01 & CUL & $04 / 18 / 05$ & 437.65 & 133.40 & $3,075.19$ & 937.32 & $3,079.57$ \\
\hline SNL-01 & CUL & $05 / 18 / 05$ & 437.26 & 133.28 & $3,075.58$ & 937.44 & $3,079.97$ \\
\hline SNL-01 & CUL & 06/16/05 & 437.14 & 133.24 & $3,075.70$ & 937.47 & $3,080.62^{*}$ \\
\hline SNL-01 & CUL & 07/18/05 & 437.15 & 133.24 & $3,075.69$ & 937.47 & $3,080.61^{*}$ \\
\hline SNL-01 & CUL & 08/15/05 & 437.11 & 133.23 & $3,075.73$ & 937.48 & $3,080.65^{*}$ \\
\hline SNL-01 & CUL & $09 / 12 / 05$ & 436.93 & 133.18 & $3,075.91$ & 937.54 & $3,080.84^{*}$ \\
\hline SNL-01 & CUL & $10 / 12 / 05$ & 436.08 & 132.92 & $3,076.76$ & 937.80 & $3,081.71^{*}$ \\
\hline SNL-01 & CUL & $11 / 08 / 05$ & 435.05 & 132.60 & $3,077.79$ & 938.11 & $3,082.77^{*}$ \\
\hline SNL-01 & CUL & $12 / 07 / 05$ & 434.82 & 132.53 & $3,078.02$ & 938.18 & $3,083.01^{*}$ \\
\hline SNL-02 & CUL & $03 / 07 / 05$ & 251.93 & 76.79 & $3,071.10$ & 936.07 & $3,074.38$ \\
\hline SNL-02 & CUL & $04 / 18 / 05$ & 251.38 & 76.62 & $3,071.65$ & 936.24 & $3,074.94$ \\
\hline SNL-02 & CUL & $05 / 17 / 05$ & 251.17 & 76.56 & $3,071.86$ & 936.30 & $3,075.15$ \\
\hline SNL-02 & CUL & $06 / 13 / 05$ & 251.49 & 76.65 & $3,071.54$ & 936.21 & $3,073.73^{*}$ \\
\hline SNL-02 & CUL & 07/18/05 & 251.44 & 76.64 & $3,071.59$ & 936.22 & $3,073.78^{*}$ \\
\hline SNL-02 & CUL & 08/16/05 & 251.33 & 76.61 & $3,071.70$ & 936.25 & $3,073.89^{*}$ \\
\hline SNL-02 & CUL & $09 / 12 / 05$ & 250.59 & 76.38 & $3,072.44$ & 936.48 & $3,074.64^{*}$ \\
\hline SNL-02 & CUL & $10 / 11 / 05$ & 250.22 & 76.27 & $3,072.81$ & 936.59 & $3,075.01^{*}$ \\
\hline SNL-02 & CUL & $11 / 08 / 05$ & 251.75 & 76.73 & $3,071.28$ & 936.13 & $3,073.47^{*}$ \\
\hline SNL-02 & CUL & $12 / 06 / 05$ & 249.42 & 76.02 & $3,073.61$ & 936.84 & $3,075.82^{*}$ \\
\hline SNL-03 & CUL & $01 / 18 / 05$ & 422.50 & 128.78 & $3,067.84$ & 935.08 & $3,077.49$ \\
\hline SNL-03 & CUL & $02 / 15 / 05$ & 432.79 & 131.91 & $3,057.55$ & 931.94 & $3,066.91$ \\
\hline SNL-03 & CUL & $03 / 07 / 05$ & 428.34 & 130.56 & $3,062.00$ & 933.30 & $3,071.48$ \\
\hline SNL-03 & CUL & 04/18/05 & 422.85 & 128.88 & $3,067.49$ & 934.97 & $3,077.13$ \\
\hline SNL-03 & CUL & $05 / 17 / 05$ & 421.75 & 128.55 & $3,068.59$ & 935.31 & $3,078.26$ \\
\hline SNL-03 & CUL & 06/16/05 & 421.33 & 128.42 & $3,069.01$ & 935.43 & $3,081.11^{*}$ \\
\hline SNL-03 & CUL & 07/18/05 & 421.18 & 128.38 & $3,069.16$ & 935.48 & $3,081.26^{*}$ \\
\hline SNL-03 & CUL & 08/15/05 & 421.00 & 128.32 & $3,069.34$ & 935.53 & $3,081.45^{*}$ \\
\hline SNL-03 & CUL & $09 / 14 / 05$ & 420.76 & 128.25 & $3,069.58$ & 935.61 & $3,081.70^{*}$ \\
\hline SNL-03 & CUL & $10 / 11 / 05$ & 420.20 & 128.08 & $3,070.14$ & 935.78 & $3,082.28^{*}$ \\
\hline
\end{tabular}


Waste Isolation Pilot Plant Annual Site Environmental Report for 2005 DOE/WIPP-06-2225

\begin{tabular}{|c|c|c|c|c|c|c|c|}
\hline Well Number & Zone & Date & $\begin{array}{c}\text { Measured } \\
\text { Depth from } \\
\text { Top of } \\
\text { Casing }\end{array}$ & $\begin{array}{c}\text { Measured } \\
\text { Depth in } \\
\text { Meters }\end{array}$ & $\begin{array}{c}\text { Elevation } \\
\text { in Feet } \\
\text { AMSL }\end{array}$ & $\begin{array}{l}\text { Elevation } \\
\text { in Meters }\end{array}$ & $\begin{array}{l}\text { Elevation in Feet } \\
\text { AMSL Adjusted to } \\
\text { Equivalent Fresh } \\
\text { Water Head }\end{array}$ \\
\hline SNL-03 & CUL & $11 / 08 / 05$ & 419.70 & 127.92 & $3,070.64$ & 935.93 & $3,082.80^{*}$ \\
\hline SNL-03 & CUL & $12 / 07 / 05$ & 419.60 & 127.89 & $3,070.74$ & 935.96 & $3,082.90^{*}$ \\
\hline SNL-05 & CUL & 01/18/05 & 310.15 & 94.53 & $3,071.73$ & 936.26 & $3,073.77$ \\
\hline SNL-05 & CUL & $02 / 15 / 05$ & 320.13 & 97.58 & $3,061.75$ & 933.22 & $3,063.73$ \\
\hline SNL-05 & CUL & 03/07/05 & 315.67 & 96.22 & $3,066.21$ & 934.58 & $3,068.22$ \\
\hline SNL-05 & CUL & $04 / 18 / 05$ & 310.37 & 94.60 & $3,071.51$ & 936.20 & $3,073.55$ \\
\hline SNL-05 & CUL & $05 / 17 / 05$ & 309.44 & 94.32 & $3,072.44$ & 936.48 & $3,074.49$ \\
\hline SNL-05 & CUL & $06 / 13 / 05$ & 309.20 & 94.24 & $3,072.68$ & 936.55 & $3,076.43^{*}$ \\
\hline SNL-05 & CUL & 07/18/05 & 309.13 & 94.22 & $3,072.75$ & 936.57 & $3,076.51^{*}$ \\
\hline SNL-05 & CUL & 08/16/05 & 308.90 & 94.15 & $3,072.98$ & 936.64 & $3,076.74^{*}$ \\
\hline SNL-05 & CUL & $09 / 12 / 05$ & 308.73 & 94.10 & $3,073.15$ & 936.70 & $3,076.91^{*}$ \\
\hline SNL-05 & CUL & $10 / 11 / 05$ & 308.14 & 93.92 & $3,073.74$ & 936.88 & $3,077.51^{*}$ \\
\hline SNL-05 & CUL & $11 / 08 / 05$ & 307.54 & 93.74 & $3,074.34$ & 937.06 & $3,078.11^{*}$ \\
\hline SNL-05 & CUL & $12 / 05 / 05$ & 307.48 & 93.72 & $3,074.40$ & 937.08 & $3,078.17^{*}$ \\
\hline SNL-08 & CUL & $12 / 07 / 05$ & 526.59 & 160.50 & $3,029.20$ & 923.30 & $3,053.98$ \\
\hline SNL-09 & CUL & $01 / 18 / 05$ & 312.41 & 95.22 & $3,048.54$ & 929.19 & $3,057.61$ \\
\hline SNL-09 & CUL & $02 / 15 / 05$ & 312.13 & 95.14 & $3,048.82$ & 929.28 & $3,053.11$ \\
\hline SNL-09 & CUL & 03/07/05 & 311.92 & 95.07 & $3,049.03$ & 929.34 & $3,053.32$ \\
\hline SNL-09 & CUL & $04 / 18 / 05$ & 311.29 & 94.88 & $3,049.66$ & 929.54 & $3,053.96$ \\
\hline SNL-09 & CUL & $05 / 17 / 05$ & 311.03 & 94.80 & $3,049.92$ & 929.62 & $3,054.23$ \\
\hline SNL-09 & CUL & 06/13/05 & 311.04 & 94.80 & $3,049.91$ & 929.61 & $3,055.48^{*}$ \\
\hline SNL-09 & CUL & 07/18/05 & 311.17 & 94.84 & $3,049.78$ & 929.57 & $3,055.35^{\star}$ \\
\hline SNL-09 & CUL & 08/16/05 & 311.10 & 94.82 & $3,049.85$ & 929.59 & $3,055.42^{*}$ \\
\hline SNL-09 & CUL & $09 / 13 / 05$ & 310.63 & 94.68 & $3,050.32$ & 929.74 & $3,055.90^{*}$ \\
\hline SNL-09 & CUL & $10 / 11 / 05$ & 310.46 & 94.63 & $3,050.49$ & 929.79 & $3,056.08^{*}$ \\
\hline SNL-09 & CUL & $11 / 08 / 05$ & 310.24 & 94.56 & $3,050.71$ & 929.86 & $3,056.30^{*}$ \\
\hline SNL-09 & CUL & $12 / 06 / 05$ & 309.93 & 94.47 & $3,051.02$ & 929.95 & $3,056.62^{*}$ \\
\hline SNL-12 & CUL & $01 / 19 / 05$ & 337.65 & 102.92 & $3,001.79$ & 914.95 & $3,002.72$ \\
\hline SNL-12 & CUL & $02 / 16 / 05$ & 337.31 & 102.81 & $3,002.13$ & 915.05 & $3,003.06$ \\
\hline SNL-12 & CUL & 03/10/05 & 337.01 & 102.72 & $3,002.43$ & 915.14 & $3,003.36$ \\
\hline SNL-12 & CUL & $04 / 18 / 05$ & 336.73 & 102.64 & $3,002.71$ & 915.23 & $3,003.64$ \\
\hline SNL-12 & CUL & $05 / 17 / 05$ & 336.64 & 102.61 & $3,002.80$ & 915.25 & $3,003.73$ \\
\hline SNL-12 & CUL & $06 / 20 / 05$ & 336.97 & 102.71 & $3,002.47$ & 915.15 & $3,003.40$ \\
\hline SNL-12 & CUL & 07/18/05 & 336.63 & 102.60 & $3,002.81$ & 915.26 & $3,003.74$ \\
\hline SNL-12 & CUL & 08/16/05 & 343.42 & 104.67 & $2,996.02$ & 913.19 & $2,996.92$ \\
\hline SNL-12 & CUL & $09 / 12 / 05$ & 343.29 & 104.63 & $2,996.15$ & 913.23 & $2,997.05$ \\
\hline SNL-12 & CUL & $10 / 12 / 05$ & 340.03 & 103.64 & $2,999.41$ & 914.22 & $3,000.33$ \\
\hline SNL-12 & CUL & $11 / 07 / 05$ & 338.60 & 103.21 & $3,000.84$ & 914.66 & $3,001.76$ \\
\hline SNL-12 & CUL & $12 / 05 / 05$ & 337.92 & 103.00 & $3,001.52$ & 914.86 & $3,002.44$ \\
\hline SNL-13 & CUL & 06/21/05 & 286.98 & 87.47 & $3,007.25$ & 916.61 & $3,013.49$ \\
\hline SNL-13 & CUL & 07/18/05 & 286.74 & 87.40 & $3,007.49$ & 916.68 & $3,013.75$ \\
\hline SNL-13 & CUL & 08/15/05 & 286.82 & 87.42 & $3,007.41$ & 916.66 & $3,013.66$ \\
\hline SNL-13 & CUL & 09/13/05 & 286.98 & 87.47 & $3,007.25$ & 916.61 & $3,013.49$ \\
\hline
\end{tabular}




\section{Waste Isolation Pilot Plant Annual Site Environmental Report for 2005 DOE/WIPP-06-2225}

\begin{tabular}{|c|c|c|c|c|c|c|c|}
\hline Well Number & Zone & Date & $\begin{array}{c}\text { Measured } \\
\text { Depth from } \\
\text { Top of } \\
\text { Casing }\end{array}$ & $\begin{array}{c}\text { Measured } \\
\text { Depth in } \\
\text { Meters }\end{array}$ & $\begin{array}{l}\text { Elevation } \\
\text { in Feet } \\
\text { AMSL }\end{array}$ & $\begin{array}{l}\text { Elevation } \\
\text { in Meters }\end{array}$ & $\begin{array}{l}\text { Elevation in Feet } \\
\text { AMSL Adjusted to } \\
\text { Equivalent Fresh } \\
\text { Water Head }\end{array}$ \\
\hline SNL-13 & CUL & $10 / 10 / 05$ & 287.25 & 87.55 & $3,006.98$ & 916.53 & $3,013.21$ \\
\hline SNL-13 & CUL & $11 / 08 / 05$ & 287.39 & 87.60 & $3,006.84$ & 916.48 & $3,013.06$ \\
\hline SNL-13 & CUL & $12 / 05 / 05$ & 287.07 & 87.50 & $3,007.16$ & 916.58 & $3,013.40$ \\
\hline SNL-14 & CUL & 06/20/05 & 371.16 & 113.13 & $2,997.22$ & 913.55 & $3,013.74$ \\
\hline SNL-14 & CUL & $11 / 07 / 05$ & 378.50 & 115.37 & $2,989.88$ & 911.32 & $3,007.72$ \\
\hline SNL-14 & CUL & $12 / 06 / 05$ & 377.54 & 115.07 & $2,990.84$ & 911.61 & $3,008.74$ \\
\hline WIPP-11 & CUL & $06 / 13 / 05$ & 366.17 & 111.61 & $3,064.36$ & 934.02 & $3,083.12$ \\
\hline WIPP-11 & CUL & 07/18/05 & 366.02 & 111.56 & $3,064.51$ & 934.06 & $3,083.28$ \\
\hline WIPP-11 & CUL & 08/16/05 & 365.66 & 111.45 & $3,064.87$ & 934.17 & $3,083.65$ \\
\hline WIPP-11 & CUL & 09/12/05 & 365.52 & 111.41 & $3,065.01$ & 934.22 & $3,083.80$ \\
\hline WIPP-11 & CUL & $10 / 11 / 05$ & 365.12 & 111.29 & $3,065.41$ & 934.34 & $3,084.21$ \\
\hline WIPP-11 & CUL & $11 / 08 / 05$ & 364.40 & 111.07 & $3,066.13$ & 934.56 & $3,084.96$ \\
\hline WIPP-11 & CUL & $12 / 05 / 05$ & 364.28 & 111.03 & $3,066.25$ & 934.59 & $3,085.08$ \\
\hline WIPP-13 & CUL & 01/19/05 & 347.53 & 105.93 & $3,058.18$ & 932.13 & $3,068.77$ \\
\hline WIPP-13 & CUL & $02 / 14 / 05$ & 370.79 & 113.02 & $3,034.92$ & 925.04 & $3,044.84$ \\
\hline WIPP-13 & CUL & 03/07/05 & 356.72 & 108.73 & $3,048.99$ & 929.33 & $3,059.32$ \\
\hline WIPP-13 & CUL & $04 / 18 / 05$ & 348.44 & 106.20 & $3,057.27$ & 931.86 & $3,067.84$ \\
\hline WIPP-13 & CUL & 05/16/05 & 347.24 & 105.84 & $3,058.47$ & 932.22 & $3,069.07$ \\
\hline WIPP-13 & CUL & $06 / 13 / 05$ & 346.73 & 105.68 & $3,058.98$ & 932.38 & $3,077.29^{*}$ \\
\hline WIPP-13 & CUL & 07/18/05 & 346.55 & 105.63 & $3,059.16$ & 932.43 & $3,077.48^{*}$ \\
\hline WIPP-13 & CUL & 08/15/05 & 346.39 & 105.58 & $3,059.32$ & 932.48 & $3,077.64^{*}$ \\
\hline WIPP-13 & CUL & 09/12/05 & 346.10 & 105.49 & $3,059.61$ & 932.57 & $3,077.95^{*}$ \\
\hline WIPP-13 & CUL & $10 / 11 / 05$ & 345.80 & 105.40 & $3,059.91$ & 932.66 & $3,078.26^{*}$ \\
\hline WIPP-13 & CUL & $11 / 08 / 05$ & 345.23 & 105.23 & $3,060.48$ & 932.83 & $3,078.86^{*}$ \\
\hline WIPP-13 & CUL & $12 / 05 / 05$ & 345.05 & 105.17 & $3,060.66$ & 932.89 & $3,079.05^{*}$ \\
\hline WIPP-19 & CUL & $01 / 20 / 05$ & 394.14 & 120.13 & $3,041.00$ & 926.90 & $3,078.91$ \\
\hline WIPP-19 & CUL & $02 / 17 / 05$ & 396.84 & 120.96 & $3,038.30$ & 926.07 & $3,075.94$ \\
\hline WIPP-19 & CUL & 03/16/05 & 399.80 & 121.86 & $3,035.34$ & 925.17 & $3,072.68$ \\
\hline WIPP-19 & CUL & $04 / 19 / 05$ & 396.63 & 120.89 & $3,038.51$ & 926.14 & $3,076.17$ \\
\hline WIPP-19 & CUL & $05 / 16 / 05$ & 395.22 & 120.46 & $3,039.92$ & 926.57 & $3,077.72$ \\
\hline WIPP-19 & CUL & $06 / 20 / 05$ & 393.90 & 120.06 & $3,041.24$ & 926.97 & $3,063.78^{*}$ \\
\hline WIPP-19 & CUL & 07/19/05 & 393.40 & 119.91 & $3,041.74$ & 927.12 & $3,064.31^{*}$ \\
\hline WIPP-19 & CUL & $08 / 15 / 05$ & 392.93 & 119.77 & $3,042.21$ & 927.27 & $3,064.80^{*}$ \\
\hline WIPP-19 & CUL & 09/13/05 & 392.70 & 119.69 & $3,042.44$ & 927.34 & $3,065.05^{*}$ \\
\hline WIPP-19 & CUL & $10 / 10 / 05$ & 392.64 & 119.68 & $3,042.50$ & 927.35 & $3,065.11^{*}$ \\
\hline WIPP-19 & CUL & $11 / 07 / 05$ & 392.67 & 119.69 & $3,042.47$ & 927.34 & $3,065.08^{*}$ \\
\hline WIPP-19 & CUL & $12 / 05 / 05$ & 392.58 & 119.66 & $3,042.56$ & 927.37 & $3,065.18^{*}$ \\
\hline WIPP-25 (PIP) & CUL & $01 / 18 / 05$ & 149.06 & 45.43 & $3,065.33$ & 934.31 & $3,062.21$ \\
\hline WIPP-25 (PIP) & CUL & $02 / 15 / 05$ & 148.48 & 45.26 & $3,065.91$ & 934.49 & $3,062.78$ \\
\hline WIPP-25 (PIP) & CUL & 03/07/05 & 148.22 & 45.18 & $3,066.17$ & 934.57 & $3,063.04$ \\
\hline WIPP-25 (PIP) & CUL & $04 / 25 / 05$ & 147.71 & 45.02 & $3,066.68$ & 934.72 & $3,063.54$ \\
\hline WIPP-25 (PIP) & CUL & $05 / 17 / 05$ & 147.60 & 44.99 & $3,066.79$ & 934.76 & $3,063.65$ \\
\hline WIPP-25 (PIP) & CUL & 06/13/05 & 147.70 & 45.02 & $3,066.69$ & 934.73 & $3,073.59^{*}$ \\
\hline
\end{tabular}




\section{Waste Isolation Pilot Plant Annual Site Environmental Report for 2005 DOE/WIPP-06-2225}

\begin{tabular}{|c|c|c|c|c|c|c|c|}
\hline Well Number & Zone & Date & $\begin{array}{c}\text { Measured } \\
\text { Depth from } \\
\text { Top of } \\
\text { Casing }\end{array}$ & $\begin{array}{c}\text { Measured } \\
\text { Depth in } \\
\text { Meters }\end{array}$ & $\begin{array}{l}\text { Elevation } \\
\text { in Feet } \\
\text { AMSL }\end{array}$ & $\begin{array}{l}\text { Elevation } \\
\text { in Meters }\end{array}$ & $\begin{array}{l}\text { Elevation in Feet } \\
\text { AMSL Adjusted to } \\
\text { Equivalent Fresh } \\
\text { Water Head }\end{array}$ \\
\hline WIPP-25 (PIP) & CUL & 07/18/05 & 147.85 & 45.06 & $3,066.54$ & 934.68 & $3,073.44^{*}$ \\
\hline WIPP-25 (PIP) & CUL & 08/16/05 & 147.71 & 45.02 & $3,066.68$ & 934.72 & $3,073.58^{*}$ \\
\hline WIPP-25 (PIP) & CUL & $09 / 14 / 05$ & 146.97 & 44.80 & $3,067.42$ & 934.95 & $3,074.34^{*}$ \\
\hline WIPP-25 (PIP) & CUL & $10 / 11 / 05$ & 146.71 & 44.72 & $3,067.68$ & 935.03 & $3,074.60^{*}$ \\
\hline WIPP-25 (PIP) & CUL & $12 / 06 / 05$ & 145.99 & 44.50 & $3,068.40$ & 935.25 & $3,075.34^{*}$ \\
\hline WIPP-26 & CUL & 03/07/05 & 127.31 & 38.80 & $3,025.89$ & 922.29 & $3,026.03$ \\
\hline WIPP-26 & CUL & $04 / 25 / 05$ & 127.01 & 38.71 & $3,026.19$ & 922.38 & $3,026.33$ \\
\hline WIPP-26 & CUL & 05/17/05 & 127.19 & 38.77 & $3,026.01$ & 922.33 & $3,026.15$ \\
\hline WIPP-26 & CUL & $06 / 13 / 05$ & 126.92 & 38.69 & $3,026.28$ & 922.41 & $3,027.65^{*}$ \\
\hline WIPP-26 & CUL & 07/18/05 & 127.42 & 38.84 & $3,025.78$ & 922.26 & $3,027.14^{*}$ \\
\hline WIPP-26 & CUL & 08/16/05 & 127.83 & 38.96 & $3,025.37$ & 922.13 & $3,026.72^{*}$ \\
\hline WIPP-26 & CUL & 09/14/05 & 127.31 & 38.80 & $3,025.89$ & 922.29 & $3,027.25^{*}$ \\
\hline WIPP-26 & CUL & $10 / 11 / 05$ & 127.63 & 38.90 & $3,025.57$ & 922.19 & $3,026.93^{*}$ \\
\hline WIPP-26 & CUL & $11 / 10 / 05$ & 127.82 & 38.96 & $3,025.38$ & 922.14 & $3,026.73^{*}$ \\
\hline WIPP-26 & CUL & $12 / 06 / 05$ & 127.75 & 38.94 & $3,025.45$ & 922.16 & $3,026.80^{*}$ \\
\hline WIPP-27 (PIP) & CUL & $01 / 18 / 05$ & 92.78 & 28.28 & $3,086.20$ & 940.67 & $3,092.41$ \\
\hline WIPP-27 (PIP) & CUL & 02/15/05 & 92.86 & 28.30 & $3,086.12$ & 940.65 & $3,092.32$ \\
\hline WIPP-27 (PIP) & CUL & 03/07/05 & 93.06 & 28.36 & $3,085.92$ & 940.59 & $3,092.12$ \\
\hline WIPP-27 (PIP) & CUL & $04 / 25 / 05$ & 93.68 & 28.55 & $3,085.30$ & 940.40 & $3,091.48$ \\
\hline WIPP-27 (PIP) & CUL & $05 / 17 / 05$ & 93.71 & 28.56 & $3,085.27$ & 940.39 & $3,091.45$ \\
\hline WIPP-27 (PIP) & CUL & 06/13/05 & 92.94 & 28.33 & $3,086.04$ & 940.62 & $3,094.60^{*}$ \\
\hline WIPP-27 (PIP) & CUL & 07/18/05 & 92.78 & 28.28 & $3,086.20$ & 940.67 & $3,094.76^{*}$ \\
\hline WIPP-27 (PIP) & CUL & $08 / 17 / 05$ & 92.45 & 28.18 & $3,086.53$ & 940.77 & $3,095.10^{*}$ \\
\hline WIPP-27 (PIP) & CUL & $09 / 14 / 05$ & 91.91 & 28.01 & $3,087.07$ & 940.94 & $3,095.67^{*}$ \\
\hline WIPP-27 (PIP) & CUL & $10 / 12 / 05$ & 91.38 & 27.85 & $3,087.60$ & 941.10 & $3,096.22^{*}$ \\
\hline WIPP-27 (PIP) & CUL & $11 / 08 / 05$ & 91.06 & 27.76 & $3,087.92$ & 941.20 & $3,096.55^{*}$ \\
\hline WIPP-30 (PIP) & CUL & 07/18/05 & 353.13 & 107.63 & $3,075.92$ & 937.54 & $3,083.18$ \\
\hline WIPP-30 (PIP) & CUL & 08/17/05 & 351.66 & 107.19 & $3,077.39$ & 937.99 & $3,084.69$ \\
\hline WIPP-30 (PIP) & CUL & $09 / 14 / 05$ & 350.93 & 106.96 & $3,078.12$ & 938.21 & $3,085.44$ \\
\hline WIPP-30 (PIP) & CUL & $10 / 11 / 05$ & 350.59 & 106.86 & $3,078.46$ & 938.31 & $3,085.78$ \\
\hline WIPP-30 (PIP) & CUL & $11 / 08 / 05$ & 350.08 & 106.70 & $3,078.97$ & 938.47 & $3,086.31$ \\
\hline WIPP-30 (PIP) & CUL & $12 / 05 / 05$ & 349.73 & 106.60 & $3,079.32$ & 938.58 & $3,086.67$ \\
\hline WQSP-1 & CUL & $01 / 20 / 05$ & 363.13 & 110.68 & $3,056.07$ & 931.49 & $3,072.87$ \\
\hline WQSP-1 & CUL & $04 / 18 / 05$ & 364.01 & 110.95 & $3,055.19$ & 931.22 & $3,071.95$ \\
\hline WQSP-1 & CUL & 05/16/05 & 362.77 & 110.57 & $3,056.43$ & 931.60 & $3,073.25$ \\
\hline WQSP-1 & CUL & $06 / 20 / 05$ & 362.18 & 110.39 & $3,057.02$ & 931.78 & $3,071.06^{*}$ \\
\hline WQSP-1 & CUL & $07 / 19 / 05$ & 361.87 & 110.30 & $3,057.33$ & 931.87 & $3,071.38^{*}$ \\
\hline WQSP-1 & CUL & 08/16/05 & 361.64 & 110.23 & $3,057.56$ & 931.94 & $3,071.62^{*}$ \\
\hline WQSP-1 & CUL & $09 / 12 / 05$ & 361.50 & 110.19 & $3,057.70$ & 931.99 & $3,071.76^{*}$ \\
\hline WQSP-1 & CUL & $10 / 11 / 05$ & 361.18 & 110.09 & $3,058.02$ & 932.08 & $3,072 \cdot 10^{*}$ \\
\hline WQSP-1 & CUL & $11 / 08 / 05$ & 362.55 & 110.51 & $3,056.65$ & 931.67 & $3,070.67^{*}$ \\
\hline WQSP-1 & CUL & $12 / 05 / 05$ & 360.44 & 109.86 & $3,058.76$ & 932.31 & $3,072.87^{*}$ \\
\hline WQSP-2 & CUL & 01/20/05 & 402.90 & 122.80 & $3,061.00$ & 932.99 & $3,080.82$ \\
\hline
\end{tabular}


Waste Isolation Pilot Plant Annual Site Environmental Report for 2005 DOE/WIPP-06-2225

\begin{tabular}{|c|c|c|c|c|c|c|c|}
\hline Well Number & Zone & Date & $\begin{array}{c}\text { Measured } \\
\text { Depth from } \\
\text { Top of } \\
\text { Casing }\end{array}$ & $\begin{array}{c}\text { Measured } \\
\text { Depth in } \\
\text { Meters }\end{array}$ & $\begin{array}{l}\text { Elevation } \\
\text { in Feet } \\
\text { AMSL }\end{array}$ & $\begin{array}{l}\text { Elevation } \\
\text { in Meters }\end{array}$ & $\begin{array}{l}\text { Elevation in Feet } \\
\text { AMSL Adjusted to } \\
\text { Equivalent Fresh } \\
\text { Water Head }\end{array}$ \\
\hline WQSP-2 & CUL & 04/19/05 & 403.45 & 122.97 & $3,060.45$ & 932.83 & $3,080.24$ \\
\hline WQSP-2 & CUL & 05/16/05 & 402.59 & 122.71 & $3,061.31$ & 933.09 & $3,081.14$ \\
\hline WQSP-2 & CUL & $06 / 20 / 05$ & 401.85 & 122.48 & $3,062.05$ & 933.31 & $3,078.96^{*}$ \\
\hline WQSP-2 & CUL & 07/19/05 & 401.46 & 122.37 & $3,062.44$ & 933.43 & $3,079.36^{*}$ \\
\hline WQSP-2 & CUL & 08/15/05 & 401.38 & 122.34 & $3,062.52$ & 933.46 & $3,079.44^{*}$ \\
\hline WQSP-2 & CUL & $09 / 12 / 05$ & 401.04 & 122.24 & $3,062.86$ & 933.56 & $3,079.80^{*}$ \\
\hline WQSP-2 & CUL & 10/11/05 & 400.77 & 122.15 & $3,063.13$ & 933.64 & $3,080.08^{*}$ \\
\hline WQSP-2 & CUL & $11 / 08 / 05$ & 400.16 & 121.97 & $3,063.74$ & 933.83 & $3,080.71^{*}$ \\
\hline WQSP-2 & CUL & $12 / 05 / 05$ & 399.97 & 121.91 & $3,063.93$ & 933.89 & $3,080.91^{*}$ \\
\hline WQSP-3 & CUL & 01/20/05 & 467.63 & 142.53 & $3,012.67$ & 918.26 & $3,069.93$ \\
\hline WQSP-3 & CUL & 04/19/05 & 470.30 & 143.35 & $3,010.00$ & 917.45 & $3,066.87$ \\
\hline WQSP-3 & CUL & 05/16/05 & 467.88 & 142.61 & $3,012.42$ & 918.19 & $3,069.64$ \\
\hline WQSP-3 & CUL & 06/20/05 & 468.12 & 142.68 & $3,012.18$ & 918.11 & $3,067.02^{*}$ \\
\hline WQSP-3 & CUL & 07/19/05 & 467.05 & 142.36 & $3,013.25$ & 918.44 & $3,068.24^{*}$ \\
\hline WQSP-3 & CUL & 08/15/05 & 466.46 & 142.18 & $3,013.84$ & 918.62 & $3,068.91^{*}$ \\
\hline WQSP-3 & CUL & 09/13/05 & 465.94 & 142.02 & $3,014.36$ & 918.78 & $3,069.50^{*}$ \\
\hline WQSP-3 & CUL & $10 / 10 / 05$ & 468.57 & 142.82 & $3,011.73$ & 917.98 & $3,066.50^{*}$ \\
\hline WQSP-3 & CUL & $11 / 07 / 05$ & 466.09 & 142.06 & $3,014.21$ & 918.73 & $3,069.33^{*}$ \\
\hline WQSP-3 & CUL & $12 / 05 / 05$ & 465.74 & 141.96 & $3,014.56$ & 918.84 & $3,069.73^{*}$ \\
\hline WQSP-4 & CUL & $01 / 20 / 05$ & 444.19 & 135.39 & $2,988.81$ & 910.99 & $3,013.86$ \\
\hline WQSP-4 & CUL & $02 / 17 / 05$ & 444.08 & 135.36 & $2,988.92$ & 911.02 & $3,013.98$ \\
\hline WQSP-4 & CUL & 03/08/05 & 444.18 & 135.39 & $2,988.82$ & 910.99 & $3,013.87$ \\
\hline WQSP-4 & CUL & $04 / 19 / 05$ & 443.78 & 135.26 & $2,989.22$ & 911.11 & $3,014.30$ \\
\hline WQSP-4 & CUL & 05/16/05 & 443.66 & 135.23 & $2,989.34$ & 911.15 & $3,014.43$ \\
\hline WQSP-4 & CUL & 06/20/05 & 443.52 & 135.18 & $2,989.48$ & 911.19 & $3,009.56^{*}$ \\
\hline WQSP-4 & CUL & 07/19/05 & 443.46 & 135.17 & $2,989.54$ & 911.21 & $3,009.62^{*}$ \\
\hline WQSP-4 & CUL & 08/15/05 & 447.14 & 136.29 & $2,985.86$ & 910.09 & $3,005.72^{*}$ \\
\hline WQSP-4 & CUL & 09/13/05 & 453.31 & 138.17 & $2,979.69$ & 908.21 & $2,999.18^{*}$ \\
\hline WQSP-4 & CUL & $10 / 10 / 05$ & 450.19 & 137.22 & $2,982.81$ & 909.16 & $3,002.49^{*}$ \\
\hline WQSP-4 & CUL & $11 / 07 / 05$ & 448.39 & 136.67 & $2,984.61$ & 909.71 & $3,004.40^{*}$ \\
\hline WQSP-4 & CUL & $12 / 05 / 05$ & 447.53 & 136.41 & $2,985.47$ & 909.97 & $3,005.31^{*}$ \\
\hline WQSP-5 & CUL & 01/20/05 & 380.15 & 115.87 & $3,004.25$ & 915.70 & $3,011.34$ \\
\hline WQSP-5 & CUL & $02 / 17 / 05$ & 379.96 & 115.81 & $3,004.44$ & 915.75 & $3,011.54$ \\
\hline WQSP-5 & CUL & 03/08/05 & 379.88 & 115.79 & $3,004.52$ & 915.78 & $3,011.62$ \\
\hline WQSP-5 & CUL & 04/19/05 & 379.92 & 115.80 & $3,004.48$ & 915.77 & $3,011.58$ \\
\hline WQSP-5 & CUL & 05/16/05 & 379.69 & 115.73 & $3,004.71$ & 915.84 & $3,011.81$ \\
\hline WQSP-5 & CUL & 06/20/05 & 379.42 & 115.65 & $3,004.98$ & 915.92 & $3,010.67^{*}$ \\
\hline WQSP-5 & CUL & 07/19/05 & 379.34 & 115.62 & $3,005.06$ & 915.94 & $3,010.75^{*}$ \\
\hline WQSP-5 & CUL & 08/15/05 & 379.62 & 115.71 & $3,004.78$ & 915.86 & $3,010.46^{*}$ \\
\hline WQSP-5 & CUL & 09/13/05 & 384.86 & 117.31 & $2,999.54$ & 914.26 & $3,005.12^{*}$ \\
\hline WQSP-5 & CUL & $10 / 10 / 05$ & 384.77 & 117.28 & $2,999.63$ & 914.29 & $3,005.21^{*}$ \\
\hline WQSP-5 & CUL & $11 / 07 / 05$ & 384.02 & 117.05 & $3,000.38$ & 914.52 & $3,005.98^{*}$ \\
\hline WQSP-5 & CUL & $12 / 05 / 05$ & 383.70 & 116.95 & $3,000.70$ & 914.61 & $3,006.30^{*}$ \\
\hline
\end{tabular}




\section{Waste Isolation Pilot Plant Annual Site Environmental Report for 2005 DOE/WIPP-06-2225}

\begin{tabular}{|c|c|c|c|c|c|c|c|}
\hline Well Number & Zone & Date & $\begin{array}{l}\text { Measured } \\
\text { Depth from } \\
\text { Top of } \\
\text { Casing }\end{array}$ & $\begin{array}{c}\text { Measured } \\
\text { Depth in } \\
\text { Meters }\end{array}$ & $\begin{array}{l}\text { Elevation } \\
\text { in Feet } \\
\text { AMSL }\end{array}$ & $\begin{array}{l}\text { Elevation } \\
\text { in Meters }\end{array}$ & $\begin{array}{l}\text { Elevation in Feet } \\
\text { AMSL Adjusted to } \\
\text { Equivalent Fresh } \\
\text { Water Head }\end{array}$ \\
\hline WQSP-6 & CUL & $01 / 20 / 05$ & 346.64 & 105.66 & $3,018.06$ & 919.90 & $3,021.82$ \\
\hline WQSP-6 & CUL & $02 / 17 / 05$ & 346.44 & 105.59 & $3,018.26$ & 919.97 & $3,022.02$ \\
\hline WQSP-6 & CUL & 03/08/05 & 346.06 & 105.48 & $3,018.64$ & 920.08 & $3,022.41$ \\
\hline WQSP-6 & CUL & $04 / 19 / 05$ & 348.55 & 106.24 & $3,016.15$ & 919.32 & $3,019.88$ \\
\hline WQSP-6 & CUL & 05/16/05 & 345.64 & 105.35 & $3,019.06$ & 920.21 & $3,022.84$ \\
\hline WQSP-6 & CUL & $06 / 20 / 05$ & 345.38 & 105.27 & $3,019.32$ & 920.29 & $3,021.84^{*}$ \\
\hline WQSP-6 & CUL & $07 / 19 / 05$ & 345.34 & 105.26 & $3,019.36$ & 920.30 & $3,021.88^{*}$ \\
\hline WQSP-6 & CUL & 08/15/05 & 345.12 & 105.19 & $3,019.58$ & 920.37 & $3,022.10^{*}$ \\
\hline WQSP-6 & CUL & 09/13/05 & 345.24 & 105.23 & $3,019.46$ & 920.33 & $3,021.98^{*}$ \\
\hline WQSP-6 & CUL & 10/10/05 & 345.66 & 105.36 & $3,019.04$ & 920.20 & $3,021.56^{*}$ \\
\hline WQSP-6 & CUL & $11 / 07 / 05$ & 347.27 & 105.85 & $3,017.43$ & 919.71 & $3,019.93^{*}$ \\
\hline WQSP-6 & CUL & $12 / 05 / 05$ & 346.79 & 105.70 & $3,017.91$ & 919.86 & $3,019.93^{*}$ \\
\hline C-2737 (ANNULUS) & MAG & $01 / 20 / 05$ & 256.15 & 78.07 & $3,143.15$ & 958.03 & N/A \\
\hline C-2737 (ANNULUS) & MAG & $02 / 16 / 05$ & 255.93 & 78.01 & $3,143.37$ & 958.10 & $N / A$ \\
\hline C-2737 (ANNULUS) & MAG & 03/16/05 & 255.80 & 77.97 & $3,143.50$ & 958.14 & N/A \\
\hline C-2737 (ANNULUS) & MAG & 04/19/05 & 255.67 & 77.93 & $3,143.63$ & 958.18 & N/A \\
\hline C-2737 (ANNULUS) & MAG & $05 / 18 / 05$ & 255.57 & 77.90 & $3,143.73$ & 958.21 & N/A \\
\hline C-2737 (ANNULUS) & MAG & $06 / 21 / 05$ & 255.70 & 77.94 & $3,143.60$ & 958.17 & N/A \\
\hline C-2737 (ANNULUS) & MAG & 07/19/05 & 255.86 & 77.99 & $3,143.44$ & 958.12 & $\mathrm{~N} / \mathrm{A}$ \\
\hline C-2737 (ANNULUS) & MAG & 08/15/05 & 255.50 & 77.88 & $3,143.80$ & 958.23 & N/A \\
\hline C-2737 (ANNULUS) & MAG & $09 / 14 / 05$ & 255.77 & 77.96 & $3,143.53$ & 958.15 & N/A \\
\hline C-2737 (ANNULUS) & MAG & $10 / 12 / 05$ & 255.67 & 77.93 & $3,143.63$ & 958.18 & N/A \\
\hline C-2737 (ANNULUS) & MAG & 11/07/05 & 255.55 & 77.89 & $3,143.75$ & 958.22 & N/A \\
\hline C-2737 (ANNULUS) & MAG & $12 / 07 / 05$ & 255.58 & 77.90 & $3,143.72$ & 958.21 & N/A \\
\hline $\mathrm{H}-02 \mathrm{~b} 1$ & MAG & $01 / 20 / 05$ & 234.82 & 71.57 & $3,143.64$ & 958.18 & N/A \\
\hline $\mathrm{H}-02 \mathrm{~b} 1$ & MAG & $02 / 16 / 05$ & 234.86 & 71.59 & $3,143.60$ & 958.17 & N/A \\
\hline $\mathrm{H}-02 \mathrm{~b} 1$ & MAG & 03/08/05 & 234.89 & 71.59 & $3,143.57$ & 958.16 & N/A \\
\hline $\mathrm{H}-02 \mathrm{~b} 1$ & MAG & $04 / 25 / 05$ & 54.20 & 16.52 & $3,324.26$ & $1,013.23$ & N/A \\
\hline $\mathrm{H}-02 \mathrm{~b} 1$ & MAG & 05/16/05 & 94.43 & 28.78 & $3,284.03$ & $1,000.97$ & N/A \\
\hline $\mathrm{H}-02 \mathrm{~b} 1$ & MAG & 06/20/05 & 139.20 & 42.43 & $3,239.26$ & 987.33 & N/A \\
\hline $\mathrm{H}-02 \mathrm{~b} 1$ & MAG & 07/19/05 & 164.22 & 50.05 & $3,214.24$ & 979.70 & N/A \\
\hline $\mathrm{H}-02 \mathrm{~b} 1$ & MAG & 08/15/05 & 509.20 & 155.20 & $2,869.26$ & 874.55 & N/A \\
\hline $\mathrm{H}-02 \mathrm{~b} 1$ & MAG & $09 / 13 / 05$ & 418.73 & 127.63 & $2,959.73$ & 902.13 & N/A \\
\hline $\mathrm{H}-02 \mathrm{~b} 1$ & MAG & $10 / 12 / 05$ & 363.19 & 110.70 & $3,015.27$ & 919.05 & N/A \\
\hline $\mathrm{H}-02 \mathrm{~b} 1$ & MAG & $11 / 08 / 05$ & 328.40 & 100.10 & $3,050.07$ & 929.66 & N/A \\
\hline $\mathrm{H}-02 \mathrm{~b} 1$ & MAG & $12 / 05 / 05$ & 303.66 & 92.56 & $3,074.81$ & 937.20 & N/A \\
\hline $\mathrm{H}-03 \mathrm{~b} 1$ & MAG & $01 / 20 / 05$ & 245.38 & 74.79 & $3,145.26$ & 958.68 & N/A \\
\hline $\mathrm{H}-03 \mathrm{~b} 1$ & MAG & $02 / 17 / 05$ & 245.08 & 74.70 & $3,145.56$ & 958.77 & N/A \\
\hline $\mathrm{H}-03 \mathrm{~b} 1$ & MAG & 03/08/05 & 244.84 & 74.63 & $3,145.80$ & 958.84 & N/A \\
\hline $\mathrm{H}-03 \mathrm{~b} 1$ & MAG & $04 / 19 / 05$ & 244.71 & 74.59 & $3,145.93$ & 958.88 & N/A \\
\hline $\mathrm{H}-03 \mathrm{~b} 1$ & MAG & 05/16/05 & 244.64 & 74.57 & $3,146.00$ & 958.90 & N/A \\
\hline $\mathrm{H}-03 \mathrm{~b} 1$ & MAG & $06 / 21 / 05$ & 53.10 & 16.18 & $3,337.54$ & $1,017.28$ & N/A \\
\hline $\mathrm{H}-03 \mathrm{~b} 1$ & MAG & 07/19/05 & 97.70 & 29.78 & $3,292.94$ & $1,003.69$ & N/A \\
\hline
\end{tabular}




\section{Waste Isolation Pilot Plant Annual Site Environmental Report for 2005 DOE/WIPP-06-2225}

\begin{tabular}{|c|c|c|c|c|c|c|c|}
\hline Well Number & Zone & Date & $\begin{array}{l}\text { Measured } \\
\text { Depth from } \\
\text { Top of } \\
\text { Casing }\end{array}$ & $\begin{array}{l}\text { Measured } \\
\text { Depth in } \\
\text { Meters }\end{array}$ & $\begin{array}{c}\text { Elevation } \\
\text { in Feet } \\
\text { AMSL }\end{array}$ & $\begin{array}{l}\text { Elevation } \\
\text { in Meters }\end{array}$ & $\begin{array}{l}\text { Elevation in Feet } \\
\text { AMSL Adjusted to } \\
\text { Equivalent Fresh } \\
\text { Water Head }\end{array}$ \\
\hline $\mathrm{H}-03 \mathrm{~b} 1$ & MAG & $08 / 15 / 05$ & 290.42 & 88.52 & $3,100.22$ & 944.95 & $\mathrm{~N} / \mathrm{A}$ \\
\hline $\mathrm{H}-03 \mathrm{~b} 1$ & MAG & 09/13/05 & 245.20 & 74.74 & $3,145.44$ & 958.73 & $\mathrm{~N} / \mathrm{A}$ \\
\hline $\mathrm{H}-03 \mathrm{~b} 1$ & MAG & $10 / 10 / 05$ & 244.59 & 74.55 & $3,146.05$ & 958.92 & $\mathrm{~N} / \mathrm{A}$ \\
\hline $\mathrm{H}-03 \mathrm{~b} 1$ & MAG & $11 / 07 / 05$ & 244.49 & 74.52 & $3,146.19$ & 958.96 & $\mathrm{~N} / \mathrm{A}$ \\
\hline $\mathrm{H}-03 \mathrm{~b} 1$ & MAG & $12 / 05 / 05$ & 244.41 & 74.50 & $3,146.27$ & 958.98 & $\mathrm{~N} / \mathrm{A}$ \\
\hline $\mathrm{H}-04 \mathrm{c}$ & MAG & $01 / 19 / 05$ & 193.01 & 58.83 & $3,141.03$ & 957.39 & $\mathrm{~N} / \mathrm{A}$ \\
\hline $\mathrm{H}-04 \mathrm{c}$ & MAG & $02 / 14 / 05$ & 193.01 & 58.83 & $3,141.03$ & 957.39 & $\mathrm{~N} / \mathrm{A}$ \\
\hline $\mathrm{H}-04 \mathrm{c}$ & MAG & 03/08/05 & 193.04 & 58.84 & $3,141.00$ & 957.38 & N/A \\
\hline $\mathrm{H}-04 \mathrm{C}$ & MAG & $04 / 19 / 05$ & 193.20 & 58.89 & $3,140.84$ & 957.33 & $\mathrm{~N} / \mathrm{A}$ \\
\hline $\mathrm{H}-04 \mathrm{c}$ & MAG & 05/16/05 & 144.00 & 43.89 & $3,190.04$ & 972.32 & $\mathrm{~N} / \mathrm{A}$ \\
\hline $\mathrm{H}-04 \mathrm{C}$ & MAG & 06/20/05 & 184.25 & 56.16 & $3,149.79$ & 960.06 & $\mathrm{~N} / \mathrm{A}$ \\
\hline $\mathrm{H}-04 \mathrm{c}$ & MAG & 07/19/05 & 185.57 & 56.56 & $3,148.47$ & 959.65 & $\mathrm{~N} / \mathrm{A}$ \\
\hline $\mathrm{H}-04 \mathrm{c}$ & MAG & $08 / 15 / 05$ & 283.15 & 86.30 & $3,050.89$ & 929.91 & $\mathrm{~N} / \mathrm{A}$ \\
\hline $\mathrm{H}-04 \mathrm{c}$ & MAG & 09/13/05 & 191.80 & 58.46 & $3,142.24$ & 957.75 & $\mathrm{~N} / \mathrm{A}$ \\
\hline $\mathrm{H}-04 \mathrm{C}$ & MAG & $10 / 10 / 05$ & 188.60 & 57.49 & $3,145.44$ & 958.73 & $\mathrm{~N} / \mathrm{A}$ \\
\hline $\mathrm{H}-04 \mathrm{C}$ & MAG & $11 / 07 / 05$ & 188.00 & 57.30 & $3,146.09$ & 958.93 & $\mathrm{~N} / \mathrm{A}$ \\
\hline $\mathrm{H}-04 \mathrm{c}$ & MAG & $12 / 05 / 05$ & 187.84 & 57.25 & $3,146.25$ & 958.98 & $\mathrm{~N} / \mathrm{A}$ \\
\hline $\mathrm{H}-05 \mathrm{c}$ & MAG & $01 / 18 / 05$ & 349.65 & 106.57 & $3,156.39$ & 962.07 & $\mathrm{~N} / \mathrm{A}$ \\
\hline $\mathrm{H}-05 \mathrm{c}$ & MAG & $02 / 16 / 05$ & 349.47 & 106.52 & $3,156.57$ & 962.12 & $\mathrm{~N} / \mathrm{A}$ \\
\hline $\mathrm{H}-05 \mathrm{c}$ & MAG & 03/10/05 & 349.43 & 106.51 & $3,156.61$ & 962.13 & $\mathrm{~N} / \mathrm{A}$ \\
\hline $\mathrm{H}-05 \mathrm{c}$ & MAG & 04/19/05 & 349.40 & 106.50 & $3,156.64$ & 962.14 & $\mathrm{~N} / \mathrm{A}$ \\
\hline $\mathrm{H}-05 \mathrm{c}$ & MAG & $05 / 18 / 05$ & 349.36 & 106.48 & $3,156.68$ & 962.16 & N/A \\
\hline $\mathrm{H}-05 \mathrm{c}$ & MAG & $06 / 16 / 05$ & 53.60 & 16.34 & $3,452.44$ & $1,052.30$ & $\mathrm{~N} / \mathrm{A}$ \\
\hline $\mathrm{H}-05 \mathrm{c}$ & MAG & 07/19/05 & 64.65 & 19.71 & $3,441.39$ & $1,048.94$ & $\mathrm{~N} / \mathrm{A}$ \\
\hline $\mathrm{H}-05 \mathrm{c}$ & MAG & $08 / 15 / 05$ & 71.80 & 21.88 & $3,434.24$ & $1,046.76$ & $\mathrm{~N} / \mathrm{A}$ \\
\hline $\mathrm{H}-05 \mathrm{c}$ & MAG & $10 / 12 / 05$ & 699.20 & 213.12 & $2,806.84$ & 855.52 & $\mathrm{~N} / \mathrm{A}$ \\
\hline $\mathrm{H}-05 \mathrm{c}$ & MAG & $11 / 10 / 05$ & 698.47 & 212.89 & $2,807.59$ & 855.75 & $\mathrm{~N} / \mathrm{A}$ \\
\hline $\mathrm{H}-05 \mathrm{c}$ & MAG & $12 / 07 / 05$ & 698.00 & 212.75 & $2,808.06$ & 855.90 & $\mathrm{~N} / \mathrm{A}$ \\
\hline $\mathrm{H}-06 \mathrm{c}$ & MAG & $01 / 18 / 05$ & 281.75 & 85.88 & $3,066.77$ & 934.75 & $\mathrm{~N} / \mathrm{A}$ \\
\hline $\mathrm{H}-06 \mathrm{c}$ & MAG & $02 / 15 / 05$ & 281.41 & 85.77 & $3,067.11$ & 934.86 & $\mathrm{~N} / \mathrm{A}$ \\
\hline $\mathrm{H}-06 \mathrm{c}$ & MAG & $03 / 07 / 05$ & 281.36 & 85.76 & $3,067.16$ & 934.87 & $\mathrm{~N} / \mathrm{A}$ \\
\hline $\mathrm{H}-06 \mathrm{c}$ & MAG & $04 / 18 / 05$ & 281.26 & 85.73 & $3,067.26$ & 934.90 & $\mathrm{~N} / \mathrm{A}$ \\
\hline $\mathrm{H}-06 \mathrm{c}$ & MAG & $05 / 16 / 05$ & 267.18 & 81.44 & $3,081.34$ & 939.19 & $\mathrm{~N} / \mathrm{A}$ \\
\hline $\mathrm{H}-06 \mathrm{c}$ & MAG & $06 / 13 / 05$ & 269.24 & 82.06 & $3,079.28$ & 938.56 & $\mathrm{~N} / \mathrm{A}$ \\
\hline $\mathrm{H}-06 \mathrm{c}$ & MAG & $07 / 18 / 05$ & 280.20 & 85.40 & $3,068.32$ & 935.22 & $\mathrm{~N} / \mathrm{A}$ \\
\hline $\mathrm{H}-06 \mathrm{c}$ & MAG & $08 / 16 / 05$ & 280.65 & 85.54 & $3,067.87$ & 935.09 & $\mathrm{~N} / \mathrm{A}$ \\
\hline $\mathrm{H}-06 \mathrm{c}$ & MAG & 09/13/05 & 280.35 & 85.45 & $3,068.17$ & 935.18 & $\mathrm{~N} / \mathrm{A}$ \\
\hline $\mathrm{H}-06 \mathrm{c}$ & MAG & $10 / 11 / 05$ & 282.38 & 86.07 & $3,066.14$ & 934.56 & $\mathrm{~N} / \mathrm{A}$ \\
\hline $\mathrm{H}-06 \mathrm{c}$ & MAG & $11 / 08 / 05$ & 281.17 & 85.70 & $3,067.35$ & 934.93 & $\mathrm{~N} / \mathrm{A}$ \\
\hline $\mathrm{H}-06 \mathrm{c}$ & MAG & $12 / 06 / 05$ & 281.13 & 85.69 & $3,067.39$ & 934.94 & $\mathrm{~N} / \mathrm{A}$ \\
\hline $\mathrm{H}-08 \mathrm{a}$ & MAG & $01 / 19 / 05$ & 405.70 & 123.66 & $3,027.29$ & 922.72 & $\mathrm{~N} / \mathrm{A}$ \\
\hline $\mathrm{H}-08 \mathrm{a}$ & MAG & $02 / 16 / 05$ & 405.68 & 123.65 & $3,027.31$ & 922.72 & $\mathrm{~N} / \mathrm{A}$ \\
\hline $\mathrm{H}-08 \mathrm{a}$ & MAG & $03 / 10 / 05$ & 405.60 & 123.63 & $3,027.39$ & 922.75 & $\mathrm{~N} / \mathrm{A}$ \\
\hline
\end{tabular}




\section{Waste Isolation Pilot Plant Annual Site Environmental Report for 2005 DOE/WIPP-06-2225}

\begin{tabular}{|c|c|c|c|c|c|c|c|}
\hline Well Number & Zone & Date & $\begin{array}{c}\text { Measured } \\
\text { Depth from } \\
\text { Top of } \\
\text { Casing }\end{array}$ & $\begin{array}{c}\text { Measured } \\
\text { Depth in } \\
\text { Meters }\end{array}$ & $\begin{array}{c}\text { Elevation } \\
\text { in Feet } \\
\text { AMSL }\end{array}$ & $\begin{array}{l}\text { Elevation } \\
\text { in Meters }\end{array}$ & $\begin{array}{l}\text { Elevation in Feet } \\
\text { AMSL Adjusted to } \\
\text { Equivalent Fresh } \\
\text { Water Head }\end{array}$ \\
\hline $\mathrm{H}-08 \mathrm{a}$ & MAG & $04 / 18 / 05$ & 405.60 & 123.63 & $3,027.39$ & 922.75 & $\mathrm{~N} / \mathrm{A}$ \\
\hline $\mathrm{H}-08 \mathrm{a}$ & MAG & $05 / 17 / 05$ & 405.60 & 123.63 & $3,027.39$ & 922.75 & N/A \\
\hline $\mathrm{H}-08 \mathrm{a}$ & MAG & $06 / 21 / 05$ & 405.60 & 123.63 & $3,027.39$ & 922.75 & $\mathrm{~N} / \mathrm{A}$ \\
\hline $\mathrm{H}-08 \mathrm{a}$ & MAG & 07/18/05 & 405.63 & 123.64 & $3,027.36$ & 922.74 & $N / A$ \\
\hline $\mathrm{H}-08 \mathrm{a}$ & MAG & 08/16/05 & 405.75 & 123.67 & $3,027.24$ & 922.70 & N/A \\
\hline $\mathrm{H}-08 \mathrm{a}$ & MAG & $09 / 12 / 05$ & 405.79 & 123.68 & $3,027.20$ & 922.69 & $N / A$ \\
\hline $\mathrm{H}-08 \mathrm{a}$ & MAG & $10 / 11 / 05$ & 405.84 & 123.70 & $3,027.15$ & 922.68 & $\mathrm{~N} / \mathrm{A}$ \\
\hline $\mathrm{H}-08 \mathrm{a}$ & MAG & $11 / 07 / 05$ & 405.84 & 123.70 & $3,027.15$ & 922.68 & N/A \\
\hline $\mathrm{H}-08 \mathrm{a}$ & MAG & $12 / 06 / 05$ & 405.93 & 123.73 & $3,027.06$ & 922.65 & N/A \\
\hline H-09c (ANNULUS) & MAG & $01 / 19 / 05$ & 271.65 & 82.80 & $3,135.65$ & 955.75 & $N / A$ \\
\hline H-09c (ANNULUS) & MAG & $02 / 16 / 05$ & 271.07 & 82.62 & $3,136.23$ & 955.92 & N/A \\
\hline H-09c (ANNULUS) & MAG & $03 / 10 / 05$ & 270.94 & 82.58 & $3,136.36$ & 955.96 & $\mathrm{~N} / \mathrm{A}$ \\
\hline H-09c (ANNULUS) & MAG & $04 / 18 / 05$ & 270.95 & 82.59 & $3,136.35$ & 955.96 & N/A \\
\hline H-09c (ANNULUS) & MAG & $05 / 17 / 05$ & 270.88 & 82.56 & $3,136.42$ & 955.98 & $N / A$ \\
\hline H-09c (ANNULUS) & MAG & $06 / 20 / 05$ & 271.13 & 82.64 & $3,136.17$ & 955.90 & N/A \\
\hline H-09c (ANNULUS) & MAG & $07 / 18 / 05$ & 271.17 & 82.65 & $3,136.13$ & 955.89 & $\mathrm{~N} / \mathrm{A}$ \\
\hline H-09c (ANNULUS) & MAG & 08/16/05 & 271.26 & 82.68 & $3,136.04$ & 955.86 & $\mathrm{~N} / \mathrm{A}$ \\
\hline H-09c (ANNULUS) & MAG & $09 / 12 / 05$ & 271.20 & 82.66 & $3,136.10$ & 955.88 & $\mathrm{~N} / \mathrm{A}$ \\
\hline H-09c (ANNULUS) & MAG & $10 / 11 / 05$ & 271.19 & 82.66 & $3,136.11$ & 955.89 & N/A \\
\hline H-09c (ANNULUS) & MAG & $11 / 07 / 05$ & 271.28 & 82.69 & $3,136.02$ & 955.86 & $\mathrm{~N} / \mathrm{A}$ \\
\hline H-09c (ANNULUS) & MAG & $12 / 06 / 05$ & 271.37 & 82.71 & $3,135.93$ & 955.83 & $\mathrm{~N} / \mathrm{A}$ \\
\hline $\mathrm{H}-10 \mathrm{a}$ & MAG & 01/19/05 & 466.75 & 142.27 & $3,221.92$ & 982.04 & N/A \\
\hline $\mathrm{H}-10 \mathrm{a}$ & MAG & $02 / 16 / 05$ & 466.73 & 142.26 & $3,221.94$ & 982.05 & N/A \\
\hline $\mathrm{H}-10 \mathrm{a}$ & MAG & 03/10/05 & 466.71 & 142.25 & $3,221.96$ & 982.05 & $\mathrm{~N} / \mathrm{A}$ \\
\hline $\mathrm{H}-10 \mathrm{a}$ & MAG & $04 / 19 / 05$ & 466.76 & 142.27 & $3,221.91$ & 982.04 & N/A \\
\hline $\mathrm{H}-10 \mathrm{a}$ & MAG & $05 / 17 / 05$ & 466.81 & 142.28 & $3,221.86$ & 982.02 & N/A \\
\hline $\mathrm{H}-10 \mathrm{a}$ & MAG & 06/20/05 & 466.90 & 142.31 & $3,221.77$ & 982.00 & N/A \\
\hline $\mathrm{H}-10 \mathrm{a}$ & MAG & $07 / 19 / 05$ & 467.05 & 142.36 & $3,221.62$ & 981.95 & $\mathrm{~N} / \mathrm{A}$ \\
\hline $\mathrm{H}-10 \mathrm{a}$ & MAG & 08/16/05 & 467.10 & 142.37 & $3,221.57$ & 981.93 & $\mathrm{~N} / \mathrm{A}$ \\
\hline $\mathrm{H}-10 \mathrm{a}$ & MAG & $09 / 12 / 05$ & 467.17 & 142.39 & $3,221.50$ & 981.91 & $N / A$ \\
\hline $\mathrm{H}-10 \mathrm{a}$ & MAG & $10 / 12 / 05$ & 467.19 & 142.40 & $3,221.48$ & 981.91 & $\mathrm{~N} / \mathrm{A}$ \\
\hline $\mathrm{H}-10 \mathrm{a}$ & MAG & $11 / 07 / 05$ & 467.20 & 142.40 & $3,221.47$ & 981.90 & $\mathrm{~N} / \mathrm{A}$ \\
\hline $\mathrm{H}-10 \mathrm{a}$ & MAG & $12 / 06 / 05$ & 465.34 & 141.84 & $3,223.33$ & 982.47 & $\mathrm{~N} / \mathrm{A}$ \\
\hline $\mathrm{H}-11 \mathrm{~b} 2$ & MAG & $01 / 19 / 05$ & 278.61 & 84.92 & $3,133.03$ & 954.95 & N/A \\
\hline $\mathrm{H}-11 \mathrm{~b} 2$ & MAG & $02 / 14 / 05$ & 278.36 & 84.84 & $3,133.28$ & 955.02 & $\mathrm{~N} / \mathrm{A}$ \\
\hline $\mathrm{H}-11 \mathrm{~b} 2$ & MAG & 03/10/05 & 278.35 & 84.84 & $3,133.29$ & 955.03 & $\mathrm{~N} / \mathrm{A}$ \\
\hline $\mathrm{H}-11 \mathrm{~b} 2$ & MAG & 04/19/05 & 278.20 & 84.80 & $3,133.44$ & 955.07 & $\mathrm{~N} / \mathrm{A}$ \\
\hline $\mathrm{H}-11 \mathrm{~b} 2$ & MAG & 05/16/05 & 278.18 & 84.79 & $3,133.46$ & 955.08 & $N / A$ \\
\hline $\mathrm{H}-11 \mathrm{~b} 2$ & MAG & 06/20/05 & 261.16 & 79.60 & $3,150.48$ & 960.27 & $\mathrm{~N} / \mathrm{A}$ \\
\hline $\mathrm{H}-11 \mathrm{~b} 2$ & MAG & $07 / 19 / 05$ & 261.64 & 79.75 & $3,150.00$ & 960.12 & $\mathrm{~N} / \mathrm{A}$ \\
\hline $\mathrm{H}-11 \mathrm{~b} 2$ & MAG & 08/16/05 & 261.75 & 79.78 & $3,149.89$ & 960.09 & $\mathrm{~N} / \mathrm{A}$ \\
\hline $\mathrm{H}-11 \mathrm{~b} 2$ & MAG & 09/13/05 & 274.52 & 83.67 & $3,137.12$ & 956.19 & $\mathrm{~N} / \mathrm{A}$ \\
\hline $\mathrm{H}-11 \mathrm{~b} 2$ & MAG & $10 / 10 / 05$ & 273.86 & 83.47 & $3,137.78$ & 956.40 & $\mathrm{~N} / \mathrm{A}$ \\
\hline
\end{tabular}




\section{Waste Isolation Pilot Plant Annual Site Environmental Report for 2005 DOE/WIPP-06-2225}

\begin{tabular}{|c|c|c|c|c|c|c|c|}
\hline Well Number & Zone & Date & $\begin{array}{c}\text { Measured } \\
\text { Depth from } \\
\text { Top of } \\
\text { Casing }\end{array}$ & $\begin{array}{c}\text { Measured } \\
\text { Depth in } \\
\text { Meters }\end{array}$ & $\begin{array}{c}\text { Elevation } \\
\text { in Feet } \\
\text { AMSL }\end{array}$ & $\begin{array}{l}\text { Elevation } \\
\text { in Meters }\end{array}$ & $\begin{array}{l}\text { Elevation in Feet } \\
\text { AMSL Adjusted to } \\
\text { Equivalent Fresh } \\
\text { Water Head }\end{array}$ \\
\hline $\mathrm{H}-11 \mathrm{~b} 2$ & MAG & $11 / 07 / 05$ & 273.84 & 83.47 & $3,138.07$ & 956.48 & N/A \\
\hline $\mathrm{H}-11 \mathrm{~b} 2$ & MAG & $12 / 06 / 05$ & 273.84 & 83.47 & $3,138.07$ & 956.48 & N/A \\
\hline $\mathrm{H}-14$ & MAG & $01 / 19 / 05$ & 236.51 & 72.09 & $3,110.60$ & 948.11 & N/A \\
\hline $\mathrm{H}-14$ & MAG & $02 / 16 / 05$ & 236.19 & 71.99 & $3,110.92$ & 948.21 & $N / A$ \\
\hline $\mathrm{H}-14$ & MAG & 03/08/05 & 235.90 & 71.90 & $3,111.21$ & 948.30 & N/A \\
\hline $\mathrm{H}-14$ & MAG & $04 / 19 / 05$ & 235.47 & 71.77 & $3,111.64$ & 948.43 & $N / A$ \\
\hline $\mathrm{H}-14$ & MAG & 05/16/05 & 51.64 & 15.74 & $3,295.47$ & $1,004.46$ & $\mathrm{~N} / \mathrm{A}$ \\
\hline $\mathrm{H}-14$ & MAG & 06/20/05 & 78.95 & 24.06 & $3,268.16$ & 996.14 & N/A \\
\hline $\mathrm{H}-14$ & MAG & 07/19/05 & 363.30 & 110.73 & $2,983.81$ & 909.47 & N/A \\
\hline $\mathrm{H}-14$ & MAG & 08/15/05 & 326.17 & 99.42 & $3,020.94$ & 920.78 & $N / A$ \\
\hline $\mathrm{H}-14$ & MAG & 09/13/05 & 300.10 & 91.47 & $3,047.01$ & 928.73 & $N / A$ \\
\hline $\mathrm{H}-14$ & MAG & $10 / 12 / 05$ & 281.23 & 85.72 & $3,065.88$ & 934.48 & $N / A$ \\
\hline $\mathrm{H}-14$ & MAG & $11 / 08 / 05$ & 267.96 & 81.67 & $3,079.17$ & 938.53 & N/A \\
\hline $\mathrm{H}-14$ & MAG & $12 / 05 / 05$ & 257.46 & 78.47 & $3,089.67$ & 941.73 & $\mathrm{~N} / \mathrm{A}$ \\
\hline $\mathrm{H}-15$ & MAG & 06/20/05 & 358.62 & 109.31 & $3,123.01$ & 951.89 & $N / A$ \\
\hline $\mathrm{H}-15$ & MAG & $07 / 19 / 05$ & 357.63 & 109.01 & $3,124.00$ & 952.20 & $\mathrm{~N} / \mathrm{A}$ \\
\hline $\mathrm{H}-15$ & MAG & 08/15/05 & 357.67 & 109.02 & $3,123.96$ & 952.18 & $\mathrm{~N} / \mathrm{A}$ \\
\hline $\mathrm{H}-15$ & MAG & $09 / 13 / 05$ & 358.53 & 109.28 & $3,123.10$ & 951.92 & N/A \\
\hline $\mathrm{H}-15$ & MAG & $10 / 10 / 05$ & 357.42 & 108.94 & $3,124.21$ & 952.26 & N/A \\
\hline WIPP-18 & MAG & $01 / 20 / 05$ & 314.27 & 95.79 & $3,144.49$ & 958.44 & $\mathrm{~N} / \mathrm{A}$ \\
\hline WIPP-18 & MAG & $02 / 17 / 05$ & 314.16 & 95.76 & $3,144.60$ & 958.47 & N/A \\
\hline WIPP-18 & MAG & 03/16/05 & 314.22 & 95.77 & $3,144.54$ & 958.46 & N/A \\
\hline WIPP-18 & MAG & $04 / 19 / 05$ & 314.13 & 95.75 & $3,144.63$ & 958.48 & N/A \\
\hline WIPP-18 & MAG & 05/16/05 & 314.13 & 95.75 & $3,144.63$ & 958.48 & $\mathrm{~N} / \mathrm{A}$ \\
\hline WIPP-18 & MAG & $06 / 20 / 05$ & 296.29 & 90.31 & $3,162.47$ & 963.92 & N/A \\
\hline WIPP-18 & MAG & 07/19/05 & 304.96 & 92.95 & $3,153.80$ & 961.28 & N/A \\
\hline WIPP-18 & MAG & 08/15/05 & 305.62 & 93.15 & $3,153.14$ & 961.08 & N/A \\
\hline WIPP-18 & MAG & 09/13/05 & 311.03 & 94.80 & $3,147.73$ & 959.43 & $\mathrm{~N} / \mathrm{A}$ \\
\hline WIPP-18 & MAG & $10 / 10 / 05$ & 309.57 & 94.36 & $3,149.19$ & 959.87 & N/A \\
\hline WIPP-18 & MAG & $11 / 07 / 05$ & 309.33 & 94.28 & $3,148.41$ & 959.64 & $\mathrm{~N} / \mathrm{A}$ \\
\hline WIPP-18 & MAG & $12 / 05 / 05$ & 309.18 & 94.24 & $3,148.56$ & 959.68 & $\mathrm{~N} / \mathrm{A}$ \\
\hline WIPP-25 (ANNULUS) & MAG & $01 / 18 / 05$ & 152.62 & 46.52 & $3,061.77$ & 933.23 & N/A \\
\hline WIPP-25 (ANNULUS) & MAG & $02 / 15 / 05$ & 152.35 & 46.44 & $3,062.04$ & 933.31 & $\mathrm{~N} / \mathrm{A}$ \\
\hline WIPP-25 (ANNULUS) & MAG & 03/07/05 & 152.14 & 46.37 & $3,062.25$ & 933.37 & N/A \\
\hline WIPP-25 (ANNULUS) & MAG & $04 / 25 / 05$ & 151.74 & 46.25 & $3,062.65$ & 933.50 & $\mathrm{~N} / \mathrm{A}$ \\
\hline WIPP-25 (ANNULUS) & MAG & $05 / 17 / 05$ & 151.60 & 46.21 & $3,062.79$ & 933.54 & $\mathrm{~N} / \mathrm{A}$ \\
\hline WIPP-25 (ANNULUS) & MAG & $06 / 13 / 05$ & 151.43 & 46.16 & $3,062.96$ & 933.59 & $\mathrm{~N} / \mathrm{A}$ \\
\hline WIPP-25 (ANNULUS) & MAG & 07/18/05 & 151.31 & 46.12 & $3,063.08$ & 933.63 & $N / A$ \\
\hline WIPP-25 (ANNULUS) & MAG & 08/16/05 & 151.27 & 46.11 & $3,063.12$ & 933.64 & $\mathrm{~N} / \mathrm{A}$ \\
\hline WIPP-25 (ANNULUS) & MAG & 09/14/05 & 151.08 & 46.05 & $3,063.31$ & 933.70 & $\mathrm{~N} / \mathrm{A}$ \\
\hline WIPP-25 (ANNULUS) & MAG & 10/11/05 & 150.80 & 45.96 & $3,063.59$ & 933.78 & $\mathrm{~N} / \mathrm{A}$ \\
\hline WIPP-25 (ANNULUS) & MAG & $12 / 06 / 05$ & 150.42 & 45.85 & $3,063.97$ & 933.90 & $\mathrm{~N} / \mathrm{A}$ \\
\hline WIPP-30 (ANNULUS) & MAG & 07/18/05 & 353.30 & 107.69 & $3,075.75$ & 937.49 & N/A \\
\hline
\end{tabular}




\section{Waste Isolation Pilot Plant Annual Site Environmental Report for 2005 DOE/WIPP-06-2225}

\begin{tabular}{|c|c|c|c|c|c|c|c|}
\hline Well Number & Zone & Date & $\begin{array}{l}\text { Measured } \\
\text { Depth from } \\
\text { Top of } \\
\text { Casing }\end{array}$ & $\begin{array}{c}\text { Measured } \\
\text { Depth in } \\
\text { Meters }\end{array}$ & $\begin{array}{c}\text { Elevation } \\
\text { in Feet } \\
\text { AMSL }\end{array}$ & $\begin{array}{l}\text { Elevation } \\
\text { in Meters }\end{array}$ & $\begin{array}{l}\text { Elevation in Feet } \\
\text { AMSL Adjusted to } \\
\text { Equivalent Fresh } \\
\text { Water Head }\end{array}$ \\
\hline WIPP-30 (ANNULUS) & MAG & 08/17/05 & 352.36 & 107.40 & $3,076.69$ & 937.78 & N/A \\
\hline WIPP-30 (ANNULUS) & MAG & $09 / 14 / 05$ & 351.80 & 107.23 & $3,077.25$ & 937.95 & $\mathrm{~N} / \mathrm{A}$ \\
\hline WIPP-30 (ANNULUS) & MAG & $10 / 11 / 05$ & 351.46 & 107.13 & $3,077.59$ & 938.05 & $\mathrm{~N} / \mathrm{A}$ \\
\hline WIPP-30 (ANNULUS) & MAG & $11 / 08 / 05$ & 351.03 & 106.99 & $3,078.02$ & 938.18 & $N / A$ \\
\hline WIPP-30 (ANNULUS) & MAG & $12 / 05 / 05$ & 350.71 & 106.90 & $3,078.34$ & 938.28 & N/A \\
\hline WQSP-6a & $\mathrm{DL}$ & 01/20/05 & 166.66 & 50.80 & $3,197.14$ & 974.49 & N/A \\
\hline WQSP-6a & $\mathrm{DL}$ & $02 / 17 / 05$ & 166.81 & 50.84 & $3,196.99$ & 974.44 & N/A \\
\hline WQSP-6a & $\mathrm{DL}$ & 03/08/05 & 166.64 & 50.79 & $3,197.16$ & 974.49 & N/A \\
\hline WQSP-6a & $\mathrm{DL}$ & $04 / 18 / 05$ & 166.70 & 50.81 & $3,197.10$ & 974.48 & $\mathrm{~N} / \mathrm{A}$ \\
\hline WQSP-6a & DL & 05/16/05 & 166.77 & 50.83 & $3,197.03$ & 974.45 & $\mathrm{~N} / \mathrm{A}$ \\
\hline WQSP-6a & $\mathrm{DL}$ & 06/20/05 & 166.97 & 50.89 & $3,196.83$ & 974.39 & $\mathrm{~N} / \mathrm{A}$ \\
\hline WQSP-6a & $\mathrm{DL}$ & 07/19/05 & 166.84 & 50.85 & $3,196.96$ & 974.43 & $\mathrm{~N} / \mathrm{A}$ \\
\hline WQSP-6a & DL & 08/15/05 & 166.84 & 50.85 & $3,196.96$ & 974.43 & N/A \\
\hline WQSP-6a & $\mathrm{DL}$ & 09/13/05 & 166.73 & 50.82 & $3,197.07$ & 974.47 & $\mathrm{~N} / \mathrm{A}$ \\
\hline WQSP-6a & $\mathrm{DL}$ & $10 / 10 / 05$ & 166.62 & 50.79 & $3,197.18$ & 974.50 & $N / A$ \\
\hline WQSP-6a & $\mathrm{DL}$ & $11 / 07 / 05$ & 166.83 & 50.85 & $3,196.97$ & 974.44 & N/A \\
\hline WQSP-6a & $\mathrm{DL}$ & $12 / 05 / 05$ & 167.07 & 50.92 & $3,196.73$ & 974.36 & $\mathrm{~N} / \mathrm{A}$ \\
\hline $\mathrm{H}-08 \mathrm{c}$ & RUS/SAL & $01 / 19 / 05$ & 451.64 & 137.66 & $2,981.26$ & 908.69 & N/A \\
\hline $\mathrm{H}-08 \mathrm{c}$ & RUS/SAL & $02 / 16 / 05$ & 451.55 & 137.63 & $2,981.35$ & 908.72 & N/A \\
\hline $\mathrm{H}-08 \mathrm{c}$ & RUS/SAL & $03 / 10 / 05$ & 451.48 & 137.61 & $2,981.42$ & 908.72 & $\mathrm{~N} / \mathrm{A}$ \\
\hline $\mathrm{H}-08 \mathrm{c}$ & RUS/SAL & $04 / 18 / 05$ & 451.42 & 137.59 & $2,981.48$ & 908.76 & N/A \\
\hline $\mathrm{H}-08 \mathrm{c}$ & RUS/SAL & $05 / 17 / 05$ & 451.38 & 137.58 & $2,981.52$ & 908.77 & N/A \\
\hline $\mathrm{H}-08 \mathrm{c}$ & RUS/SAL & $06 / 21 / 05$ & 451.30 & 137.56 & $2,981.60$ & 908.79 & N/A \\
\hline $\mathrm{H}-08 \mathrm{c}$ & RUS/SAL & $07 / 18 / 05$ & 451.28 & 137.55 & $2,981.62$ & 908.80 & $\mathrm{~N} / \mathrm{A}$ \\
\hline $\mathrm{H}-08 \mathrm{c}$ & RUS/SAL & 08/16/05 & 451.28 & 137.55 & $2,981.62$ & 908.80 & $\mathrm{~N} / \mathrm{A}$ \\
\hline $\mathrm{H}-08 \mathrm{c}$ & RUS/SAL & $09 / 12 / 05$ & 451.29 & 137.55 & $2,981.61$ & 908.79 & N/A \\
\hline CB-1(PIP) & $B / C$ & $01 / 19 / 05$ & 603.09 & 183.82 & $2,725.78$ & 830.82 & N/A \\
\hline CB-1(PIP) & $B / C$ & $02 / 14 / 05$ & 602.83 & 183.74 & $2,726.04$ & 830.90 & $\mathrm{~N} / \mathrm{A}$ \\
\hline CB-1(PIP) & $B / C$ & $03 / 10 / 05$ & 602.74 & 183.72 & $2,726.13$ & 830.92 & N/A \\
\hline CB-1(PIP) & $B / C$ & $04 / 19 / 05$ & 602.55 & 183.66 & $2,726.32$ & 830.98 & N/A \\
\hline CB-1(PIP) & $B / C$ & 05/16/05 & 602.52 & 183.65 & $2,726.35$ & 830.99 & $\mathrm{~N} / \mathrm{A}$ \\
\hline CB-1(PIP) & $B / C$ & $06 / 20 / 05$ & 602.41 & 183.61 & $2,726.46$ & 831.03 & $\mathrm{~N} / \mathrm{A}$ \\
\hline CB-1(PIP) & $B / C$ & 07/19/05 & 602.30 & 183.58 & $2,726.57$ & 831.06 & $N / A$ \\
\hline CB-1(PIP) & $B / C$ & 08/16/05 & 602.24 & 183.56 & $2,726.63$ & 831.08 & $\mathrm{~N} / \mathrm{A}$ \\
\hline CB-1(PIP) & $B / C$ & $09 / 13 / 05$ & 602.08 & 183.51 & $2,726.79$ & 831.13 & $\mathrm{~N} / \mathrm{A}$ \\
\hline CB-1(PIP) & $\mathrm{B} / \mathrm{C}$ & $10 / 10 / 05$ & 601.86 & 183.45 & $2,727.01$ & 831.19 & $\mathrm{~N} / \mathrm{A}$ \\
\hline CB-1(PIP) & $B / C$ & $11 / 07 / 05$ & 601.85 & 183.44 & $2,727.02$ & 831.20 & N/A \\
\hline CB-1(PIP) & $B / C$ & $12 / 06 / 05$ & 601.82 & 183.43 & $2,727.05$ & 831.20 & N/A \\
\hline DOE-2 & $B / C$ & $01 / 18 / 05$ & 741.97 & 226.15 & $2,676.99$ & 815.95 & $\mathrm{~N} / \mathrm{A}$ \\
\hline DOE-2 & $B / C$ & $02 / 16 / 05$ & 741.12 & 225.89 & $2,677.84$ & 816.21 & $\mathrm{~N} / \mathrm{A}$ \\
\hline DOE-2 & $B / C$ & 03/07/05 & 740.63 & 225.74 & $2,678.33$ & 816.35 & $N / A$ \\
\hline DOE-2 & $B / C$ & $04 / 18 / 05$ & 739.69 & 225.46 & $2,679.27$ & 816.64 & $\mathrm{~N} / \mathrm{A}$ \\
\hline DOE-2 & $B / C$ & $05 / 18 / 05$ & 738.98 & 225.24 & $2,679.98$ & 816.86 & N/A \\
\hline
\end{tabular}


Waste Isolation Pilot Plant Annual Site Environmental Report for 2005 DOE/WIPP-06-2225

\begin{tabular}{|c|c|c|c|c|c|c|c|}
\hline Well Number & Zone & Date & $\begin{array}{c}\text { Measured } \\
\text { Depth from } \\
\text { Top of } \\
\text { Casing }\end{array}$ & $\begin{array}{c}\text { Measured } \\
\text { Depth in } \\
\text { Meters }\end{array}$ & $\begin{array}{l}\text { Elevation } \\
\text { in Feet } \\
\text { AMSL }\end{array}$ & $\begin{array}{l}\text { Elevation } \\
\text { in Meters }\end{array}$ & $\begin{array}{l}\text { Elevation in Feet } \\
\text { AMSL Adjusted to } \\
\text { Equivalent Fresh } \\
\text { Water Head }\end{array}$ \\
\hline DOE-2 & $B / C$ & 06/21/05 & 738.21 & 225.01 & $2,680.75$ & 817.09 & N/A \\
\hline DOE-2 & $B / C$ & 07/19/05 & 737.67 & 224.84 & $2,681.29$ & 817.26 & N/A \\
\hline DOE-2 & $B / C$ & 08/15/05 & 737.12 & 224.67 & $2,681.84$ & 817.42 & $\mathrm{~N} / \mathrm{A}$ \\
\hline DOE-2 & $B / C$ & $09 / 12 / 05$ & 736.71 & 224.55 & $2,682.25$ & 817.55 & N/A \\
\hline DOE-2 & $B / C$ & 10/11/05 & 736.16 & 224.38 & $2,682.80$ & 817.72 & N/A \\
\hline DOE-2 & $B / C$ & 11/08/05 & 735.70 & 224.24 & $2,683.26$ & 817.86 & N/A \\
\hline DOE-2 & $B / C$ & $12 / 05 / 05$ & 735.34 & 224.13 & $2,683.62$ & 817.97 & N/A \\
\hline C-2505 & SR/D & 03/16/05 & 44.04 & 13.42 & $3,369.01$ & $1,026.87$ & $N / A$ \\
\hline C-2505 & SR/D & 06/21/05 & 43.79 & 13.35 & $3,369.26$ & $1,026.95$ & N/A \\
\hline C-2505 & SR/D & 09/14/05 & 43.40 & 13.23 & $3,369.65$ & $1,027.07$ & N/A \\
\hline C-2505 & SR/D & $12 / 07 / 05$ & 43.51 & 13.26 & $3,369.54$ & $1,027.04$ & $N / A$ \\
\hline C-2506 & SR/D & 03/16/05 & 43.46 & 13.25 & $3,369.41$ & $1,027.00$ & N/A \\
\hline C-2506 & SR/D & $06 / 21 / 05$ & 43.21 & 13.17 & $3,369.66$ & $1,027.07$ & N/A \\
\hline C-2506 & SR/D & $09 / 14 / 05$ & 43.54 & 13.27 & $3,369.33$ & $1,026.97$ & N/A \\
\hline C-2506 & SR/D & $12 / 07 / 05$ & 42.93 & 13.09 & $3,369.94$ & $1,027.16$ & $N / A$ \\
\hline C-2507 & SR/D & 03/16/05 & 43.85 & 13.37 & $3,366.16$ & $1,026.01$ & N/A \\
\hline C-2507 & SR/D & $06 / 21 / 05$ & 43.60 & 13.29 & $3,366.41$ & $1,026.08$ & N/A \\
\hline C-2507 & SR/D & 09/14/05 & 42.96 & 13.09 & $3,367.05$ & $1,026.28$ & N/A \\
\hline C-2507 & SR/D & $12 / 07 / 05$ & 43.44 & 13.24 & $3,366.57$ & $1,026.13$ & $\mathrm{~N} / \mathrm{A}$ \\
\hline C-2811 & SR/D & 03/16/05 & 56.38 & 17.18 & $3,342.54$ & $1,018.81$ & $\mathrm{~N} / \mathrm{A}$ \\
\hline C-2811 & SR/D & 06/21/05 & 56.22 & 17.14 & $3,342.70$ & $1,018.85$ & $\mathrm{~N} / \mathrm{A}$ \\
\hline C-2811 & SR/D & 09/14/05 & 55.32 & 16.86 & $3,343.60$ & $1,019.13$ & N/A \\
\hline C-2811 & SR/D & $12 / 07 / 05$ & 54.80 & 16.70 & $3,344.12$ & $1,019.29$ & N/A \\
\hline PZ-01 & SR/D & 03/16/05 & 41.44 & 12.63 & $3,371.97$ & $1,027.78$ & N/A \\
\hline PZ-01 & SR/D & $06 / 21 / 05$ & 41.01 & 12.50 & $3,372.40$ & $1,027.91$ & N/A \\
\hline PZ-01 & SR/D & $09 / 14 / 05$ & 40.55 & 12.36 & $3,372.86$ & $1,028.05$ & N/A \\
\hline PZ-01 & SR/D & $12 / 07 / 05$ & 40.43 & 12.32 & $3,372.98$ & $1,028.08$ & N/A \\
\hline PZ-02 & SR/D & 03/16/05 & 42.11 & 12.84 & $3,371.31$ & $1,027.58$ & $\mathrm{~N} / \mathrm{A}$ \\
\hline PZ-02 & SR/D & $06 / 21 / 05$ & 41.72 & 12.72 & $3,371.70$ & $1,027.69$ & N/A \\
\hline PZ-02 & SR/D & $09 / 14 / 05$ & 41.00 & 12.50 & $3,372.42$ & $1,027.91$ & N/A \\
\hline PZ-02 & SR/D & $12 / 07 / 05$ & 40.85 & 12.45 & $3,372.57$ & $1,027.96$ & $\mathrm{~N} / \mathrm{A}$ \\
\hline PZ-03 & SR/D & 03/16/05 & 43.98 & 13.41 & $3,372.17$ & $1,027.84$ & N/A \\
\hline PZ-03 & SR/D & $06 / 21 / 05$ & 43.51 & 13.26 & $3,372.64$ & $1,027.98$ & $\mathrm{~N} / \mathrm{A}$ \\
\hline PZ-03 & SR/D & $09 / 14 / 05$ & 42.72 & 13.02 & $3,373.43$ & $1,028.22$ & N/A \\
\hline PZ-03 & SR/D & $12 / 07 / 05$ & 42.59 & 12.98 & $3,373.56$ & $1,028.26$ & N/A \\
\hline PZ-04 & SR/D & 03/16/05 & 45.32 & 13.81 & $3,366.78$ & $1,026.19$ & $\mathrm{~N} / \mathrm{A}$ \\
\hline PZ-04 & SR/D & $06 / 21 / 05$ & 44.93 & 13.69 & $3,367.17$ & $1,026.31$ & N/A \\
\hline PZ-04 & SR/D & $09 / 14 / 05$ & 44.41 & 13.54 & $3,367.69$ & $1,026.47$ & $\mathrm{~N} / \mathrm{A}$ \\
\hline PZ-04 & SR/D & $12 / 07 / 05$ & 44.33 & 13.51 & $3,367.77$ & $1,026.50$ & $\mathrm{~N} / \mathrm{A}$ \\
\hline PZ-05 & SR/D & 03/16/05 & 40.58 & 12.37 & $3,374.73$ & $1,028.62$ & $\mathrm{~N} / \mathrm{A}$ \\
\hline PZ-05 & SR/D & $06 / 21 / 05$ & 40.26 & 12.27 & $3,375.05$ & $1,028.72$ & N/A \\
\hline PZ-05 & SR/D & $09 / 14 / 05$ & 39.83 & 12.14 & $3,375.48$ & $1,028.85$ & N/A \\
\hline PZ-05 & SR/D & $12 / 07 / 05$ & 39.85 & 12.15 & $3,375.46$ & $1,028.84$ & N/A \\
\hline
\end{tabular}


Waste Isolation Pilot Plant Annual Site Environmental Report for 2005 DOE/WIPP-06-2225

\begin{tabular}{|c|c|c|c|c|c|c|c|}
\hline Well Number & Zone & Date & $\begin{array}{l}\text { Measured } \\
\text { Depth from } \\
\text { Top of } \\
\text { Casing }\end{array}$ & $\begin{array}{c}\text { Measured } \\
\text { Depth in } \\
\text { Meters }\end{array}$ & $\begin{array}{c}\text { Elevation } \\
\text { in Feet } \\
\text { AMSL }\end{array}$ & $\begin{array}{l}\text { Elevation } \\
\text { in Meters }\end{array}$ & $\begin{array}{l}\text { Elevation in Feet } \\
\text { AMSL Adjusted to } \\
\text { Equivalent Fresh } \\
\text { Water Head }\end{array}$ \\
\hline PZ-06 & SR/D & $03 / 16 / 05$ & 42.14 & 12.84 & $3,371.35$ & $1,027.59$ & $\mathrm{~N} / \mathrm{A}$ \\
\hline PZ-06 & SR/D & $06 / 21 / 05$ & 41.88 & 12.77 & $3,371.61$ & $1,027.67$ & N/A \\
\hline PZ-06 & SR/D & $09 / 14 / 05$ & 41.55 & 12.66 & $3,371.94$ & $1,027.77$ & N/A \\
\hline PZ-06 & SR/D & $12 / 07 / 05$ & 41.59 & 12.68 & $3,371.90$ & $1,027.76$ & N/A \\
\hline PZ-07 & SR/D & 03/16/05 & 36.20 & 11.03 & $3,377.79$ & $1,029.55$ & N/A \\
\hline PZ-07 & SR/D & $06 / 21 / 05$ & 36.04 & 10.98 & $3,377.95$ & $1,029.60$ & N/A \\
\hline PZ-07 & SR/D & 09/14/05 & 35.49 & 10.82 & $3,378.50$ & $1,029.77$ & $\mathrm{~N} / \mathrm{A}$ \\
\hline PZ-07 & SR/D & $12 / 07 / 05$ & 35.64 & 10.86 & $3,378.35$ & $1,029.72$ & N/A \\
\hline PZ-09 & SR/D & $03 / 16 / 05$ & 54.74 & 16.68 & $3,366.47$ & $1,026.10$ & $\mathrm{~N} / \mathrm{A}$ \\
\hline PZ-09 & SR/D & $06 / 21 / 05$ & 55.04 & 16.78 & $3,366.17$ & $1,026.01$ & N/A \\
\hline PZ-09 & SR/D & $09 / 14 / 05$ & 54.98 & 16.76 & $3,366.23$ & $1,026.03$ & $\mathrm{~N} / \mathrm{A}$ \\
\hline PZ-09 & SR/D & $12 / 07 / 05$ & 55.39 & 16.88 & $3,365.82$ & $1,025.90$ & N/A \\
\hline PZ-10 & SR/D & 03/16/05 & 33.54 & 10.22 & $3,372.26$ & $1,027.86$ & $\mathrm{~N} / \mathrm{A}$ \\
\hline PZ-10 & SR/D & $06 / 21 / 05$ & 33.68 & 10.27 & $3,372.12$ & $1,027.82$ & $\mathrm{~N} / \mathrm{A}$ \\
\hline PZ-10 & SR/D & $09 / 14 / 05$ & 33.70 & 10.27 & $3,372.10$ & $1,027.82$ & N/A \\
\hline PZ-10 & SR/D & $12 / 07 / 05$ & 34.04 & 10.38 & $3,371.76$ & $1,027.71$ & N/A \\
\hline PZ-11 & SR/D & 03/16/05 & 44.37 & 13.52 & $3,374.58$ & $1,028.57$ & N/A \\
\hline PZ-11 & SR/D & $06 / 21 / 05$ & 44.29 & 13.50 & $3,374.66$ & $1,028.60$ & N/A \\
\hline PZ-11 & SR/D & $09 / 14 / 05$ & 43.88 & 13.37 & $3,375.07$ & $1,028.72$ & $\mathrm{~N} / \mathrm{A}$ \\
\hline PZ-11 & SR/D & $12 / 07 / 05$ & 43.93 & 13.39 & $3,375.02$ & $1,028.71$ & N/A \\
\hline PZ-12 & SR/D & $03 / 16 / 05$ & 50.10 & 15.27 & $3,358.89$ & $1,023.79$ & $\mathrm{~N} / \mathrm{A}$ \\
\hline PZ-12 & SR/D & $06 / 21 / 05$ & 50.30 & 15.33 & $3,358.69$ & $1,023.73$ & N/A \\
\hline PZ-12 & $S R / D$ & $09 / 14 / 05$ & 50.02 & 15.25 & $3,358.97$ & $1,023.81$ & N/A \\
\hline PZ-12 & SR/D & $12 / 7 / 05$ & 50.18 & 15.29 & $3,358.81$ & $1,023.77$ & N/A \\
\hline
\end{tabular}

* Groundwater density value was updated in June 2005 and will affect freshwater head equivalent elevation. 
Waste Isolation Pilot Plant Annual Site Environmental Report for 2005

DOE/WIPP-06-2225

This page intentionally left blank 


\section{Appendix G \\ Air Sampling Data: Concentrations of Radionuclides}

\begin{tabular}{|c|c|c|c|c|c|c|c|c|c|c|}
\hline \multirow[t]{2}{*}{ Location } & Qtr. & RN & $2 \times$ TPU & MDC & RN & $2 \times$ TPU & MDC & RN & $2 \times$ TPU & MDC \\
\hline & & \multicolumn{3}{|c|}{ Am-241 } & \multicolumn{3}{|c|}{$\mathrm{Pu}-238$} & \multicolumn{3}{|c|}{$\mathrm{Pu}-239+240$} \\
\hline \multirow[t]{4}{*}{ CBD } & 1 & $-6.08 E-08$ & $1.24 \mathrm{E}-07$ & $2.72 \mathrm{E}-04$ & $1.19 \mathrm{E}-07$ & $2.25 \mathrm{E}-07$ & $1.24 \mathrm{E}-04$ & $-1.58 \mathrm{E}-08$ & $6.68 \mathrm{E}-08$ & $1.36 \mathrm{E}-04$ \\
\hline & 2 & $-1.34 \mathrm{E}-09$ & 5.33E-08 & 9.90E-05 & $1.48 \mathrm{E}-08$ & $6.29 \mathrm{E}-08$ & $9.90 \mathrm{E}-05$ & $1.15 \mathrm{E}-08$ & 4.09E-08 & $1.24 \mathrm{E}-04$ \\
\hline & 3 & 3.94E-08 & 8.08E-08 & $1.61 \mathrm{E}-04$ & $3.29 \mathrm{E}-08$ & 7.24E-08 & $9.90 \mathrm{E}-05$ & 4.76E-08 & $6.47 \mathrm{E}-08$ & $1.24 \mathrm{E}-04$ \\
\hline & 4 & $-1.23 \mathrm{E}-09$ & $4.88 \mathrm{E}-08$ & 1.73E-04 & 5.38E-08 & $7.28 \mathrm{E}-08$ & 3.72E-05 & $2.41 \mathrm{E}-08$ & 5.30E-08 & 1.24E-05 \\
\hline \multirow[t]{4}{*}{ MLR } & 1 & $-1.80 \mathrm{E}-08$ & $9.61 \mathrm{E}-08$ & 3.22E-04 & $-8.11 \mathrm{E}-08$ & $1.26 \mathrm{E}-07$ & $1.24 \mathrm{E}-04$ & $-3.19 \mathrm{E}-08$ & 7.89E-08 & 1.36E-04 \\
\hline & 2 & 4.57E-08 & 8.48E-08 & 9.90E-05 & $-5.67 \mathrm{E}-10$ & 6.57E-08 & 9.90E-05 & $2.58 \mathrm{E}-08$ & 5.09E-08 & $1.24 \mathrm{E}-04$ \\
\hline & 3 & 5.95E-08 & 1.10E-07 & $1.61 \mathrm{E}-04$ & $6.73 E-08$ & 3.07E-07 & 9.92E-05 & $-2.88 \mathrm{E}-08$ & 8.76E-08 & $1.24 \mathrm{E}-04$ \\
\hline & 4 & 1.18E-08 & 7.32E-08 & 1.73E-04 & $-4.73 \mathrm{E}-09$ & 4.40E-08 & 3.72E-05 & 9.44E-09 & 3.35E-08 & $1.24 \mathrm{E}-05$ \\
\hline \multirow[t]{4}{*}{ SEC } & 1 & 3.04E-08 & 7.21E-08 & 3.22E-04 & $-1.50 \mathrm{E}-08$ & 3.64E-08 & $1.24 \mathrm{E}-04$ & $-6.31 \mathrm{E}-09$ & 2.35E-08 & 1.36E-04 \\
\hline & 2 & 5.88E-08 & 6.89E-08 & 9.90E-05 & 2.21E-08 & 7.20E-08 & 9.91E-05 & 4.39E-08 & 8.24E-08 & $1.24 \mathrm{E}-04$ \\
\hline & 3 & 6.77E-09 & 6.31E-08 & $1.61 \mathrm{E}-04$ & $-2.03 E-08$ & 4.50E-08 & 9.91E-05 & -1.47E-08 & 3.82E-08 & $1.24 \mathrm{E}-04$ \\
\hline & 4 & 2.35E-08 & 4.71E-08 & 1.73E-04 & 6.41E-08 & 8.59E-08 & 3.72E-05 & 2.79E-08 & 5.27E-08 & $1.24 \mathrm{E}-05$ \\
\hline \multirow[t]{4}{*}{ SMR } & 1 & 5.34E-09 & 7.89E-08 & 3.22E-04 & 8.59E-09 & $1.27 \mathrm{E}-07$ & $1.24 \mathrm{E}-04$ & $-2.56 \mathrm{E}-08$ & 6.86E-08 & 1.36E-04 \\
\hline & 2 & 8.55E-09 & $6.53 \mathrm{E}-08$ & 9.90E-05 & 5.76E-08 & $1.01 \mathrm{E}-07$ & $9.90 \mathrm{E}-05$ & 1.13E-08 & 4.50E-08 & $1.24 \mathrm{E}-04$ \\
\hline & 3 & 5.99E-08 & 1.34E-07 & $1.61 \mathrm{E}-04$ & 5.11E-08 & $1.45 \mathrm{E}-07$ & 9.91E-05 & $-2.44 \mathrm{E}-08$ & 5.26E-08 & $1.24 \mathrm{E}-04$ \\
\hline & 4 & $-2.97 \mathrm{E}-09$ & 4.99E-08 & 1.73E-04 & $1.79 \mathrm{E}-08$ & 6.63E-08 & 3.72E-05 & 1.37E-09 & $5.24 \mathrm{E}-08$ & 1.24E-05 \\
\hline \multirow[t]{4}{*}{ WEE } & 1 & $-2.29 E-08$ & 4.56E-08 & 3.22E-04 & 1.97E-09 & $1.59 \mathrm{E}-07$ & $1.24 \mathrm{E}-04$ & 3.97E-09 & $1.57 \mathrm{E}-07$ & 1.36E-04 \\
\hline & 2 & 3.57E-08 & 7.01E-08 & 9.90E-05 & $4.50 \mathrm{E}-08$ & 8.07E-08 & 9.90E-05 & $1.81 \mathrm{E}-08$ & 5.92E-08 & 1.24E-04 \\
\hline & 3 & 2.33E-08 & 8.59E-08 & $1.61 \mathrm{E}-04$ & $-5.01 \mathrm{E}-08$ & 6.33E-08 & 9.91E-05 & $-1.14 \mathrm{E}-08$ & 3.01E-08 & $1.24 \mathrm{E}-04$ \\
\hline & 4 & $0.00 \mathrm{E}+00$ & 8.24E-08 & 1.73E-04 & 5.08E-08 & 8.43E-08 & 3.72E-05 & 5.74E-08 & $6.78 \mathrm{E}-08$ & 1.24E-05 \\
\hline \multirow[t]{4}{*}{ WFF } & 1 & 1.70E-09 & $6.70 \mathrm{E}-08$ & 3.22E-04 & 3.37E-09 & $6.53 \mathrm{E}-08$ & $1.24 \mathrm{E}-04$ & 4.02E-08 & 7.29E-08 & 1.36E-04 \\
\hline & 2 & 2.32E-09 & $6.09 \mathrm{E}-08$ & 9.91E-05 & $2.12 \mathrm{E}-08$ & $1.52 \mathrm{E}-07$ & 9.91E-05 & 8.79E-09 & $6.43 E-08$ & $1.24 \mathrm{E}-04$ \\
\hline & 3 & $-2.39 \mathrm{E}-08$ & 4.68E-08 & $1.61 \mathrm{E}-04$ & $1.07 \mathrm{E}-08$ & 7.05E-08 & 9.90E-05 & $2.00 \mathrm{E}-08$ & 6.52E-08 & $1.24 \mathrm{E}-04$ \\
\hline & 4 & $0.00 \mathrm{E}+00$ & 5.60E-08 & $1.73 \mathrm{E}-04$ & 3.49E-08 & 8.72E-08 & 3.72E-05 & 4.53E-08 & 6.59E-08 & $1.24 \mathrm{E}-05$ \\
\hline \multirow[t]{4}{*}{ WSS } & 1 & $-1.22 \mathrm{E}-08$ & $1.06 \mathrm{E}-07$ & $3.22 \mathrm{E}-04$ & $-4.38 \mathrm{E}-08$ & 7.22E-08 & $1.24 \mathrm{E}-04$ & 2.34E-08 & 6.73E-08 & 1.36E-04 \\
\hline & 2 & $-2.06 \mathrm{E}-08$ & $3.90 \mathrm{E}-08$ & 9.90E-05 & 3.32E-08 & $1.04 \mathrm{E}-07$ & 9.91E-05 & 7.17E-08 & 8.70E-08 & $1.24 \mathrm{E}-04$ \\
\hline & 3 & 4.73E-08 & 8.78E-08 & $1.61 \mathrm{E}-04$ & 3.36E-08 & 8.24E-08 & $9.90 \mathrm{E}-05$ & 9.41E-09 & 4.02E-08 & $1.24 \mathrm{E}-04$ \\
\hline & 4 & 2.63E-08 & 6.83E-08 & 1.73E-04 & 1.35E-08 & 6.66E-08 & 3.72E-05 & 1.71E-08 & 4.97E-08 & $1.24 \mathrm{E}-05$ \\
\hline \multirow[t]{4}{*}{$W^{\prime} B^{a}$} & 1 & $6.03 E-05$ & $6.51 \mathrm{E}-04$ & $1.00 \mathrm{E}-03$ & $-2.64 \mathrm{E}-04$ & 5.81E-04 & $1.02 \mathrm{E}-03$ & $-4.57 \mathrm{E}-05$ & 2.41E-04 & 1.03E-03 \\
\hline & 2 & $1.52 \mathrm{E}-04$ & 3.87E-04 & 4.23E-04 & 1.92E-04 & 5.17E-04 & 5.27E-04 & -8.98E-05 & 2.33E-04 & $5.50 \mathrm{E}-04$ \\
\hline & 3 & 1.87E-04 & 5.27E-04 & 5.94E-04 & $-5.11 \mathrm{E}-05$ & 3.94E-04 & 4.51E-04 & 8.79E-05 & 2.92E-04 & $4.75 \mathrm{E}-04$ \\
\hline & 4 & 7.04E-04 & 7.04E-04 & $5.45 \mathrm{E}-04$ & $3.44 \mathrm{E}-04$ & 4.95E-04 & 3.44E-04 & 7.02E-05 & $2.60 \mathrm{E}-04$ & 3.19E-04 \\
\hline Minimum & & $-6.08 \mathrm{E}-08$ & $1.24 \mathrm{E}-07$ & 2.72E-04 & $-8.11 \mathrm{E}-08$ & $1.26 \mathrm{E}-07$ & $1.24 \mathrm{E}-04$ & $-3.19 \mathrm{E}-08$ & $7.89 E-08$ & 1.36E-04 \\
\hline Maximum & & 5.99E-08 & $1.34 \mathrm{E}-07$ & $1.61 \mathrm{E}-04$ & 1.19E-07 & $2.25 \mathrm{E}-07$ & $1.24 \mathrm{E}-04$ & 7.17E-08 & 8.70E-08 & $1.24 \mathrm{E}-04$ \\
\hline Mean & & $1.15 \mathrm{E}-08$ & 7.38E-08 & $1.87 \mathrm{E}-04$ & $1.94 \mathrm{E}-08$ & $9.79 \mathrm{E}-08$ & 8.98E-05 & $1.28 \mathrm{E}-08$ & $6.14 \mathrm{E}-08$ & 9.91E-05 \\
\hline
\end{tabular}

${ }^{a}$ WIPP Air Blank

\begin{tabular}{lllll}
\multirow{3}{*}{ CBD } & & \multicolumn{3}{c}{ U-234 } \\
\cline { 3 - 5 } & 1 & $2.49 \mathrm{E}-06$ & $4.69 \mathrm{E}-07$ & $1.32 \mathrm{E}-03$ \\
& 2 & $2.76 \mathrm{E}-06$ & $4.63 \mathrm{E}-07$ & $1.40 \mathrm{E}-03$ \\
& 3 & $2.24 \mathrm{E}-06$ & $3.78 \mathrm{E}-07$ & $1.25 \mathrm{E}-03$ \\
\multirow{3}{*}{$\mathrm{MLR}$} & 4 & $3.29 \mathrm{E}-06$ & $4.51 \mathrm{E}-07$ & $8.54 \mathrm{E}-04$ \\
& 1 & $2.24 \mathrm{E}-06$ & $4.57 \mathrm{E}-07$ & $1.32 \mathrm{E}-03$ \\
& 2 & $2.36 \mathrm{E}-06$ & $3.73 \mathrm{E}-07$ & $1.40 \mathrm{E}-03$ \\
& 3 & $2.32 \mathrm{E}-06$ & $3.93 \mathrm{E}-07$ & $1.25 \mathrm{E}-03$ \\
& 4 & $2.35 \mathrm{E}-06$ & $4.13 \mathrm{E}-07$ & $8.54 \mathrm{E}-04$
\end{tabular}

\begin{tabular}{ccc} 
RN & $\mathbf{2} \mathbf{X}$ TPU & MDC \\
\hline & U-235 & \\
\hline $1.85 \mathrm{E}-07$ & $1.43 \mathrm{E}-07$ & $2.23 \mathrm{E}-04$ \\
$1.15 \mathrm{E}-07$ & $1.05 \mathrm{E}-07$ & $1.86 \mathrm{E}-04$ \\
$9.42 \mathrm{E}-08$ & $8.70 \mathrm{E}-08$ & $1.86 \mathrm{E}-04$ \\
$1.08 \mathrm{E}-07$ & $9.01 \mathrm{E}-08$ & $1.61 \mathrm{E}-04$ \\
$1.39 \mathrm{E}-07$ & $1.27 \mathrm{E}-07$ & $2.23 \mathrm{E}-04$ \\
$1.38 \mathrm{E}-07$ & $1.00 \mathrm{E}-07$ & $1.86 \mathrm{E}-04$ \\
$1.37 \mathrm{E}-07$ & $1.07 \mathrm{E}-07$ & $1.86 \mathrm{E}-04$ \\
$8.33 \mathrm{E}-08$ & $8.95 \mathrm{E}-08$ & $1.61 \mathrm{E}-04$
\end{tabular}

\begin{tabular}{ccc} 
RN & $\mathbf{2} \mathbf{X}$ TPU & MDC \\
\hline & U-238 \\
\hline $2.01 \mathrm{E}-06$ & $4.20 \mathrm{E}-07$ & $7.43 \mathrm{E}-04$ \\
$2.77 \mathrm{E}-06$ & $4.63 \mathrm{E}-07$ & $8.54 \mathrm{E}-04$ \\
$2.46 \mathrm{E}-06$ & $3.97 \mathrm{E}-07$ & $7.05 \mathrm{E}-04$ \\
3.07E-06 & $4.34 \mathrm{E}-07$ & $5.32 \mathrm{E}-04$ \\
1.81E-06 & $4.10 \mathrm{E}-07$ & $7.43 \mathrm{E}-04$ \\
2.15E-06 & $3.54 \mathrm{E}-07$ & $8.54 \mathrm{E}-04$ \\
2.15E-06 & $3.77 \mathrm{E}-07$ & $7.05 \mathrm{E}-04$ \\
1.99E-06 & $3.79 \mathrm{E}-07$ & $5.32 \mathrm{E}-04$
\end{tabular}


Waste Isolation Pilot Plant Annual Site Environmental Report for 2005 DOE/WIPP-06-2225

\begin{tabular}{|c|c|c|c|c|c|c|c|c|c|c|}
\hline Location & Qtr. & RN & $2 \times$ TPU & MDC & RN & $2 \times$ TPU & MDC & RN & $2 \times$ TPU & MDC \\
\hline \multirow[t]{4}{*}{ SEC } & 1 & 2.09E-06 & 4.14E-07 & $1.32 \mathrm{E}-03$ & $2.18 \mathrm{E}-07$ & $1.50 \mathrm{E}-07$ & $2.23 \mathrm{E}-04$ & $2.01 \mathrm{E}-06$ & 4.04E-07 & 7.43E-04 \\
\hline & 2 & 2.09E-06 & 3.79E-07 & $1.40 \mathrm{E}-03$ & $1.20 \mathrm{E}-07$ & 1.03E-07 & 1.86E-04 & 1.79E-06 & 3.49E-07 & 8.54E-04 \\
\hline & 3 & 1.98E-06 & 3.91E-07 & $1.25 \mathrm{E}-03$ & 6.27E-08 & 8.47E-08 & 1.86E-04 & 2.39E-06 & 4.30E-07 & 7.05E-04 \\
\hline & 4 & 2.34E-06 & 3.64E-07 & 8.54E-04 & 1.36E-07 & 9.69E-08 & 1.61E-04 & 2.12E-06 & $3.46 \mathrm{E}-07$ & 5.32E-04 \\
\hline \multirow[t]{4}{*}{ SMR } & 1 & 2.29E-06 & 4.32E-07 & 1.32E-03 & 2.44E-07 & 1.56E-07 & 2.23E-04 & 2.26E-06 & $4.28 \mathrm{E}-07$ & 7.43E-04 \\
\hline & 2 & 2.03E-06 & $3.46 \mathrm{E}-07$ & 1.40E-03 & 2.15E-07 & $1.23 \mathrm{E}-07$ & 1.86E-04 & $2.46 \mathrm{E}-06$ & $3.82 \mathrm{E}-07$ & $8.54 \mathrm{E}-04$ \\
\hline & 3 & 2.07E-06 & 4.23E-07 & $1.25 \mathrm{E}-03$ & $1.03 \mathrm{E}-07$ & $1.06 \mathrm{E}-07$ & 1.86E-04 & $2.15 \mathrm{E}-06$ & 4.30E-07 & 7.05E-04 \\
\hline & 4 & 3.66E-06 & 5.57E-07 & 8.54E-04 & $1.74 \mathrm{E}-07$ & 1.34E-07 & 1.61E-04 & $3.42 \mathrm{E}-06$ & 5.36E-07 & 5.32E-04 \\
\hline \multirow[t]{4}{*}{ WEE } & 1 & $2.41 \mathrm{E}-06$ & 4.10E-07 & 1.32E-03 & 1.77E-07 & $1.30 \mathrm{E}-07$ & 2.23E-04 & $2.22 \mathrm{E}-06$ & 3.93E-07 & 7.43E-04 \\
\hline & 2 & $2.28 \mathrm{E}-06$ & 3.91E-07 & 1.40E-03 & $1.56 \mathrm{E}-07$ & 1.17E-07 & 1.86E-04 & 2.23E-06 & 3.87E-07 & 8.54E-04 \\
\hline & 3 & 2.31E-06 & 3.74E-07 & $1.25 \mathrm{E}-03$ & 1.57E-07 & 1.11E-07 & 1.86E-04 & 1.85E-06 & 3.33E-07 & 7.05E-04 \\
\hline & 4 & $2.30 \mathrm{E}-06$ & 4.00E-07 & 8.54E-04 & $1.61 \mathrm{E}-07$ & $1.22 \mathrm{E}-07$ & 1.61E-04 & $2.75 \mathrm{E}-06$ & 4.39E-07 & 5.32E-04 \\
\hline \multirow[t]{4}{*}{ WFF } & 1 & $2.25 \mathrm{E}-06$ & $4.00 \mathrm{E}-07$ & 1.32E-03 & $1.02 \mathrm{E}-07$ & $9.82 \mathrm{E}-08$ & 2.23E-04 & 2.03E-06 & $3.79 \mathrm{E}-07$ & 7.43E-04 \\
\hline & 2 & 2.07E-06 & 3.98E-07 & 1.40E-03 & $1.35 \mathrm{E}-07$ & 1.15E-07 & 1.86E-04 & 2.26E-06 & 4.14E-07 & 8.54E-04 \\
\hline & 3 & $1.70 \mathrm{E}-06$ & 3.09E-07 & $1.25 \mathrm{E}-03$ & 1.33E-07 & 9.69E-08 & 1.86E-04 & $1.73 \mathrm{E}-06$ & $3.10 \mathrm{E}-07$ & 7.05E-04 \\
\hline & 4 & $2.44 \mathrm{E}-06$ & 4.21E-07 & 8.54E-04 & $1.70 \mathrm{E}-07$ & $1.24 \mathrm{E}-07$ & 1.61E-04 & $2.52 \mathrm{E}-06$ & 4.27E-07 & 5.32E-04 \\
\hline \multirow[t]{4}{*}{ WSS } & 1 & $2.46 \mathrm{E}-06$ & 4.87E-07 & $1.32 \mathrm{E}-03$ & 1.66E-07 & $1.44 \mathrm{E}-07$ & 2.23E-04 & 1.99E-06 & 4.35E-07 & 7.43E-04 \\
\hline & 2 & $2.74 \mathrm{E}-06$ & 4.70E-07 & 1.40E-03 & $1.85 \mathrm{E}-07$ & $1.38 \mathrm{E}-07$ & 1.86E-04 & $2.45 \mathrm{E}-06$ & 4.41E-07 & 8.54E-04 \\
\hline & 3 & 1.96E-06 & 3.55E-07 & $1.25 \mathrm{E}-03$ & $9.04 \mathrm{E}-08$ & 8.80E-08 & 1.86E-04 & $2.09 \mathrm{E}-06$ & 3.64E-07 & 7.05E-04 \\
\hline & 4 & $2.43 \mathrm{E}-06$ & 3.87E-07 & 8.54E-04 & 2.33E-07 & 1.33E-07 & 1.61E-04 & $2.22 \mathrm{E}-06$ & 3.67E-07 & 5.32E-04 \\
\hline \multirow[t]{4}{*}{ WAB } & 1 & 1.57E-02 & 3.32E-03 & $1.80 \mathrm{E}-03$ & 1.26E-03 & $1.05 \mathrm{E}-03$ & 8.08E-04 & 1.37E-02 & 3.10E-03 & $1.22 \mathrm{E}-03$ \\
\hline & 2 & 1.37E-02 & 3.00E-03 & $1.84 \mathrm{E}-03$ & 1.38E-03 & 1.06E-03 & 7.34E-04 & $1.56 \mathrm{E}-02$ & $3.20 \mathrm{E}-03$ & $1.30 \mathrm{E}-03$ \\
\hline & 3 & 1.31E-02 & 2.57E-03 & 1.59E-03 & 7.54E-04 & 6.89E-04 & 6.06E-04 & 1.43E-02 & 2.69E-03 & $1.04 \mathrm{E}-03$ \\
\hline & 4 & 1.44E-02 & $2.62 \mathrm{E}-03$ & 1.17E-03 & $1.00 \mathrm{E}-03$ & 7.65E-04 & 5.56E-04 & 1.31E-02 & $2.49 \mathrm{E}-03$ & 8.51E-04 \\
\hline Minimum & & 1.70E-06 & 3.09E-07 & 1.25E-03 & 6.27E-08 & 8.47E-08 & 1.86E-04 & 1.73E-06 & 3.10E-07 & 7.05E-04 \\
\hline Maximum & & 3.66E-06 & 5.57E-07 & 8.54E-04 & 2.44E-07 & $1.56 \mathrm{E}-07$ & 2.23E-04 & $3.42 \mathrm{E}-06$ & 5.36E-07 & 5.32E-04 \\
\hline Mean & & 2.36E-06 & 4.11E-07 & $1.21 \mathrm{E}-03$ & $1.48 \mathrm{E}-07$ & 1.15E-07 & 1.89E-04 & 2.26E-06 & 4.01E-07 & 7.09E-04 \\
\hline
\end{tabular}

\begin{tabular}{|c|c|c|c|c|c|c|c|c|c|c|}
\hline \multirow{3}{*}{ CBD } & \multirow[b]{3}{*}{1} & RN & $2 \times$ TPU & MDC & RN & $2 \times$ TPU & MDC & RN & $2 \times$ TPU & MDC \\
\hline & & \multicolumn{3}{|c|}{$\mathrm{K}-40$} & \multicolumn{3}{|c|}{ Co-60 } & \multicolumn{3}{|c|}{ Cs-137 } \\
\hline & & $2.16 \mathrm{E}-04$ & $1.32 \mathrm{E}-04$ & $1.92 E-04$ & $-8.56 \mathrm{E}-06$ & $2.29 \mathrm{E}-05$ & $\overline{2.48 E-05}$ & $2.53 \mathrm{E}-06$ & $1.51 \mathrm{E}-05$ & $1.80 \mathrm{E}-05$ \\
\hline & 2 & 2.33E-04 & $1.55 \mathrm{E}-04$ & 2.31E-04 & $-4.33 E-06$ & $2.25 \mathrm{E}-05$ & $2.50 \mathrm{E}-05$ & 2.07E-06 & 1.56E-05 & 1.85E-05 \\
\hline \multirow{5}{*}{ MLR } & 3 & 2.38E-04 & $1.58 \mathrm{E}-04$ & 2.36E-04 & 1.19E-05 & $2.10 \mathrm{E}-05$ & 2.52E-05 & $1.23 \mathrm{E}-06$ & 1.64E-05 & 1.93E-05 \\
\hline & 4 & 5.29E-04 & 4.19E-04 & $6.58 \mathrm{E}-04$ & 5.30E-05 & 3.66E-05 & 4.31E-05 & $1.31 \mathrm{E}-06$ & 3.16E-05 & 3.51E-05 \\
\hline & 1 & 2.59E-04 & $2.60 \mathrm{E}-04$ & 4.13E-04 & $2.28 \mathrm{E}-05$ & 3.54E-05 & 4.07E-05 & $-2.90 \mathrm{E}-05$ & 3.30E-05 & 3.95E-05 \\
\hline & 2 & 5.94E-04 & 2.06E-04 & 2.61E-04 & 1.59E-05 & 3.68E-05 & 4.19E-05 & $-1.80 \mathrm{E}-05$ & 3.18E-05 & 4.00E-05 \\
\hline & 3 & $1.52 \mathrm{E}-04$ & 1.36E-04 & $2.12 \mathrm{E}-04$ & -1.03E-05 & $2.24 \mathrm{E}-05$ & 2.39E-05 & $-7.38 \mathrm{E}-07$ & 1.53E-05 & 1.80E-05 \\
\hline & 4 & 3.16E-04 & 1.54E-04 & 2.09E-04 & $1.06 \mathrm{E}-05$ & 2.32E-05 & 2.73E-05 & 2.77E-06 & 1.87E-05 & 2.23E-05 \\
\hline \multirow[t]{4}{*}{ SEC } & 1 & 4.20E-04 & 2.67E-04 & 4.06E-04 & 1.31E-06 & $3.52 \mathrm{E}-05$ & 3.96E-05 & $-2.06 \mathrm{E}-05$ & 3.54E-05 & 3.83E-05 \\
\hline & 2 & 7.61E-04 & $2.40 \mathrm{E}-04$ & 2.92E-04 & $-1.16 \mathrm{E}-05$ & 3.88E-05 & 4.24E-05 & $-4.60 \mathrm{E}-06$ & 3.66E-05 & 4.08E-05 \\
\hline & 3 & 1.32E-04 & 1.37E-04 & 2.17E-04 & 5.55E-07 & $2.10 \mathrm{E}-05$ & $2.41 \mathrm{E}-05$ & 7.98E-06 & 1.52E-05 & 1.85E-05 \\
\hline & 4 & $2.78 \mathrm{E}-04$ & $2.51 \mathrm{E}-04$ & 3.09E-04 & $1.81 \mathrm{E}-05$ & 2.23E-05 & 2.76E-05 & $-9.81 \mathrm{E}-06$ & 1.85E-05 & 2.07E-05 \\
\hline \multirow[t]{4}{*}{ SMR } & 1 & 2.86E-04 & 2.70E-04 & 4.27E-04 & 2.57E-05 & $3.48 \mathrm{E}-05$ & 4.02E-05 & 7.08E-06 & 2.80E-05 & 3.83E-05 \\
\hline & 2 & $1.80 \mathrm{E}-04$ & 1.43E-04 & 2.19E-04 & $-2.17 \mathrm{E}-05$ & 2.63E-05 & 2.67E-05 & 1.79E-06 & $1.55 \mathrm{E}-06$ & 1.84E-05 \\
\hline & 3 & $9.62 \mathrm{E}-04$ & $3.12 \mathrm{E}-04$ & 3.79E-04 & -1.73E-05 & 3.96E-05 & $6.15 \mathrm{E}-05$ & $-6.97 \mathrm{E}-05$ & 5.32E-05 & 5.98E-05 \\
\hline & 4 & 1.47E-04 & $2.74 \mathrm{E}-04$ & 3.17E-04 & 3.31E-05 & 2.47E-05 & 3.14E-05 & $-5.31 \mathrm{E}-06$ & 2.06E-05 & 2.24E-05 \\
\hline \multirow[t]{4}{*}{ WEE } & 1 & 7.13E-04 & 3.73E-04 & 4.29E-04 & $2.14 \mathrm{E}-05$ & $3.49 \mathrm{E}-05$ & 4.01E-05 & 1.07E-05 & $2.59 \mathrm{E}-05$ & 3.90E-05 \\
\hline & 2 & 5.67E-04 & 3.66E-04 & 4.21E-04 & 2.56E-06 & 3.70E-05 & 4.16E-05 & -1.64E-05 & 3.67E-05 & 4.00E-05 \\
\hline & 3 & $2.74 \mathrm{E}-04$ & 2.13E-04 & 2.68E-04 & 2.18E-05 & 2.02E-05 & 2.53E-05 & $6.27 \mathrm{E}-06$ & 1.56E-05 & 1.88E-05 \\
\hline & 4 & $3.45 \mathrm{E}-04$ & $1.24 \mathrm{E}-04$ & 1.67E-04 & $-1.36 \mathrm{E}-06$ & $2.38 \mathrm{E}-05$ & 2.64E-05 & $-2.14 \mathrm{E}-05$ & 2.12E-05 & 2.10E-05 \\
\hline \multirow[t]{4}{*}{ WFF } & 1 & $2.45 \mathrm{E}-04$ & $1.24 \mathrm{E}-04$ & 1.71E-04 & $1.53 \mathrm{E}-05$ & 1.93E-05 & 2.39E-05 & 3.12E-06 & $1.55 \mathrm{E}-05$ & 1.85E-05 \\
\hline & 2 & $1.66 \mathrm{E}-04$ & $2.59 \mathrm{E}-04$ & 3.13E-04 & $-1.09 \mathrm{E}-05$ & $2.80 \mathrm{E}-05$ & 3.03E-05 & $1.13 \mathrm{E}-05$ & 1.80E-05 & 2.20E-05 \\
\hline & 3 & 5.17E-04 & $1.88 \mathrm{E}-04$ & 2.40E-04 & 2.91E-05 & $3.50 \mathrm{E}-05$ & 4.06E-05 & $-2.55 E-06$ & 3.60E-05 & 4.03E-05 \\
\hline & 4 & 2.54E-04 & 34E-04 & 4 & 1.63 & $2.50 \mathrm{E}$ & 5 & -06 & 1.85E-05 & . \\
\hline
\end{tabular}


Waste Isolation Pilot Plant Annual Site Environmental Report for 2005 DOE/WIPP-06-2225

\begin{tabular}{|c|c|c|c|c|c|c|c|c|c|c|}
\hline Location & Qtr. & RN & $2 \times$ TPU & MDC & RN & $2 \times$ TPU & MDC & RN & $2 \times$ TPU & MDC \\
\hline \multirow[t]{4}{*}{ WSS } & 1 & 2.30E-04 & $1.31 \mathrm{E}-04$ & 1.87E-04 & $-2.01 \mathrm{E}-05$ & 2.67E-05 & $2.74 \mathrm{E}-05$ & $1.68 \mathrm{E}-06$ & 1.60E-05 & $1.90 \mathrm{E}-05$ \\
\hline & 2 & 1.36E-04 & 1.49E-04 & 2.37E-04 & -8.97E-06 & 2.36E-05 & 2.55E-05 & $2.35 \mathrm{E}-06$ & 1.62E-05 & 1.93E-05 \\
\hline & 3 & 6.17E-04 & 2.07E-04 & 2.57E-04 & 1.12E-05 & 3.49E-05 & 3.97E-05 & $-1.20 \mathrm{E}-05$ & 2.99E-05 & 3.82E-05 \\
\hline & 4 & $9.72 \mathrm{E}-04$ & 3.76E-04 & 4.35E-04 & 6.22E-05 & 3.52E-05 & 4.19E-05 & $-9.91 E-06$ & 3.16E-05 & $3.45 E-05$ \\
\hline \multirow[t]{4}{*}{ WAB } & 1 & $1.21 E+00$ & $1.58 \mathrm{E}+00$ & $1.93 E+00$ & $-2.59 \mathrm{E}-02$ & 1.57E-01 & $1.76 \mathrm{E}-01$ & 6.57E-02 & 1.12E-01 & 1.36E-01 \\
\hline & 2 & $1.12 E+00$ & $1.10 \mathrm{E}+00$ & $1.74 \mathrm{E}+00$ & 8.65E-02 & $1.55 \mathrm{E}-01$ & 1.87E-01 & 8.07E-02 & $1.09 \mathrm{E}-01$ & 1.34E-01 \\
\hline & 3 & $5.43 E+00$ & $1.72 \mathrm{E}+00$ & $2.08 \mathrm{E}+00$ & $-7.51 \mathrm{E}-02$ & 2.69E-01 & 2.94E-01 & $-1.30 \mathrm{E}-01$ & 2.70E-01 & 2.94E-01 \\
\hline & 4 & $7.45 E+00$ & $2.79 \mathrm{E}+00$ & $3.24 \mathrm{E}+00$ & 3.93E-01 & $2.73 \mathrm{E}-01$ & $3.22 \mathrm{E}-01$ & $-1.30 \mathrm{E}-01$ & 2.47E-01 & 2.65E-01 \\
\hline Minimum & & $1.32 \mathrm{E}-04$ & $1.37 \mathrm{E}-04$ & $2.17 \mathrm{E}-04$ & $-2.17 \mathrm{E}-05$ & $2.63 \mathrm{E}-05$ & 2.67E-05 & $-6.97 \mathrm{E}-05$ & 5.32E-05 & $5.98 \mathrm{E}-05$ \\
\hline Maximum & & $9.72 \mathrm{E}-04$ & $3.76 \mathrm{E}-04$ & 4.35E-04 & $6.22 \mathrm{E}-05$ & $3.52 \mathrm{E}-05$ & 4.19E-05 & 1.13E-05 & 1.80E-05 & $2.20 \mathrm{E}-05$ \\
\hline Mean & & $3.84 \mathrm{E}-04$ & $2.20 \mathrm{E}-04$ & 2.96E-04 & $8.63 \mathrm{E}-06$ & 2.88E-05 & 3.34E-05 & $-5.97 E-06$ & 2.38E-05 & 2.85E-05 \\
\hline
\end{tabular}

\begin{tabular}{|c|c|c|c|c|}
\hline & & RN & $2 \times$ TPU & MDC \\
\hline & & & Sr-90 & \\
\hline CBD & 1 & $-5.77 \mathrm{E}-07$ & $2.68 \mathrm{E}-06$ & $1.15 \mathrm{E}-06$ \\
\hline & 2 & $-9.13 E-08$ & 3.91E-06 & $1.62 \mathrm{E}-03$ \\
\hline & 3 & -2.67E-06 & 4.77E-06 & $1.91 \mathrm{E}-03$ \\
\hline & 4 & $1.02 \mathrm{E}-06$ & 5.75E-06 & $1.44 \mathrm{E}-03$ \\
\hline MLR & 1 & -1.06E-06 & $2.70 \mathrm{E}-06$ & $1.20 \mathrm{E}-06$ \\
\hline & 2 & $-1.53 E-06$ & 3.77E-06 & $1.62 \mathrm{E}-03$ \\
\hline & 3 & $-1.14 \mathrm{E}-06$ & 4.61E-06 & $1.91 \mathrm{E}-03$ \\
\hline & 4 & -1.07E-06 & 4.83E-06 & $1.44 \mathrm{E}-03$ \\
\hline SEC & 1 & 1.10E-07 & 2.61E-06 & $1.09 \mathrm{E}-06$ \\
\hline & 2 & $-1.26 \mathrm{E}-06$ & 3.85E-06 & $1.62 \mathrm{E}-03$ \\
\hline & 3 & 9.92E-07 & 5.50E-06 & $1.91 \mathrm{E}-03$ \\
\hline & 4 & $-9.53 E-07$ & 5.38E-06 & $1.44 \mathrm{E}-03$ \\
\hline SMR & 1 & $-4.74 \mathrm{E}-07$ & $2.59 \mathrm{E}-06$ & 1.10E-06 \\
\hline & 2 & -1.17E-06 & 3.87E-06 & $1.62 \mathrm{E}-03$ \\
\hline & 3 & -8.99E-07 & 7.36E-06 & $1.91 \mathrm{E}-03$ \\
\hline & 4 & $-2.15 \mathrm{E}-08$ & 5.98E-06 & $1.44 \mathrm{E}-03$ \\
\hline WEE & 1 & 8.22E-07 & $2.68 \mathrm{E}-06$ & $1.13 \mathrm{E}-06$ \\
\hline & 2 & $-2.10 \mathrm{E}-06$ & $3.68 \mathrm{E}-06$ & $1.62 \mathrm{E}-03$ \\
\hline & 3 & $-1.82 \mathrm{E}-06$ & 5.03E-06 & $1.91 \mathrm{E}-03$ \\
\hline & 4 & $-3.91 \mathrm{E}-06$ & 5.46E-06 & $1.44 \mathrm{E}-03$ \\
\hline WFF & 1 & 2.86E-07 & 2.61E-06 & $1.09 \mathrm{E}-06$ \\
\hline & 2 & -1.73E-06 & 4.39E-06 & $1.62 \mathrm{E}-03$ \\
\hline & 3 & $-3.34 E-06$ & 4.40E-06 & $1.91 \mathrm{E}-03$ \\
\hline & 4 & $-2.73 E-06$ & 4.80E-06 & $1.44 \mathrm{E}-03$ \\
\hline WSS & 1 & $-9.75 \mathrm{E}-07$ & 2.81E-06 & $1.20 \mathrm{E}-06$ \\
\hline & 2 & 5.37E-08 & 3.71E-06 & $1.62 \mathrm{E}-03$ \\
\hline & 3 & $-1.45 \mathrm{E}-06$ & 4.37E-06 & $1.91 \mathrm{E}-03$ \\
\hline & 4 & $2.80 \mathrm{E}-06$ & 5.05E-06 & $1.44 \mathrm{E}-03$ \\
\hline WAB & 1 & 4.13E-03 & $2.52 \mathrm{E}-02$ & $1.28 \mathrm{E}-02$ \\
\hline & 2 & $-3.18 \mathrm{E}-03$ & $2.80 \mathrm{E}-02$ & 3.47E-03 \\
\hline & 3 & $-1.35 \mathrm{E}-02$ & 3.61E-02 & 4.36E-03 \\
\hline & 4 & $-1.15 \mathrm{E}-02$ & $3.82 \mathrm{E}-02$ & 4.43E-03 \\
\hline Minimum & & $-3.91 \mathrm{E}-06$ & $5.46 \mathrm{E}-06$ & $1.44 \mathrm{E}-03$ \\
\hline Maxim & & $2.80 \mathrm{E}-06$ & 5.05E-06 & $1.44 \mathrm{E}-03$ \\
\hline Mean & & $-8.89 \mathrm{E}-07$ & 4.26E-06 & $1.24 \mathrm{E}-03$ \\
\hline
\end{tabular}


Waste Isolation Pilot Plant Annual Site Environmental Report for 2005

DOE/WIPP-06-2225

This page intentionally left blank 


\section{Appendix $\mathrm{H}$ \\ Comparison of Detected Radionuclides to the Radiological Baseline}

The figures in this appendix show the highest detected radionuclides from 2005 environmental monitoring sample analysis results compared to the 99 percent confidence interval radiological baseline values established for these isotopes (DOE/WIPP 92-037). Figures address air filter composite, groundwater, surface water, sediment, soil, vegetation results, rabbit, quail, and fish. Note, all results with the exception of vegetation and animals were compared to the baseline upper 99 percentile probability value. The baseline did not include probability distributions for these, therefore these sample results are compared to the baseline mean values. There are no figures illustrating the results for deer samples as the baseline did not include analysis of deer. A detailed discussion of environmental monitoring radionuclide sample results is contained in Chapter 4.

\section{Comparison of Detected K-40 in Air Filter Composites to the Baseline}

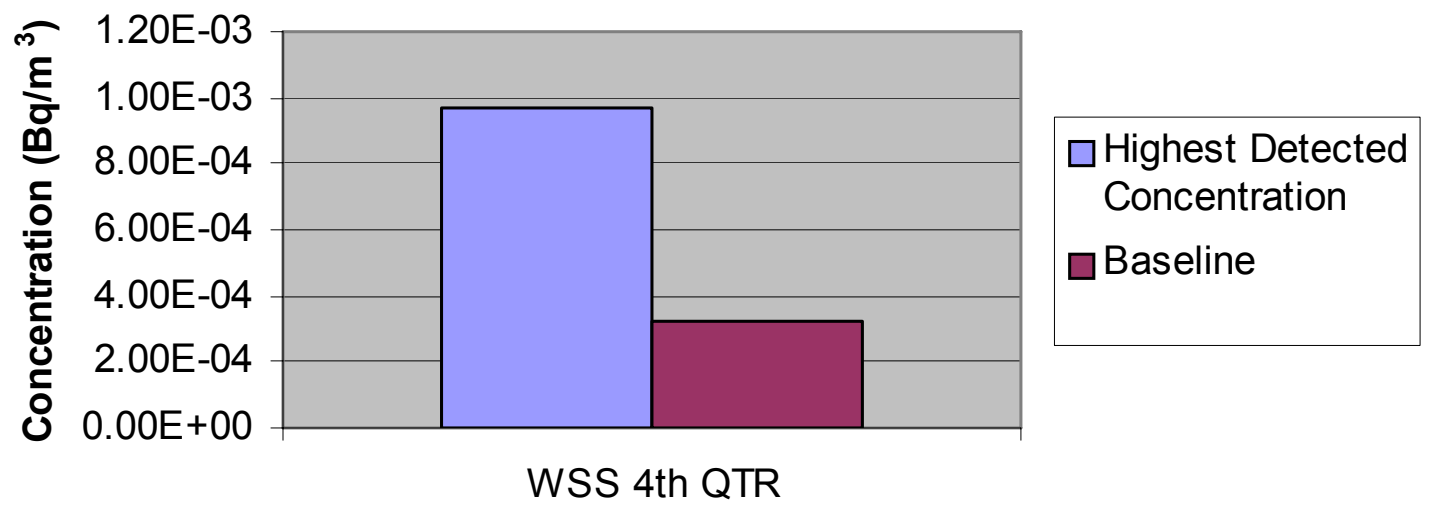




\section{Comparison of Detected Co-60 in Air Filter}

Composites to the Baseline

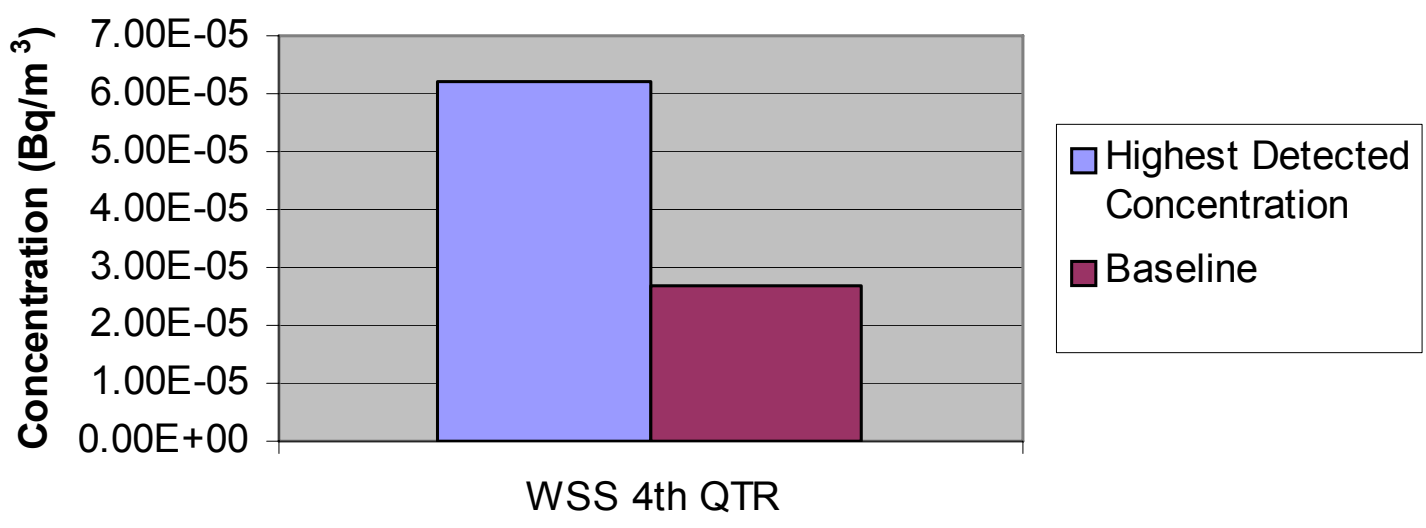

Comparison of Detected U-234 in Groundwater to the Baseline

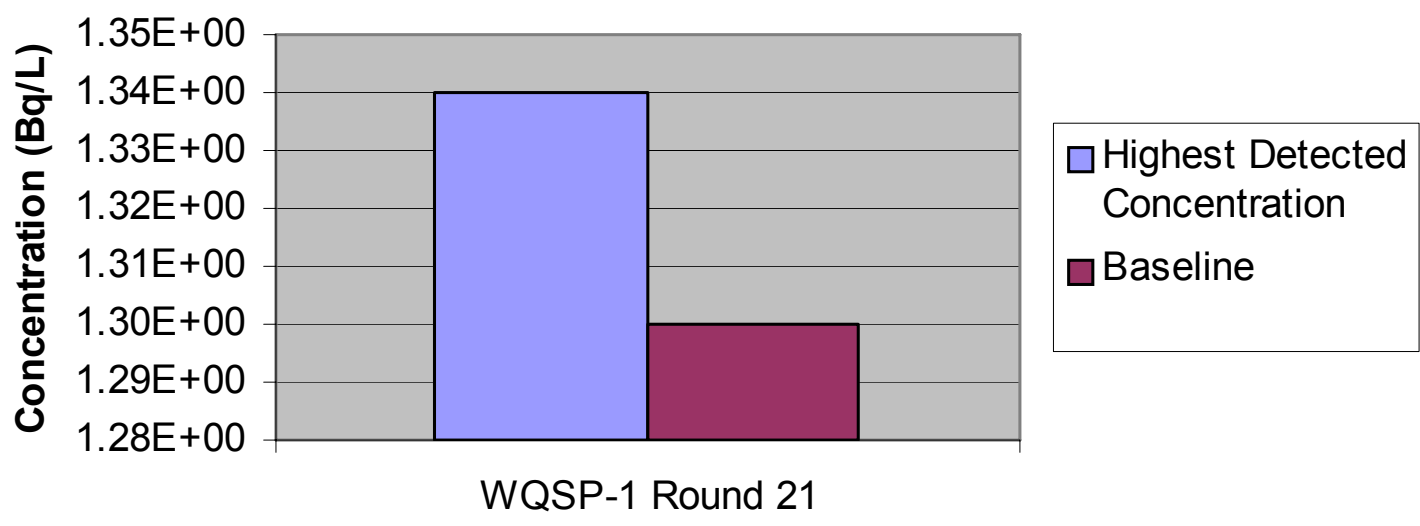




\section{Comparison of Detected U-235 in Groundwater to the Baseline}

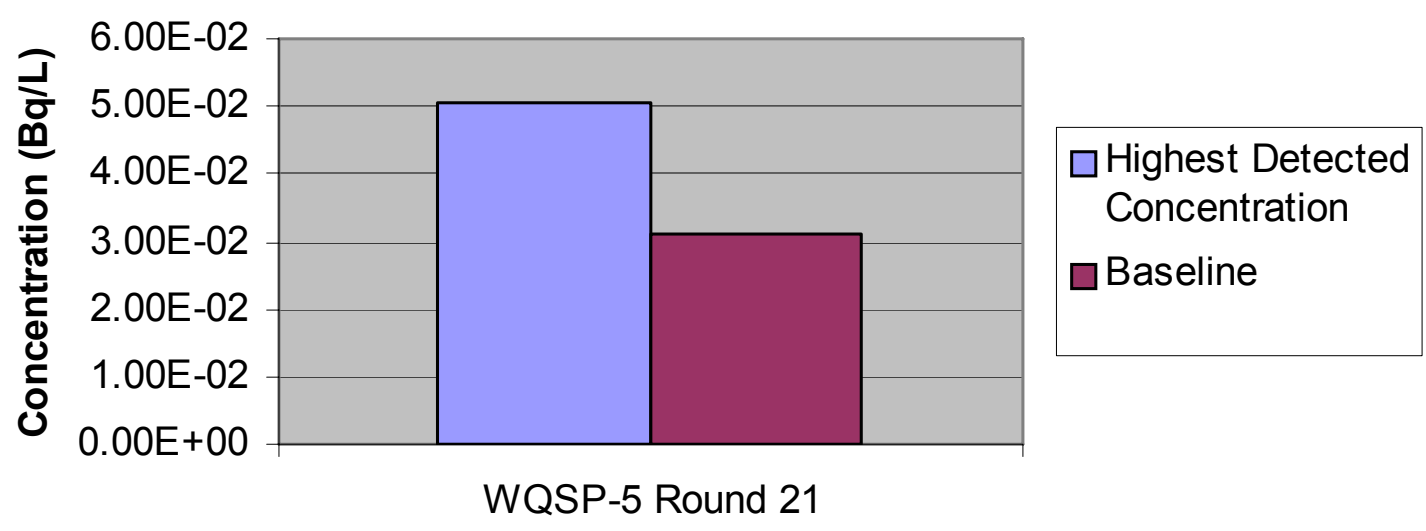

Comparison of Detected U-238 in Groundwater to the Baseline

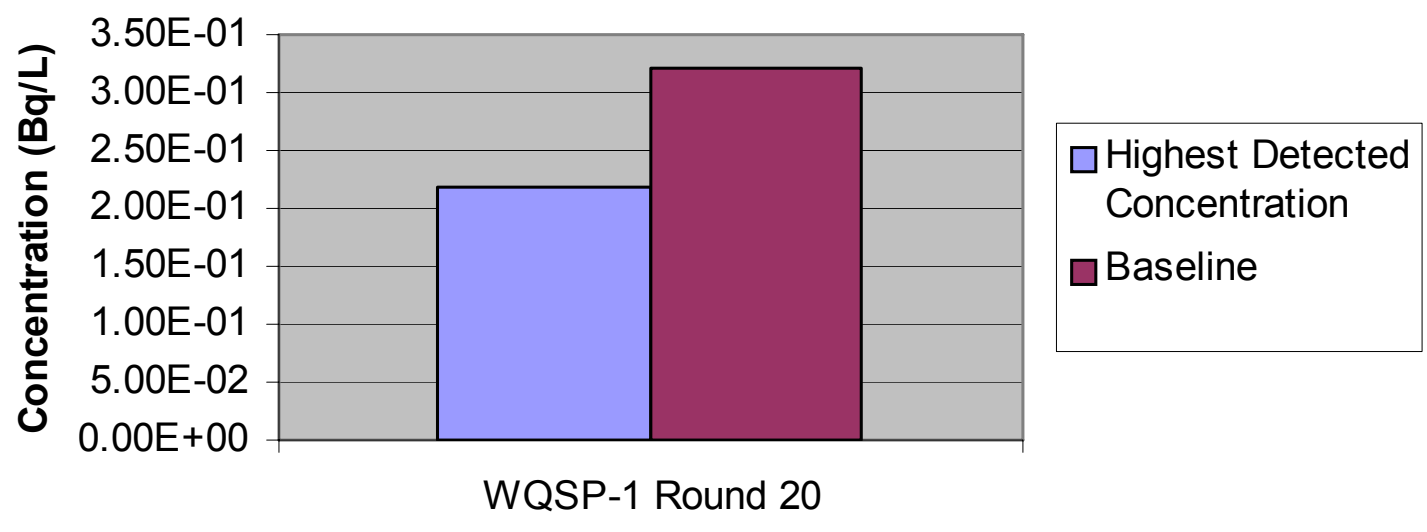


Comparison of Detected K-40 in Groundwater to the Baseline

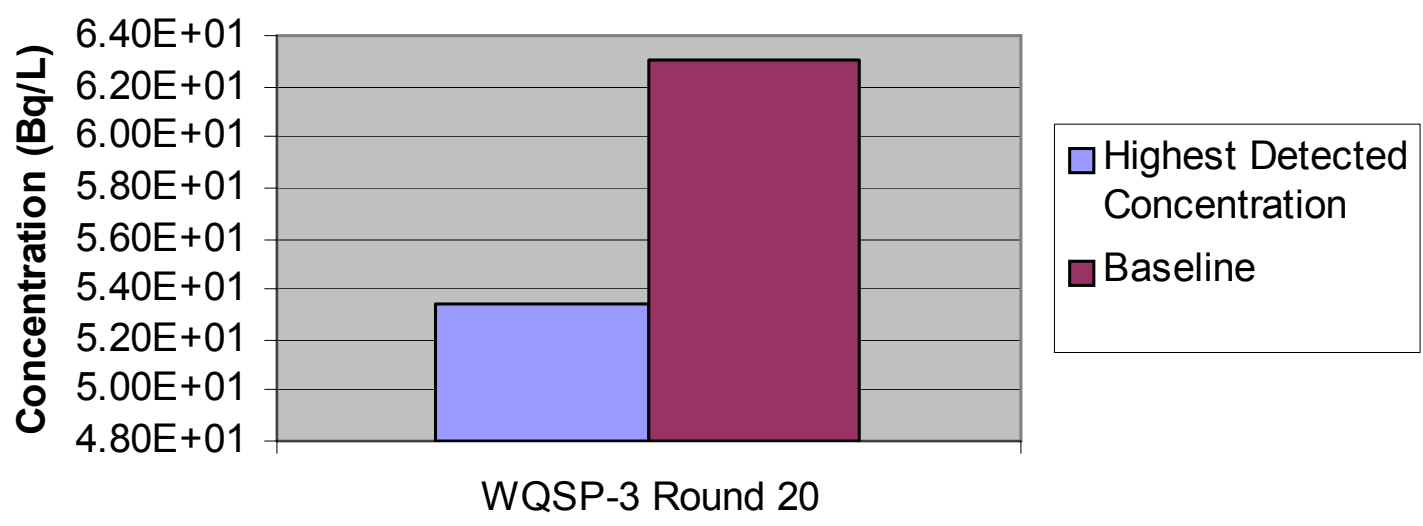

Comparison of Detected Co-60 in Groundwater to the Baseline

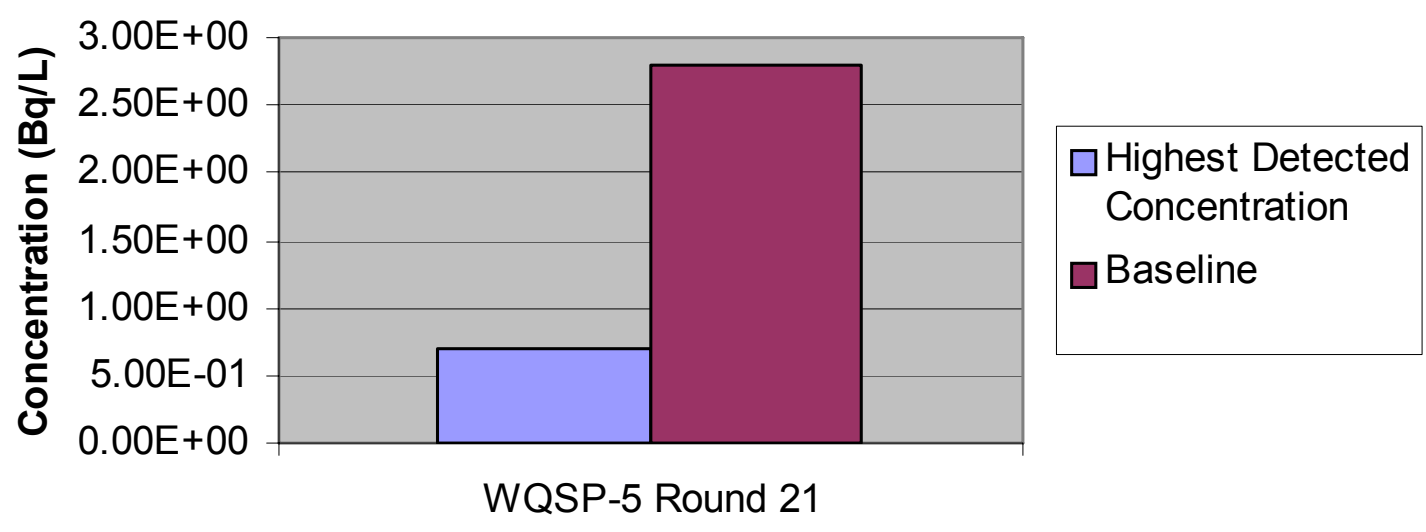




\section{Comparison of Detected U-234 in Surface Water to the Baseline}

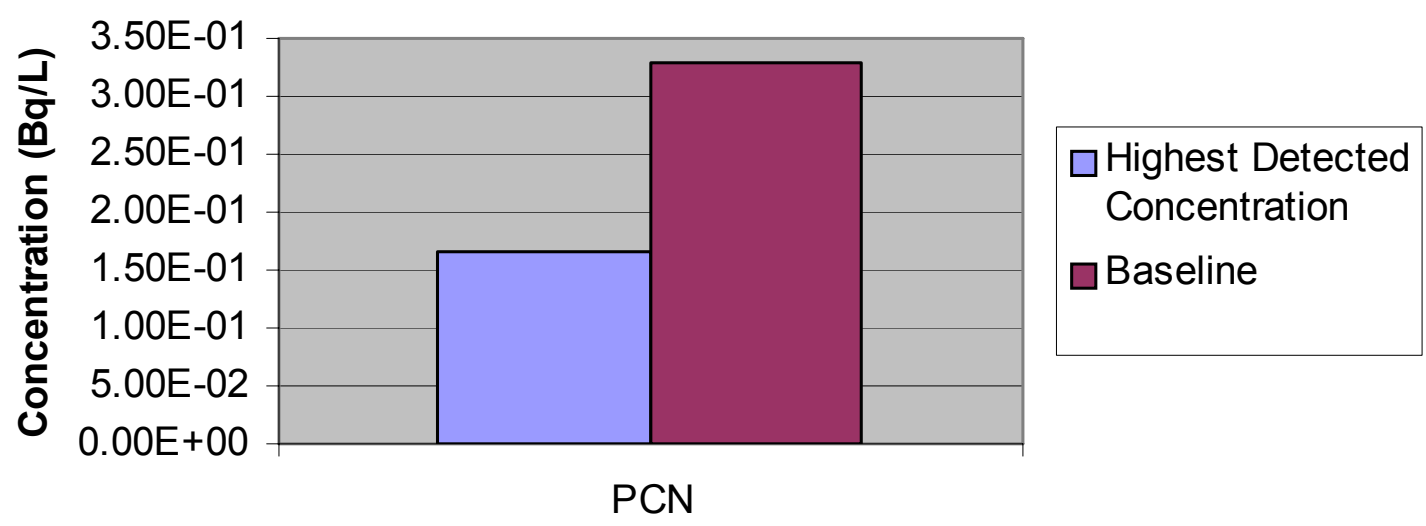

Comparison of Detected U-235 in Surface Water to the Baseline

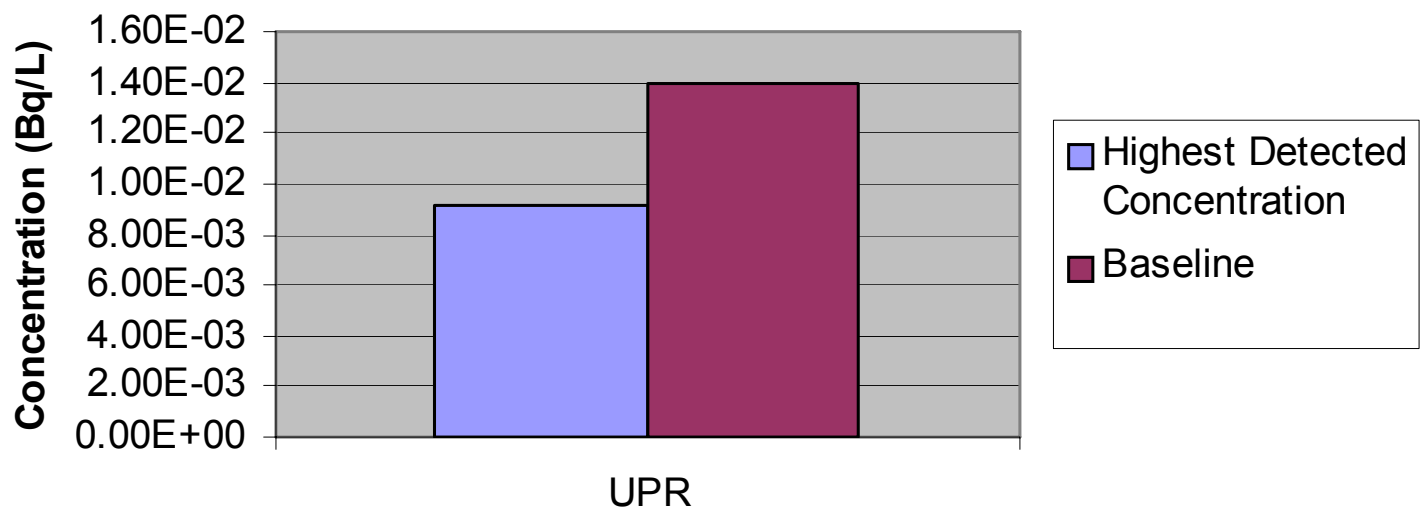




\section{Comparison of Detected U-238 in Surface Water to the Baseline}

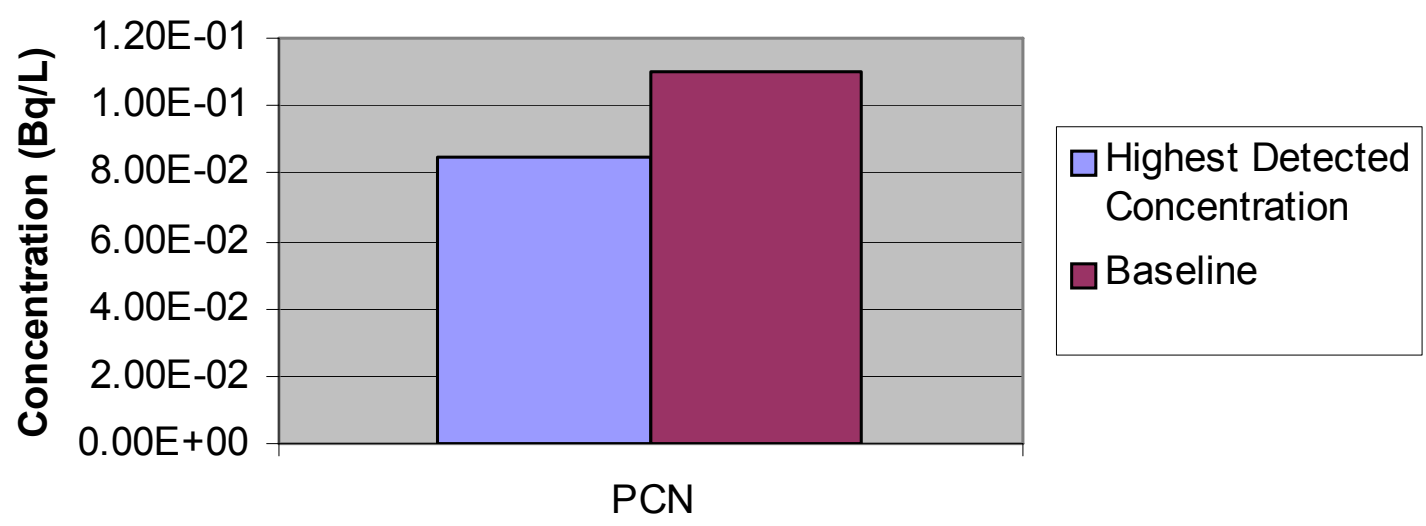

Comparison of Detected K-40 in Surface Water to the Baseline

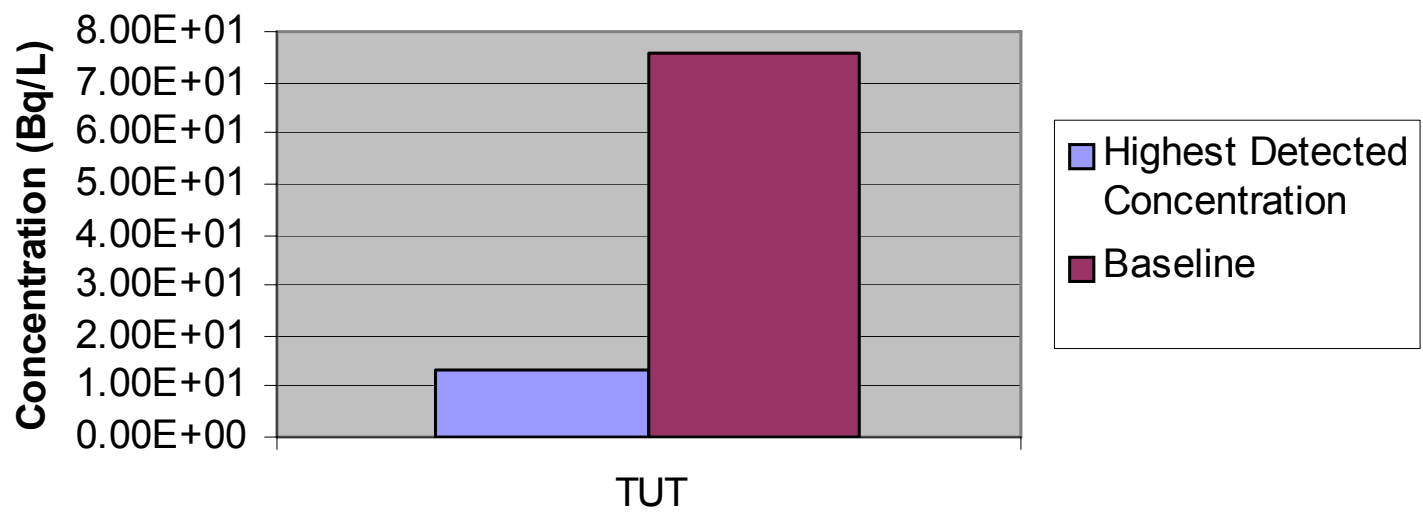




\section{Comparison of Detected Co-60 in Surface Water to the Baseline}

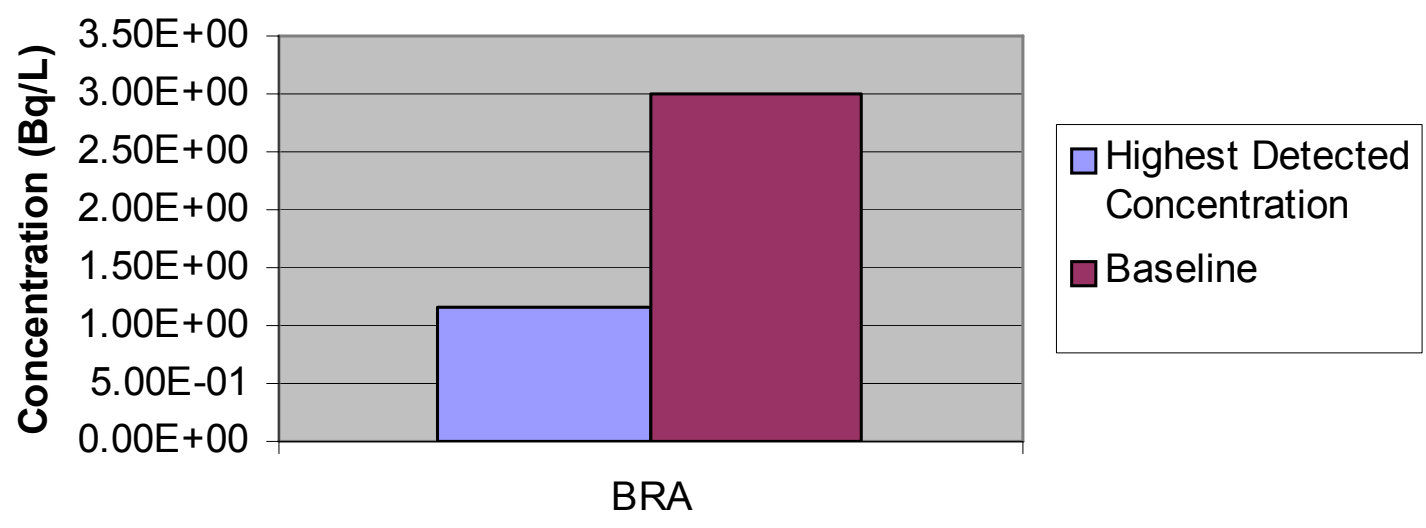

Comparison of Detected Pu-239+240 in Sediment to the Baseline

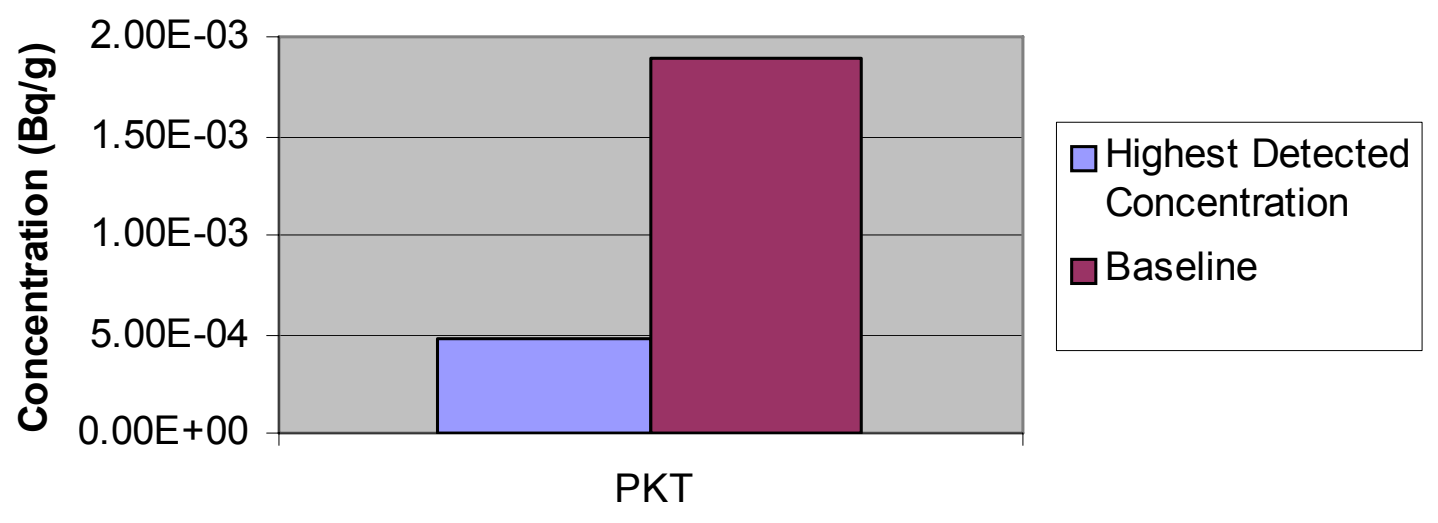


Comparison of Detected U-234 in Sediment to the Baseline

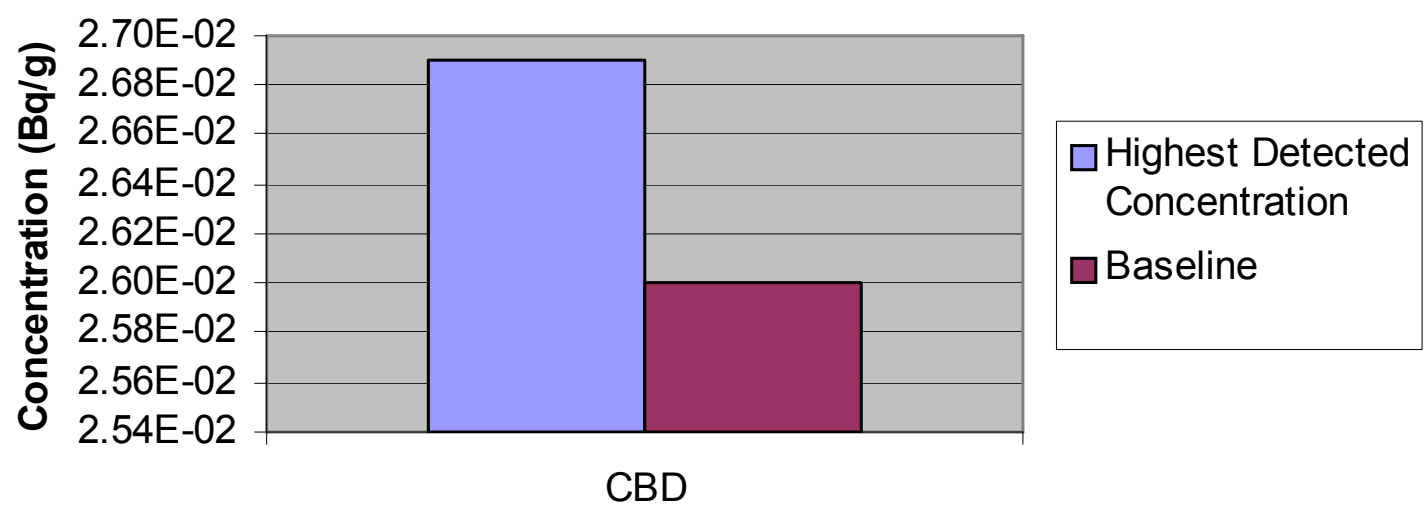

Comparison of Detected U-235 in Sediment to the Baseline

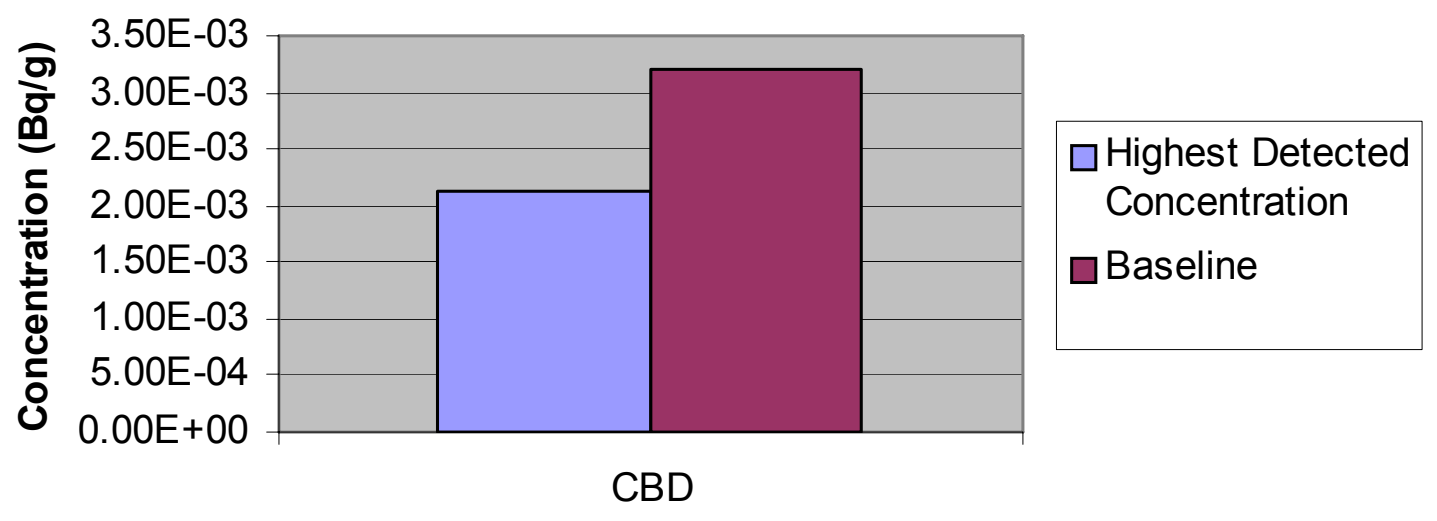


Comparison of Detected U-238 in Sediment to the Baseline

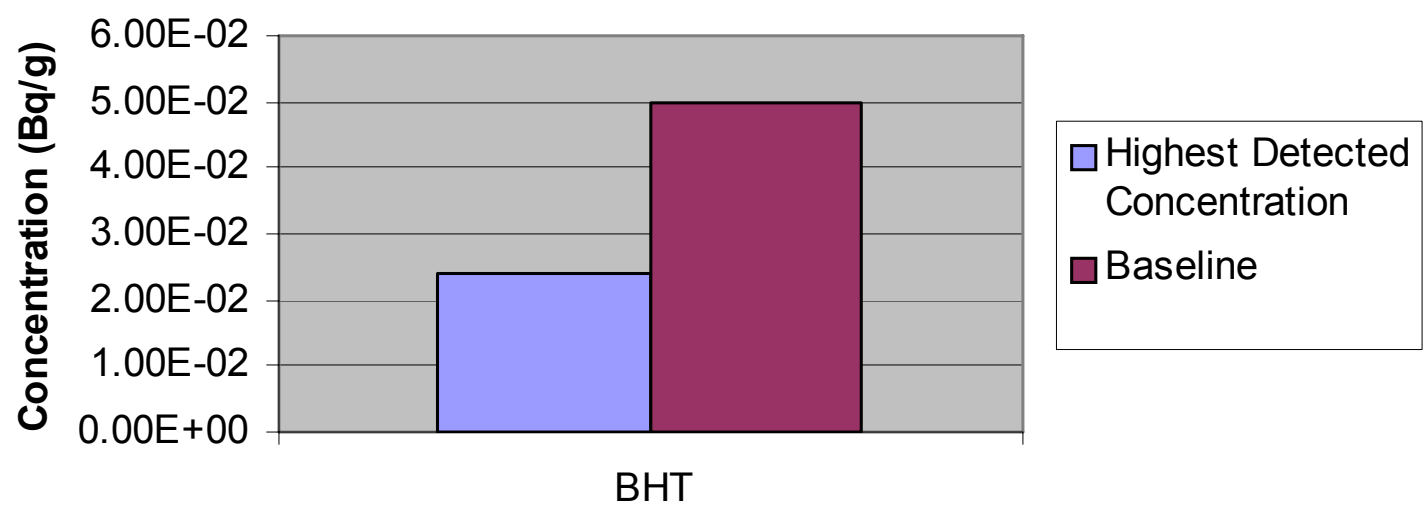

Comparison of Detected K-40 in Sediment to the Baseline

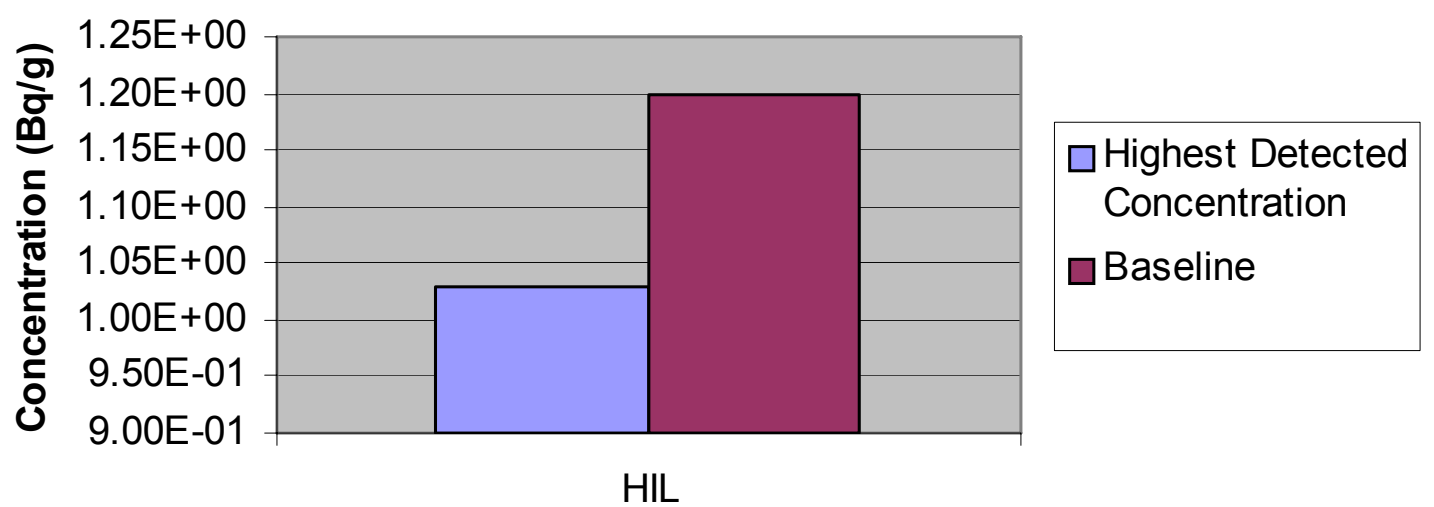


Comparison of Detected Co-60 in Sediment to the Baseline

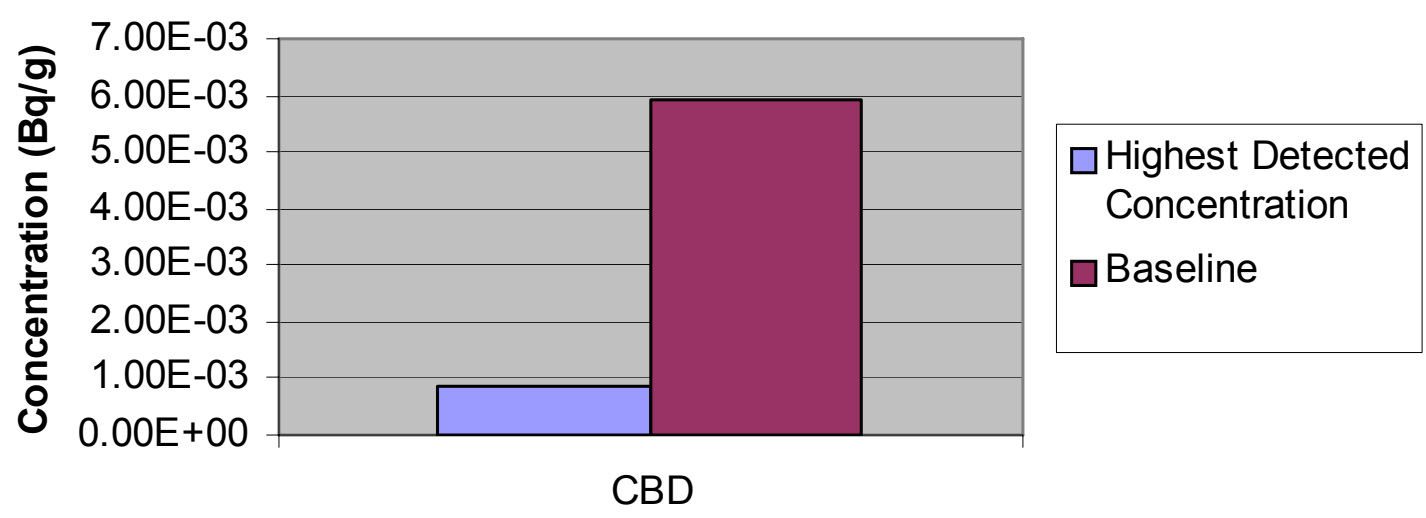

Comparison of Detected Cs-137 in Sediment to the Baseline

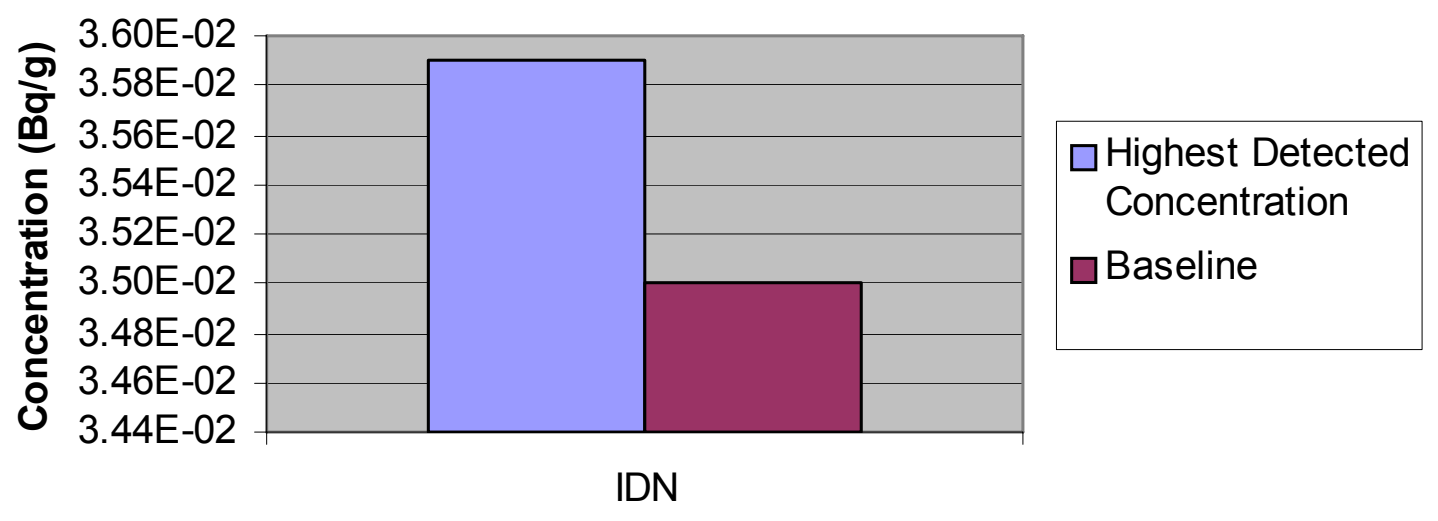




\section{Comparison of Detected Am-241 in Soil to the}

\section{Baseline}

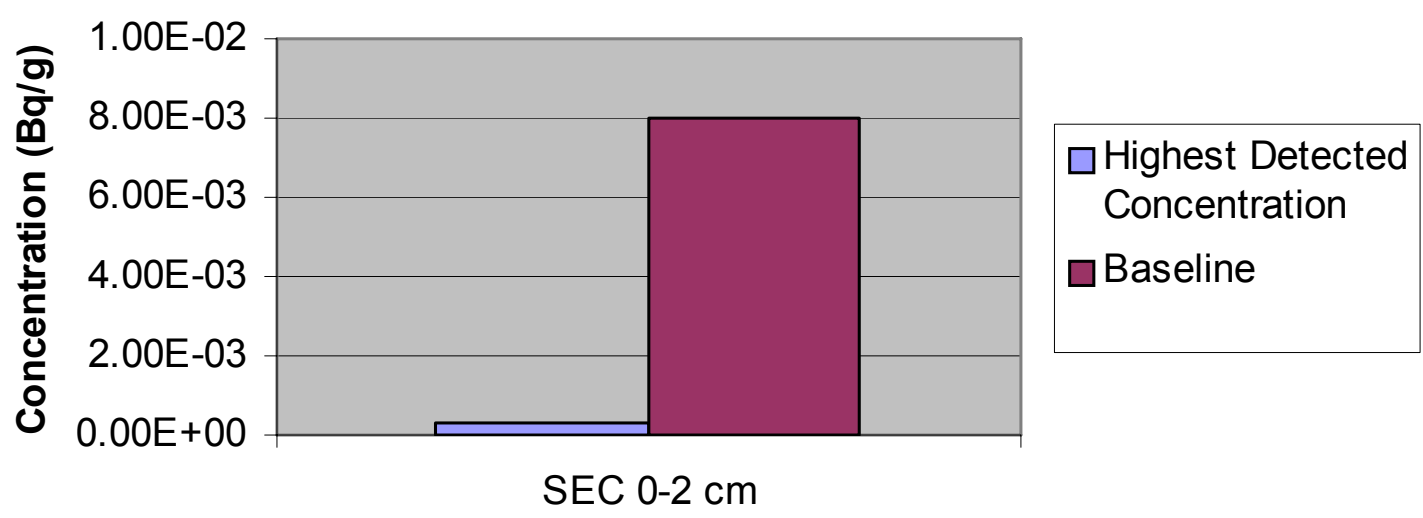

Comparison of Detected Pu-239+240 in Soil to the Baseline

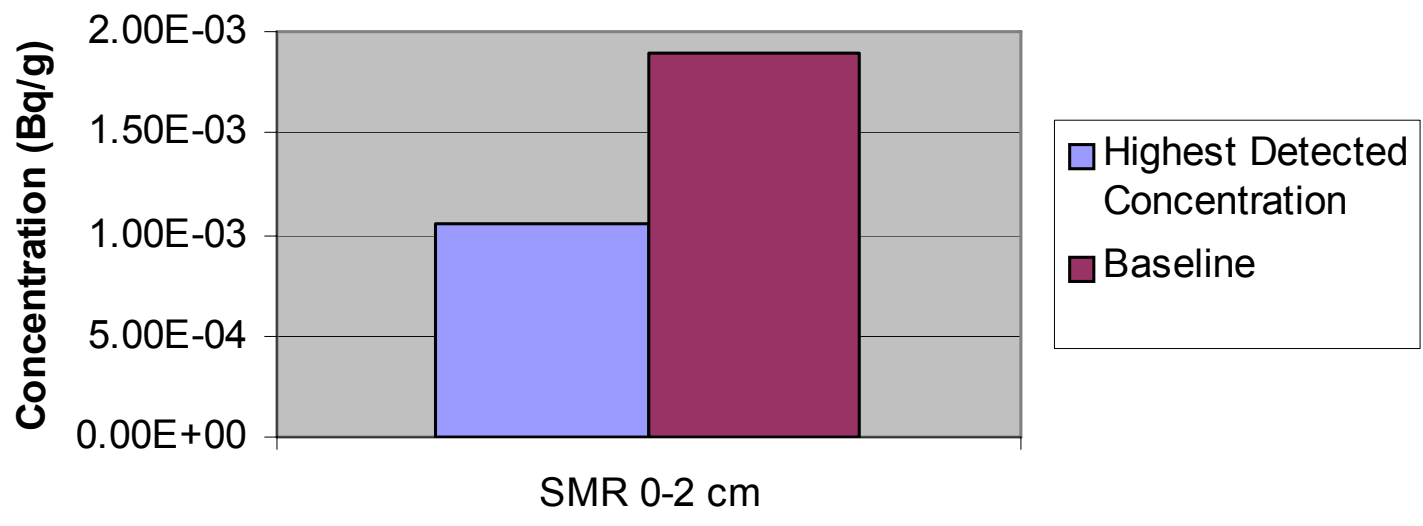




\section{Comparison of Detected U-234 in Soil to the}

\section{Baseline}

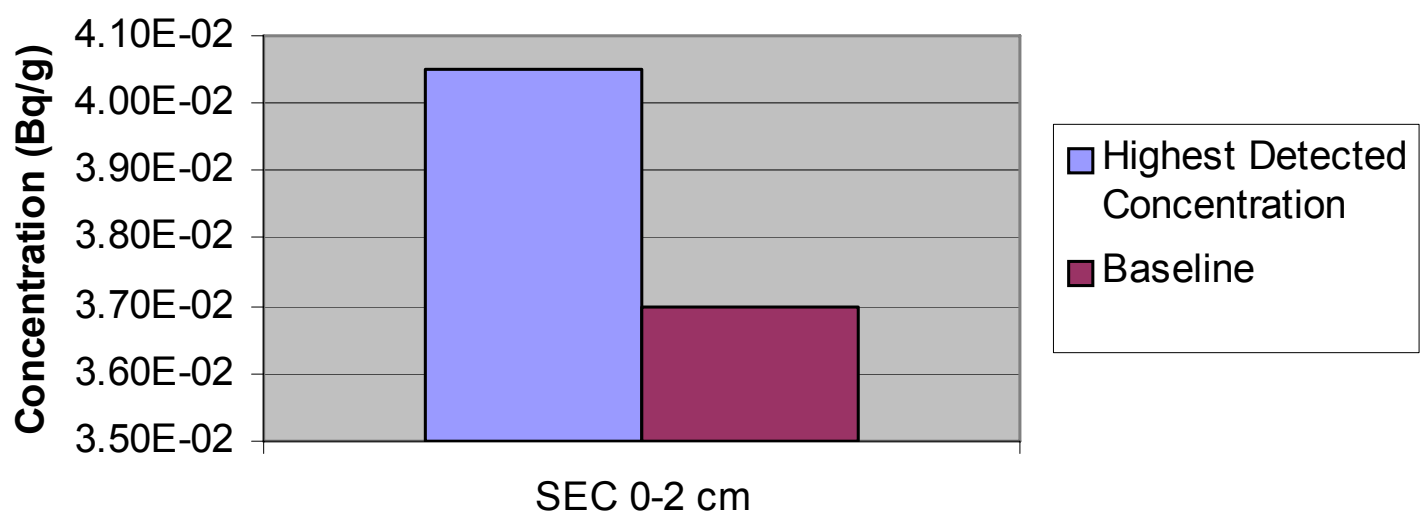

Comparison of Detected U-235 in Soil to the Baseline

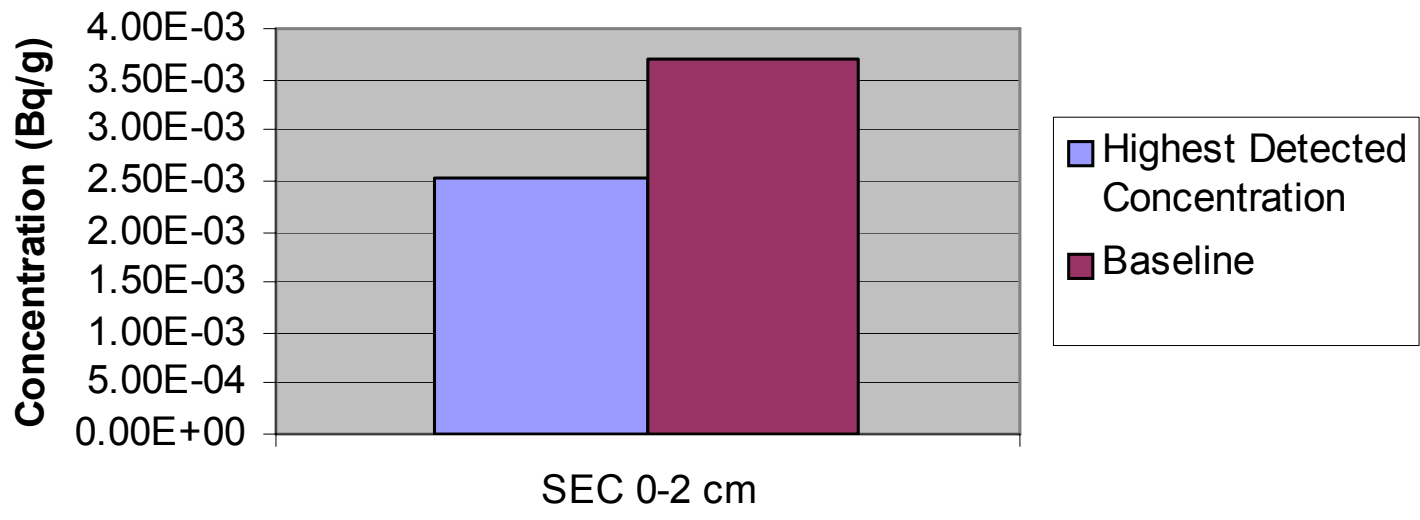


Comparison of Detected U-238 in Soil to the Baseline

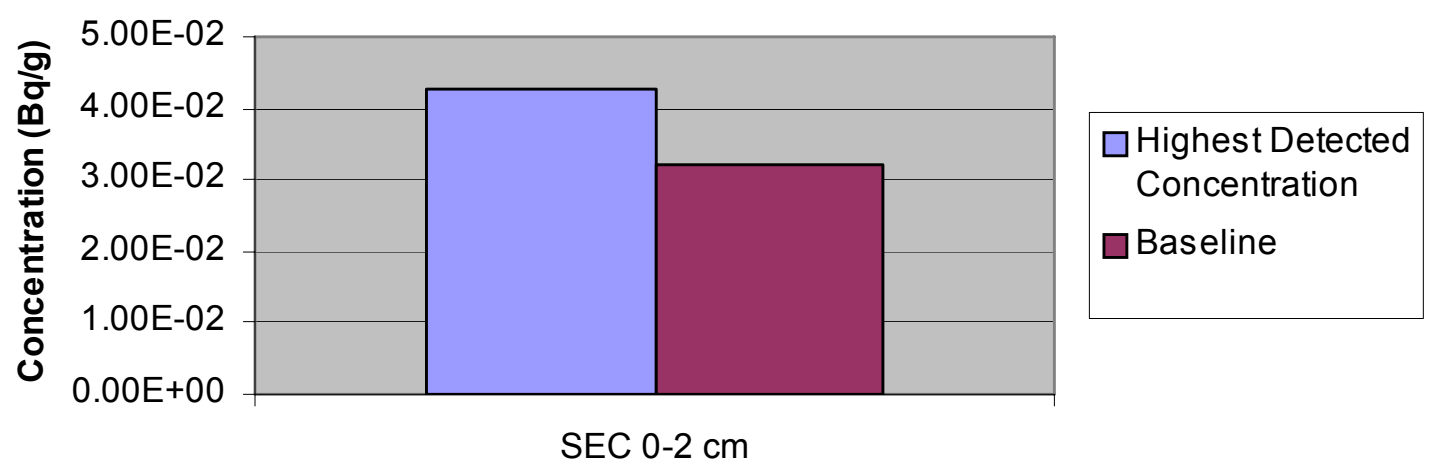

Comparison of Detected K-40 in Soil to the Baseline

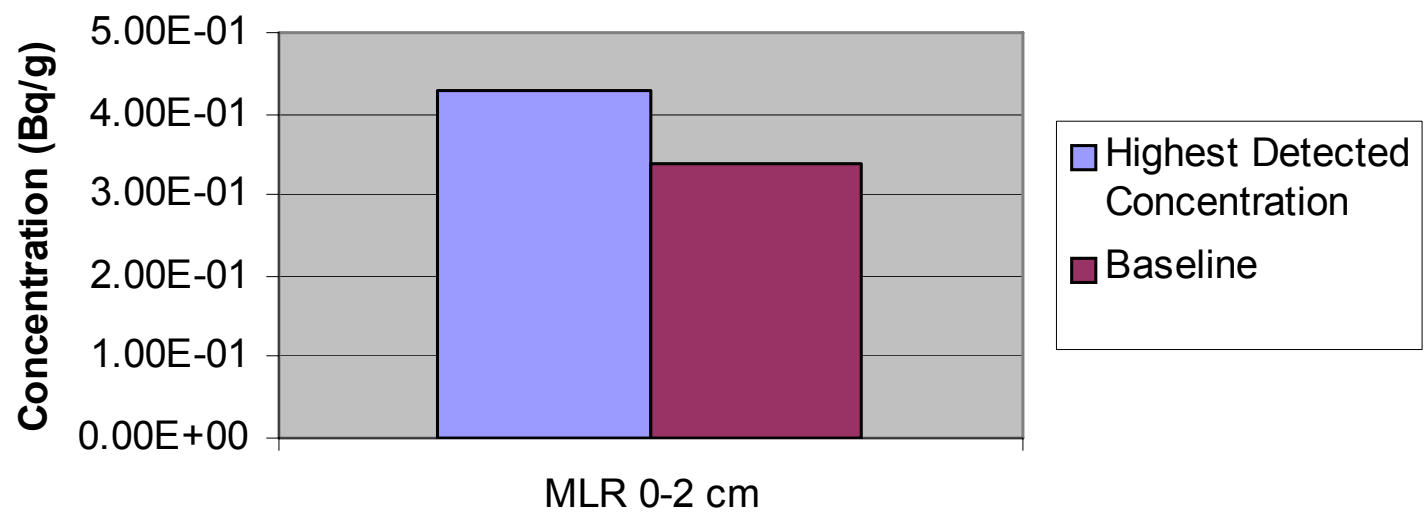




\section{Comparison of Detected Co-60 in Soil to the} Baseline

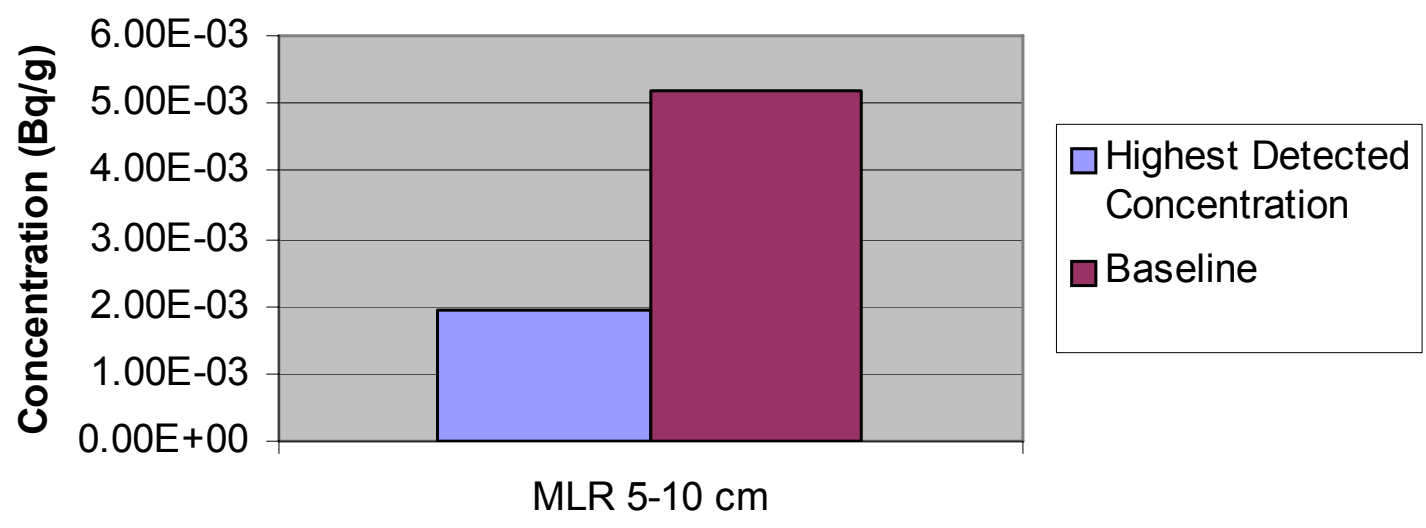

Comparison of Detected Cs-137 in Soil to the Baseline

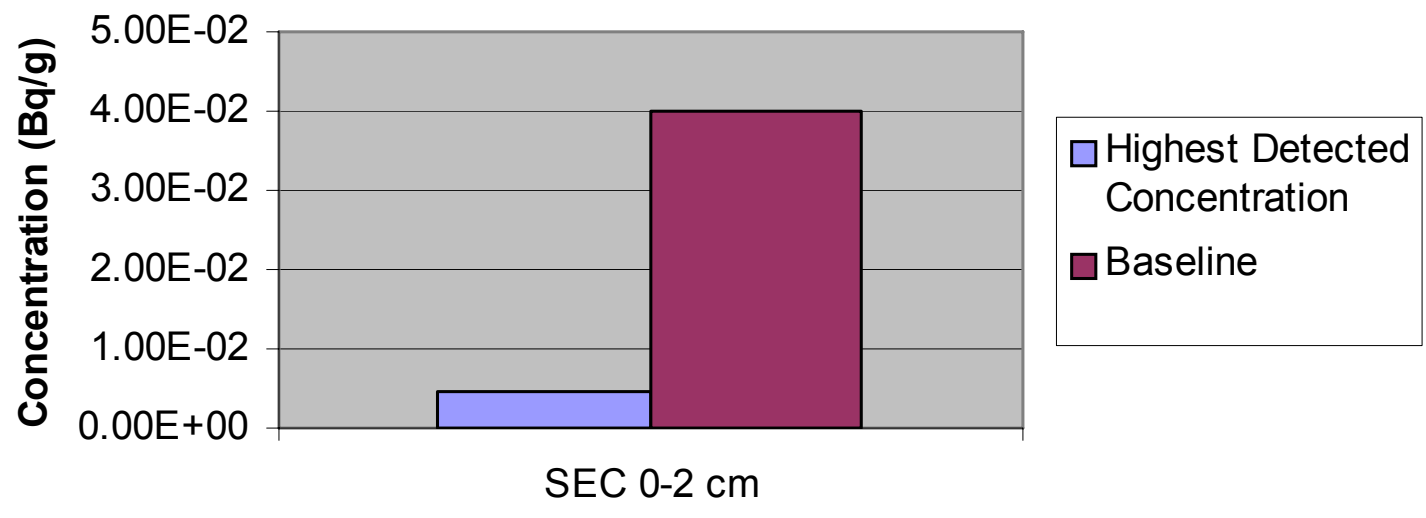




\section{Comparison of Detected U-238 in Vegetation to the}

Baseline

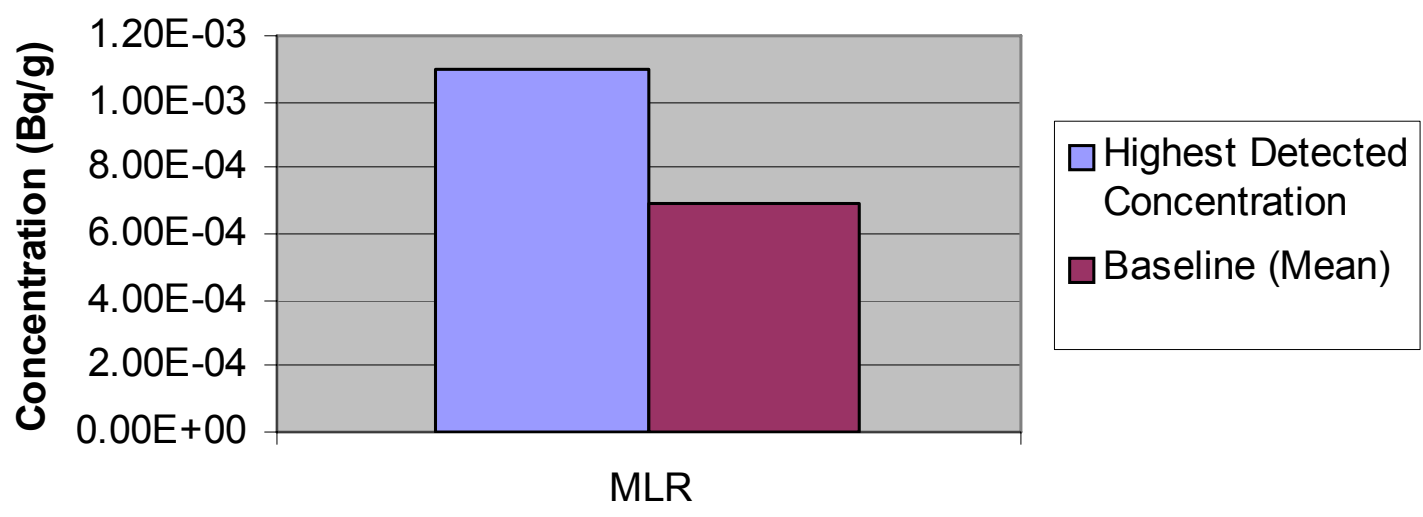

Comparison of Detected K-40 in Vegetation to the Baseline

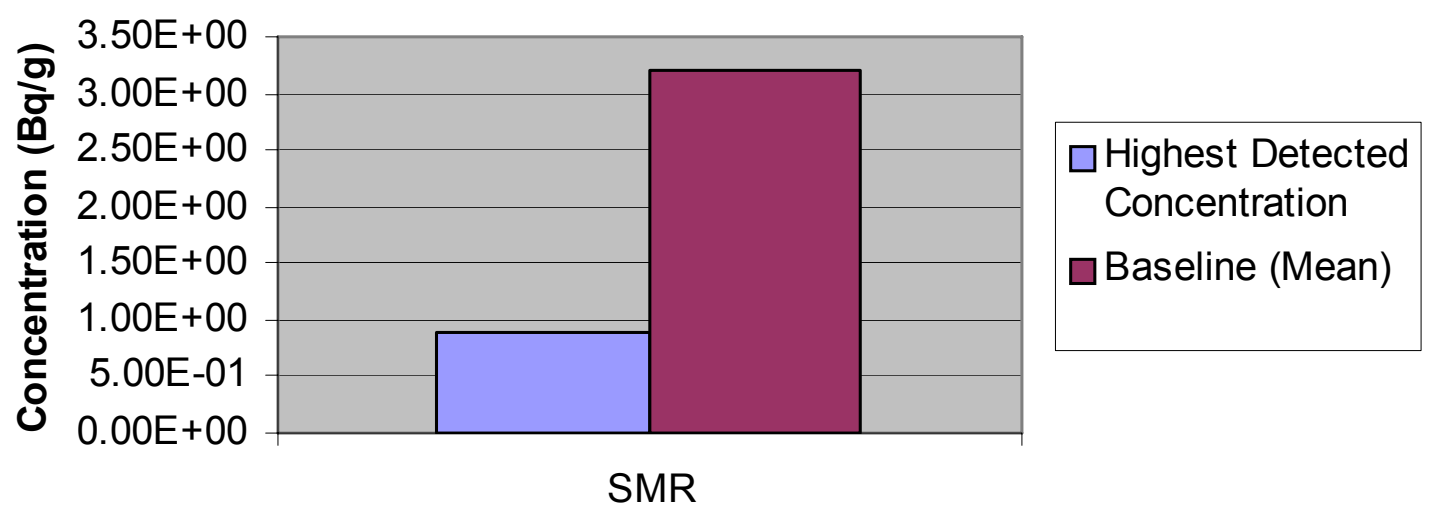




\section{Comparison of Detected Co-60 in Vegetation to the}

\section{Baseline}

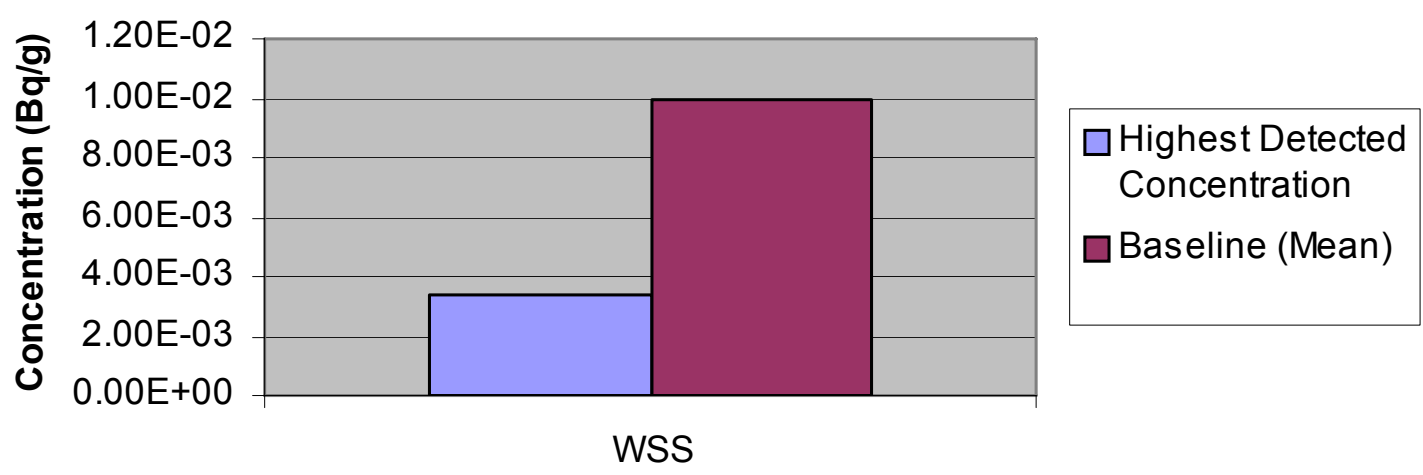

Comparison of Detected Sr-90 in Quail to the

Baseline

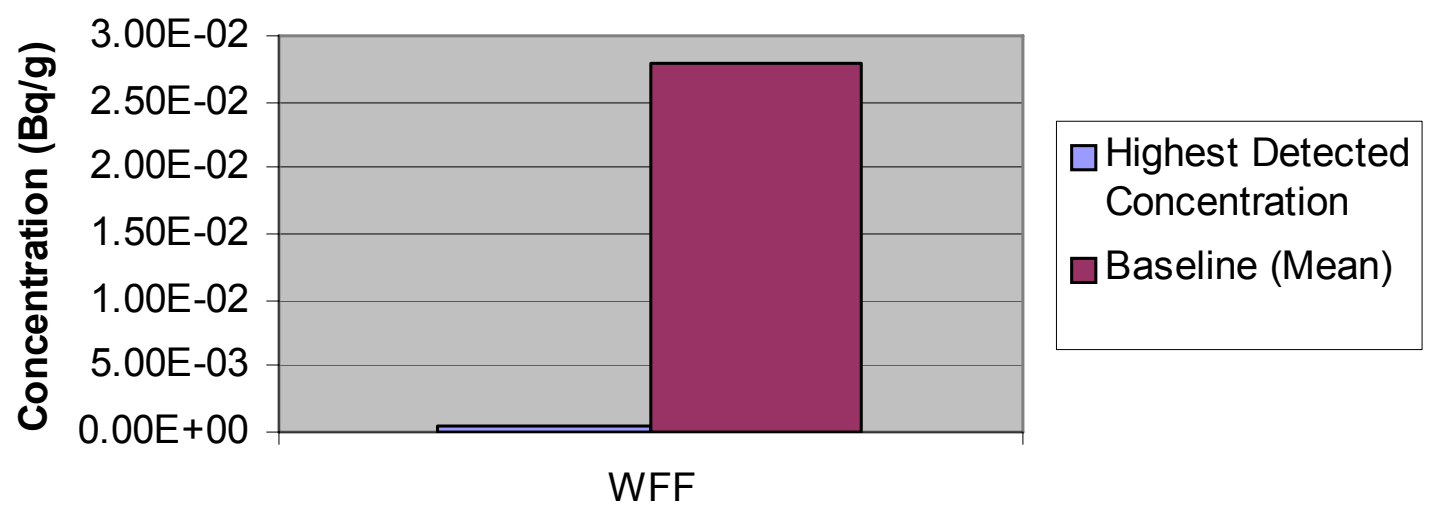


Comparison of Detected K-40 in Quail to the Baseline

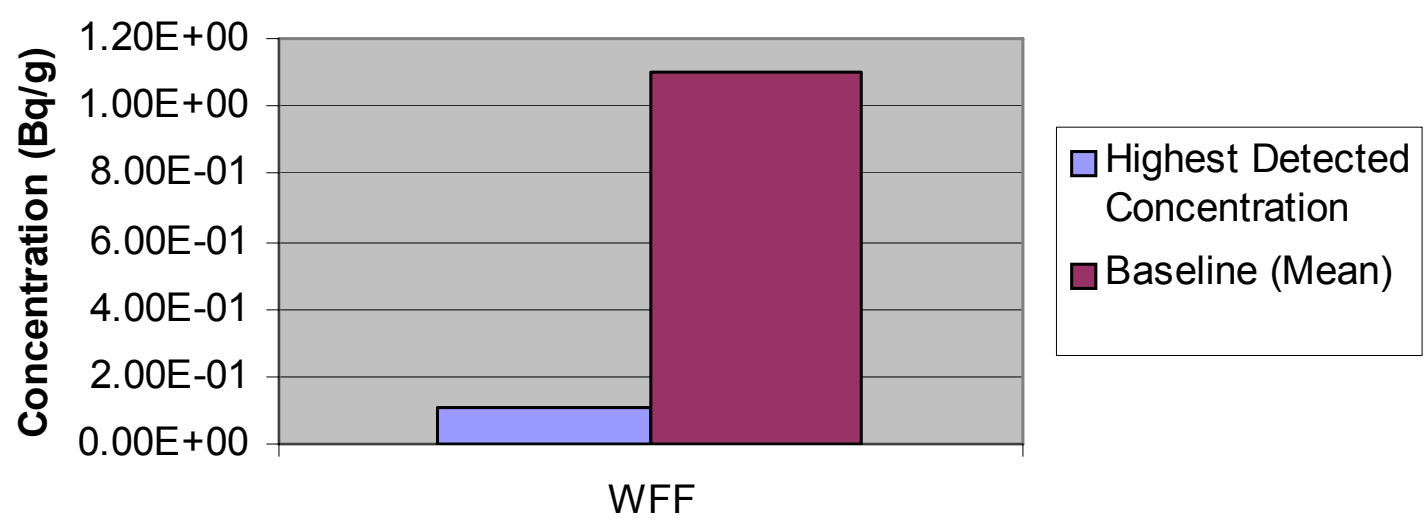

Comparison of Detected K-40 in Rabbit to the Baseline

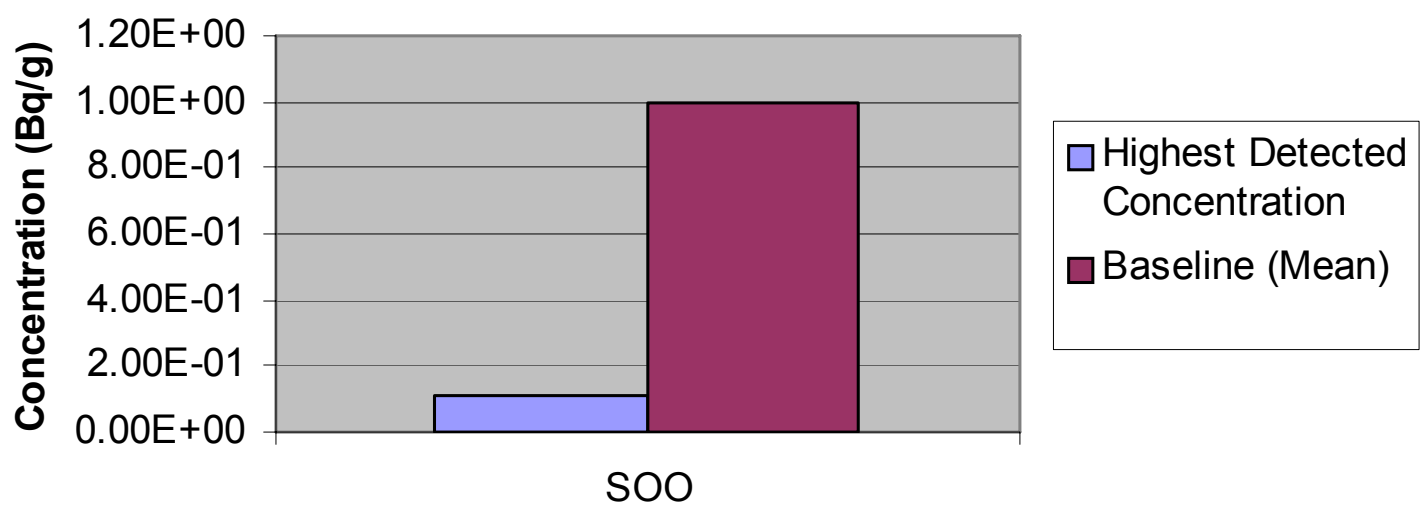




\section{Comparison of Detected K-40 in Fish to the Baseline}

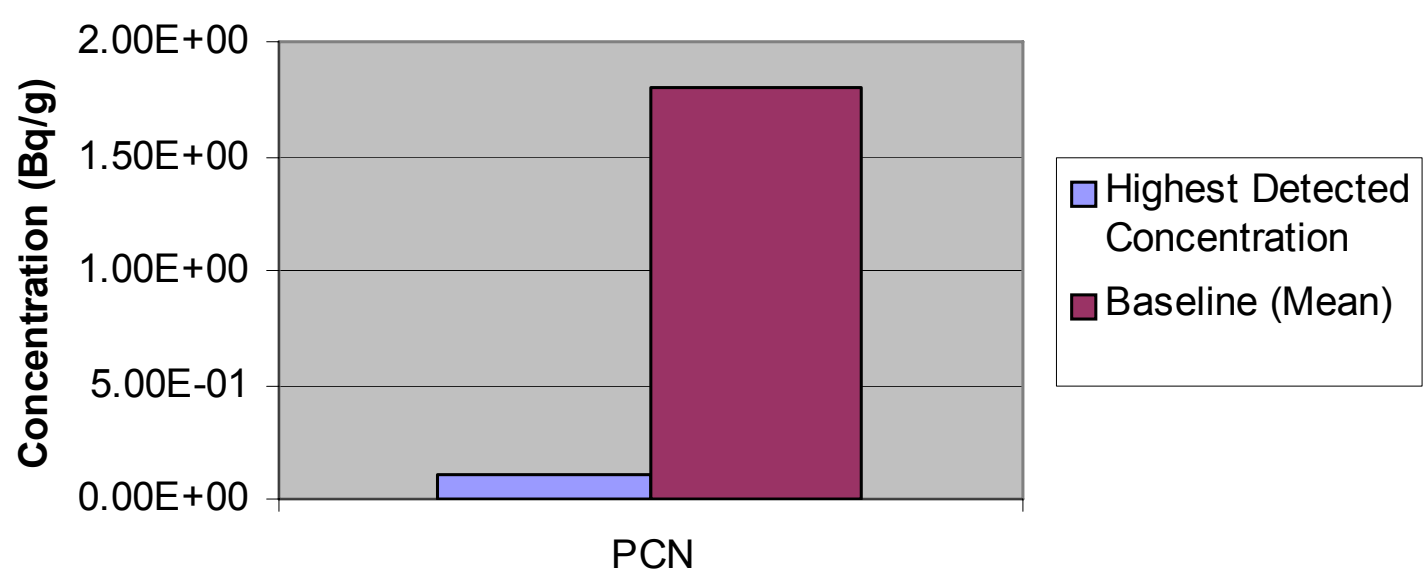

Comparison of Detected Sr-90 in Rabbit to the Baseline

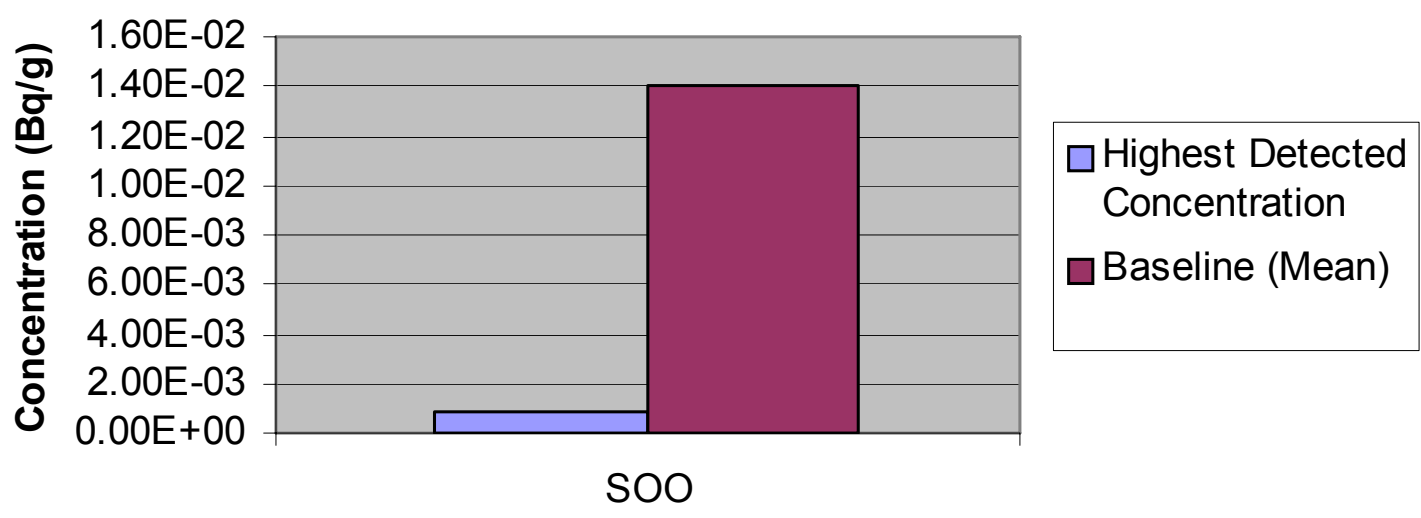

